\title{
Late-Transition Metal Complexes with Ambiphilic Phosphinoborane Ligands: Synthesis, Characterization and Catalysis.
}

Brian R. Nichols

Follow this and additional works at: https://researchrepository.wvu.edu/etd

\section{Recommended Citation}

Nichols, Brian R., "Late-Transition Metal Complexes with Ambiphilic Phosphinoborane Ligands: Synthesis, Characterization and Catalysis." (2018). Graduate Theses, Dissertations, and Problem Reports. 8188.

https://researchrepository.wvu.edu/etd/8188

This Dissertation is protected by copyright and/or related rights. It has been brought to you by the The Research Repository @ WVU with permission from the rights-holder(s). You are free to use this Dissertation in any way that is permitted by the copyright and related rights legislation that applies to your use. For other uses you must obtain permission from the rights-holder(s) directly, unless additional rights are indicated by a Creative Commons license in the record and/ or on the work itself. This Dissertation has been accepted for inclusion in WVU Graduate Theses, Dissertations, and Problem Reports collection by an authorized administrator of The Research Repository @ WVU.

For more information, please contact researchrepository@mail.wvu.edu. 


\title{
Late-Transition Metal Complexes with Ambiphilic Phosphinoborane Ligands: \\ Synthesis, Characterization and Catalysis
}

\author{
Brian R. Nichols \\ Dissertation submitted to the \\ Eberly College of Arts and Sciences \\ at West Virginia University
}

In partial fulfillment of the requirements for the degree of

Doctor of Philosophy in Chemistry

\author{
Brian V. Popp, Ph.D., Chair \\ Jessica M. Hoover, Ph.D. \\ Björn Söderberg, Ph.D. \\ Jeffrey L. Petersen, Ph.D. \\ James Lewis, Ph.D.
}

Department of Chemistry

Morgantown, West Virginia 2018

Keywords: Frustrated Lewis Pairs, Hydroboration, $\beta$-phosphinoethylborane, Ambiphilic Ligand, Lewis Acid

Copyright 2018 Brian R. Nichols 


\title{
ABSTRACT \\ Late-Transition Metal Complexes with Ambiphilic \\ Phosphinoborane Ligands: \\ Synthesis, Characterization and Catalysis
}

\author{
Brian R. Nichols
}

A significant amount of research has explored the impact of phosphinoborane ligand environments on the structure of the coordination sphere of inorganic and organometallic complexes. Ambiphilic phosphinoborane ligands possess a phosphine and a borane that are attached through a chosen linker. This traditionally involves hydrocarbon linkers and leads to either a conformationally free or a constrained ligand system. In particular, this dissertation will focus on the application of phosphinoborane ligands with flexible alkyl linkers. The goal of this study is to utilize the activation and coordination of Lewis acids in the second coordination sphere to influence reactivity at the transition metal center.

In the field of transition metal catalysis, there is a predominant amount of literature in substrate activation that relies on the cooperativity of Lewis bases aiding metal catalysis. The application of frustrated Lewis pairs bearing Lewis acidic moieties to organometallic catalysis may provide new opportunities for small molecule activation and catalyst development. This dissertation explores rhodium and iridium phosphinoborane complexes with the objective of understanding: (1) the role of Lewis acidic pendant boranes in intramolecular interactions on Group IX transition metal complexes and (2) the role of these same Lewis acidic groups on the activation of reagents in catalysis. This work is anticipated to contribute to a better understanding of the function of Lewis acidic moieties in cooperative catalysis with transition metals, but also the stabilizing interactions that lead to the isolation of specific complexes.

The limited work on $\beta$-phosphinoethylborane ligands with late transition metals has focused on the pendant Lewis acid's role in stabilizing reactive intermediates and performing difficult bond activations. The overall goal of this dissertation is to understand the role of pendant Lewis acids in a model catalytic system of hydrofunctionalization. This will also help gain insight into bond activations and how these functionalities modify the second coordination sphere of late transition metals.

Herein, this dissertation involves the synthesis of late transition metals bearing Lewis acidic $\beta$-phosphinoethylborane ligand scaffolds. The interaction of the second coordination sphere Lewis acid and the dynamics involved in this interaction are studied by utilizing a variety of spectroscopic techniques and standard synthetic methods. By relying on ${ }^{11} \mathrm{~B}$ NMR spectroscopy, we are able to probe the coordination environment around the Lewis acid. The investigations into the coordination environment led to questions of how changes in the coordination environment of rhodium and iridium complexes with tethered Lewis acids impact catalysis. 
During the investigation of the hydroboration of styrenyl substrates, the newly synthesized rhodium phosphinoborane catalysts provided high selectivity for the branched products. During this study, vinyldiphenyl phosphine was investigated owing to the limited applications of this substrate in hydroborations with pinacolborane. As a result, we sought to investigate whether pendant Lewis acids were able to temper the Lewis basicity of phosphine species. While the phosphinoborane ligand was not necessary for this catalysis, we were able to achieve regioselective control over product formation with simple rhodium catalysts. The hydroboration products of this reaction were then carried forward for further functionalization.

In the previous chapters, the Lewis acidic borane moiety showed a propensity to interact with ligands in the primary coordination sphere of the transition metal center. Therefore, we sought to explore the effect of pendant Lewis acids on stabilizing the oxidative addition products of hydroacylation. These rhodium(III) intermediates are known to undergo decarbonylation, which ultimately leads to catalyst decomposition. We were interested in whether the Lewis acidic ligand frameworks could stabilize these intermediates to allow for the development of hydroacylation catalysts. These fundamental studies will lead to the development of new catalyst systems bearing cooperative ligand motifs. 
To my parents,

Christine and Jeffrey Nichols

Your endless support and care has not only led me to be who I am today but, will continue to lead me in all my future endeavors. 


\section{Acknowledgements}

First and foremost, I would like to thank my advisor, Dr. Brian V. Popp. His advice over the past years will never be forgotten and will be carried with me for years to come. Without his wisdom and knowledge, I would never be the person that I am today and for that I am eternally grateful. It was not just what he did for me as an advisor or as a professor that I appreciate. He is truly an amazing person and I wish him the best as the group continues to grow and thrive.

I would like to thank Dr. Petersen for not only the crystallographic analysis and countless hours that were spent refining my crystal structures, but for everything else that he does for us as graduate students. The opportunity to learn from him and share in his knowledge will never be forgotten.

I would like to express my sincere thanks to Dr. Hoover for being someone that never turned down the opportunity to help me. I would also like to thank Dr. Söderberg for his guidance in helping me get through my first organic lecturing experience. Lastly, I would like to thank Dr. Lewis for his support throughout my time in Morgantown.

I would like to sincerely thank Dr. Akhmedov for his assistance in collecting full NMR characterization for several of my more complex products.

To all the Popp group members, both graduate and undergraduate, I am proud that I have gotten to know all of them. Despite me being far away from my family in Massachusetts, I feel that I have made another one in West Virginia. I wish them all the best in life and the lab as we all continue to grow and mature in our future endeavors.

I thank my parents, grandparents and family back home for supporting this long journey through graduate school and life. Without them supporting my slips and falls, I would not be in the position I am today.

Lastly, I would like to thank the most important person in my life, Trina. I wouldn't be the same person I am today without her. Her friendship and relationship with me extends far beyond the classroom and laboratory. The connection I share with her is one that I am proud to say I will share with her forever. As I take a step into my future off of this campus and outside of Morgantown, I am excited to share every step of that journey with her. 


\section{Table of Contents}

Abstract

Dedication

ii

Acknowledgements

iv

Table of Contents

vi

List of Tables

List of Figures

List of Schemes

viii

$\mathbf{x i}$

List of Acronyms \& Abbreviations

xxix

XXXV

Chapter 1. Cooperative Transition Metal-Lewis Acid Catalysis: A Survey

1.1 Introduction

1.2 Application of Lewis Acids in Non-Transition Metal Catalyzed $\mathbf{4}$ Hydrofunctionalization Reactions

1.3 Cooperative Utilization of Lewis Acids in Transition Metal Catalyzed 17 Hydrofunctionalization Reactions

1.4 Conclusion

1.5 References and Notes

Chapter 2. Synthesis and Characterization of Rhodium and Iridium Complexes featuring a Conformationally Flexible Ambiphilic $\beta$-Phosphinoethylborane Ligand

2.1 Introduction

2.2 Results and Discussion

2.3 Conclusion

2.4 Methods

2.5 References and Notes

Chapter 3. Application of Rhodium Metal Complexes Bearing $\beta$-Phosphinoethylborane Ligands to the Catalytic Hydroboration of Vinyl Arenes

3.1 Introduction 81

3.2 Results and Discussion

3.3 Conclusion

3.4 Methods

3.5 References and Notes

Chapter 4. Access to a Pair of Ambiphilic Phosphine- Borane Regioisomers by Rhodium-Catalyzed Hydroboration

4.1 Introduction

4.2 Results and Discussion

4.3 Conclusion

4.4 Methods

4.5 References and Notes 
Chapter 5. Influence of Second Coordination Sphere Boranes on Rhodium(I) Oxidative Addition of Aldehydes

5.1 Introduction

5.2 Results and Discussion

153

5.3 Conclusion

164

5.4 Methods

165

5.5 References and Notes

167

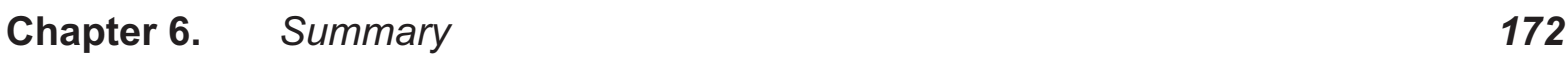

Appendix 1. X-Ray Crystallography Data Tables and Instrumental Information 177

Appendix 2. Spectroscopic Characterization of Inorganic Complexes and $\mathbf{2 2 8}$ Organic Products 


\section{List of Tables}

Table 1.1. Rates of ethylene hydrogenation catalyzed Wilkinson's complex with and without Lewis acid additive.

Table 1.2. Hydrogenation of alkene substrates with rhenium hydride/Lewis acid system compared to precious metal catalysts.

Table 1.3. Hydroboration of alkenes with $\mathrm{Rh}(\mathrm{I})$ catalyst in the presence of catalytic Lewis acid.

Table 2.1. Depiction of the fold angle in $\left[\mathrm{Rh}\left(\mathrm{Ph}_{2} \mathrm{PCH}_{2} \mathrm{CH}_{2} \mathrm{~B}^{\mathrm{BBN}}\right)_{2} \mathrm{Cl}\right]_{2}$ and the crystallographic comparison amongst known $\mathrm{Rh}(\mathrm{I})$ chloride bridged dimer systems.

Table 2.2. Calculated geometry index values $\left(\mathrm{T}_{4}{ }^{\prime}\right)$ for prepared rhodium and iridium complexes.

Table 3.1. Screening of solvents for the hydroboration of styrene with HBCat using the $\mathrm{Rh}(\mathrm{COD})\left[\mathrm{Ph}_{2} \mathrm{PCH}_{2} \mathrm{CH}_{2} \mathrm{~B}^{\mathrm{BBN}}\right] \mathrm{Cl}$ as the catalyst.

Table 3.2. Screening of complexes and ligand loading for the hydroboration of styrene with HBCat.

Table 3.3. Screening of borane reagents for the hydroboration of styrene using the $\mathrm{Rh}(\mathrm{COD})\left[\mathrm{Ph}_{2} \mathrm{PCH}_{2} \mathrm{CH}_{2} \mathrm{~B}^{\mathrm{BBN}}\right] \mathrm{Cl}$ as the catalyst.

Table 3.4. Screening of different silver salts for the hydroboration of styrene with HBPin using the $\mathrm{Rh}(\mathrm{COD})\left[\mathrm{Ph}_{2} \mathrm{PCH}_{2} \mathrm{CH}_{2} \mathrm{~B}^{\mathrm{BBN}}\right] \mathrm{Cl}$ as the catalyst with 2.5 mol\% of exogenous ligand. 
Table 3.5. Screening of different silver salts for the hydroboration of styrene with $\mathrm{HBPin}$ using the $\mathrm{Rh}(\mathrm{COD})\left[\mathrm{Ph}_{2} \mathrm{PCH}_{2} \mathrm{CH}_{2} \mathrm{~B}^{\mathrm{BBN}}\right] \mathrm{Cl}$ as the catalyst with $2.5 \mathrm{~mol} \%$ of exogenous ligand and $0.5 \mathrm{~mol} \%$ of AgOTf.

Table 3.6. Substrate Scope for the hydroboration of olefins with HBPin using $\mathrm{Rh}(\mathrm{COD})\left[\mathrm{Ph}_{2} \mathrm{PCH}_{2} \mathrm{CH}_{2} \mathrm{~B}^{\mathrm{BBN}}\right] \mathrm{Cl}$ as the catalyst with $2.5 \mathrm{~mol} \%$ of exogenous ligand and $0.5 \mathrm{~mol} \%$ of $\mathrm{AgOTf}$.

Table 4.1. Silver salt optimization of the reaction conditions to obtain the branched isomer in the hydroboration of vinyldiphenylphosphine with HBPin.

Table 4.2. Solvent optimization of the reaction conditions to obtain the branched isomer in the hydroboration of vinyldiphenylphosphine with HBPin.

Table 4.3. Vinyl phosphine to borane optimization of the reaction conditions to obtain the branched isomer in the hydroboration of vinyldiphenylphosphine with HBPin.

Table 4.4. Temperature optimization of the reaction conditions to obtain the branched isomer in the hydroboration of vinyldiphenylphosphine with HBPin.

Table 4.5. Catalyst optimization of the reaction conditions to obtain the branched isomer in the hydroboration of vinyldiphenylphosphine with HBPin. 
Table 4.6. Catalyst optimization of the reaction conditions to obtain the branched isomer in the hydroboration of vinyldiphenylphosphine with HBPin.

Table 4.7. Catalyst optimization of the reaction conditions to obtain the linear isomer in the hydroboration of vinyldiphenylphosphine with HBPin.

Table 5.1. Catalytic hydroacylation with the use of chelating bis(phosphine) $\mathrm{Rh}(\mathrm{I})$ complexes.

Table 5.2. Effect of zwitterionic complexes on stability of Rh(III) hydroacylation intermediates. 


\section{List of Figures}

Figure 2.1. Different binding modes of transition metal complexes of ambiphilic phosphinoborane ligands.

Figure 2.2. X-ray crystallographic structures of $\mathrm{Rh}(\mathrm{COD})\left[\mathrm{Ph}_{2} \mathrm{PCH}_{2} \mathrm{CH}_{2} \mathrm{~B}^{\mathrm{BBN}}\right] \mathrm{Cl}$ and $\operatorname{Ir}(\mathrm{COD})\left[\mathrm{Ph}_{2} \mathrm{PCH}_{2} \mathrm{CH}_{2} \mathrm{~B}^{\mathrm{BBN}}\right] \mathrm{Cl}$ (thermal ellipsoids at $50 \%$ probability) with hydrogens removed for clarity.

Figure 2.3. ${ }^{11} \mathrm{~B}\left\{{ }^{1} \mathrm{H}\right\}$ NMR depiction of the chemical shifts of the various X-type ligands of a $\mathrm{Rh}(\mathrm{COD})$ phosphinoborane complex.

Figure 2.4. X-ray crystallographic structure $\mathrm{Rh}(\mathrm{COD})\left[\mathrm{Ph}_{2} \mathrm{PCH}_{2} \mathrm{CH}_{2} \mathrm{~B}^{\mathrm{BBN}}\right] \mathrm{Br}$ and $\mathrm{Rh}(\mathrm{COD})\left[\mathrm{Ph}_{2} \mathrm{PCH}_{2} \mathrm{CH}_{3}\right] \mathrm{Br}$ (thermal ellipsoids at $50 \%$ probability) with hydrogens removed for clarity.

Figure 2.5. X-ray crystallographic structure of $\mathrm{Rh}(\mathrm{CO})\left[\mathrm{Ph}_{2} \mathrm{PCH}_{2} \mathrm{CH}_{2} \mathrm{~B}^{\mathrm{BBN}}\right]_{2} \mathrm{Cl}$ (thermal ellipsoids at $50 \%$ probability) with hydrogens removed for clarity.

Figure 2.6. X-ray crystallographic structure of $\left[\mathrm{Rh}\left[\mathrm{Ph}_{2} \mathrm{PCH}_{2} \mathrm{CH}_{2} \mathrm{~B}^{\mathrm{BBN}}\right]_{2} \mathrm{Cl}\right]_{2}$ (thermal ellipsoids at $50 \%$ probability) with hydrogens removed for clarity.

Figure 2.7. ${ }^{31} \mathrm{P}\left\{{ }^{1} \mathrm{H}\right\} \quad \mathrm{NMR}$ spectrum of $\mathrm{Rh}\left[\mathrm{Ph}_{2} \mathrm{PCH}_{2} \mathrm{CH}_{2} \mathrm{~B}\left(\mathrm{C}_{8} \mathrm{H}_{14}\right)\right]_{3} \mathrm{Cl}$ complex in $d^{2}$-dichloromethane.

Figure 2.8. Dependence of the ${ }^{11} \mathrm{~B}\left\{{ }^{1} \mathrm{H}\right\}$ NMR chemical shift of the $\mathrm{Rh}(\mathrm{COD})$ phosphinoborane chloride complex on the solvent dielectric constant in mixtures of $d_{2}$-dichloromethane and $d_{6}$-benzene. 
Figure 2.9. Dependence of ${ }^{11} \mathrm{~B}\left\{{ }^{1} \mathrm{H}\right\} \quad \mathrm{NMR}$ chemical shift of a $\mathrm{Rh}(\mathrm{COD})$ phosphinoborane chloride complex on the donicity of the solvent.

Figure 2.10. Comparison of the ${ }^{11} \mathrm{~B}\left\{{ }^{1} \mathrm{H}\right\}$ NMR spectra of $\operatorname{Ir}(\mathrm{COD})\left[\mathrm{Ph}_{2} \mathrm{PCH}_{2} \mathrm{CH}_{2} \mathrm{~B}^{\mathrm{BBN}}\right] \mathrm{Cl} \quad$ complex with $\mathrm{Rh}(\mathrm{COD})\left[\mathrm{Ph}_{2} \mathrm{PCH}_{2} \mathrm{CH}_{2} \mathrm{~B}^{\mathrm{BBN}}\right] \mathrm{Cl}$ in $\mathrm{d}_{2}$-dichloromethane and $\mathrm{d}_{6^{-}}$ benzene.

Figure 2.11. X-ray crystallographic structure of $\operatorname{Ir}(\mathrm{COD})\left[\mathrm{Ph}_{2} \mathrm{PCH}_{2} \mathrm{CH}_{2} \mathrm{~B}^{\mathrm{BBN}}\right.$ $\left.\mathrm{NCCH}_{3}\right] \mathrm{Cl}$ (thermal ellipsoids at $50 \%$ probability) with hydrogens removed for clarity.

Figure 2.12. Low temperature NMR analysis of $\mathrm{Rh}(\mathrm{COD})\left[\mathrm{Ph}_{2} \mathrm{PCH}_{2} \mathrm{CH}_{2} \mathrm{~B}^{\mathrm{BBN}}\right] \mathrm{Cl}$ complex in $\mathrm{d}_{2}$-dichloromethane.

Figure 2.13. Low temperature $\mathrm{NMR}$ analysis of $\mathrm{Rh}(\mathrm{COD})\left[\mathrm{Ph}_{2} \mathrm{PCH}_{2} \mathrm{CH}_{2} \mathrm{~B}^{\mathrm{BBN}}\right] \mathrm{Cl}$ complex in $\mathrm{d}_{8}$-toluene.

Figure 2.14. ${ }^{11} \mathrm{~B}\left\{{ }^{1} \mathrm{H}\right\} \quad \mathrm{NMR}$ of $\mathrm{Rh}$ - and Ir-azide complexes with comparison to $\mathrm{Rh}(\mathrm{COD})\left[\mathrm{Ph}_{2} \mathrm{PCH}_{2} \mathrm{CH}_{2} \mathrm{~B}^{\mathrm{BBN}}\right] \mathrm{Cl}$.

Figure 2.15. X-ray crystallographic structures of $\mathrm{Rh}(\mathrm{COD})\left[\mathrm{Ph}_{2} \mathrm{PCH}_{2} \mathrm{CH}_{2} \mathrm{~B}^{\mathrm{BBN}}\right] \mathrm{N}_{3}$ and $\operatorname{Ir}(\mathrm{COD})\left[\mathrm{Ph}_{2} \mathrm{PCH}_{2} \mathrm{CH}_{2} \mathrm{~B}^{\mathrm{BBN}}\right] \mathrm{N}_{3}$ (thermal ellipsoids at $50 \%$ probability) with hydrogens removed for clarity.

Figure 3.1. Upfield shifted ${ }^{1} \mathrm{H}$ NMR of the reaction of $\mathrm{Rh}(\mathrm{COD})$ phosphinoborane chloride complex with AgOTf and HBPin in $d_{6}$-benzene (green). Blue spectra is that of the $\mathrm{Rh}(\mathrm{COD})$ phosphinoborane triflate complex in $d_{6}$-benzene without HBpin. 
Figure 3.2. A) Reaction of the Wilkinson's analog (top) and bis(phosphinoborane) $\mathrm{Rh}^{1}$ chloride dimer (bottom) with HBPin. B) ${ }^{31} \mathrm{P}\left\{{ }^{1} \mathrm{H}\right\}$ NMR spectra of reaction between bis(phosphinoborane) $R h^{1}$ chloride dimer and HBPin. C) zoomed in spectra of hydride region of reaction between bis(phosphinoborane) $\mathrm{Rh}^{\prime}$ chloride dimer and HBPin.

Figure 3.3. Reaction of the Wilkinson's analog with HBPin (top), bis(phosphinoborane) $\mathrm{Rh}^{\prime}$ chloride dimer and HBPin (middle) and Wilkinson's analog with $\mathrm{H}_{2}$ (bottom). Inset represents a zoomed in view of boxed hydride signal in the bottom spectra.

Figure 3.4. Reaction of $\left[\mathrm{Rh}\left(\mathrm{PPh}_{3}\right)_{2} \mathrm{Cl}\right]_{2}$ with $\mathrm{HBpin}$ showing the ${ }^{1} \mathrm{H}\left\{{ }^{31} \mathrm{P}\right\} \mathrm{NMR}$ (top) and the ${ }^{1} \mathrm{H}$ NMR (bottom) of the upfield (hydride) region of the NMR.

Figure 4.1. Examples of vinylphosphine hydroboration with and without transition-metal catalysts.

Figure 4.2. $\quad{ }^{1} \mathrm{H}$ NMR displaying the hydroboration of vinyl phosphine (top) and selective decoupling of the ${ }^{1} \mathrm{H}$ NMR using ${ }^{31} \mathrm{P}$ signal at $\delta=-4.62$ ppm. Residual THF marked with $\left(^{*}\right)$.

Figure 4.3. NMRs of the obtained hydroboration products. A) gHSQCAD NMR spectrum, B) ${ }^{31} \mathrm{P}\left\{{ }^{1} \mathrm{H}\right\}$ NMR spectrum, C) ${ }^{11} \mathrm{~B}\left\{{ }^{1} \mathrm{H}\right\}$ NMR spectrum.

Figure 4.4. 1D TOCSY of the hydroboration of vinyl phosphine with selective excitation of $2.2 \mathrm{ppm}$ resonance. 
Figure 4.5. Effect of temperature on the branched to linear product distribution in the hydroboration of vinyl phosphine with HBPin.

Figure 4.6. $\quad{ }^{11} \mathrm{~B}\left\{{ }^{1} \mathrm{H}\right\} \mathrm{NMR}$ of the $\mathrm{Rh}(\mathrm{COD})$ branched phosphinoborane chloride complex (top) and the mixture of the two unbound regio-isomers, branched and linear (bottom).

Figure 4.7. Products of the hydroboration reaction of vinyldiphenylphosphine with pinacolborane before protection with $\mathrm{BH}_{3}$ - THF (borttom) and after addition of $\mathrm{BH}_{3}$-THF (top).

Figure 4.8. $\quad{ }^{11} \mathrm{~B}\left\{{ }^{1} \mathrm{H}\right\}$ NMR spectra of $\mathrm{BH}_{3}$-protected vinylphosphine hydroboration product bearing a pinacol boronic ester (bottom) and a potassium trifluoroborate salt (top).

Figure 4.9. X-ray crystallographic structure of $\mathrm{K}\left[\mathrm{Ph}{ }_{2} \mathrm{P}\left(\mathrm{BH}_{3}\right) \mathrm{CH}\left(\mathrm{CH}_{3}\right) \mathrm{BF}_{3}\right]$ (thermal ellipsoids at $30 \%$ probability) with hydrogens removed for clarity.

Figure 5.1. Upfield ${ }^{1} \mathrm{H}$ NMR spectra demonstrating the formation of hydrides by oxidative addition to the $\mathrm{Rh}(\mathrm{I})$ precursor.

Figure 5.2. Upfield ${ }^{1} \mathrm{H}$ NMR spectra of the reaction of bis(phosphinoborane) $\mathrm{Rh}(\mathrm{I})$ chloride dimer with 8-quinolinecarbaldehyde.

Figure 5.3. Infrared spectra of acyl-Rh(III)-hydride phosphineborane complex.

Figure 5.4. NMR spectra of the obtained hydroboration products. A) Experimental and calculated 1D TOCSY NMR spectra, B) ${ }^{11} B\left\{{ }^{1} H\right\}$ NMR spectrum, C) ${ }^{4} \mathrm{~J}_{\mathrm{HC}}$ correlations using HMBC NMR spectrum. 
Figure 5.5. X-ray crystallographic structure $\mathrm{Rh}(\mathrm{COD})\left[\mathrm{Ph}_{2} \mathrm{PCH}_{2} \mathrm{CH} 2 \mathrm{~B}\left(\mathrm{C}_{8} \mathrm{H}_{13}\right)\right][2-$ pyridine- $\mathrm{CH}_{2} \mathrm{O}$ JOTf (thermal ellipsoids at $50 \%$ probability) with hydrogens removed for clarity.

Figure A1.1 Perspective view of the molecular structure of $\mathrm{RhCl}(\mathrm{COD})\left[\mathrm{PPh}_{2} \mathrm{CH}_{2} \mathrm{CH}_{2} \mathrm{~B}\left(\mathrm{C}_{8} \mathrm{H}_{14}\right)\right]$ with the atom labeling scheme for the independent non-hydrogen atoms. The thermal ellipsoids are scaled to enclosed $30 \%$ probability.

Figure A1.2 Perspective view of the molecular structure of IrCl(COD) $\left[\mathrm{PPh}_{2} \mathrm{CH}_{2} \mathrm{CH}_{2} \mathrm{~B}\left(\mathrm{C}_{8} \mathrm{H}_{14}\right)\right]$ with the atom labeling scheme provided for the non-hydrogen atoms. The thermal ellipsoids are scaled to enclose $30 \%$ probability.

Figure A1.3 Perspective view of the molecular arrangement of (COD) RhBr$\left[\mathrm{PPh}_{2} \mathrm{CH}_{2} \mathrm{CH}_{2} \mathrm{~B}\left(\mathrm{C}_{8} \mathrm{H}_{14}\right)\right]$ with the atom labeling scheme for the non-hydrogen atoms. The thermal ellipsoids are scaled to enclose $50 \%$ probability.

Figure A1.4 Perspective view of the molecular structure of $\mathrm{RhBr}(\mathrm{COD})\left(\mathrm{PPh}_{2} \mathrm{Et}\right)$ with the atom labeling scheme for the non-hydrogen atoms. The thermal ellipsoids are scaled to enclose $30 \%$ probability.

Figure A1.5 Perspective view of the molecular structure of $\mathrm{Rh}(\mathrm{CO}) \mathrm{Cl}\left(\mathrm{PPh}_{2} \mathrm{CH}_{2} \mathrm{CH}_{2}-9-\mathrm{BBN}\right)_{2}$ with the atom labeling scheme.

The thermal ellipsoids are scaled to enclose $30 \%$ probability. 
Figure A1.6 Perspective view of the molecular structure of $\left[\left(\mathrm{C}_{44} \mathrm{H}_{56} \mathrm{P}_{2} \mathrm{~B}_{2}\right) \mathrm{Rh}(\mu\right.$ $\mathrm{Cl})]_{2}$ with the atom labeling scheme for the non-hydrogen atoms. The thermal ellipsoids are scaled to enclose $50 \%$ probability.

Figure A1.7 Perspective view of the molecular structure of IrCl(COD) $\left[\mathrm{PPh}_{2} \mathrm{CH}_{2} \mathrm{CH}_{2} \mathrm{~B}\left(\mathrm{C}_{8} \mathrm{H}_{14}\right)(\mathrm{NCMe})\right]$ with the atom labeling scheme provided for the non-hydrogen atoms. The thermal ellipsoids are scaled to enclose $30 \%$ probability.

Figure A1.8 Perspective view of the molecular structure of $\mathrm{C}_{30} \mathrm{H}_{40} \mathrm{PBN}_{3} \mathrm{Rh}$ with the atom labeling scheme for the non-hydrogen atoms. The thermal ellipsoids are scaled to enclose $30 \%$ probability.

Figure A1.9 Perspective view of the molecular structure of $\mathrm{C}_{30} \mathrm{H}_{40} \mathrm{PBN}_{3}$ Ir with the atom labeling scheme for the non-hydrogen atoms. The thermal ellipsoids are scaled to enclose $30 \%$ probability.

Figure A1.10 Perspective view of the molecular arrangement of four $\mathrm{K}\left[\mathrm{PPh}_{2}\left(\mathrm{BH}_{3}\right)\left(\mathrm{CHMeBF}_{3}\right)\right] \cdot \mathrm{OCMe}_{2}$ units in the lattice with an atom labeling scheme for selected non-hydrogen atoms. The thermal ellipsoids are scaled to enclose $30 \%$ probability. The dashed lines indicate the close contacts between the $\mathrm{K}+$ cations and the fluorine atoms of the neighboring anions and the $\mathrm{O}$ of the closest acetone molecule of solvation.

Figure A2.1 ${ }^{1} \mathrm{H}$ NMR Spectrum of $\mathrm{Ph}_{2} \mathrm{PCH}_{2} \mathrm{CH}_{2} \mathrm{~B}\left(\mathrm{C}_{8} \mathrm{H}_{14}\right)$ in $\mathrm{d}_{6}$-Benzene. 229

Figure A2.2 ${ }^{31} \mathrm{P}\left\{{ }^{1} \mathrm{H}\right\}$ NMR Spectrum of $\mathrm{Ph}_{2} \mathrm{PCH}_{2} \mathrm{CH}_{2} \mathrm{~B}\left(\mathrm{C}_{8} \mathrm{H}_{14}\right)$ in $\mathrm{d}_{6}$-Benzene. $\quad 230$ 
Figure A2.3 ${ }^{1} \mathrm{H}$ NMR Spectrum of $\mathrm{Rh}(\mathrm{COD})\left[\mathrm{Ph}_{2} \mathrm{PCH}_{2} \mathrm{CH}_{2} \mathrm{~B}\left(\mathrm{C}_{8} \mathrm{H}_{14}\right)\right] \mathrm{Cl}$ in $\mathrm{d}_{6^{-}}$

Benzene.

Figure A2.4 ${ }^{31} \mathrm{P}\left\{{ }^{1} \mathrm{H}\right\}$ NMR Spectrum of $\mathrm{Rh}(\mathrm{COD})\left[\mathrm{Ph}_{2} \mathrm{PCH}_{2} \mathrm{CH}_{2} \mathrm{~B}\left(\mathrm{C}_{8} \mathrm{H}_{14}\right)\right] \mathrm{Cl}$ in $\mathrm{d}_{6^{-}}$

Benzene.

Figure A2.5 ${ }^{11} \mathrm{~B}\left\{{ }^{1} \mathrm{H}\right\}$ NMR Spectrum of $\mathrm{Rh}(\mathrm{COD})\left[\mathrm{Ph}_{2} \mathrm{PCH}_{2} \mathrm{CH} \mathrm{H}_{2} \mathrm{~B}\left(\mathrm{C}_{8} \mathrm{H}_{14}\right)\right] \mathrm{Cl}$ in $\mathrm{d}_{6^{-}}$

Benzene.

Figure A2.6 ${ }^{13} \mathrm{C}\left\{{ }^{1} \mathrm{H}\right\}$ NMR Spectrum of $\mathrm{Rh}(\mathrm{COD})\left[\mathrm{Ph}_{2} \mathrm{PCH}_{2} \mathrm{CH}_{2} \mathrm{~B}\left(\mathrm{C}_{8} \mathrm{H}_{14}\right)\right] \mathrm{Cl}$ in $\mathrm{d}_{6^{-}}$

Benzene.

Figure A2.7 ${ }^{1} \mathrm{H}$ NMR Spectrum of $\operatorname{Ir}(\mathrm{COD})\left[\mathrm{Ph}_{2} \mathrm{PCH}_{2} \mathrm{CH}_{2} \mathrm{~B}\left(\mathrm{C}_{8} \mathrm{H}_{14}\right)\right] \mathrm{Cl}$ in $\mathrm{d}_{6^{-}}$

Benzene.

Figure A2.8 ${ }^{31} \mathrm{P}\left\{{ }^{1} \mathrm{H}\right\}$ NMR Spectrum of $\operatorname{Ir}(\mathrm{COD})\left[\mathrm{Ph}_{2} \mathrm{PCH}_{2} \mathrm{CH}_{2} \mathrm{~B}\left(\mathrm{C}_{8} \mathrm{H}_{14}\right)\right] \mathrm{Cl}$ in $\mathrm{d}_{6}-$

Benzene.

Figure A2.9 ${ }^{11} \mathrm{~B}\left\{{ }^{1} \mathrm{H}\right\}$ NMR Spectrum of $\operatorname{Ir}(\mathrm{COD})\left[\mathrm{Ph}_{2} \mathrm{PCH}_{2} \mathrm{CH}{ }_{2} \mathrm{~B}\left(\mathrm{C}_{8} \mathrm{H}_{14}\right)\right] \mathrm{Cl}$ in $\mathrm{d}_{6^{-}}$

Benzene.

Figure A2.10 ${ }^{13} \mathrm{C}\left\{{ }^{1} \mathrm{H}\right\}$ NMR Spectrum of $\operatorname{Ir}(\mathrm{COD})\left[\mathrm{Ph}_{2} \mathrm{PCH}_{2} \mathrm{CH} \mathrm{B}_{2} \mathrm{~B}\left(\mathrm{C}_{8} \mathrm{H}_{14}\right)\right] \mathrm{Cl}$ in $\mathrm{d}_{2^{-}}$

Dichloromethane.

Figure A2.11 ${ }^{1} \mathrm{H}$ NMR Spectrum of $\mathrm{Rh}(\mathrm{COD})\left[\mathrm{Ph}_{2} \mathrm{PCH}_{2} \mathrm{CH}_{2} \mathrm{~B}\left(\mathrm{C}_{8} \mathrm{H}_{14}\right)\right] \mathrm{OTf}$ in $\mathrm{d}_{6^{-}}$

Benzene.

Figure A2.12 ${ }^{31} \mathrm{P}\left\{{ }^{1} \mathrm{H}\right\}$ NMR Spectrum of $\mathrm{Rh}(\mathrm{COD})\left[\mathrm{Ph}_{2} \mathrm{PCH}_{2} \mathrm{CH}_{2} \mathrm{~B}\left(\mathrm{C}_{8} \mathrm{H}_{14}\right)\right] \mathrm{OTf}$ in $\mathrm{d}_{6^{-}}$

Benzene.

Figure A2.13 ${ }^{19} \mathrm{~F}$ NMR Spectrum of $\mathrm{Rh}(\mathrm{COD})\left[\mathrm{Ph}_{2} \mathrm{PCH}_{2} \mathrm{CH}_{2} \mathrm{~B}\left(\mathrm{C}_{8} \mathrm{H}_{14}\right)\right] \mathrm{OTf}$ in $\mathrm{d}_{6^{-}}$ Benzene. 
Figure A2.14 ${ }^{11} \mathrm{~B}\left\{{ }^{1} \mathrm{H}\right\}$ NMR Spectrum of $\mathrm{Rh}(\mathrm{COD})\left[\mathrm{Ph}_{2} \mathrm{PCH}_{2} \mathrm{CH}_{2} \mathrm{~B}\left(\mathrm{C}_{8} \mathrm{H}_{14}\right)\right] \mathrm{OTf}$ in $\mathrm{d}_{6^{-}}$

Benzene.

Figure A2.15 ${ }^{1} \mathrm{H}$ NMR Spectrum of $\mathrm{Rh}(\mathrm{COD})\left[\mathrm{Ph}_{2} \mathrm{PCH}_{2} \mathrm{CH}_{2} \mathrm{~B}\left(\mathrm{C}_{8} \mathrm{H}_{14}\right)\right]$ in $\mathrm{d}_{6}$ -

Benzene.

Figure A2.16 ${ }^{31} \mathrm{P}\left\{{ }^{1} \mathrm{H}\right\}$ NMR Spectrum of $\mathrm{Rh}(\mathrm{COD})\left[\mathrm{Ph}_{2} \mathrm{PCH}_{2} \mathrm{CH}_{2} \mathrm{~B}\left(\mathrm{C}_{8} \mathrm{H}_{14}\right)\right] l$ in $\mathrm{d}_{6^{-}}$

Benzene.

Figure A2.17 ${ }^{11} \mathrm{~B}\left\{{ }^{1} \mathrm{H}\right\}$ NMR Spectrum of $\mathrm{Rh}(\mathrm{COD})\left[\mathrm{Ph}_{2} \mathrm{PCH}_{2} \mathrm{CH}_{2} \mathrm{~B}\left(\mathrm{C}_{8} \mathrm{H}_{14}\right)\right] l$ in $\mathrm{d}_{6^{-}}$

Benzene.

Figure A2.18 ${ }^{13} \mathrm{C}\left\{{ }^{1} \mathrm{H}\right\}$ NMR Spectrum of $\mathrm{Rh}(\mathrm{COD})\left[\mathrm{Ph}_{2} \mathrm{PCH}_{2} \mathrm{CH} \mathrm{B}_{2} \mathrm{~B}\left(\mathrm{C}_{8} \mathrm{H}_{14}\right)\right] 1$ in $\mathrm{d}_{6}-$

Benzene

Figure A2.19 ${ }^{1} \mathrm{H}$ NMR Spectrum of $\mathrm{Rh}(\mathrm{COD})\left[\mathrm{Ph}_{2} \mathrm{PCH}_{2} \mathrm{CH}_{2} \mathrm{~B}\left(\mathrm{C}_{8} \mathrm{H}_{14}\right)\right] \mathrm{Br}$ in $\mathrm{d}_{6}-$

Benzene.

Figure A2.20 ${ }^{31} \mathrm{P}\left\{{ }^{1} \mathrm{H}\right\}$ NMR Spectrum of $\mathrm{Rh}(\mathrm{COD})\left[\mathrm{Ph}_{2} \mathrm{PCH}_{2} \mathrm{CH}_{2} \mathrm{~B}\left(\mathrm{C}_{8} \mathrm{H}_{14}\right)\right] \mathrm{Br}$ in $\mathrm{d}_{6^{-}}$

Benzene

Figure A2.21 ${ }^{11} \mathrm{~B}\left\{{ }^{1} \mathrm{H}\right\}$ NMR Spectrum of $\mathrm{Rh}(\mathrm{COD})\left[\mathrm{Ph}_{2} \mathrm{PCH}_{2} \mathrm{CH}_{2} \mathrm{~B}\left(\mathrm{C}_{8} \mathrm{H}_{14}\right)\right] \mathrm{Br}$ in $\mathrm{d}_{6^{-}}$

Benzene.

Figure A2.22 ${ }^{13} \mathrm{C}\left\{{ }^{1} \mathrm{H}\right\}$ NMR Spectrum of $\mathrm{Rh}(\mathrm{COD})\left[\mathrm{Ph}_{2} \mathrm{PCH}_{2} \mathrm{CH}_{2} \mathrm{~B}\left(\mathrm{C}_{8} \mathrm{H}_{14}\right)\right] \mathrm{Br}$ in $\mathrm{d}_{6^{-}}$

Benzene.

Figure A2.23 ${ }^{1} \mathrm{H}$ NMR Spectrum of $\mathrm{Rh}(\mathrm{COD})\left[\mathrm{Ph}_{2} \mathrm{PCH}_{2} \mathrm{CH}_{2} \mathrm{~B}\left(\mathrm{C}_{8} \mathrm{H}_{14}\right)\right] \mathrm{F}$ in $\mathrm{d}_{6}{ }^{-}$

Benzene.

Figure A2.24 ${ }^{31} \mathrm{P}\left\{{ }^{1} \mathrm{H}\right\} \mathrm{NMR}$ Spectrum of $\mathrm{Rh}(\mathrm{COD})\left[\mathrm{Ph}_{2} \mathrm{PCH}_{2} \mathrm{CH}_{2} \mathrm{~B}\left(\mathrm{C}_{8} \mathrm{H}_{14}\right)\right] \mathrm{F}$ in $\mathrm{d}_{6^{-}}$ Benzene. 
Figure A2.25 ${ }^{11} \mathrm{~B}\left\{{ }^{1} \mathrm{H}\right\}$ NMR Spectrum of $\mathrm{Rh}(\mathrm{COD})\left[\mathrm{Ph}_{2} \mathrm{PCH}_{2} \mathrm{CH}_{2} \mathrm{~B}\left(\mathrm{C}_{8} \mathrm{H}_{14}\right)\right] \mathrm{F}$ in $\mathrm{d}_{6^{-}}$

Benzene.

Figure A2.26 ${ }^{19} \mathrm{~F}$ NMR Spectrum of $\mathrm{Rh}(\mathrm{COD})\left[\mathrm{Ph}_{2} \mathrm{PCH}_{2} \mathrm{CH}_{2} \mathrm{~B}\left(\mathrm{C}_{8} \mathrm{H}_{14}\right)\right] \mathrm{F}$ in $\mathrm{d}_{6^{-}}$

Benzene.

Figure A2.27 ${ }^{11} \mathrm{C}\left\{{ }^{1} \mathrm{H}\right\}$ NMR Spectrum of $\mathrm{Rh}(\mathrm{COD})\left[\mathrm{Ph}_{2} \mathrm{PCH}_{2} \mathrm{CH}_{2} \mathrm{~B}\left(\mathrm{C}_{8} \mathrm{H}_{14}\right)\right] \mathrm{F}$ in $\mathrm{d}_{6}-$

Benzene.

Figure A2.28 ${ }^{1} \mathrm{H}$ NMR Spectrum of $\mathrm{Rh}(\mathrm{CO})\left[\mathrm{Ph}_{2} \mathrm{PCH}_{2} \mathrm{CH}_{2} \mathrm{~B}\left(\mathrm{C}_{8} \mathrm{H}_{14}\right)\right]_{2} \mathrm{Cl}$ in $\mathrm{d}_{6^{-}}$

Benzene.

Figure A2.29 ${ }^{31} \mathrm{P}\left\{{ }^{1} \mathrm{H}\right\}$ NMR Spectrum of $\mathrm{Rh}(\mathrm{CO})\left[\mathrm{Ph}_{2} \mathrm{PCH}_{2} \mathrm{CH}_{2} \mathrm{~B}\left(\mathrm{C}_{8} \mathrm{H}_{14}\right)\right]_{2} \mathrm{Cl}$ in $\mathrm{d}_{6^{-}}$

Benzene.

Figure A2.30 ${ }^{11} \mathrm{~B}\left\{{ }^{1} \mathrm{H}\right\}$ NMR Spectrum of $\mathrm{Rh}(\mathrm{CO})\left[\mathrm{Ph}_{2} \mathrm{PCH}_{2} \mathrm{CH}_{2} \mathrm{~B}\left(\mathrm{C}_{8} \mathrm{H}_{14}\right)\right]_{2} \mathrm{Cl}$ in $\mathrm{d}_{6^{-}}$

Benzene.

Figure A2.31 ${ }^{13} \mathrm{C}\left\{{ }^{1} \mathrm{H}\right\}$ NMR Spectrum of $\mathrm{Rh}(\mathrm{CO})\left[\mathrm{Ph}_{2} \mathrm{PCH}_{2} \mathrm{CH}_{2} \mathrm{~B}\left(\mathrm{C}_{8} \mathrm{H}_{14}\right)\right]_{2} \mathrm{Cl}$ in $\mathrm{d}_{6}-$

Benzene.

Figure A2.32 FTIR Spectrum of $\mathrm{Rh}(\mathrm{CO})\left[\mathrm{Ph}_{2} \mathrm{PCH}_{2} \mathrm{CH}_{2} \mathrm{~B}\left(\mathrm{C}_{8} \mathrm{H}_{14}\right)\right]_{2} \mathrm{Cl} \quad 260$

Figure A2.33 ${ }^{1} \mathrm{H}$ NMR Spectrum of $\left[\mathrm{Rh}\left[\mathrm{Ph}_{2} \mathrm{PCH}_{2} \mathrm{CH}_{2} \mathrm{~B}\left(\mathrm{C}_{8} \mathrm{H}_{14}\right)\right]_{2} \mathrm{Cl}\right]_{2}$ in $\mathrm{d}_{6}$-Benzene. $\quad 261$

Figure A2.34 ${ }^{31} \mathrm{P}\left\{{ }^{1} \mathrm{H}\right\}$ NMR Spectrum of $\left[\mathrm{Rh}\left[\mathrm{Ph}_{2} \mathrm{PCH}_{2} \mathrm{CH}_{2} \mathrm{~B}\left(\mathrm{C}_{8} \mathrm{H}_{14}\right)\right]_{2} \mathrm{Cl}\right]_{2}$ in $\mathrm{d}_{6}{ }^{-}$

Benzene.

Figure A2.35 ${ }^{11} \mathrm{~B}\left\{{ }^{1} \mathrm{H}\right\}$ NMR Spectrum of $\left[\mathrm{Rh}\left[\mathrm{Ph}_{2} \mathrm{PCH}_{2} \mathrm{CH}_{2} \mathrm{~B}\left(\mathrm{C}_{8} \mathrm{H}_{14}\right)\right]_{2} \mathrm{Cl}\right]_{2}$ in $\mathrm{d}_{6^{-}}$

Benzene.

Figure A2.36 $\quad{ }^{1} \mathrm{H}$ NMR Spectrum of $\mathrm{Rh}\left[\mathrm{Ph}_{2} \mathrm{PCH}_{2} \mathrm{CH}_{2} \mathrm{~B}\left(\mathrm{C}_{8} \mathrm{H}_{14}\right)\right]_{3} \mathrm{Cl}$ in $\mathrm{d}_{6}-$-Benzene. $\quad 264$

Figure A2.37 ${ }^{31} \mathrm{P}\left\{{ }^{1} \mathrm{H}\right\}$ NMR Spectrum of $\mathrm{Rh}\left[\mathrm{Ph}_{2} \mathrm{PCH}_{2} \mathrm{CH}_{2} \mathrm{~B}\left(\mathrm{C}_{8} \mathrm{H}_{14}\right)\right]_{3} \mathrm{Cl}$ in $\mathrm{d}_{6}-$ 
Figure A2.38 ${ }^{11} \mathrm{~B}\left\{{ }^{1} \mathrm{H}\right\}$ NMR Spectrum of $\mathrm{Rh}\left[\mathrm{Ph}_{2} \mathrm{PCH}_{2} \mathrm{CH}_{2} \mathrm{~B}\left(\mathrm{C}_{8} \mathrm{H}_{14}\right)\right]_{3} \mathrm{Cl}$ in $\mathrm{d}_{2}-$ Dichloromethane.

Figure A2.39 ${ }^{13} \mathrm{C}\left\{{ }^{1} \mathrm{H}\right\} \mathrm{NMR}$ Spectrum of $\mathrm{Rh}\left[\mathrm{Ph}_{2} \mathrm{PCH}_{2} \mathrm{CH}_{2} \mathrm{~B}\left(\mathrm{C}_{8} \mathrm{H}_{14}\right)\right]_{3} \mathrm{Cl}$ in $\mathrm{d}_{2^{-}}$ Dichloromethane.

Figure A2.40 ${ }^{11} \mathrm{~B}\left\{{ }^{1} \mathrm{H}\right\}$ NMR Spectrum of $\mathrm{Rh}(\mathrm{COD})\left[\mathrm{Ph}_{2} \mathrm{PCH}_{2} \mathrm{CH}_{2} \mathrm{~B}\left(\mathrm{C}_{8} \mathrm{H}_{14}\right)\right] \mathrm{Cl}$ in mixed solvents.

Figure A2.41 ${ }^{11} \mathrm{~B}\left\{{ }^{1} \mathrm{H}\right\}$ NMR Spectrum of $\mathrm{Rh}(\mathrm{COD})\left[\mathrm{Ph}_{2} \mathrm{PCH}_{2} \mathrm{CH}_{2} \mathrm{~B}\left(\mathrm{C}_{8} \mathrm{H}_{14}\right)\right] \mathrm{Cl}$ in different solvents.

Figure A2.42 ${ }^{1} \mathrm{H}$ NMR NMR Spectrum of $\mathrm{Rh}(\mathrm{COD})\left[\mathrm{Ph}_{2} \mathrm{PCH}_{2} \mathrm{CH}_{2} \mathrm{~B}\left(\mathrm{C}_{8} \mathrm{H}_{14}\right)\right] \mathrm{Cl}$ in $\mathrm{d}_{2^{-}}$ Dichloromethane at low temperature.

Figure A2.43 ${ }^{1} \mathrm{H}$ NMR spectra at $\mathrm{Rh}(\mathrm{COD})\left[\mathrm{Ph}_{2} \mathrm{PCH}_{2} \mathrm{CH}_{2} \mathrm{~B}\left(\mathrm{C}_{8} \mathrm{H}_{14}\right)\right] \mathrm{Cl}$ in d8-toluene at low temperature.

Figure A2.44 ${ }^{31} \mathrm{P}\left\{{ }^{1} \mathrm{H}\right\} \mathrm{NMR}$ spectra at $\mathrm{Rh}(\mathrm{COD})\left[\mathrm{Ph}_{2} \mathrm{PCH}_{2} \mathrm{CH}_{2} \mathrm{~B}\left(\mathrm{C}_{8} \mathrm{H}_{14}\right)\right] \mathrm{Cl}$ in $\mathrm{d}_{8^{-}}$ toluene at low temperature.

Figure A2.45 ${ }^{1} \mathrm{H}$ NMR Spectrum of $\mathrm{Rh}(\mathrm{COD})\left[\mathrm{Ph}_{2} \mathrm{PCH}_{2} \mathrm{CH}_{2} \mathrm{~B}\left(\mathrm{C}_{8} \mathrm{H}_{14}\right)\right] \mathrm{N}_{3}$ in $\mathrm{d}_{2^{-}}$ Dichloromethane.

Figure A2.46 ${ }^{31} \mathrm{P}\left\{{ }^{1} \mathrm{H}\right\}$ NMR Spectrum of $\mathrm{Rh}(\mathrm{COD})\left[\mathrm{Ph}_{2} \mathrm{PCH}_{2} \mathrm{CH} \mathrm{B}_{2}\left(\mathrm{C}_{8} \mathrm{H}_{14}\right)\right] \mathrm{N}_{3}$ in $\mathrm{d}_{2^{-}}$ Dichloromethane.

Figure A2.47 ${ }^{11} \mathrm{~B}\left\{{ }^{1} \mathrm{H}\right\}$ NMR Spectrum of $\mathrm{Rh}(\mathrm{COD})\left[\mathrm{Ph}_{2} \mathrm{PCH}_{2} \mathrm{CH}_{2} \mathrm{~B}\left(\mathrm{C}_{8} \mathrm{H}_{14}\right)\right] \mathrm{N}_{3}$ in $\mathrm{d}_{2-}$ Dichloromethane.

Figure A2.48 ${ }^{13} \mathrm{C}\left\{{ }^{1} \mathrm{H}\right\}$ NMR Spectrum of $\mathrm{Rh}(\mathrm{COD})\left[\mathrm{Ph}_{2} \mathrm{PCH}_{2} \mathrm{CH} \mathrm{B}_{2}\left(\mathrm{C}_{8} \mathrm{H}_{14}\right)\right] \mathrm{N}_{3}$ in $\mathrm{d}_{2^{-}}$ Dichloromethane.

Figure A2.49 FTIR Spectrum of $\mathrm{Rh}(\mathrm{COD})\left[\mathrm{Ph}_{2} \mathrm{PCH}_{2} \mathrm{CH}_{2} \mathrm{~B}\left(\mathrm{C}_{8} \mathrm{H}_{14}\right)\right] \mathrm{N}_{3}$. 
Figure A2.50 ${ }^{1} \mathrm{H}$ NMR Spectrum of $\operatorname{Ir}(\mathrm{COD})\left[\mathrm{Ph}_{2} \mathrm{PCH}_{2} \mathrm{CH}_{2} \mathrm{~B}\left(\mathrm{C}_{8} \mathrm{H}_{14}\right)\right] \mathrm{N}_{3}$ in $\mathrm{d}_{2^{-}}$ Dichloromethane.

Figure A2.51 ${ }^{31} \mathrm{P}\left\{{ }^{1} \mathrm{H}\right\}$ NMR Spectrum of $\operatorname{Ir}(\mathrm{COD})\left[\mathrm{Ph}_{2} \mathrm{PCH}_{2} \mathrm{CH} \mathrm{H}_{2} \mathrm{~B}\left(\mathrm{C}_{8} \mathrm{H}_{14}\right)\right] \mathrm{N}_{3}$ in $\mathrm{d}_{2}$ -

Dichloromethane.

Figure A2.52 ${ }^{11} \mathrm{~B}\left\{{ }^{1} \mathrm{H}\right\}$ NMR Spectrum of $\operatorname{Ir}(\mathrm{COD})\left[\mathrm{Ph}_{2} \mathrm{PCH}_{2} \mathrm{CH}_{2} \mathrm{~B}\left(\mathrm{C}_{8} \mathrm{H}_{14}\right)\right] \mathrm{N}_{3}$ in $\mathrm{d}_{2^{-}}$ Dichloromethane.

Figure A2.53 ${ }^{13} \mathrm{C}\left\{{ }^{1} \mathrm{H}\right\}$ NMR Spectrum of $\operatorname{Ir}(\mathrm{COD})\left[\mathrm{Ph}_{2} \mathrm{PCH}_{2} \mathrm{CH} \mathrm{B}_{2} \mathrm{~B}\left(\mathrm{C}_{8} \mathrm{H}_{14}\right)\right] \mathrm{N}_{3}$ in $\mathrm{d}_{2^{-}}$ Dichloromethane.

Figure A2.54 FTIR Spectrum of $\operatorname{Ir}(\mathrm{COD})\left[\mathrm{Ph}_{2} \mathrm{PCH}_{2} \mathrm{CH}_{2} \mathrm{~B}\left(\mathrm{C}_{8} \mathrm{H}_{14}\right)\right] \mathrm{N}_{3}$.

Figure A2.55 Hydroboration of Styrene with Catecholborane (5 equiv. excess PB Ligand) with RhCODPBCl catalyst.

Figure A2.56 ${ }^{1} \mathrm{H}$ NMR Spectrum of $\mathrm{Rh}(\mathrm{COD})\left[\mathrm{Ph}_{2} \mathrm{PCH}_{2} \mathrm{CH}_{2} \mathrm{~B}\left(\mathrm{C}_{8} \mathrm{H}_{14}\right) \mathrm{Cl}+\mathrm{AgOTf}\right.$ in $\mathrm{d}_{8}$-THF with (top) and without (bottom) HBPin.

Figure A2.57 ${ }^{31} \mathrm{P}\left\{{ }^{1} \mathrm{H}\right\} \quad \mathrm{NMR}$ Spectrum of $\mathrm{Rh}(\mathrm{COD})\left[\mathrm{Ph}_{2} \mathrm{PCH}_{2} \mathrm{CH}_{2} \mathrm{~B}\left(\mathrm{C}_{8} \mathrm{H}_{14}\right) \mathrm{Cl}+\right.$ AgOTf in $d_{8}$-THF with (top) and without (bottom) HBPin.

Figure A2.58 ${ }^{11} \mathrm{~B}\left\{{ }^{1} \mathrm{H}\right\}$ NMR Spectrum of $\mathrm{Rh}(\mathrm{COD})\left[\mathrm{Ph}_{2} \mathrm{PCH}_{2} \mathrm{CH}_{2} \mathrm{~B}\left(\mathrm{C}_{8} \mathrm{H}_{14}\right) \mathrm{Cl}+\right.$ AgOTf in $\mathrm{d}_{8}$-THF with HBPin.

Figure A2.59 Time-course of $\left[\mathrm{Rh}\left[\mathrm{Ph}_{2} \mathrm{PCH}_{2} \mathrm{CH}_{2} \mathrm{~B}\left(\mathrm{C}_{8} \mathrm{H}_{14}\right)\right]_{2} \mathrm{Cl}\right]_{2}$ Reaction with HBPin ${ }^{31} \mathrm{P}\left\{{ }^{1} \mathrm{H}\right\}$ NMR Spectrum in $\mathrm{d}_{6}$-Benzene.

Figure A2.60 ${ }^{1} \mathrm{H}$ NMR Spectrum of $\left[\mathrm{Rh}\left[\mathrm{Ph}_{2} \mathrm{PCH}_{2} \mathrm{CH}_{2} \mathrm{~B}\left(\mathrm{C}_{8} \mathrm{H}_{14}\right)\right]_{2} \mathrm{Cl}\right]_{2}$ Reaction with HBPin in $\mathrm{d}_{6}$-Benzene.

Figure A2.61 ${ }^{31} \mathrm{P}\left\{{ }^{1} \mathrm{H}\right\}$ NMR Spectrum of $\left[\mathrm{Rh}\left[\mathrm{Ph}_{2} \mathrm{PCH}_{2} \mathrm{CH}_{2} \mathrm{~B}\left(\mathrm{C}_{8} \mathrm{H}_{14}\right)\right]_{2} \mathrm{Cl}\right]_{2}$ Reaction with HBPin in $d_{6}$-Benzene. 
Figure A2.62 ${ }^{11} \mathrm{~B}\left\{{ }^{1} \mathrm{H}\right\}$ NMR Spectrum of $\left[\mathrm{Rh}\left[\mathrm{Ph}_{2} \mathrm{PCH}_{2} \mathrm{CH}_{2} \mathrm{~B}\left(\mathrm{C}_{8} \mathrm{H}_{14}\right)\right]_{2} \mathrm{Cl}\right]_{2}$ Reaction with HBPin in $\mathrm{d}_{6}$-Benzene.

Figure A2.63 ${ }^{1} \mathrm{H}$ NMR Spectrum of $\mathrm{Rh}\left[\mathrm{Ph}_{2} \mathrm{PCH}_{2} \mathrm{CH}_{2} \mathrm{~B}\left(\mathrm{C}_{8} \mathrm{H}_{14}\right)\right]_{3} \mathrm{Cl}$ Reaction with $\mathrm{H}_{2}$ in $\mathrm{d}_{8}$-Toluene at $-78^{\circ} \mathrm{C}$.

Figure A2.64 ${ }^{31} \mathrm{P}\left\{{ }^{1} \mathrm{H}\right\} \mathrm{NMR}$ Spectrum of $\mathrm{Rh}\left[\mathrm{Ph}_{2} \mathrm{PCH}_{2} \mathrm{CH}_{2} \mathrm{~B}\left(\mathrm{C}_{8} \mathrm{H}_{14}\right)\right]_{3} \mathrm{Cl}$ Reaction with $\mathrm{H}_{2}$ in $\mathrm{d}_{8}$-Toluene at $-78^{\circ} \mathrm{C}$.

Figure A2.65 ${ }^{1} \mathrm{H}$ (bottom) and ${ }^{1} \mathrm{H}\left\{{ }^{31} \mathrm{P}\right\}$ (top) NMR Spectra of $\left[\mathrm{Rh}\left(\mathrm{PPh}_{3}\right)_{2} \mathrm{Cl}\right]_{2}$ Reaction with HBPin in $d_{6}$-Benzene.

Figure A2.66 $\left[\mathrm{Rh}\left[\mathrm{Ph}_{2} \mathrm{PCH}_{2} \mathrm{CH}_{2} \mathrm{~B}\left(\mathrm{C}_{8} \mathrm{H}_{14}\right)\right]_{2} \mathrm{Cl}\right]_{2}$ Reaction with $\mathrm{HBPin}{ }^{1} \mathrm{H}$ (bottom) and ${ }^{1} \mathrm{H}\left\{{ }^{31} \mathrm{P}\right\}$ (top) NMR Spectra in $\mathrm{d}_{6}$-Benzene.

Figure A2.67 ${ }^{1} \mathrm{H}$ NMR Spectrum of Vinylphosphine Pinacolborane Hydroboration Products in $d_{6}$-Benzene.

Figure A2.68 ${ }^{31} \mathrm{P}\left\{{ }^{1} \mathrm{H}\right\}$ NMR Spectrum of Vinylphosphine Pinacolborane Hydroboration Products in $\mathrm{d}_{6}$-Benzene.

Figure A2.69 ${ }^{11} \mathrm{~B}\left\{{ }^{1} \mathrm{H}\right\}$ NMR Spectrum of Vinylphosphine Pinacolborane Hydroboration Products in $\mathrm{d}_{6}$-Benzene.

Figure A2.70 $\quad{ }^{11}$ B NMR Spectrum of Vinylphosphine Pinacolborane Hydroboration

Products in $d_{6}$-Benzene.

Figure A2.71 ${ }^{1} \mathrm{H}$ - Selective ${ }^{31} \mathrm{P}$ decoupled NMR Spectrum of $2.10 \mathrm{ppm}$ Resonance of Vinylphosphine Pinacolborane Hydroboration Products in $d_{6}$-Benzene. 
Figure A2.72 TOCSY1D NMR Spectrum on $2.24 \mathrm{ppm}$ Resonance of Vinylphosphine Pinacolborane Hydroboration Products in $\mathrm{d}_{6^{-}}$ Benzene.

Figure A2.73 $\mathrm{Rh}(\mathrm{COD})\left[\mathrm{Ph}_{2} \mathrm{PCH}_{2} \mathrm{CH}_{2} \mathrm{~B}\left(\mathrm{C}_{8} \mathrm{H}_{14}\right)\right] \mathrm{Cl}$ Catalyzed Hydroboration of Vinyldiphenylphosphine with 2 equivalents of $\mathrm{HBCat}$ at $70^{\circ} \mathrm{C}$.

Figure A2.74 $\mathrm{Rh}(\mathrm{CO})\left[\mathrm{Ph}_{2} \mathrm{PCH}_{2} \mathrm{CH}_{2} \mathrm{~B}\left(\mathrm{C}_{8} \mathrm{H}_{14}\right)\right]_{2} \mathrm{Cl}$ Catalyzed Hydroboration of Vinyldiphenylphosphine with 2 equivalents of $\mathrm{HBPin}$ at $70^{\circ} \mathrm{C}$.

Figure A2.75 $\mathrm{Rh}(\mathrm{COD})\left(\mathrm{PPh}_{3}\right) \mathrm{Cl}$ Catalyzed Hydroboration of

Vinyldiphenylphosphine with 2 equivalents of $\mathrm{HBPin}$ at $70^{\circ} \mathrm{C}$.

Figure A2.76 $\quad[\mathrm{Rh}(\mathrm{COD}) \mathrm{Cl}]_{2}$ Catalyzed Hydroboration of Vinyldiphenylphosphine with 2 equivalents of $\mathrm{HBCat}$ at $70^{\circ} \mathrm{C}$.

Figure A2.77 $\mathrm{RhCl}_{3} \square 3 \mathrm{H}_{2} \mathrm{O}$ Catalyzed Hydroboration of Vinyldiphenylphosphine with 2 equivalents of $\mathrm{HBPin}$ at $70^{\circ} \mathrm{C}$ Overnight without Silver.

Figure A2.78 $\left[\mathrm{Rh}(\mathrm{COE})_{2} \mathrm{Cl}\right]_{2}$ Catalyzed Hydroboration of Vinyldiphenylphosphine with 2 equivalents of $\mathrm{HBPin}$ at $70^{\circ} \mathrm{C}$.

Figure A2.79 $\quad\left[\mathrm{Rh}\left(\mathrm{PPh}_{3}\right)_{2} \mathrm{Cl}\right]_{2}$ Catalyzed Hydroboration of Vinyldiphenylphosphine with 2 equivalents of $\mathrm{HBPin}$ at $70^{\circ} \mathrm{C}$.

Figure A2.80 $\mathrm{Rh}\left(\mathrm{PPh}_{3}\right)_{3} \mathrm{Cl}$ Catalyzed Hydroboration of Vinyldiphenylphosphine with 2 equivalents of $\mathrm{HBPin}$ at $70^{\circ} \mathrm{C}$.

Figure A2.81 ${ }^{1} \mathrm{H}$ NMR Spectrum of $\mathrm{Rh}(\mathrm{COD})\left[\mathrm{Ph}_{2} \mathrm{PCH}(\mathrm{BPin}) \mathrm{CH}_{3}\right] \mathrm{Cl}$ in $\mathrm{d}_{6}-$ Benzene. $\quad 313$

Figure A2.82 ${ }^{31} \mathrm{P}\left\{{ }^{1} \mathrm{H}\right\}$ NMR Spectrum of $\mathrm{Rh}(\mathrm{COD})\left[\mathrm{Ph}_{2} \mathrm{PCH}(\mathrm{BPin}) \mathrm{CH}_{3}\right] \mathrm{Cl}$ in $\mathrm{d}_{6^{-}}$

Benzene. 
Figure A2.83 ${ }^{11} \mathrm{~B}\left\{{ }^{1} \mathrm{H}\right\}$ NMR Spectrum of $\mathrm{Rh}(\mathrm{COD})\left[\mathrm{Ph}_{2} \mathrm{PCH}(\mathrm{BPin}) \mathrm{CH}_{3}\right] \mathrm{Cl}$ in $\mathrm{d}_{6^{-}}$

Benzene.

Figure A2.84 ${ }^{13} \mathrm{C}\left\{{ }^{1} \mathrm{H}\right\}$ NMR Spectrum of $\mathrm{Rh}(\mathrm{COD})\left[\mathrm{Ph}_{2} \mathrm{PCH}(\mathrm{BPin}) \mathrm{CH}_{3}\right] \mathrm{Cl}$ in $\mathrm{d}_{6^{-}}$

Benzene.

Figure A2.85 ${ }^{1} \mathrm{H}$ NMR Spectrum of $\mathrm{Ph}_{2} \mathrm{P}\left(\mathrm{BH}_{3}\right) \mathrm{CH}(\mathrm{BPin}) \mathrm{CH}_{3}$ in $\mathrm{d}_{6}$-Benzene.

Figure A2.86

${ }^{31} \mathrm{P}\left\{{ }^{1} \mathrm{H}\right\}$ NMR Spectrum of $\mathrm{Ph}_{2} \mathrm{P}\left(\mathrm{BH}_{3}\right) \mathrm{CH}(\mathrm{BPin}) \mathrm{CH}_{3}$ in $\mathrm{d}_{6}$-Benzene.

Figure A2.87

${ }^{11} \mathrm{~B}\left\{{ }^{1} \mathrm{H}\right\}$ NMR Spectrum of $\mathrm{Ph}_{2} \mathrm{P}\left(\mathrm{BH}_{3}\right) \mathrm{CH}(\mathrm{BPin}) \mathrm{CH}_{3}$ in $\mathrm{d}_{6}$-Benzene.

Figure A2.88 ${ }^{11} \mathrm{~B}$ NMR Spectrum of $\mathrm{Ph}_{2} \mathrm{P}\left(\mathrm{BH}_{3}\right) \mathrm{CH}(\mathrm{BPin}) \mathrm{CH}_{3}$ in $\mathrm{d}_{6}-$ Benzene.

Figure A2.89 ${ }^{13} \mathrm{C}\left\{{ }^{1} \mathrm{H}\right\}$ NMR Spectrum of $\mathrm{Ph}_{2} \mathrm{P}\left(\mathrm{BH}_{3}\right) \mathrm{CH}(\mathrm{BPin}) \mathrm{CH}_{3}$ in $\mathrm{d}_{6}$-Benzene.

Figure A2.90 ${ }^{1} \mathrm{H}$ NMR Spectrum of $\mathrm{Ph}_{2} \mathrm{P}\left(\mathrm{BH}_{3}\right) \mathrm{CH}\left(\mathrm{BF}_{3} \mathrm{~K}\right) \mathrm{CH}_{3}$ in $\mathrm{d}_{6}$-Acetone.

Figure A2.91 ${ }^{31} \mathrm{P}\left\{{ }^{1} \mathrm{H}\right\}$ NMR Spectrum of $\mathrm{Ph}_{2} \mathrm{P}\left(\mathrm{BH}_{3}\right) \mathrm{CH}\left(\mathrm{BF}_{3} \mathrm{~K}\right) \mathrm{CH}_{3}$ in $\mathrm{d}_{6}-$ Acetone.

323

Figure A2.92 ${ }^{31} \mathrm{P}$ NMR Spectrum of $\mathrm{Ph}_{2} \mathrm{P}\left(\mathrm{BH}_{3}\right) \mathrm{CH}\left(\mathrm{BF}_{3} \mathrm{~K}\right) \mathrm{CH}_{3}$ in $\mathrm{d}_{6}-$ Acetone.

Figure A2.93

${ }^{11} \mathrm{~B}\left\{{ }^{1} \mathrm{H}\right\}$ NMR Spectrum of $\mathrm{Ph}_{2} \mathrm{P}\left(\mathrm{BH}_{3}\right) \mathrm{CH}\left(\mathrm{BF}_{3} \mathrm{~K}\right) \mathrm{CH}_{3}$ in $\mathrm{d}_{6}$-Acetone.

325

Figure A2.94 ${ }^{11} \mathrm{~B}$ NMR Spectrum of $\mathrm{Ph}_{2} \mathrm{P}\left(\mathrm{BH}_{3}\right) \mathrm{CH}\left(\mathrm{BF}_{3} \mathrm{~K}\right) \mathrm{CH}_{3}$ in $\mathrm{d}_{6}$-Acetone.

Figure A2.95 ${ }^{19} \mathrm{~F}$ NMR Spectrum of $\mathrm{Ph}_{2} \mathrm{P}\left(\mathrm{BH}_{3}\right) \mathrm{CH}\left(\mathrm{BF}_{3} \mathrm{~K}\right) \mathrm{CH}_{3}$ in $\mathrm{d}_{6}$-Acetone.

Figure A2.96 ${ }^{13} \mathrm{C}\left\{{ }^{1} \mathrm{H}\right\}$ NMR Spectrum of $\mathrm{Ph}_{2} \mathrm{P}\left(\mathrm{BH}_{3}\right) \mathrm{CH}\left(\mathrm{BF}_{3} \mathrm{~K}\right) \mathrm{CH}_{3}$ in $\mathrm{d}_{6}$-Acetone.

Figure A2.97 ${ }^{1} \mathrm{H}$ NMR Spectrum of $\mathrm{Rh}(\mathrm{COD})\left[\mathrm{Ph}_{2} \mathrm{PCH}_{2} \mathrm{CH}_{2} \mathrm{~B}\left(\mathrm{C}_{8} \mathrm{H}_{14}\right)\right] \mathrm{OTf}$ with 8Quinolinecarbaldehyde in $\mathrm{d}_{6}$-Benzene.

Figure A2.98 ${ }^{31} \mathrm{P}\left\{{ }^{1} \mathrm{H}\right\}$ NMR Spectrum of $\mathrm{Rh}(\mathrm{COD})\left[\mathrm{Ph}_{2} \mathrm{PCH}_{2} \mathrm{CH} \mathrm{B}_{2}\left(\mathrm{C}_{8} \mathrm{H}_{14}\right)\right] \mathrm{OTf}$ with 8-Quinolinecarbaldehyde in $d_{6}$-Benzene.

Figure A2.99 ${ }^{11} \mathrm{~B}\left\{{ }^{1} \mathrm{H}\right\}$ NMR Spectrum of $\mathrm{Rh}(\mathrm{COD})\left[\mathrm{Ph}_{2} \mathrm{PCH}_{2} \mathrm{CH} \mathrm{B}_{2}\left(\mathrm{C}_{8} \mathrm{H}_{14}\right)\right] \mathrm{OTf}$ with 8-Quinolinecarbaldehyde in $d_{6}$-Benzene. 
Figure A2.100 ${ }^{19} \mathrm{~F}$ NMR Spectrum of $\mathrm{Rh}(\mathrm{COD})\left[\mathrm{Ph}_{2} \mathrm{PCH}_{2} \mathrm{CH}_{2} \mathrm{~B}\left(\mathrm{C}_{8} \mathrm{H}_{14}\right)\right] \mathrm{OTf}$ with 8Quinolinecarbaldehyde in $\mathrm{d}_{6}$-Benzene.

Figure A2.101 ${ }^{1} \mathrm{H}$ NMR Spectrum of $\mathrm{Rh}\left[\mathrm{Ph}_{2} \mathrm{PCH}_{2} \mathrm{CH}_{2} \mathrm{~B}\left(\mathrm{C}_{8} \mathrm{H}_{14}\right)\right]_{3} \mathrm{Cl}$ with $\mathrm{AgOTf}$ and 8-Quinolinecarbaldehyde in $d_{6}$-Benzene.

Figure A2.102 ${ }^{31} \mathrm{P}\left\{{ }^{1} \mathrm{H}\right\} \mathrm{NMR}$ Spectrum of $\mathrm{Rh}\left[\mathrm{Ph}_{2} \mathrm{PCH}_{2} \mathrm{CH}_{2} \mathrm{~B}\left(\mathrm{C}_{8} \mathrm{H}_{14}\right)\right]_{3} \mathrm{Cl}$ with AgOTf and 8-Quinolinecarbaldehyde in $d_{6}$-Benzene.

Figure A2.103 ${ }^{11} \mathrm{~B}\left\{{ }^{1} \mathrm{H}\right\}$ NMR Spectrum of $\mathrm{Rh}\left[\mathrm{Ph}_{2} \mathrm{PCH}_{2} \mathrm{CH} \mathrm{B}_{2} \mathrm{~B}\left(\mathrm{C}_{8} \mathrm{H}_{14}\right)\right]_{3} \mathrm{Cl}$ with AgOTf and 8-Quinolinecarbaldehyde in $\mathrm{d}_{6}$-Benzene.

Figure A2.104 ${ }^{1} \mathrm{H}$ NMR Spectrum of $\left[\mathrm{Rh}\left[\mathrm{Ph}_{2} \mathrm{PCH}_{2} \mathrm{CH}_{2} \mathrm{~B}\left(\mathrm{C}_{8} \mathrm{H}_{14}\right)\right]_{2} \mathrm{Cl}\right]_{2}$ with $\mathrm{AgOTf}$ and 8-Quinolinecarbaldehyde in $d_{6}$-Benzene.

Figure A2.105 ${ }^{31} \mathrm{P}\left\{{ }^{1} \mathrm{H}\right\}$ NMR Spectrum of $\left[\mathrm{Rh}\left[\mathrm{Ph}_{2} \mathrm{PCH}_{2} \mathrm{CH}_{2} \mathrm{~B}\left(\mathrm{C}_{8} \mathrm{H}_{14}\right)\right]_{2} \mathrm{Cl}\right]_{2}$ with AgOTf and 8-Quinolinecarbaldehyde in $\mathrm{d}_{6}$-Benzene.

Figure A2.106 ${ }^{11} \mathrm{~B}\left\{{ }^{1} \mathrm{H}\right\}$ NMR Spectrum of $\left[\mathrm{Rh}\left[\mathrm{Ph}_{2} \mathrm{PCH}_{2} \mathrm{CH}_{2} \mathrm{~B}\left(\mathrm{C}_{8} \mathrm{H}_{14}\right)\right]_{2} \mathrm{Cl}\right]_{2}$ with AgOTf and 8-Quinolinecarbaldehyde in $\mathrm{d}_{6}$-Benzene.

Figure A2.107 ${ }^{1} \mathrm{H}$ NMR Spectrum of $\mathrm{Rh}(\mathrm{COD})\left[\mathrm{Ph}_{2} \mathrm{PCH}_{2} \mathrm{CH}_{2} \mathrm{~B}\left(\mathrm{C}_{8} \mathrm{H}_{14}\right)\right] \mathrm{OTf}$ with 2-

Pyridinecarboxaldehyde in $\mathrm{d}_{6}$-Benzene.

Figure A2.108 ${ }^{31} \mathrm{P}\left\{{ }^{1} \mathrm{H}\right\} \mathrm{NMR}$ Spectrum of $\mathrm{Rh}(\mathrm{COD})\left[\mathrm{Ph}_{2} \mathrm{PCH}_{2} \mathrm{CH}_{2} \mathrm{~B}\left(\mathrm{C}_{8} \mathrm{H}_{14}\right)\right] \mathrm{OTf}$ with 2-Pyridinecarboxaldehyde in $d_{6}$-Benzene.

Figure A2.109 ${ }^{11} \mathrm{~B}\left\{{ }^{1} \mathrm{H}\right\}$ NMR Spectrum of $\mathrm{Rh}(\mathrm{COD})\left[\mathrm{Ph}_{2} \mathrm{PCH}_{2} \mathrm{CH}_{2} \mathrm{~B}\left(\mathrm{C}_{8} \mathrm{H}_{14}\right)\right] \mathrm{OTf}$ with 2-Pyridinecarboxaldehyde in $d_{6}$-Benzene.

Figure A2.110 ${ }^{19} \mathrm{~F}$ NMR Spectrum of $\mathrm{Rh}(\mathrm{COD})\left[\mathrm{Ph}_{2} \mathrm{PCH}_{2} \mathrm{CH}_{2} \mathrm{~B}\left(\mathrm{C}_{8} \mathrm{H}_{14}\right)\right] \mathrm{OTf}$ with 2Pyridinecarboxaldehyde in $\mathrm{d}_{6}$-Benzene. 
Figure A2.111 Conformation of Product in $\mathrm{Rh}(\mathrm{COD})\left[\mathrm{Ph}_{2} \mathrm{PCH}_{2} \mathrm{CH}_{2} \mathrm{~B}\left(\mathrm{C}_{8} \mathrm{H}_{14}\right)\right] \mathrm{OTf}$

Reaction with 2-Pyridinecarboxaldehyde

Figure A2.112 $\mathrm{Rh}(\mathrm{COD})\left[\mathrm{Ph}_{2} \mathrm{PCH}_{2} \mathrm{CH}_{2} \mathrm{~B}\left(\mathrm{C}_{8} \mathrm{H}_{14}\right)\right] \mathrm{OTf}$ Reaction with 2-

Pyridinecarboxaldehyde NMR Shifts and Coupling Constants

Figure A2.113 $\mathrm{Rh}(\mathrm{COD})\left[\mathrm{Ph}_{2} \mathrm{PCH}_{2} \mathrm{CH}_{2} \mathrm{~B}\left(\mathrm{C}_{8} \mathrm{H}_{14}\right)\right] \mathrm{OTf}$ Reaction with 2-

Pyridinecarboxaldehyde 1D TOCSY COD Resonances

Figure A2.114 $\mathrm{Rh}(\mathrm{COD})\left[\mathrm{Ph}_{2} \mathrm{PCH}_{2} \mathrm{CH}_{2} \mathrm{~B}\left(\mathrm{C}_{8} \mathrm{H}_{14}\right)\right] \mathrm{OTf}$ Reaction with 2-

Pyridinecarboxaldehyde 1D TOCSY Methylene Resonances of

$\mathrm{PCH}_{2} \mathrm{CH}_{2} \mathrm{~B}(\mathrm{OHP})$ Fragment

Figure A2.115 $\mathrm{Rh}(\mathrm{COD})\left[\mathrm{Ph}_{2} \mathrm{PCH}_{2} \mathrm{CH}_{2} \mathrm{~B}\left(\mathrm{C}_{8} \mathrm{H}_{14}\right)\right] \mathrm{OTf}$ Reaction with 2-

Pyridinecarboxaldehyde PSYCHE Experiment

Figure A2.116 $\mathrm{Rh}(\mathrm{COD})\left[\mathrm{Ph}_{2} \mathrm{PCH}_{2} \mathrm{CH}_{2} \mathrm{~B}\left(\mathrm{C}_{8} \mathrm{H}_{14}\right)\right] \mathrm{OTf}$ Reaction with 2-

Pyridinecarboxaldehyde Experimental and Calculated Spectra for

$\mathrm{PCH}_{2} \mathrm{CH}_{2} \mathrm{~B}(\mathrm{OHP})$ Fragment

Figure A2.117 $\mathrm{Rh}(\mathrm{COD})\left[\mathrm{Ph}_{2} \mathrm{PCH}_{2} \mathrm{CH}_{2} \mathrm{~B}\left(\mathrm{C}_{8} \mathrm{H}_{14}\right)\right] \mathrm{OTf}$ Reaction with 2-

Pyridinecarboxaldehyde DPFGESNOE Experiment

Figure A2.118 $\mathrm{Rh}(\mathrm{COD})\left[\mathrm{Ph}_{2} \mathrm{PCH}_{2} \mathrm{CH}_{2} \mathrm{~B}\left(\mathrm{C}_{8} \mathrm{H}_{14}\right)\right] \mathrm{OTf}$ Reaction with 2-

Pyridinecarboxaldehyde Experimental and Calculated ${ }^{1} \mathrm{H}\left\{{ }^{13} \mathrm{C}\right\}$ NMR

Spectra for Phenyl and Pyridine Resonances

Figure A2.119 $\mathrm{Rh}(\mathrm{COD})\left[\mathrm{Ph}_{2} \mathrm{PCH}_{2} \mathrm{CH}_{2} \mathrm{~B}\left(\mathrm{C}_{8} \mathrm{H}_{14}\right)\right] \mathrm{OTf}$ Reaction with 2-

Pyridinecarboxaldehyde ${ }^{13} \mathrm{C}\left\{{ }^{1} \mathrm{H}\right\}$ NMR Spectrum 
Figure A2.120 $\mathrm{Rh}(\mathrm{COD})\left[\mathrm{Ph}_{2} \mathrm{PCH}_{2} \mathrm{CH}_{2} \mathrm{~B}\left(\mathrm{C}_{8} \mathrm{H}_{14}\right)\right] \mathrm{OTf}$ Reaction with 2-

Pyridinecarboxaldehyde gHSQCAD NMR Spectrum for Assignment of COD Resonances

Figure A2.121 $\mathrm{Rh}(\mathrm{COD})\left[\mathrm{Ph}_{2} \mathrm{PCH}_{2} \mathrm{CH}_{2} \mathrm{~B}\left(\mathrm{C}_{8} \mathrm{H}_{14}\right)\right] \mathrm{OTf}$ Reaction with 2-

Pyridinecarboxaldehyde ${ }^{1} \mathrm{H}_{-}{ }^{31} \mathrm{P}$ gHMBCAD NMR Spectrum

Figure A2.122 $\mathrm{Rh}(\mathrm{COD})\left[\mathrm{Ph}_{2} \mathrm{PCH}_{2} \mathrm{CH}_{2} \mathrm{~B}\left(\mathrm{C}_{8} \mathrm{H}_{14}\right)\right] \mathrm{OTf}$ Reaction with 2-

Pyridinecarboxaldehyde gHSQCAD NMR Spectrum for Assignment of OHP Resonances

Figure A2.123 $\mathrm{Rh}(\mathrm{COD})\left[\mathrm{Ph}_{2} \mathrm{PCH}_{2} \mathrm{CH}_{2} \mathrm{~B}\left(\mathrm{C}_{8} \mathrm{H}_{14}\right)\right] \mathrm{OTf}$ Reaction with 2-

Pyridinecarboxaldehyde gCOSY NMR Spectrum

Figure A2.124 $\mathrm{Rh}(\mathrm{COD})\left[\mathrm{Ph}_{2} \mathrm{PCH}_{2} \mathrm{CH}_{2} \mathrm{~B}\left(\mathrm{C}_{8} \mathrm{H}_{14}\right)\right] \mathrm{OTf}$ Reaction with 2-

Pyridinecarboxaldehyde gHSQCAD NMR Spectrum for Assignment of $\mathrm{PCH}_{2} \mathrm{CH}_{2} \mathrm{~B}(\mathrm{OHP})$ Fragment

Figure A2.125 $\mathrm{Rh}(\mathrm{COD})\left[\mathrm{Ph}_{2} \mathrm{PCH}_{2} \mathrm{CH}_{2} \mathrm{~B}\left(\mathrm{C}_{8} \mathrm{H}_{14}\right)\right] \mathrm{OTf}$ Reaction with 2-

Pyridinecarboxaldehyde gHSQCAD NMR Spectrum for Assignment of Phenyl and Pyridine Resonances

Figure A2.126 $\mathrm{Rh}(\mathrm{COD})\left[\mathrm{Ph}_{2} \mathrm{PCH}_{2} \mathrm{CH}_{2} \mathrm{~B}\left(\mathrm{C}_{8} \mathrm{H}_{14}\right)\right] \mathrm{OTf}$ Reaction with 2-

Pyridinecarboxaldehyde gHSQCAD NMR Spectrum for Assignment of Methylene Resonances

Figure A2.127 $\mathrm{Rh}(\mathrm{COD})\left[\mathrm{Ph}_{2} \mathrm{PCH}_{2} \mathrm{CH}_{2} \mathrm{~B}\left(\mathrm{C}_{8} \mathrm{H}_{14}\right)\right] \mathrm{OTf}$ Reaction with 2-

Pyridinecarboxaldehyde gHMBCAD NMR Spectrum for Assignment of ipso-Phenyl Resonances 
Figure A2.128 $\mathrm{Rh}(\mathrm{COD})\left[\mathrm{Ph}_{2} \mathrm{PCH}_{2} \mathrm{CH}_{2} \mathrm{~B}\left(\mathrm{C}_{8} \mathrm{H}_{14}\right)\right] \mathrm{OTf}$ Reaction with 2-

Pyridinecarboxaldehyde gHMBC NMR Spectrum for Assignment of

J-Coupling Values within Pyridine Ring System

Figure A2.129 $\mathrm{Rh}(\mathrm{COD})\left[\mathrm{Ph}_{2} \mathrm{PCH}_{2} \mathrm{CH}_{2} \mathrm{~B}\left(\mathrm{C}_{8} \mathrm{H}_{14}\right)\right] \mathrm{OTf}$ Reaction with 2-

Pyridinecarboxaldehyde gHMBC NMR Spectrum for Assignment of

Structure

Figure A2.130 $\mathrm{Rh}(\mathrm{COD})\left[\mathrm{Ph}_{2} \mathrm{PCH}_{2} \mathrm{CH}_{2} \mathrm{~B}\left(\mathrm{C}_{8} \mathrm{H}_{14}\right)\right] \mathrm{OTf}$ Reaction with 2-

Pyridinecarboxaldehyde ${ }^{19} \mathrm{~F}-{ }^{13} \mathrm{C}$ gHMBC NMR Spectrum for

Assignment of Triflate Resonance 


\section{List of Schemes}

Scheme 1.1. Depiction of the cooperative activation of a simple substrate utilizing a transition metal and a Lewis base (left) and two representative examples of metal-Lewis basic cooperative catalyst systems (right). 2

Scheme 1.2. Application of Ru-sulfur cooperativity to aid in the activation of small molecule H-E bonds.

Scheme 1.3. The application of Lewis acids to the formation of transition-metal hydrides via cooperative activation strategies.

Scheme 1.4. Generic hydrofunctionalization of unsaturated substrates.

Scheme 1.5. Different reactions depicting the activation of $\mathrm{H}-\mathrm{X}$ bonds by Lewis acids.

Scheme 1.6. Mechanism for the use of traditional Lewis pairs for reduction of unsaturated substrates.

Scheme 1.7. Hydroboration of alkynes catalyzed by Piers' borane (A) and dicyclohexylborane (B).

Scheme 1.8. Proposed mechanism for generation of activated catalyst $(A)$ and for the hydroboration of alkene substrates catalyzed by tris $(3,5-$ trifluoromethylphenyl)borane $\left(\mathrm{BAr}_{3}\right)(\mathrm{B})$.

Scheme 1.9. Key activation steps in the catalytic hydrosilylation of imines using tris(pentafluorophenyl)borane.

Scheme 1.10. Hydrosilation of silyl enol ethers and enones by $B\left(C_{6} F_{5}\right)_{3}$.

Scheme 1.11. Alterative proposed mechanisms for the Lewis acid catalyzed transhydrosilylation of alkenes, allenes and alkynes. 
Scheme 1.12. Divergent regioselectivity with Lewis acid or $\operatorname{Pd}(0)$ as the catalyst for hydrostannylation of allenes.

Scheme 1.13. Comparison of $\operatorname{Pd}(0)$ and $B\left(C_{6} F_{5}\right)_{3}$ catalyzed hydrostannylations.

Scheme 1.14. Solvent dependent Lewis acid catalyzed hydrostannylation of proparglyic alcohols.

Scheme 1.15. Lewis acid catalyzed hydrostannylation of propargylic alcohols with A) hindered R-group in polar (THF) solvent and B) unhindered Rgroup in non-polar (toluene) solvent.

Scheme 1.16 Representative examples of Lewis acid assisted transition metal catalysis.

Scheme 1.17. Lowest energy activation pathway for dihydrogen activation with $\mathrm{Ni}$ PBP complex.

Scheme 1.18 Hydrogenation of styrene and 3,3-dimethyl-1-butene with [PhB(o$\left.\left.\mathrm{PPh}_{2} \mathrm{C}_{6} \mathrm{H}_{4}\right)_{2}\right]\left(\mu_{2}-\mathrm{H}\right) \mathrm{NiH}$ complex.

Scheme 1.19. Reversible activation of dihydrogen at a Pt(dppf-borane) complex.

Scheme 1.20. Platinum (boryl)iminomethane complex for the activation of dihydrogen.

Scheme 1.21. Reversible activation of dihydrogen at Co-PBP boryl pincer complexes.

Scheme 1.22. Activation of dihydrogen by an iridium PBP-pincer complex.

Scheme 1.23. Change in the coordination environment at rhenium upon binding of Lewis acid co-catalyst. 
Scheme 1.24. One of the proposed modes of activation of Jiang/Berke hydrogenation catalysts.

Scheme 1.25. Mechanism for the hydrogenation of 1-hexene by Jiang/Berke catalyst.

Scheme 1.26. Hydrogenation of internal and terminal alkynes catalyzed by Rupincer complex bearing Lewis acid moiety.

Scheme 1.27. Installation of BPin units in second coordination sphere of Rucomplex with proton-switchable ligand. Structure depicts the presence of a borane interaction with $\mathrm{Ru}-\mathrm{H}$.

Scheme 1.28. Mechanism for the hydroboration of nitriles using a ruthenium complex with Lewis acids in second coordination sphere.

Scheme 2.1. Synthesis of $\beta$-phosphinoethylborane ligand frameworks.

Scheme 2.2. Synthesis of rhodium(I)- and iridium(I) cyclooctadiene complexes with $\beta$-phosphinoethylborane ligand scaffold (top) and Bourissou's synthesis of $\mathrm{Rh}(\mathrm{nbd}) \mathrm{PB}^{\mathrm{Cy}} \mathrm{Cl}$ complex 68 (bottom).

Scheme 2.3. Synthesis of a phosphinoborane analog of a $\mathrm{Rh}(\mathrm{I})$ Vaska's complex. 47

Scheme 2.4. Synthesis of the $\mu_{2}-\mathrm{Cl}$ bridged $\mathrm{Rh}(\mathrm{I})$ phosphinoborane dimer. $\quad 50$

Scheme 2.5. Synthesis of a phosphinoborane analog of Wilkinson's complex. 53

Scheme 2.6. Reactivity of Rh or Ir-nitrido complex bearing a redox active ligand scaffold.

Scheme 2.7. Reactivity of Rh-nitrido bearing a PNP-pincer type ligand scaffold.

Scheme 2.8. Synthesis of $\operatorname{Rh}(\mathrm{I})$ and $\operatorname{Ir}(\mathrm{I})$-azide complexes bearing phosphinoborane ligand. 
Scheme 3.1. Classical organic and Rh-catalyzed approach to the hydroboration of styrene.

Scheme 3.2. Decomposition of HBCat in the presence of nucleophilic phosphine ligand (top) and Wilkinson's catalyst (bottom).

Scheme 3.3. $\mathrm{Rh}(\mathrm{I})$-catalyzed hydroboration of vinyl arenes with pinacolborane utilizing commercially available transition-metal complexes.

Scheme 3.4. Mechanism of hydroboration utilizing rhodium and Lewis acid catalysts that was proposed by Crudden and coworkers.

Scheme 3.5. Proposed in-situ generation of the phosphinoborane $\mathrm{Rh}(\mathrm{I})$ chloride dimer and Wilkinson's analog.

Scheme 3.6. Proposed structure of the product of the reaction of the phosphinoborane $\mathrm{Rh}(\mathrm{I})$ chloride dimer with HBPin (left) and the Wilkinson's analog with $\mathrm{H}_{2}$ (right).

Scheme 4.1. Side-reactions of Lewis basic substrates responsible for lower catalytic hydroboration reactivity.

Scheme 4.2. $\mathrm{Cu}(\mathrm{I})$-catalyzed hydroboration of vinylic diphenylphosphine oxides with $\mathrm{B}_{2} \mathrm{Pin}_{2}$ and subsequent deprotection.

Scheme 4.3. Hydroboration of vinyl diphenylphosphine using a $R h(I)$ complexes bearing an ambiphilic ligand.

Scheme 4.4. Optimized conditions for the regio-divergent synthesis of branched and linear hydroboration products of diphenyl vinylphosphine with HBPin. 
Scheme 4.5 Mechanistic rationale for the observed product selectivity in the hydroboration of diphenylvinylphosphine.

Scheme 4.6. Synthesis of a branched phosphinoborane complex of $\mathrm{Rh}(\mathrm{COD})$ chloride.

Scheme 4.7. Protection of the vinylphosphine hydroboration products with $\mathrm{BH}_{3}$ THF to yield the air- and water-stable $\mathrm{BH}_{3}$-phosphine adducts.

Scheme 4.8. Synthesis of the potassium trifluoroborate salt by reaction of the phosphine-protected pinacol boronic ester with potassium hydrogen difluoride.

Scheme 5.1. Stoichiometric intramolecular hydroacylation with Wilkinson's complex.

Scheme 5.2. Mechanism for the intermolecular hydroacylation catalyzed by a $\mathrm{Rh}(\mathrm{I})$ complex.

Scheme 5.3. Isolation of an acyl $\mathrm{Rh}$ (III) hydride complex as a key intermediate in hydroacylation.

Scheme 5.4. Methods employed for the prevention of decabonylation. (A) Utilization of high pressure of ethylene, (B) use of chelating substrates (chelating groups shown in red) and (C) the condensation of 2-amino-3-picoline onto aldehydes for hydroiminoacylation.

Scheme 5.5. Structures of Brookhart's and Peters' Rh complexes for hydroacylation. 
Scheme 5.6. Rh-Cp type complexes utilized for the intermolecular hydroacylation.

Scheme 5.7. Use of hemi-labile coordination environment for the prevention of decarbonylation.

Scheme 5.8. Proposed stabilization of $\mathrm{Rh}(\mathrm{III})$ acyl complexes by use of pendant Lewis acids.

Scheme 5.9. Reaction of cationic Rh(I) complex with 8-quinolinecarbaldehyde along with desired octahedral $\mathrm{Rh}(\mathrm{III})$ acyl complex.

Scheme 5.10. Reaction of tris(phosphinoborane) $\mathrm{Rh}(\mathrm{I})$ complex with 8- 155 quinolinecarbaldehyde.

Scheme 5.11. Reaction of bis(phosphinoborane) $\mathrm{Rh}(\mathrm{I})$ chloride dimer with 8- 155 quinolinecarbaldehyde.

Scheme 5.12. Reaction of the cationic $\mathrm{Rh}(\mathrm{COD})$ phosphinoborane complex with 2- 158 pyridinecarboxaldehyde.

Scheme 5.13. Reaction of (top) 9-BBN borate salts with acid chlorides resulting in 161 ring migration to form a new $\mathrm{C}-\mathrm{C}$ bond within 9-BBN and (bottom) $\mathrm{Pt}(\mathrm{II})$ complex resulting in a 9-BBN ring rearrangement.

Scheme 5.14. Proposed mechanism for the formation of the ring migration product upon reaction of cationic $\mathrm{Rh}(\mathrm{COD})$ phosphinoborane complex with 2-pyridiencarboxaldehyde. 


\title{
List of Acronyms and Abbreviations
}

\author{
Atm \\ Atmosphere \\ $\mathrm{BAr}_{3}$ \\ Tris(3,5-trifluoromethylphenyl)borane \\ BBN \\ 9-borabicyclo[3.3.1]nonone \\ $\mathrm{Bn}$ \\ Benzyl \\ COD \\ 1,5-cyclooctadiene \\ COE \\ Cyclooctene \\ DABCO \\ 1,4-diazabicyclo[2.2.2]octane \\ DCM \\ Dichloromethane or methylene chloride \\ 1,2-DCE \\ 1,2-dichloroethane \\ DMF \\ $\mathrm{N}, \mathrm{N}$-dimethylformamide \\ DMSO \\ Dimethyl sulfoxide \\ dppe \\ 1,2-bis(diphenylphosphinoethane) \\ dppp \\ 1,2-bis(diphenylphosphinopropane) \\ $\mathrm{dppb}$ \\ 1,2-bis(diphenylphosphinobutane) \\ dppbz \\ 1,2-bis(diphenylphosphinobenzene) \\ DPVP or VP \\ Diphenyl vinylphosphine \\ DPFGESNOE \\ Double-Pulsed Field Gradient Spin-Echo Nuclear \\ Overhauser Effect Spectroscopy \\ FTIR \\ Fourier Transform Infrared Spectroscopy \\ gCOSY \\ Gradient-Selected Correlation Spectroscopy \\ gHMBC \\ Gradient-Selected Phase-Sensitive Heteronuclear \\ Multiple-Bond Correlation Spectroscopy
}




$\begin{array}{cl}\text { gHSQC } & \text { Gradient-Selected Phase-Sensitive Heteronuclear Single } \\ \text { gHSQCAD } & \text { Quantum Correlation Spectroscopy } \\ & \text { Gradient-Selected Phase-Sensitive Heteronuclear Single } \\ \text { HBCat } & \text { Quantum Correlation Adiabatic Spectroscopy } \\ \text { HBPin } & \text { Catecholborane } \\ \text { KIE } & \text { Pinacolborane } \\ \text { NMR } & \text { Ninetic isotope effect } \\ \text { NaN }{ }_{3} & \text { Sodium azide } \\ \text { OTf } & \text { Triflate or trifluoromethanesulfonate } \\ \text { OHP } & \text { Octahydropentalene } \\ \text { PSYCHE } & \text { Pure Shift Yielded by Chirp Excitation } \\ \text { THF } & \text { Tetrahydrofuran } \\ 1 \mathrm{D} \mathrm{TOCSY} & \text { One-Dimensional Total Correlation Spectroscopy } \\ { }^{31} \mathrm{P}\left\{{ }^{1} \mathrm{H}\right\} \text { NMR } & \text { Proton-decoupled phosphorus-31 NMR } \\ { }^{11} \mathrm{~B}\left\{{ }^{1} \mathrm{H}\right\} \mathrm{NMR} & \text { Proton-decoupled boron-11 NMR } \\ { }^{1} \mathrm{H}\left\{{ }^{31} \mathrm{P}\right\} \mathrm{NMR} & \text { Phosphorus-decoupled proton NMR } \\ \end{array}$


CHAPTER 1

Cooperative Transition Metal-Lewis Acid Catalysis: A Survey 


\subsection{Overview}

Cooperative activation of substrates is broadly defined as the creation of a new bond by utilizing two catalytic systems in harmony. Multi-catalyst systems provide enhanced activation of difficult substrates and improved control over selectivity. ${ }^{1-16}$

Biological systems have supplied the chemical community with a myriad of examples pertaining to the cooperative activation of substrates by either ligands or external reagents. The highly active [FeFe]-hydgrogenase enzymes feature amine ligands in close proximity to the iron active site that are believed to function as proton relays or shuttles in conjunction with the metal center. ${ }^{17-19}$ Several other biological systems, including hemoglobin, ${ }^{20}$ nitrogenase enzymes, ${ }^{15}$ oxygenase enzymes, ${ }^{21}$ cytochrome P450, ${ }^{15,16}$ and other metalloenzymes ${ }^{22}$ have been shown to bear critical Lewis basic amino-acid residues in their active sites that are responsible for the stabilization and activation of substrates. The majority of cooperative catalytic systems utilize transition metal catalysts that work synergistically with proximal Lewis basic moieties (Scheme 1.1).

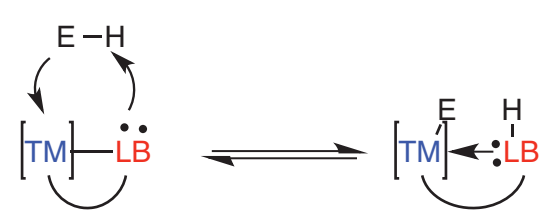

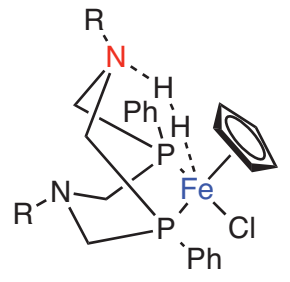

1

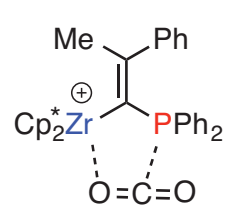

2

Scheme 1.1. Depiction of cooperative activation of a simple substrate utilizing a transition metal and a Lewis base (left) and two representative examples of metal-Lewis basic cooperative catalyst systems 1 and 2 (right).

Cooperative activation of hydrogen gas has since been extended to other homogeneous metal centers, such as nickel, cobalt, or manganese, in an effort to 
develop highly active synthetic hydrogenation catalysts. $^{17,18,23,24}$ Oestreich and coworkers investigated the application of Lewis basic pendant sulfur moieties that assist transition metals for cooperative bond activation (Scheme 1.2). ${ }^{7,25-28}$

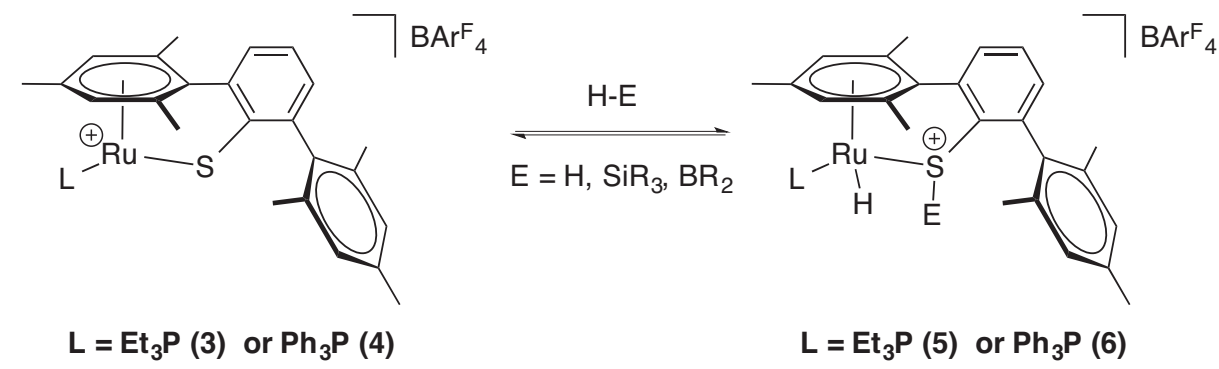

Scheme 1.2. Application of Ru-sulfur cooperativity to aid in the activation of small molecule $\mathrm{H}-\mathrm{E}$ bonds.

One important feature of the systems described thus far is that the activation of the substrate occurs between the transition metal and the Lewis basic ligand. ${ }^{29,30}$ There have also been several examples of main-group Lewis acids for the stabilization and generation of late transition metal hydride systems (Scheme $1.3 \mathrm{~A}) .{ }^{14}$ In addition, several examples of Lewis acid mediated intra- and inter-molecular activation of $\mathrm{H}_{2}$ have been reported (Scheme 1.3B). ${ }^{14}$

A

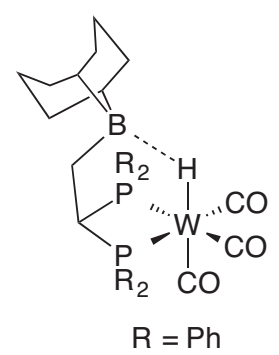

7
B

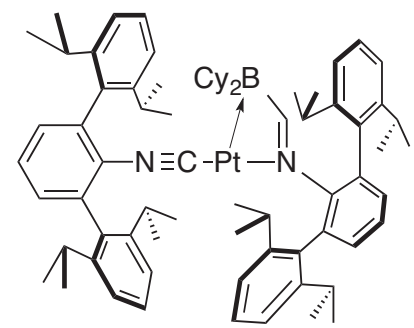

8

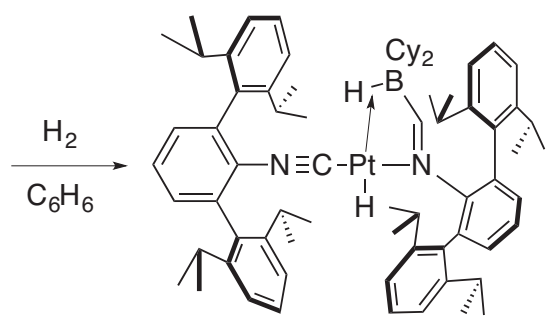

9

Scheme 1.3. The application of Lewis acids to the formation of transition metal hydrides via cooperative activation strategies.

Xi and coworkers highlighted Lewis acids for having several different effects on transition metal catalysis. ${ }^{31}$ Lewis acids were suggested to be capable of improving 
reactivity by lowering the activation barrier of reactions to improve yields in cases where there was limited or no reactivity. This change in the energetics of the reaction can lead to an enhancement in product selectivity. The addition of Lewis acids with or without transition metal co-catalysts can lead to novel products not attainable by traditional transition metal catalyzed routes. In the following sections, Lewis acidic hydrofunctionalization catalysts will be compared and contrasted with traditional transition metal systems. The differences in reactivity and selectivity between these two independent catalyst systems will be highlighted. This will provide insight into the importance of Lewis acidic catalysts and their impact on transition metal catalyzed reactions.

\subsection{Application of Lewis Acids in Non-Transition Metal Catalyzed Hydrofunctionalization Reactions}

Hydrofunctionalization is the addition of hydrogen and another functional group across a carbon-carbon or carbon-heteroatom multiple bond (Scheme 1.4). This transformation can either occur via the activation of an $\mathrm{H}-\mathrm{E}$ bond or by use of other reagents over multiple synthetic steps (formal hydrofunctionalization).

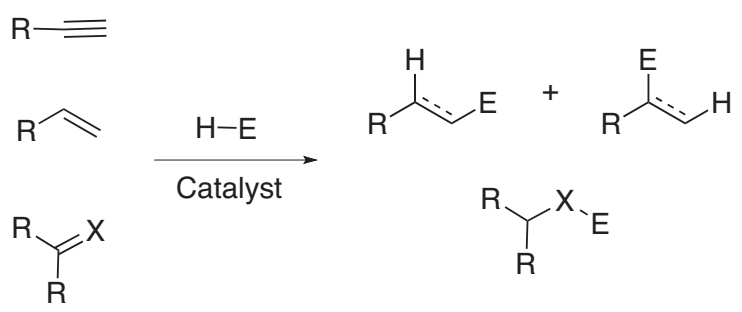

Scheme 1.4. Generic hydrofunctionalization of unsaturated substrates.

In the literature, Lewis acids have shown to play a critical role in the activation of the $\mathrm{H}$-E reagents responsible for hydrofunctionalization reactions (Scheme 1.5$).{ }^{32}$ In the case of $\mathrm{Sn}-\mathrm{H}^{33}{ }^{33} \mathrm{H}-\mathrm{H}^{34,35}$ and $\mathrm{H}-\mathrm{B}$ bonds, ${ }^{36}$ the activation occurs with cleavage of the 
bond and generation of the stabilized hydridoborate. In the case of Si-H bonds, ${ }^{37,38}$ the activation of the bond occurs via a bridged Si-H-B bond.

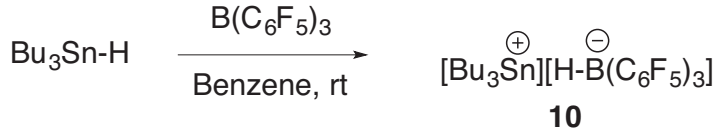

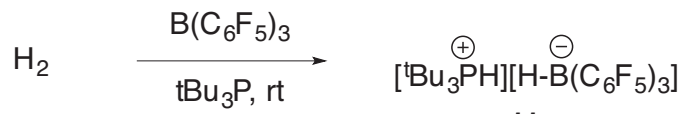

$$
\begin{aligned}
& 11
\end{aligned}
$$

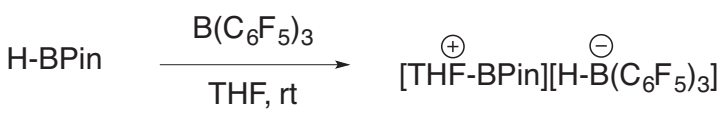

$$
\begin{aligned}
& 12 \\
& \mathrm{R}_{3} \mathrm{Si}-\mathrm{H} \underset{\text { Benzene, rt }}{\stackrel{\mathrm{B}\left(\mathrm{C}_{6} \mathrm{~F}_{5}\right)_{3}}{\longrightarrow}} \quad \mathrm{R}_{3} \mathrm{Si}-\cdots-\mathrm{H}-\mathrm{B}\left(\mathrm{C}_{6} \mathrm{~F}_{5}\right)_{3}
\end{aligned}
$$

Scheme 1.5. Several reactions depicting the activation of $\mathrm{H}-\mathrm{X}$ bonds by $\mathrm{B}\left(\mathrm{C}_{6} \mathrm{~F}_{5}\right)_{3}$.

\subsubsection{Lewis Acid Catalyzed Hydroboration Reactions}

While transition metals are widely known to catalyze hydrofunctionalization reactions, there are several examples where catalytic Lewis acids in the absence of transition metals are able to facilitate the transformation. Frustrated Lewis pairs are capable of reversibly activating $\mathrm{H}_{2}$ and reducing unsaturated substrates under mild conditions. Similar reduction chemistry can be achieved through borenium ion catalysis using an easier to handle reducing equivalent (HBPin) rather than $\mathrm{H}_{2}$ (Scheme 1.6). ${ }^{39}$ 


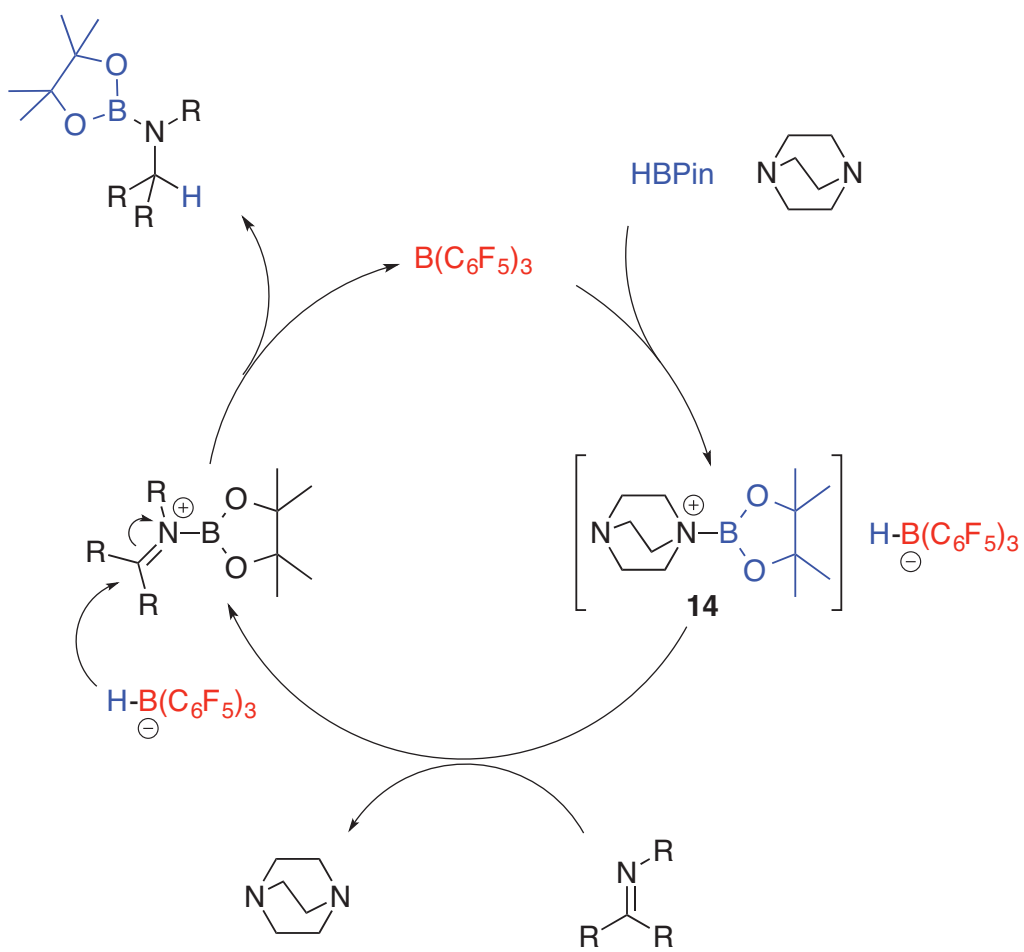

Scheme 1.6. Mechanism for the use of traditional Lewis pairs for reduction of unsaturated substrates.

The reaction is proposed to first proceed by addition of HBPin and 1,4diazabicyclo[2.2.2]octane (DABCO), generating a borenium hydridoborate salt 14 . This hydridoborate then transfers the hydride equivalent to the unsaturated iminoborate substrate to generate the corresponding amine-boronic ester product. Due to the necessity to form the imino-borate species prior to hydride transfer, the reaction was limited in substrate scope to those bearing nitrogen-containing substituents (nitriles, aldimines and N-heterocycles). This mechanism differs from metal catalyzed approaches that proceed through Mg-amide complexes generated via insertion into magnesium hydrides. ${ }^{40}$

In addition to the reduction of polar imine substrates, boranes are also capable of catalyzing the hydroboration of alkynes (Scheme $1.7 \mathrm{~A}) .{ }^{41}$ The proposed mechanism of 
this transformation starts with the catalytically competent geminal diborane 15 . The highly Lewis acidic pentafluorophenylborane moiety of geminal diborane 15 activates the acetylene prior to reaction with HBPin. This mechanism differs from the dicyclohexylborane-catalyzed process, which involves the hydroboration of substituted acetylenes. This is achieved by transfer of the alkenyl moiety from the vinylic cyclohexylborane to the pinacol boronic ester (Scheme 1.7B). ${ }^{42}$ While this method provides routes to the E-alkenylborane product, transition metal catalyzed reactions provide access to either the $E^{-43-51}$ or the $Z$-isomer ${ }^{51-56}$ selectively. 


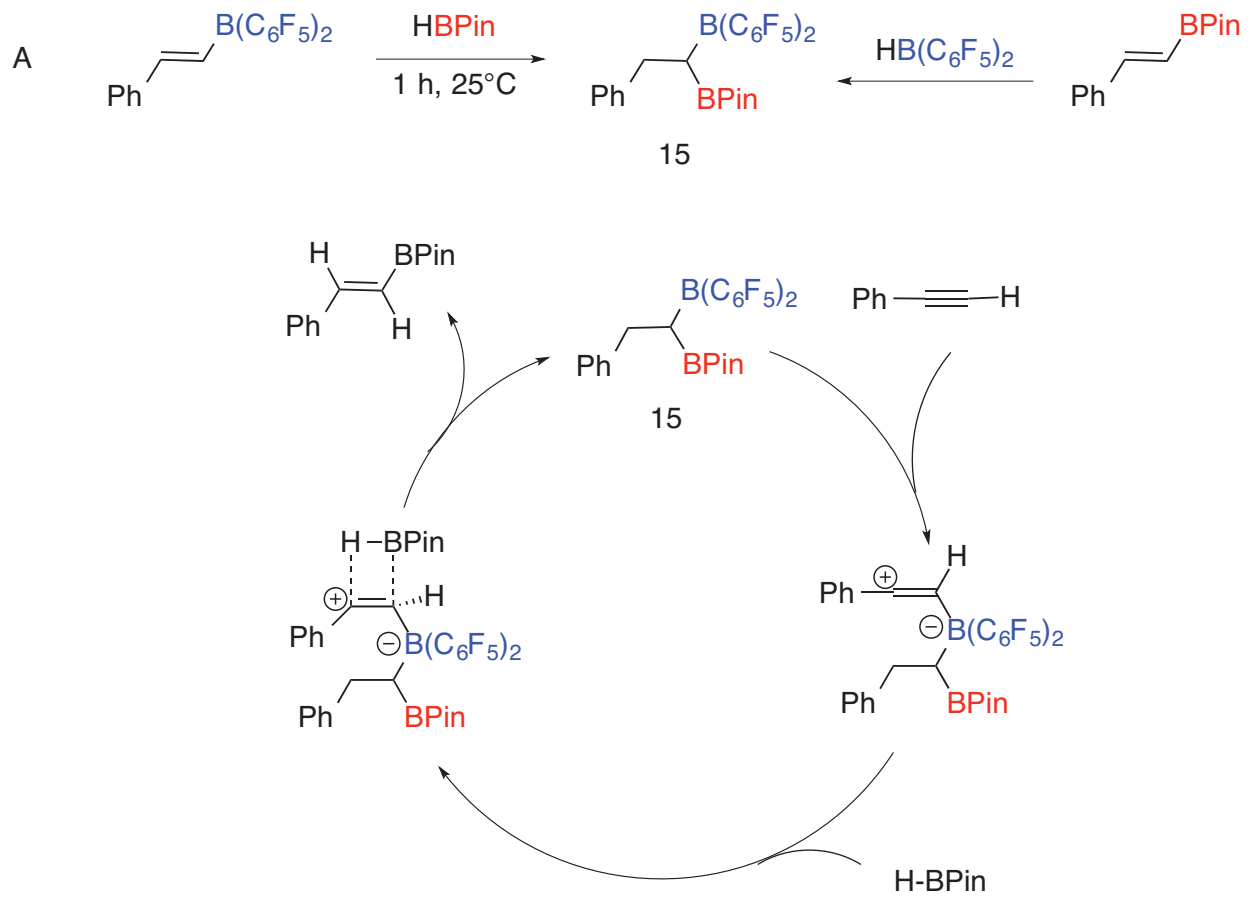

B

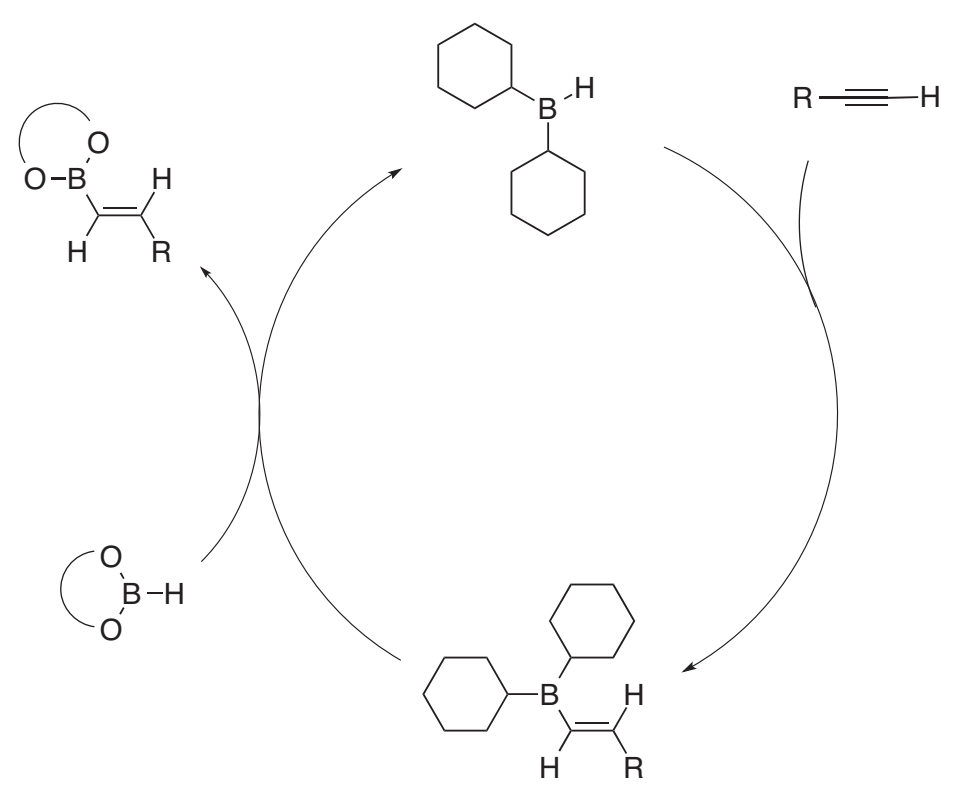

Scheme 1.7. Hydroboration of alkynes catalyzed by perfluorophenylborane $(A)$ and dicyclohexylborane (B).

Perfluorophenylboranes were often utilized in the hydroboration of alkynes; the use of these boron Lewis acids was not sufficient as catalysts for the hydroboration of 
alkenyl substates. ${ }^{57}$ In order to conduct these reactions, $\mathrm{BAr}_{3}{ }_{3}$ Lewis acids containing 3,5-trifluoromethylphenyl substituents were optimal and gave the desired product in moderate to good yields by the mechanism illustrated in Scheme 1.8. When evaluating imino substrates, $\mathrm{BAr}_{3}$ Lewis acids catalyze the hydroboration more efficiently than $\mathrm{B}\left(\mathrm{C}_{6} \mathrm{~F}_{5}\right)_{3}$. When $\mathrm{B}\left(\mathrm{C}_{6} \mathrm{~F}_{5}\right)_{3}$ was used, an additional Lewis base was needed to acquire similar catalytic activity. ${ }^{39,58}$

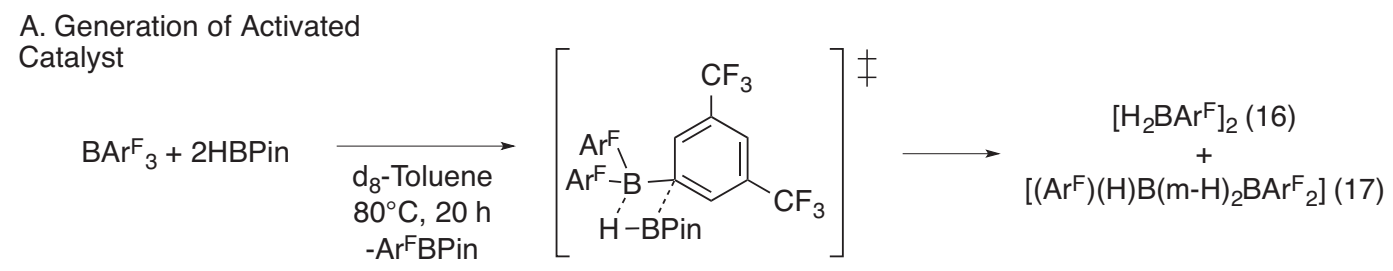

B. Mechanism of Reaction

$$
\begin{gathered}
{\left[\mathrm{H}_{2} \mathrm{BArF}_{2}\right]_{2}(16)} \\
+ \\
{\left[\left(\mathrm{ArF}^{\mathrm{F}}\right)(\mathrm{H}) \mathrm{B}(\mathrm{m}-\mathrm{H})_{2} \mathrm{BAr}_{2}\right](17)}
\end{gathered}
$$
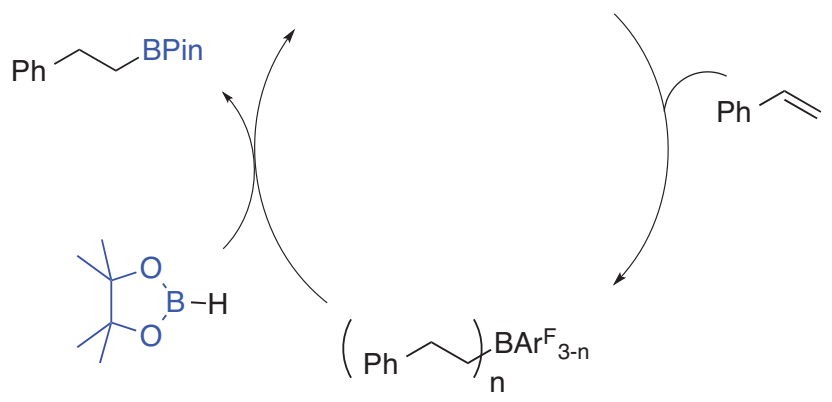

$\mathrm{n}=1$ or 2

Scheme 1.8. Proposed mechanism for generation of activated catalyst $(A)$ and for the hydroboration of alkene substrates catalyzed by tris(3,5-trifluoromethylphenyl)borane $\left(\mathrm{BAr}_{3}\right)(\mathrm{B})$.

The reaction between the Lewis acid and HBPin leads to the formation of borane 16 and the hydrido-bridged diborane 17 through a traditional four-membered metathesis transition state (Scheme 1.8A). Hydridoboranes 16 and 17 can subsequently react with styrene in a 1,2-fashion to produce the linear hydroboration product. The hydroboration product undergoes ligand metathesis to furnish the desired product and regenerate the 
hydridoboranes 16 and 17 . This reaction is distinct from those discussed earlier because it does not proceed through borenium ion catalysis. This $\mathrm{BAr}_{3}$-catalyzed hydroboration is regioselective for the linear product, which differs from transition metal mediated methods. Transition metal catalyzed hydroborations of alkenes provide either the linear hydroboration product or the branched product depending on catalyst choice ${ }^{59-69}$ For example, while iridium(I) catalysts ${ }^{59}$ tend to favor the linear product, the use of rhodium based catalysts tend to favor the branched product. ${ }^{67,68}$

\subsubsection{Lewis Acid Catalyzed Hydrosilylation Reactions}

While $\mathrm{B}\left(\mathrm{C}_{6} \mathrm{~F}_{5}\right)_{3}$ has not been reported to catalyze the hydroboration of ketones, aldehydes, and esters, $\mathrm{B}\left(\mathrm{C}_{6} \mathrm{~F}_{5}\right)_{3}$ has been reported to catalyze the corresponding hydrosilylation. ${ }^{37,38}$ Piers and coworkers determined that the Lewis acid catalyst in the hydrosilylation reaction generates a borane-silane complex, differing from the distinct borenium ion observed in the $\mathrm{B}\left(\mathrm{C}_{6} \mathrm{~F}_{5}\right)_{3}$ catalyzed hydroboration of imines (Scheme 1.9A). ${ }^{70}$ During a catalyzed hydrosilylation reaction, this activated borane-silane complex 18 , in the absence of substrate, only exists in low concentrations. ${ }^{38} \mathrm{~A}$ boranesilane complex was supported by rapid H/D scrambling experiments conducted with $\mathrm{Et}_{3} \mathrm{SiH}$ and $\mathrm{Ph}_{3} \mathrm{SiD}$, as well as DFT computational studies. $\mathrm{B}\left(\mathrm{C}_{6} \mathrm{~F}_{5}\right)_{3}$ generates the hydridoborate and a silylium ion upon decomposition of the borane-silane complex. After silylium ion binding to the carbonyl, $\mathrm{HB}\left(\mathrm{C}_{6} \mathrm{~F}_{5}\right)_{3}$ transfers a hydride to the electrophilic carbonyl carbon (Scheme 1.9B). Ruthenium complexes featuring the Lewis basic sulfur ligand (See Scheme 1.2) were also capable of achieving this reaction; however, these complexes yielded the $\mathrm{N}$-silylenamine, which in a subsequent step was 
capable of undergoing reduction to the corresponding amine through transfer hydrogenation. ${ }^{25,26}$

A. Generation of Borane-Silane Complex

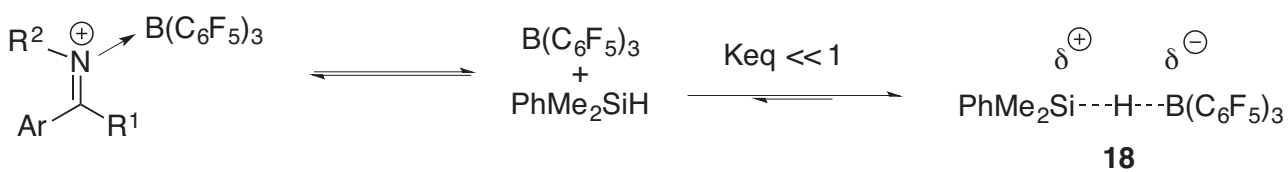

B. Catalytic Hydrosilylation with Borane-Silane Complex

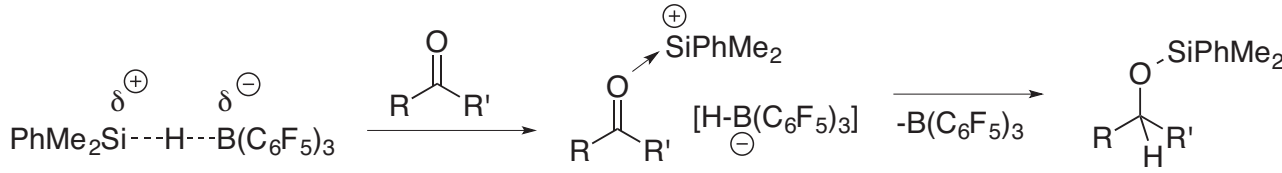

18

Scheme 1.9. Key activation steps in the catalytic hydrosilylation of imines using tris(pentafluorophenyl)borane.

This same concept was applied by Piers and coworkers for the hydrosilylation of silyl enol ethers and enones utilizing $B\left(C_{6} F_{5}\right)_{3}$ as a Lewis acid catalyst (Scheme 1.10). ${ }^{71}$ The reaction is believed to proceed in a similar fashion to that described in Scheme 1.9, in which the initial activation of the silylating agent occurs with $B\left(\mathrm{C}_{6} \mathrm{~F}_{5}\right)_{3}$ to produce a silylenium-stabilized hydridoborate. In the case of the silyl enol ethers (Scheme 1.10A), the hydrosilation occurs across the double bond by nucleophilic hydride addition from the borate anion to the silacarboxonium ion. However, the enone (Scheme 1.10B) hydrosilylation occurs in a 1,4-fashion with the hydride adding to the $\beta$-position. For cyclopentyl-based enones, the reaction works well for un-substituted substrates and $\alpha$ Me substituted substrates. However when a $\beta$-substituent is introduced, the reaction yields a complex mixture of products. When the substrate is $\alpha$ - and $\beta$-substituted, the yield decreases from $90 \%$ for the un-substituted case to $55 \%$ for the di-substituted case. In the case of $\alpha, \beta$-unsaturated cyclohexenones, the yield is above $80 \%$. When a substrate contains an internal $\alpha, \beta$-unsaturation and an external alkene, the reaction 
hydrosilylated the internal olefin preferentially. The reaction also works quite well on non-cyclic styrenyl enones and enals with yields greater than $85 \%$, but when methylvinylketone is used, a complex mixture of products is obtained.

A. Silyl Enol Ethers

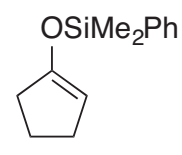

1 h., $-40^{\circ} \mathrm{C}, 85 \%$

$\mathrm{PhMe}_{2} \mathrm{SiH}$

(5 mmol)

$\mathrm{B}\left(\mathrm{C}_{6} \mathrm{~F}_{5}\right)_{3}$

$\mathrm{OSiMe}_{2} \mathrm{Ph}$

$2 \mathrm{~mol} \%$

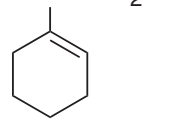

40 h., rt, $50-60 \%$

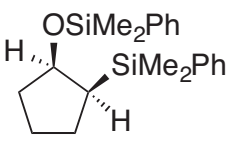

B. Enones
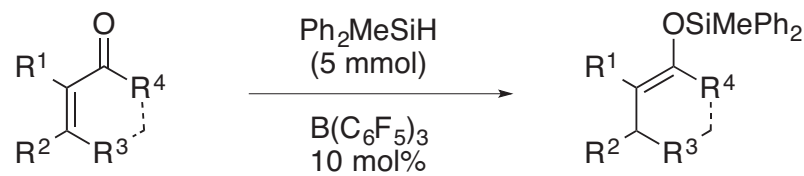

Scheme 1.10. Hydrosilation of silyl enol ethers and enones by $B\left(C_{6} F_{5}\right)_{3}$.

While Oestreich and coworkers determined that $\mathrm{B}\left(\mathrm{C}_{6} \mathrm{~F}_{5}\right)_{3}$ could not hydroborate alkenes, ${ }^{57}$ it was able to catalyze the hydrosilylation of alkenes. ${ }^{72}$ The use of Lewis acids in hydrosilylation provides the trans-hydrosilylation product, which is uncommon for transition metal catalyzed processes. ${ }^{73-86}$ Gevorgyan and coworkers demonstrated that with a variety of silane reagents, ranging from trialkylsilanes to triarylsilanes (with the exclusion of tri-isopropylsilane), they were able to hydrosilylate styrene in an antiMarkovnikov fashion. ${ }^{72}$ By changing the silane source, they were able to extend this reactivity to internal and external cyclic alkenes, linear alkenes, and allylic and homoallylic alkenes. In addition, this reaction is high yielding and eliminates the polymerization by-product common of Lewis acid hydrosilylation reactions. ${ }^{87}$ 
This proposed mechanism of borane Lewis acid hydrosilylation differs from those proposed previously by Weller (Scheme $1.11 \mathrm{~A})^{88}$ and Yamamoto (Scheme 1.11B) for aluminum Lewis-acid-catalyzed trans-hydrosilylations of alkenes and alkynes. The borane Lewis acids are known to proceed through silane-borane complexes, whereas the aluminum Lewis acids activate the substrate toward reaction with the silane.

A

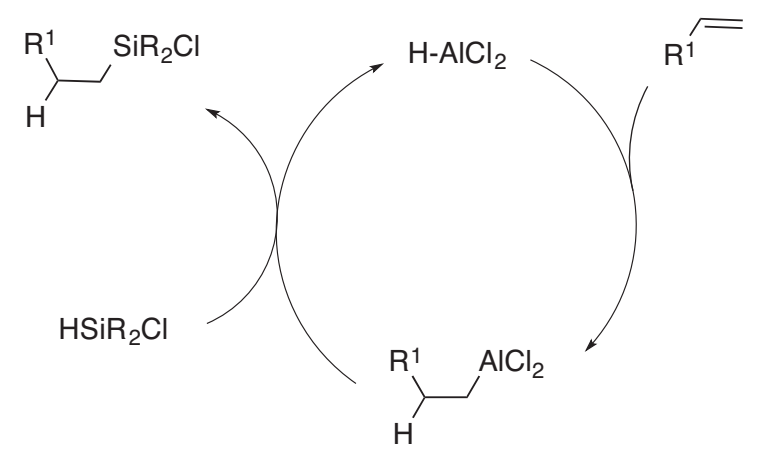

B

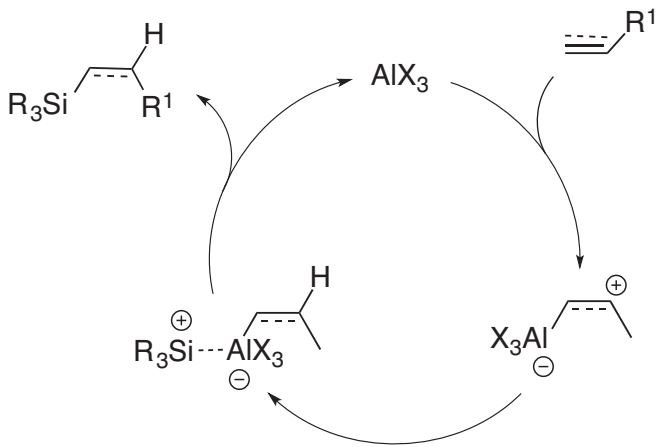

Scheme 1.11. Alternative proposed mechanisms for the Lewis acid catalyzed transhydrosilylation of alkenes, allenes, and alkynes.

\subsubsection{Lewis Acid Catalyzed Hydrostannylation Reactions}

Yamamoto and coworkers published an example of a Lewis acid catalyzed allene hydrostannylation that provided different regioselectivity than was seen with $\operatorname{Pd}(0)$ catalysts. $^{91}$ This example demonstrates the critical importance of Lewis acids in catalysis. In the Lewis acid catalyzed route, the regioisomer opposite to the $\operatorname{Pd}(0)$ catalyzed route was obtained (Scheme 1.12). While transition metals have been shown to hydrostannylate alkynes, ${ }^{92-96}$ limited examples of Lewis acids have been reported to achieve this reactivity. ${ }^{32}$

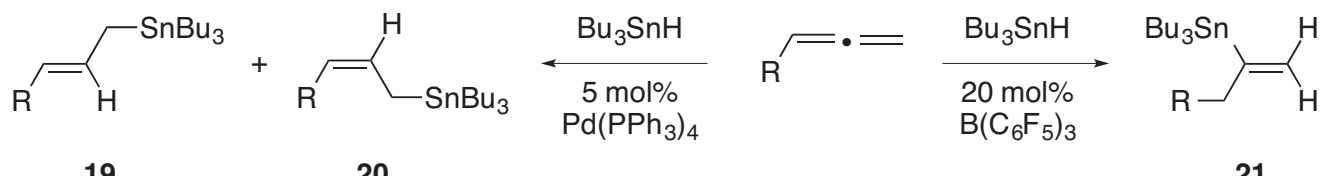

19

20

21

Scheme 1.12. Divergent regioselectivity with Lewis acid or $\operatorname{Pd}(0)$ as the catalyst for hydrostannylation of allenes. 
Allylic stannane product was obtained as a mixture of cis- and trans-isomers 19 and 20 when $\operatorname{Pd}(0)$ was utilized as the catalyst. When $R$ is aromatic, trans-isomer 19 is preferred in a 95:5 ratio. When $\mathrm{R}$ is non-aromatic, cis-isomer 20 is favored as the major product. In the case of the Lewis acid catalyzed method, vinylstannane 21 is formed. Higher yields of 21 are observed when $\mathrm{R}$ is aromatic (57-77\%). The other nonaromatic substrates gave yields between $12-41 \%$.

$\mathrm{Pd}\left(\mathrm{PPh}_{3}\right)_{4}$ is proposed to proceed through an allene insertion into the $\mathrm{Pd}-\mathrm{H}$ bond (hydropalladation) through either the $\eta^{3}$-allyl-Pd(II) (22) or the vinyl- (23) complex. Alternatively, the allene can insert into the $\mathrm{Pd}-\mathrm{Sn}$ bond (palladastannylation) resulting in the formation of a vinyl-Pd(II) (24) complex (Scheme 1.13A). Lewis acid catalyzed hydrostannylation begins by coordination and addition of the Lewis acid to the allene to generate the zwitterionic intermediate 25 , which is trapped with $\mathrm{HSnBu}_{3}$ to form the complex 26. The subsequent transmetallation generates the product and closes the catalytic cycle.

\section{A. Hydrostannylation with $\mathrm{Pd}\left(\mathrm{PPh}_{3}\right)_{4}$ Catalyst}

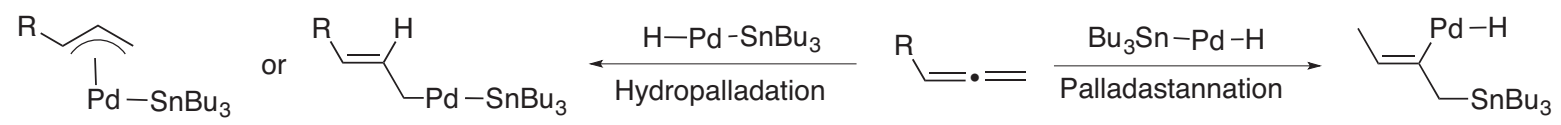

22

23

24

B. Hydrostannylation with $\mathrm{B}\left(\mathrm{C}_{6} \mathrm{~F}_{5}\right)_{3}$ Catalyst

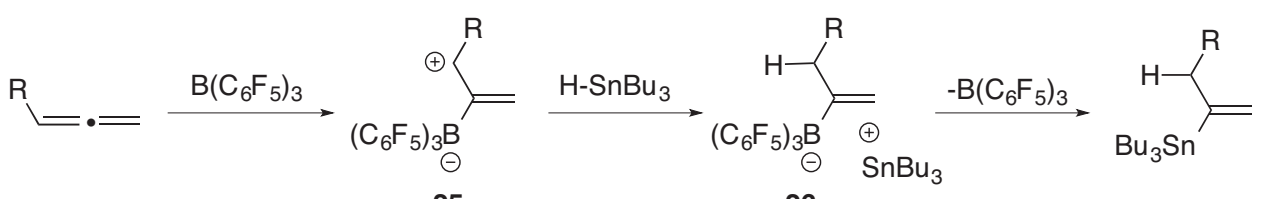

25

26

Scheme 1.13. Comparison of $\operatorname{Pd}(0)$ and $B\left(C_{6} F_{5}\right)_{3}$ catalyzed hydrostannylations.

In addition to allenes, Organ and coworkers established that $\mathrm{B}\left(\mathrm{C}_{6} \mathrm{~F}_{5}\right)_{3}$ could also catalyze the hydrostannylation of propargylic alcohols. ${ }^{32}$ The reaction is highly solvent 
dependent, with more sterically demanding $\mathrm{R}$ groups requiring the use of THF (Scheme 1.14).

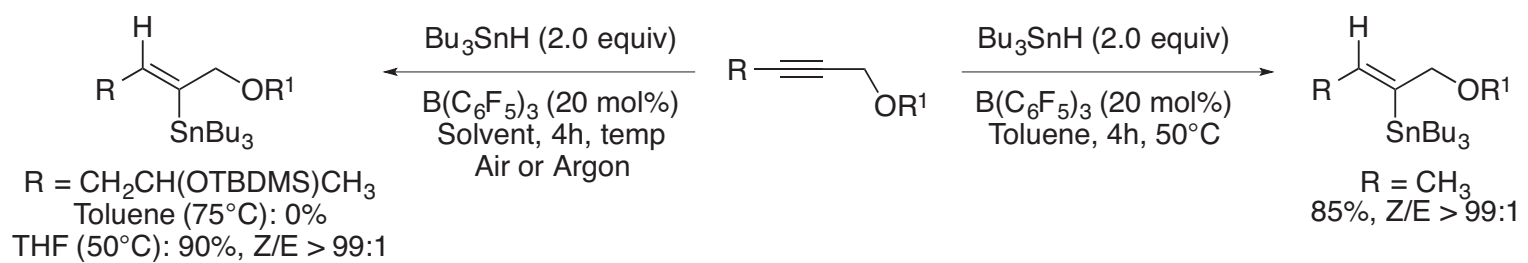

Scheme 1.14. Solvent dependent Lewis acid catalyzed hydrostannylation of proparglyic alcohols.

Hydrostannylation of propargylic alcohols was proposed to proceed through one of two different mechanisms depending on the degree of sterics of the $R$ group (Scheme 1.15). Mechanism $B$ is preferred when $R$ is methyl, while all other substrates preferred mechanism $\mathrm{A}$. In mechanism $\mathrm{A}, \mathrm{Bu} \mathrm{H}_{3} \mathrm{SnH}$ is activated to form THF-SnBu 3 hydridoborate 10 (See Scheme 1.5). Regioselective addition of $\mathrm{THF}_{-} \mathrm{SnBu}_{3}$ to propargylic alcohols forms the corresponding vinyl cation 26 , which is then trapped by another equivalent of the $\mathrm{Bu}_{3} \mathrm{SnH}$. Use of $\mathrm{Bu}_{3} \mathrm{SnD}$ leads to incorporation of deuterium into the product, implying that the $\mathrm{Sn}-\mathrm{H}$ bond traps the vinyl cation 26 . This is consistent with computational data on main group metal hydrides, in which hydrides of organostannanes were shown to be more hydridic than those of organoboranes or organosilanes. ${ }^{97}$ Given that $\beta$-oxygen carbocations are disfavored, addition of the stannane occurs regioselectively. ${ }^{98}$ In the absence of THF (Scheme 1.15B), the stannyl cation is not stabilitzed and undergoes rapid complexation of the alkyne. The next two steps are similar to mechanism $A$ in that the alkyne undergoes regioselective addition of the stannyl cation, followed by trapping with the $\mathrm{Sn}-\mathrm{H}$. 


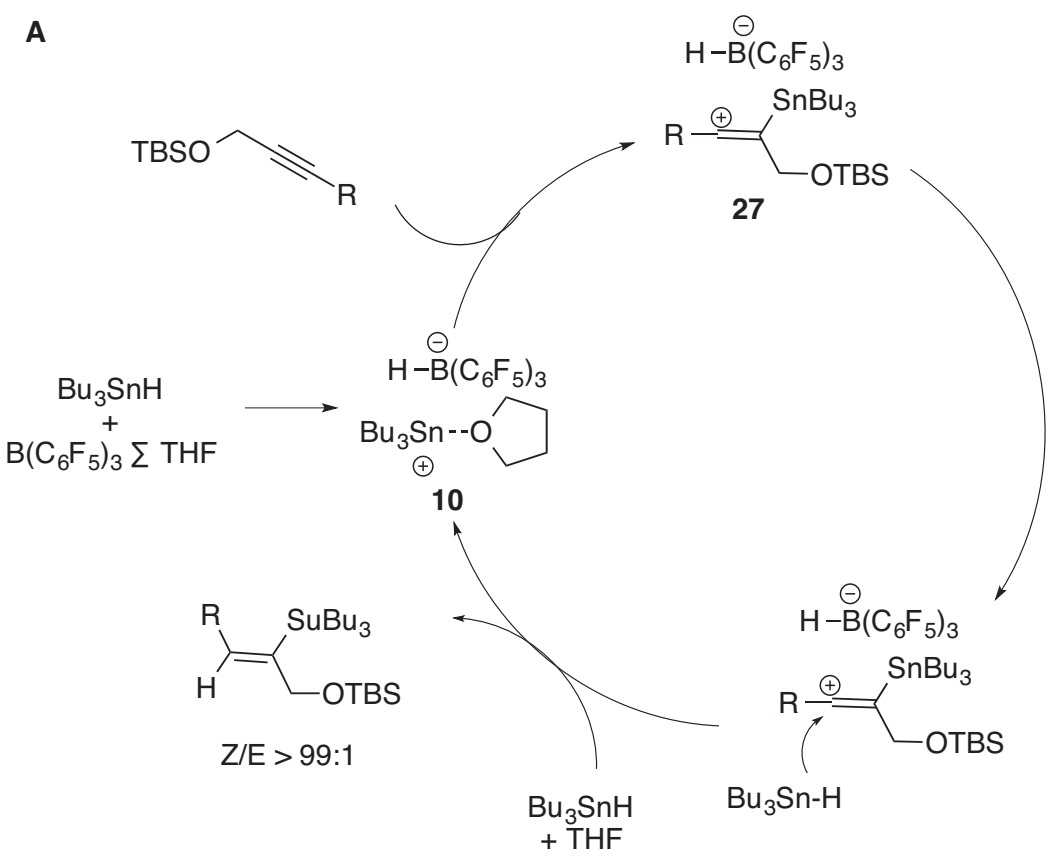

B
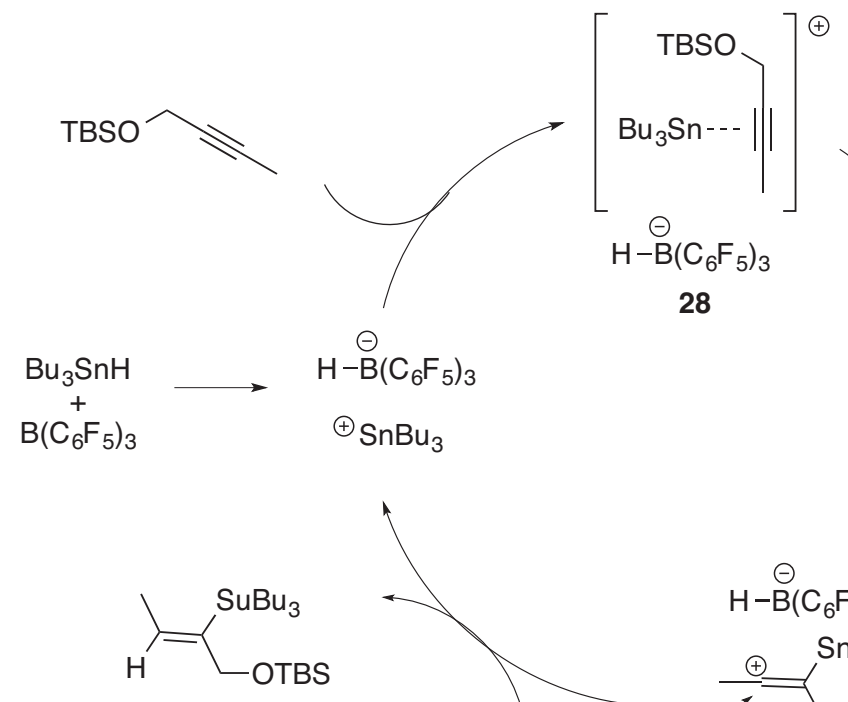

Z/E > 99:1
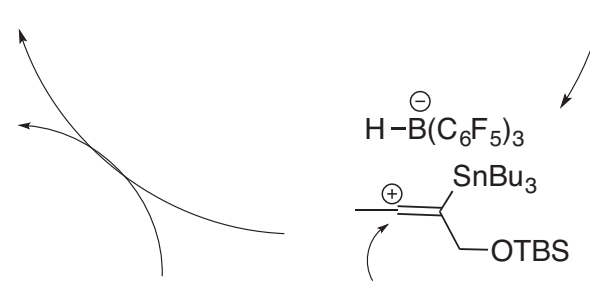

$\mathrm{Bu}_{3} \mathrm{SnH}$

$\mathrm{Bu}_{3} \mathrm{Sn}-\mathrm{H}$

Scheme 1.15. Lewis acid catalyzed hydrostannylation of propargylic alcohols with (A) substrates with hindered $R$ group in polar (THF) solvent and (B) substrates with unhindered $\mathrm{R}$ group in non-polar (toluene) solvent. 


\subsection{Cooperative Utilization of Lewis Acids in Transition Metal Catalyzed Hydrofunctionalization Reactions}

Cooperative activation of substrates with a transition metal and Lewis acid cocatalyst system has been utilized in a variety of reactions. One example is that of the Heck reaction, which has shown accelerated kinetics in the presence of Lewis acids (Scheme 1.16B). ${ }^{99}$ Other Pd-catalyzed reactions, such as arylations and acylations, have shown acceleratory effects in the presence of Lewis acids. ${ }^{100,101}$ Another example is Ziegler-Natta catalysis for the polymerization of $\alpha$-olefins, which uses an early $\mathrm{d}^{0}$ transition metal catalyst with either an aluminum or borane Lewis acid (Scheme 1.16A). ${ }^{98,102-110}$ These Lewis acids serve as alkylating agents to initiate the catalytic process or act as alkene activators. The simplest form of hydrofunctionalization is the hydrogenation of unsaturated substrates (Scheme 1.15C). ${ }^{111-116}$ Despite the progress in transition metal Lewis acid cooperative polymerization catalysts, hydrofunctionalization reactions have been limited.

A. Ziegler-Natta Polymerization

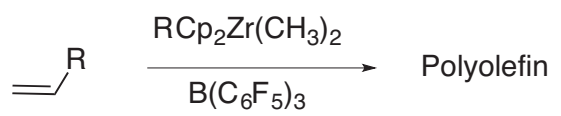

B. Heck Reaction

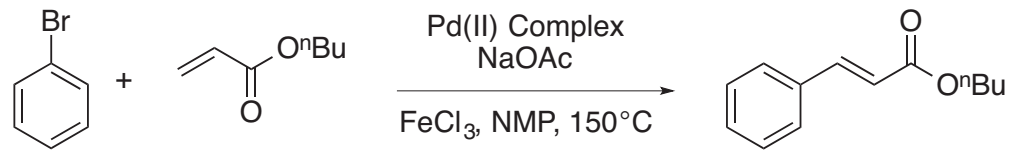

C. Hydrogenation

Cat. $\operatorname{Re}(\mathrm{I})$ Complex

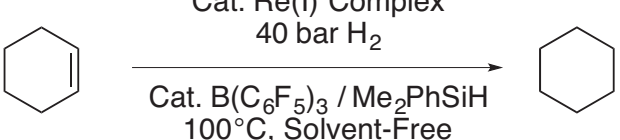

Scheme 1.16. Representative examples of Lewis acid assisted transition metal catalysis. 


\subsubsection{Transition Metal Lewis Acid Cooperative Activation of Dihydrogen for Catalytic Hydrogenation}

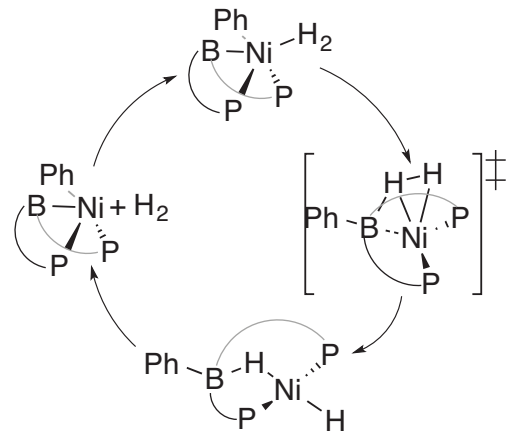

Scheme 1.17. Lowest energy activation pathway for dihydrogen activation with Ni-PBP complex.

While transition metal complexes typically undergo oxidative addition of dihydrogen at an electron-rich metal center, Ke and coworkers discussed several activation pathways for dihydrogen in transition metal/Lewis acid cooperative systems. ${ }^{117}$ A computational analysis of the mechanism of dihydrogen activation with a Ni-PBP complex revealed that the lowest energy mode of dihydrogen activation was the synergetic heterolytic mode (Scheme 1.17). ${ }^{112,118}$ In this mode of activation, the borane assists the heterolytic cleavage of dihydrogen in the key transition state to produce $\left[\mathrm{PhB}\left(\mathrm{o}-\mathrm{PPh}_{2} \mathrm{C}_{6} \mathrm{H}_{4}\right)_{2}\right]\left(\mu_{2}-\mathrm{H}\right) \mathrm{NiH}$. These calculations are in agreement with results obtained by Sakaki and coworkers that demonstrated the borane Lewis acid plays a critical role in the dihydrogen cleavage step. ${ }^{119}$ Peters and coworkers were able to extend this system to the hydrogenation of styrene and 3,3-dimethyl-1-butene (Scheme 1.18). ${ }^{112}$ 


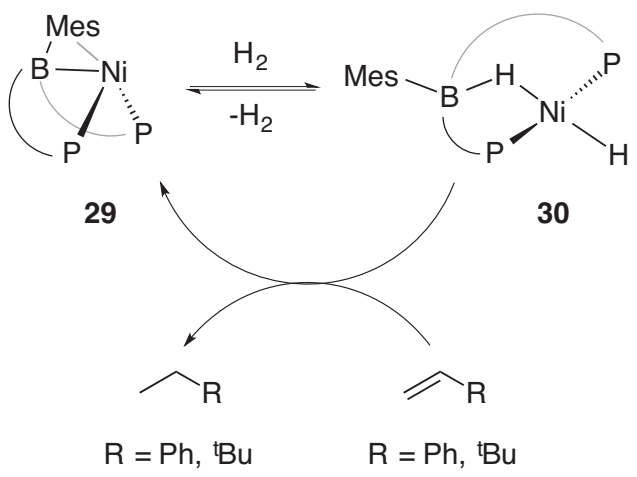

Scheme 1.18. Hydrogenation of styrene and 3,3-dimethyl-1-butene with [PhB(o$\left.\left.\mathrm{PPh}_{2} \mathrm{C}_{6} \mathrm{H}_{4}\right)_{2}\right]\left(\mu_{2}-\mathrm{H}\right) \mathrm{NiH}$ complex.

A similar mode of $\mathrm{H}_{2}$ activation was observed in the platinum complex of the borane-modified dppf ligand synthesized by Emslie and coworkers. ${ }^{120}$ In this system, they noted that dihydrogen activation was reversible (Scheme 1.19). This mode of reversible activation was similar to the $\left[\mathrm{PhB}\left(\mathrm{o}-\mathrm{PPh}_{2} \mathrm{C}_{6} \mathrm{H}_{4}\right)_{2}\right]$ nickel(II) complex described above. $^{112}$

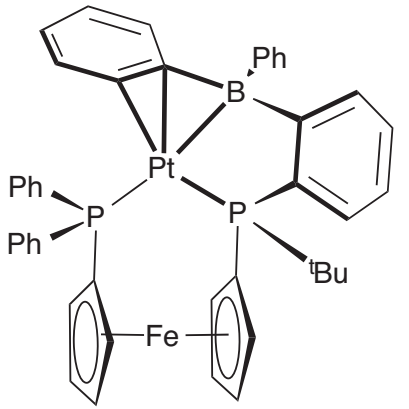

31

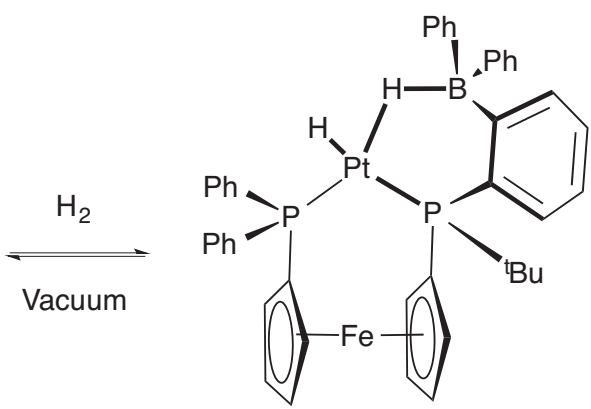

32

Scheme 1.19. Reversible activation of dihydrogen at a Pt(dppf-borane) complex.

Figueroa and coworkers recently demonstrated that platinum (boryl)iminomethane complexes were capable of activating dihydrogen across the Pt-B bond similar to that described above (Scheme 1.20). ${ }^{114}$ Dihydrogen bond activation results in the generation of the $\eta^{2}-\mathrm{B}-\mathrm{H} \sigma$-complex along with a platinum hydride as a result of a cooperative activation between the metal center and the boryl ligand. 


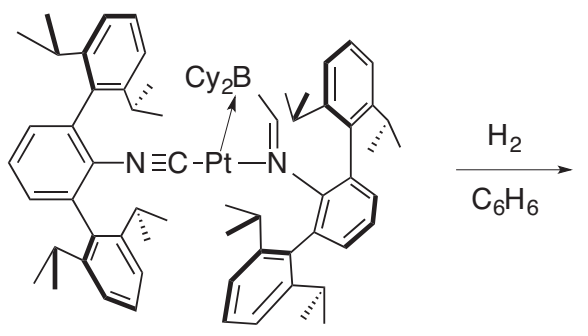

8

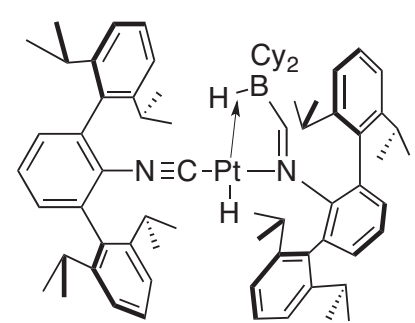

9

Scheme 1.20. Platinum (boryl)iminomethane complex for the activation of dihydrogen.

Peters and coworkers extended dihydrogen activation by utilizing Co-boryl pincer complexes to generate bridged dihydride species (Scheme 1.21). ${ }^{111}$ The addition of dihydrogen to the complex results in the formation of two distinct sets of hydride ligands. The ${ }^{1} \mathrm{H}$ NMR spectrum at $-90{ }^{\circ} \mathrm{C}$ reveals two hydride signals at $\delta-4.1$ and $\delta-11.5 \mathrm{ppm}$, corresponding to cobalt-boryl bridging hydrides and the cobalt hydrides, respectively. These complexes hydrogenated styrene and 1-hexene and dehydrogenated amineborane adducts. Ultimately by using amine-boranes as the source of dihydrogen, these complexes catalyzed the transfer hydrogenation of styrene.

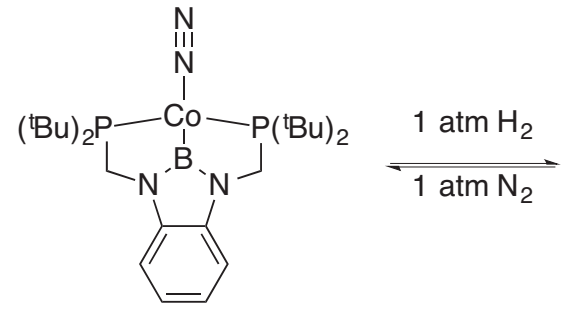

33

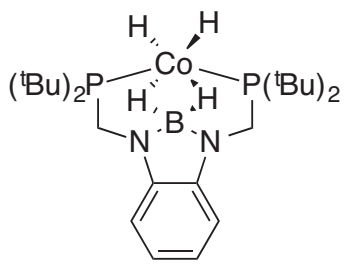

34

Scheme 1.21. Reversible activation of dihydrogen at Co-PBP boryl pincer complexes.

A classic example of a $\mathrm{Rh}(\mathrm{I})$-based homogeneous hydrogenation catalyst is Wilkinson's complex, $\mathrm{Rh}\left(\mathrm{PPh}_{3}\right)_{3} \mathrm{Cl}\left(\right.$ Table 1.1). ${ }^{121}$ While the rates of $\mathrm{Rh}\left(\mathrm{PPh}_{3}\right)_{3} \mathrm{Cl}$ and $\left[\mathrm{Rh}\left(\mathrm{PPh}_{3}\right)_{2} \mathrm{Cl}\right]_{2}$ are similar, the use of $\mathrm{Rh}\left(\mathrm{PPh}_{3}\right)_{3} \mathrm{H}$ as a catalyst generates a rate 39 times faster. The $\mathrm{Rh}\left(\mathrm{PPh}_{3}\right)_{3} \mathrm{H}$ can be accessed by a rapid transmetallation with the 
Lewis acid to produce the corresponding ethyl complex, which then undergoes $\beta$ hydride elimination to produce the hydride complex. While previous examples utilize Lewis acids in the bond activation process, the hypothesis here is that the Lewis acid generates active rhodium-hydrides. It is important to note that $\mathrm{Rh}(\mathrm{I})$ complexes featuring Lewis acid co-catalysts for hydrofunctionalization are understudied in the literature. ${ }^{36,122}$

Table 1.1. Rates of ethylene hydrogenation catalyzed Wilkinson's complex with and without Lewis acid additive.

\begin{tabular}{|c|c|}
\hline Catalyst & $\mathbf{K}_{\text {obs }}\left(\mathbf{\times 1 0 ^ { 3 }}\right), \mathbf{s}^{-1}$ \\
\hline $\mathrm{Rh}\left(\mathrm{PPh}_{3}\right)_{3} \mathrm{Cl}$ & 0.025 \\
\hline$\left[\mathrm{RhCl}\left(\mathrm{PPh}_{3}\right)_{2}\right]_{2}$ & 0.024 \\
\hline $\mathrm{RhH}\left(\mathrm{PPh}_{3}\right)_{3}$ & 0.98 \\
\hline $\mathrm{RhCl}\left(\mathrm{PPh}_{3}\right)_{3}+\mathrm{AlEt}_{3}$ & 1.0 \\
\hline
\end{tabular}

Ozerov and coworkers were able to activate dihydrogen utilizing an iridium complex bearing a PBP-pincer ligand (Scheme 1.22). ${ }^{123}$ They applied these complexes to the dehydrogenation of alkanes with sacrificial alkenes as the dihydrogen acceptor. These complexes proceed through a similar $\eta^{2}-\mathrm{B}-\mathrm{H} \sigma$-complex as seen by Figueroa and coworkers. ${ }^{114}$ Two distinct sets of hydrides were obtained upon treatment of the complex with dihydrogen in the presence of sodium triethylborohydride at ambient temperature.

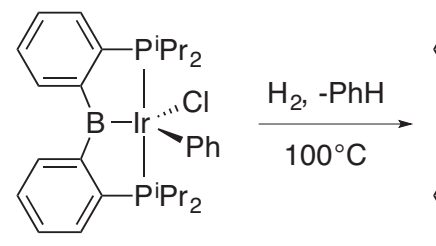

35

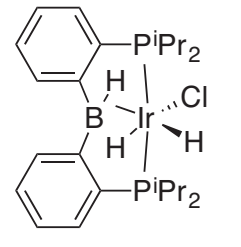

36
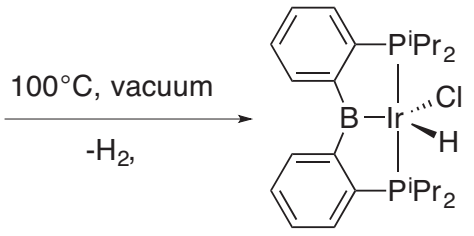

37

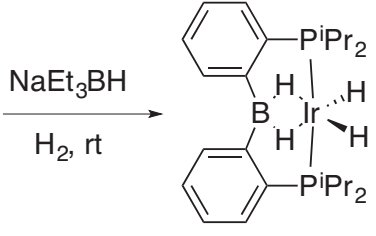

38

Scheme 1.22. Activation of dihydrogen by an iridium PBP-pincer complex.

While the majority of transition metal/Lewis acid catalysts have focused on late transition metal complexes, several examples utilizing late early transition metals have been explored. Rhenium hydride complexes, ${ }^{124-127}$ activated by Lewis acids, have 
emerged as competent hydrogenation catalysts with higher activities that previously reported rhodium and iridium complexes. ${ }^{126}$ Lewis acid binding to nitrosyl ligands on these complexes induces structural changes within the coordination environment. ${ }^{127}$ This effect is largely due to the ability of nitrosyl ligands to adopt both the linear and bent coordination mode. The change in the coordination mode of the NO ligand results in a $2 \mathrm{e}^{-}$change in oxidation state, $\operatorname{Re}(\mathrm{I})->\operatorname{Re}(-\mathrm{I}){ }^{121}$ This change in oxidation state opens a vacant coordination site as can be seen in the dinitrosyl rhenium hydride complex 40 (Scheme 1.23). ${ }^{124,128}$

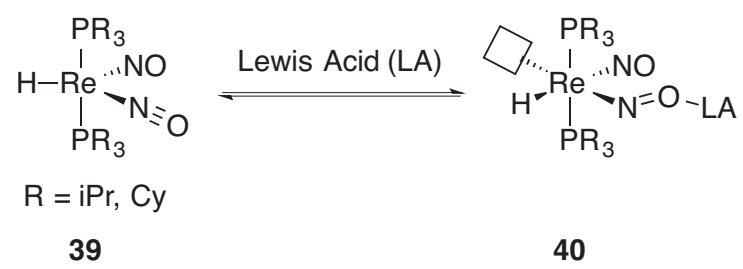

Scheme 1.23. Change in the coordination environment at rhenium upon binding of Lewis acid co-catalyst.

The mode of activation of these complexes in the presence of $B\left(C_{6} F_{5}\right)_{3}$ is proposed (Scheme 1.23) to proceed through a Negishi-type "super-electrophilic" $14 \mathrm{e}^{-}$ complex 43. ${ }^{129,131}$ The bending of the NO ligands and subsequent loss of phosphine ligand generates a complex with two open coordination site that is doubly Lewis acidic. While this species is unobservable, the electron-deficient metal complex is proposed to facilitate the insertion of alkenes into the $\mathrm{Re}-\mathrm{H}$ through a low-energy pathway that leads to higher activities of these complexes. Due to the heightened reactivity of these species, it was also recently demonstrated that these complexes were capable of hydrogenating weakly electrophilic carbon dioxide to form formic acid. ${ }^{125}$ 


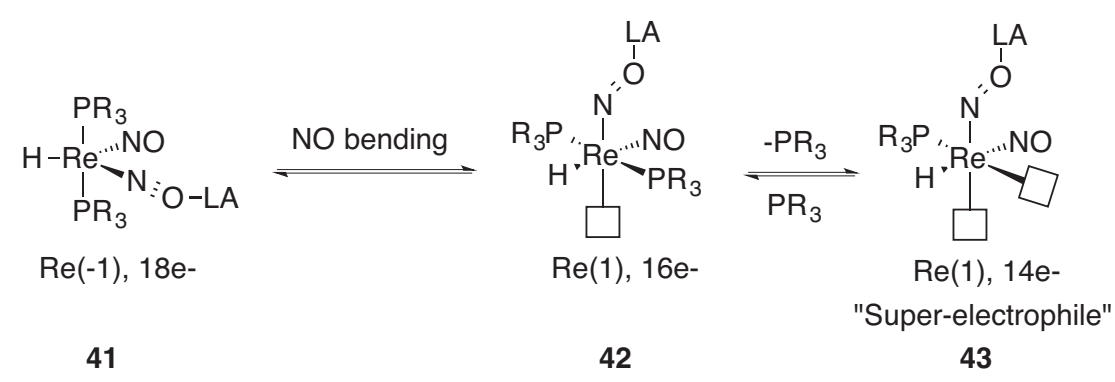

Scheme 1.24. One of the proposed modes of activation of Jiang/Berke hydrogenation catalysts.

These rhenium(-I) hydride complexes $\left(R={ }^{i} \operatorname{Pr}\right.$ or $\left.C y\right)$ were capable of obtaining turnover numbers of 120,000 and $82,000 \mathrm{~h}^{-1}$ for the hydrogenation of 1-octene and 1hexene, respectively, with 40 bars of dihydrogen at $100^{\circ} \mathrm{C}$. The hydrogenation is proposed to proceed through a mechanism similar to that of the Schrock-Osborn catalyst system (Scheme 1.25). ${ }^{130-132}$ Jiang/Berke rhenium hydride catalyst can be run neat without solvent. Despite showing the reactivity for the bromide rhenium hydride complex, the iodide analog is more active than the bromide. The activity of the complexes decreased with increasing electronegativity of the halide. 


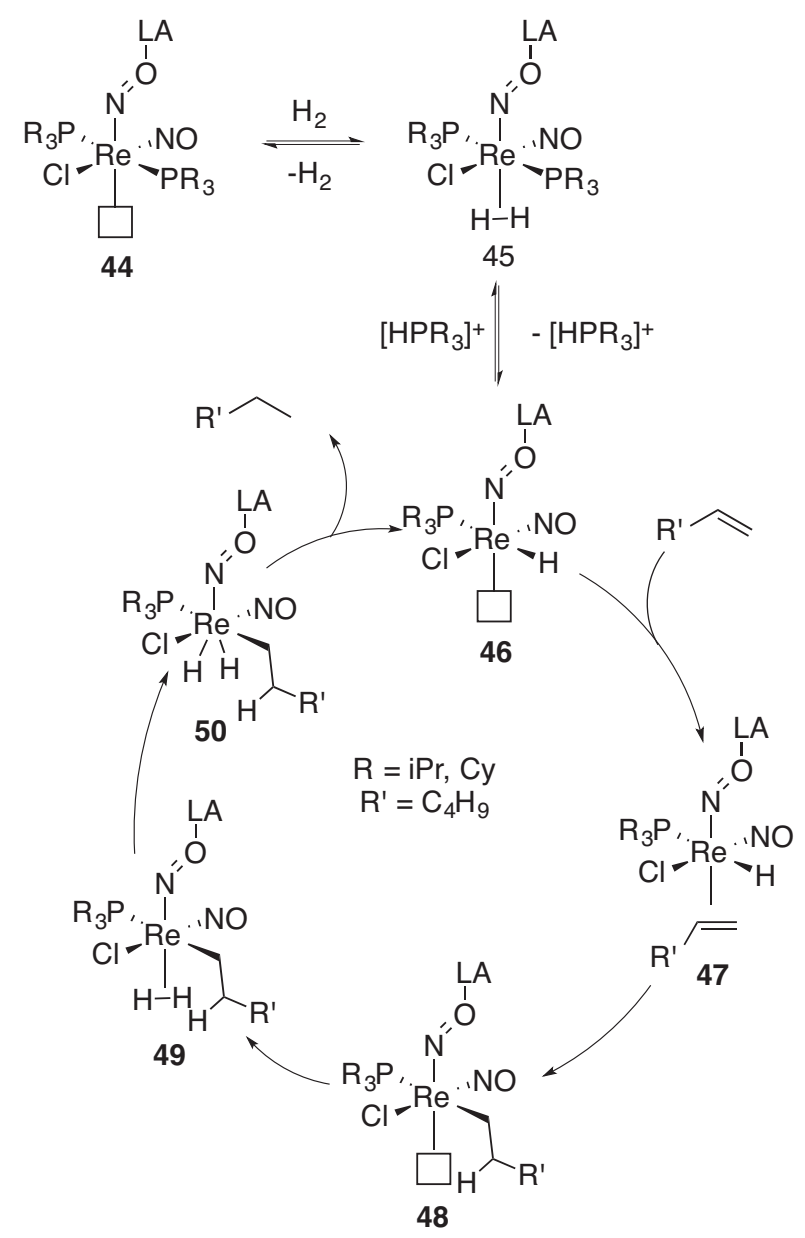

Scheme 1.25. Mechanism for the hydrogenation of 1-hexene by Jiang/Berke catalyst. 
Table 1.2. Hydrogenation of alkene substrates with rhenium hydride/Lewis acid system compared to precious metal catalysts.

\begin{tabular}{|c|c|c|c|c|c|}
\hline \multirow[b]{2}{*}{ Catalyst } & \multirow[b]{2}{*}{ Conditions } & \multicolumn{4}{|c|}{ Relative TOF $\left(h^{-1}\right)$} \\
\hline & & 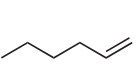 & (1) & & \rangle$=\langle$ \\
\hline 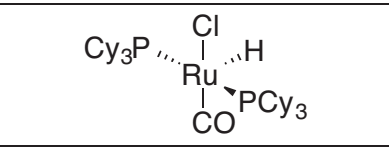 & $\begin{array}{c}23^{\circ} \mathrm{C}, 1 \text { bar } \mathrm{H}_{2} \\
\mathrm{C}_{6} \mathrm{H}_{6}\end{array}$ & 120 & $(\underbrace{96})$ & ---- & ---- \\
\hline $\begin{array}{c}\mathrm{Ph}_{3} \mathrm{P}_{1 \ldots} \mathrm{Ph}_{3} . \mathrm{NPPh}_{3} \\
\mathrm{Ph}_{3} \mathrm{P}-\mathrm{Cl}_{\mathrm{Cl}} \\
\text { Wilkinson's Complex }\end{array}$ & $\begin{array}{c}25^{\circ} \mathrm{C}, 1 \text { bar H } \\
\mathrm{C}_{6} \mathrm{H}_{6} / \mathrm{EtOH}\end{array}$ & 65 & 70 & 1.3 & ---- \\
\hline 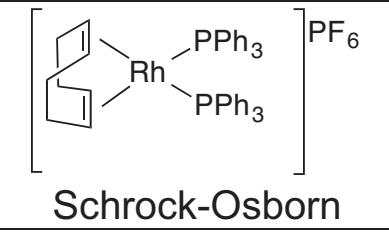 & $\begin{array}{c}25^{\circ} \mathrm{C}, 1 \text { bar } \mathrm{H}_{2} \\
\mathrm{CH}_{2} \mathrm{Cl}_{2}\end{array}$ & 400 & 1 & --- & ---- \\
\hline Crabtree's Complex & $\begin{array}{c}0^{\circ} \mathrm{C}, 1 \text { bar } \mathrm{H}_{2} \text {, } \\
\mathrm{CH}_{2} \mathrm{Cl}_{2}\end{array}$ & 640 & 450 & 380 & 400 \\
\hline $\mathrm{R}_{3} \mathrm{P} \ldots \mathrm{Br}_{\mathrm{I}}^{\mathrm{Br}}$ & $\begin{array}{c}23^{\circ} \mathrm{C}, 1 \text { bar } \mathrm{H}_{2} \\
\text { Neat }\end{array}$ & 172.5 & 23 & --- & ---- \\
\hline 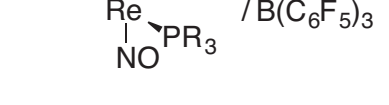 & $\begin{array}{c}90^{\circ} \mathrm{C}, 1 \text { bar } \mathrm{H}_{2} \\
\text { Neat }\end{array}$ & 201.3 & 38.4 & 15.2 & ---- \\
\hline $\begin{aligned} R & =i \mathrm{Pr}\end{aligned}$ & $\begin{array}{c}23^{\circ} \mathrm{C}, 10 \text { bar } \mathrm{H}_{2} \text {, } \\
\text { Neat }\end{array}$ & 1700 & 1400 & ---- & ---- \\
\hline $\begin{array}{l}\text { Jiang/Berke Catalyst } \\
\text { System }\end{array}$ & $\begin{array}{c}90^{\circ} \mathrm{C}, 10 \text { bar } \mathrm{H}_{2}, \\
\text { Neat }\end{array}$ & 5600 & 1300 & 155.1 & ---- \\
\hline
\end{tabular}

The placement of Lewis acids in the secondary coordination sphere can dramatically alter the reactivity of a complex. Szymczak and coworkers demonstrated that by appending Lewis acids to NNN-ligated ruthenium complexes, they were able to modulate the reactivity and control selectivity of alkyne hydrogenation (Scheme 1.26). ${ }^{133}$ The ruthenium complex shown in Scheme 1.21 hydrogenated diphenylacetylene to give complete conversion of the acetylene and 98:2 selectivity for the Z-isomer with no overreduction to the alkane observed. In the case of terminal alkynes, when the $\mathrm{R}$ group is phenyl, hexyl or 1-cyanopropane, there was no observed formation of the alkane 
product. When the $\mathrm{R}$ group was $\mathrm{N}, \mathrm{N}$-diethyl-N-methylamine, the ratio of the alkene to alkane was approximately $2: 1$. When the Lewis acid is not present, there is no reactivity at room temperature and low selectivity at elevated temperatures. When the less Lewis acidic catecholborane replaced the borabicyclo[3.3.1]nonane (BBN), the complex is less catalytically active. These results indicate that the hydricity of the ruthenium hydride, along with the location and Lewis acidity of the borane all influence the reactivity of these complexes.
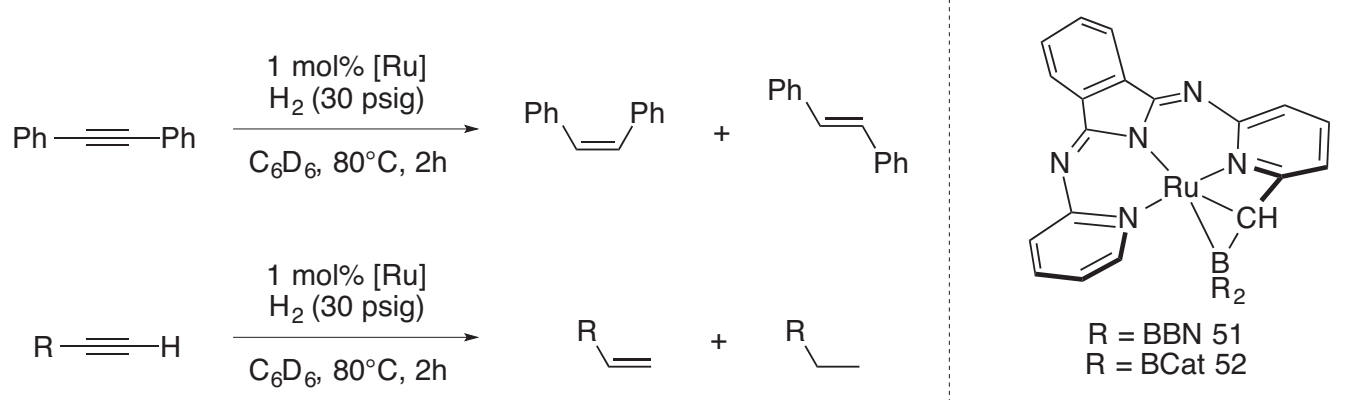

Scheme 1.26. Hydrogenation of internal and terminal alkynes catalyzed by Ru-pincer complexes bearing Lewis acid moiety.

\subsubsection{Transition Metal Lewis Acid Cooperative Activation of Boranes for Catalytic Hydroboration}

Beyond simple hydrogenation with transition metal/Lewis acid catalysts, Szymczak and coworkers designed a ruthenium complex with pendant second coordination sphere Lewis acids to catalyze the hydroboration of nitriles (Scheme 1.26). ${ }^{134}$ The Lewis acids are integral to nitrile activation in several key transition states (Scheme 1.27). 

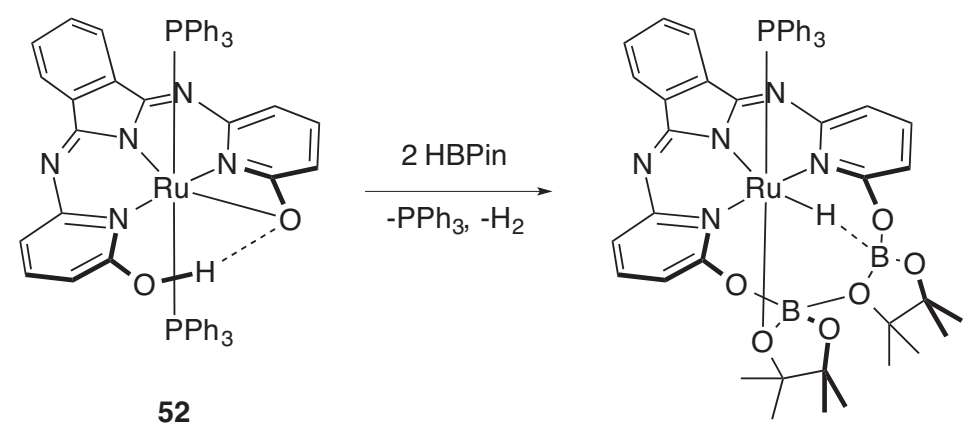

52

53

Scheme 1.27. Installation of BPin groups in the second coordination sphere of the Rucomplex with a proton-switchable ligand. Structure 53 depicts the presence of a borane interaction with $\mathrm{Ru}-\mathrm{H}$ bond. 


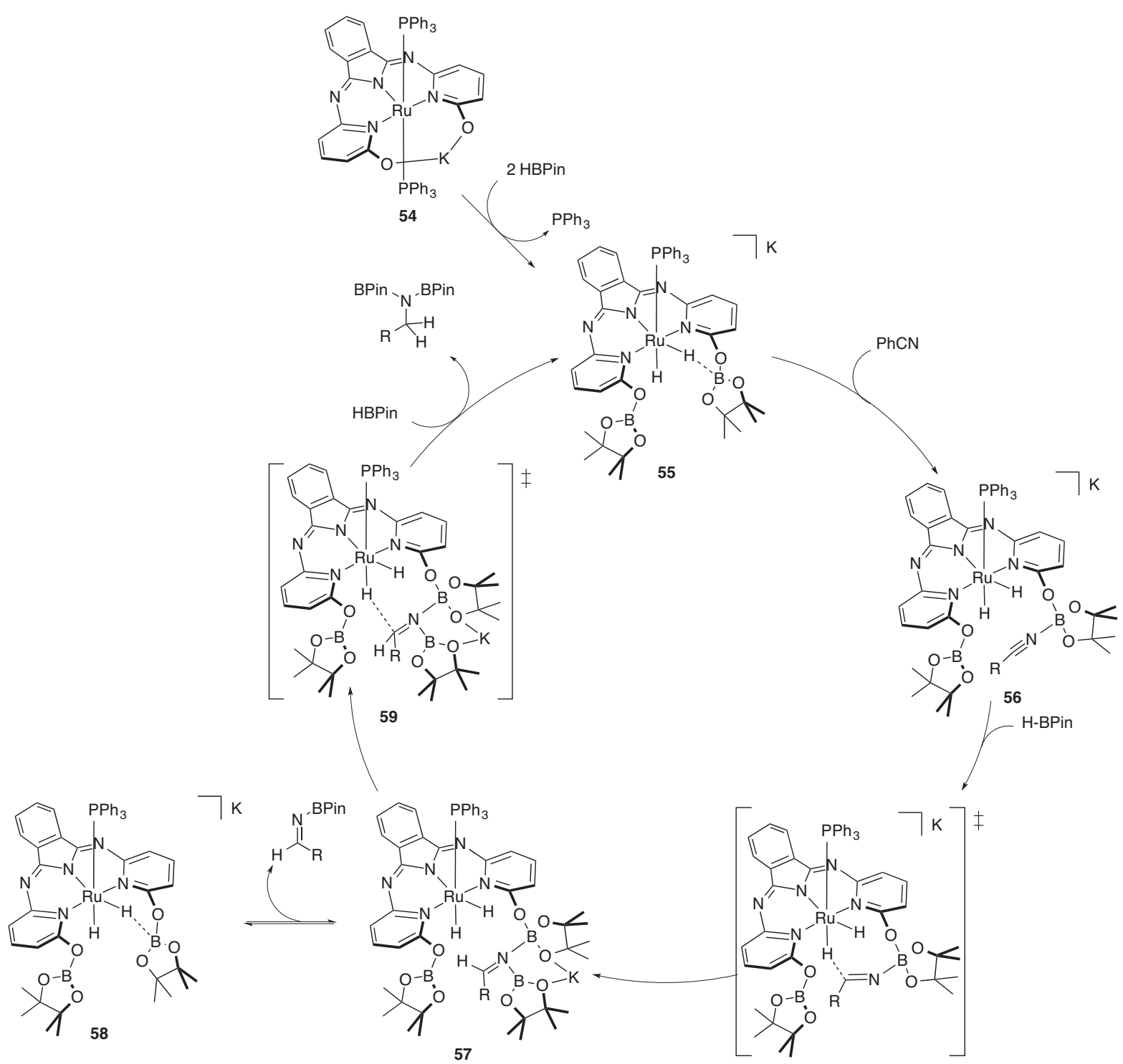

Scheme 1.28. Mechanism for the hydroboration of nitriles using a ruthenium complex with borapinacol Lewis acids in the second coordination sphere.

Pendant borapinacol Lewis acids interact with hydride ligands on ruthenium complex 55. Upon introducing HBPin, borapinacol Lewis acids coordinate to the Lewis basic nitrile nitrogen. During this key transition state, nitrile reduction to the imine occurs. The imine substrate can either be further reduced to the product by proceeding through a similar transition state (57 -> 59) or undergo reversible de-coordination from the complex (57 -> 58). 
Crudden and coworkers reported another example of using catalytic Lewis acids in conjunction with transition metals for hydroboration. ${ }^{36}$ While $B\left(C_{6} F_{5}\right)_{3}$ was inadequate as a catalyst for alkene hydroboration, ${ }^{57}$ addition of the Lewis acid in cooperativity with a cationic rhodium complex yielded the desired alkene hydroboration products (Table 1.3). The reactions in the absence of Lewis acid gave low yield and low selectivity. When the Lewis acid co-catalyst was added, the yield and selectivity of the reactions improved. The addition of Lewis acid co-catalyst and HBPin in the presence of a $\mathrm{Rh}(\mathrm{I})$ catalyst generated the anionic hydridoborate $\left[\mathrm{HB}\left(\mathrm{C}_{6} \mathrm{~F}_{5}\right)_{3}\right]$ species. The reaction was proposed to proceed through the borenium ion shown in Scheme 1.5, which was confirmed by ${ }^{11} \mathrm{~B}\left\{{ }^{1} \mathrm{H}\right\}$ NMR spectroscopy.

Table 1.3. Hydroboration of alkenes with $\mathrm{Rh}(\mathrm{I})$ catalyst in the presence of catalytic Lewis acid

\begin{tabular}{|c|c|c|c|}
\hline Starting Material & Product & No Lewis Acid & $\mathrm{B}\left(\mathrm{C}_{6} \mathrm{~F}_{5}\right)_{3}(2 \mathrm{~mol} \%)$ \\
\hline & & $\begin{array}{c}15 \% \text { yield } \\
2.5: 1\end{array}$ & $\begin{array}{c}84 \% \text { yield } \\
75: 1\end{array}$ \\
\hline 11 & & $12 \%$ yield & $\begin{array}{c}87 \% \text { yield } \\
>99: 1\end{array}$ \\
\hline $\mathrm{Ph}^{-}$ & BPin & $\begin{array}{c}19 \% \text { yield } \\
9: 1\end{array}$ & $\begin{array}{c}70 \% \text { yield } \\
32: 1\end{array}$ \\
\hline & & No reaction & $90 \%$ yield \\
\hline & & No reaction & $\begin{array}{c}84 \% \text { yield } \\
>99: 1\end{array}$ \\
\hline
\end{tabular}

\subsection{Conclusion}

While Lewis acids and transition metals are known to catalyze hydrofunctionalization reactions independent of each other, the recent melding of the two fields together has provided significant catalytic advancement. The use of Lewis acids has been shown to improve the yield and selectivity of traditional transition metal catalyzed reactions. One such way that Lewis acids alter reactivity is by accessing 
alternative bond activation pathways. ${ }^{33,34,36,70,71}$ Lewis acids have also been shown to interact with Lewis basic functionalities, such as carbonyls and hydrides. ${ }^{14}$ The use of Lewis acids and transition metals together in one catalytic system has however been limited for the most part to hydrogenation with only a few examples exploring alternative reactions, such as hydroboration.

\subsection{References}

(1) Wang, M. H.; Scheidt, K. A. Angew. Chem. Int. Edit. 2016, 55, 14912.

(2) van der Vlugt, J. I. Eur. J. Inorg. Chem. 2012, 363.

(3) Tang, W.; Xiao, J. Synthesis-Stuttgart 2014, 46, 1297.

(4) Stegbauer, L.; Sladojevich, F.; Dixon, D. J. Chem. Sci. 2012, 3, 942.

(5) Sawamura, M.; Sudoh, M.; Ito, Y. J. Am. Chem. Soc. 1996, 118, 3309.

(6) Park, Y. J.; Park, J-W.; Jun, C-H. Acc. Chem. Res. 2008, 41, 222.

(7) Omann, L.; Königs, C. D. F.; Klare, H. F. T.; Oestreich, M. Acc. Chem. Res. 2017, 50, 1258.

(8) Nakao, Y. Chem. Soc. Jpn. 2012, 85, 731.

(9) Li, H.; Zheng, B.; Huang, K-W. Coordin. Chem. Rev. 2015, 293, 116.

(10) Kim, D-S.; Park, W-J.; Jun, C-H. Chem. Rev. 2017, 117, 8977.

(11) Jun, C-H.; Park, J-W. C-C Bond Activation 2014, 346, 59.

(12) Jindal, G.; Kisan, H. K.; Sunoj, R. B. ACS Catal. 2015, 5, 480.

(13) Chen, D-F.; Han, Z-Y.; Zhou, X-L.; Gong, L-Z. Acc. Chem. Res. 2014, 47, 2365.

(14) Maity, A.; Teets, T. S. Chem. Rev. 2016, 116, 8873.

(15) Geri, J. B.; Shanahan, J. P.; Szymczak, N. K. J. Am. Chem. Soc. 2017, 139, 5952. 
(16) Tutusaus, O.; Ni, C.; Szymczak, N. K. J. Am. Chem. Soc. 2013, 135, 3403.

(17) Hulley, E. B.; Helm, M. L.; Bullock, R. M. Chem. Sci. 2014, 5, 4729.

(18) Helm, M. L.; Stewart, M. P.; Bullock, R. M.; DuBois, M. R.; DuBois, D. L. Science 2011, 333, 863.

(19) Barton, B. E.; Olsen, M. T.; Rauchfuss, T. B. J. Am. Chem. Soc. 2008, 130, 16834.

(20) Perutz, M. F.; Fermi, G.; Luisi, B.; Shaanan, B.; Liddington, R. C. Acc. Chem. Res. 1987, 20, 309.

(21) Groves, J. T. Proc. Natl. Acad. Sci. USA 2003, 100, 3569.

(22) Christianson, D. W.; Cox, J. D. Annu. Rev. Biochem. 1999, 68, 33.

(23) Wilson, A. D.; Fraze, K.; Twamley, B.; Miller, S. M.; DuBois, D. L.; DuBois, M. R. J. Am. Chem. Soc. 2008, 130, 1061.

(24) Fang, M.; Wiedner, E. S.; Dougherty, W. G.; Kassel, W. S.; Liu, T.; DuBois, D. L.; Bullock, R. M. Organometallics 2014, 33, 5820.

(25) Bähr, S.; Oestreich, M. Organometallics 2017, 36, 935.

(26) Hermeke, J.; Klare, H. F. T.; Oestreich, M. Chem. Eur. J. 2014, 20, 9250.

(27) Königs, C. D. F.; Klare, H. F. T.; Oestreich, M. Angew. Chem. Int. Edit. 2013, 52, 10076.

(28) Stahl, T.; Müther, K.; Ohki, Y.; Tatsumi, K.; Oestreich, M. J. Am. Chem. Soc. 2013, 135, 10978.

(29) Devillard, M.; Bouhadir, G.; Bourissou, D. Angew. Chem. Int. Edit. 2015, 54, 730.

(30) Flynn, S. R.; Wass, D. F. ACS Catal. 2013, 3, 2574.

(31) Wang, C.; Xi, Z. Chem. Soc. Rev. 2007, 36, 1395. 
(32) Oderinde, M. S.; Organ, M. G. Angew. Chem. Int. Edit. 2012, 51, 9834.

(33) Lambert, J. B.; Kuhlmann, B. J. Chem. Soc. Chem. Comm. 1992, 931.

(34) Welch, G. C.; Stephan, D. W. J. Am. Chem. Soc. 2007, 129, 1880.

(35) Marwitz, A. J. V.; Dutton, J. L.; Mercier, L. G.; Piers, W. E. J. Am. Chem. Soc. 2011, 133, 10026.

(36) Lata, C. J.; Crudden, C. M. J. Am. Chem. Soc. 2010, 132, 131.

(37) Parks, D. J.; Piers, W. E. J. Am. Chem. Soc. 1996, 118, 9440.

(38) Parks, D. J.; Blackwell, J. M.; Piers, W. E. J. Org. Chem. 2000, 65, 3090.

(39) Eisenberger, P.; Bailey, A. M.; Crudden, C. M. J. Am. Chem. Soc. 2012, 134, 17384.

(40) Arrowsmith, M.; Hill, M. S.; Kociok-Köhn, G. Chem. Eur. J. 2013, 19, 2776.

(41) Fleige, M.; Möbus, J.; vom Stein, T.; Glorius, F.; Stephan, D. W. Chem. Commun. 2016, 52, 10830.

(42) Shirakawa, K.; Arase, A.; Hoshi, M. Synthesis-Stuttgart 2004, 1814.

(43) Wang, Y. D.; Kimball, G.; Prashad, A. S.; Wang, Y. Tetrahedron Lett. 2005, 46, 8777.

(44) Tai, C-C.; Yu, M-S.; Chen, Y-L.; Chuang, W-H.; Lin, T-H.; Yap, G. P. A.; Ong, TG. Chem. Commun. 2014, 50, 4344.

(45) Romero, E. A.; Jazzar, R.; Bertrand, G. J. Organomet. Chem. 2017, 829, 11.

(46) Mitrofanov, A. Y.; Bessmertnykh-Lemeune, A. G.; Beletskaya, I. P. Inorg. Chim. Acta. 2015, 431, 297.

(47) Mazzacano, T. J.; Mankad, N. P. ACS Catal. 2017, 7, 146.

(48) Lee, J-E.; Kwon, J.; Yun, J. Chem. Commun. 2008, 733. 
(49) Jung, H-Y.; Feng, X.; Kim, H.; Yun, J. Tetrahedron 2012, 68, 3444.

(50) Haberberger, M.; Enthaler, S. Chem-Asian J. 2013, 8, 50.

(51) Jang, W. J.; Lee, W. L.; Moon, J. H.; Lee, J. Y.; Yun, J. Org. Lett. 2016, 18, 1390.

(52) Sun, C.; Liu, M.; Sun, H.; Hang, F.; Sun, N.; Chen, D. Int. J. Quantum Chem. 2015, 115, 59.

(53) Obligacion, J. V.; Neely, J. M.; Yazdani, A. N.; Pappas, I.; Chirik, P. J. J. Am. Chem. Soc. 2015, 137, 5855.

(54) Kiesewetter, E. T.; O'Brien, R. V.; Yu, E. C.; Meek, S. J.; Schrock, R. R.; Hoveyda, A. H. J. Am. Chem. Soc. 2013, 135, 6026.

(55) Gunanathan, C.; Hölscher, M.; Pan, F.; Leitner, W. J. Am. Chem. Soc. 2012, 134, 14349.

(56) Chang, N-H.; Chen, X-C.; Nonobe, H.; Okuda, Y.; Mori, H.; Nakajima, K.; Nishihara, Y. Org. Lett. 2013, 15, 3558.

(57) Yin, Q.; Kemper, S.; Klare, H. F. T.; Oestreich, M. Chem. Eur. J. 2016, 22, 13840.

(58) Yin, Q.; Soltani, Y.; Melen, R. L.; Oestreich, M. Organometallics 2017, 36, 2381.

(59) Yamamoto, Y.; Fujikawa, R.; Umemoto, T.; Miyaura, N. Tetrahedron 2004, 60, 10695.

(60) Zhang, G.; Zeng, H.; Wu, J.; Yin, Z.; Zheng, S.; Fettinger, J. C. Angew. Chem. Int. Edit. 2016, 55, 14367.

(61) Won, J.; Noh, D.; Yun, J.; Lee, J. Y. J. Phys. Chem. A 2010, 114, 12112.

(62) Unsworth, P. J.; Leonori, D.; Aggarwal, V. K. Angew. Chem. Int. Edit. 2014, 53, 9846. 
(63) Touney, E. E.; Van Hoveln, R.; Buttke, C. T.; Freidberg, M. D.; Guzei, I. A.; Schomaker, J. M. Organometallics 2016, 35, 3436.

(64) Scheuermann, M. L.; Johnson, E. J.; Chirik, P. J. Org. Lett. 2015, 17, 2716.

(65) Noh, D.; Chea, H.; Ju, J.; Yun, J. Angew. Chem. Int. Edit. 2009, 48, 6062.

(66) Espinal-Viguri, M.; Woof, C. R.; Webster, R. L. Chem. Eur. J. 2016, 22, 11605.

(67) Endo, K.; Hirokami, M.; Shibata, T. Organometallics 2008, 27, 5390.

(68) Crudden, C. M.; Hleba, Y. B.; Chen, A. C. J. Am. Chem. Soc. 2004, 126, 9200.

(69) Chen, X.; Cheng, Z.; Lu, Z. Org. Lett. 2017, 19, 969.

(70) Blackwell, J. M.; Sonmor, E. R.; Scoccitti, T.; Piers, W. E. Org. Lett. 2000, 2, 3921.

(71) Blackwell, J. M.; Morrison, D. J.; Piers, W. E. Tetrahedron 2002, 58, 8247.

(72) Rubin, M.; Schwier, T.; Gevorgyan, V. J. Org. Chem. 2002, 67, 1936.

(73) Sunada, Y.; Noda, D.; Soejima, H.; Tsutsumi, H.; Nagashima, H. Organometallics 2015, 34, 2896.

(74) Sridevi, V. S.; Fan, W. Y.; Leong, W. K. Organometallics 2007, 26, 1157.

(75) Silbestri, G. F.; Flores, J. C.; de Jesus, E. Organometallics 2012, 31, 3355.

(76) Seki, Y.; Takeshita, K.; Kawamoto, K.; Murai, S.; Sonoda, N. J. Org. Chem. 1986, 51, 3890.

(77) Rocha, B. G. M.; Valishina, E. A.; Chay, R. S.; da Silva, M. F. C. G.; Buslaeva, T. M.; Pombeiro, A. J. L.; Kukushkin, V. Y.; Luzyanin, K. V. J. Catal. 2014, 309, 79.

(78) Maifeld, S. V.; Tran, M. N.; Lee, D. Tetrahedron Lett. 2005, 46, 105.

(79) Li, J.; Peng, J.; Zhang, G.; Bai, Y.; Lai, G.; Li, X. New J. Chem. 2010, 34, 1330. 
(80) Iovel, I. G.; Goldberg, Y. S.; Shymanska, M. V.; Lukevics, E. Organometallics $1987,6,1410$.

(81) Iglesias, M.; Pérez-Nicolás, M.; Miguel, P. J. S.; Polo, V.; Fernández-Alvarez, F. J.; Pérez-Torrente, J. J.; Oro, L. A. Chem. Commun. 2012, 48, 9480.

(82) Hamze, A.; Provot, O.; Brion, J-D.; Alami, M. J. Organomet Chem. 2008, 693, 2789 .

(83) Hamze, A.; Provot, O.; Brion, J-D.; Alami, M. Tetrahedron Lett. 2008, 49, 2429.

(84) Gao, R.; Pahls, D. R.; Cundari, T. R.; Yi, C. S. Organometallics 2014, 33, 6937.

(85) Caseri, W.; Pregosin, P. S. Organometallics 1988, 7, 1373.

(86) Aneetha, H.; Wu, W.; Verkade, J. G. Organometallics 2005, 24, 2590.

(87) Song, Y-S.; Yoo, B. R.; Lee, G-H.; Jung, I. N. Organometallics 1999, 18, 3109.

(88) Oertle, K.; Wetter, H. Tetrahedron Lett. 1985, 26, 5511.

(89) Sudo, T.; Asao, N.; Gevorgyan, V.; Yamamoto, Y. J. Org. Chem. 1999, 64, 2494.

(90) Asao, N.; Sudo, T.; Yamamoto, Y. J. Org. Chem. 1996, 61, 7654.

(91) Gevorgyan, V.; Liu, J-X.; Yamamoto, Y. J. Org. Chem. 1997, 62, 2963.

(92) Zhang, H. X.; Guibé, F.; Balavoine, G. J. Org. Chem. 1990, 55, 1857.

(93) Rummelt, S. M.; Fürstner, A. Angew. Chem. Int. Edit. 2014, 53, 3626.

(94) Miao, R.; Li, S.; Chiu, P. Tetrahedron 2007, 63, 6737.

(95) Marshall, J. A.; Bourbeau, M. P. Tetrahedron Lett. 2003, 44, 1087.

(96) Leung, L. T.; Leung, S. K.; Chiu, P. Org. Lett. 2005, 7, 5249.

(97) Heiden, Z. M.; Lathem, A. P. Organometallics 2015, 34, 1818.

(98) Vicart, N.; Cazes, B.; Gore, J. Tetrahedron Lett. 1995, 36, 535.

(99) Sud, A.; Deshpande, R. M.; Chaudhari, R. V. Catal. Commun. 2007, 8, 183. 
(100) Becica, J.; Dobereiner, G. E. ACS Catal. 2017, 7, 5862.

(101) Chen, D.; Gau, M. R.; Dobereiner, G. E. Organometallics 2015, 34, 4069.

(102) Xu, S.; Negishi, E. Acc. Chem. Res. 2016, 49, 2158.

(103) Erker, G. Dalton Trans. 2005, 1883.

(104) Erker, G. Chem. Commun. 2003, 1469.

(105) Eisch, J. J. Organometallics 2012, 31, 4917.

(106) Klosin, J.; Fontaine, P. P.; Figueroa, R. Acc. Chem. Res. 2015, 48, 2004.

(107) Luo, L.; Marks, T. J. Top. Catal. 1999, 7, 97.

(108) Kumawat, J.; Gupta, V. K.; Vanka, K. Organometallics 2014, 33, 4357.

(109) Ewart, S. W.; Baird, M. C. Top. Catal. 1999, 7, 1.

(110) Erker, G.; Kehr, G.; Fröhlich, R. J. Organomet. Chem. 2005, 690, 6254.

(111) Lin, T-P.; Peters, J. C. J. Am. Chem. Soc. 2013, 135, 15310.

(112) Harman, W. H.; Peters, J. C. J. Am. Chem. Soc. 2012, 134, 5080.

(113) Fong, H.; Moret, M-E.; Lee, Y.; Peters, J. C. Organometallics 2013, 32, 3053.

(114) Barnett, B. R.; Moore, C. E.; Rheingold, A. L.; Figueroa, J. S. J. Am. Chem. Soc. 2014, 136, 10262.

(115) Bernskoetter, W. H.; Hazari, N. Acc. Chem. Res. 2017, 50, 1049.

(116) Boone, M. P.; Stephan, D. W. J. Am. Chem. Soc. 2013, 135, 8508.

(117) Li, Y.; Hou, C.; Jiang, J.; Zhang, Z.; Zhao, C.; Page, A. J.; Ke, Z. ACS Catal. 2016, 6, 1655.

(118) Harman, W. H.; Lin, T-P.; Peters, J. C. Angew. Chem. Int. Edit. 2014, 53, 1081.

(119) Zeng, G.; Sakaki, S. Inorg. Chem. 2013, 52, 2844.

(120) Cowie, B. E.; Emslie, D. J. H. Chem. Eur. J. 2014, 20, 16899. 
(121) Hartwig, J. F. Organotransition Metal Chemistry: From Bonding to Catalysis; University Science Books, 2010.

(122) Strauss, S. H.; Shriver, D. F. Inorg. Chem. 1978, 17, 3069.

(123) Shih, W. C.; Ozerov, O. V. Organometallics 2017, 36, 228.

(124) Jiang, Y.; Huang, W.; Schmalle, H. W.; Blacque, O.; Fox, T.; Berke, H. Organometallics 2013, 32, 7043.

(125) Jiang, Y.; Blacque, O.; Fox, T.; Berke, H. J. Am. Chem. Soc. 2013, 135, 7751.

(126) Jiang, Y.; Hess, J.; Fox, T.; Berke, H. J. Am. Chem. Soc. 2010, 132, 18233.

(127) Jiang, Y.; Huang, W.; Schmalle, H. W.; Blacque, O.; Fox, T.; Berke, H. Eur. J. Inorg. Chem. 2014, 2014, 140.

(128) Ogasawara, M.; Huang, D.; Streib, W. E.; Huffman, J. C.; Gallego-Planas, N.; Maseras, F.; Eisenstein, O.; Caulton, K. G. J. Am. Chem. Soc. 1997, 119, 8642.

(129) Negishi, E. Chem. Eur. J. 1999, 5, 411.

(130) Schrock, R. R.; Osborn, J. A. J. Am. Chem. Soc. 1976, 98, 2143.

(131) Schrock, R. R.; Osborn, J. A. J. Am. Chem. Soc. 1976, 98, 2134.

(132) Schrock, R. R.; Osborn, J. A. J. Am. Chem. Soc. 1976, 98, 4450.

(133) Tseng, K-N. T.; Kampf, J. W.; Szymczak, N. K. J. Am. Chem. Soc. 2016, 138, 10378.

(134) Geri, J. B.; Szymczak, N. K. J. Am. Chem. Soc. 2015, 137, 12808. 


\section{CHAPTER 2}

Synthesis and Characterization of Rhodium and Iridium Complexes featuring a Conformationally Flexible Ambiphilic $\beta$-Phosphinoethylborane Ligand 


\subsection{Introduction}

The modification of the primary coordination sphere of a late transition metal complex has dramatic consequences on the stability and activity of the complex under catalytic conditions. ${ }^{1}$ Ambiphilic ligands are a class of compounds that contains both a donor group and a Lewis acidic functionality. ${ }^{2-5}$ These ligands not only provide the means of modifying the primary coordination sphere of a transition metal complex but also, the Lewis acidic functionality can serve as a means of altering the secondary coordination sphere. ${ }^{6,7}$ In particular, one class of ligand that has garnered attention in catalysis is the alkyl-linked phosphinoborane ligands due to their flexibility and ability to adopt multiple binding orientations (Figure 2.1). ${ }^{8}$ In these particular cases, coordination mode A represents one in which the borane is unbound to ligands or solvent, whereas binding mode $B$ shows an interaction with a primary coordination sphere ligand. ${ }^{9,10}$ Coordination modes $\mathrm{C}$ and $\mathrm{D}$ represent complexes in which the borane is directly bound to either the solvent or the metal, respectively. ${ }^{11}$

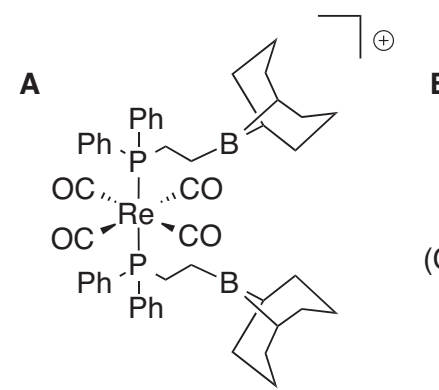

60
B

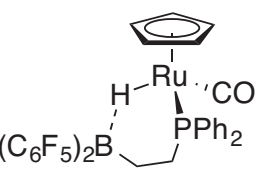

61

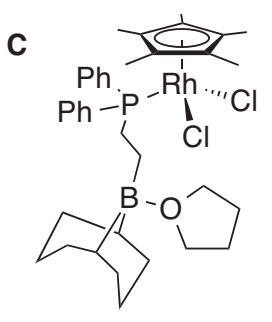

62

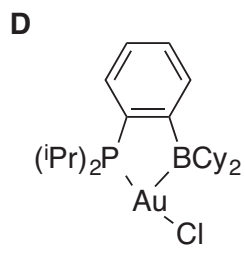

63

Figure 2.1. Different binding modes of transition metal complexes of ambiphilic phosphinoborane ligands.

There have been a variety of different chain lengths adopted within the alkyllinker, the focus of the discussion within the following chapters will be given to $\mathrm{C}_{2} \mathrm{H}_{4}{ }^{-}$ linked ambiphilic ligand frameworks. One ligand in particular is the 9- 
borabicyclo[3.3.1]nonanyl (9-BBN) based $\beta$-phosphinoethylborane framework (Scheme 2.1A), which was first synthesized by Tilley and coworkers. ${ }^{12}$ Since then, the limited work on the ambiphilic $\beta$-phosphinoethylborane ligand has focused exclusively on stoichiometric reactivity with transition metals.9,10,12-16 Bercaw and coworkers demonstrated that this ligand could stoichiometrically facilitate $\mathrm{CO}$ reductive coupling ${ }^{16}$ and CO hydrogenation ${ }^{9}$ at rhenium carbonyl complexes. More recently, Klankermayer and coworkers showed this motif provides a bifunctional ligand environment capable of engaging in the activation of metal bound ligands within the coordination sphere of the metal. ${ }^{10}$ While Crossley and coworkers prepared a few of the complexes discussed in the following chapters, no fundamental binding or dynamics studies were performed. ${ }^{17}$

We sought to explore the synthesis and structural characterization of rhodium(I) and iridium(I) complexes to gain insight into the structural implications associated with secondary coordination sphere boranes. An understanding of the structure of these complexes provides information regarding their application to catalysis. We are interested in these complexes as a means to modulate the reactivity of traditional late transition metal complexes. In particular, the interest in these complexes stems from the role of the Lewis acid in stabilizing reactive species along the catalytic cycle to lead to new or modified reactivity. 


\subsection{Results and Discussion}

\subsubsection{Synthesis and Characterization of Various $\beta$-phosphinoethylborane Ligands and their Subsequent Reactivity}

The $\beta$-phosphinoethylborane ligand has been previously synthesized via stoichiometric, classical hydroboration of the corresponding vinylphosphine with a dialkylborane to yield the desired product as an isolable solid in excellent yield (Scheme 2.1). ${ }^{12,15} \beta$-phosphinoethyl-9-borabicyclo[3.3.1]nonane (65) crystallizes in a head-to-tail fashion to form an oligomeric network of molecules. ${ }^{12}$ In addition to the previously prepared diphenylphosphine analogs, the dimesityl analog was prepared in a 95\% yield by following a procedure similar to the phenyl analog by starting with the mesitylmagnesium bromide and $\mathrm{PCl}_{3}{ }^{18,19}$ While analog 65 requires elevated temperatures in THF, preparation of analog 64 occurs at room temperature in toluene. The obtained ligand is isolated as a powdery white solid that exhibits low solubility in organic solvents. The ${ }^{31} \mathrm{P}\left\{{ }^{1} \mathrm{H}\right\}$ NMR spectra shows a single resonance at $-9.4 \mathrm{ppm} .{ }^{12,15}$ The ${ }^{11} \mathrm{~B}\left\{{ }^{1} \mathrm{H}\right\}$ NMR spectra of 64 and 65 show broadened signals at 82 and $87 \mathrm{ppm}$, respectively. ${ }^{12,15}$

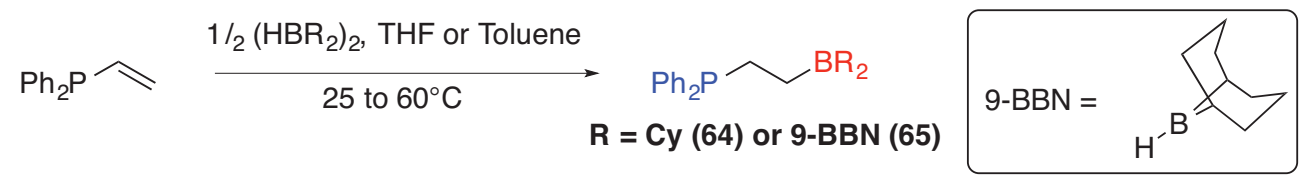

Scheme 2.1. Synthesis of $\beta$-phosphinoethylborane ligand frameworks.

\subsubsection{Synthesis and Characterization of Transition Metal Complexes Ligated with $\beta$-phosphinoethylborane}

The phosphinoborane ligand was added to $[\mathrm{Rh}(\mathrm{COD}) \mathrm{Cl}]_{2}$ in toluene and allowed to stir overnight at room temperature (Scheme 2.2). After removal of the solvent in vacuo, the yellow solid complex was isolated in quantitative yield. The complex can be 
recrystallized by layering a cold DCM solution with pentane at $-40^{\circ} \mathrm{C}$. The ${ }^{31} \mathrm{P}\left\{{ }^{1} \mathrm{H}\right\} N M R$ spectrum in $d_{2}$-dichloromethane showed a doublet at $29 \mathrm{ppm}\left({ }^{1} J_{R h-P}=148 \mathrm{~Hz}\right)$. The structure was confirmed by X-ray crystallography. Rh(COD) complex 66 possesses a square planar orientation at the metal center and a B-Cl Lewis interaction (Figure 2.2). The ${ }^{11} \mathrm{~B}\left\{{ }^{1} \mathrm{H}\right\}$ NMR signal was shifted slightly upfield from $86 \mathrm{ppm}$ (free ligand) to $78 \mathrm{ppm}$ in the complex. This is similar to $\mathrm{Rh}(\mathrm{nbd})$ phosphinoborane complex 68 that similarly contains a B-Cl interaction (B-Cl $=2.117(2) \AA$ ) and upfield shifted ${ }^{11} \mathrm{~B}$ NMR spectrum. ${ }^{20}$ Bond lengths for $\mathrm{B}-\mathrm{Cl}$ interactions in complexes 66 and 68 are longer, indicating a weaker $\mathrm{B}-\mathrm{Cl}$ interaction, than those observed by Emslie and coworkers for their complex with a halide bridging rhodium borane interaction $(\mathrm{B}-\mathrm{Cl}=1.995(9) \AA) .{ }^{21}$

As a point of comparison, the iridium(I) complex was prepared by addition of the phosphinoborane ligand to $[\operatorname{Ir}(\mathrm{COD}) \mathrm{Cl}]_{2}$ in a 3:1 mixture of DCM and pentane (Scheme $2.2)^{23,24}$ The complex was isolated in $65 \%$ yield after recrystallization from a DCMpentane solution via layering at $-40^{\circ} \mathrm{C}$. NMR spectroscopy and X-ray crystallography (Figure 2.2) were used to characterize this complex. The ${ }^{31} \mathrm{P}\left\{{ }^{1} \mathrm{H}\right\}$ NMR spectrum in $\mathrm{d}_{2^{-}}$ dichloromethane displayed one singlet resonance at $18.2 \mathrm{ppm}$. The ${ }^{11} \mathrm{~B}\left\{{ }^{1} \mathrm{H}\right\}$ NMR showed a small shift from the free ligand signal to $84 \mathrm{ppm}$. This was a significantly smaller shift than seen in $d_{2}$-dichloromethane for the rhodium(l) complex. The crystal structure displayed a slightly distorted square planar orientation at the metal center, with a weak interaction between the borane and the chloride ligand. The $\mathrm{B}-\mathrm{Cl}$ distance in the case of the iridium complex is longer than that observed for the rhodium complex (2.188(5) $\AA$ for rhodium complex and 2.233(11) $\AA$ for iridium complex). The acetonitrile bound borane complex was also prepared by cooling a dilute sample of complex 67 in 
acetonitrile. This complex bears a solvent bound borane with no $\mathrm{B}-\mathrm{Cl}$ interaction present. By comparing these two complexes, it was determined that the $\mathrm{B}-\mathrm{Cl}$ interaction results in an elongation of the $\mathrm{Ir}-\mathrm{Cl}$ bond by $0.026(4) \AA$.

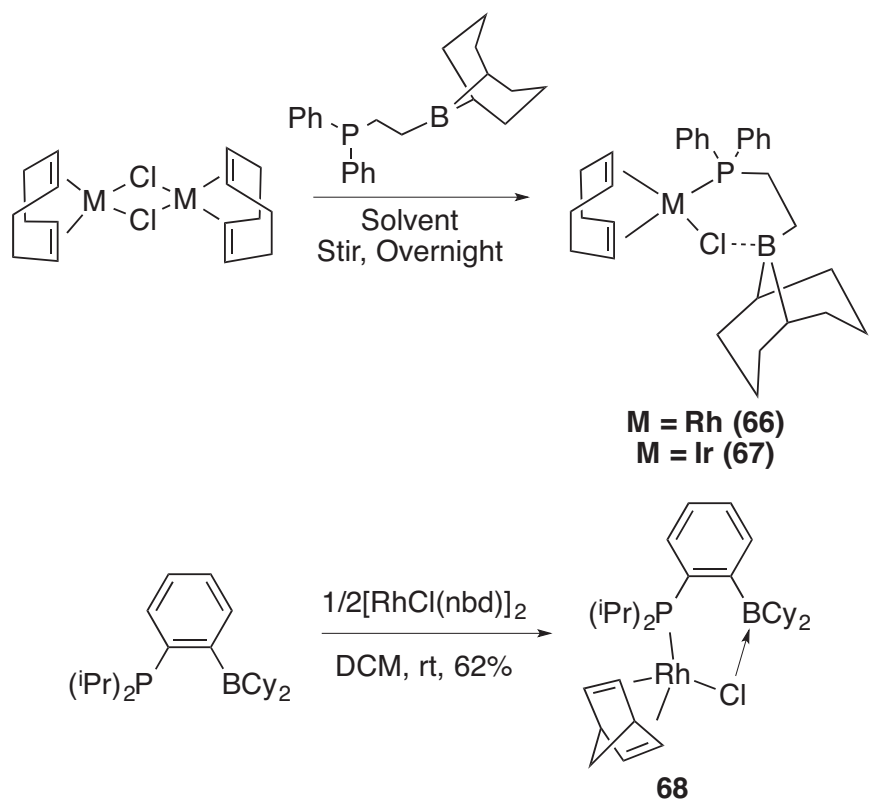

Scheme 2.2. Synthesis of rhodium $(I)$ and iridium $(I)$ cyclooctadiene complexes with $\beta$ phosphinoethylborane ligand scaffold (top) and Bourissou's synthesis of Rh(nbd) $\mathrm{PB}^{\mathrm{Cy}} \mathrm{Cl}$ complex 68 (bottom). 

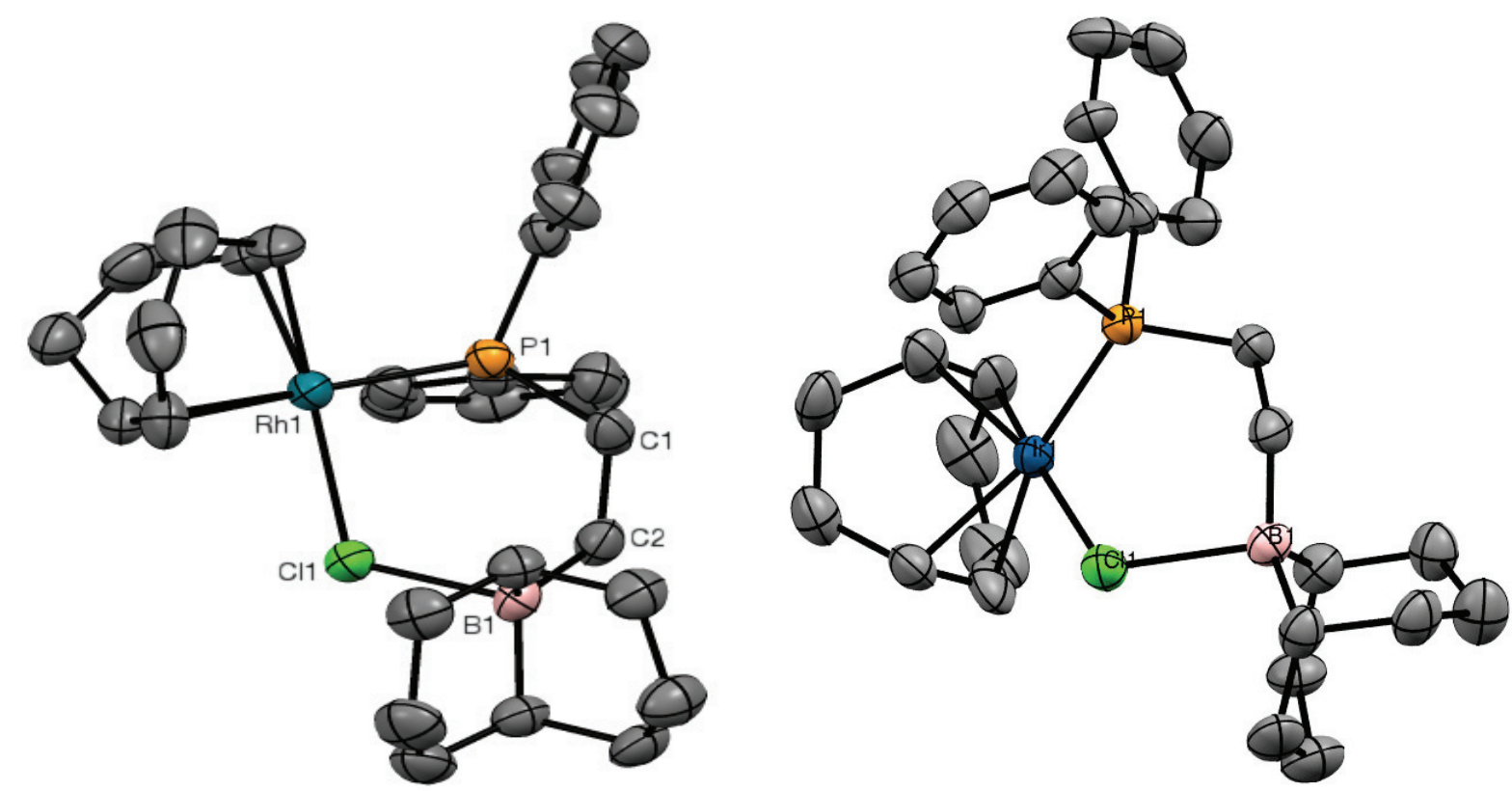

Figure 2.2. X-ray crystallographic structures of $\mathrm{Rh}(\mathrm{COD})\left[\mathrm{Ph}_{2} \mathrm{PCH}_{2} \mathrm{CH}_{2} \mathrm{~B}^{\mathrm{BBN}}\right] \mathrm{Cl}(66)$ and $\operatorname{Ir}(\mathrm{COD})\left[\mathrm{Ph}_{2} \mathrm{PCH}_{2} \mathrm{CH}_{2} \mathrm{~B}^{\mathrm{BBN}}\right] \mathrm{Cl}$ (67) (thermal ellipsoids at $50 \%$ probability) with hydrogens removed for clarity. Selected bond lengths $[\AA]$ and angles $\left[{ }^{\circ}\right]$ for $\mathrm{Rh}(\mathrm{COD})\left[\mathrm{Ph}_{2} \mathrm{PCH}_{2} \mathrm{CH}_{2} \mathrm{~B}^{\mathrm{BBN}}\right] \mathrm{Cl}: \mathrm{Rh}(1)-\mathrm{Cl}(1)$ 2.394(1), $\mathrm{Rh}(1)-\mathrm{P}(1)$ 2.295(2), $\mathrm{Cl}(1)-\mathrm{B}(1)$ 2.189(5), B(1)-C(2) 1.607(7), $\mathrm{P}(1)-\mathrm{Rh}(1)-\mathrm{Cl}(1)$ 89.07(5), $\mathrm{B}(1)-\mathrm{Cl}(1)-\mathrm{Rh}(1)$ 112.6(2), $\mathrm{Cl}(1)-\mathrm{B}(1)-\mathrm{C}(2)$ 101.1(4). Selected bond lengths $[\AA]$ and angles $\left.{ }^{\circ}\right]$ for $\operatorname{Ir}(\mathrm{COD})\left[\mathrm{Ph}_{2} \mathrm{PCH}_{2} \mathrm{CH}_{2} \mathrm{~B}^{\mathrm{BBN}}\right] \mathrm{Cl}: \operatorname{Ir}(1)-\mathrm{Cl}(1) \quad 2.378(3), \quad \operatorname{Ir}(1)-\mathrm{P}(1) \quad 2.305(2), \quad \mathrm{Cl}(1)-\mathrm{B}(1)$ 2.233(11), B(1)-C(2) 1.615(15), $\mathrm{P}(1)-\operatorname{Ir}(1)-\mathrm{Cl}(1)$ 90.19(9), $\mathrm{B}(1)-\mathrm{Cl}(1)-\operatorname{Ir}(1)$ 112.4(3), $\mathrm{Cl}(1)-\mathrm{B}(1)-\mathrm{C}(2) 100.7(6)$.

In an effort to understand the role of the halide in the internal Lewis adduct, the iodide, bromide, and fluoride complexes were prepared and characterized by NMR spectroscopy. These complexes were prepared by either a halogen exchange reaction or by treatment of the corresponding dimer with the phosphinoborane ligand. As seen in Figure 2.3, the ${ }^{11} \mathrm{~B}\left\{{ }^{1} \mathrm{H}\right\}$ NMR spectra show an increase in the formation of the boranehalide Lewis adduct as the electronegativity of the halide increases. This observation is consistent with previously published results by Britten and coworkers. ${ }^{21}$ The crystal 
structure of the $\mathrm{Rh}-\mathrm{Br}$ complex can be seen in Figure 2.4. The fluoride complex has an ${ }^{11} \mathrm{~B}\left\{{ }^{1} \mathrm{H}\right\}$ NMR signal that is significantly shifted from that seen for the other halide complexes. The location of the chemical shift of the fluoride complex is indicative of the formation of the zwitterionic "ate" complex. In addition, the ${ }^{19} \mathrm{~F}$ NMR shows a broad resonance at $-160 \mathrm{ppm}$. The ${ }^{19} \mathrm{~F}$ NMR chemical shift of $\mathrm{Rh}(\mathrm{COD}) \mathrm{PPh}_{3} \mathrm{~F}$ appears at -257 $\mathrm{ppm}^{22}$ but the zwitterionic rhodium(I) fluoroborate complex reported by Britten and coworkers, bearing a different borane and ligand framework, appears at a chemical shift of $-186 \mathrm{ppm}^{21}$ Our results for the rhodium(I) fluoride complex 72 are more consistent with the formation of the zwitterionic complex, in which the fluoride resides on the borane rather than the metal center. As opposed to the solution-state structure of $\mathbf{7 2}$, the solid-state structure obtained via x-ray crystallography shows the presence of an elongated Rh-F bond along with a stronger B-F interaction. The ${ }^{31} \mathrm{P}\left\{{ }^{1} \mathrm{H}\right\} \mathrm{NMR}$ resonances for these complexes shift upfield as the halides go from iodide to fluoride. In the crystal structure of the chloride and bromide complex, the bond angles around the borane are closer to $120^{\circ}$ rather than the $109.5^{\circ}$ expected for a tetrahedral borate, which is consistent with a weak borane-halide interaction. The prevention of water/moisture is of critical importance since the carbon-boron bond of the ligand is susceptible to hydrolysis and subsequent cleavage to the undesired $\mathrm{Ph}_{2} \mathrm{PEt}$ ligand containing rhodium(I) complex (Figure 2.4). In the case of the fluoride complex $\mathbf{7 2}$, exposing the complex to dichloromethane results in the regeneration of rhodium chloride complex 66 . 

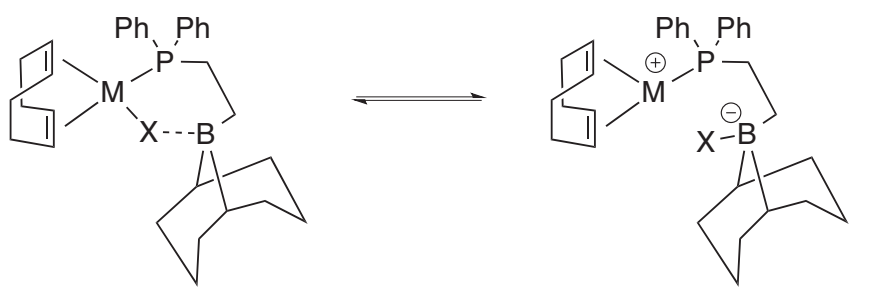

$$
\begin{gathered}
X=\text { OTf (69) } \\
X=I(70) \\
X=\operatorname{Br}(71)
\end{gathered}
$$

$X=F(72)$

\section{Triflate (69)}

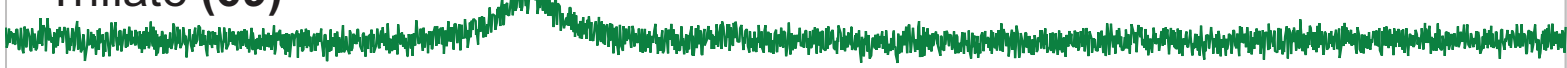

lodide (70)

\section{Bromide (71)}

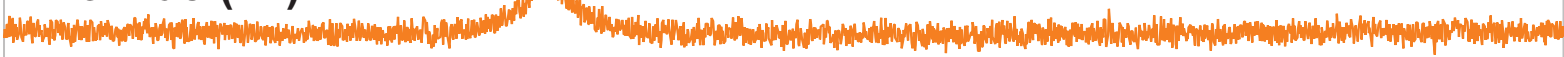

\section{Chloride (66)}

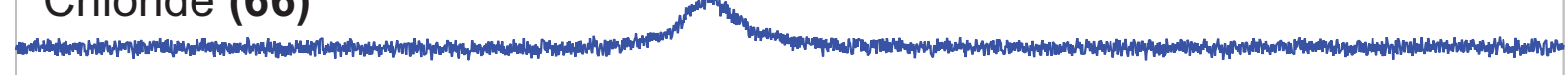

Fluoride (72)

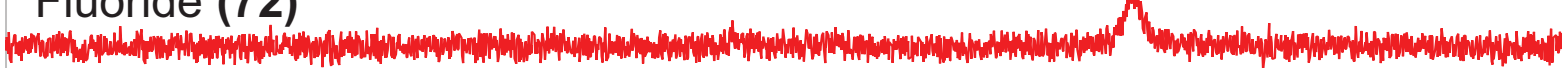

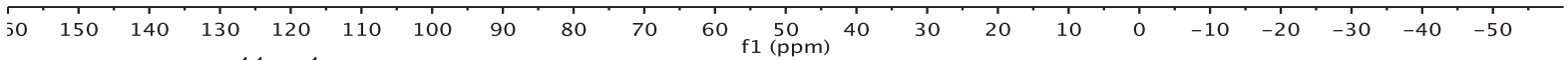

Figure 2.3. ${ }^{11} \mathrm{~B}\left\{{ }^{1} \mathrm{H}\right\}$ NMR spectra depicting chemical shifts of the various ligands of $\mathrm{Rh}(\mathrm{COD})\left[\mathrm{Ph}_{2} \mathrm{PCH}_{2} \mathrm{CH}_{2} \mathrm{~B}\left(\mathrm{C}_{8} \mathrm{H}_{14}\right)\right] \mathrm{X}$ complexes. 

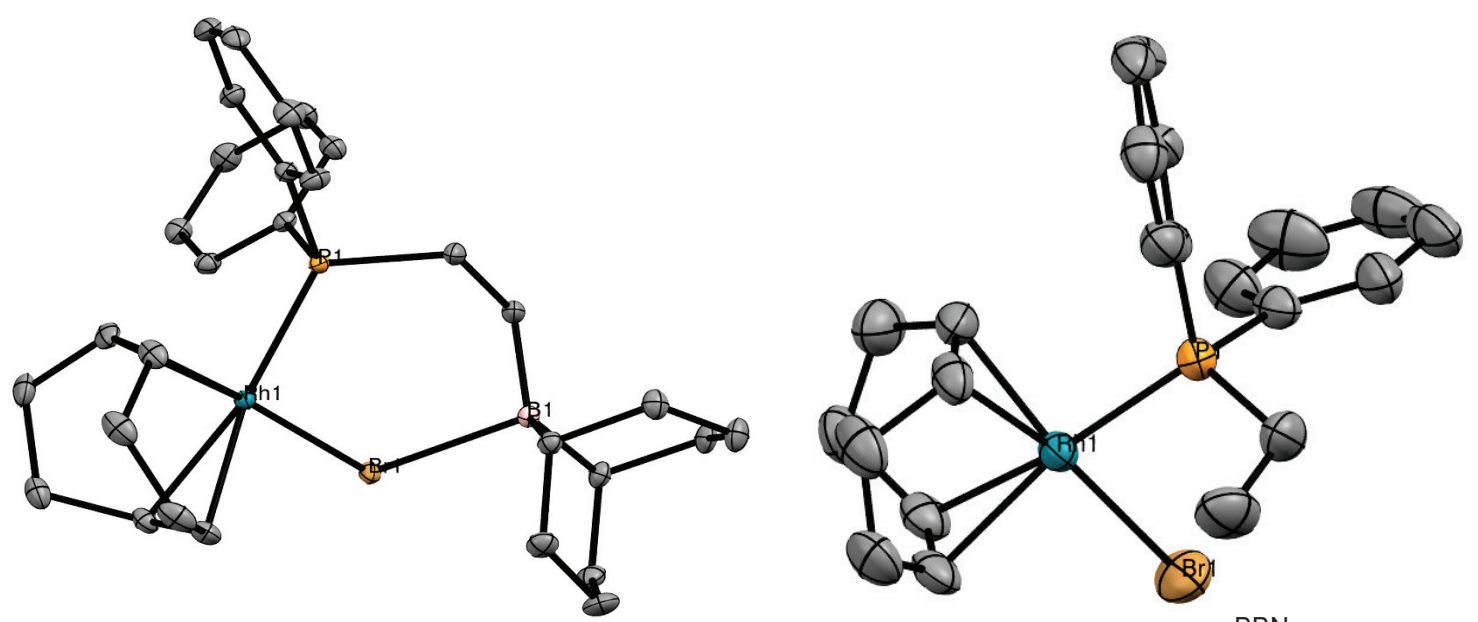

Figure 2.4. X-ray crystallographic structures of $\mathrm{Rh}(\mathrm{COD})\left[\mathrm{Ph}_{2} \mathrm{PCH}_{2} \mathrm{CH}_{2} \mathrm{~B}^{\mathrm{BBN}}\right] \mathrm{Br}(71)$ and $\mathrm{Rh}(\mathrm{COD})\left[\mathrm{Ph}_{2} \mathrm{PCH}_{2} \mathrm{CH}_{3}\right] \mathrm{Br}$ (72) (thermal ellipsoids at $50 \%$ probability) with hydrogens removed for clarity. Selected bond lengths $[\AA]$ and angles $\left[{ }^{\circ}\right]$ for $\mathrm{Rh}(\mathrm{COD})\left[\mathrm{Ph}_{2} \mathrm{PCH}_{2} \mathrm{CH}_{2} \mathrm{~B}^{\mathrm{BBN}}\right] \mathrm{Cl}: \mathrm{Rh}(1)-\mathrm{Br}(1)$ 2.49632(17), $\mathrm{Rh}(1)-\mathrm{P}(1) 2.2940(3), \operatorname{Br}(1)-$ $\mathrm{B}(1)$ 2.3499(14), B(1)-C(2) 1.6037(19), P(1)-Rh(1)-Br(1) 88.848(10), B(1)-Br(1)-Rh(1) 109.54(4), $\mathrm{Br}(1)-\mathrm{B}(1)-\mathrm{C}(2)$ 100.32(8). Selected bond lengths $[\AA]$ and angles $\left[{ }^{\circ}\right]$ for $\mathrm{Rh}(\mathrm{COD})\left[\mathrm{Ph}_{2} \mathrm{PCH}_{2} \mathrm{CH}_{3}\right] \mathrm{Br}: \mathrm{Rh}(1)-\mathrm{Br}(1)$ 2.5027(5), Rh(1)-P(1) 2.2766(8), P(1)-Rh(1)$\operatorname{Br}(1) 87.96(2)$.

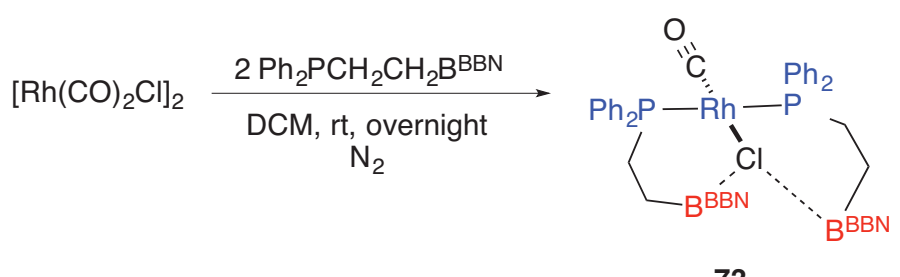

73

Scheme 2.3. Synthesis of a phosphinoborane analog of a $\mathrm{Rh}^{\prime} \mathrm{Vaska's} \mathrm{complex.}$

In order to increase the available library of phosphinoborane complexes of rhodium(I), the bis(phosphinoborane) analog of Vaska's complex (73) was prepared and characterized by X-ray crystallography and NMR and FTIR spectroscopy. The complex was prepared in quantitative yield by treatment of $\left[\mathrm{Rh}(\mathrm{CO})_{2} \mathrm{Cl}\right]_{2}$ with two equivalents of the phosphinoborane ligand (Scheme 2.3). When the reaction was conducted on a 
larger scale, the bubbling/evolution of carbon monoxide was visible. The sample was crystallized from a DCM/pentane layered solution at $-40^{\circ} \mathrm{C}$ (Figure 2.5). The ${ }^{31} \mathrm{P}\left\{{ }^{1} \mathrm{H}\right\}$ NMR showed a single doublet resonance at $29.9 \mathrm{ppm}$ in $\mathrm{d}_{6}$-benzene $\left({ }^{1} \mathrm{~J}_{\mathrm{Rh}-\mathrm{P}}=123 \mathrm{~Hz}\right)$. These values agree with previously prepared rhodium(I) Vaska complex analogs. ${ }^{17}$ The ${ }^{11} \mathrm{~B}\left\{{ }^{1} \mathrm{H}\right\}$ NMR spectrum showed a broad signal at $84 \mathrm{ppm}$, consistent with a relatively free borane. As opposed to the monophosphine rhodium(I) cyclooctadiene complex, the ${ }^{11} \mathrm{~B}\left\{{ }^{1} \mathrm{H}\right\}$ NMR of this complex was not solvent dependent. This can be explained by the X-ray crystal structure obtained of this complex. The metal center is in a slightly distorted square planar orientation, as would be expected for a rhodium(I) complex. However, it can be seen that the two boron atoms are different distances from the chloride (2.353(3) and 4.186(3) $\AA$, respectively). This, along with the NMR data, suggests that the borane moieties are in rapid exchange between free borane and the rhodium-chloride interaction. The FTIR spectrum shows a carbon monoxide stretch at $1970 \mathrm{~cm}^{-1}$, which is in agreement for the $\mathrm{Ph}_{2} \mathrm{PEt}$ analog of Vaska's that possesses a carbon monoxide stretch at $1973 \mathrm{~cm}^{-1}{ }^{26}$ 


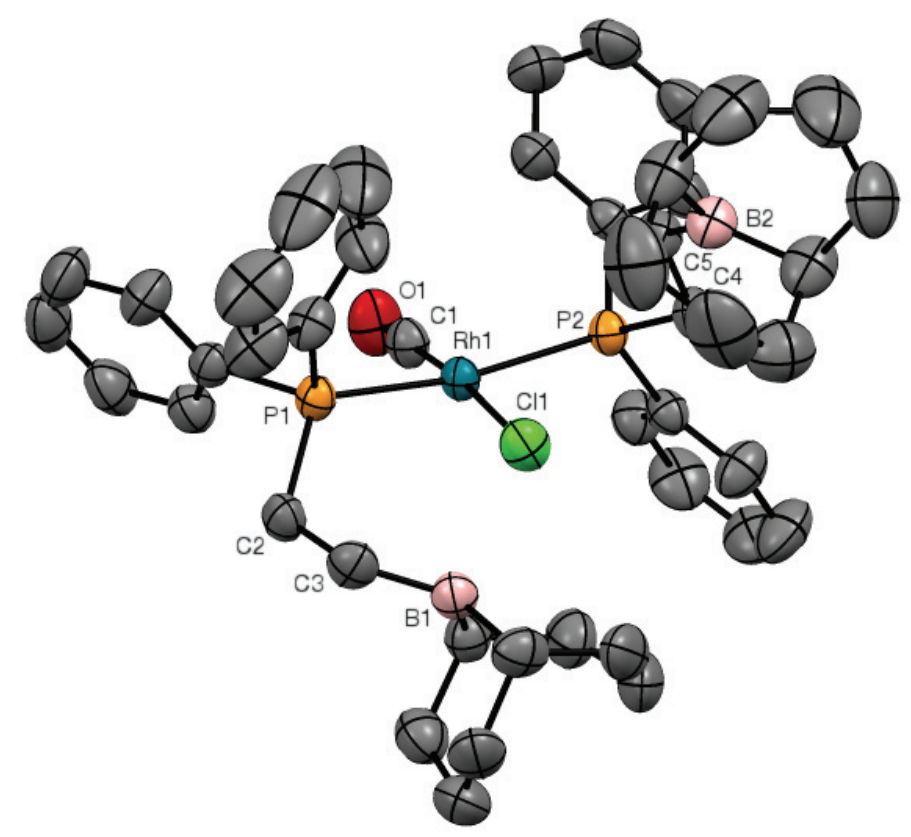

Figure 2.5. X-ray crystallographic structure of $\mathrm{Rh}(\mathrm{CO})\left[\mathrm{Ph}_{2} \mathrm{PCH}_{2} \mathrm{CH}_{2} \mathrm{~B}^{\mathrm{BBN}}\right]_{2} \mathrm{Cl}$ (73) (thermal ellipsoids at $50 \%$ probability) with hydrogens removed for clarity. Selected bond lengths $[\AA]$ and angles $\left[^{\circ}\right]$ for $\mathrm{Rh}(\mathrm{CO})\left[\mathrm{Ph}_{2} \mathrm{PCH}_{2} \mathrm{CH}_{2} \mathrm{~B}^{\mathrm{BBN}}\right]_{2} \mathrm{Cl}: \mathrm{Rh}(1)-\mathrm{Cl}(1)$ 2.3780(7), $\mathrm{Rh}(1)-\mathrm{P}(1)$ 2.3091(6), $\mathrm{Rh}(1)-\mathrm{P}(2)$ 2.3294(6), $\mathrm{Rh}(1)-\mathrm{C}$ (1) 1.792(2), Cl(1)$\mathrm{B}(1)$ 1.591(3), $\mathrm{Cl}(1)-\mathrm{B}(2) 4.186(3), \mathrm{C}(1)-\mathrm{O}(1)$ 1.147(3), C(3)-B(1) 1.591(4), C(5)-B(2) 1.546(4), $\mathrm{P}(1)-\mathrm{Rh}(1)-\mathrm{Cl}(1)$ 85.39(2), $\mathrm{P}(2)-\mathrm{Rh}(1)-\mathrm{Cl}(1) 92.59$ (2), $\mathrm{C}(1)-\mathrm{Rh}(1)-\mathrm{Cl}(1)$ 173.32(8), $\mathrm{B}(1)-\mathrm{Cl}(1)-\mathrm{Rh}(1)$ 102.18(8), $\mathrm{Cl}(1)-\mathrm{B}(1)-\mathrm{C}(3)$ 98.2(2).

While the preparation of the rhodium analog of Vaska's complex was demonstrated above, attempts to prepare the corresponding iridium analog were unsuccessful. These reactions typically are conducted with either a hydrated metal salt or in alcohol/protic solvents. These solvents are problematic for the phosphinoborane ligand as water can cleave the C-B bond and alcohol solvents are Lewis basic enough to bind strongly to the borane of the ligand. In cases where water or alcohol are not used, such as treatment of $\operatorname{Ir}(C O D)$ complex 67 with carbon monoxide, multiple products were obtained. In the case of the rhodium complex analog, there is an 
isolatable $\left[\mathrm{Rh}(\mathrm{CO})_{2} \mathrm{Cl}\right]_{2}$ precursor and the reaction with the phosphine ligand can be conducted in dichloromethane. However in the case of the iridium complex, the precursor is $\left[\mathrm{NH}_{2}\left(\mathrm{CH}_{3}\right)_{2}\right]\left[\operatorname{Ir}(\mathrm{CO})_{2} \mathrm{Cl}_{2}\right]$ which can be prepared in dimethylformamide (DMF) via decarbonylation and isolated in low yields (20\%). ${ }^{27}$ This precursor is soluble in DMF and the complex with $\mathrm{PPh}_{3}$ was precipitated with water. This could not be done for the phosphinoborane analog and all attempts to precipitate the complex from DMF were unsuccessful. In addition, DMF is also capable of coordinating to the borane to form a solvent bound species.

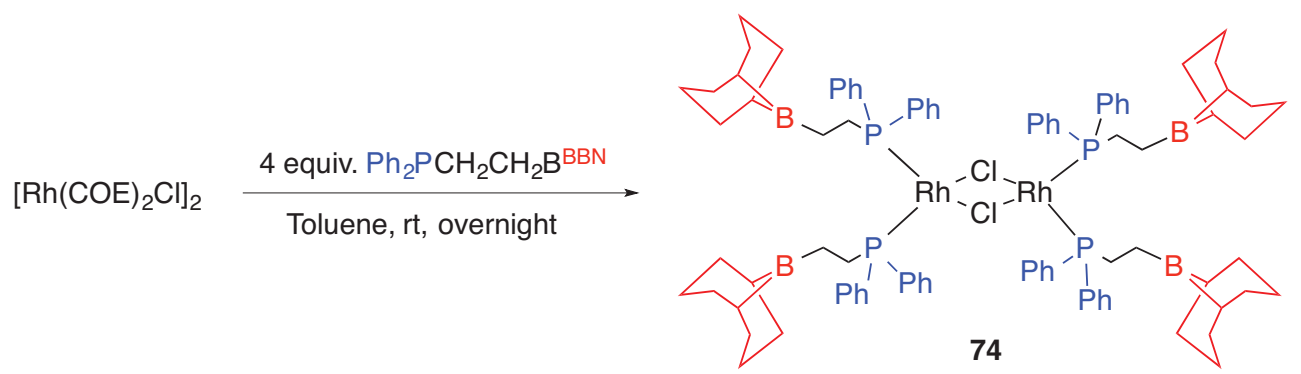

Scheme 2.4. Synthesis of the $\mu_{2}-\mathrm{Cl}$ bridged $\mathrm{Rh}^{\prime}$ phosphinoborane dimer.

The bis(phosphinoborane)Rh(I) chloride dimer was prepared in quantitative yields by treatment of $\left[\mathrm{Rh}(\mathrm{COE})_{2} \mathrm{Cl}\right]_{2}$ with four equivalents of the phosphinoborane ligand (Scheme 2.4). This complex was characterized via NMR spectroscopy and X-ray crystallography. The ${ }^{31} \mathrm{P}\left\{{ }^{1} \mathrm{H}\right\}$ NMR spectrum was consistent with the literature and displays a single doublet at $46.4 \mathrm{ppm}$ with a coupling constant of $197 \mathrm{~Hz}$. The ${ }^{11} \mathrm{~B}\left\{{ }^{1} \mathrm{H}\right\}$ NMR shows a single resonance at $88 \mathrm{ppm}$, which is consistent with completely free boranes. The X-ray structure shows the presence of two $\mu_{2}$-chloride ligands (Figure 2.6). 


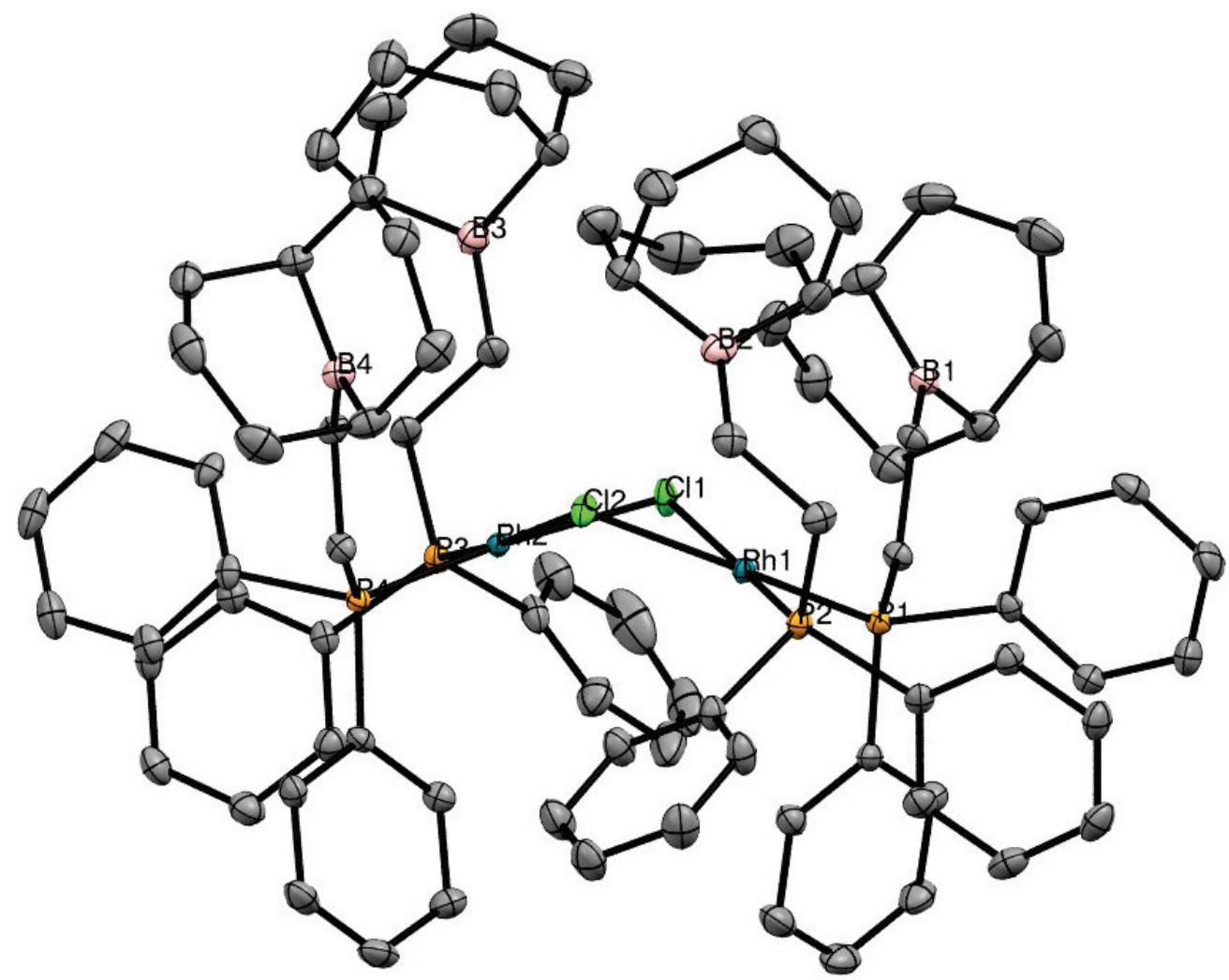

Figure 2.6. X-ray crystallographic structure of $\left[\mathrm{Rh}\left[\mathrm{Ph}_{2} \mathrm{PCH}_{2} \mathrm{CH}_{2} \mathrm{~B}^{\mathrm{BBN}}\right]_{2} \mathrm{Cl}\right]_{2}$ (74) (thermal ellipsoids at $50 \%$ probability) with hydrogens removed for clarity. Selected bond lengths $[\AA \AA]$ and angles [ $\left.{ }^{\circ}\right]$ for $\left[\mathrm{Rh}\left[\mathrm{Ph}_{2} \mathrm{PCH}_{2} \mathrm{CH}_{2} \mathrm{~B}^{\mathrm{BBN}}\right]_{2} \mathrm{Cl}\right]_{2}: \mathrm{Rh}(1)-\mathrm{Cl}(1)$ 2.4077(6), $\mathrm{Rh}(1)-\mathrm{Cl}(2)$ 2.4053(6), $\mathrm{Rh}(2)-\mathrm{Cl}(1)$ 2.4032(6), $\mathrm{Rh}(2)-\mathrm{Cl}(2)$ 2.3988(6), $\mathrm{Rh}(1)-\mathrm{P}(1)$ 2.2101(6), $\mathrm{Rh}(1)-$ $\mathrm{P}(2) \quad 2.2121(6), \quad \mathrm{Rh}(2)-\mathrm{P}(3) \quad 2.2115(6), \quad \mathrm{Rh}(2)-\mathrm{P}(4) \quad 2.2004(6), \quad \mathrm{P}(1)-\mathrm{Rh}(1)-\mathrm{Cl}(1)$ 90.65(2), $\mathrm{P}(1)-\mathrm{Rh}(1)-\mathrm{Cl}(2)$ 171.34(2), $\mathrm{P}(2)-\mathrm{Rh}(1)-\mathrm{Cl}(1)$ 171.81(2), $\mathrm{P}(2)-\mathrm{Rh}(1)-\mathrm{Cl}(2)$ 91.14(2), $\mathrm{P}(3)-\mathrm{Rh}(2)-\mathrm{Cl}(1)$ 90.31(2), $\mathrm{P}(3)-\mathrm{Rh}(2)-\mathrm{Cl}(2)$ 170.57(2), $\mathrm{P}(4)-\mathrm{Rh}(2)-\mathrm{Cl}(1)$ 171.22(2), $\mathrm{P}(4)-\mathrm{Rh}(2)-\mathrm{Cl}(2)$ 91.65(2).

One notable feature of rhodium(I) bridged dimers is that they feature a fold angle, which is the dihedral angle associated with the bend of the complex around the two bridging atoms. In the case of $\left[\left(\mathrm{PPh}_{3}\right)_{2} \mathrm{RhCl}\right]_{2}$, the fold angle is $180^{\circ}$, as the chloride atoms lie in the plane of the two rhodium metal centers. ${ }^{28}$ In the case of the phosphinoborane rhodium (I) chloride bridged dimer, the fold angle is $135^{\circ}$. These, along 
with several other crystallographic features of the phosphinoborane complex, are compared with other known rhodium(I) chloride bridged dimers in Table 2.1. Both the triphenylphosphine and phosphineborane rhodium $(\mathrm{I})$ chloride dimers bear $\pi$-stacking interactions between two phenyl rings on each of the adjacent phosphine ligands, acting to stabilize the complexes. When compared to the other rhodium dimers in Table 2.1, there is a general trend that as the fold angle decreases, the distance between the two rhodium metal centers becomes smaller. There appears to be no trend observed regarding the $\mathrm{Rh}-\mathrm{Cl}$ bond length.

Table 2.1. Depiction of the fold angle in $\left[\mathrm{Rh}\left(\mathrm{Ph}_{2} \mathrm{PCH}_{2} \mathrm{CH}_{2} \mathrm{~B}^{\mathrm{BBN}}\right)_{2} \mathrm{Cl}\right]_{2}$ and the crystallographic comparison amongst known $\mathrm{Rh}^{\prime}$ chloride bridged dimers.

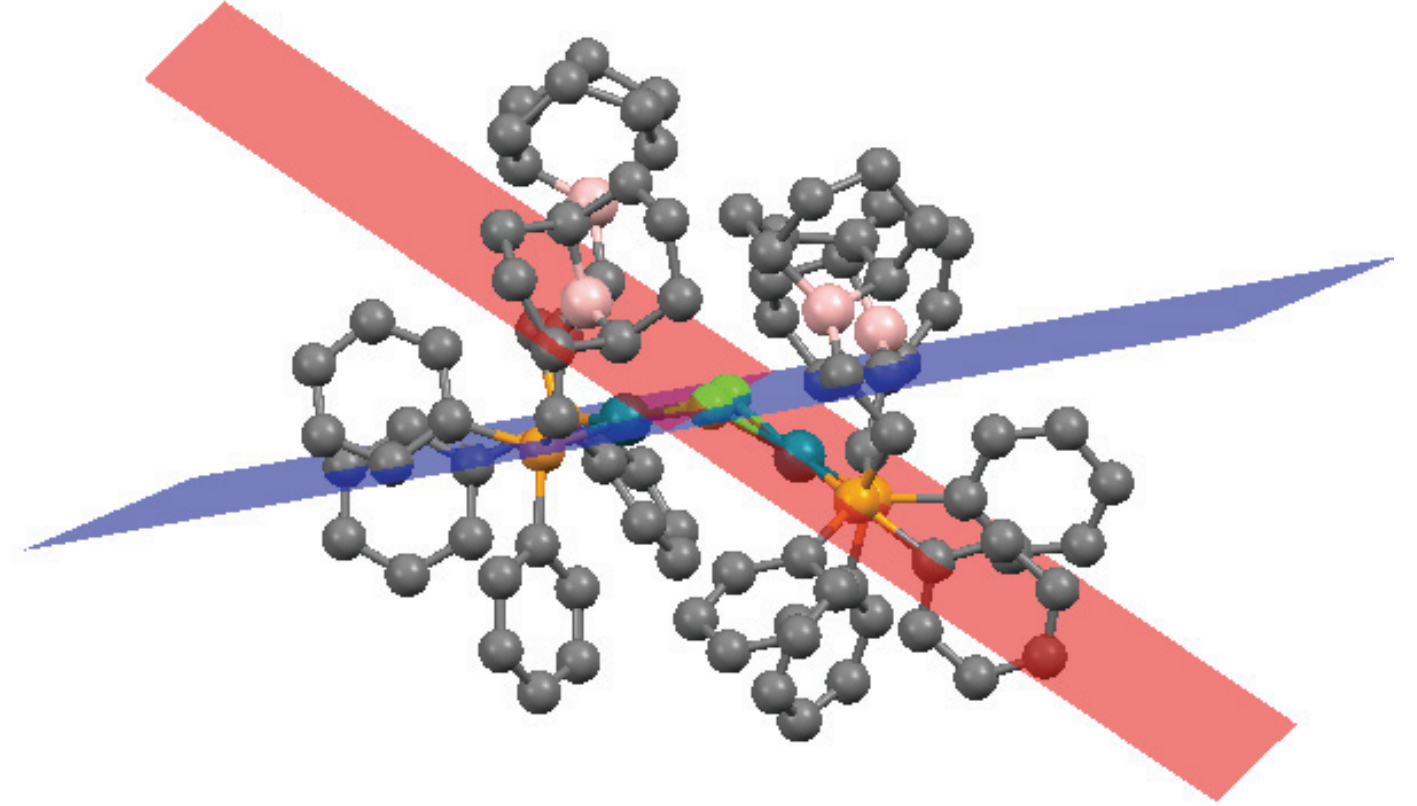

\begin{tabular}{|c|c|c|c|}
\hline Complex & $\lambda$ (Fold Angle), deg & Rh $\square \square \square$ Rh, $\AA$ & Rh-Cl, $\AA$ \\
\hline$\left[R h\left(\mathrm{Ph}_{2} \mathrm{PCH}_{2} \mathrm{CH}_{2} \mathrm{~B}^{\mathrm{BBN}}\right)_{2} \mathrm{Cl}\right]_{2}$ & 135 & 3.38 & 2.40 \\
\hline$\left[\mathrm{Rh}\left(\mathrm{Ph}_{3} \mathrm{P}\right)_{2} \mathrm{Cl}\right]_{2}{ }^{135}$ & 180 & 3.66 & 2.40 \\
\hline$[\mathrm{Rh}(\mathrm{COD}) \mathrm{Cl}]_{2}{ }^{136}$ & 180 & 3.50 & 2.38 \\
\hline$\left[\mathrm{Rh}(\mathrm{CO})_{2} \mathrm{Cl}\right]_{2}{ }^{137}$ & 124 & 3.12 & 2.35 \\
\hline$\left[\mathrm{Rh}\left(\mathrm{C}_{2} \mathrm{H}_{4}\right)_{2} \mathrm{Cl}_{2}{ }^{138}\right.$ & 116 & 3.02 & 2.40 \\
\hline
\end{tabular}

Four-coordinate geometry index $\left(\mathrm{T}_{4}{ }^{\prime}\right)$ values provide a measurement of the deviation of a complex from either a square-planar $\left(\mathrm{T}_{4}{ }^{\prime}=0\right)$ or a tetrahedral $\left(\mathrm{T}_{4}{ }^{\prime}=1\right)$ 
geometry. ${ }^{32,33}$ The calculated $\mathrm{T}_{4}$ ' values are shown in Table 2.2 for each of the prepared rhodium and iridium phosphinoborane complexes. The values are calculated based on the crystal structure, where $\alpha$ and $\beta$ are the two largest angles around the metal center. The values indicated that there is only minor deviation from the expected square planar orientation for the complexes shown.

Table 2.2. Calculated geometry index values $\left(\mathrm{T}_{4}{ }^{\prime}\right)$ for prepared rhodium and iridium complexes.

$$
\tau_{4^{\prime}}=\frac{\beta-\alpha}{360^{\circ}-\theta}+\frac{180^{\circ}-\beta}{180^{\circ}-\theta} \quad \theta=\cos ^{-1}\left(-\frac{1}{3}\right) \approx 109.5^{\circ}
$$

\begin{tabular}{|c|c|}
\hline Complex & $\mathrm{T}_{4}{ }^{\prime}$ \\
\hline $\mathrm{Rh}(\mathrm{COD})\left[\mathrm{Ph}_{2} \mathrm{PCH}_{2} \mathrm{CH}_{2} \mathrm{~B}\left(\mathrm{C}_{8} \mathrm{H}_{14}\right)\right] \mathrm{Cl}$ & 0.039 \\
\hline $\operatorname{Rh}(\mathrm{CO})\left[\mathrm{Ph}_{2} \mathrm{PCH}_{2} \mathrm{CH}_{2} \mathrm{~B}\left(\mathrm{C}_{8} \mathrm{H}_{14}\right)\right]_{2} \mathrm{Cl}$ & 0.068 \\
\hline$\left[\mathrm{Rh}\left(\mathrm{Ph}_{2} \mathrm{PCH}_{2} \mathrm{CH}_{2} \mathrm{~B}\left(\mathrm{C}_{8} \mathrm{H}_{14}\right)_{2}\right) \mathrm{Cl}\right]_{2}$ & $0.111,0.116$ \\
\hline $\operatorname{Ir}(\mathrm{COD})\left[\mathrm{Ph}_{2} \mathrm{PCH}_{2} \mathrm{CH}_{2} \mathrm{~B}_{(}\left(\mathrm{C}_{8} \mathrm{H}_{14}\right)\right] \mathrm{Cl}$ & 0.036 \\
\hline $\operatorname{Ir}(\mathrm{COD})\left[\mathrm{Ph}_{2} \mathrm{PCH}_{2} \mathrm{CH}_{2} \mathrm{~B}\left(\mathrm{C}_{8} \mathrm{H}_{14}\right)\right] \mathrm{Cl}-\mathrm{CAN}$ & 0.058 \\
\hline
\end{tabular}

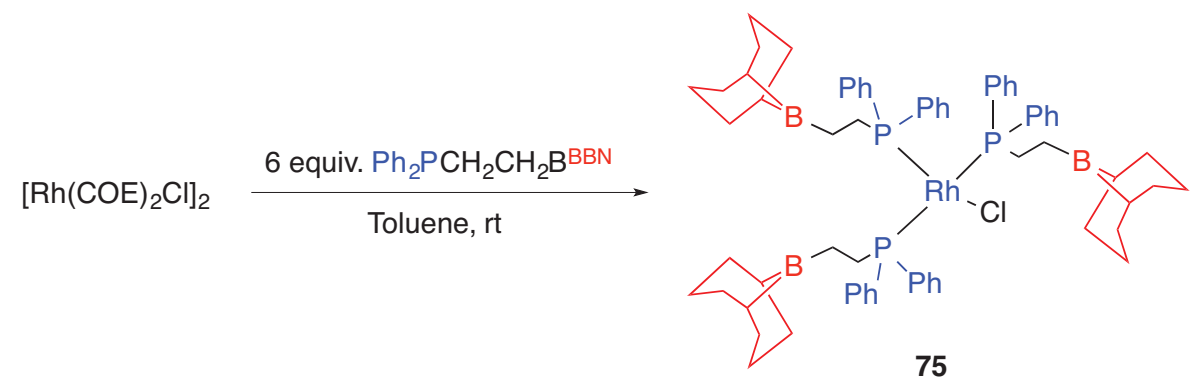

Scheme 2.5. Synthesis of a phosphinoborane analog of Wilkinson's complex.

The last target complex to synthesize was an analog of Wilkinson's complex, $\mathrm{Rh}\left(\mathrm{Ph}_{2} \mathrm{PCH}_{2} \mathrm{CH}_{2} \mathrm{~B}^{\mathrm{BBN}}\right)_{3} \mathrm{Cl}$ (Scheme 2.5). This desired complex was synthesized by addition of six equivalents of the phosphinoborane ligand to $\left[\mathrm{Rh}(\mathrm{COE})_{2} \mathrm{Cl}\right]_{2}$. The Wilkinson's analog was obtained in $50 \%$ yield as a red solid. While an X-ray quality crystal was not obtained, the complex was characterized by NMR spectroscopy. The ${ }^{31} \mathrm{P}\left\{{ }^{1} \mathrm{H}\right\}$ NMR shows a doublet of triplets at $44.8 \mathrm{ppm}$, with coupling constants of 192 and $40 \mathrm{~Hz}$, and a doublet of doublets at $26.9 \mathrm{ppm}$, with coupling constants of 138 and 
$40 \mathrm{~Hz}$ (Figure 2.7). The larger of the two coupling constants is in agreement with ${ }^{1} \mathrm{~J}_{\mathrm{Rh}-\mathrm{P}}$ coupling. These values are consistent with a square planar $\mathrm{Rh}(\mathrm{I})$ tris-phosphine complex. For example, $\mathrm{Rh}\left(\mathrm{PMe}_{3}\right)_{3} \mathrm{Cl}$ has a $180 \mathrm{~Hz}$ coupling constant for the phosphine trans to the chloride and a $131 \mathrm{~Hz}$ coupling constant for the phosphine atoms cis to the chloride. ${ }^{34}$ Since the two trans-phosphine ligands are related by symmetry, they will be identical and lead to a coupling pattern that is a doublet of doublets, where the second doublet is due to cis ${ }^{2} \mathrm{~J}_{\mathrm{P}-\mathrm{P}}$ coupling. The phosphine ligand trans to the chloride appears as a doublet of triplets consistent with ${ }^{1} \mathrm{~J}_{\mathrm{Rh}-\mathrm{P}}$ coupling, as well as ${ }^{2} \mathrm{~J}_{\mathrm{P}-\mathrm{P}}$ coupling to the two trans-symmetric phosphine ligands. The ${ }^{11} \mathrm{~B}\left\{{ }^{1} \mathrm{H}\right\}$ NMR shows the presence of a broad singlet at 83 ppm.

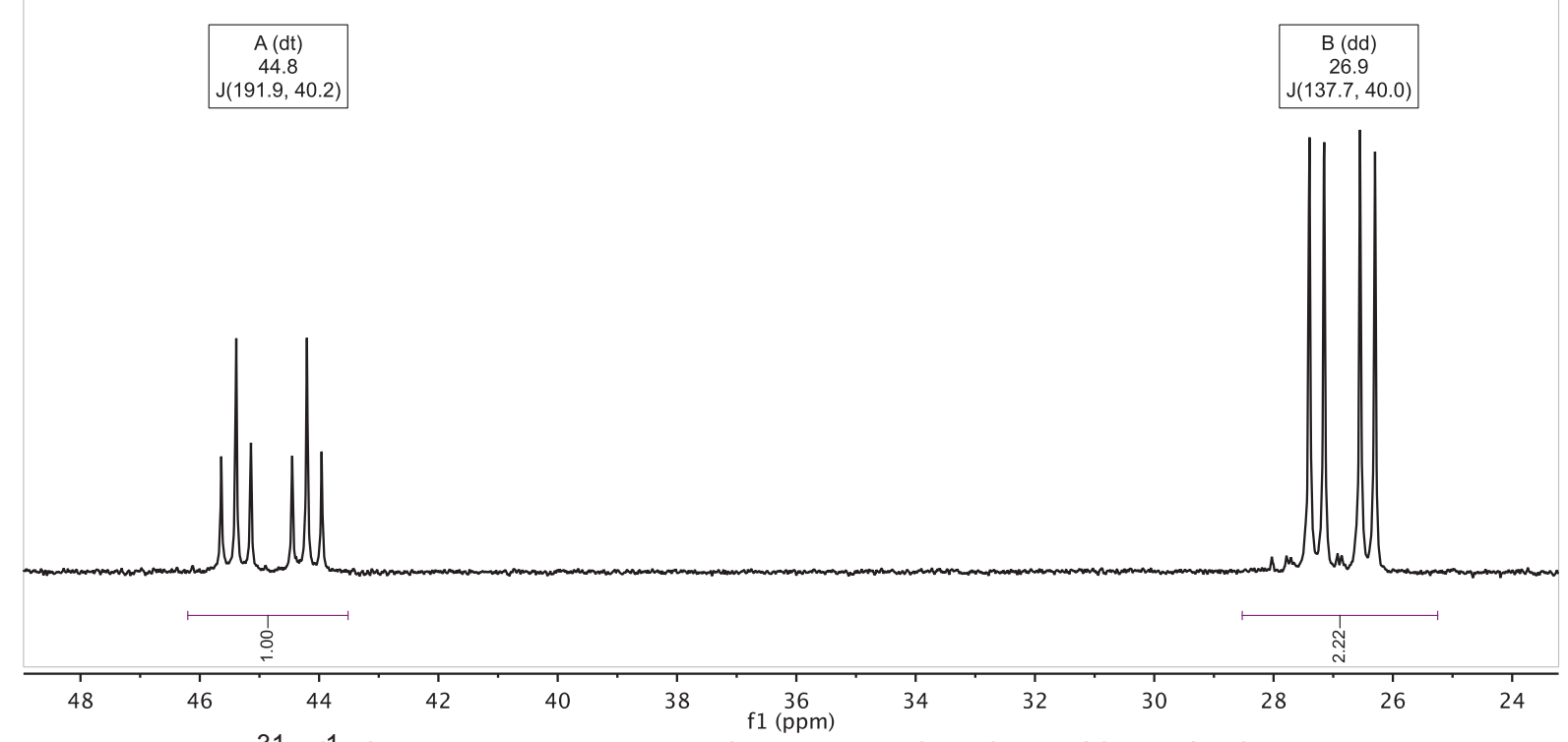

Figure 2.7. ${ }^{31} \mathrm{P}\left\{{ }^{1} \mathrm{H}\right\}$ NMR spectrum of $\mathrm{Rh}\left[\mathrm{Ph}_{2} \mathrm{PCH}_{2} \mathrm{CH}_{2} \mathrm{~B}\left(\mathrm{C}_{8} \mathrm{H}_{14}\right)\right]_{3} \mathrm{Cl}$ complex in $\mathrm{d}_{2}-$ dichloromethane.

Solvent can have a dramatic influence on not only reaction rates, but also selectivity. ${ }^{35}$ It was previously reported by Crossley and coworkers that the $\mathrm{Rh}(\mathrm{COD})$ complex 66 had a ${ }^{11} B\left\{{ }^{1} H\right\}$ NMR chemical shift of 87 ppm in $d_{2}$-dichloromethane, which 
was proposed to be an uncoordinated borane. ${ }^{17}$ However, the crystal structure that was obtained showed a close contact interaction between the borane and the chloride. In catalysis, it is often these interactions with substrates that stabilize reactive intermediates. This data can provide insight into the factors that govern these through space interactions. Firstly, as the dielectric constant of the solvent is decreased in the NMR sample by addition of $d_{6}$-benzene (added to $d_{2}$-dichloromethane), there is a linear upfield shift in the ${ }^{11} B\left\{{ }^{1} H\right\}$ NMR signal until finally with pure $d_{6}$-benzene the signal appears at 61 ppm (Figure 2.8).

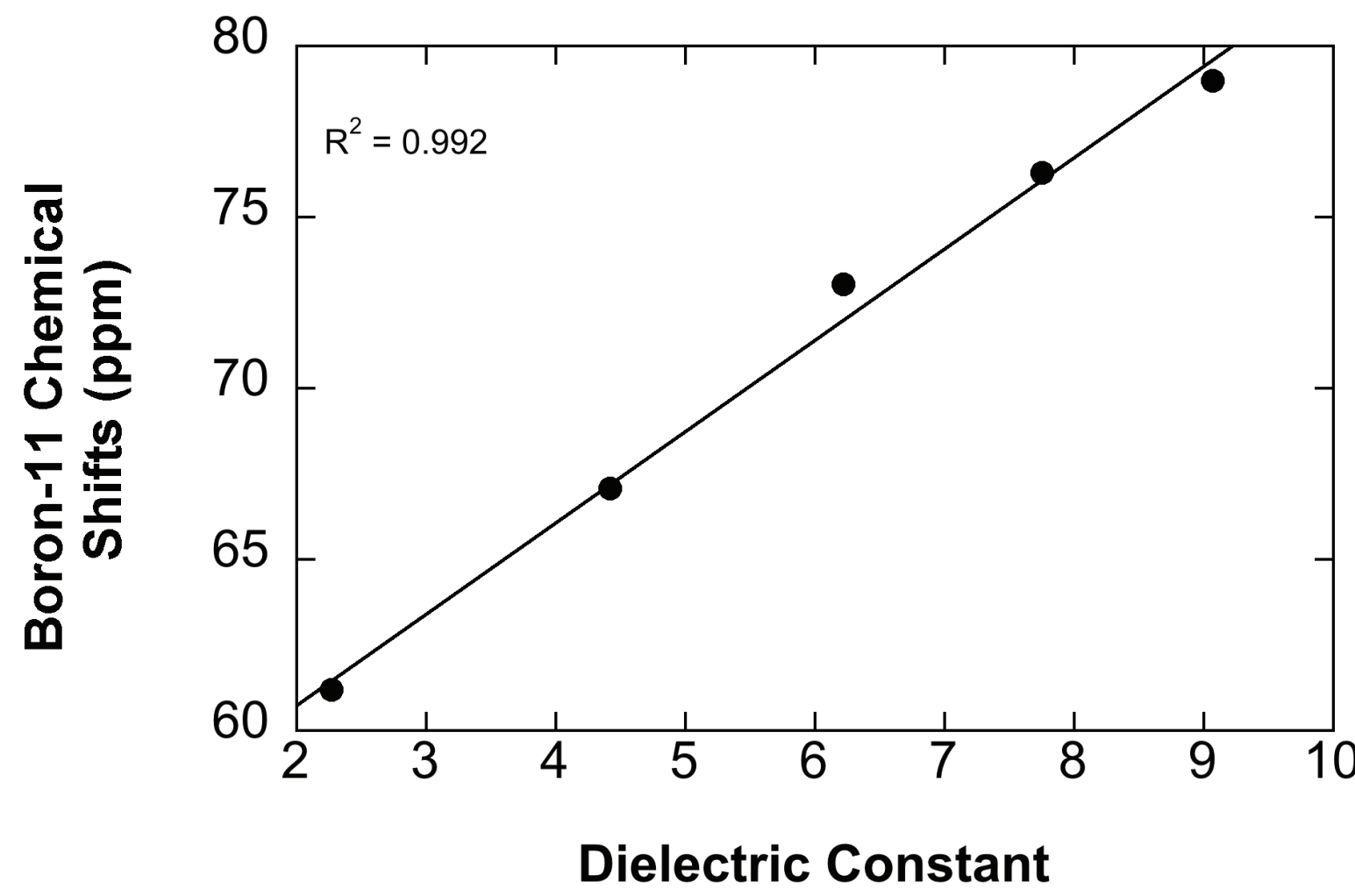

Figure 2.8. Dependence of the ${ }^{11} \mathrm{~B}\left\{{ }^{1} \mathrm{H}\right\}$ NMR chemical shift of the $\mathrm{Rh}(\mathrm{COD})$ complex 66 on the solvent dielectric constant in mixtures of $d_{2}$-dichloromethane and $d_{6}$-benzene. Ratio of dielectric constants is assumed to be proportional to the volume ratio of solvents. 
As the NMR solvent is changed, the ${ }^{11} B\left\{{ }^{1} H\right\}$ NMR signal for the corresponding complex changes. The term "donor number" was introduced by Viktor Gutmann and refers to the measurement of the enthalpy of the formation of the $1: 1$ adduct between the solvent and a standard Lewis acid, $\mathrm{SbCl}_{5} .{ }^{36-38}$ There are two different regimes of interest shown in Figure 2.9. Chemical shifts of the poorly Lewis basic solvents, such as dichloromethane, chloroform, benzene, toluene, and 1,2-dichloroethane, possess ${ }^{11} \mathrm{~B}\left\{{ }^{1} \mathrm{H}\right\}$ NMR peaks that shift downfield as solvent polarity decreases (i.e. benzene and toluene). This type of chemical environment favors the formation of the internal Lewis adducts since the solvent is too poorly Lewis basic to form adducts with boranes. As the solvents become increasingly more Lewis basic (i.e. acetone, THF, DMF, and DMSO), the formation of the solvent-bound borane becomes more favorable and ${ }^{11} \mathrm{~B}\left\{{ }^{1} \mathrm{H}\right\} \mathrm{NMR}$ peaks have more borate character. This phenomena is observed in THF where two ${ }^{11} \mathrm{~B}\left\{{ }^{1} \mathrm{H}\right\}$ NMR signals appear, which is presumably a result of both the Lewis adduct between the borane and the chloride, as well as the formation of the solvent bound Lewis adduct. The use of ACN resulted in solvent adduct formation with the borane, which can be characterized crystallographically for the corresponding iridium(I) complex (Figure 2.11). In the case of the $\operatorname{Ir}(C O D)$ complex 67, there is a less dramatic change in the chemical shift as a function of solvent. When comparing the ${ }^{11} \mathrm{~B}\left\{{ }^{1} \mathrm{H}\right\}$ chemical shift of the complex in $d_{2}$-dichloromethane and $d_{6}$-benzene, there is only a 5 ppm upfield shift in the case of $d_{6}$-benzene compared to a 15 ppm shift in $d_{6}$-benzene for the corresponding rhodium(I) complex (Figure 2.10). 


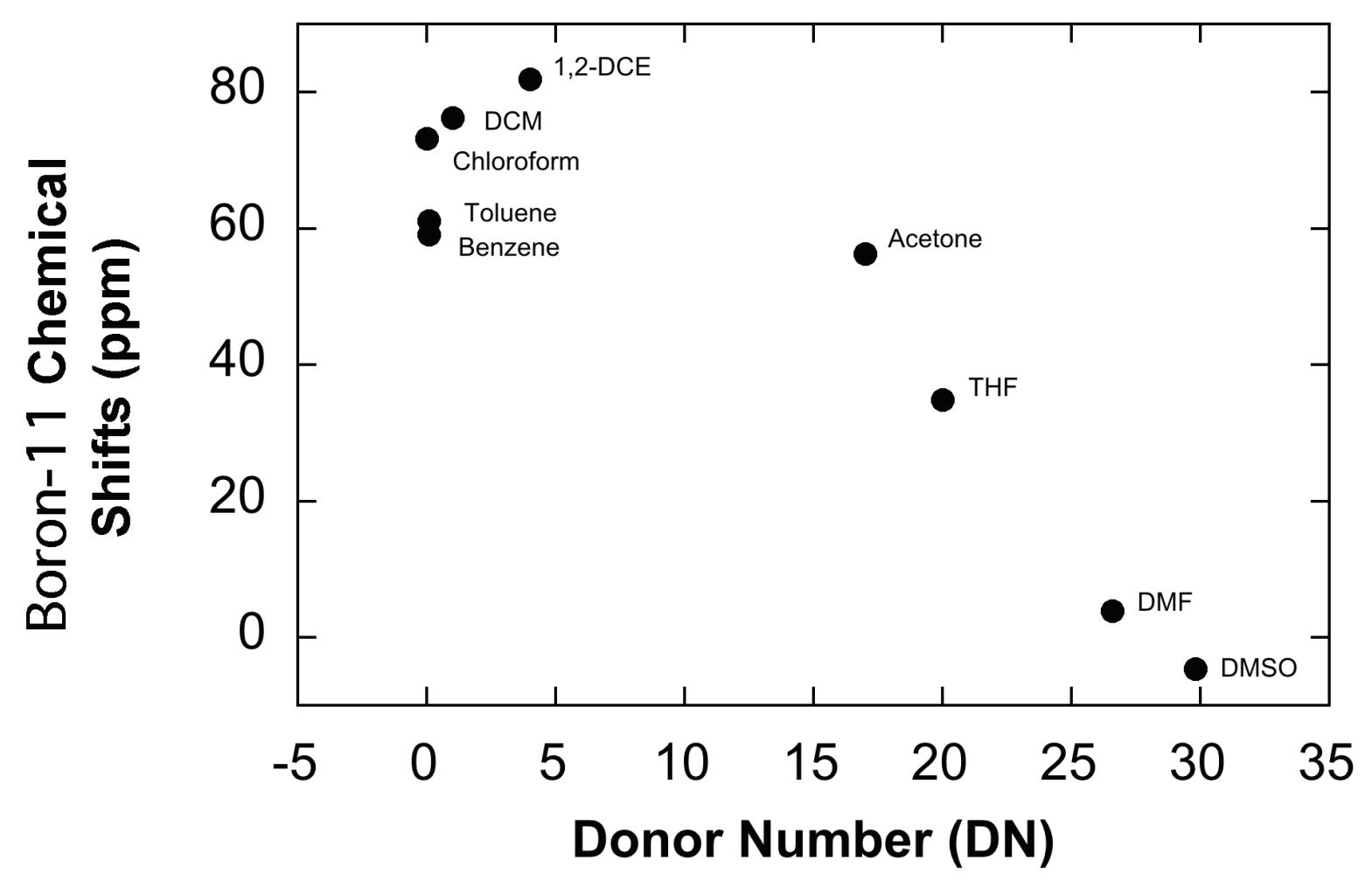

\begin{tabular}{|c|c|c|}
\hline Solvent & Donor Number & ${ }^{11} \mathrm{~B}$ NMR Chemical Shift (ppm) \\
\hline Toluene & 0.1 & 59 \\
\hline Benzene & 0.1 & 61 \\
\hline Chloroform & 4 & 82 \\
\hline Dichloromethane (DCM) & 1 & 76 \\
\hline 1,2-Dichloroethane (1,2-DCE) & 0 & 73 \\
\hline Acetone & 17 & 56 \\
\hline Tetrahydrofuran (THF) & 20 & 35 \\
\hline Dimethylformamide (DMF) & 26.6 & 4 \\
\hline Dimethyl Sulfoxide (DMSO) & 29.8 & -5 \\
\hline
\end{tabular}

Figure 2.9. Dependence of ${ }^{11} \mathrm{~B}\left\{{ }^{1} \mathrm{H}\right\}$ NMR Chemical Shift of Rh(COD) complex 67 on the donicity of the solvent. 

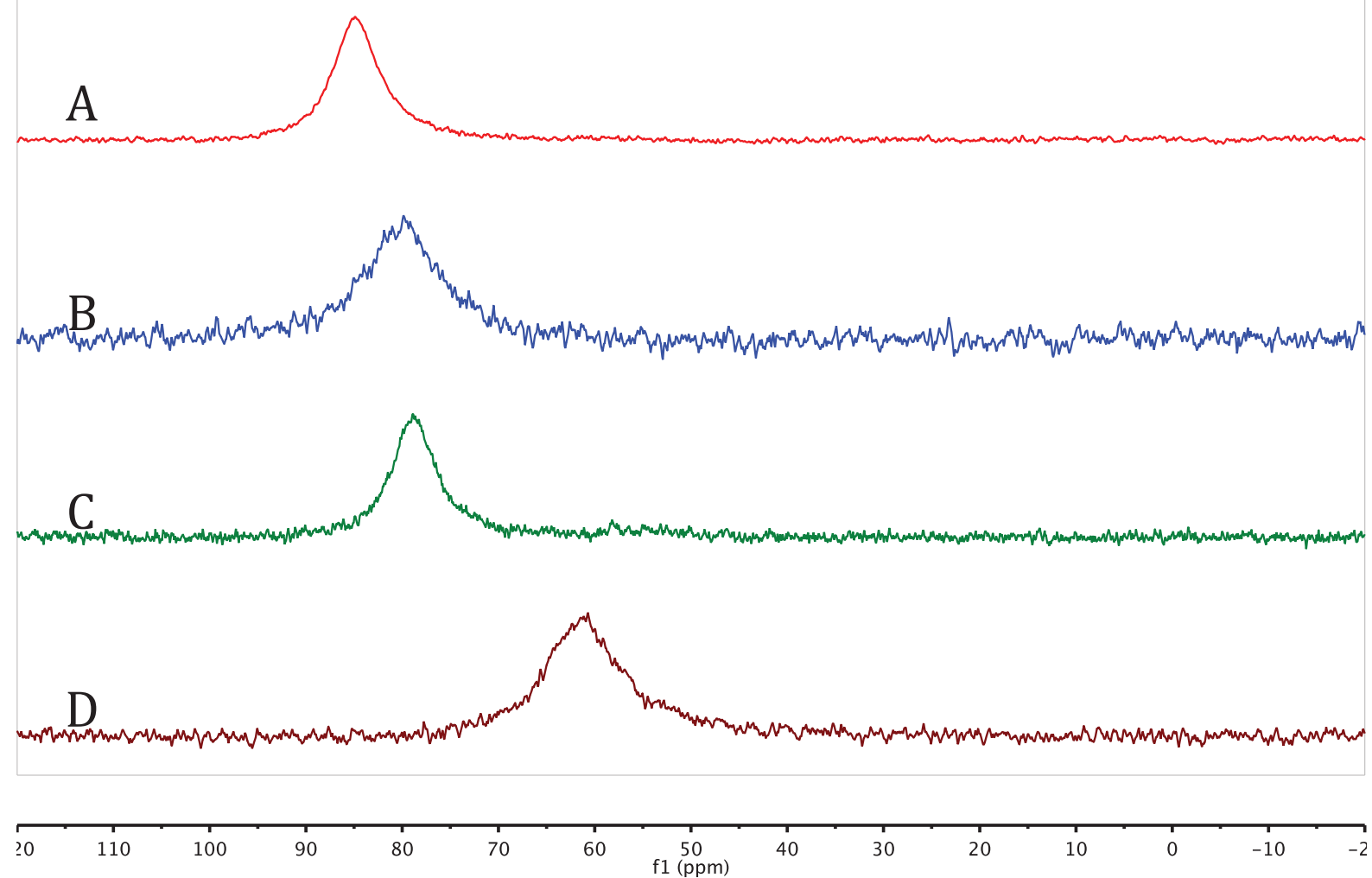

Figure 2.10. Comparison of the ${ }^{11} \mathrm{~B}\left\{{ }^{1} \mathrm{H}\right\}$ NMR spectra of $\operatorname{Ir}(\mathrm{COD})\left[\mathrm{Ph}_{2} \mathrm{PCH}_{2} \mathrm{CH}_{2} \mathrm{~B}^{\mathrm{BBN}}\right] \mathrm{Cl}$ complex with $\mathrm{Rh}(\mathrm{COD})\left[\mathrm{Ph}_{2} \mathrm{PCH}_{2} \mathrm{CH}_{2} \mathrm{~B}^{\mathrm{BBN}}\right] \mathrm{Cl}$ in $\mathrm{d}_{2}$-dichlormethane and $\mathrm{d}_{6}$-benzene. $\mathrm{A}$ ) $\operatorname{Ir}(\mathrm{COD})\left[\mathrm{Ph}_{2} \mathrm{PCH}_{2} \mathrm{CH}_{2} \mathrm{~B}^{\mathrm{BBN}}\right] \mathrm{Cl}$ in $\mathrm{d}_{2}$-dichloromethane. B) $\operatorname{Ir}(\mathrm{COD})\left[\mathrm{Ph}_{2} \mathrm{PCH}_{2} \mathrm{CH}_{2} \mathrm{~B}^{\mathrm{BBN}}\right] \mathrm{Cl}$ in $\mathrm{d}_{6}$-benzene. C) $\mathrm{Rh}(\mathrm{COD})\left[\mathrm{Ph}_{2} \mathrm{PCH}_{2} \mathrm{CH}_{2} \mathrm{~B}^{\mathrm{BBN}}\right] \mathrm{Cl}$ in $\mathrm{d}_{2}$-dichloromethane. D) $\mathrm{Rh}(\mathrm{COD})\left[\mathrm{Ph}_{2} \mathrm{PCH}_{2} \mathrm{CH}_{2} \mathrm{~B}^{\mathrm{BBN}}\right] \mathrm{Cl}$ in $\mathrm{d}_{6}$-benzene. 


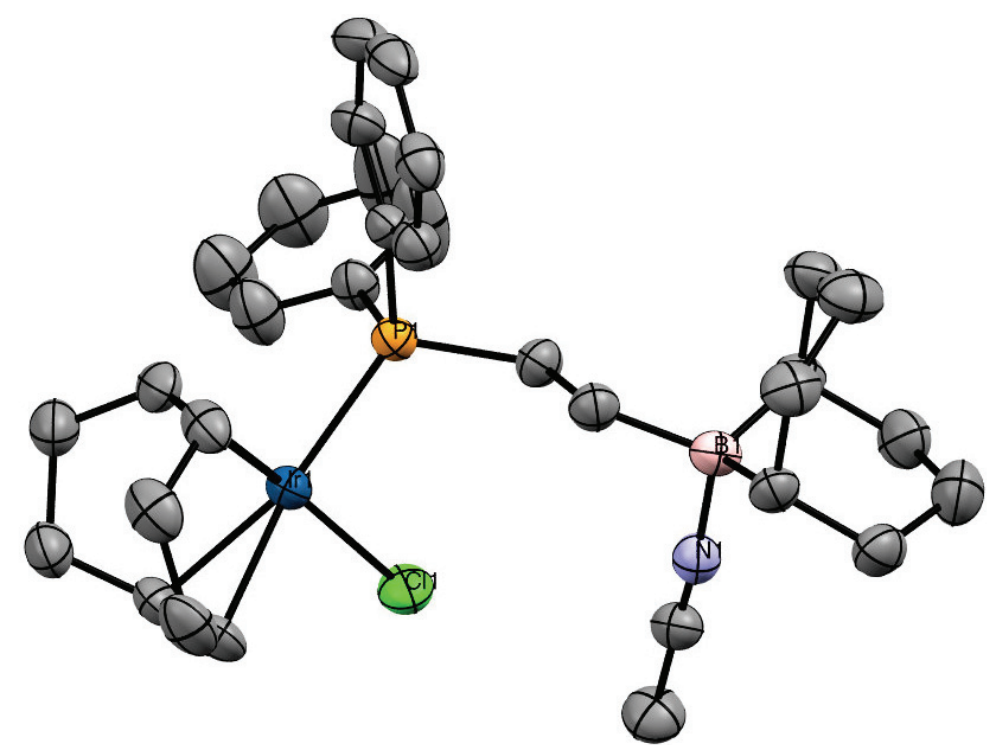

Figure 2.11. X-ray crystallographic structure of $\operatorname{Ir}(\mathrm{COD})\left[\mathrm{Ph}_{2} \mathrm{PCH}_{2} \mathrm{CH}_{2} \mathrm{~B}^{\mathrm{BBN}}-\mathrm{NCCH}_{3}\right] \mathrm{Cl}$ (thermal ellipsoids at $50 \%$ probability) with hydrogens removed for clarity. Selected bond lengths $[\AA]$ and angles $\left[{ }^{\circ}\right]$ for $\operatorname{Ir}(\mathrm{COD})\left[\mathrm{Ph}_{2} \mathrm{PCH}_{2} \mathrm{CH}_{2} \mathrm{~B}^{\mathrm{BBN}}-\mathrm{NCCH}_{3}\right] \mathrm{Cl}$ : $\operatorname{Ir}(1)-\mathrm{Cl}(1)$ 2.352(1), $\quad \operatorname{Ir}(1)-\mathrm{P}(1)$ 2.318(1), $\quad \operatorname{Ir}(1)-\mathrm{P}(2)$ 2.3294(6), $\mathrm{N}(1)-\mathrm{B}(1)$ 1.624(7), $\mathrm{B}(1)-\mathrm{C}(2)$ 1.630(9), $\mathrm{P}(1)-\operatorname{Ir}(1)-\mathrm{Cl}(1)$ 87.78(5), N(1)-B(1)-C(2) 103.3(4).

In order to study the dynamic nature of the interaction between the Lewis acidic borane and the Lewis basic chloride in rhodium complex 66, variable temperature NMR spectroscopy in $\mathrm{d}_{2}$-dichloromethane was conducted on the complex. The borane signal in the ${ }^{11} B\left\{{ }^{1} H\right\}$ NMR spectra appeared broadened and began to shift upfield as the probe temperature decreased (Figure 2.12). 

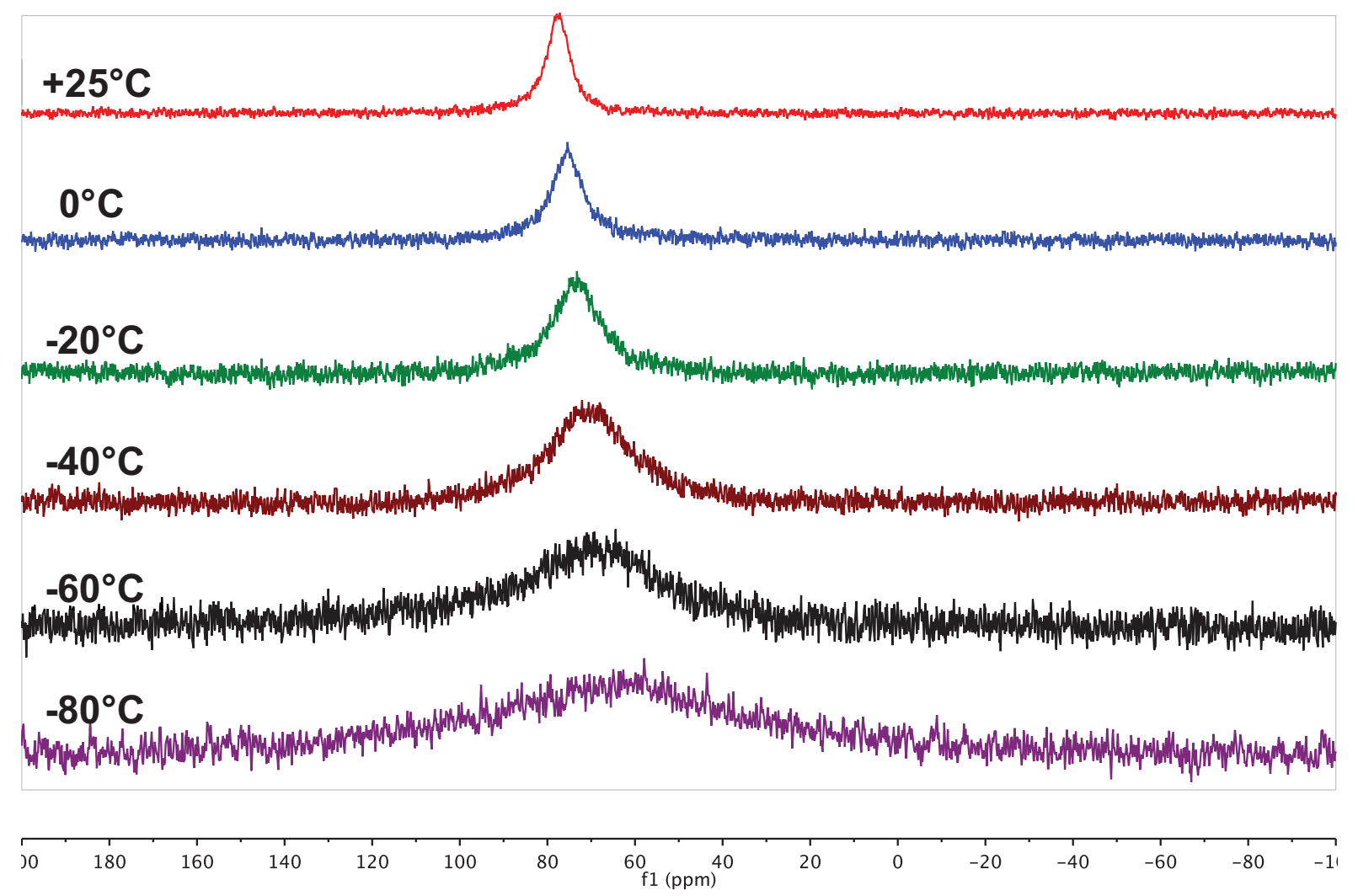

Figure 2.12. Low temperature NMR analysis of rhodium(l) complex 66 in $d_{2^{-}}$ dichloromethane.

The broadening of the ${ }^{11} \mathrm{~B}\left\{{ }^{1} \mathrm{H}\right\}$ NMR signals as the temperature decreases is indicative of a dynamic interaction, where at lower temperatures more of the $\mathrm{B}-\mathrm{Cl}$ interaction state is being sampled. The NMR chemical shift of the borane at $-80^{\circ} \mathrm{C}$ is approaching that of $\mathrm{d}_{6}$-benzene at room temperature. ${ }^{39}$ Upon warming the solution to room temperature, the ${ }^{11} \mathrm{~B}\left\{{ }^{1} \mathrm{H}\right\}$ NMR signal returned to the original chemical shift, which is indicative of a reversible process. 
$+25^{\circ} \mathrm{C}$

$0^{\circ} \mathrm{C}$

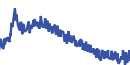

$-20^{\circ} \mathrm{C}$

$-40^{\circ} \mathrm{C}$

Hinlm,

$-60^{\circ} \mathrm{C}$

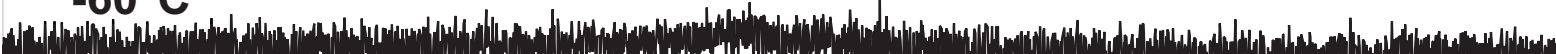

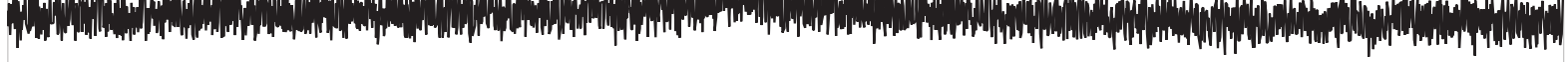

$-80^{\circ} \mathrm{C}$

(n)

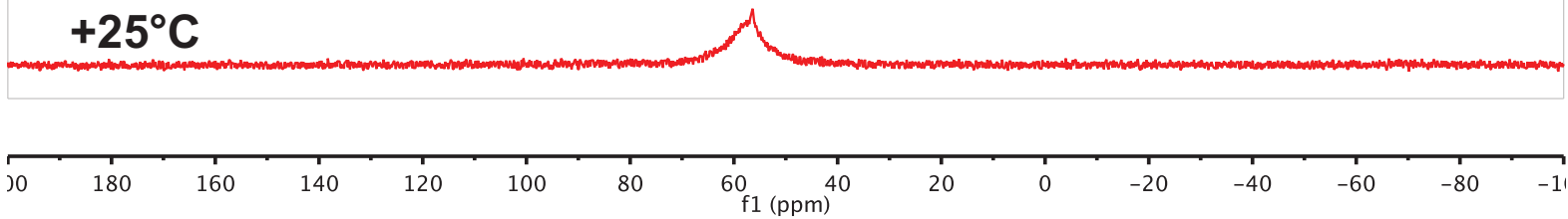

Figure 2.13. Low temperature NMR analysis of rhodium(I) complex 66 in $\mathrm{d}_{8}$-toluene.

Upon cooling a solution of rhodium complex 66 in $\mathrm{d}_{8}$-toluene, a new broad resonance appears in the ${ }^{11} \mathrm{~B}\left\{{ }^{1} \mathrm{H}\right\}$ NMR spectra at $55 \mathrm{ppm}$. This resonance shifts upfield and broadens as the temperature is lowered. Upon returning the sample to room temperature, the ${ }^{11} \mathrm{~B}\left\{{ }^{1} \mathrm{H}\right\}$ NMR spectrum shows one signal located at the same resonance as before cooling, which indicates reversible behavior.

\subsubsection{Synthesis and Characterization of Cationic $M(C O D)$ and $M(C O D) N_{3}$ Complexes Bearing a Phosphinoborane Ligand}

In preparation of the cationic rhodium complex, the $\mathrm{Rh}(\mathrm{COD})$ complex 66 was treated with silver(I) triflate in dichloromethane to produce the desired product in $75 \%$ yield as a orange oil after filtration through Celite (Scheme A4.1). The ${ }^{31} \mathrm{P}\left\{{ }^{1} \mathrm{H}\right\}$ NMR appears as a doublet, that is downfield shifted with respect to the neutral complex, at 
28.3 ppm with a coupling constant of $148 \mathrm{~Hz}$. The ${ }^{11} \mathrm{~B}\left\{{ }^{1} \mathrm{H}\right\}$ NMR in $\mathrm{d}_{6}$-benzene shows a signal at 86 ppm, which is in stark contrast to the chemical shift of $61 \mathrm{ppm}$ observed for the neutral complex in the same solvent.

Given that the phosphinoborane ligand is known to interact with ligands in the primary coordination sphere of the rhodium $(I)$ metal center, placing functionalities other than halides in the now vacant coordination site of the cationic rhodium(I) metal center was explored. While early transition metal complexes are known for their ability to form metal-ligand multiple bonds, late transition metal complexes are less common and are typically observed as reactive intermediates. ${ }^{40}$ Usually the complexes that contain an isolable Group VIII metal nitrido complex are heterobimetallic and stabilized by a secondary interaction. ${ }^{41}$ There only exists a handful of characterized and/or isolated rhodium(I) or iridium(I) nitrido species that do not contain a second metallic element. Burger and coworkers demonstrated that with the use of sterically-bulky PDI ligands, they were able to isolate an iridium-nitrido complex that underwent subsequent reactivity. However, the isolation of the rhodium nitrido proved difficult, as these species underwent reactivity with the ligand to generate amino complexes (Scheme 2.6). ${ }^{42-45}$ 

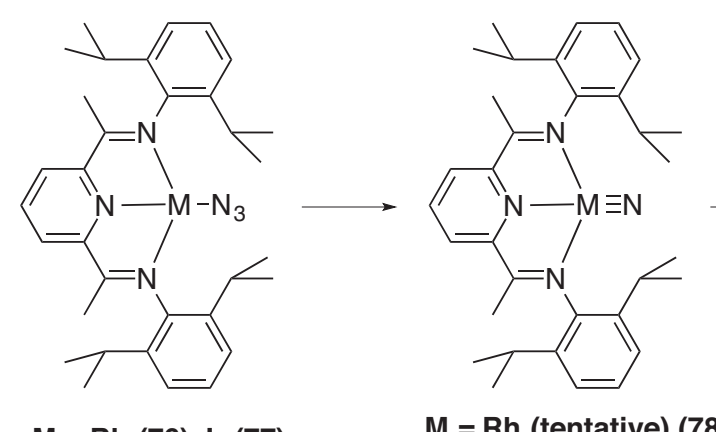

$M=\operatorname{Rh}(76), \operatorname{Ir}(77)$
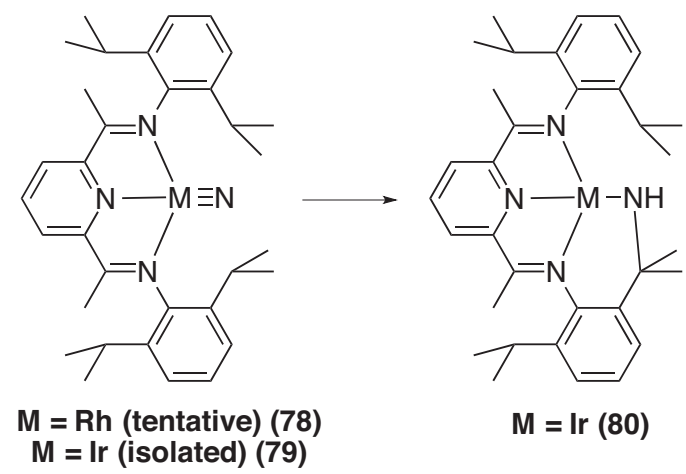

$M=\operatorname{Ir}(\mathbf{8 0})$
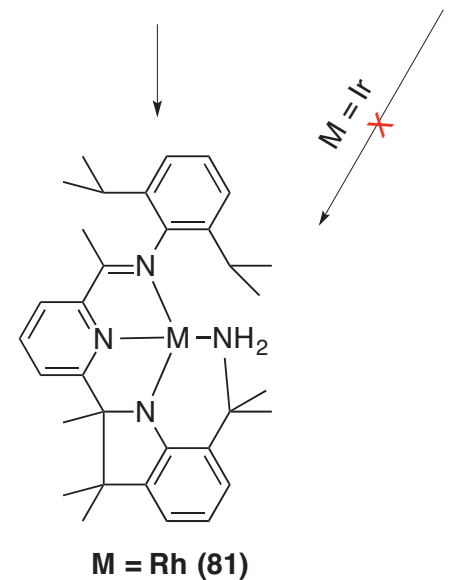

(81)

Scheme 2.6. Reactivity of rhodium or iridium nitrido complexes bearing a redox active ligand scaffold.

Schneider and coworkers were able to synthesize rhodium and iridium nitrido complexes with the use of a bulky PNP-pincer ligand and fully characterize them at low temperature, however upon warming, the complex underwent dimerization to generate the $\mu_{2}-\mathrm{N}_{2}$ bridged bimetallic species (Scheme 2.7). ${ }^{46,47}$

Schneider and coworkers were also able to computationally and crystallographically characterize a nitridyl radical bridged dirhodium complex bearing the same PNP-pincer ligand scaffold. ${ }^{48}$ In terms of cobalt-based systems, there have been several examples of azide complexes that are presumed to go through cobalt nitrido species but the nitrido complex itself has never been isolated. ${ }^{49,50}$ As a result, we 
sought to utilize the borane interaction as a means to stabilize and isolate a rhodium and iridium nitrido complex.

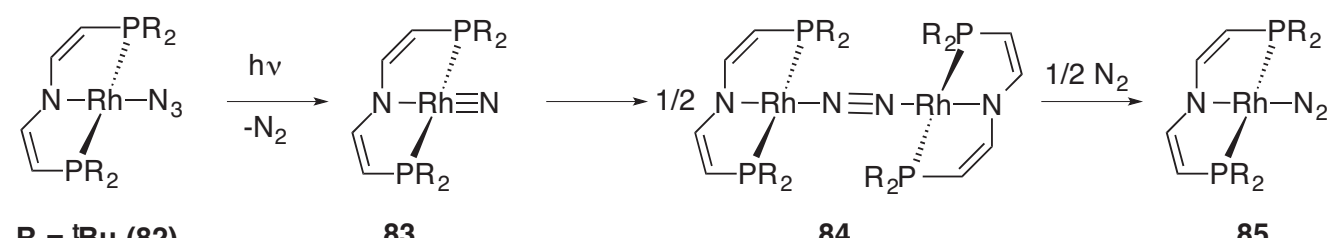

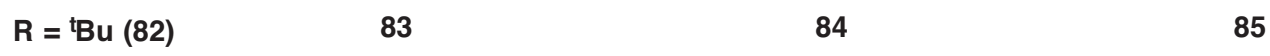

Scheme 2.7. Reactivity of rhodium nitrido complex bearing a PNP-pincer type ligand scaffold.

Typically, nitrido complexes are generated from the corresponding azide complex by heating or photolysis that results in the formation of $\mathrm{N}_{2}$ gas as a direct byproduct. The corresponding rhodium and iridium azide complexes were synthesized from the cationic tetrafluoroborate salt, which was chosen due to the low solubility of $\mathrm{NaBF}_{4}$ in organic solvents. The in-situ generated tetrafluoroborate salt was then treated with $\mathrm{NaN}_{3}$ to generate the metal-azide complex, which was filtered to remove $\mathrm{NaBF}_{4}$ and isolated in $91 \%$ and $65 \%$ yield for rhodium and iridium azides, respectively (Scheme 2.8).

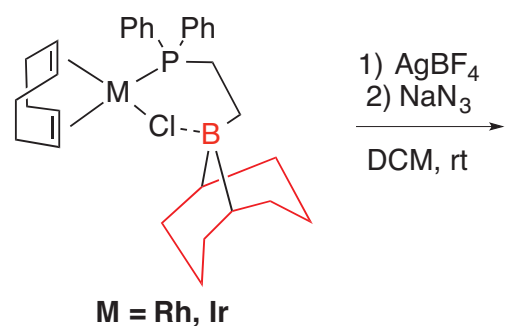

Scheme 2.8. Synthesis of rhodium(I) and iridium(I) azide complexes bearing a phosphinoborane ligand.

The ${ }^{31} \mathrm{P}\left\{{ }^{1} \mathrm{H}\right\}$ NMR spectrum showed a doublet at $22.4 \mathrm{ppm}$ with a coupling constant of $150 \mathrm{~Hz}$ for the rhodium azide complex, whereas the iridium azide complex appeared at $10.9 \mathrm{ppm}$ as a singlet. The ${ }^{11} \mathrm{~B}\left\{{ }^{1} \mathrm{H}\right\}$ NMR (Figure 2.14) of the azide 
complexes showed a significantly upfield shifted signal that was at 4 ppm and 5 ppm for the rhodium and iridium, respectively. The rhodium azide complex was determined by FTIR to have an azide stretch at $2082 \mathrm{~cm}^{-1}$, which compares to the value of $2038 \mathrm{~cm}^{-1}$ reported for the $\mathrm{Rh}(\mathrm{COD})\left(\mathrm{Ph}_{3} \mathrm{P}\right) \mathrm{N}_{3} .{ }^{51}$ This implies that the degree of $\mathrm{N}-\mathrm{N}$ triple bond character in rhodium complex $\mathbf{8 6}$ is higher than in the corresponding $\mathrm{PPh}_{3}$ complex, which is consistent with the structural data obtained for this complex.
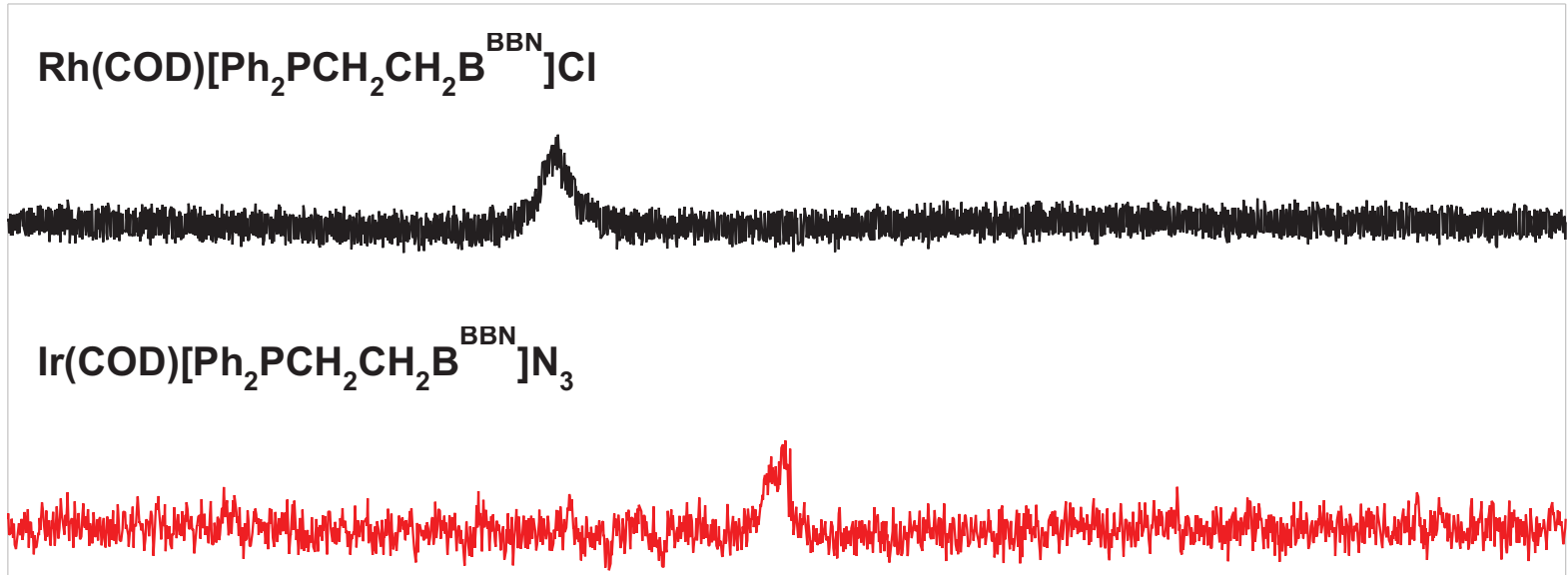

$$
\operatorname{Rh}(\mathrm{COD})\left[\mathrm{Ph}_{2} \mathrm{PCH}_{2} \mathrm{CH}_{2} \mathrm{~B}^{\mathrm{BBN}}\right] \mathrm{N}_{3}
$$
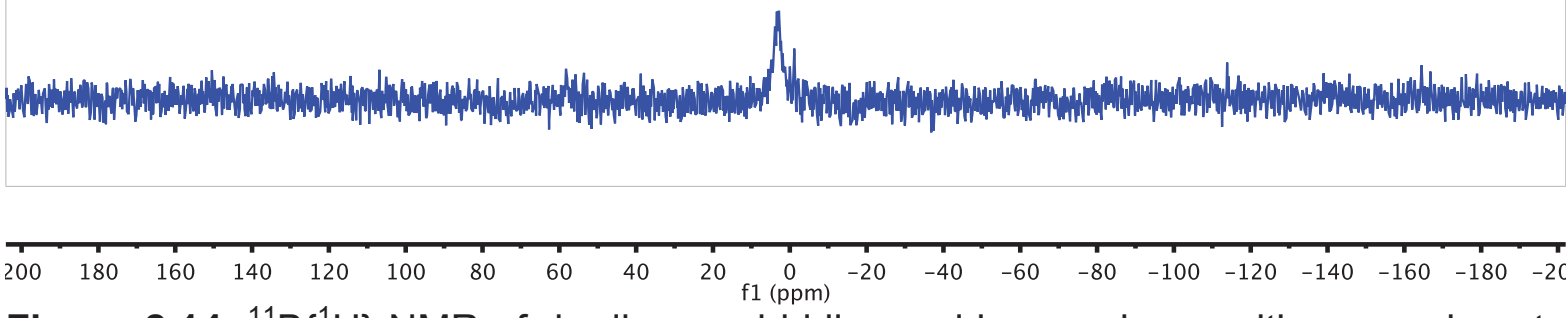

Figure 2.14. ${ }^{11} \mathrm{~B}\left\{{ }^{1} \mathrm{H}\right\}$ NMR of rhodium and iridium azide complexes with comparison to $\mathrm{Rh}(\mathrm{COD})\left[\mathrm{Ph}_{2} \mathrm{PCH}_{2} \mathrm{CH}_{2} \mathrm{~B}^{\mathrm{BBN}}\right] \mathrm{Cl}$.

The crystals of the two azide complexes were grown by layering a solution of $\mathrm{DCM}$ with pentane at $-40^{\circ} \mathrm{C}$ (Figure 2.15). The rhodium(I) complex shows a close contact interaction between the borane and N1 in the structure. The interaction distance is 1.694(4) $\AA$, which is longer than the $B-N$ bond distance of $1.564(6) \AA$ observed in 
ammonia-borane and longer than the covalent radius of $1.56 \AA$ for a B-N single bond. ${ }^{52}$ The N1-N2 bond length of $1.222(3) \AA$ is closer to a $N=N$ of $1.24 \AA$ than to the $N \equiv N$ length of $1.10 \AA$, while the N2-N3 bond length of $1.137(4) \AA$ is closer to that of the $N \equiv N$ bond length. In the case of the iridium(I) complex, the interaction between the borane and N1 (1.704(6) $\AA$ ) is slightly longer than that in the rhodium(I) azide complex.
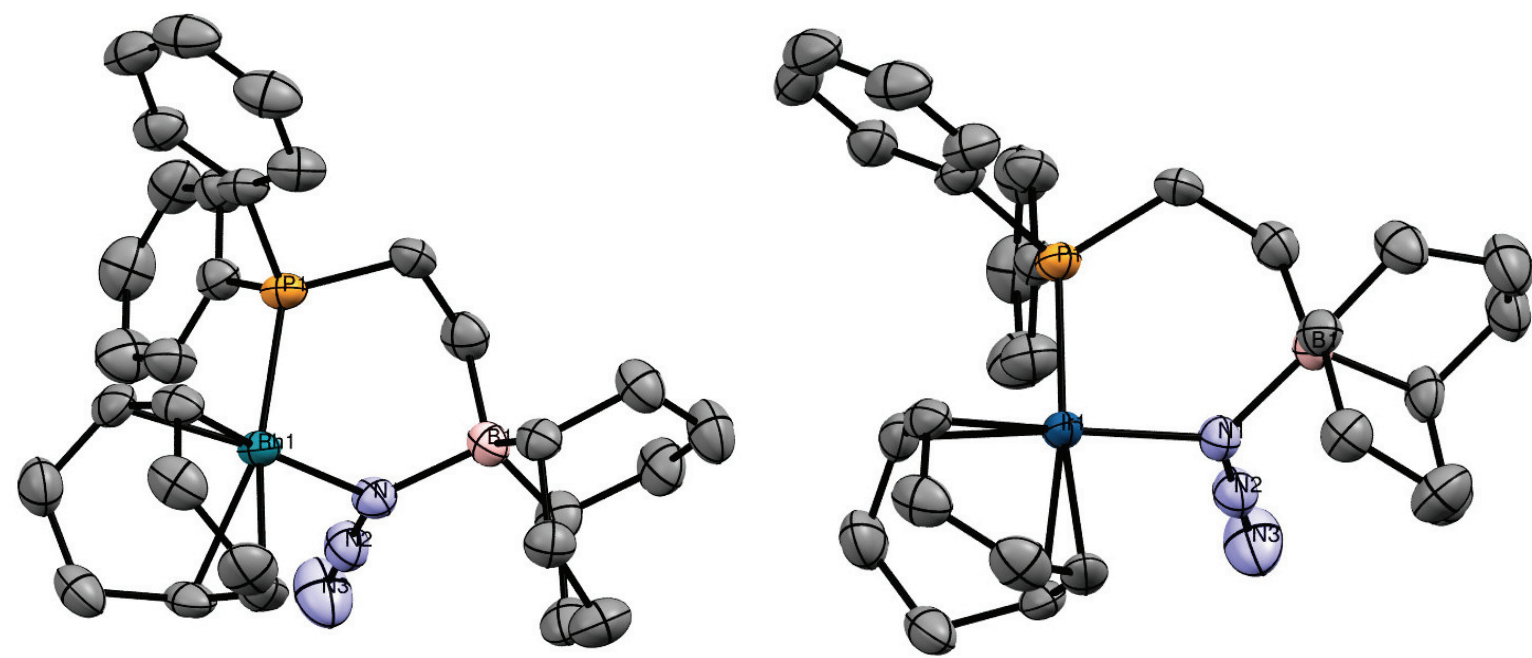

Figure 2.15. X-ray crystallographic structures of $\mathrm{Rh}(\mathrm{COD})\left[\mathrm{Ph}_{2} \mathrm{PCH}_{2} \mathrm{CH}_{2} \mathrm{~B}^{\mathrm{BBN}}\right] \mathrm{N}_{3}$ (86) and $\operatorname{Ir}(\mathrm{COD})\left[\mathrm{Ph}_{2} \mathrm{PCH}_{2} \mathrm{CH}_{2} \mathrm{~B}^{\mathrm{BBN}}\right] \mathrm{N}_{3}$ (87) (thermal ellipsoids at $50 \%$ probability) with hydrogens removed for clarity. Selected bond lengths $[\AA \AA]$ and angles $\left[{ }^{\circ}\right]$ for $\mathrm{Rh}(\mathrm{COD})\left[\mathrm{Ph}_{2} \mathrm{PCH}_{2} \mathrm{CH}_{2} \mathrm{~B}^{\mathrm{BBN}}\right] \mathrm{N}_{3}: \mathrm{Rh}(1)-\mathrm{N}(1)$ 2.133(2), $\mathrm{Rh}(1)-\mathrm{P}(1)$ 2.3008(7), N(1)-B(1) 1.694(4), N(1)-N(2) 1.222(3), N(2)-N(3) 1.137(4), B(1)-C(2) 1.630(4), P(1)-Rh(1)-N(1) 87.01(6), $\mathrm{B}(1)-\mathrm{N}(1)-\mathrm{Rh}(1)$ 125.26(16), N(1)-B(1)-C(2) 104.1(2). Selected bond lengths $[\AA]$ and angles $\left[{ }^{\circ}\right]$ for $\operatorname{Ir}(\mathrm{COD})\left[\mathrm{Ph}_{2} \mathrm{PCH}_{2} \mathrm{CH}_{2} \mathrm{~B}^{\mathrm{BBN}}\right] \mathrm{N}_{3}$ : $\operatorname{Ir}(1)-\mathrm{N}(1)$ 2.117(4), $\operatorname{Ir}(1)-\mathrm{P}(1)$ 2.3062(11), $\mathrm{N}(1)-\mathrm{B}(1)$ 1.704(6), $\mathrm{N}(1)-\mathrm{N}(2)$ 1.224(5), $\mathrm{N}(2)-\mathrm{N}(3)$ 1.135(6), $\mathrm{B}(1)-\mathrm{C}(2)$ 1.628(7), $\mathrm{P}(1)-\operatorname{Ir}(1)-\mathrm{N}(1)$ 87.75(10), B(1)-N(1)-Ir(1) 125.3(2), N(1)-B(1)-C(2) 103.8(4).

\subsection{Conclusion}

Through a detailed crystallographic and spectroscopic analysis, it was determined that the interaction of a tri-coordinate borane with a metal bound halide or 
azide results in a weak, solvent-dependent interaction. This interaction is dependent on the donor strength and polarity of the solvent and for strong donor solvents, such as acetonitrile, the solvent-bound adduct can be crystallographically characterized. The strength of the interaction within the complex can be tracked by ${ }^{11} \mathrm{~B}\left\{{ }^{1} \mathrm{H}\right\} N M R$ spectroscopy. The borane interaction also is strongly dependent on the interacting group (halide or azide), with the fluoride and the azide bearing the strongest interaction. The utilization of the interaction as a stabilizing force in catalysis is still under investigation and will be followed up in subsequent chapters.

\subsection{Methods}

\subsubsection{General Considerations}

The manipulation of air- and moisture-sensitive compounds was conducted and performed under a nitrogen atmosphere utilizing either standard Schlenk or glove box techniques, employing dry solvent and glassware. Glovebox experiments were carried out in a MBraun 200B dual-port inert atmosphere glovebox equipped with a $-40^{\circ} \mathrm{C}$ freezer. Dry solvents were obtained utilizing a glass contour solvent purification system and stored in the glovebox over $4 \AA$ molecular sieves. Deuterated solvents were obtained from Cambridge Isotope Laboratories, Inc. and passed through neutral alumina and stored over $4 \AA$ molecular sieves. In the event that NMR data was recorded in non-deuterated NMR solvent, an internal capillary was used that was charged with $d_{6}$-benzene and sealed by flame. Electrospray ionization (ESI) mass spectra were recorded on a Thermo-Finnigan LCQ DECA XP. High-resolution mass spectra were recorded on a Thermo-Finnigan LTQ MS equipped with an ICR FTMS. Infrared spectra were recorded using either a standard salt plate method or on a universal ATR assembly on a Perkin-Elmer Spectrum 100 FTIR. NMR spectra were 
recorded on either a $400 \mathrm{MHz}$ Agilent or a $600 \mathrm{MHz}$ Varian Inova NMR. Spectra were referenced to residual protio-solvent peaks as an internal standard for ${ }^{1} \mathrm{H}$ and ${ }^{13} \mathrm{C}$. The ${ }^{31} \mathrm{P}$ NMR was referenced to an external $\mathrm{H}_{3} \mathrm{PO}_{4}$ standard and the ${ }^{11} \mathrm{~B}$ and ${ }^{19} \mathrm{~F}$ NMR was referenced to an external $\mathrm{BF}_{3} \cdot \mathrm{OEt}_{2}$ standard. X-ray crystallography instrumental information can be found in Appendix 1. The phosphinoborane ligand ${ }^{12,15}$, $[\mathrm{Rh}(\mathrm{COD}) \mathrm{Cl}]_{2}^{53}$ and $\left[\mathrm{Rh}(\mathrm{COE})_{2} \mathrm{Cl}\right]_{2}{ }^{54}$ were prepared according to previously published methods. The $\mathrm{Rh}(\mathrm{COD})\left[\mathrm{Ph}_{2} \mathrm{PCH}_{2} \mathrm{CH}_{2} \mathrm{~B}^{\mathrm{BBN}}\right] \mathrm{Cl}$ and $\mathrm{Rh}(\mathrm{CO})\left[\mathrm{Ph}_{2} \mathrm{PCH}_{2} \mathrm{CH}_{2} \mathrm{~B}^{\mathrm{BBN}}\right]_{2} \mathrm{Cl}$ were prepared by modification of literature procedures. ${ }^{17}$

\subsubsection{Procedure for Synthesis of Rh- and $\operatorname{Ir}(C O D)$ Phosphinoborane Complexes}

A sample of $[\mathrm{Rh}(\mathrm{COD}) \mathrm{Cl}]_{2}(51.0 \mathrm{mg}, 0.103 \mathrm{mmol})$ was dissolved in $3 \mathrm{~mL}$ of toluene in a $20 \mathrm{~mL}$ scintillation vial equipped with a magnetic stir bar. The phosphinoborane, $\mathrm{Ph}_{2} \mathrm{PCH}_{2} \mathrm{CH}_{2} \mathrm{~B}\left(\mathrm{C}_{8} \mathrm{H}_{14}\right)(69.4 \mathrm{mg}, 0.207 \mathrm{mmol})$, was added as a solid and the walls of the vial were rinsed with an additional $2 \mathrm{~mL}$ of toluene. The sample was stirred overnight, after which the sample was concentrated in vacuo and washed with pentane. The yellow solid was isolated (113 mg, 94\%). ${ }^{1} \mathrm{H}$ NMR $\left(400 \mathrm{MHz}, \mathrm{C}_{6} \mathrm{D}_{6}\right)$ : $\delta 7.6-7.7$ (m, 4H, o-Ph), $\delta 7.0-7.1$ (m, 6H, m-Ph, p-Ph), $\delta 5.66$ (br. s, 2H, COD-CH, trans-P), $\delta 4.31$ (br. s, 1H, COD-CH, trans-Cl), $\delta 3.08$ (br. s, 2H, COD-CH), $\delta 2.74$ (m, $\left.2 \mathrm{H}, \mathrm{PCH}_{2}\right), \delta 1.97-2.2(\mathrm{~m}, 14 \mathrm{H}, \mathrm{BBN}), \delta 1.48-1.98\left(10 \mathrm{H}, \mathrm{COD}-\mathrm{CH}_{2}, \mathrm{CH}_{2} \mathrm{~B}\right) .{ }^{13} \mathrm{C}\left\{{ }^{1} \mathrm{H}\right\}$ $\operatorname{NMR}\left(100 \mathrm{MHz}, \mathrm{C}_{6} \mathrm{D}_{6}\right): \delta 134.0\left(\mathrm{~d}, 2 \mathrm{C},{ }^{1} \mathrm{~J}_{\mathrm{P}-\mathrm{C}}=39.7 \mathrm{~Hz}\right.$, ipso-Ph), $\delta 134.0\left(\mathrm{~d}, 4 \mathrm{C},{ }^{2} \mathrm{~J}_{\mathrm{P}-\mathrm{C}}=\right.$ $10.0 \mathrm{~Hz}$, o-Ph), $\delta 130.1$ (d, 2C, $\left.{ }^{4} \mathrm{~J}_{\mathrm{P}-\mathrm{C}}=1.5 \mathrm{~Hz}, \mathrm{p}-\mathrm{Ph}\right), \delta 128.4$ (d, $4 \mathrm{C},{ }^{3} \mathrm{~J}_{\mathrm{P}-\mathrm{C}}=9.9 \mathrm{~Hz}, \mathrm{~m}-$ $\mathrm{Ph}), \delta 105.4\left(\mathrm{dd}, 2 \mathrm{C},{ }^{1} \mathrm{~J}_{\mathrm{Rh}-\mathrm{C}}=12.2 \mathrm{~Hz},{ }^{2} \mathrm{~J}_{\mathrm{Rh}-\mathrm{P}}=6.8 \mathrm{~Hz}, \mathrm{COD}-\mathrm{CH}\right.$, trans-P), $\delta 78.6(\mathrm{~d}, 1 \mathrm{C}$, ${ }^{1} \mathrm{~J}_{\mathrm{Rh}-\mathrm{C}}=13.7 \mathrm{~Hz}, \mathrm{COD}-\mathrm{CH}$, trans-Cl), $\delta 70.6\left(\mathrm{~d}, 1 \mathrm{C},{ }^{1} \mathrm{~J}_{\mathrm{Rh}-\mathrm{C}}=13.8 \mathrm{~Hz}, \mathrm{COD}-\mathrm{CH}\right.$, transCl), $\delta 34.0$ (s, 6C, $\beta-B B N, y-B B N), \delta 33.2\left(\mathrm{~d}, 2 \mathrm{C},{ }^{3} \mathrm{~J}_{\mathrm{P}-\mathrm{C}}=3.1 \mathrm{~Hz}, \mathrm{COD}-\mathrm{CH}_{2}\right.$, trans-P), $\delta$ 
30.9 (s, 1C, $\mathrm{CH}_{2} \mathrm{~B}$ ), $\delta 30.5$ (br. s, 2C, $\left.\alpha-B B N\right), \delta 29.0$ (s, 2C, COD-CH $\mathrm{CH}_{2}$ trans-Cl), $\delta 24.0$ $\left(\mathrm{d}, 1 \mathrm{C},{ }^{1} \mathrm{~J}_{\mathrm{P}-\mathrm{C}}=26.0 \mathrm{~Hz}, \mathrm{PCH}\right) .{ }^{31} \mathrm{P}\left\{{ }^{1} \mathrm{H}\right\} \mathrm{NMR}\left(162 \mathrm{MHz}, \mathrm{C}_{6} \mathrm{D}_{6}\right): \delta 28.5\left(\mathrm{~d},{ }^{1} \mathrm{~J}_{\mathrm{Rh}-\mathrm{P}}=148.2\right.$ $\mathrm{Hz}) .{ }^{11} \mathrm{~B}\left\{{ }^{1} \mathrm{H}\right\} \operatorname{NMR}\left(128 \mathrm{MHz}, \mathrm{C}_{6} \mathrm{D}_{6}\right): \delta 61.8$ (br. s). ${ }^{11} \mathrm{~B}\left\{{ }^{1} \mathrm{H}\right\} \mathrm{NMR}\left(128 \mathrm{MHz}, \mathrm{CD}_{2} \mathrm{Cl}_{2}\right): \delta$ 78.9 (br. s). HRMS: m/z 586.22430 [ $\mathrm{C}_{32} \mathrm{H}_{43} \mathrm{BNPRh}-(\mathrm{M}-\mathrm{Cl}+\mathrm{ACN})^{+}$requires 586.22757].

A sample of $[\mathrm{Rh}(\mathrm{COD}) \mathrm{Br}]_{2}(100 \mathrm{mg}, 0.172 \mathrm{mmol})$ was dissolved in $3 \mathrm{~mL}$ of toluene in a $20 \mathrm{~mL}$ scintillation vial equipped with a magnetic stir bar. The phosphinoborane, $\mathrm{Ph}_{2} \mathrm{PCH}_{2} \mathrm{CH}_{2} \mathrm{~B}\left(\mathrm{C}_{8} \mathrm{H}_{14}\right)(114.9 \mathrm{mg}, 0.344 \mathrm{mmol})$, was added as a solid and the walls of the vial were rinsed with an additional $2 \mathrm{~mL}$ of toluene. The sample was stirred overnight, after which the sample was dried in vacuo and washed with pentane. The yellow solid was isolated in near quantitative yield $(200 \mathrm{mg}, 93 \%) .{ }^{1} \mathrm{H}$ NMR (400 MHz, $\left.\mathrm{C}_{6} \mathrm{D}_{6}\right): \delta 7.6-7.7(\mathrm{~m}, 4 \mathrm{H}$, o-Ph), $\delta 6.9-7.1(\mathrm{~m}, 6 \mathrm{H}, \mathrm{m}-\mathrm{Ph}, \mathrm{p}-\mathrm{Ph}), \delta$ 5.80 (br. s, 2H, COD-CH, trans-P), $\delta 4.39$ (br. s, 1H, COD-CH, trans-Cl), $\delta 3.10$ (br. s, $2 \mathrm{H}, \mathrm{COD}-\mathrm{CH}), \delta 2.88\left(\mathrm{~m}, 2 \mathrm{H}, \mathrm{PCH}_{2}\right), \delta 1.9-2.1(\mathrm{~m}, 10 \mathrm{H}, \mathrm{BBN}), \delta 1.53-1.90(14 \mathrm{H}$, COD-CH, $\left.\mathrm{CH}_{2} \mathrm{~B}\right), 1.15-1.32(3 \mathrm{H}, \mathrm{BBN}) .{ }^{13} \mathrm{C}\left\{{ }^{1} \mathrm{H}\right\} \mathrm{NMR}\left(100 \mathrm{MHz}, \mathrm{C}_{6} \mathrm{D}_{6}\right): \delta 134.4$ (d, $2 \mathrm{C},{ }^{1} \mathrm{~J}_{\mathrm{P}_{-} \mathrm{C}}=40.4 \mathrm{~Hz}$, ipso-Ph), $\delta 134.2\left(\mathrm{~d}, 4 \mathrm{C},{ }^{2} \mathrm{~J}_{\mathrm{P}-\mathrm{C}}=10.0 \mathrm{~Hz}, \mathrm{o}-\mathrm{Ph}\right), \delta 130.0\left(\mathrm{~d}, 2 \mathrm{C},{ }^{4} \mathrm{~J}_{\mathrm{P}-}\right.$ $\mathrm{c}=2.0 \mathrm{~Hz}, \mathrm{p}-\mathrm{Ph}), \delta 128.1\left(\mathrm{~d}, 4 \mathrm{C},{ }^{3} \mathrm{~J}_{\mathrm{P}-\mathrm{C}}=15.1 \mathrm{~Hz}, \mathrm{~m}-\mathrm{Ph}\right), \delta 104.2\left(\mathrm{dd}, 2 \mathrm{C},{ }^{1} \mathrm{~J}_{\mathrm{Rh}-\mathrm{C}}=12.4\right.$ $\mathrm{Hz},{ }^{2} \mathrm{~J}_{\mathrm{Rh}-\mathrm{P}}=6.8 \mathrm{~Hz}, \mathrm{COD}-\mathrm{CH}$, trans-P), $\delta 78.7\left(\mathrm{~d}, 1 \mathrm{C},{ }^{1} \mathrm{~J}_{\mathrm{Rh}-\mathrm{C}}=13.7 \mathrm{~Hz}, \mathrm{COD}-\mathrm{CH}\right.$, transCl), $\delta 71.0\left(\mathrm{~d}, 1 \mathrm{C},{ }^{1} \mathrm{~J}_{\mathrm{Rh}-\mathrm{C}}=13.6 \mathrm{~Hz}, \mathrm{COD}-\mathrm{CH}\right.$, trans-Cl), $\delta 33.8(\mathrm{~s}, 6 \mathrm{C}, \beta-B B N, y-B B N), \delta$ $33.1\left(\mathrm{~d}, 2 \mathrm{C},{ }^{3} \mathrm{JP}_{\mathrm{P} C}=3.0 \mathrm{~Hz}, \mathrm{COD}-\mathrm{CH}_{2}\right.$, trans-P), $\delta 31.5$ (br. s, $1 \mathrm{C}, \mathrm{CH}_{2} \mathrm{~B}$ ), $\delta 31.1$ (br. s, 2C, $\alpha-B B N), \delta 29.3\left(\mathrm{~s}, 2 \mathrm{C}, \mathrm{COD}-\mathrm{CH}_{2}\right.$, trans-Cl), $\delta 24.9\left(\mathrm{~d}, 1 \mathrm{C},{ }^{1} \mathrm{~J}_{\mathrm{P}-\mathrm{C}}=25.7 \mathrm{~Hz}, \mathrm{PCH}_{2}\right.$ ). ${ }^{31} \mathrm{P}\left\{{ }^{1} \mathrm{H}\right\} \operatorname{NMR}\left(162 \mathrm{MHz}, \mathrm{C}_{6} \mathrm{D}_{6}\right): \delta 31.2\left(\mathrm{~d},{ }^{1} \mathrm{~J}_{\mathrm{Rh}-\mathrm{P}}=147.4 \mathrm{~Hz}\right) .{ }^{11} \mathrm{~B}\left\{{ }^{1} \mathrm{H}\right\} \mathrm{NMR}(128 \mathrm{MHz}$, $\left.\mathrm{C}_{6} \mathrm{D}_{6}\right): \delta 83.6$ (br. s). 
A sample of $[\mathrm{Rh}(\mathrm{COD})]_{2}(100 \mathrm{mg}, 0.148 \mathrm{mmol})$ was dissolved in $3 \mathrm{~mL}$ of toluene in a $20 \mathrm{~mL}$ scintillation vial equipped with a magnetic stir bar. The phosphinoborane, $\mathrm{Ph}_{2} \mathrm{PCH}_{2} \mathrm{CH}_{2} \mathrm{~B}\left(\mathrm{C}_{8} \mathrm{H}_{14}\right)(98.9 \mathrm{mg}, 0.296 \mathrm{mmol})$, was added as a solid and the walls of the vial were rinsed with an additional $2 \mathrm{~mL}$ of toluene. The sample was stirred overnight, after which the sample was dried in vacuo and washed with pentane. The yellow solid was isolated in near quantitative yield (185 mg, 93\%). ${ }^{1} \mathrm{H}$ NMR $\left(400 \mathrm{MHz}, \mathrm{C}_{6} \mathrm{D}_{6}\right): \delta 7.6-$ 7.7 (m, 4H, o-Ph), ठ 6.9- 7.1 (m, 6H, m-Ph, p-Ph), ठ 5.92 (br. s, 2H, COD-CH, trans-P),

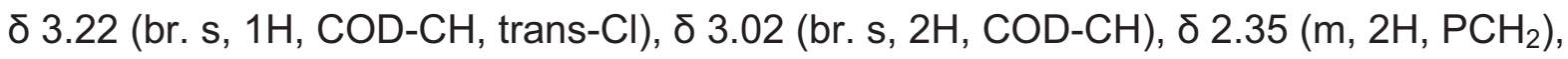
$\delta 1.9-2.1(\mathrm{~m}, 8 \mathrm{H}, \mathrm{BBN}), \delta 1.69-1.87\left(13 \mathrm{H}, \mathrm{COD}-\mathrm{CH}_{2}, \mathrm{CH}_{2} \mathrm{~B}, \mathrm{BBN}\right), 1.28-1.69(4 \mathrm{H}$, BBN). ${ }^{13} \mathrm{C}\left\{{ }^{1} \mathrm{H}\right\}$ NMR (100 MHz, $\left.\mathrm{C}_{6} \mathrm{D}_{6}\right): \delta 135.1$ (d, 2C, ${ }^{1} \mathrm{JP}_{\mathrm{C}} \mathrm{C}=38.3 \mathrm{~Hz}$, ipso-Ph), $\delta 134.2$ $\left(\mathrm{d}, 4 \mathrm{C},{ }^{2} \mathrm{JP}_{\mathrm{P}-\mathrm{C}}=9.7 \mathrm{~Hz}, \mathrm{o}-\mathrm{Ph}\right), \delta 130.0\left(\mathrm{~d}, 2 \mathrm{C},{ }^{4} \mathrm{JP}_{\mathrm{P}-\mathrm{C}}=2.0 \mathrm{~Hz}, \mathrm{p}-\mathrm{Ph}\right), \delta 128.2\left(\mathrm{~d}, 4 \mathrm{C},{ }^{3} \mathrm{JP}_{\mathrm{P}-\mathrm{C}}\right.$ $=10.1 \mathrm{~Hz}, \mathrm{~m}-\mathrm{Ph}$ ), $\delta 102.4\left(\mathrm{dd}, 2 \mathrm{C},{ }^{1} \mathrm{~J}_{\mathrm{Rh}-\mathrm{C}}=12.2 \mathrm{~Hz},{ }^{2} \mathrm{~J}_{\mathrm{Rh}-\mathrm{P}}=6.8 \mathrm{~Hz}, \mathrm{COD}-\mathrm{CH}\right.$, trans-P), $\delta 73.3\left(\mathrm{~d}, 2 \mathrm{C},{ }^{1} \mathrm{~J}_{\mathrm{Rh}-\mathrm{C}}=13.5 \mathrm{~Hz}, \mathrm{COD}-\mathrm{CH}\right.$, trans-Cl), $\delta 33.6(\mathrm{~s}, 6 \mathrm{C}, \beta-\mathrm{BBN}, \mathrm{y}-\mathrm{BBN}), \delta$ $32.7\left(\mathrm{~d}, 2 \mathrm{C},{ }^{3} \mathrm{~J}_{\mathrm{P}-\mathrm{C}}=2.8 \mathrm{~Hz}, \mathrm{COD}-\mathrm{CH}_{2}\right.$, trans-P), $\delta 31.5$ (br. s, $\left.1 \mathrm{C}, \mathrm{CH}_{2} \mathrm{~B}\right), \delta 29.9$ (s, 2C, COD-CH $\mathrm{CH}_{2}$, trans-Cl), $\delta 27.3$ (d, 1C, ${ }^{1} \mathrm{~J}_{\mathrm{P}-\mathrm{C}}=27.1 \mathrm{~Hz}, \mathrm{PCH}_{2}$ ), $\delta 26.1$ (br. s, 2C, $\left.\alpha-B B N\right)$. ${ }^{31} \mathrm{P}\left\{{ }^{1} \mathrm{H}\right\}$ NMR $\left(162 \mathrm{MHz}, \mathrm{C}_{6} \mathrm{D}_{6}\right): \delta 31 . !\left(\mathrm{d},{ }^{1} \mathrm{~J}_{\mathrm{Rh}-\mathrm{P}}=145.2 \mathrm{~Hz}\right) .{ }^{11} \mathrm{~B}\left\{{ }^{1} \mathrm{H}\right\} \mathrm{NMR}(128 \mathrm{MHz}$, $\left.\mathrm{C}_{6} \mathrm{D}_{6}\right): \delta 87.8$ (br. s).

A sample of $[\operatorname{lr}(\mathrm{COD}) \mathrm{Cl}]_{2}(100 \mathrm{mg}, 0.149 \mathrm{mmol})$ was dissolved in $4 \mathrm{~mL}$ of $3: 1$ mixture of dichloromethane/pentane in a $20 \mathrm{~mL}$ scintillation vial equipped with a magnetic stir bar and a cap. The phosphinoborane, $\mathrm{Ph}_{2} \mathrm{PCH}_{2} \mathrm{CH}_{2} \mathrm{~B}\left(\mathrm{C}_{8} \mathrm{H}_{14}\right)(99.5 \mathrm{mg}$, $0.298 \mathrm{mmol}$ ), was added as a solid and the walls of the vial were rinsed with an additional $2 \mathrm{~mL}$ of a 3:1 mixture of dichloromethane/pentane. The sample was stirred for 20 hours after which the sample dried in vacuo. The sample was re-dissolved in 
dichloromethane and pentane was added until solution appears cloudy. The sample was placed in the freezer overnight. The orange solid was isolated $(113 \mathrm{mg}, 57 \%) .{ }^{1} \mathrm{H}$ NMR (400 MHz, $\left.\mathrm{CD}_{2} \mathrm{Cl}_{2}\right): \delta 7.58-7.73(\mathrm{~m}, 2 \mathrm{H}, \mathrm{Ph}), \delta 7.38-7.49(\mathrm{~m}, 3 \mathrm{H}, \mathrm{Ph}), \delta$ 4.7-5.2

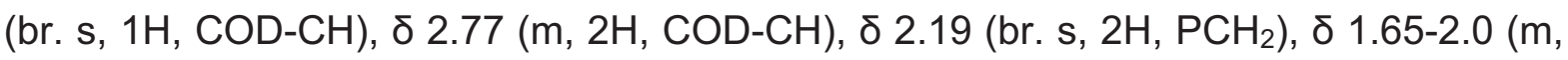
$\left.8 \mathrm{H}, \mathrm{COD}-\mathrm{CH}_{2}\right), \delta 1.17-1.43\left(16 \mathrm{H}, \mathrm{CH}_{2} \mathrm{~B}, \mathrm{BBN}\right) \cdot{ }^{13} \mathrm{C}\left\{{ }^{1} \mathrm{H}\right\} \mathrm{NMR}\left(100 \mathrm{MHz}, \mathrm{CD}_{2} \mathrm{Cl}_{2}\right): \delta$ $134.3\left(\mathrm{~d}, 2 \mathrm{C},{ }^{2} \mathrm{~J}_{\mathrm{P}-\mathrm{C}}=9.96 \mathrm{~Hz}, \mathrm{o}-\mathrm{Ph}\right), \delta 132.6\left(\mathrm{~d}, 2 \mathrm{C},{ }^{1} \mathrm{JP}_{\mathrm{P}-\mathrm{C}}=46.7 \mathrm{~Hz}\right.$, ipso-Ph), $\delta 130.6$ (d, 2C, $\left.{ }^{4} \mathrm{JP}_{\mathrm{P}-\mathrm{C}}=3.0 \mathrm{~Hz}, \mathrm{p}-\mathrm{Ph}\right), \delta 128.5\left(\mathrm{~d}, 2 \mathrm{C},{ }^{3} \mathrm{JP}_{\mathrm{P}-\mathrm{C}}=9.96 \mathrm{~Hz}\right.$, meta-Ph), $\delta 93.2$ (br. s, 4C, COD-CH), $\delta 34.1$ (s, 6C, $\beta$-BBN, $\gamma-B B N$ ), $\delta 33.2$ (s, 2C, COD-CH (s, 1C, $\mathrm{CH}_{2} B$ ), $\delta 22.1$ (br. s, 2C, $\left.\alpha-B B N\right), \delta 21.4\left(\mathrm{~d}, 1 \mathrm{C},{ }^{1} \mathrm{~J}_{\mathrm{P}-\mathrm{C}}=29.8 \mathrm{~Hz}, \mathrm{PCH}_{2}\right.$ ), $\delta 13.8$ (s, 2C, COD-CH $\mathrm{CH}_{2}$ trans-Cl), ${ }^{31} \mathrm{P}\left\{{ }^{1} \mathrm{H}\right\}$ NMR (162 MHz, $\mathrm{CD}_{2} \mathrm{Cl}_{2}$ ): $\delta 18.2$ (s). ${ }^{11} \mathrm{~B}\left\{{ }^{1} \mathrm{H}\right\}$ NMR (128 MHz, $\mathrm{CD}_{2} \mathrm{Cl}_{2}$ ): $\delta 85.2$ (br. s). HRMS: m/z $676.28229\left[\mathrm{C}_{32} \mathrm{H}_{43} \mathrm{BNPIr}-(\mathrm{M}-\mathrm{Cl}+\mathrm{ACN})^{+}\right.$ requires 676.28499].

\subsubsection{Procedure for Synthesis of Bis(phosphinoborane) Rh(I) Carbonyl Chloride}

A sample of $\left[\mathrm{Rh}(\mathrm{CO})_{2} \mathrm{Cl}\right]_{2}(53 \mathrm{mg}, 0.136 \mathrm{mmol})$ was dissolved in $9 \mathrm{~mL}$ of dichloromethane in a $20 \mathrm{~mL}$ scintillation vial equipped with a magnetic stir bar. The phosphinoborane, $\mathrm{Ph}_{2} \mathrm{PCH}_{2} \mathrm{CH}_{2} \mathrm{~B}\left(\mathrm{C}_{8} \mathrm{H}_{14}\right)(91 \mathrm{mg}, 0.271 \mathrm{mmol})$, was added as a solid and the walls of the vial were rinsed with an additional $2 \mathrm{~mL}$ of dichloromethane. The sample was stirred for 24 hours after which the sample was concentrated in vacuo and washed with pentane. The yellow solid was isolated $(224.9 \mathrm{mg}, 99 \%)$. If necessary, the sample can be recrystallized by layering a cold solution of DCM with pentane. ${ }^{1} \mathrm{H}$ NMR (400 MHz, $\left.\mathrm{C}_{6} \mathrm{D}_{6}\right): \delta 7.87(\mathrm{~m}, 9 \mathrm{H}, \mathrm{Ph}), \delta 7.07(\mathrm{~m}, 11 \mathrm{H}, \mathrm{Ph}), \delta 2.92\left(\mathrm{~m}, 4 \mathrm{H}, \mathrm{PCH}_{2}\right), \delta 1.94$ (m, 4H, CH $\left.\mathrm{CH}_{2} \mathrm{~B}\right), \delta$ 1.88-1.64 (m, 24H, BBN), $\delta 1.24-1.14(\mathrm{~m}, 4 \mathrm{H}, \mathrm{BBN}) .{ }^{13} \mathrm{C}\left\{{ }^{1} \mathrm{H}\right\} \mathrm{NMR}$ (100 MHz, $\mathrm{C}_{6} \mathrm{D}_{6}$ ): $\delta 135.1$ (t, J = $21.12 \mathrm{~Hz}$, ipso-Ph, 4C), $\delta 133.9$ (t, J = $5.93 \mathrm{~Hz}, \mathrm{o}-\mathrm{Ph}$,

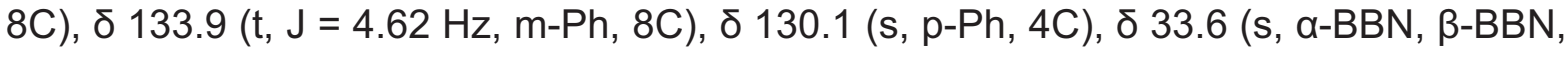




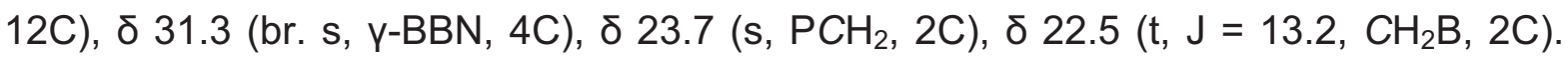
${ }^{31} \mathrm{P}\left\{{ }^{1} \mathrm{H}\right\} \operatorname{NMR}\left(162 \mathrm{MHz}, \mathrm{C}_{6} \mathrm{D}_{6}\right): \delta 27.3\left(\mathrm{~d},{ }^{1} \mathrm{~J}_{\mathrm{Rh}-\mathrm{P}}=124.8 \mathrm{~Hz}\right) .{ }^{11} \mathrm{~B}\left\{{ }^{1} \mathrm{H}\right\} \mathrm{NMR}(128 \mathrm{MHz}$, $\left.\mathrm{C}_{6} \mathrm{D}_{6}\right): \delta 82.9$ (br. s). FTIR: $1968 \mathrm{~cm}^{-1}$ (CO stretch). ESI-MS: $840.14 \mathrm{~m} / \mathrm{z}(\mathrm{M}-\mathrm{Cl}+\mathrm{ACN})^{+}$. HR-MS: m/z 840.32623 [ $\mathrm{C}_{47} \mathrm{H}_{59} \mathrm{~B}_{2} \mathrm{NOP}_{2} \mathrm{Rh}-(\mathrm{M}-\mathrm{Cl}+\mathrm{ACN})^{+}$requires 840.33075].

\subsubsection{Procedure for Synthesis of Bis(phosphinoborane) Rh(I) Chloride Dimer}

A sample of $\left[\mathrm{Rh}(\mathrm{COE})_{2} \mathrm{Cl}\right]_{2}(100 \mathrm{mg}, 0.139 \mathrm{mmol})$ was dissolved in toluene in a $20 \mathrm{~mL}$ scintillation vial equipped with a magnetic stir bar and a cap. The phosphinoborane ligand, $\mathrm{Ph}_{2} \mathrm{PCH}_{2} \mathrm{CH}_{2} \mathrm{~B}\left(\mathrm{C}_{8} \mathrm{H}_{14}\right)(186.3 \mathrm{mg}, 0.557 \mathrm{mmol})$, was added as a solid and the walls of the vial were rinsed with additional toluene. The sample was stirred for 22 hours after which the sample was concentrated in vacuo and washed with pentane to remove cyclooctene. The product was recrystallized by layering a cold toluene solution with pentane (321 mg, 71\%). ${ }^{31} \mathrm{P}\left\{{ }^{1} \mathrm{H}\right\} \mathrm{NMR}\left(162 \mathrm{MHz}, \mathrm{CD}_{2} \mathrm{Cl}_{2}\right): \delta 45.5$ $\left(\mathrm{d},{ }^{1} \mathrm{~J}_{\mathrm{Rh}-\mathrm{P}}=196.2 \mathrm{~Hz}, 4 \mathrm{P}\right) .{ }^{11} \mathrm{~B}\left\{{ }^{1} \mathrm{H}\right\} \mathrm{NMR}\left(128 \mathrm{MHz}, \mathrm{CD}_{2} \mathrm{Cl}_{2}\right): \delta 87$ (br. s, 4B).

\subsubsection{Procedure for Synthesis of Tris(phosphinoborane) Rh(I) Chloride}

A sample of $\left[\mathrm{Rh}(\text { cyclooctene })_{2} \mathrm{Cl}\right]_{2}(100.0 \mathrm{mg}, 0.139 \mathrm{mmol})$ was dissolved in toluene in a $20 \mathrm{~mL}$ scintillation vial equipped with a magnetic stir bar and a cap. The phosphinoborane, $\mathrm{Ph}_{2} \mathrm{PCH}_{2} \mathrm{CH}_{2} \mathrm{~B}\left(\mathrm{C}_{8} \mathrm{H}_{14}\right)(279.5 \mathrm{mg}, 0.836 \mathrm{mmol})$, was added as a solid and the walls of the vial were rinsed with additional toluene. The sample was stirred for overnight after which the sample was concentrated in vacuo and placed in the freezer. The solid was collected by filtration and washed with pentane. The red solid was isolated (160 mg, 50\%). ${ }^{1} \mathrm{H}$ NMR (400 MHz, $\left.\mathrm{CD}_{2} \mathrm{Cl}_{2}\right): \delta 7.64-7.76(\mathrm{~m}, 3 \mathrm{H}, \mathrm{Ph}), \delta 7.53$ - $7.64(\mathrm{~m}, 7 \mathrm{H}, \mathrm{Ph}), \delta 7.21-7.32(\mathrm{~m}, 7 \mathrm{H}, \mathrm{Ph}), \delta 7.07-7.21(\mathrm{~m}, 13 \mathrm{H}, \mathrm{Ph}), \delta 2.35(\mathrm{~m}$,

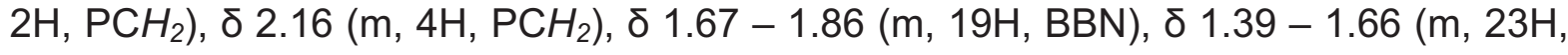


BBN), $\delta 1.01-1.22\left(\mathrm{~m}, 6 \mathrm{H}, \mathrm{CH}_{2} \mathrm{~B}\right) .{ }^{13} \mathrm{C}\left\{{ }^{1} \mathrm{H}\right\} \mathrm{NMR}\left(100 \mathrm{MHz}, \mathrm{CD}_{2} \mathrm{Cl}_{2}\right): \delta 139.7(\mathrm{~d}, \mathrm{~J}=38.5$ Hz, ipso-Ph, 2C), $\delta 137.2$ (t, J = 17.9 Hz, ipso-Ph, 4C), $\delta 134.6$ (t, J = 5.6 Hz, m-Ph,

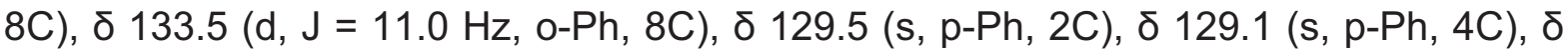
128.1 (d, J = 9.2 Hz, o-Ph, 4C), ठ 127.8 (t, J = 4.3 Hz, m-Ph, 4C), $\delta 33.7$ (s, BBN, 16C),

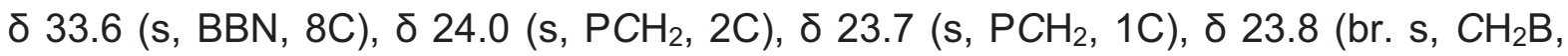
3C). ${ }^{31} \mathrm{P}\left\{{ }^{1} \mathrm{H}\right\}$ NMR $\left(162 \mathrm{MHz}, \mathrm{CD}_{2} \mathrm{Cl}_{2}\right): \delta 44.8\left(\mathrm{dt},{ }^{1} \mathrm{~J}_{\mathrm{Rh}-\mathrm{P}}=192.6 \mathrm{~Hz},{ }^{2} \mathrm{~J}_{\mathrm{P}-\mathrm{P}(\mathrm{cis})}=41.6 \mathrm{~Hz}\right.$, 1P), $\delta 26.9\left(\mathrm{dd},{ }^{1} \mathrm{~J}_{\mathrm{Rh}-\mathrm{P}}=137.0 \mathrm{~Hz},{ }^{2} \mathrm{~J}_{\mathrm{P}-\mathrm{P}(\mathrm{cis})}=39.9 \mathrm{~Hz}, 2 \mathrm{P}\right) .{ }^{11} \mathrm{~B}\left\{{ }^{1} \mathrm{H}\right\} \operatorname{NMR}(128 \mathrm{MHz}$, $\mathrm{CD}_{2} \mathrm{Cl}_{2}$ ): $\delta 82$ (br. s).

\subsubsection{Procedure for Synthesis of $\mathrm{Rh}(\mathrm{COD})\left[\mathrm{Ph}_{2} \mathrm{PCH}_{2} \mathrm{CH}_{2} \mathrm{~B}^{\mathrm{BBN}}\right] \mathrm{F}$}

A sample of $\mathrm{Rh}(\mathrm{COD}) \mathrm{PBCl}(66)(100 \mathrm{mg}, 0.172 \mathrm{mmol})$ and potassium fluoride (100 mg, $1.72 \mathrm{mmol}$ ) were suspended in $10 \mathrm{~mL}$ of dry acetone in a $20 \mathrm{~mL}$ scintillation vial equipped with a magnetic stir bar. The sample was stirred overnight, after which the sample was filtered and dried in vacuo. The crude NMR was recorded in $C_{6} D_{6}$ and the NMR sample filtered again. The solvent was removed and 1-2 $\mathrm{mL}$ of dry acetone was added. The liquid was decanted and the solid sample dried in vacuo to yield a yellow/orange solid (28 mg, 29\%). ${ }^{1} \mathrm{H}$ NMR (400 MHz, $\left.\mathrm{C}_{6} \mathrm{D}_{6}\right)$ : $\delta 7.58-7.66(\mathrm{~m}, 4 \mathrm{H}, \mathrm{Ph})$, $\delta 7.03-7.08$ (m, 6H, Ph), $\delta 4.68-4.76$ (br. s, 2H, COD-CH), $3.14-3.39$ (br. s, 2H,

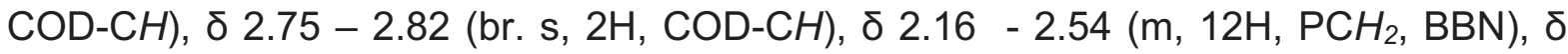
$1.93-2.09\left(\mathrm{~m}, 6 \mathrm{H}, \mathrm{COD}-\mathrm{CH}_{2}, \mathrm{BBN}\right), \delta 1.42-1.52\left(\mathrm{~m}, 4 \mathrm{H}, \mathrm{COD}-\mathrm{CH}_{2}\right), \delta 0.98-1.20$ (m, 4H, CH$\left.H_{2} \mathrm{~B}, \mathrm{BBN}\right) .{ }^{13} \mathrm{C}\left\{{ }^{1} \mathrm{H}\right\} \operatorname{NMR}\left(100 \mathrm{MHz}, \mathrm{C}_{6} \mathrm{D}_{6}\right): \delta 134.2\left(\mathrm{~d}, 2 \mathrm{C},{ }^{1} \mathrm{~J}_{\mathrm{P}-\mathrm{C}}=40.0 \mathrm{~Hz}\right.$, ipso-Ph), $\delta 133.7$ (d, 2C, $\left.{ }^{2} \mathrm{~J}_{\mathrm{P}-\mathrm{C}}=10.2 \mathrm{~Hz}, \mathrm{o}-\mathrm{Ph}\right), \delta 130.2\left(\mathrm{~d}, 2 \mathrm{C},{ }^{4} \mathrm{~J}_{\mathrm{P}-\mathrm{C}}=2.1 \mathrm{~Hz}, \mathrm{p}-\mathrm{Ph}\right), \delta$ $128.6\left(\mathrm{~d}, 2 \mathrm{C},{ }^{3} \mathrm{~J}_{\mathrm{P}-\mathrm{C}}=9.3 \mathrm{~Hz}\right.$, meta-Ph), $\delta 104.4\left(\mathrm{dd}, 2 \mathrm{C},{ }^{2} \mathrm{~J}_{\mathrm{P}-\mathrm{C}}=10.9 \mathrm{~Hz},{ }^{1} \mathrm{~J}_{\mathrm{Rh}-\mathrm{C}}=7.4 \mathrm{~Hz}\right.$, COD-CH), 67.9 (d, 2C, $\left.{ }^{2} \mathrm{~J}_{\mathrm{P}-\mathrm{C}}=13.7 \mathrm{~Hz}, \mathrm{COD}-\mathrm{CH}\right), \delta 33.8$ (s, 2C, BBN), $\delta 33.4$ (s, 2C, 
BBN), $\delta 33.0\left(\mathrm{~d}, 2 \mathrm{C},{ }^{3} \mathrm{~J}_{\mathrm{P}-\mathrm{C}}=2.5 \mathrm{~Hz}, \mathrm{COD}-\mathrm{CH}_{2}\right.$, trans-P), $\delta 28.6$ (br. s, $1 \mathrm{C}, \mathrm{CH}_{2} \mathrm{~B}$ ), $\delta 28.3$ (s, 2C, BBN), $\delta 28.3(\mathrm{~s}, 2 \mathrm{C}, \mathrm{BBN}), \delta 26.3\left(\mathrm{~d}, 2 \mathrm{C},{ }^{3} \mathrm{~J}_{\mathrm{P}-\mathrm{C}}=3.9 \mathrm{~Hz}, \mathrm{COD}-\mathrm{CH}_{2}\right.$, trans-Cl), $\delta$ $23.5\left(\mathrm{~d}, 1 \mathrm{C},{ }^{1} \mathrm{~J}_{\mathrm{P}-\mathrm{C}}=23.5 \mathrm{~Hz}, \mathrm{PCH}_{2}\right) .{ }^{31} \mathrm{P}\left\{{ }^{1} \mathrm{H}\right\} \operatorname{NMR}\left(162 \mathrm{MHz}, \mathrm{C}_{6} \mathrm{D}_{6}\right): \delta 22.1\left(\mathrm{~d},{ }^{1} \mathrm{~J}_{\mathrm{Rh}-\mathrm{P}}=\right.$ 154.4 Hz). ${ }^{11} \mathrm{~B}\left\{{ }^{1} \mathrm{H}\right\}$ NMR (128 MHz, $\left.\mathrm{C}_{6} \mathrm{D}_{6}\right): \delta 0.9$ (br. s). ${ }^{19} \mathrm{~F}\left\{{ }^{13} \mathrm{C}\right\}$ NMR $\left(376 \mathrm{MHz}, \mathrm{C}_{6} \mathrm{D}_{6}\right)$ : $\delta-160.3$ (br. s).

\subsubsection{General Procedure for Synthesis of $\mathrm{Rh}(\mathrm{I})$ - and $\operatorname{Ir}(\mathrm{I})$-azide Complexes}

A sample of $\mathrm{Rh}(\mathrm{COD})\left[\mathrm{Ph}_{2} \mathrm{PCH}_{2} \mathrm{CH}_{2} \mathrm{~B}\left(\mathrm{C}_{8} \mathrm{H}_{14}\right)\right] \mathrm{Cl}$ (20 mg, $0.034 \mathrm{mmol}$ ) was dissolved in dichloromethane in a $20 \mathrm{~mL}$ scintillation vial equipped with a magnetic stir bar and a cap. The silver tetrafluoroborate, $\mathrm{AgBF}_{4}(7 \mathrm{mg}, 0.036 \mathrm{mmol})$, was added as a solid and the walls of the vial were rinsed with additional dichloromethane. The sample was stirred for 1.5 hours after which the sample was passed through Celite to remove the silver chloride and treated with an excess of sodium azide. The sample was stirred overnight after which it was passed through Celite to remove the sodium tetrafluoroborate, washed with pentane, and dried in vacuo. ${ }^{1} \mathrm{H} \mathrm{NMR}(400 \mathrm{MHz}$, $\left.\mathrm{CD}_{2} \mathrm{Cl}_{2}\right): \delta 7.7-7.76(\mathrm{~m}, 4 \mathrm{H}$, o-Ph), $\delta 7.4-7.5(\mathrm{~m}, 6 \mathrm{H}, m-P h, p-P h), \delta 5.27-5.31$ (br. s,

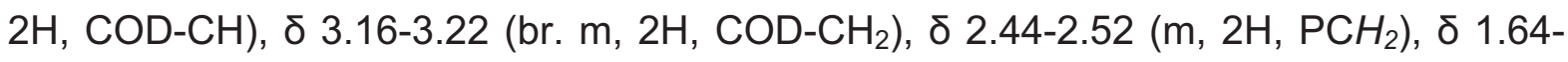
$2.4\left(\mathrm{~m}, 22 \mathrm{H}, \mathrm{BBN}, \mathrm{COD}-\mathrm{CH}_{2}, \mathrm{CH}_{2} \mathrm{~B}\right) \cdot{ }^{13} \mathrm{C}\left\{{ }^{1} \mathrm{H}\right\} \mathrm{NMR}\left(100 \mathrm{MHz}, \mathrm{CD}_{2} \mathrm{Cl}_{2}\right): \delta 133.9$ (d, 2C, $\left.{ }^{2} \mathrm{~J}_{\mathrm{P}-\mathrm{C}}=10.3 \mathrm{~Hz}, \mathrm{o}-\mathrm{Ph}\right), \delta 132.7\left(\mathrm{~d}, 2 \mathrm{C},{ }^{1} \mathrm{~J}_{\mathrm{P}-\mathrm{C}}=40.5 \mathrm{~Hz}\right.$, ipso-Ph), $\delta 130.9\left(\mathrm{~d}, 2 \mathrm{C},{ }^{4} \mathrm{JP}_{\mathrm{P} C}=\right.$ $2.5 \mathrm{~Hz}, \mathrm{p}-\mathrm{Ph}$ ), $\delta 129.1$ (d, 2C, ${ }^{3} \mathrm{~J}_{\mathrm{P}-\mathrm{C}}=9.4 \mathrm{~Hz}$, meta-Ph), $\delta 104.8\left(\mathrm{dd}, 2 \mathrm{C},{ }^{!} \mathrm{J}_{\mathrm{Rh}-\mathrm{C}}=10.7\right.$ $\left.\mathrm{Hz},{ }^{2} \mathrm{~J}_{\mathrm{P}-\mathrm{C}}=7.4 \mathrm{~Hz}, \mathrm{COD}-\mathrm{CH}\right), 74.8\left(\mathrm{~d}, 2 \mathrm{C}, !_{\mathrm{Rh}-\mathrm{C}}=13.4 \mathrm{~Hz}, \mathrm{COD}-\mathrm{CH}\right), \delta 33.0(\mathrm{~s}, 2 \mathrm{C}$, $B B N$ ), $\delta 32.8$ (s, 2C, COD-CH 2 , trans-P), $\delta 32.8$ (s, 2C, COD-CH $\mathrm{CH}_{2}$ trans-Cl), $\delta 29.3$ (s,

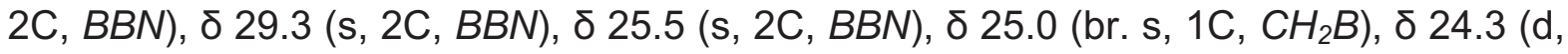


1C, $\left.{ }^{1} \mathrm{JP}_{\mathrm{P}-\mathrm{C}}=24.4 \mathrm{~Hz}, \mathrm{PCH}\right) \cdot{ }^{31} \mathrm{P}\left\{{ }^{1} \mathrm{H}\right\} \operatorname{NMR}\left(162 \mathrm{MHz}, \mathrm{CD}_{2} \mathrm{Cl}_{2}\right): \delta 22.4\left(\mathrm{~d},{ }^{1} \mathrm{~J}_{\mathrm{Rh}-\mathrm{P}}=150.1\right.$ $\mathrm{Hz}) .{ }^{11} \mathrm{~B}\left\{{ }^{1} \mathrm{H}\right\}$ NMR (128 MHz, $\left.\mathrm{CD}_{2} \mathrm{Cl}_{2}\right): \delta 3.4$ (br. s). FTIR: $\mathrm{vas}_{2} 2082 \mathrm{~cm}^{-1}$ (vs).

A sample of $\operatorname{Ir}(\mathrm{COD})\left[\mathrm{Ph}_{2} \mathrm{PCH}_{2} \mathrm{CH}_{2} \mathrm{~B}\left(\mathrm{C}_{8} \mathrm{H}_{14}\right)\right] \mathrm{Cl}(47 \mathrm{mg}, 0.07 \mathrm{mmol})$ was dissolved in dichloromethane in a $20 \mathrm{~mL}$ scintillation vial equipped with a magnetic stir bar and a cap. The silver tetrafluoroborate, $\mathrm{AgBF}_{4}(13.7 \mathrm{mg}, 0.07 \mathrm{mmol})$, was added as a solid and the walls of the vial were rinsed with additional dichloromethane. The sample was stirred for 1.5 hours after which the sample was passed through Celite to remove the silver chloride and treated with an excess of sodium azide. The sample was stirred over-night after which it was passed through Celite to remove the sodium tetrafluoroborate. The pure, crystalline material was isolated by recrystallization from dichloromethane and pentane. ${ }^{1} \mathrm{H}$ NMR $\left(400 \mathrm{MHz}, \mathrm{CD}_{2} \mathrm{Cl}_{2}\right): \delta 7.69(\mathrm{~m}, 4 \mathrm{H}, \mathrm{o}-\mathrm{Ph}), \delta$ $7.45-7.50(\mathrm{~m}, 6 \mathrm{H}, m-P h, p-P h), \delta 4.85-5.06\left(\mathrm{dd}, 2 \mathrm{H},{ }^{3} \mathrm{~J}_{\mathrm{P}-\mathrm{H}}=5.6 \mathrm{~Hz}, \mathrm{~J}_{\mathrm{H}-\mathrm{H}}=3.3 \mathrm{~Hz}\right.$, COD-CH), ठ $2.87\left(\mathrm{q}, 2 \mathrm{H}, \mathrm{J}_{\mathrm{H}-\mathrm{H}}=3.3 \mathrm{~Hz}, \mathrm{COD}-\mathrm{CH}\right), \delta 2.57(\mathrm{~m}, 2 \mathrm{H}, \mathrm{PCH}), \delta 2.28(\mathrm{~m}, 2 \mathrm{H}$, COD-CH $\left.{ }_{2}\right), \delta 2.14\left(\mathrm{~m}, 2 \mathrm{H}, \mathrm{COD}-\mathrm{CH}_{2}\right), \delta$ 1.79-1.94 (m, 9H, BBN, COD-CH $)_{2}, \delta$ 1.57-1.74 (m, 7H, BBN, COD-CH $\mathrm{CH}_{2}, \delta 1.45-1.55(\mathrm{~m}, 2 \mathrm{H}, \mathrm{BBN}), \delta 0.70\left(\mathrm{~m}, 2 \mathrm{H}, \mathrm{CH}_{2} \mathrm{~B}\right) \cdot{ }^{13} \mathrm{C}\left\{{ }^{1} \mathrm{H}\right\} \mathrm{NMR}$ $\left(100 \mathrm{MHz}, \mathrm{CD}_{2} \mathrm{Cl}_{2}\right): \delta 134.2\left(\mathrm{~d}, 2 \mathrm{C},{ }^{2} \mathrm{~J}_{\mathrm{P}-\mathrm{C}}=10.0 \mathrm{~Hz}, \mathrm{o}-\mathrm{Ph}\right), \delta 132.0\left(\mathrm{~d}, 2 \mathrm{C},{ }^{1} \mathrm{~J}_{\mathrm{P}-\mathrm{C}}=48.8\right.$ $\mathrm{Hz}$, ipso-Ph), $\delta 131.1$ (d, 2C, $\left.{ }^{4} \mathrm{JP}_{\mathrm{P} C}=2.4 \mathrm{~Hz}, \mathrm{p}-\mathrm{Ph}\right), \delta 129.0\left(\mathrm{~d}, 2 \mathrm{C},{ }^{3} \mathrm{~J}_{\mathrm{P}-\mathrm{C}}=9.6 \mathrm{~Hz}\right.$, meta$\mathrm{Ph}), \delta 91.9\left(\mathrm{~d}, 2 \mathrm{C},{ }^{2} \mathrm{~J}_{\mathrm{P}-\mathrm{C}}=12.6 \mathrm{~Hz}, \mathrm{COD}-\mathrm{CH}\right), 59.5$ (s, 2C, COD-CH), $\delta 33.0$ (s, 2C, $B B N), \delta 33.1\left(\mathrm{~s}, 2 \mathrm{C}, \mathrm{COD}-\mathrm{CH}_{2}\right.$, trans- $P$ ), $\delta 33.1$ (s, 2C, COD-CH , trans-Cl), $\delta 32.9$ (s,

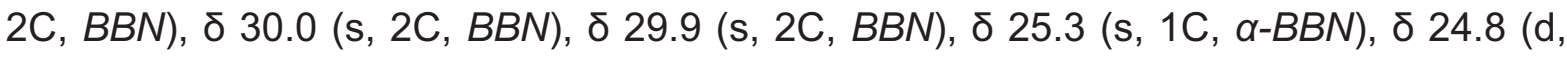
1C, ${ }^{1} \mathrm{JP}_{\mathrm{C}}=30.2 \mathrm{~Hz}, \mathrm{PCH}$ ), $\delta 25.3$ (br. s, 1C, $\left.\mathrm{CH}_{2} \mathrm{~B}\right) .{ }^{31} \mathrm{P}\left\{{ }^{1} \mathrm{H}\right\} \mathrm{NMR}\left(162 \mathrm{MHz}, \mathrm{CD}_{2} \mathrm{Cl}_{2}\right): \delta$ 10.8 (s). ${ }^{11} \mathrm{~B}\left\{{ }^{1} \mathrm{H}\right\}$ NMR (128 MHz, ds-toluene): $\delta 4.6$ (br. s). FTIR: $\mathrm{v}_{\text {as }} 2086 \mathrm{~cm}^{-1}$ (vs). 


\subsection{References}

(1) Hartwig, J. F. Organotransition Metal Chemistry: From Bonding to Catalysis; University Science Books, 2010.

(2) Mingos, D. M. P. J. Organomet. Chem. 2014, 751, 153.

(3) Kuzu, I.; Krummenacher, I.; Meyer, J.; Armbruster, F.; Breher, F. Dalton Trans. 2008, 5836 .

(4) Fontaine, F-G.; Boudreau, J.; Thibault, M. H. Eur. J. Inorg. Chem. 2008, 5439.

(5) Bouhadir, G.; Bourissou, D. Chem. Soc. Rev. 2016, 45, 1065.

(6) Tseng, K-N. T.; Kampf, J. W.; Szymczak, N. K. J. Am. Chem. Soc. 2016, 138, 10378.

(7) Tutusaus, O.; Ni, C.; Szymczak, N. K. J. Am. Chem. Soc. 2013, 135, 3403.

(8) Bouhadir, G.; Amgoune, A.; Bourissou, D. In Adv. Organomet. Chem.; Hill, A. F., Fink, M. J., Eds. 2010; Vol. 58, p 1.

(9) Miller, A. J. M.; Labinger, J. A.; Bercaw, J. E. Organometallics 2010, 29, 4499.

(10) Ostapowicz, T. G.; Merkens, C.; Hölscher, M.; Klankermayer, J.; Leitner, W. J. Am. Chem. Soc. 2013, 135, 2104.

(11) Bontemps, S.; Bouhadir, G.; Miqueu, K.; Bourissou, D. J. Am. Chem. Soc. 2006, $128,12056$.

(12) Fischbach, A.; Bazinet, P. R.; Waterman, R.; Tilley, T. D. Organometallics 2008, 27, 1135.

(13) Jana, R.; Blacque, O.; Jiang, Y.; Berke, H. Eur. J. Inorg. Chem. 2013, 3155.

(14) Huang, S-H.; Wang, X.; Richmond, M. G. J. Organomet. Chem. 2012, 700, 103.

(15) Vergnaud, J.; Grellier, M.; Bouhadir, G.; Vendier, L.; Sabo-Etienne, S.; Bourissou, D. Organometallics 2008, 27, 1140. 
(16) Miller, A. J. M.; Labinger, J. A.; Bercaw, J. E. J. Am. Chem. Soc. 2008, 130, 11874.

(17) Greenacre, V. K.; Ansell, M. B.; Roe, S. M.; Crossley, I. R. Eur. J. Inorg. Chem. 2014, 5053.

(18) Padial, J. S.; de Gelder, R.; Guerra, C. F.; Bickelhaupt, F. M.; Mecinović, J. Chemistry 2014, 20, 6268.

(19) Spies, P.; Erker, G.; Kehr, G.; Bergander, K.; Fröhlich, R.; Grimme, S.; Stephan, D. W. Chem. Commun. 2007, 5072.

(20) Bontemps, S.; Bouhadir, G.; Apperley, D. C.; Dyer, P. W.; Miqueu, K.; Bourissou, D. Chem. Asian J. 2009, 4, 428.

(21) Cowie, B. E.; Emslie, D. J. H.; Jenkins, H. A.; Britten, J. F. Inorg. Chem. 2010, 49, 4060.

(22) Vicente, J.; Gil-Rubio, J.; Bautista, D. Inorg. Chem. 2001, 40, 2636.

(23) Chen, S.; Manoury, E.; Poli, R. Eur. J. Inorg. Chem. 2014, 5820.

(24) Mantilli, L.; Gérard, D.; Besnard, C.; Mazet, C. Eur. J. Inorg. Chem. 2012, 3320.

(25) Abraham, R. J.; Byrne, J. J.; Griffiths, L.; Perez, M. Magn. Reson. Chem. 2006, $44,491$.

(26) Otto, S.; Roodt, A. Inorg. Chim. Acta. 2004, 357, 1.

(27) Serp, P.; Hernandez, M.; Richard, B.; Kalck, P. Eur. J. Inorg. Chem. 2001, 2327.

(28) Curtis, M. D.; Butler, W. M.; Greene, J. Inorg. Chem. 1978, 17, 2928.

(29) Ibers, J. A.; Snyder, R. G. Acta. Crystallogr. 1962, 15, 923.

(30) Dahl, L. F.; Martell, C.; Wampler, D. L. J. Am. Chem. Soc. 1961, 83, 1761.

(31) Bateman, L. R.; Maitlis, P. M.; Dahl, L. F. J. Am. Chem. Soc. 1969, 91, 7292. 
(32) Yang, L.; Powell, D. R.; Houser, R. P. Dalton Trans. 2007, 955.

(33) Okuniewski, A.; Rosiak, D.; Chojnacki, J.; Becker, B. Polyhedron 2015, 90, 47.

(34) Pregosin, P. S. NMR in Organometallic Chemistry; Wiley-VCH Verlay \& Co, 2012.

(35) Reichardt, C.; Welton, T. Solvents and Solvent Effects in Organic Chemistry, 4th Edition; Wiley-VCH Verlag GmbH \& Co. KGaA, 2011.

(36) Beckett, M. A.; Strickland, G. C.; Holland, J. R.; Varma, K. S. Polymer 1996, 37, 4629.

(37) Sivaev, I. B.; Bregadze, V. I. Coordin. Chem. Rev. 2014, 270, 75.

(38) Gutmann, V. Coordin. Chem. Rev. 1976, 18, 225.

(39) More experiments need to be conducted to further evaluate the dynamics of these complexes in solution.

(40) Berry, J. F. Comment Inorg. Chem. 2009, 30, 28.

(41) Jones, C. M.; Doherty, N. M. Polyhedron 1995, 14, 81.

(42) Sieh, D.; Burger, P. J. Am. Chem. Soc. 2013, 135, 3971.

(43) Sieh, D.; Schöffel, J.; Burger, P. Dalton Trans. 2011, 40, 9512.

(44) Schöffel, J.; Šušnjar, N.; Nuckel, S.; Sieh, D.; Burger, P. Eur. J. Inorg. Chem. 2010, 4911.

(45) Schöffel, J.; Rogachev, A. Y.; George, S. D.; Burger, P. Angew. Chem. Int. Ed. Engl. 2009, 48, 4734.

(46) Scheibel, M. G.; Wu, Y.; Stückl, A. C.; Krause, L.; Carl, E.; Stalke, D.; de Bruin, B.; Schneider, S. J. Am. Chem. Soc. 2013, 135, 17719. 
(47) Scheibel, M. G.; Askevold, B.; Heinemann, F. W.; Reijerse, E. J.; de Bruin, B.; Schneider, S. Nat. Chem. 2012, 4, 552.

(48) Gloaguen, Y.; Rebreyend, C.; Lutz, M.; Kumar, P.; Huber, M.; van der Vlugt, J. I.; Schneider, S.; de Bruin, B. Angew. Chem. Int. Ed. Engl. 2014, 53, 6814.

(49) Saouma, C. T.; Peters, J. C. Coordin. Chem. Rev. 2011, 255, 920.

(50) Atienza, C. C. H.; Bowman, A. C.; Lobkovsky, E.; Chirik, P. J. J. Am. Chem. Soc. 2010, 132, 16343.

(51) Busetto, L.; Palazzi, A.; Ros, R. Inorg. Chem. 1970, 9, 2792.

(52) Stephens, F. H.; Pons, V.; Baker, R. T. Dalton Trans. 2007, 2613.

(53) Giordano, G.; Crabtree, R. H. Inorg. Syn. 1990, 28, 88.

(54) van der Ent, A.; Onderdelinden, A. L. Inorg. Syn. 1990, 28, 90. 
CHAPTER 3

Application of Rhodium Metal Complexes Bearing $\beta$ Phosphinoethylborane Ligands to the Catalytic Hydroboration of Vinyl Arenes 


\subsection{Introduction}

The hydrofunctionalization of olefins represents an important and well-studied class of organometallic reactions that provides the chemistry community with versatile chemical compounds for synthesis. ${ }^{1}$ Transition metals catalysis opens up new reaction pathways that are different from standard organic reaction manifolds. As a result, understanding the bond activation of the $\mathrm{E}-\mathrm{H}$ bond by late transition metals remains of critical importance as it controls not only the reactivity, but the selectivity as well. ${ }^{2-5}$

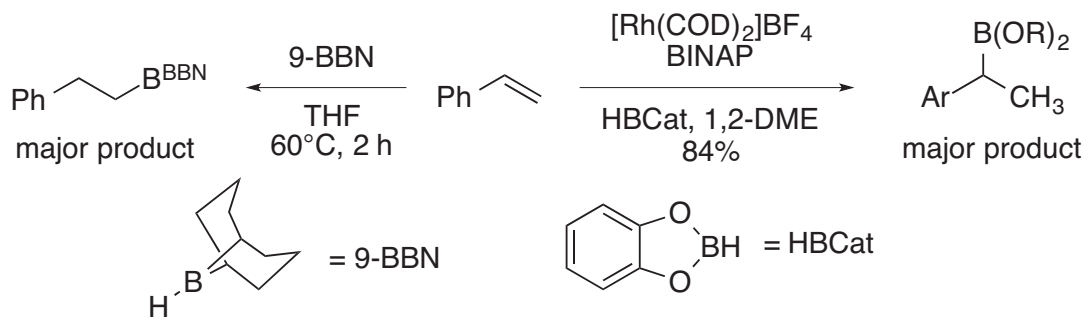

Scheme 3.1. Classical organic and Rh-catalyzed approach to the hydroboration of styrene.

One reaction that highlights that change in selectivity is hydroboration. The uncatalyzed hydroboration of vinyl arenes with boranes traditionally provides the antiMarkovnikov product as the only product. In the case of the transition-metal catalyzed approach with boronic esters, such as catecholborane (HBCat), the insertion typically occurs in a 2,1-fashion to yield the Markovnikov product as the major product (Scheme 3.1) ${ }^{6-11}$ However, pinacolborane (HBPin) remains the more synthetically relevant boronic ester due to its increased stability and ease of handling. ${ }^{7,12}$ In addition to the catecholborane product being very sensitive to oxidizing conditions, it readily decomposes in air to the corresponding alcohol or boronic acid making it difficult to isolate the products by silica gel flash column chromatography. Most importantly, HBCat is known to decompose in the presence of nucleophiles, ${ }^{12}$ such as triphenylphosphine, 
and rhodium(I) complexes, such as Wilkinson's complex (Scheme 3.2$)^{7}$ While all of these degradation pathways are problematic, the formation of various hydride complexes and hydroboration reagents $\left(\mathrm{HBCat}\right.$ and $\left.\mathrm{BH}_{3}\right)$ results in a loss of regioselectivity for the catalytic reaction. ${ }^{7}$ Since the ligand in these reactions is so critical for their selectivity and the overall lifetime of the catalyst, the side reactions that result from the reaction of free ligand with HBCat can lead to loss of selectivity and turnovers.

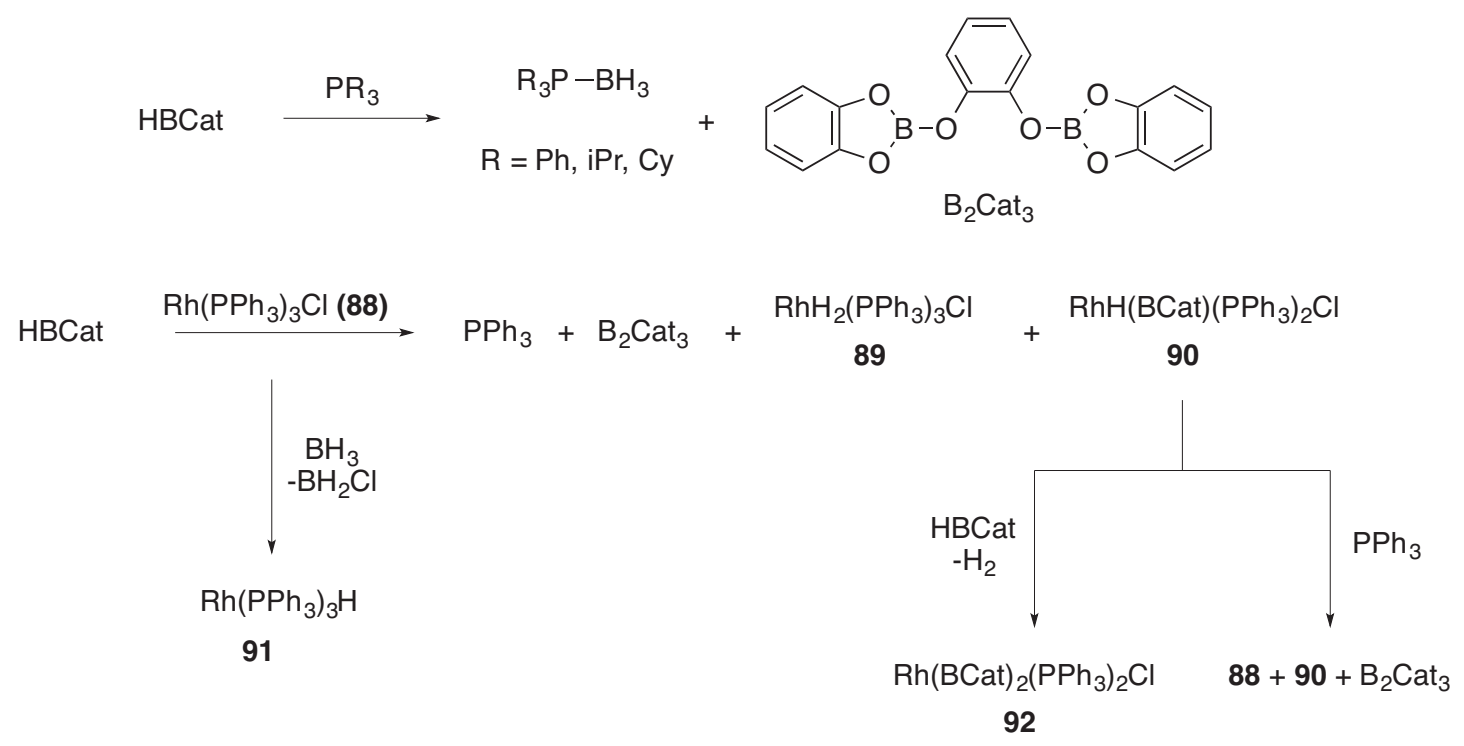

Scheme 3.2. Decomposition of HBCat in the presence of nucleophilic phosphine ligand (top) and Wilkinson's catalyst (bottom).

However, the use of HBPin as the hydroboration reagent is not without its issues. The use of pinacolborane typically provides multiple products in the Rh-catalyzed hydroboration of vinylic alkenes with the major product rarely being the Markovnikov addition product (Scheme 3.3). ${ }^{13,14}$ 


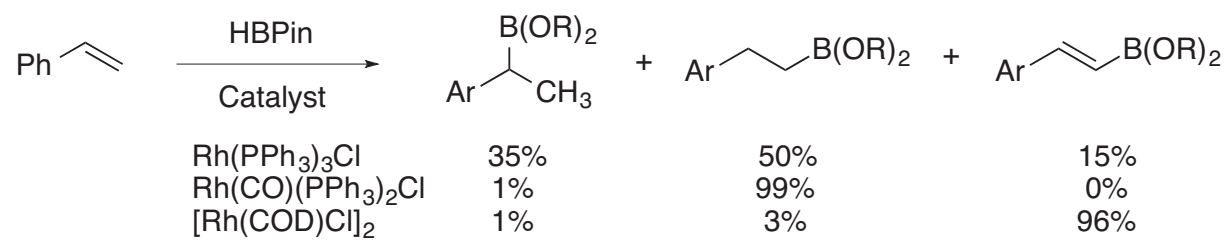

Scheme 3.3. Rhodium(I)-catalyzed hydroboration of vinyl arenes with pinacolborane utilizing commercially available transition-metal complexes.

Crudden and coworkers have demonstrated that by altering the cationic rhodium ligand environment with the appropriate phosphine ligands, the hydroboration of vinyl arenes was made possible in high selectivity for the Markovnikov addition product. $^{15}$ This reaction was extended to additional substrates and greatly accelerated through the addition of the strong Lewis acid $\mathrm{B}\left(\mathrm{C}_{6} \mathrm{~F}_{5}\right)_{3}$ as a co-catalyst (Scheme 3.4). ${ }^{16}$ Importantly, the $\mathrm{B}\left(\mathrm{C}_{6} \mathrm{~F}_{5}\right)_{3}$ will not catalyze the hydroboration of vinyl arenes by itself. ${ }^{17} \mathrm{~B}\left(\mathrm{C}_{6} \mathrm{~F}_{5}\right)_{3}$ is believed to activate HBPin to generate a borenium hydridoborate species, $\left[\mathrm{HB}\left(\mathrm{C}_{6} \mathrm{~F}_{5}\right)_{3}\right]\left[\mathrm{THF}-\mathrm{BP}\right.$ in]. The hydridoborate species $\left[\mathrm{HB}\left(\mathrm{C}_{6} \mathrm{~F}_{5}\right)_{3}\right]$ undergoes hydride transfer with the metal center to generate 94 . This reaction is followed by the oxidative addition of [THF-BPin] to produce rhodium species 95 . This cationic rhodium(III) species undergoes insertion and reductive elimination, by proceeding through species 96 , to generate the desired product and regenerate the active catalyst. The generation of borenium-ions is well studied in the literature and evidence of this species is seen typically seen by ${ }^{11} B\left\{{ }^{1} H\right\}$ NMR spectroscopy. ${ }^{16,18-25}$ 


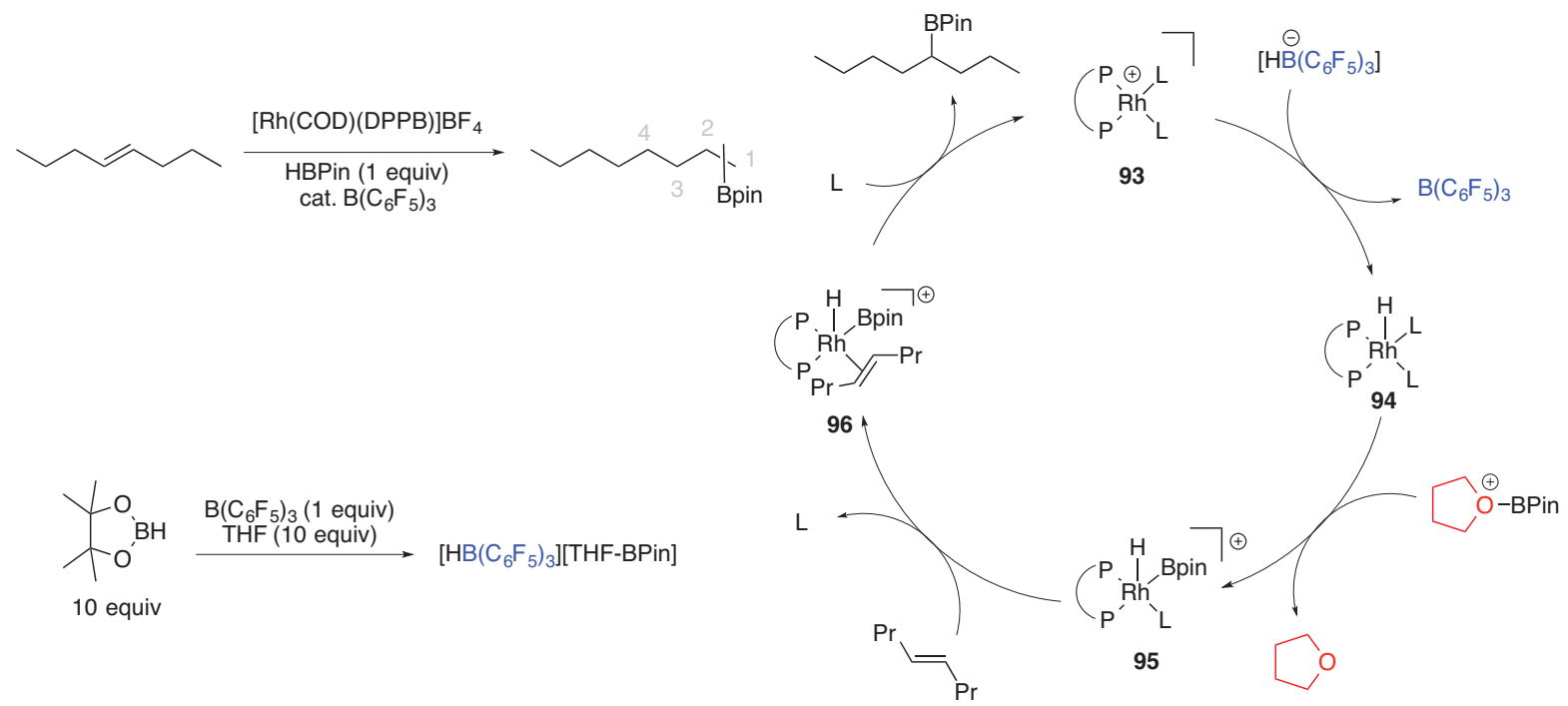

Scheme 3.4. Mechanism of hydroboration utilizing rhodium and Lewis acid catalysts that was proposed by Crudden and coworkers.

It is known that Lewis acidic borane functionalities will interact with molecules within the second coordination sphere. ${ }^{16,36,133}$ Herein, we seek to understand the role of the $\beta$-phosphinoethylborane late-transition metal complexes in $\mathrm{H}-\mathrm{H}$ and $\mathrm{H}-\mathrm{B}$ bond activations by applying Rh-complexes to the catalytic hydroboration of vinylic alkenes. The hypothesis is that rhodium complexes bearing phosphine ligands featuring pendant Lewis acids, discussed previously in Chapter 2, are capable of activating HBPin in a similar fashion as described by Crudden and coworkers. ${ }^{16}$ In addition to activating HBPin, these flexible, ambiphilic ligands were shown in Chapter 2 to interact with ligands in the primary coordination sphere of the metal-center. These interactions could alter reactivity within the coordination sphere of rhodium. The goal of this work is to use rhodium catalyzed hydroboration as a model system to understand the effect of pendant Lewis acids on catalysis. 


\subsection{Results and Discussion}

\subsubsection{Screening and Catalytic Activity of Group IX Transition Metal Complexes Bearing Phosphinoborane Ligands in the Hydroboration of Vinyl Arenes}

We began by screening conditions for the hydroboration of styrene with HBCat with the $\mathrm{Rh}(\mathrm{COD})\left[\mathrm{Ph}_{2} \mathrm{PCH}_{2} \mathrm{CH}_{2} \mathrm{~B}^{\mathrm{BBN}}\right] \mathrm{Cl}$ complex (Table 3.1). HBCat was chosen since it has been previously demonstrated to give high selectivity for the branched product. Based on the above results, it was determined that the reaction worked best in THF, while halogenated solvents, such as DCM and 1,2-DCE, gave large yields of undesired polystyrene byproduct (10 and $39 \%$, respectively). The use of 1,4-dioxane afforded lower yields of the desired branched product and higher yields of the diborylated sideproduct when compared to THF. The fact that THF is a better solvent than the DCM or the 1,2-DCE correlated well with the fact that the interaction observed in Figure 2.5 is stronger in THF than it is in lower donor number solvents, such as DCM or 1,2-DCE. 


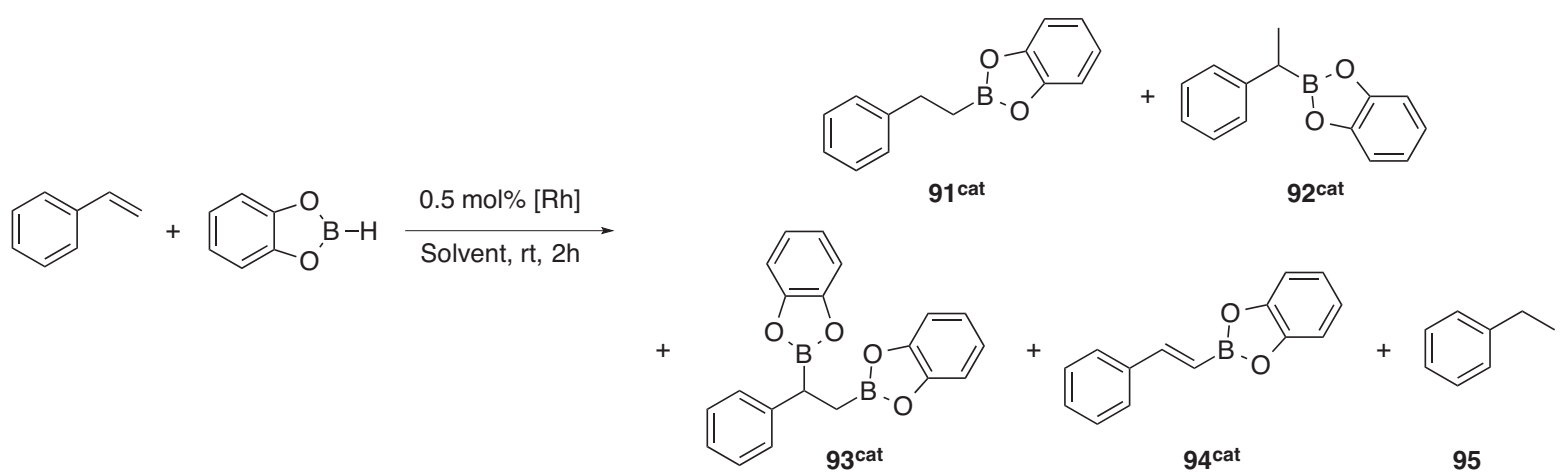

Table 3.1. Screening of solvents for the hydroboration of styrene with HBCat using $\mathrm{Rh}(\mathrm{COD})\left[\mathrm{Ph}_{2} \mathrm{PCH}_{2} \mathrm{CH}_{2} \mathrm{~B}^{\mathrm{BBN}}\right] \mathrm{Cl}$ complex 66 as the catalyst. ${ }^{\mathrm{b}}$

\begin{tabular}{|c|c|c|c|c|c|c|c|}
\hline \multirow{2}{*}{ Entry } & \multirow{2}{*}{ Solvent } & Conversion & \multicolumn{5}{|c|}{ Yield(\%) $^{\text {a }}$} \\
\cline { 4 - 8 } & & $(\%)$ & $91^{\text {cat }}$ & $92^{\text {cat }}$ & $93^{\text {cat }}$ & $94^{\text {cat }}$ & 95 \\
\hline 1 & THF & 100 & 45 & 29 & 0 & 4 & 29 \\
\hline 2 & DCM & 89 & 32 & 12 & 4 & 2 & 22 \\
\hline 3 & $1,2-$ DCE & 100 & 30 & 11 & 7 & 3 & 9 \\
\hline 4 & $1,4-$ Dioxane & 100 & 41 & 26 & 2 & 2 & 22 \\
\hline
\end{tabular}

${ }^{a 1} \mathrm{H}$ NMR spectroscopy using 1,3,5-trimethoxybenzene as the internal standard determined the yields of each of the products. ${ }^{6}$ Reactions conducted with $0.5 \mathrm{~mol} \%$ loading of $\mathrm{Rh}(\mathrm{COD})\left[\mathrm{Ph}_{2} \mathrm{PCH}_{2} \mathrm{CH}_{2} \mathrm{~B}^{\mathrm{BBN}}\right] \mathrm{Cl}$ with $70 \mu \mathrm{mol}$ in limiting reagent at room temperature under nitrogen.

Because undesired byproducts may arise from catalyst decomposition due to oxidation as originally reported by Evans and coworkers for Wilkinson's complex ${ }^{28}$, it was postulated that the addition of excess phosphinoborane ligand will lead to higher selectivity and prolonged catalyst lifetimes. It was postulated that the use of "aged" or decomposed Wilkinson's complex, produced upon exposure to oxygen, could lead to decreased regioselectivity for the branched isomer. ${ }^{28}$ In addition, catalyst speciation plays a critical role in the regioselectivity of a reaction. Thus, it is postulated that the addition of exogeneous ligand will achieve a more homogeneous mixture of catalyst species. As a result, we sought to explore different ratios of added exogenous ligand (Table 3.2), while simultaneously screening the rhodium(I) Vaska analog, $\mathrm{Rh}\left[\mathrm{Ph}_{2} \mathrm{PCH}_{2} \mathrm{CH}_{2} \mathrm{~B}^{\mathrm{BBN}}\right]_{2}(\mathrm{CO}) \mathrm{Cl}$. As seen in Table 3.2, the loading of ligand has a dramatic effect on the reactivity. When looking at the $\mathrm{Rh}(\mathrm{COD})$ phosphinoborane 
complex 66, an increase in loading of exogenous ligand increases the selectivity for desired branched product $\left(92^{\text {cat }}\right)$, while minimizing side-products. There is not nearly as dramatic a change when examining the rhodium(I) Vaska's complex analog. As a result, the remainder of the screening will occur with the addition of 5 equivalents or $2.5 \mathrm{~mol} \%$ of exogenous phosphinoborane ligand. In the case of Wilkinson's complex, Evans and coworkers observed that two equivalents of exogeneous ligand with respect to metal complex were sufficient to reestablish a $>99: 1$ regioselectivity for the branched isomer. ${ }^{28}$ These findings are consistent with other examples in the literature that demonstrate improved selectivity upon addition of phosphine ligand. ${ }^{29-31}$

Table 3.2. Screening of complexes and ligand loading for the hydroboration of styrene with HBCat. ${ }^{b}$

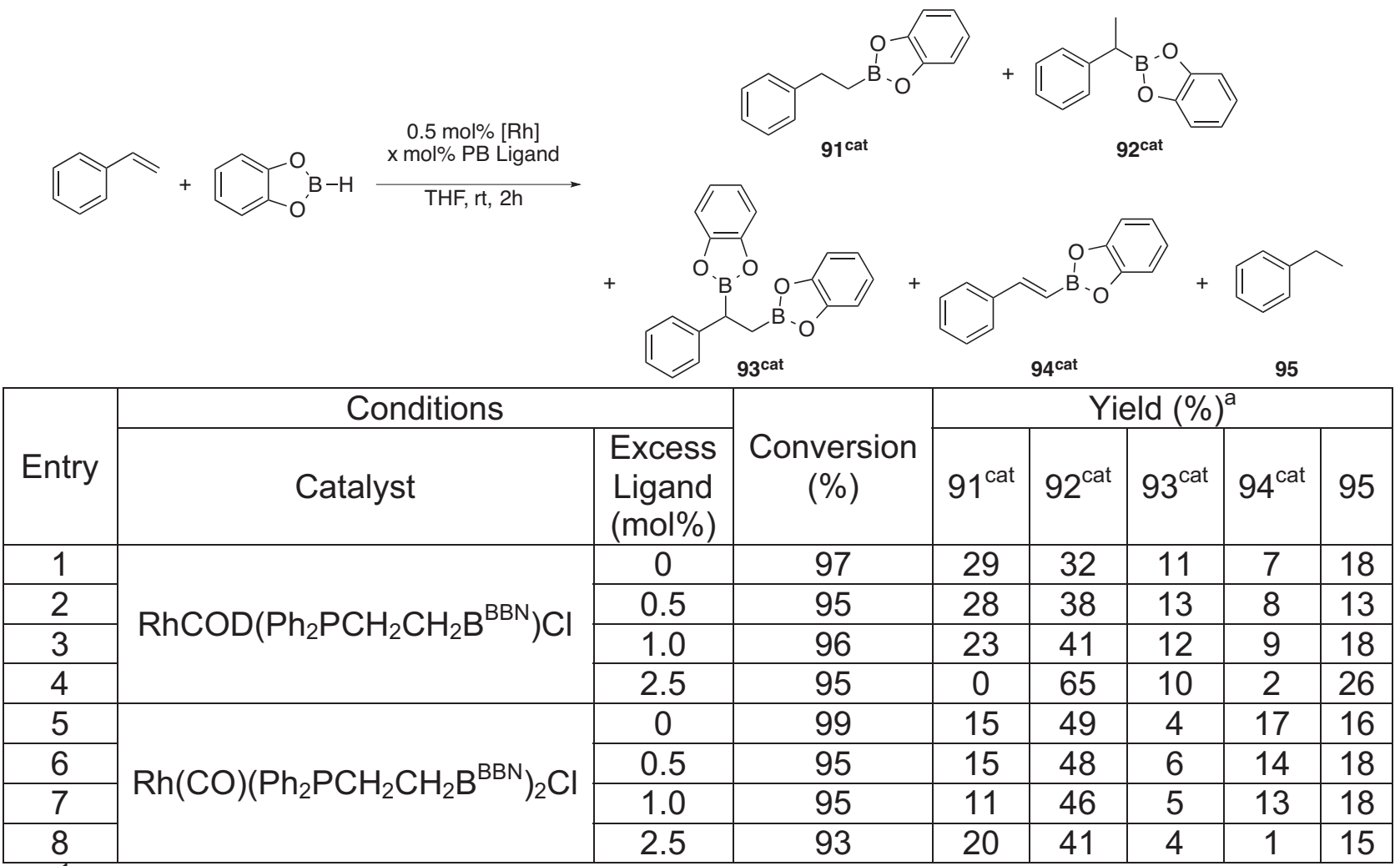

${ }^{\mathrm{a}} \mathrm{H}$ NMR spectroscopy using 1,3,5-trimethoxybenzene as the internal standard determined the yields of each of the products. ${ }^{b}$ Reactions conducted with $0.5 \mathrm{~mol} \%$ loading of $\mathrm{Rh}(\mathrm{COD})\left[\mathrm{Ph}_{2} \mathrm{PCH}_{2} \mathrm{CH}_{2} \mathrm{~B}^{\mathrm{BBN}}\right] \mathrm{Cl}$ with $70 \mu \mathrm{mol}$ in limiting reagent at room temperature under nitrogen. 
Despite the previous screening tables (3.1 and 3.2), the use of HBCat is less than ideal due to the sensitivity issues highlighted in Scheme 3.2. Thus, we were interested in determining how HBPin (Table 3.3) performed under the reaction conditions. The results shown in Table 3.3 demonstrate that HBPin is a less effective hydroboration reagent under the given conditions. Despite this, we were still interested in the use of HBPin over HBCat due to the sensitivity issues associated with HBCat. There is still promise in the results shown above since there is still no yield of the undesired linear product and only minimal side-reactions.

Table 3.3. Comparison of borane reagents for the hydroboration of styrene using $\mathrm{Rh}(\mathrm{COD})\left[\mathrm{Ph}_{2} \mathrm{PCH}_{2} \mathrm{CH}_{2} \mathrm{~B}^{\mathrm{BBN}}\right] \mathrm{Cl}$ as the catalyst. ${ }^{\mathrm{b}}$

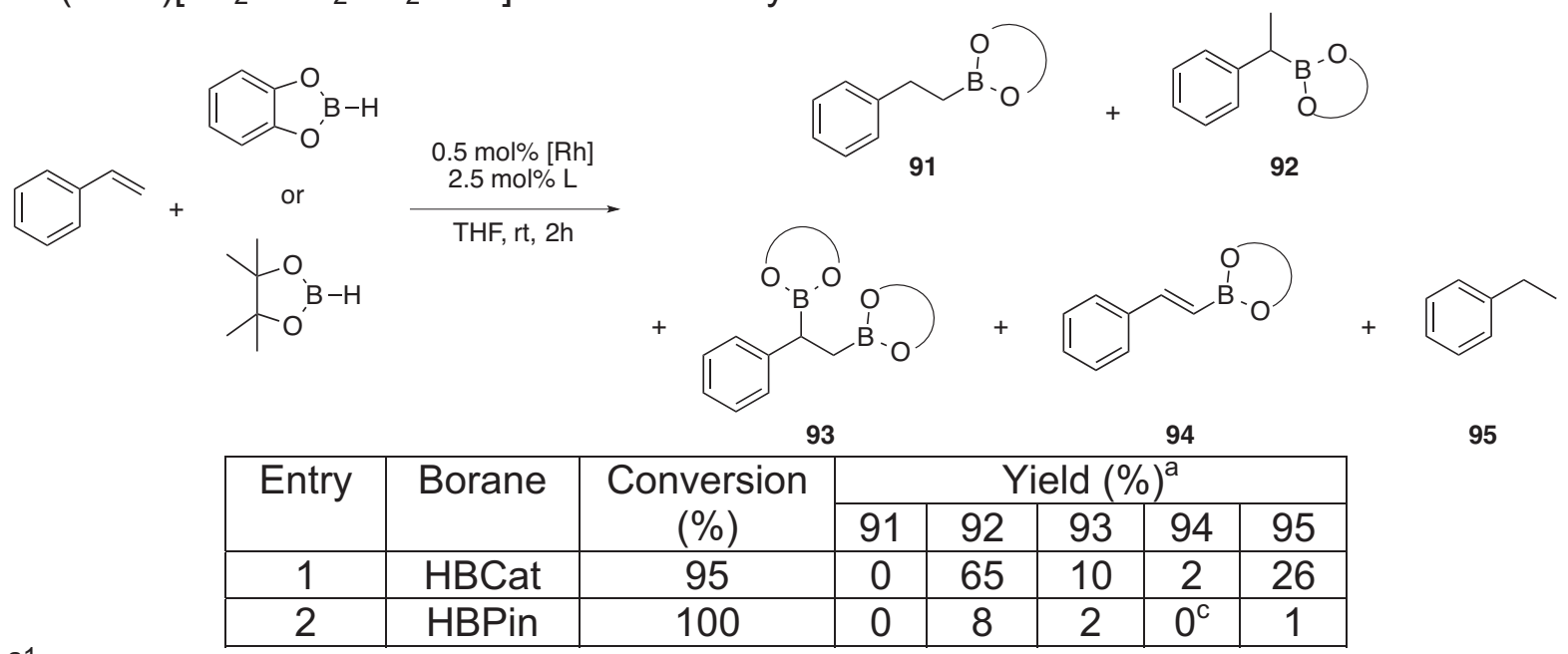

${ }^{\mathrm{a}} \mathrm{H}$ NMR spectroscopy using 1,3,5-trimethoxybenzene as the internal standard determined the yields of each of the products. ${ }^{b}$ Reactions conducted with $0.5 \mathrm{~mol} \%$ loading of $\mathrm{Rh}(\mathrm{COD})\left[\mathrm{Ph}_{2} \mathrm{PCH}_{2} \mathrm{CH}_{2} \mathrm{~B}^{\mathrm{BBN}}\right] \mathrm{Cl}$ with $70 \mu \mathrm{mol}$ in limiting reagent at room temperature under nitrogen. ${ }^{\mathrm{C}}$ Product is the dehydrogenative diborylation product.

Given the potential improvement of the reactivity by using cationic rhodium(I) metal centers, we sought to explore the role of different silver(I) salts on the hydroboration selectivity (Table 3.4). ${ }^{15,30,32,33}$ Silver(I) salts were chosen due to their propensity to generate cationic metal complexes via halide abstraction to form insoluble 
$\mathrm{AgCl}$. The addition of a silver salt bearing a non-coordinating anion, such as $\mathrm{AgBF}_{4}$, resulted in a slight decrease in the conversion and an improvement in the yield of the desired product from $8 \%$ to $19 \%$. When weakly coordinating counteranions are used, such as AgOTf, there is a further improvement in the yield of the desired product $(8 \%$ to $31 \%$ ). AgOTf provided the highest yield of desired product $92^{\text {pin }}$, while minimizing the undesired side-products. The use of the rhodium(I) Vaska's analog as the catalyst resulted in $41 \%$ yield of the desired product $92^{\text {pin }}$ and $20 \%$ yield of the linear product $91^{\text {pin }}$.

Table 3.4. Screening of different silver salts for the hydroboration of styrene with HBPin using the $\mathrm{Rh}(\mathrm{COD})\left[\mathrm{Ph}_{2} \mathrm{PCH}_{2} \mathrm{CH}_{2} \mathrm{~B}^{\mathrm{BBN}}\right] \mathrm{Cl}$ as the catalyst. ${ }^{\mathrm{C}}$

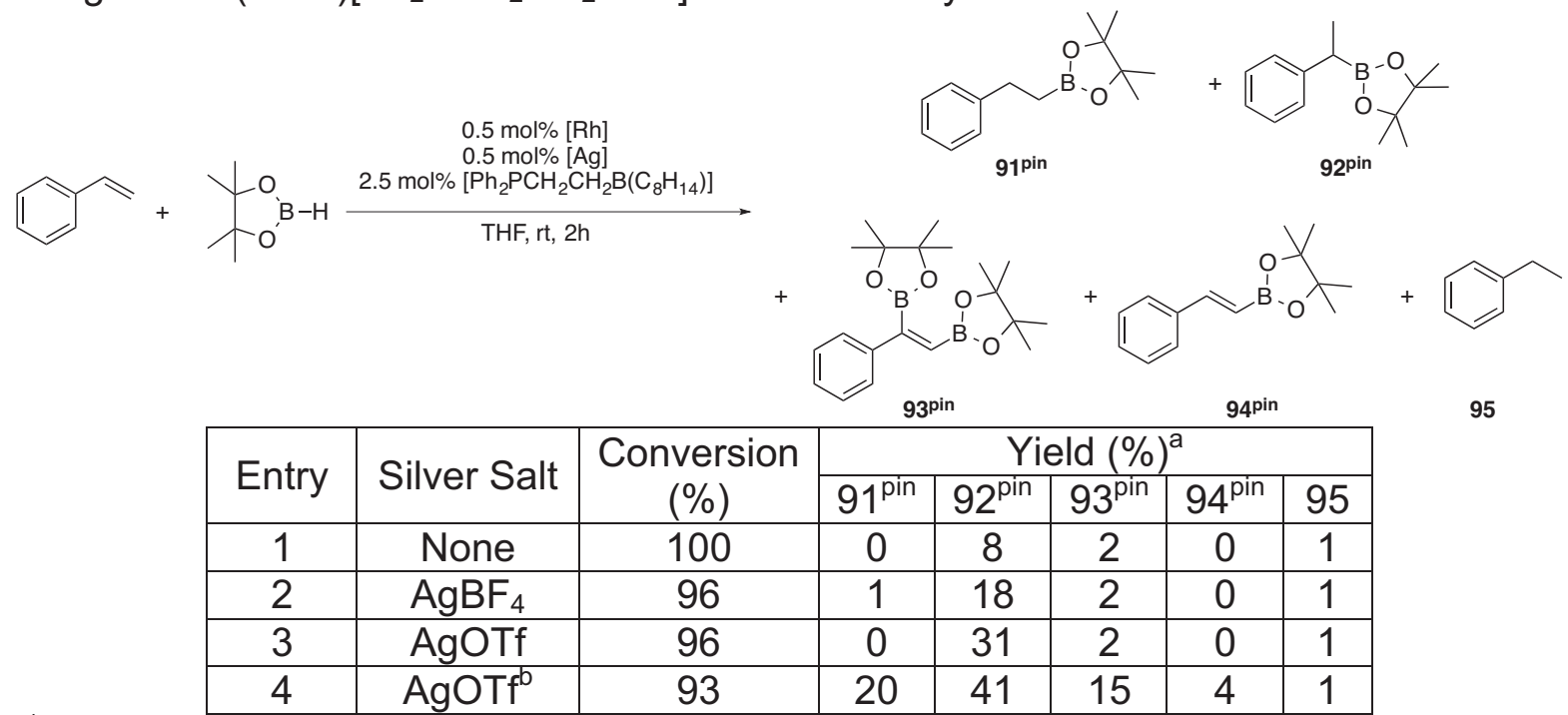

${ }^{a 1} \mathrm{H}$ NMR spectroscopy using 1,3,5-trimethoxybenzene as the internal standard determined the yields of each of the products. ${ }^{b} \mathrm{Rh}(\mathrm{CO})\left[\mathrm{Ph}_{2} \mathrm{PCH}_{2} \mathrm{CH}_{2} \mathrm{~B}\left(\mathrm{C}_{8} \mathrm{H}_{14}\right)\right]_{2} \mathrm{Cl}$ was used as the catalyst. ${ }^{\mathrm{C}}$ Reactions conducted with $0.5 \mathrm{~mol} \%$ loading of $\mathrm{Rh}(\mathrm{COD})\left[\mathrm{Ph}_{2} \mathrm{PCH}_{2} \mathrm{CH}_{2} \mathrm{~B}^{\mathrm{BBN}}\right] \mathrm{Cl}$ with $70 \mu \mathrm{mol}$ in limiting reagent at room temperature under nitrogen.

To further improve the yield of the desired reaction, we were interested in the effect of the borane to alkene ratio and whether going to borane-limiting conditions would yield the desired product in higher yields (Table 3.5). These conditions are beneficial in that the excess alkene can act as a ligand to occupy vacant coordination 
sites, which would help circumvent decomposition pathways and/or push the reaction toward product. The optimum conditions for the hydroboration of styrene with HBPin require working under borane-limiting conditions with 2 equivalents of styrene for every equivalent of borane. The linear hydroboration product was minimized along with the byproducts of diborylation and dehydrogenative borylation. The reactions that were conducted with a 5:1 and a 10:1 ratio of styrene to HBPin were comparable to the $2: 1$ ratio reaction, but to minimize the use of excess styrene the optimized conditions were chosen as the 2:1 ratio.

Table 3.5. Screening of different silver salts for the hydroboration of styrene with HBPin using the $\mathrm{Rh}(\mathrm{COD})\left[\mathrm{Ph}_{2} \mathrm{PCH}_{2} \mathrm{CH}_{2} \mathrm{~B}^{\mathrm{BBN}}\right] \mathrm{Cl}$ as the catalyst. ${ }^{\mathrm{b}}$

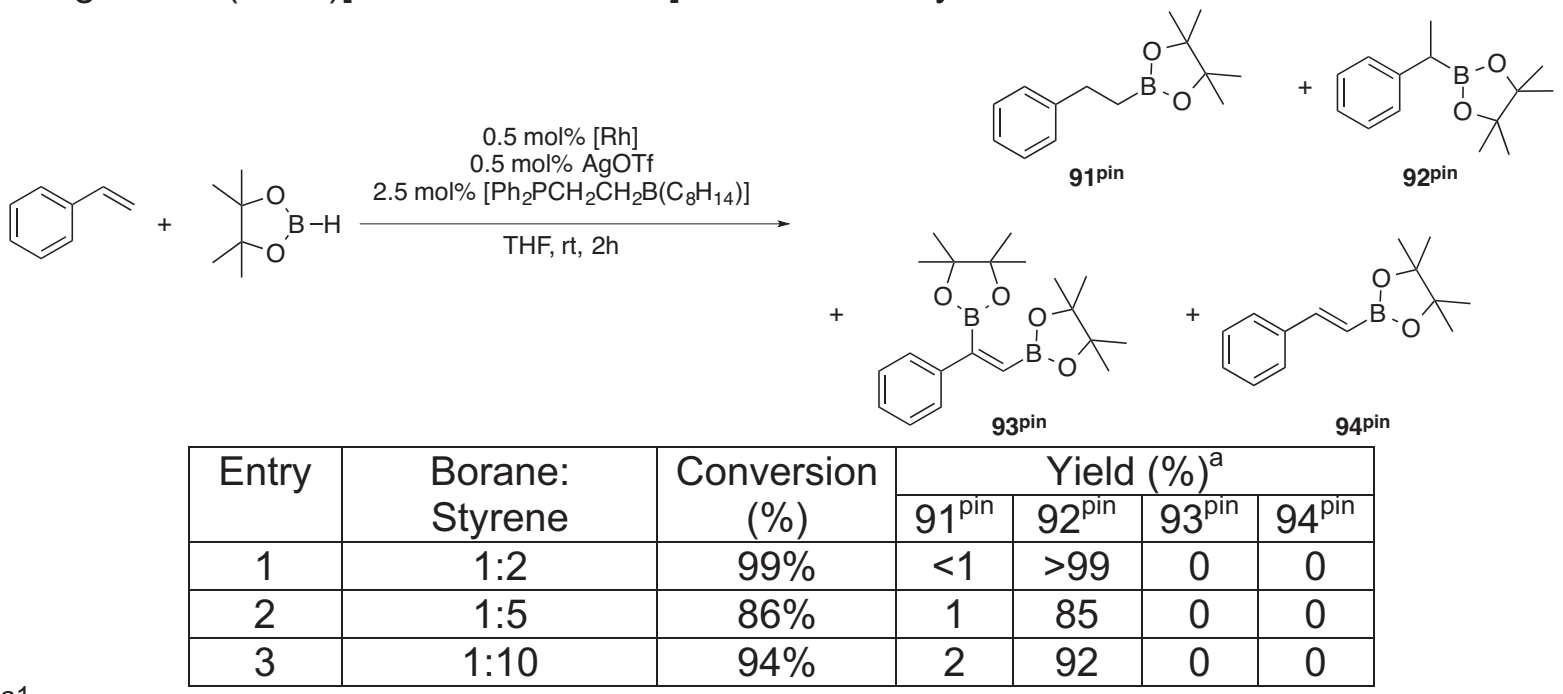

${ }^{\mathrm{a}} \mathrm{H}$ NMR spectroscopy using 1,3,5-trimethoxybenzene as the internal standard determined the yields of each of the products. ${ }^{b}$ Reactions conducted with $0.5 \mathrm{~mol} \%$ loading of $\mathrm{Rh}(\mathrm{COD})\left[\mathrm{Ph}_{2} \mathrm{PCH}_{2} \mathrm{CH}_{2} \mathrm{~B}^{\mathrm{BBN}}\right] \mathrm{Cl}$ with $70 \mu \mathrm{mol}$ in limiting reagent at room temperature under nitrogen.

When $\mathrm{Rh}\left(\mathrm{PPh}_{3}\right)_{3} \mathrm{Cl}$ and $\mathrm{Rh}\left(\mathrm{PPh}_{3}\right)_{2}(\mathrm{CO}) \mathrm{Cl}$ were used as the catalyst, the predominant product that was obtained was the linear hydroboration product. ${ }^{13}$ When $[\mathrm{Rh}(\mathrm{COD}) \mathrm{Cl}]_{2}$ was used, the linear dehydrogenative borylation product was the major product. ${ }^{14}$ Additionally when $\mathrm{PPh}_{3}$ was used as a ligand along with $\left[\mathrm{Rh}(\mathrm{COD})_{2}\right] \mathrm{BF}{ }_{4}$, a 
ratio of $80: 13$ (branched product : linear product) was obtained along with some dehydrogenative borylation side product. $^{15}$ 


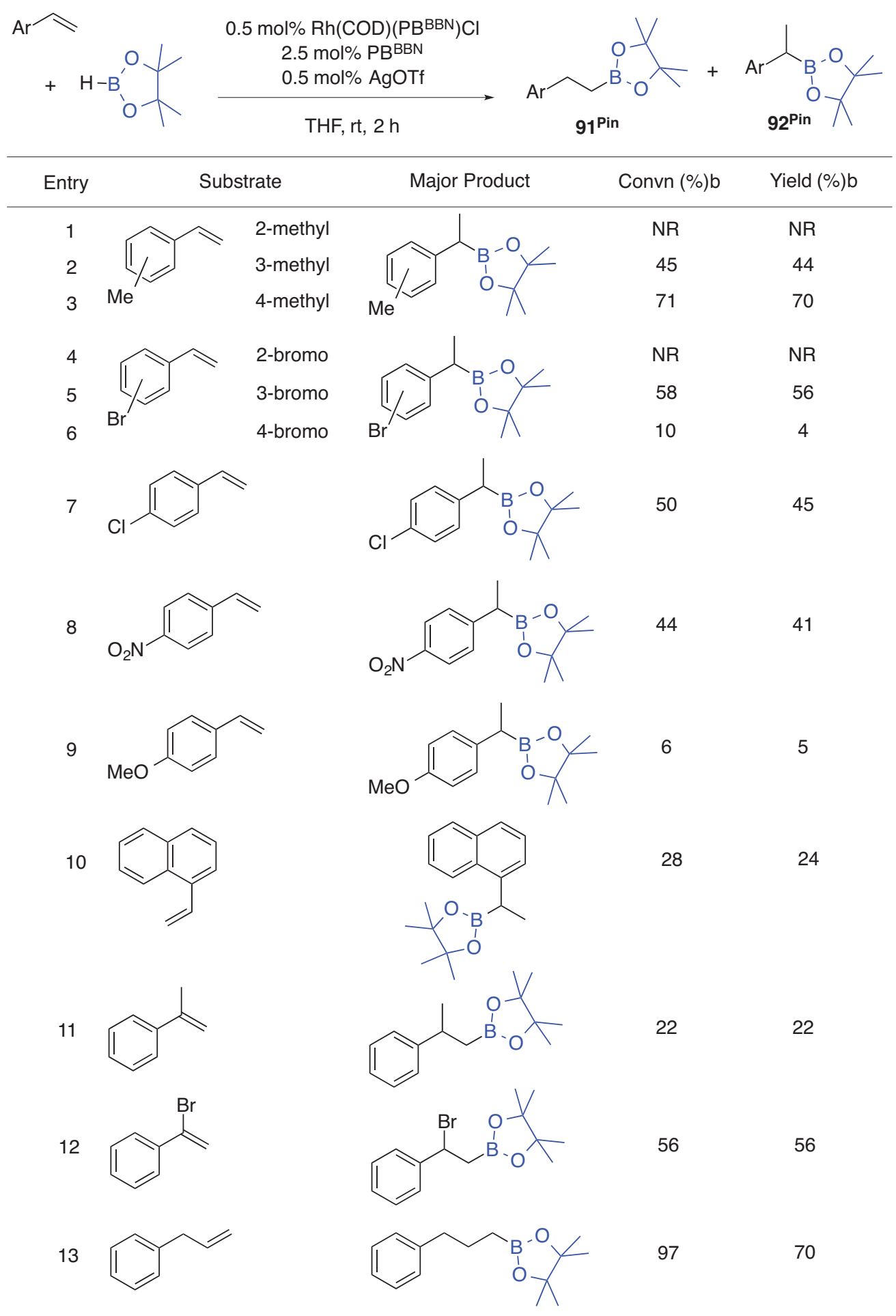

Table 3.6. Substrate scope for the hydroboration of olefins with HBPin using $0.5 \mathrm{~mol} \%$ $\mathrm{Rh}(\mathrm{COD})\left[\mathrm{Ph}_{2} \mathrm{PCH}_{2} \mathrm{CH}_{2} \mathrm{~B}^{\mathrm{BBN}}\right] \mathrm{Cl}$ as the catalyst with $2.5 \mathrm{~mol} \%$ of exogenous ligand and $0.5 \mathrm{~mol} \%$ of AgOTf. ${ }^{1} \mathrm{H}$ NMR spectroscopy using 1,3,5-trimethoxybenzene as the internal standard determined the yields of each of the products. 
Carbonyl-containing substrates ( $\mathrm{N}$-vinylpyrrolidone, ethyl acetate and N,Ndimethylacrylamide) resulted in either no reaction or no formation of desired product by NMR spectroscopy. These substrates can undergo competing formal reduction to the corresponding alcohol. ${ }^{34}$ In the case of $\mathrm{N}, \mathrm{N}$-dimethylacrylamide, no vinylic ${ }^{1} \mathrm{H}$ signals were observed after the completion of the reaction however, polymerized starting material was observed. Styrene derivatives substituted with a methyl group gave higher conversion for the para-substituted substrate when compared to the meta-substituted. There was no reaction observed when the ortho-substituted substrate was used (entries $1-3)$. In the case of the bromo-derivitized styrenyl substrates, the meta-position gave higher conversion and selectivites than the para-substituted substrate. Once again, the ortho-substituted substrate did not react (entries $4-6$ ). The 4-chlorostyrene (entry 7 ) and 4-nitrostyrene (entry 8) gave moderate conversion and high selectivity for branched product $92^{\text {pin }}$. The 4-methoxystyrene (entry 9) gave very low conversion under the optimized reaction conditions. The vinylnaphthalene (entry 10) gave low conversion and moderately high selectivity for branched product $92^{\text {pin }}$. When $\alpha$-substituted styrenes (entry 11 and 12) were utilized low to moderate conversions and high selectivities were observed for linear product $\mathbf{9} 1^{\mathrm{pin}}$. This trend is expected given that BPin is a large and sterically bulky function group and as a result provides steric interactions with $\alpha-$ substituted substrates. When allylbenzene (entry 13) was utilized as the substrate, the reaction gave linear product as the major product, as well as isomerized starting material, $\beta$-methylstyrene.

In order to further probe the mechanism of this reaction, we investigated transitional metal hydrides formed during reaction of HBPin and the rhodium(I) pre- 
catalysts to determine if pendant Lewis acids are involved in additional steps beyond $\mathrm{H}$ BPin activation. Rh(COD) phosphinoborane chloride complex was treated with AgOTf and then HBPin, resulting in a complex mixture of several hydride signals (Figure 3.3). The presence of several different hydride signals despite the formation of only one major product in the reaction led us to re-evaluate the reaction.

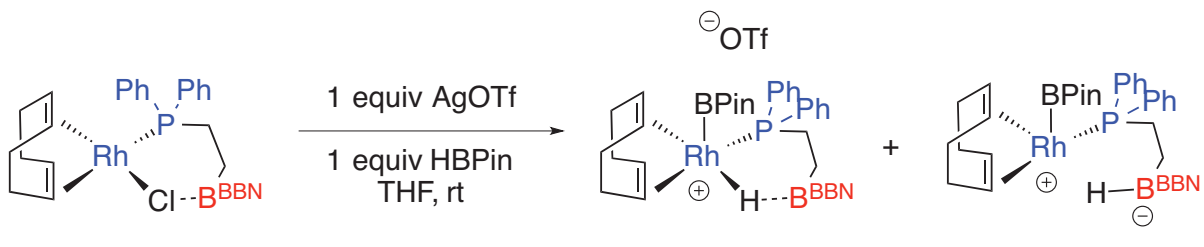

93

94

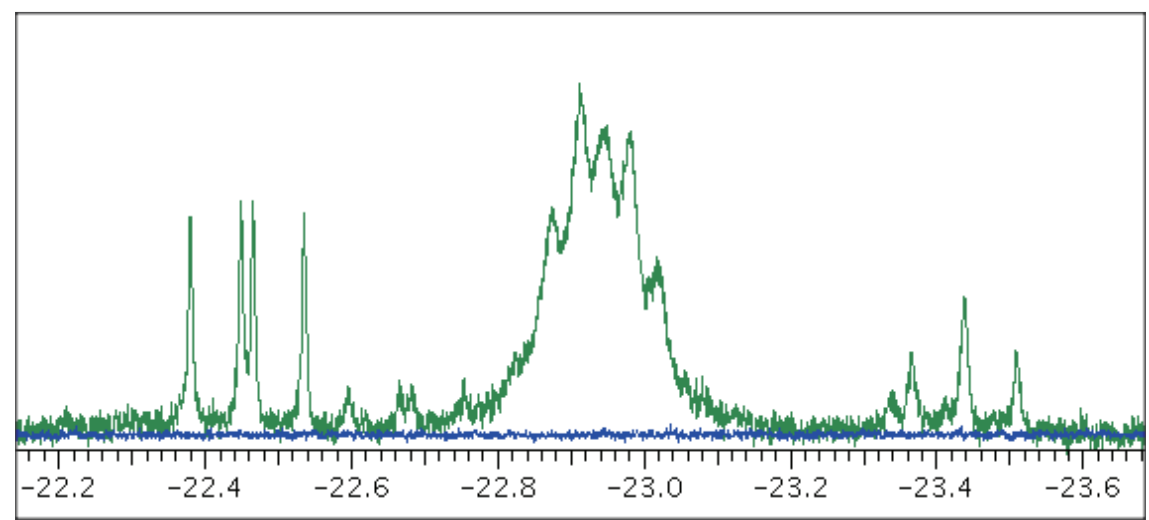

Figure 3.1. Upfield shifted ${ }^{1} \mathrm{H}$ NMR spectra of the reaction of rhodium(I) phosphinoborane complex 66 with AgOTf and HBPin in $\mathrm{d}_{6}$-benzene (light). Dark spectra is that of the $\mathrm{Rh}(C O D)$ phosphinoborane triflate complex in $\mathrm{d}_{6}$-benzene without HBpin.

Under the chosen reaction conditions, 5 equivalents of excess ligand was added to the pre-generated $\mathrm{Rh}(\mathrm{COD})$ phosphinoborane chloride complex. Treatment of $[\mathrm{Rh}(\mathrm{COD}) \mathrm{Cl}]_{2}$ with several equivalents of $\mathrm{PPh}_{3}$ and $\mathrm{HBCat}$ results in the generation of $\mathrm{Rh}\left(\mathrm{PPh}_{3}\right)_{3} \mathrm{Cl}$, which results from hydroboration of cyclooctadiene ligands and coordination of phosphines to the rhodium(I) metal center. ${ }^{9,35}$ Therefore, we investigated with reaction of HBPin with the rhodium $(\mathrm{I})$ phosphinoborane chloride dimer and the rhodium(I) WIkinson's analog bearing the phosphinoborane ligand (Figure 3.4). 

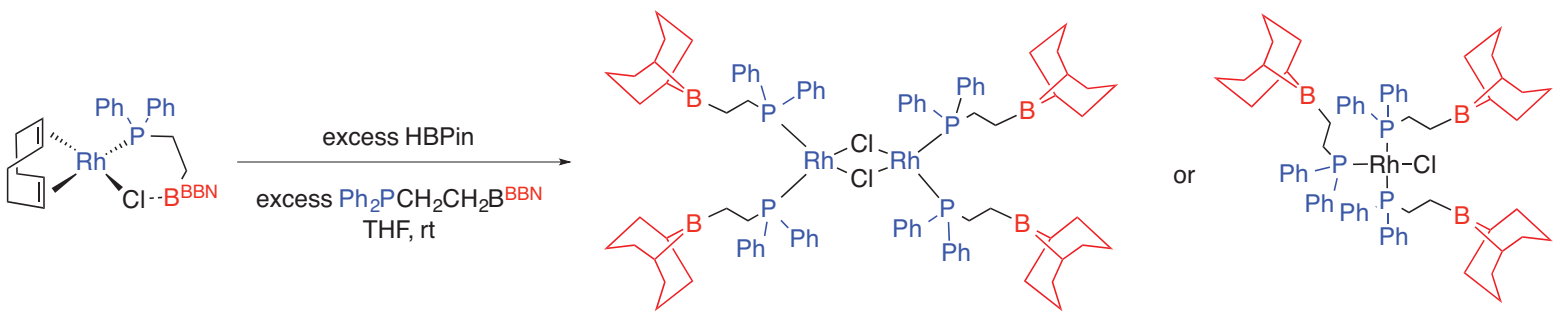

Scheme 3.5. Proposed in-situ generation of the phosphinoborane rhodium(I) dimer 74 and Wilkinson's analog.

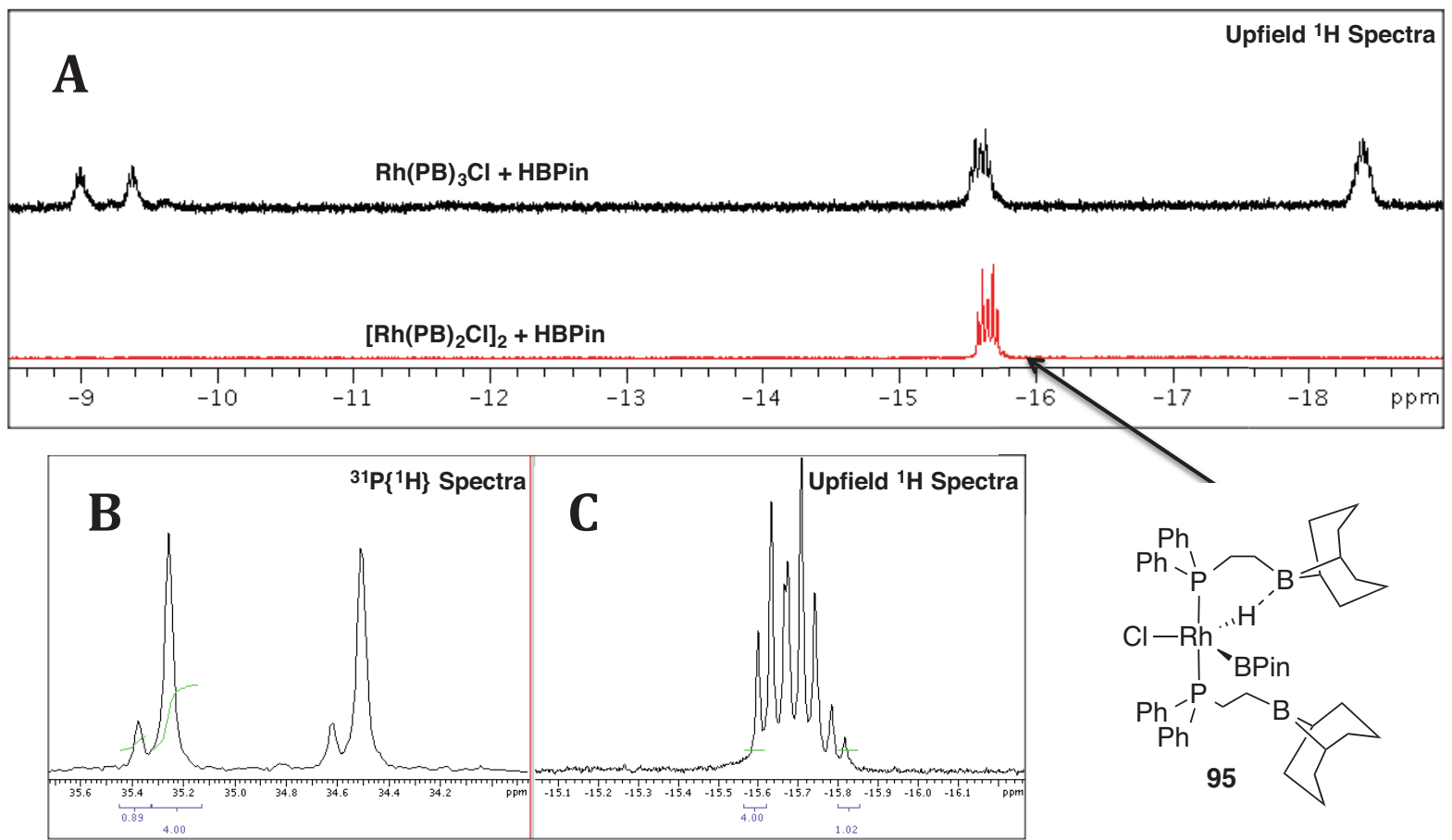

Figure 3.2. A) Reaction of the Wilkinson's analog (top) and bis(phosphinoborane) rhodium(I) dimer 74 (bottom) with HBPin. B) ${ }^{31} \mathrm{P}\left\{{ }^{1} \mathrm{H}\right\}$ NMR spectra of reaction between bis(phosphinoborane) rhodium(I) dimer 74 and HBPin. C) Zoomed in spectra of hydride region of reaction between bis(phosphinoborane) rhodium(I) dimer $\mathbf{7 4}$ and HBPin.

The reaction of the phosphinoborane rhodium $(\mathrm{I})$ chloride dimer with HBPin in $\mathrm{d}_{6^{-}}$ benzene and 2-3 drops of THF shows the formation of one hydride signal that is displayed in the inset spectra as a doublet of triplets. The observed coupling pattern for the hydride is consistent with coupling to the rhodium and the two symmetric phosphines, hereby giving a doublet of triplets. The J-coupling values of $30.1 \mathrm{~Hz}\left({ }^{1} \mathrm{~J}_{\mathrm{Rh}-\mathrm{H}}\right)$ and $13.2 \mathrm{~Hz}\left({ }^{2} \mathrm{~J}_{\mathrm{P}-\mathrm{H}}\right)$ are consistent with that previously reported in the literature. ${ }^{4}$ This is 
in agreement with previously reported structures of complexes that have the BPin, hydride and chloride ligands in a plane and two axial phosphine ligands to generate a complex with trigonal bipyramidal geometry (Scheme 3.6). ${ }^{4}$ This spectrum also features a second doublet of triplets that lies underneath the major hydride signal. This observation was confirmed by conducting the ${ }^{1} \mathrm{H}\left\{{ }^{31} \mathrm{P}\right\}$, which revealed the presence of two doublets. The smaller doublet is in an 80:20 ratio with respect to the major hydride signal. The presence of hydride signals in this ratio is indicative of an ${ }^{1} \Delta^{10 / 11} \mathrm{~B}\left({ }^{1} \mathrm{H}\right)$ isotope induced chemical shift. ${ }^{36-38}$ In fact, this phenomena was observed by Klankermayer, Leitner and coworkers for a ruthenium(II) hydride complex bearing this same phosphinoborane ligand. ${ }^{39}$ The presence of this ratio is indicative of a weak interaction between the borane and the hydride, where the equilibrium associated with this interaction lies closer to the three-coordinate borane. ${ }^{39}$ When this complex was treated with styrene in the absence of AgOTf, no product was observed. This is in agreement with the screening data that suggests that AgOTf is necessary for the hydroboration reaction to turnover. When this same reaction was conducted with AgOTf, both linear and branched product was formed from the reaction. Since this stoichiometric reaction was conducted with no exogenous phosphine ligand, this result is in agreement with the screening results that suggest that excess ligand is necessary for control over the regioselectivity of the reaction.

In the case of the reaction between the Wilkinson's analog and HBPin, the bis(phosphine) rhodium(III) hydride complex discussed above was observed, which would be consistent with the propensity of rhodium(I) tris(phosphine) complexes to decoordinate phosphine ligands. The two additional hydride signals correspond to the 
dihydride rhodium(III) tris(phosphinoborane) chloride complex and was confirmed by reaction of $\mathrm{H}_{2}$ with Wilkinson's analog (Figure 3.5).

Once again as was seen with the HBPin reaction described above, the reaction of the Wilkinson's analog shows an isotope induced chemical shift for the hydride signal around $\delta-9 \mathrm{ppm}$, but not the hydride signal at $\delta-18.5 \mathrm{ppm}$. The hydride signal at $\delta-9$ ppm can be assigned based on the literature to the hydride that is trans to the axial phosphine, whereas the signal at $\delta-18.5 \mathrm{ppm}$ corresponds to the hydride that is trans to the chloride ligand. ${ }^{5}$ This is consistent with an octahedral rhodium(III) complex containing one weak borane hydride interaction (Scheme 3.6). The observation that the reaction of HBPin with the Wilkinson's analog results in a dihydride complex is in agreement with the experimental result that the major non-boron containing product is ethylbenzene, which is the hydrogenation product of styrene. 

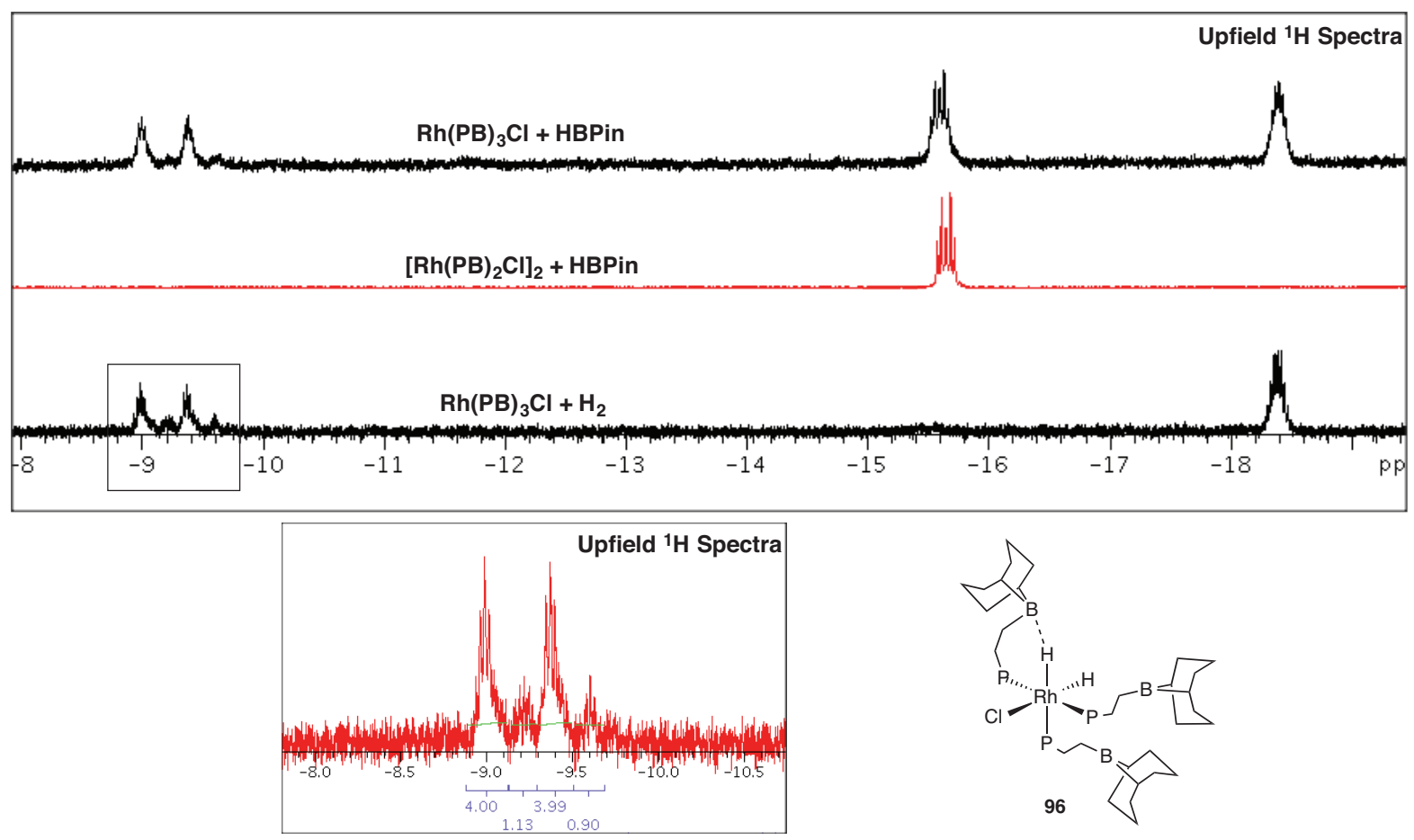

Figure 3.3. Reaction of the Wilkinson's analog with HBPin (top), bis(phosphinoborane) rhodium(I) dimer 74 and HBPin (middle) and Wilkinson's analog with $\mathrm{H}_{2}$ (bottom). Inset represents a zoomed in view of boxed hydride signal in the bottom spectra.
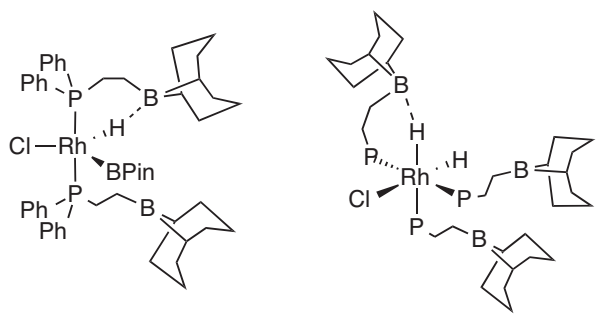

Scheme 3.6. Proposed structure of the product of the reaction of the phosphinoborane rhodium(I) dimer 74 with HBPin (95) (left) and the Wilkinson's analog with $\mathrm{H}_{2}$ (96) (right). 
In order to test the hypothesis that the ${ }^{10} \mathrm{~B} /{ }^{11} \mathrm{~B}$ isotopic chemical shift is not due to the BPin moiety in these complexes, a control experiment was conducted. The control experiment involved the reaction of $\mathrm{HBPin}$ with the $\left[\mathrm{Rh}\left(\mathrm{PPh}_{3}\right)_{2} \mathrm{Cl}\right]_{2}$ under the same reaction conditions as that of the phosphinoborane containing rhodium(I) chloride dimer 74 (Figure 3.6).

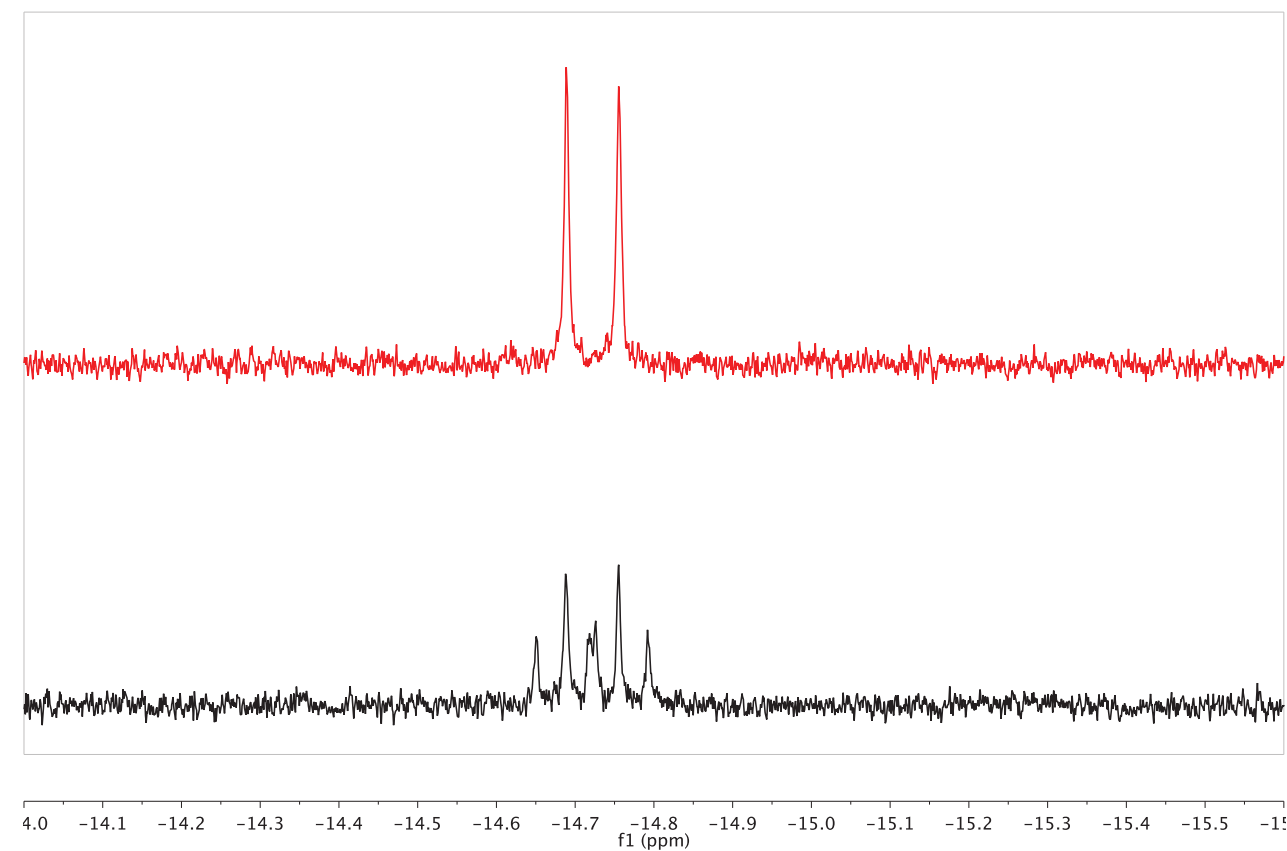

Figure 3.4. Reaction of $\left[\mathrm{Rh}\left(\mathrm{PPh}_{3}\right)_{2} \mathrm{Cl}\right]_{2}$ with HBPin showing the ${ }^{1} \mathrm{H}\left\{{ }^{31} \mathrm{P}\right\} \mathrm{NMR}$ (top) and the ${ }^{1} \mathrm{H}$ NMR (bottom) of the upfield (hydride) region of the NMR.

Upon investigation of the upfield (hydride region) of the ${ }^{1} \mathrm{H}$ NMR spectrum, it was discovered that only one doublet of triplets was present. This was confirmed by conducting the ${ }^{1} \mathrm{H}\left\{{ }^{31} \mathrm{P}\right\}$ NMR spectrum, which showed one doublet was present, as a result of ${ }^{1} J_{\mathrm{Rh}-\mathrm{H}}$ coupling. Since only one doublet was present, the $\mathrm{B}^{\mathrm{BBN}}$ was likely responsible for the ${ }^{10} \mathrm{~B} /{ }^{11} \mathrm{~B}$ isotope induced chemical shift, rather than the $\mathrm{Rh}$-bound BPin ligand. 


\subsection{Conclusion}

The conditions for utilizing phosphinoborane containing rhodium(I) complexes as catalysts for the hydroboration of vinyl arenes were optimized to give the branched hydroboration product as the sole, major boron containing product. Under the optimized conditions, the linear hydroboration, diborylation and dehydrogenative borylation were reduced to $<1 \%$. Under these same conditions, HBCat gave $88 \%$ yield of the desired branched product with the remainder of the yield being dehydrogenative linear hydroboration and the diborylation product.

Upon further investigation of the reaction mechanism, it was determined that the reaction conditions allowed for the in-situ generation of either the phosphinoborane rhodium(I) chloride dimer or the Wilkinson's analog. The stoichiometric reaction of HBPin with both revealed the presence of isotope induced chemical shifts that are consistent with weak borane hydride interactions. It was also determined that the octahedral dihydride complex is generated by reaction of HBPin with Wilkinson's analog, which explains the formation of ethylbenzene as the sole, major non-boron containing byproduct.

This investigation into the reactivity and the mechanism allows for the future development of more efficient and active catalytic systems. This type of catalyst architecture could be envisioned to bear chiral Lewis acids that can impart selectivity over the insertion of the alkene and lead to active enantioselective hydrofunctionalization processes. 


\subsection{Methods}

\subsubsection{General Considerations}

The manipulation of air- and moisture-sensitive compounds was conducted and performed under a nitrogen atmosphere utilizing either standard Schlenk or glove box techniques, employing dry solvent and glassware. Glovebox experiments were carried out in a MBraun 200B dual-port inert atmosphere glovebox equipped with a $-40^{\circ} \mathrm{C}$ freezer. Dry solvents were obtained utilizing a glass contour solvent purification system and stored in the glovebox over $4 \AA$ molecular sieves. Deuterated solvents were obtained from Cambridge Isotope Laboratories, Inc. and passed through neutral alumina and stored over $4 \AA$ molecular sieves. In the event that NMR data was recorded in non-deuterated NMR solvent, an internal capillary was used that was charged with $d_{6}$-benzene and sealed by flame. NMR spectra were recorded on either a $400 \mathrm{MHz}$ Agilent or a $600 \mathrm{MHz}$ Varian Inova NMR. Spectra were referenced to residual protio-solvent peaks as an internal standard for ${ }^{1} \mathrm{H}$ and ${ }^{13} \mathrm{C}$. The ${ }^{31} \mathrm{P}$ NMR was referenced to an external $\mathrm{H}_{3} \mathrm{PO}_{4}$ standard and the ${ }^{11} \mathrm{~B}$ and ${ }^{19} \mathrm{~F}$ NMR was referenced to an external $\mathrm{BF}_{3} \cdot \mathrm{OEt}_{2}$ standard. The phosphinoborane ligand ${ }^{40,41},[\mathrm{Rh}(\mathrm{COD}) \mathrm{Cl}]_{2}{ }^{42}$ and $\left[\mathrm{Rh}(\mathrm{COE})_{2} \mathrm{Cl}\right]_{2}^{43}$ were prepared according to previously published methods. The $\mathrm{Rh}(\mathrm{COD})\left[\mathrm{Ph}_{2} \mathrm{PCH}_{2} \mathrm{CH}_{2} \mathrm{~B}^{\mathrm{BBN}}\right] \mathrm{Cl}$ and $\mathrm{Rh}(\mathrm{CO})\left[\mathrm{Ph}_{2} \mathrm{PCH}_{2} \mathrm{CH}_{2} \mathrm{~B}^{\mathrm{BBN}}\right]_{2} \mathrm{Cl}$ were prepared by modification of literature procedures. ${ }^{44}$

\subsubsection{General Procedure for Hydroboration of Vinyl Arenes}

A sample of $0.5 \mathrm{~mol} \%$ loading for the $\mathrm{Rh}(\mathrm{COD})$ complex is dissolved in THF, along with the internal standard 1,3,5-trimethoxybenzene, in a small vial equipped with a Teflon cap. One equivalent of silver (I) triflate is added and the sample is stirred for 
$30-40$ minutes. A sample of 5 equivalents of excess phosphinoborane ligand is added and the sample is stirred for 30 minutes. To this sample, the appropriate alkene (200 $\mathrm{mM})$ is added. This sample is treated with pinacolborane $(100 \mathrm{mM})$ and allowed to stir for 2 hours. This solvent is removed from this sample and the NMR recorded in $\mathrm{CDCl}_{3}$.

\subsubsection{General Procedure for Hydroboration of Vinyl Diphenylphosphine}

A sample of $0.5 \mathrm{~mol} \%$ loading for the $\mathrm{Rh}(\mathrm{COD})$ complex is dissolved in THF, along with the internal standard 1,3,5-trimethoxybenzene, in a small vial equipped with a Teflon cap. One equivalent of silver (I) triflate is added and the sample is stirred for $30-40$ minutes. To this sample, the vinyldiphenylphosphine is added. This sample is then treated with pinacolborane at the desired temperature and allowed to stir for 2 hours. Once complete, the solvent is removed in vacuo resulting in the formation of a yellow oil.

\subsubsection{NMR Tube Experiment for Oxidative Addition of HBPin to $\left[\mathrm{Rh}\left(\mathrm{Ph}_{2} \mathrm{PCH}_{2} \mathrm{CH}_{2} \mathrm{~B}^{\mathrm{BBN}}\right)_{2} \mathrm{Cl}\right]_{2}$}

A sample of $\left[\mathrm{Rh}\left(\mathrm{Ph}_{2} \mathrm{PCH}_{2} \mathrm{CH}_{2} \mathrm{~B}^{\mathrm{BBN}}\right)_{2} \mathrm{Cl}\right]_{2}$ was added to an NMR tube equipped with a septum cap and Teflon/electrical taped to prevent oxygen and moisture from entering the tube. The sample was dissolved in $d_{6}$-benzene with a few drops of THF. The ${ }^{31} \mathrm{P}\left\{{ }^{1} \mathrm{H}\right\},{ }^{11} \mathrm{~B}\left\{{ }^{1} \mathrm{H}\right\}$ and ${ }^{1} \mathrm{H}$ NMR were recorded and then two equivalents of HBPin was added and the reaction was monitored by ${ }^{1} \mathrm{H}$ and ${ }^{31} \mathrm{P}\{\mathrm{H}\}$ NMR spectroscopy. ${ }^{1} \mathrm{H}$ NMR $\left(400 \mathrm{MHz}, \mathrm{C}_{6} \mathrm{D}_{6}\right): \delta 7.91-8.08(\mathrm{~m}, 10 \mathrm{H}, \mathrm{Ph}), \delta 7.00-7.15(\mathrm{~m}, 10 \mathrm{H}, \mathrm{Ph}), \delta$ $2.83-3.05\left(\mathrm{~m}, 4 \mathrm{H}, \mathrm{PCH}_{2}\right), \delta 1.69-1.97\left(\mathrm{~m}, 4 \mathrm{H}, \mathrm{CH}_{2} \mathrm{~B}\right), \delta 1.72-1.96(\mathrm{~m}, 25 \mathrm{H}, \mathrm{BBN}), \delta$

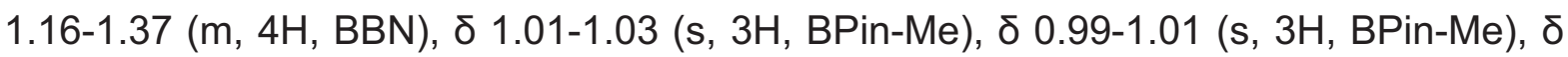
0.76-0.80 (s, 10H, BPin-Me, BBN), $\delta-15.59$ (dt, ${ }^{1} \mathrm{~J}_{\mathrm{Rh}-\mathrm{H}}=30.2 \mathrm{~Hz},{ }^{2} \mathrm{~J}_{\mathrm{P}-\mathrm{H}}=13.3 \mathrm{~Hz}, 1 \mathrm{H}$, 
Rh-H).. ${ }^{31} \mathrm{P}\left\{{ }^{1} \mathrm{H}\right\}$ NMR (162 MHz, $\left.\mathrm{C}_{6} \mathrm{D}_{6}\right): \delta 34.9\left(\mathrm{~d},{ }^{1} \mathrm{~J}_{\mathrm{Rh}-\mathrm{P}}=121.8 \mathrm{~Hz}\right) .{ }^{11} \mathrm{~B}\left\{{ }^{1} \mathrm{H}\right\} \mathrm{NMR}(128$ $\mathrm{MHz}, \mathrm{C}_{6} \mathrm{D}_{6}$ ): $\delta 78.7$ (br. s), $\delta 34.2$ (br. s), $\delta 21.9$ (s).

\subsubsection{NMR Tube Experiment for Oxidative Addition of $\mathrm{H}_{2}$ to $\mathrm{Rh}\left(\mathrm{Ph}_{2} \mathrm{PCH}_{2} \mathrm{CH}_{2} \mathrm{~B}^{\mathrm{BBN}}\right)_{3} \mathrm{Cl}$}

A sample of $\mathrm{Rh}\left(\mathrm{Ph}_{2} \mathrm{PCH}_{2} \mathrm{CH}_{2} \mathrm{~B}^{\mathrm{BBN}}\right)_{3} \mathrm{Cl}$ was added to an NMR tube equipped with a septum cap and Teflon/electrical taped to prevent oxygen and moisture from entering the tube. The sample was dissolved in $d_{8}$-toluene with a few drops of THF. The ${ }^{31} P\left\{{ }^{1} H\right\}$, ${ }^{11} \mathrm{~B}\left\{{ }^{1} \mathrm{H}\right\}$ and ${ }^{1} \mathrm{H}$ NMR were recorded and then a balloon of $\mathrm{H}_{2}$ was added while maintaining a temperature of $-78^{\circ} \mathrm{C}$. The reaction was monitored by ${ }^{1} \mathrm{H}$ and ${ }^{31} \mathrm{P}\{\mathrm{H}\}$ NMR measurements.

\subsection{References}

(1) Hartwig, J. F. Organotransition Metal Chemistry: From Bonding to Catalysis; University Science Books, 2010.

(2) Colebrooke, S. A.; Duckett, S. B.; Lohman, J. A. B.; Eisenberg, R. Chem. Eur. J. 2004, 10, 2459

(3) Jackson, S. M.; Hughes, C. E.; Monfette, S.; Rosenberg, L. Inorg. Chim. Acta. 2006, 359, 2966.

(4) Shimada, S.; Batsanov, A. S.; Howard, J. A. K.; Marder, T. B. Angew. Chem. Int. Edit. 2001, 40, 2168.

(5) Perea-Buceta, J. E.; Fernández, I.; Heikkinen, S.; Axenov, K.; King, A. W. T.; Niemi, T.; Nieger, M.; Leskelä, M.; Repo, T. Angew. Chem. Int. Ed. Engl. 2015, $54,14321$.

(6) Männig, D.; Nöth, H. Angew. Chem. Int. Ed. Engl. 1985, 24, 878. 
(7) Burgess, K.; van der Donk, W. A.; Westcott, S. A.; Marder, T. B.; Baker, R. T.; Calabrese, J. C. J. Am. Chem. Soc. 1992, 114, 9350.

(8) Westcott, S. A.; Blom, H. P.; Marder, T. B.; Baker, R. T. J. Am. Chem. Soc. 1992, $114,8863$.

(9) Westcott, S. A.; Marder, T. B.; Baker, R. T. Organometallics 1993, 12, 975.

(10) Basnet, P.; Thapa, S.; Dickie, D. A.; Giri, R. Chem. Commun. 2016, 52, 11072.

(11) Chen, A. C.; Ren, L.; Crudden, C. M. Chem. Commun. 1999, 611.

(12) Westcott, S. A.; Blom, H. P.; Marder, T. B.; Baker, R. T.; Calabrese, J. C. Inorg. Chem. 1993, 32, 2175.

(13) Pereira, S.; Srebnik, M. Tetrahedron Lett. 1996, 37, 3283.

(14) Murata, M.; Watanabe, S.; Masuda, Y. Tetrahedron Lett. 1999, 40, 2585.

(15) Crudden, C. M.; Hleba, Y. B.; Chen, A. C. J. Am. Chem. Soc. 2004, 126, 9200.

(16) Lata, C. J.; Crudden, C. M. J. Am. Chem. Soc. 2010, 132, 131.

(17) Yin, Q.; Kemper, S.; Klare, H. F. T.; Oestreich, M. Chem. Eur. J. 2016, 22, 13840.

(18) De Vries, T. S.; Prokofjevs, A.; Vedejs, E. Chem. Rev. 2012, 112, 4246.

(19) Eisenberger, P.; Bailey, A. M.; Crudden, C. M. J. Am. Chem. Soc. 2012, 134, 17384.

(20) Clark, E. R.; Del Grosso, A.; Ingleson, M. J. Chem. Eur. J. 2013, 19, 2462.

(21) Roselló-Merino, M.; López-Serrano, J.; Conejero, S. J. Am. Chem. Soc. 2013, $135,10910$.

(22) Stahl, T.; Müther, K.; Ohki, Y.; Tatsumi, K.; Oestreich, M. J. Am. Chem. Soc. 2013, 135, 10978. 
(23) Crossley, D. L.; Cid, J.; Curless, L. D.; Turner, M. L.; Ingleson, M. J. Organometallics 2015, 34, 5767.

(24) Devillard, M.; Brousses, R.; Miqueu, K.; Bouhadir, G.; Bourissou, D. Angew. Chem. Int. Ed. Engl. 2015, 54, 5722.

(25) Dureen, M. A.; Lough, A.; Gilbert, T. M.; Stephan, D. W. Chem. Commun. 2008, 4303.

(26) Tseng, K-N. T.; Kampf, J. W.; Szymczak, N. K. J. Am. Chem. Soc. 2016, 138, 10378.

(27) Tutusaus, O.; Ni, C.; Szymczak, N. K. J. Am. Chem. Soc. 2013, 135, 3403.

(28) Evans, D. A.; Fu, G. C.; Anderson, B. A. J. Am. Chem. Soc. 1992, 114, 6679.

(29) Zhang, J.; Lou, B.; Guo, G.; Dai, L. J. Org. Chem. 1991, 56, 1670.

(30) Hayashi, T.; Matsumoto, Y.; Ito, Y. J. Am. Chem. Soc. 1989, 111, 3426.

(31) Burgess, K.; van der Donk, W. A.; Kook, A. M. J. Org. Chem. 1991, 56, 2949.

(32) Smith, S. M.; Takacs, J. M. Org. Lett. 2010, 12, 4612.

(33) Hayashi, T.; Matsumoto, Y.; Ito, Y. Tetrahedron-Asymmetry 1991, 2, 601.

(34) Chong, C. C.; Kinjo, R. ACS Catal. 2015, 5, 3238.

(35) Carvalho, M.; Wieserman, L. F.; Hercules, D. M. Appl. Spectrosc. 1982, 36, 290.

(36) Wrackmeyer, B.; Tok, O. L.; Bubnov, Y. N. Angew. Chem. Int. Edit. 1999, 38, 124.

(37) Wrackmeyer, B.; Tok, O. L. Magn. Reson. Chem. 2002, 40, 406.

(38) Wrackmeyer, B.; Tok, O. L.; Bubnov, Y. N. J. Organomet. Chem. 1999, 580, 234.

(39) Ostapowicz, T. G.; Merkens, C.; Hölscher, M.; Klankermayer, J.; Leitner, W. J. Am. Chem. Soc. 2013, 135, 2104. 
(40) Fischbach, A.; Bazinet, P. R.; Waterman, R.; Tilley, T. D. Organometallics 2008, $27,1135$.

(41) Vergnaud, J.; Grellier, M.; Bouhadir, G.; Vendier, L.; Sabo-Etienne, S.; Bourissou, D. Organometallics 2008, 27, 1140.

(42) Giordano, G.; Crabtree, R. H. Inorg. Syn. 1990, 28, 88.

(43) van der Ent, A.; Onderdelinden, A. L. Inorg. Syn. 1990, 28, 90.

(44) Greenacre, V. K.; Ansell, M. B.; Roe, S. M.; Crossley, I. R. Eur. J. Inorg. Chem. 2014, 5053. 


\section{CHAPTER 4}

\section{Access to a Pair of Ambiphilic Phosphine- Borane Regioisomers by Rhodium-Catalyzed Hydroboration}

This work has been published:

Nichols, B. R.; Akhmedov, N. G.; Petersen, J. L.; Popp, B. V. Dalton Transactions 2018, 47, 8456 - 8465 and associated Supporting Information available via the internet at http://pubs.rsc.org. 


\subsection{Introduction}

Hydroboration of olefins provides a single class of products capable of being further functionalized in later steps. ${ }^{1,2}$ There have been a limited number of hydroborations conducted on vinylic substrates bearing Lewis basic functionalities, such as enamines ${ }^{3,6}$; allylic alcohols, ethers ${ }^{7-10}$ and amines ${ }^{7,11-16}$; alkenyl, allylic and vinylic sulfides $^{11,17-19}$; propargylic Lewis basic substrates $^{20-26}$ or vinyl phosphorous compounds ${ }^{27-30}$. These substrates can be problematic for transition metal catalyzed reactions as their Lewis basicity makes them potent ligands ${ }^{27,31-37}$ that potentially lead to catalyst deactivation and have the capability to form direct Lewis adducts with boron (Scheme 4.1)..$^{7,38,39}$

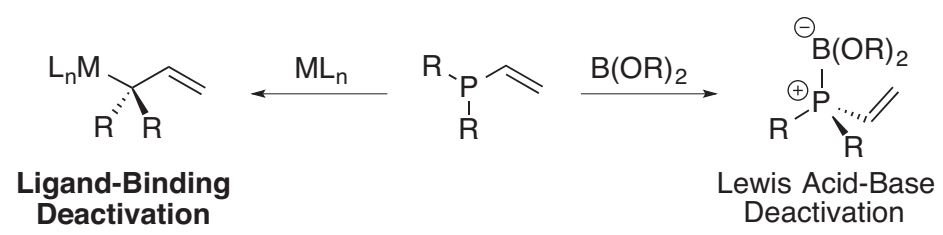

Scheme 4.1. Side-reactions of Lewis basic substrates responsible for lower catalytic hydroboration reactivity.

Vinylic phosphines can be especially troublesome, as phosphines are excellent ligands for transition metals. Vinylic compounds with phosphine functionalities are of interest because they provide access to non-rigid ambiphilic compounds that find importance in frustrated Lewis pair processes. ${ }^{40,41}$ In order to obtain desired hydroboration products for vinylic phosphine substrates, Feringa and coworkers lessened the Lewis basicity of the substrate by utilizing vinylic phosphine oxides as substrates (Scheme 4.2) ${ }^{28}$ These tempered Lewis basic substrates have since been utilized by Takacs and coworkers as directing groups for hydroboration. ${ }^{30}$ Despite these examples, application of reduced vinylphosphine species remains underexplored. 


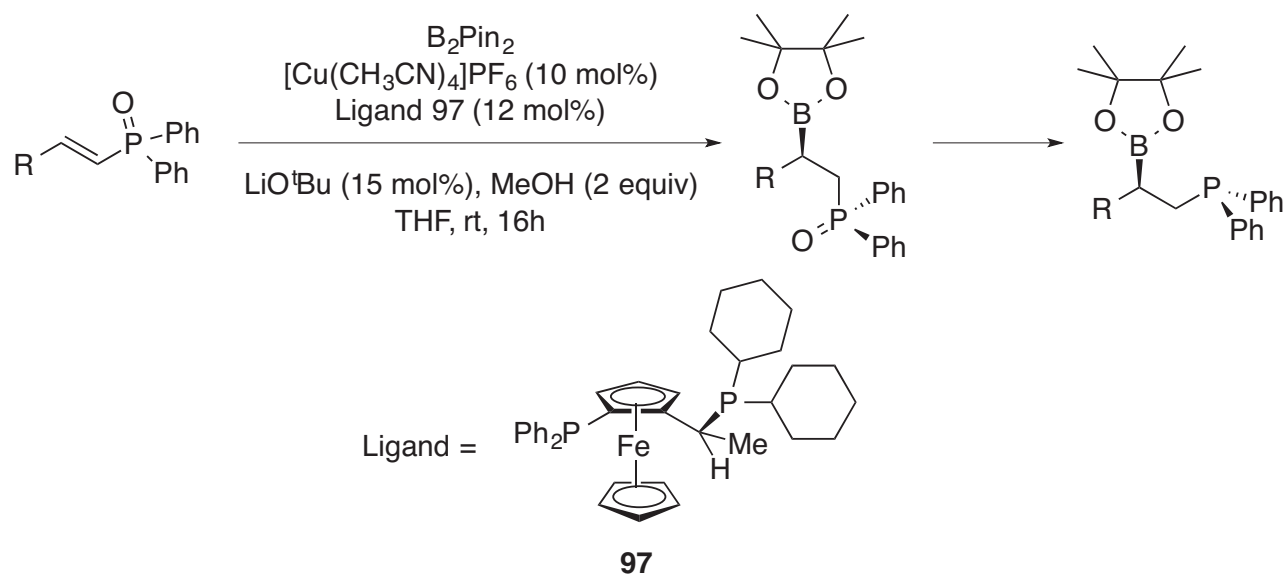

Scheme 4.2. $\mathrm{Cu}(\mathrm{I})$-catalyzed hydroboration of vinylic diphenylphosphine oxides with $\mathrm{B}_{2} \mathrm{Pin}_{2}$ and subsequent deprotection.

Hydroboration of vinyl diaryl phosphines with boranes can be accomplished under mild thermal conditions (Figure 4.1a). ${ }^{42-57}$ Less reactive boronic esters can be coupled using transition metal catalysts. For example, Muhoro and coworkers utilized a Ti-catalyst (Figure $4.1 \mathrm{~b}$ ) to afford the anti-Markovnikov phosphinoborane in modest yield, which was subsequently characterized by NMR spectroscopy and X-ray crystallography. ${ }^{29}$ This catalyst was selective for the 1,2-boratitanation producing the linear product, while the 2,1-boratitanation product was not observed. Vinylphosphines can be especially problematic for second and third-row transition metals that are known to strongly bind phosphines as ligands. ${ }^{27,31-33}$ Marder and Westcott have previously demonstrated that one can successfully achieve the direct hydroboration of vinylphosphines with a rhodium indenyl catalyst (Figure 4.1c). ${ }^{27}$ While these catalysts provided access to less Lewis acidic phosphinoborane products, the Rh-catalysts developed by Marder and coworkers yielded a mixture of four products when catechol borane was used. Pinacol borane remains the more synthetically useful boronic ester due to its increased stability and ease of handling. ${ }^{39,58}$ 
A.

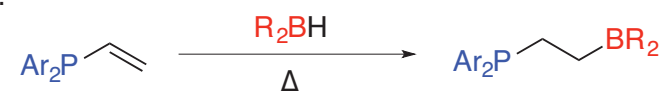

B.
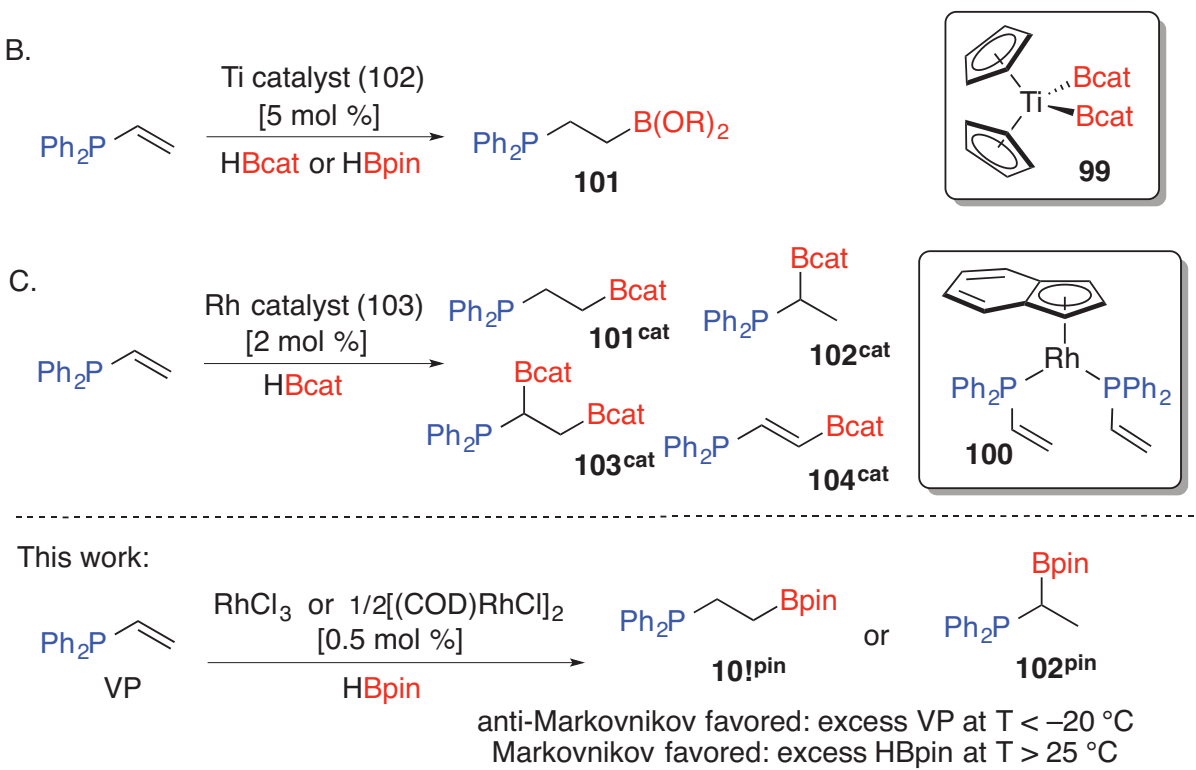

Figure 4.1. Examples of vinylphosphine hydroboration with and without transition-metal catalysts.

In the previous chapter, we explored the hydroboration of a variety of styrenyl substrates. While these substrates worked well, the optimized reaction conditions also gave high conversion and moderate regioselectivity for the hydroboration of vinyl diphenylphosphine. With only limited examples ${ }^{27}$ of catalytic alkenyl phosphine hydroboration with boronic esters by second and third-row transition metals, we initially hypothesized that secondary coordination sphere Lewis acids might temper the binding affinity of Lewis basic vinylphosphines to late-transition metal catalysts. ${ }^{59}$

\subsection{Results and Discussion}

\subsubsection{Hydroboration of Vinylphosphine Substrates en Route to Branched Boronic Esters}

Preliminary results revealed that under the optimized reaction conditions for styrene hydroboration, vinyl diphenylphosphine yielded two products, which were 
tentatively assigned to be the two regioisomers of hydroboration (Scheme 4.3). In order to determine the identity of the two products, we explored the assignment of the vinylphosphine hydroboration products by multi-nuclear NMR spectroscopy.
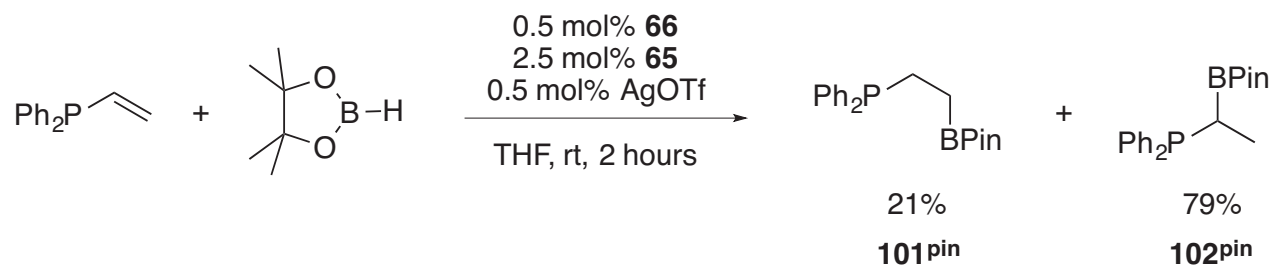

Scheme 4.3. Hydroboration of vinyl diphenylphosphine using a rhodium(I) complexes bearing an ambiphilic ligand.

The ${ }^{31} \mathrm{P}\left\{{ }^{1} \mathrm{H}\right\}$ NMR spectrum shows exclusive formation of two products with resonances at $\delta-4.6 \mathrm{ppm}$ and $\delta-10.5 \mathrm{ppm}$. To assign these peaks to their respective products, we first investigated the complex coupling pattern at $\delta 2.1 \mathrm{ppm}$ in the ${ }^{1} \mathrm{H}\left\{{ }^{13} \mathrm{C}\right\}$ NMR spectrum. Using the ${ }^{31} \mathrm{P}\left\{{ }^{1} \mathrm{H}\right\}$ signal at $\delta-4.6 \mathrm{ppm}$, selective ${ }^{31} \mathrm{P}$ decoupling simplified the complex multiplet at $\delta 2.1 \mathrm{ppm}$ in the ${ }^{1} \mathrm{H}\left\{{ }^{31} \mathrm{P}\right\}$ NMR spectrum (Figure 4.2). This signal simplified to a quartet with a ${ }^{3} \mathrm{~J}_{\mathrm{H}-\mathrm{P}}$ value of $7.3 \mathrm{~Hz}$, corresponding to the coupling of the methine $\mathrm{C}-\mathrm{H}$ to the methyl $\mathrm{C}-\mathrm{H}$ in the branched isomer. The corresponding methyl $\mathrm{C}-\mathrm{H}$ signal collapsed to a doublet, which allowed for the assignment of the ${ }^{3} \mathrm{~J}_{\mathrm{H}-\mathrm{P}}$ coupling constant of $16.4 \mathrm{~Hz}$. 


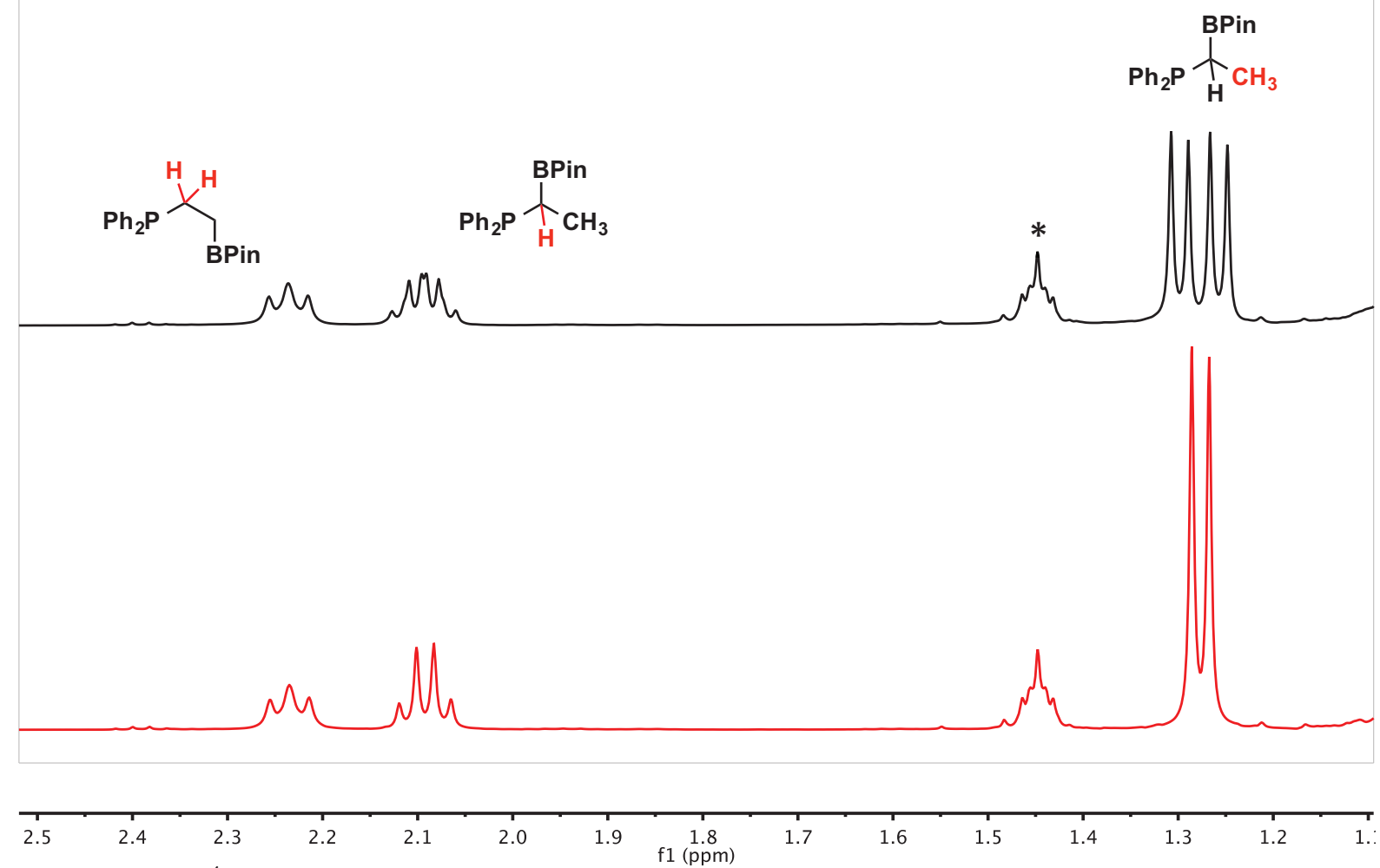

Figure 4.2. ${ }^{1} \mathrm{H}$ NMR displaying the hydroboration of vinylphosphine (top) and selective decoupling of the ${ }^{1} \mathrm{H}$ NMR using ${ }^{31} \mathrm{P}$ signal at $\delta-4.62 \mathrm{ppm}$. Residual THF marked with $\left({ }^{*}\right)$.

The methyl resonances of the BPin moiety could also be assigned through the use of gHSQCAD experiments (Figure 4.3). The methyl resonances assigned to the branched isomer appear as two singlets at $\delta 0.9 \mathrm{ppm}$. The magnetic inequivalency of the methyl resonances is likely a result of hindered rotation of the C-B bond due to the phosphine moiety. With the assignment of the alkyl functionalities in hand, we sought to explore the aryl region of the ${ }^{1} \mathrm{H}\left\{{ }^{13} \mathrm{C}\right\}$ NMR spectrum. The application of selective ${ }^{31} \mathrm{P}$ decoupling lead to the simplification of aromatic signals appearing between $\delta 7.34-$ 7.45 and $\delta 7.00-7.14$, which were assigned to the aromatic phenyl protons of the branched isomer. The branched isomer was assigned to the signal at $\delta 34 \mathrm{ppm}$ in the ${ }^{11} \mathrm{~B}$ NMR (Figure 4.3). This chemical shift is similar to boronic esters (HBPin $=\delta 28.3$ 
ppm), which indicates that there is no Lewis acid-base adduct formed between the borane and the phosphine moieties.

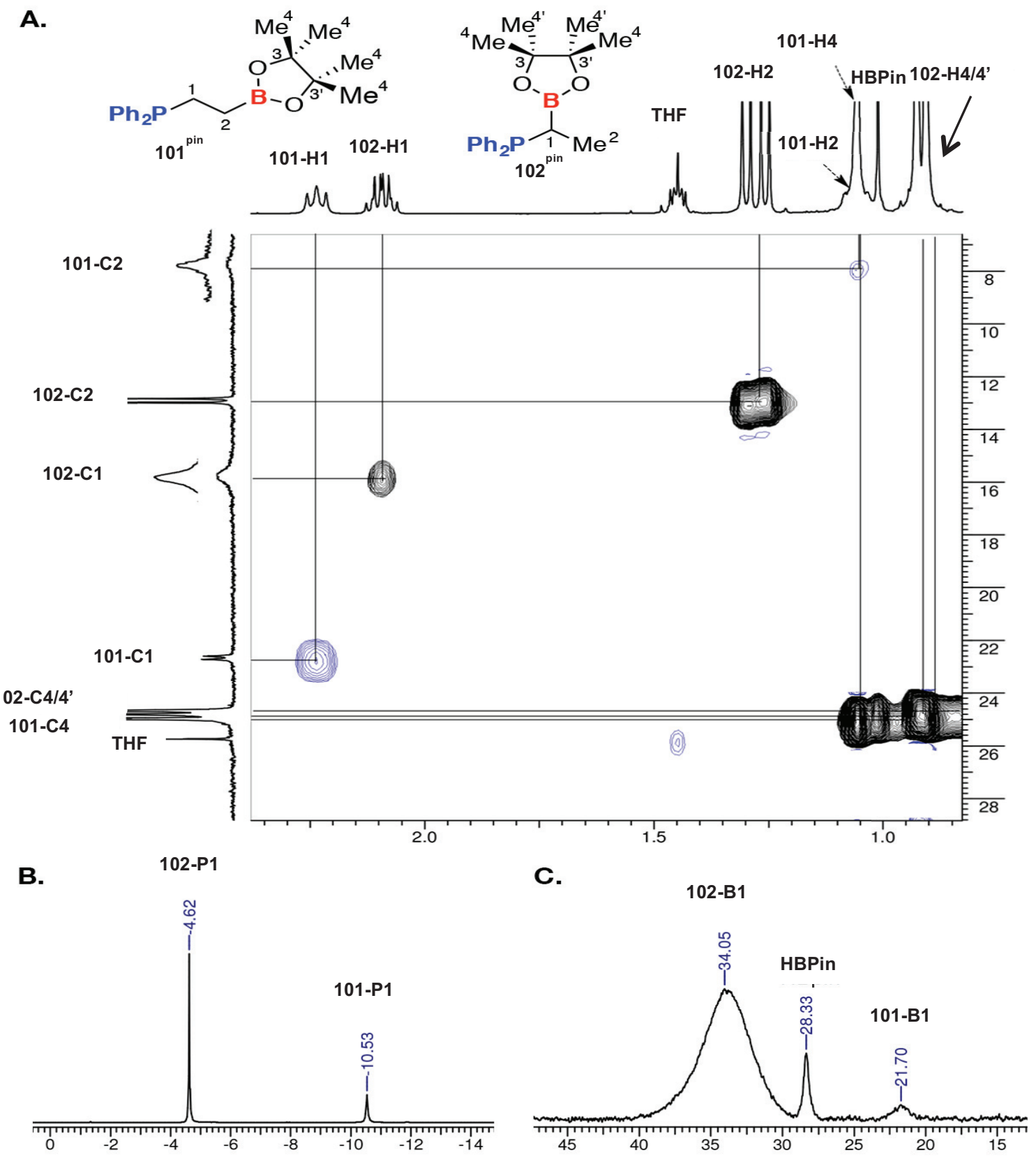

Figure 4.3. NMR spectra of the obtained hydroboration products. A) gHSQCAD NMR spectrum, B) ${ }^{31} \mathrm{P}\left\{{ }^{1} \mathrm{H}\right\}$ NMR spectrum, C) ${ }^{11} \mathrm{~B}\left\{{ }^{1} \mathrm{H}\right\}$ NMR spectrum. 
With the characterization of the $102^{\text {pin }}$ in hand, our sights were turned to the linear product $\left(101^{\mathrm{pin}}\right)$. Selectively excitation of the $\delta 2.2 \mathrm{ppm}$ resonance using a 1D TOCSY experiment (Figure 4.4) revealed correlation to the non-first order doublet of triplets at $\delta 1.05 \mathrm{ppm}$, which bears vicinal coupling $\left({ }^{3} \mathrm{~J}_{\mathrm{H}-\mathrm{P}}=8.5 \mathrm{~Hz}\right)$ to the phosphorous nuclei identified at $\delta-10.5 \mathrm{ppm}$ in the ${ }^{31} \mathrm{P}\left\{{ }^{1} \mathrm{H}\right\}$ NMR spectrum. These peaks located at $\delta$ 2.2 and $\delta 1.05 \mathrm{ppm}$ were assigned as the methylene protons next to the phosphine and the borane moieties in $101^{\text {pin }}$, respectively. The methyl resonance of the borane unit was assigned by gHSQCAD (Figure 4.3) to be located at $1.05 \mathrm{ppm}$, situated directly on top of the methylene signal in $101^{\text {pin }}$. The ${ }^{31} \mathrm{P}\left\{{ }^{1} \mathrm{H}\right\}$ and ${ }^{11} \mathrm{~B}\left\{{ }^{1} \mathrm{H}\right\}$ signals at $\delta-10.5$ and $\delta$ 22 , respectively, were also assigned to the linear isomer. The borane signal of $22 \mathrm{ppm}$ is upfield shifted from HBPin and $1 \mathbf{1 0 2}^{\mathrm{pin}}$, indicative of some degree of Lewis acid-base pairing. The aromatic resonances at $\delta 7.5-7.66 \mathrm{ppm}$ were associated to the linear isomer. These peak assignments for the linear isomer are in agreement with those previously observed for this product. ${ }^{29}$ 


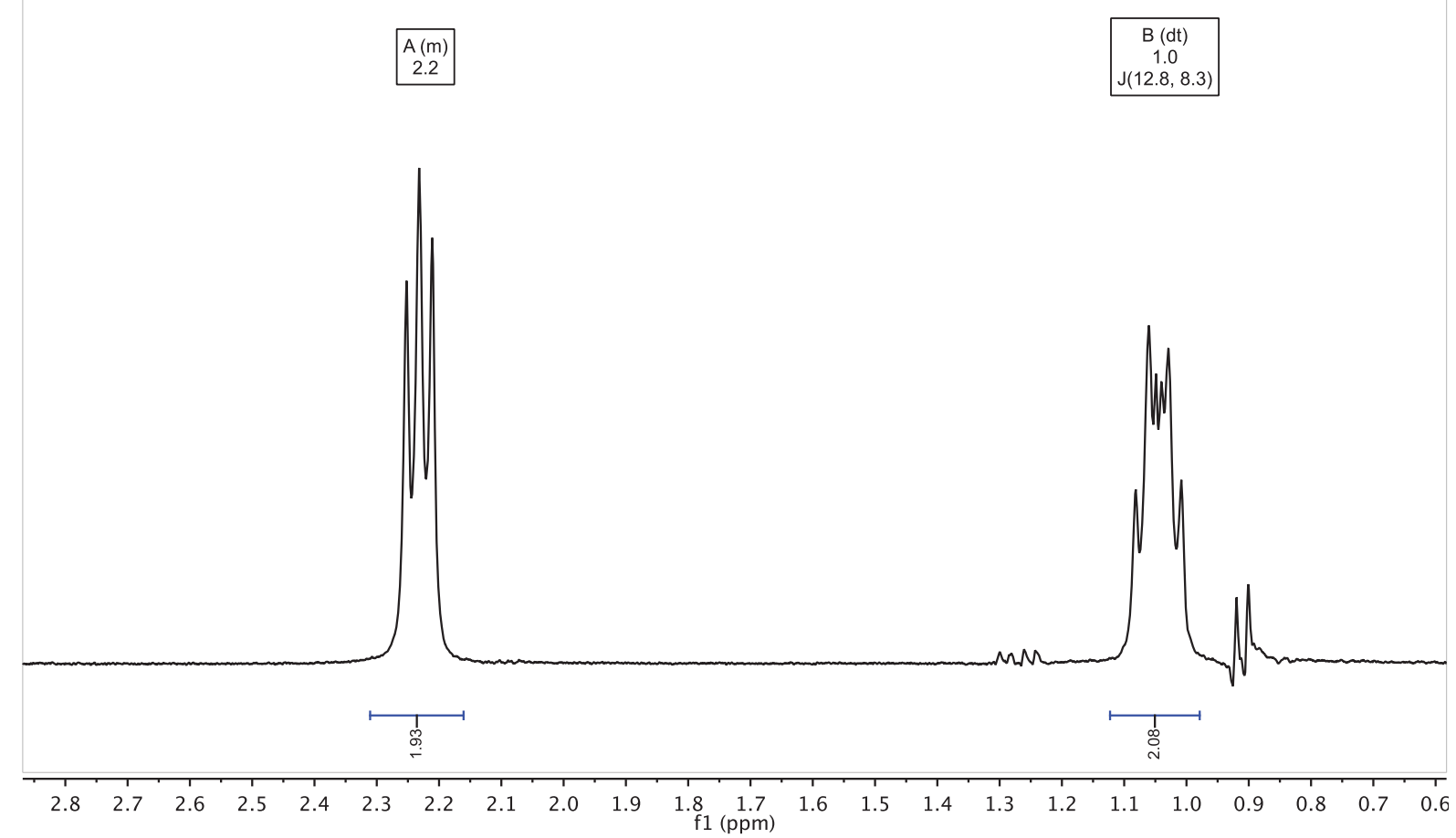

Figure 4.4. 1D TOCSY of the hydroboration of vinylphosphine with selective excitation of $\delta 2.2 \mathrm{ppm}$ resonance.

After confirming the identity of hydroboration products of VP, we examined the regioselectivity of the reaction using 66 as a catalyst (Table 4.1). As shown in Table 4.1, the use of no silver salt resulted in a branched to linear ratio of 1.3 and only a $45 \%$ conversion of the vinylphosphine starting material. By using $\mathrm{AgSbF}_{6}$, the ratio could be improved to 1.7 with an improvement in the conversion up to $66 \%$. By moving to $\mathrm{AgBF}_{4}$, the conversion could be improved to $99 \%$ with a branched to linear ratio of 2.4 . However by moving to AgOTf, the conversion was quantitative and the ratio of branched to linear could be increased further to 3.8. Therefore, the identity of the silver salt is not only important but also agrees with that seen in Chapter 3 for the hydroboration of vinyl arenes. 
Table 4.1. Silver salt optimization of the reaction conditions to obtain the branched isomer in the hydroboration of diphenylvinylphosphine with HBPin.

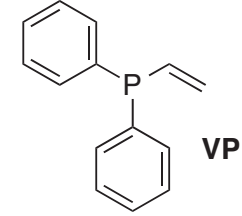

1.0 equiv

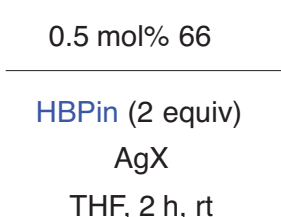

THF, 2 h, rt
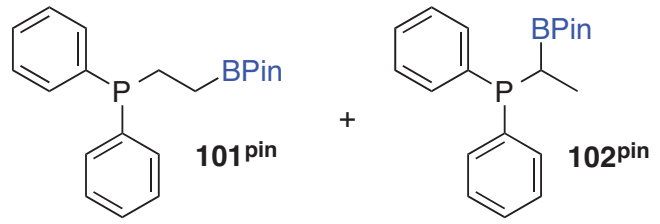

\begin{tabular}{|c|c|c|c|c|c|}
\hline \multirow{2}{*}{ Entry } & \multirow{2}{*}{ Silver Salt } & \multicolumn{2}{|c|}{${\text { Yield }(\%)^{\mathrm{a}}}$} & & Convn (\%) $^{\text {a }}$ \\
\cline { 3 - 6 } & & 101 & 102 & $102: 101$ & VP \\
\hline 1 & None & 19 & 25 & 1.3 & 45 \\
\hline 2 & AgOTf & 21 & 79 & 3.8 & 100 \\
\hline 3 & AgBF $_{4}$ & 29 & 70 & 2.4 & 99 \\
\hline 4 & AgSbF $_{6}$ & 24 & 42 & 1.7 & 66 \\
\hline
\end{tabular}

${ }^{a 1} \mathrm{H}$ NMR using 1,3,5-trimethoxybenzene as the internal standard determined the yields of each of the products.

In an attempt to further improve the yield of the branched product, the identity of the solvent was screened (Table 4.2). The optimum reaction solvent was determined to be THF, which gave quantitative conversion along with a branched to linear ratio of 3.8. When a halogenated solvent, such as DCM, was utilized as the reaction solvent, the ratio of products dropped significantly to 1.6 with only a $20 \%$ conversion. Aromatic solvents, such as toluene, provided quantitative conversion but a lower ratio of product that THF at 2.8. 
Table 4.2. Solvent optimization of the reaction conditions to obtain the branched isomer in the hydroboration of diphenylvinylphosphine with HBPin.<smiles>C=CP(c1ccccc1)c1ccccc1</smiles>

1.0 equiv
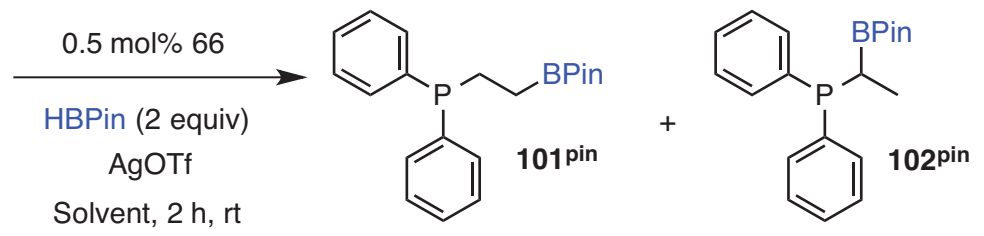

\begin{tabular}{|c|c|c|c|c|c|}
\hline \multirow{2}{*}{ Entry } & \multirow{2}{*}{ Solvent } & \multicolumn{2}{|c|}{ Yield (\%) $^{\mathrm{a}}$} & & Convn (\%) $^{\mathrm{a}}$ \\
\cline { 3 - 6 } & & 101 & 102 & $102: 101$ & VP \\
\hline 1 & THF & 21 & 79 & 3.8 & 100 \\
\hline 2 & DCM & 7 & 12 & 1.6 & 20 \\
\hline 3 & Toluene & 26 & 74 & 2.8 & 100 \\
\hline
\end{tabular}

${ }^{a}{ }^{H}$ NMR using 1,3,5-trimethoxybenzene as the internal standard determined the yields of each of the products.

Since the ratio of alkene to HBPin was a crucial factor in the hydroboration of vinyl arenes with HBPin, we sought to investigate this factor in the hydroboration of vinylphosphines (Table 4.3). Based on the results shown, it was determined that the optimal ratio for the branched product was 1:2 (VP:HBPin). It is interesting to note that by going to a system in which HBPin is the limiting reagent, the linear isomer was favored over the branched isomer. Under the 1:2 and 2:1 conditions the conversion of the limiting reagent was nearly quantitative, while the intermediate condition was only $84 \%$ conversion. 
Table 4.3. Vinylphosphine to borane optimization of the reaction conditions to obtain the branched isomer in the hydroboration of diphenylvinylphosphine with HBPin.

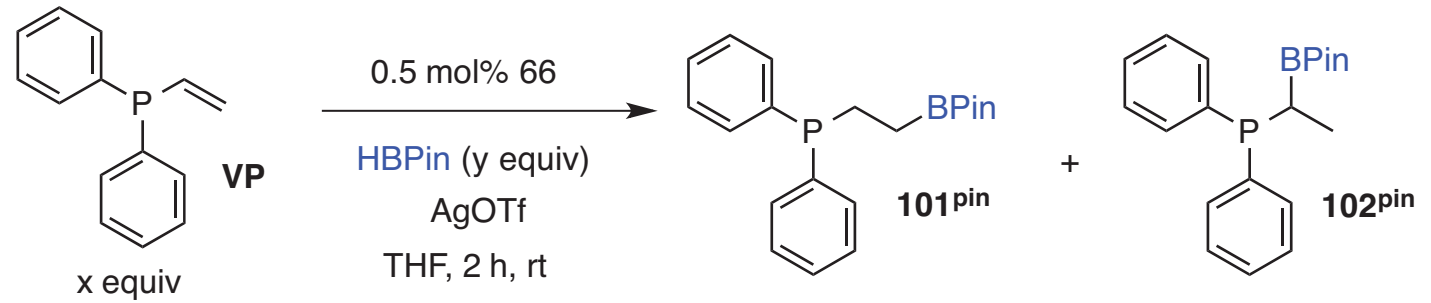

\begin{tabular}{|c|c|c|c|c|c|}
\hline \multirow{2}{*}{ Entry } & \multirow{2}{*}{ Vinylphosphine:HBPin } & \multicolumn{2}{|c|}{${\text { Yield }(\%)^{\mathrm{a}}}$} & & Convn (\%) $^{\mathrm{a}}$ \\
\cline { 3 - 6 } & & 101 & 102 & $102: 101$ & Limiting Reagent $^{-}$ \\
\hline 1 & $2: 1$ & 56 & 42 & 0.75 & 98 \\
\hline 2 & $1: 1$ & 24 & 60 & 2.6 & 84 \\
\hline 3 & $1: 2$ & 22 & 78 & 3.6 & 100 \\
\hline
\end{tabular}

${ }^{\mathrm{a} 1} \mathrm{H}$ NMR using 1,3,5-trimethoxybenzene as the internal standard determined the yields of each of the products.

After screening solvent, silver salt and reactant ratio, we turned our attention to the temperature of the reaction (Table 4.4). When the reaction was performed at $-78^{\circ} \mathrm{C}$, the linear product 101 was favored over the branched product 102 . In fact, there is a general upward trend on the ratio of 101:102 as the temperature is increased (Figure 4.5). When the temperature is raised to $70^{\circ} \mathrm{C}$, the ratio of branched to linear product is increased to 13.2 with an overall yield of the branched product of $93 \%$. Unfortunately, as the temperature of the reaction is decreased the conversion of the vinylphosphine decreases. This data suggests that the branched product is the thermodynamic product, while the linear isomer is the kinetic product. In order to explore the possibility that the linear product is isomerizing ${ }^{60,61}$ to the branched product at elevated temperatures, the reaction at room temperature was repeated for 2 hours and then heated to $70^{\circ} \mathrm{C}$. Upon heating the sample for 1 hour, there was no change in the branched to linear ratio, which indicates that the temperature does not induce product isomerization. When the reaction was conducted at $70^{\circ} \mathrm{C}$, with the use of catecholborane, a branched to linear 
ratio of 5.36 was obtained, along with the formation of the diborane product, $\mathrm{Ph}_{2} \mathrm{PCH}$ (BCat) $\mathrm{CH}_{2}$ BCat.

Table 4.4. Temperature optimization of the reaction conditions to obtain the branched isomer in the hydroboration of diphenylvinylphosphine with HBPin.<smiles>C=CP(c1ccccc1)c1ccccc1</smiles>

1.0 equiv

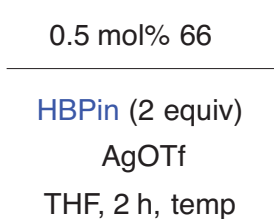

THF, 2 h, temp
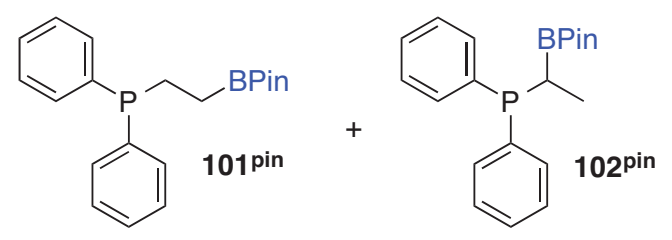

\begin{tabular}{|c|c|c|c|c|c|}
\hline \multirow{2}{*}{ Entry } & \multirow{2}{*}{ Temp $\left({ }^{\circ} \mathrm{C}\right)$} & \multicolumn{2}{|c|}{ Yield $(\%)^{\mathrm{a}}$} & & ${\text { Convn }(\%)^{\mathrm{a}}}^{\mathrm{a}}$ \\
\cline { 3 - 6 } & 101 & 102 & $102: 101$ & VP \\
\hline 1 & -78 & 40 & 28 & 0.7 & 68 \\
\hline 2 & 0 & 28 & 25 & 0.9 & 54 \\
\hline 3 & 25 & 22 & 78 & 3.6 & 100 \\
\hline 4 & 60 & 10 & 90 & 9.0 & 100 \\
\hline 5 & 70 & 7 & 93 & 13.2 & 100 \\
\hline
\end{tabular}

${ }^{a 1} \mathrm{H}$ NMR using 1,3,5-trimethoxybenzene as the internal standard determined the yields of each of the products.

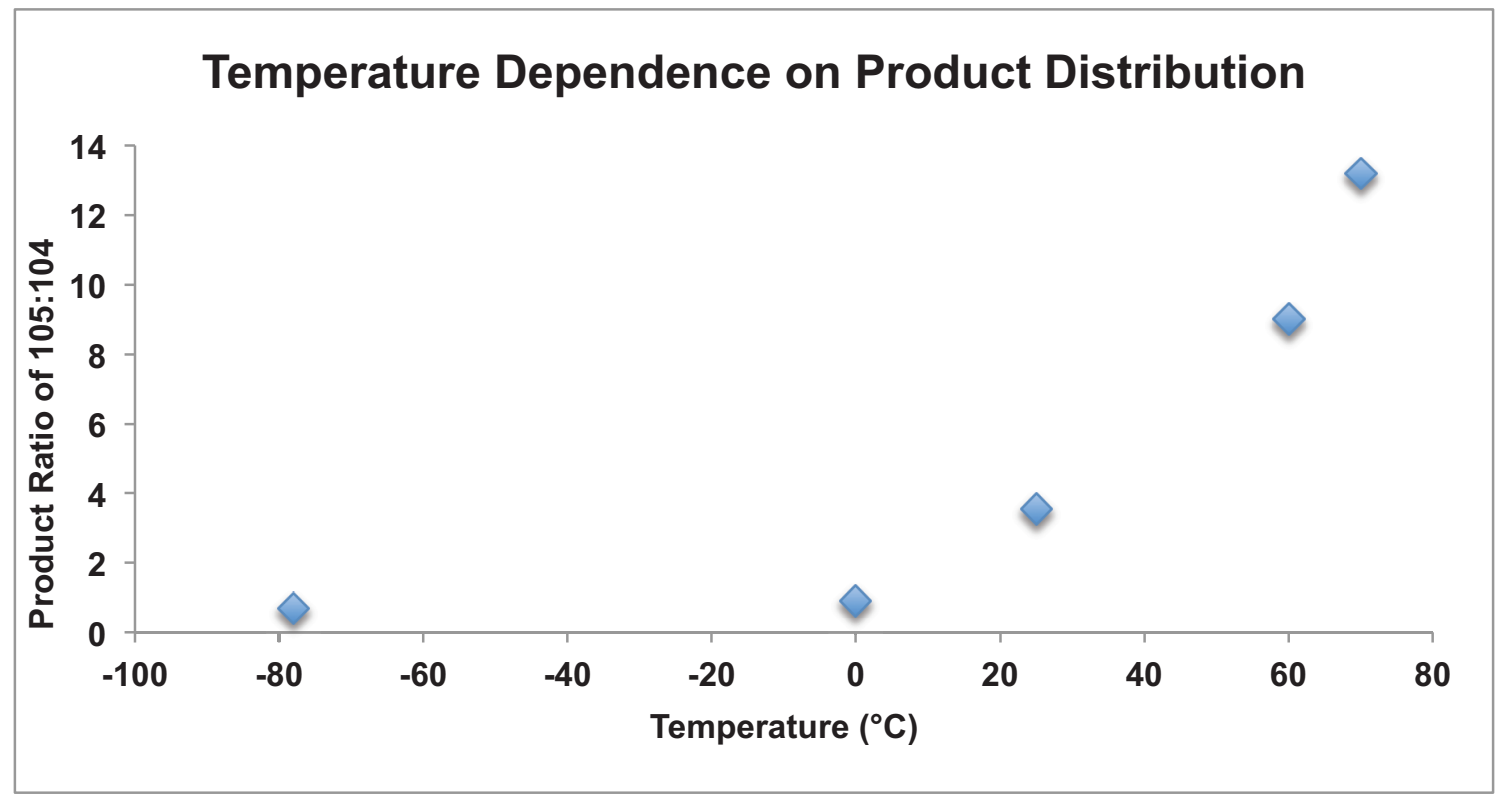

Figure 4.5. Effect of temperature on the branched to linear product distribution in the hydroboration of vinylphosphine with HBPin. 
It was of interest to see if the yield could be improved further to obtain only one of the isomers rather than a mixture of the two products by modification of the catalyst system (Table 4.5). The bis(phosphinoborane) complex 74 had a good branched to linear ratio of 8.1 , however this complex had an incomplete conversion of the diphenylvinylphosphine. The phosphinoborane ligand was replaced with the commercially available $\mathrm{PPh}_{3}$ ligand without any loss in activity. Finally, a further simplification of the catalyst system was achieved by removal of the phosphine ligand entirely, as the $\mathrm{PPh}_{3}$ proved to provide no added advantage. This observation could prove mechanistically significant, as the vinylphosphine substrate is likely acting as a spectator ligand prior to undergoing hydroboration by the rhodium-catalyst system.

Table 4.5. Catalyst optimization of the reaction conditions to obtain the branched isomer in the hydroboration of diphenylvinylphosphine with HBPin.

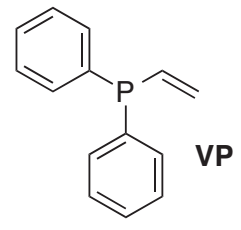

1.0 equiv

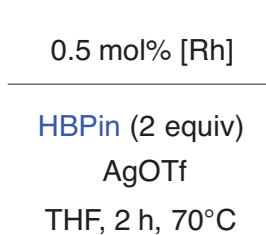

THF, $2 \mathrm{~h}, 70^{\circ} \mathrm{C}$<smiles>[Pb]CCPCc1ccccc1</smiles><smiles>Cc1ccccc1I</smiles>

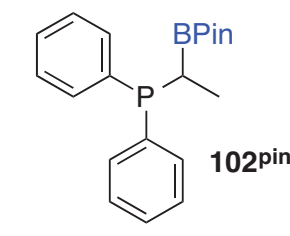

\begin{tabular}{|c|c|c|c|c|c|}
\hline \multirow{2}{*}{ Entry } & \multirow{2}{*}[\mathrm{Rh}]{} & \multicolumn{2}{|c|}{${\text { Yield }(\%)^{\mathrm{a}}}$} & & ${\text { Convn }(\%)^{\mathrm{a}}}$ \\
\cline { 3 - 6 } & & 101 & 102 & $102: 101$ & 108 \\
\hline 1 & $\mathrm{Rh}(\mathrm{COD})\left[\mathrm{Ph}_{2} \mathrm{PCH}_{2} \mathrm{CH}_{2} \mathrm{~B}^{\mathrm{BBN}}\right] \mathrm{Cl}$ & 8 & 92 & 11.5 & 100 \\
\hline 2 & $\mathrm{Rh}(\mathrm{CO})\left[\mathrm{Ph}_{2} \mathrm{PCH}_{2} \mathrm{CH}_{2} \mathrm{~B}^{\mathrm{BBN}}\right]_{2} \mathrm{Cl}$ & 6 & 52 & 8.1 & 58 \\
\hline 3 & $\mathrm{Rh}(\mathrm{COD})\left(\mathrm{PPh}_{3}\right) \mathrm{Cl}$ & 7 & 93 & 13.2 & 100 \\
\hline 4 & {$[\mathrm{Rh}(\mathrm{COD}) \mathrm{Cl}]_{2}$} & 7 & 93 & 13.2 & 100 \\
\hline
\end{tabular}

${ }^{a} \mathrm{H}$ NMR using 1,3,5-trimethoxybenzene as the internal standard determined the yields of each of the products.

Since substrate VP appeared to also act as a ligand for hydroboration and the ambiphilic phosphine-borane ligand did not impact catalyst activation to a significant degree, we sought to test the effect of other common rhodium pre-catalysts on catalytic reactivity and selectivity (Table 4.6). Under optimized conditions, $[\mathrm{Rh}(\mathrm{COD}) \mathrm{Cl}]_{2}$ gave a 
13:1 ratio of $102^{\text {pin }}: 101^{\text {pin }}$ with complete conversion. Since previous studies ${ }^{62}$ demonstrated the reversal in regio-selectivity when employing $\mathrm{RhCl}_{3}$ as the catalyst in the hydroboration of specific substrates, this $\mathrm{Rh}(\mathrm{III})$ catalyst was investigated. With the hydroboration of $\mathrm{VP}$, the use of $\mathrm{RhCl}_{3}$ necessitated significantly longer reaction times (18 h) and product selectivity eroded dramatically (entry 2 ). A slight improvement in selectivity was observed upon addition of catalytic AgOTf (entry 3). We reasoned that erosion in selectivity could arise from speciation of rhodium during reductive generation of rhodium(I) from rhodium(III) leading to poorly selective catalysis. Thus smaller initial pre-catalyst concentration could improve selectivity. However when the catalyst loading of $\mathrm{RhCl}_{3}$ was lowered from $0.5 \mathrm{~mol} \%$ to $0.005 \mathrm{~mol} \%$, linear product $101^{\text {pin }}$ was predominant in a branched to linear ratio of 0.6 (entry 4 and 5). The $\left[\mathrm{Rh}(\mathrm{COE})_{2} \mathrm{Cl}\right]_{2}$ complex again fared worse in terms of branched to linear product distribution and even at elevated temperatures had lower conversion of the vinylphosphine (entry 6). The $\left[\mathrm{Rh}\left(\mathrm{PPh}_{3}\right)_{2} \mathrm{Cl}\right]_{2}$ complex (entry 7 ) gave complete conversion of the vinylphosphine, but provided a low branched to linear ratio of 1.8. When Wilkinson's complex was utilized, the conversion and ratio of branched to linear product was low when compared to the previous systems (entry 8). We speculate that generation of the active Rhodium(I) hydroboration catalyst proceeds through an intermediate $\left[R h(C O D)(V P)_{n}\right]$ species. Successful isolation and characterization of such a species has thus far been unsuccessful though. In order to obtain a homogeneous sample of one species, the silver and Rh pre-catalyst must be reacted to completion prior to addition of the vinylphosphine. Efforts to reduce catalyst loading or use co-additives, such as $\mathrm{B}\left(\mathrm{C}_{6} \mathrm{~F}_{5}\right)_{3}{ }^{63}$ or DMAP, ${ }^{64}$ did not improve reaction selectivity (entry $9-11$ ) 
Table 4.6. Catalyst optimization of the reaction conditions to obtain the branched isomer in the hydroboration of diphenylvinylphosphine with HBPin.

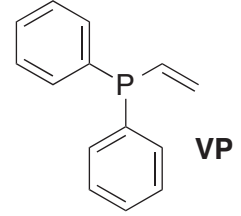

1.0 equiv

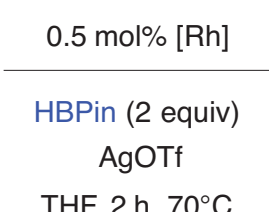

THF, $2 \mathrm{~h}, 70^{\circ} \mathrm{C}$
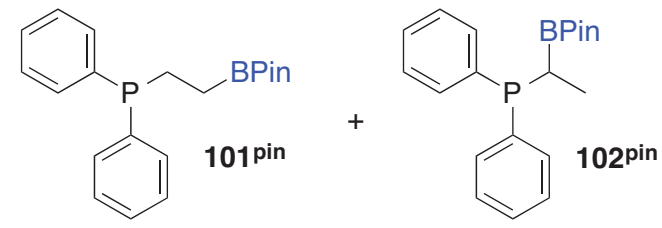

\begin{tabular}{|c|c|c|c|c|c|}
\hline \multirow{2}{*}{ Entry } & \multirow{2}{*}[\mathrm{Rh}]{} & \multicolumn{2}{|c|}{ Yield $(\%)^{a}$} & & $\overline{\text { Convn (\%) }})^{a}$ \\
\hline & & 101 & 102 & 102:101 & 108 \\
\hline 1 & {$[\mathrm{Rh}(\mathrm{COD}) \mathrm{Cl}]_{2}$} & 7 & 93 & 13.2 & 100 \\
\hline 2 & $\mathrm{RhCl}_{3} \cdot 3 \mathrm{H}_{2} \mathrm{O}^{\mathrm{b}, \mathrm{c}}$ & 40 & 60 & 1.5 & 100 \\
\hline 3 & $\mathrm{RhCl}_{3} \cdot 3 \mathrm{H}_{2} \mathrm{O}^{\mathrm{b}}$ & 20 & 72 & 3.6 & 100 \\
\hline 4 & $\mathrm{RhCl}_{3} \cdot 3 \mathrm{H}_{2} \mathrm{O}^{\mathrm{b}, \mathrm{c}, \mathrm{d}}$ & 45 & 27 & 0.6 & 72 \\
\hline 5 & $\mathrm{RhCl}_{3} \cdot 3 \mathrm{H}_{2} \mathrm{O}^{\mathrm{b}, \mathrm{d}}$ & 16 & 9 & 0.6 & 25 \\
\hline 6 & {$\left[\mathrm{Rh}(\mathrm{COE})_{2} \mathrm{Cl}\right]_{2}$} & 12 & 30 & 2.4 & 42 \\
\hline 7 & {$\left[\mathrm{Rh}\left(\mathrm{PPh}_{3}\right)_{2} \mathrm{Cl}\right]_{2}$} & 35 & 62 & 1.8 & 100 \\
\hline 8 & $\mathrm{Rh}\left(\mathrm{PPh}_{3}\right)_{3} \mathrm{Cl}$ & 18 & 28 & 1.5 & 46 \\
\hline 9 & {$\left[\mathrm{Rh}(\mathrm{COD}) \mathrm{Cl}_{2}{ }^{\mathrm{e}}\right.$} & 45 & 27 & 0.6 & 72 \\
\hline 10 & {$[\mathrm{Rh}(\mathrm{COD}) \mathrm{Cl}]_{2}^{\dagger}$} & 29 & 71 & 2.4 & 100 \\
\hline 11 & {$[\mathrm{Rh}(\mathrm{COD}) \mathrm{Cl}]_{2}^{\mathrm{g}}$} & 41 & 50 & 1.2 & 91 \\
\hline 12 & {$\left[\mathrm{Rh}(\mathrm{COD})_{2}\right] \mathrm{OTf}{ }^{\mathrm{c}}$} & 35 & 64 & 1.8 & 100 \\
\hline
\end{tabular}

${ }^{a 1} \mathrm{H}$ NMR using 1,3,5-trimethoxybenzene as the internal standard determined the yields of each of the products. ${ }^{\mathrm{b}}$ Reaction run for $18 \mathrm{~h}$. ${ }^{\mathrm{C}} \mathrm{No}$ silver added. ${ }^{\mathrm{d}} 0.005 \mathrm{~mol} \%$ [Rh] used. ${ }^{e}$ Reaction conducted for $24 \mathrm{~h}$ with $0.005 \mathrm{~mol} \% \mathrm{Rh}$ catalyst and AgOTf additive. fWith additional $0.5 \mathrm{~mol} \% \mathrm{~B}\left(\mathrm{C}_{6} \mathrm{~F}_{5}\right)_{3}$. ${ }^{9}$ With additional $0.5 \mathrm{~mol} \%$ 4-(dimethylamino)pyridine (DMAP).

When sterically hindered substrates were tried, such as vinyl diisopropylphosphine and vinyl dimesitylphosphine, no reaction occurred. This could indicate that the vinyl diphenylphosphine has the appropriate balance of sterics and electronics for this reaction to take place. While there are reported rhodium complexes bearing vinyl diphenylphosphine as a ligand, ${ }^{27,65-67}$ there are no examples of a rhodium(I) complex with dimethyl or di-isopropyl vinylphosphine. 


\subsubsection{Hydroboration of Vinylphosphine Substrates en Route to Linear Boronic Esters}

With the goal of completing the reactivity study, we sought to improve the yield and selectivity en route to linear isomer $101^{\text {pin }}$. The linear isomer was previously synthesized and isolated by Muhoro and coworkers. ${ }^{29}$ During the optimization of the branched isomer synthesis, the use of low $\left(-78^{\circ} \mathrm{C}\right)$ temperatures and excess vinylphosphine led to a higher yield of the linear isomer (Table 4.7). Under high temperatures and phosphine-limiting conditions, the formation of the branched isomer is favored. Alternatively when the reaction is conducted at low temperatures with an excess of phosphine, the linear product is favored (Scheme 4.4). At low catalyst loadings, even at conditions optimized for the branched product, the product distribution begins to favor the linear product with a $102^{\text {pin }}: 101^{\text {pin }}$ ratio of 0.59 . With 1 equivalent of HBPin at both elevated temperature and room temperature, the major product is branched product $\mathbf{1 0 2}^{\mathrm{pin}}$ in a ratio greater than 2.2. When the reaction is conducted with 2 equivalents of vinylphosphine at $-78^{\circ} \mathrm{C}$, the ratio of $102^{\text {pin }}: 101^{\text {pin }}$ reached 0.50 . The ratio of $102^{\text {pin }}: 101^{\text {pin }}$ is increased to 0.1 with no loss in conversion when 5 equivalents of vinylphosphine is utilized. 
Table 4.7. Catalyst optimization of the reaction conditions to obtain the linear isomer in the hydroboration of diphenylvinylphosphine with HBPin.

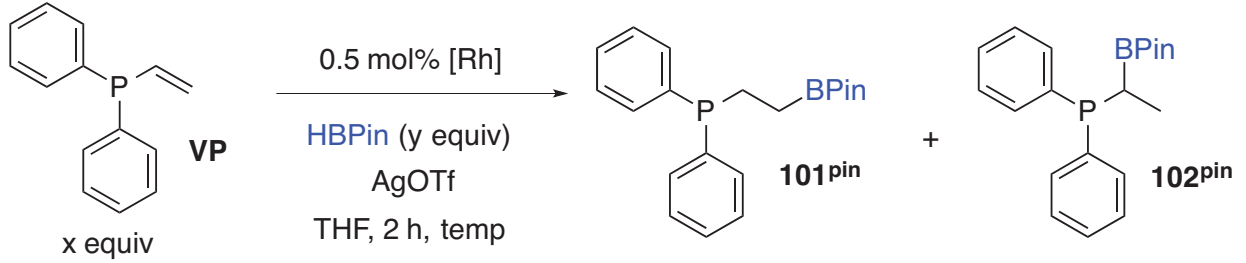

\begin{tabular}{|c|c|c|c|c|c|c|c|}
\hline \multirow{2}{*}{ Entry } & \multirow{2}{*}{ [Rh] } & & & \multicolumn{2}{|c|}{ Yield $(\%)^{b}$} & & $\begin{array}{c}\text { Convn } \\
(\%)^{b}\end{array}$ \\
\hline & & HBPin:VP & Temp $\left({ }^{\circ} \mathrm{C}\right)$ & 101 & 102 & 102:101 & VP \\
\hline 1 & {$[\mathrm{Rh}(\mathrm{COD}) \mathrm{Cl}]_{2}$} & $2: 1$ & 70 & 7 & 93 & 13.2 & 100 \\
\hline 2 & {$[\mathrm{Rh}(\mathrm{COD}) \mathrm{Cl}]_{2}$} & $1: 1$ & 70 & 29 & 65 & 2.2 & 94 \\
\hline 3 & {$[\mathrm{Rh}(\mathrm{COD}) \mathrm{Cl}]_{2}$} & $1: 1$ & 25 & 24 & 60 & 2.6 & 84 \\
\hline 4 & {$[\mathrm{Rh}(\mathrm{COD}) \mathrm{Cl}]_{2}$} & $1: 1$ & -78 & 38 & 22 & 0.59 & 66 \\
\hline 5 & {$[\mathrm{Rh}(\mathrm{COD}) \mathrm{Cl}]_{2}$} & $1: 2$ & -78 & 36 & 18 & 0.50 & 108 \\
\hline 6 & {$[\mathrm{Rh}(\mathrm{COD}) \mathrm{Cl}]_{2}$} & $1: 5$ & -78 & 49 & 5 & 0.10 & 270 \\
\hline
\end{tabular}

a Limiting reagent $(100 \mathrm{mM})$ in THF. Reactions conducted with $0.5 \mathrm{~mol} \%$ catalyst and $0.5 \mathrm{~mol} \%$ AgOTf. ${ }^{\text {b}}$ Yield and conversion were determined by ${ }^{1} \mathrm{H}$ NMR spectroscopy using 1,3,5 trimethoxybenzene as the internal standard. 'Yields calculated relative to the limiting reagent, HBPin. Conversion calculated relative to the excess reagent, VP.

A. Low Temperature and Borane Limiting Conditions

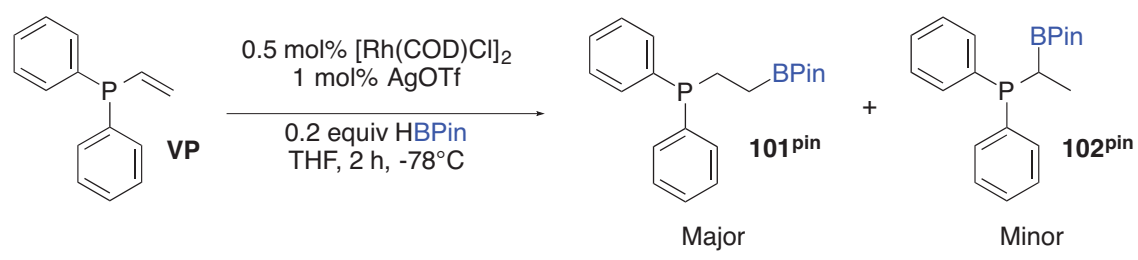

B. High Temperature and Vinylphosphine Limiting Conditions
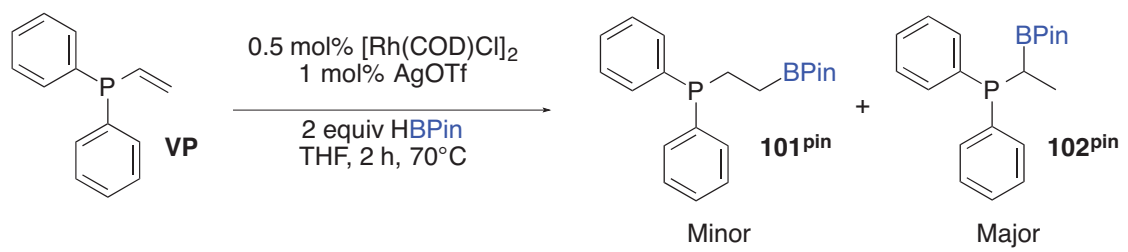

Scheme 4.4. Optimized conditions for the regio-divergent synthesis of linear $(A)$ and branched (B) hydroboration products of diphenylvinylphosphine with HBPin.

The temperature-dependent selectivity can be rationalized based on the computational studies of Ziegler and coworkers, that utilized a simplified system to study the hydroboration of alkenes with rhodium(I) complexes. ${ }^{68}$ Under low temperature 
conditions with the addition of excess VP, the selectivity for $101^{\text {pin }}$ can be explained due to kinetically favorable 1,2-insertion barriers for the rhodium-hydride over the rhodiumboryl and subsequent trapping of the insertion intermediate with the excess VP. At elevated temperatures with limiting VP, the reversal in selectivity to favor branched product $102^{\text {pin }}$ can be rationalized using Curtin-Hammett kinetics. Under CurtinHammett conditions, the kinetically favorable more favorable $\mathrm{C}-\mathrm{H}$ reductive elimination will be preferred over C-B reductive elimination. Due to substrate dependent regioselectivity $^{69}$ in hydroboration reactions, more detained kinetic and computational studies will be to be conducted to investigate other mechanistic pathways, such as 2,1migratory insertion.

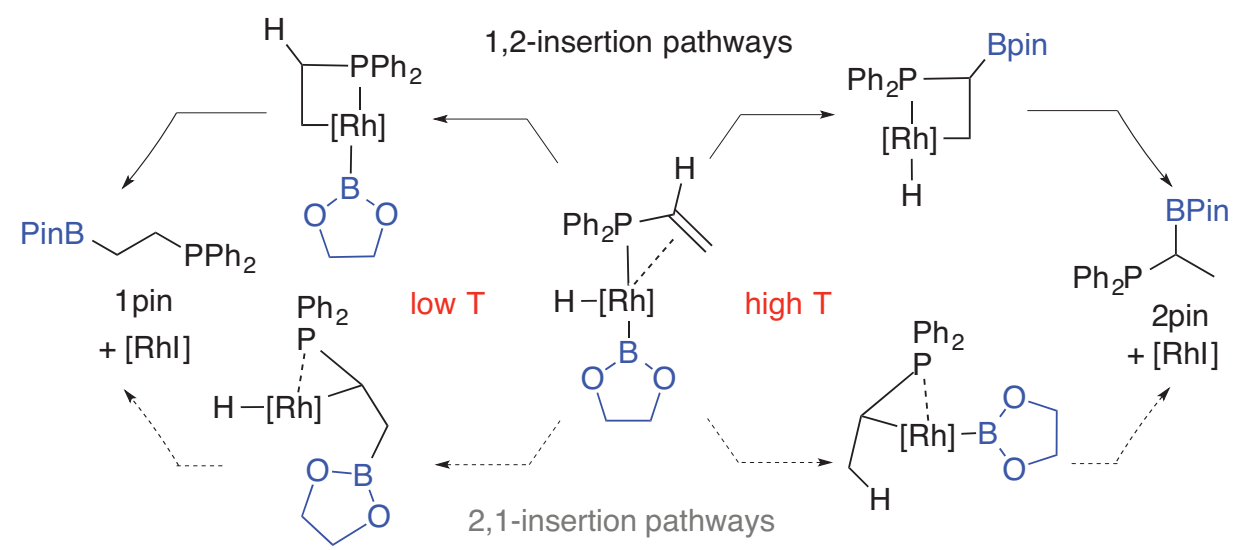

Scheme 4.5. Mechanistic rationale for the observed product selectivity in the hydroboration of diphenylvinylphosphine.

\subsubsection{Synthesis and Characterization of Metal Complexes Bearing Branched Phosphinoborane Ligand}

Owing to the inseparable nature of linear $101^{\text {pin }}$ and branched $102^{\text {pin }}$, we explored a variety of methods to isolate $102^{\text {pin }}$ by subsequent derivatization. Preparation of palladium complexes was employed by Feringa to demonstrate successful isolation of linear phosphine-boranes after reduction of the corresponding 
phosphine-oxide functional group. ${ }^{28}$ We employed the same strategy here, specifically, a mixture enriched in $\mathbf{1 0 2}^{\text {pin }}$ (c.f., Table 4.5 , entry 4 ) was added to $[\mathrm{Rh}(\mathrm{COD}) \mathrm{Cl}]_{2}$ in toluene and allowed to stir at room temperature overnight (Scheme 4.6). Crude analysis of the resulting yellow solid by ${ }^{31} \mathrm{P}$ and ${ }^{11} \mathrm{~B}$ NMR spectroscopy revealed a mixture of $\mathrm{Rh}(\mathrm{COD})\left[102^{\mathrm{pin}}\right] \mathrm{Cl}$ and $\mathrm{Rh}(\mathrm{COD})\left[101^{\text {pin }}\right] \mathrm{Cl}$. $\mathrm{Rh}(\mathrm{COD})\left[102^{\text {pin }}\right] \mathrm{Cl}$ (105) was isolated from the crude solid by dissolution in pentane, providing a $40 \%$ yield. The single doublet in the ${ }^{31} \mathrm{P}\left\{{ }^{1} \mathrm{H}\right\}$ NMR spectrum $\left({ }^{1} \mathrm{~J}_{\mathrm{Rh}-\mathrm{P}}=149.5 \mathrm{~Hz}\right)$ confirms the presence of only one regioisomeric rhodium $(\mathrm{I})$ complex. The ${ }^{11} \mathrm{~B}\left\{{ }^{1} \mathrm{H}\right\}$ NMR did not show any shift when compared to the free ligand, which is indicative of no interaction between the boronic ester and the Rh-bound chloride (Figure 4.6). The lack of an interaction provides information about the steric and electronic factors that dictate the formation of an internal Lewis acid-base pair. When comparing the electronics of a boronic ester 101 or 102 to the borabicyclo[3.3.1]nonane ligand 65, the difference in Lewis acidity arises from the presence of electron-rich heteroatoms located adjacent to the Lewis acidic boron atom. These electron-rich atoms are known to donate electron density into the empty orbital of the boron, which in turn lowers its Lewis acidity. The decreased Lewis acidity lowers the potential to interact with Lewis basic functionalities, such as the Rhbound chloride. With respect to steric bulk, the space occupied by the tetramethylethane backbone prevents the close approach of the boronic ester to the Lewis basic chloride.
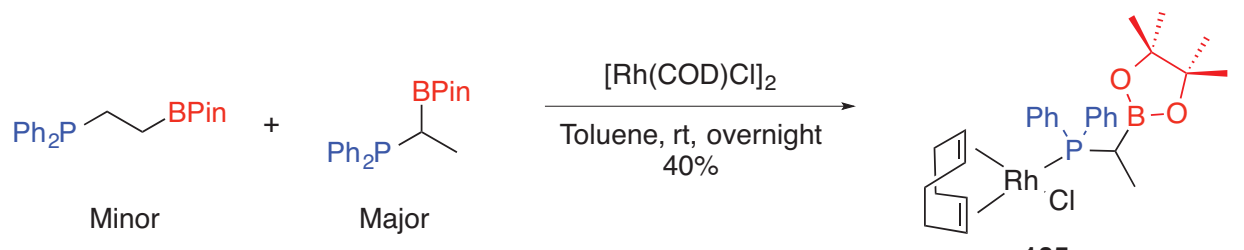

105

Scheme 4.6. Synthesis of a branched phosphinoborane complex of $\mathrm{Rh}(\mathrm{COD})$ chloride 

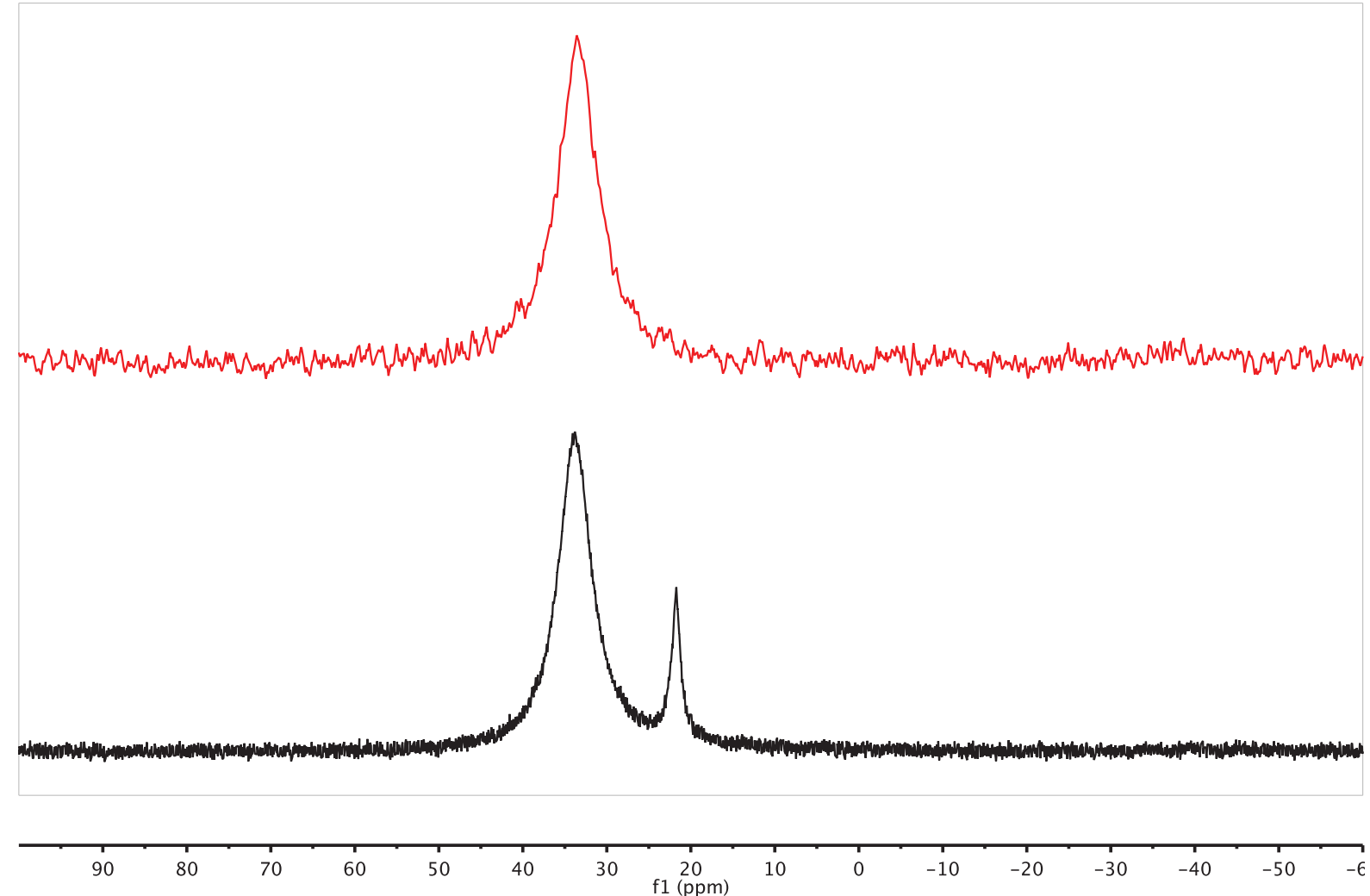

Figure 4.6. ${ }^{11} \mathrm{~B}\left\{{ }^{1} \mathrm{H}\right\} \mathrm{NMR}$ of the $\mathrm{Rh}(\mathrm{COD})$ complex 105 (top) and the mixture of the two unbound regioisomers, branched and linear (bottom).

The mixture of hydroboration products, enriched in $102^{\text {pin }}$, were also subjected to $\mathrm{BH}_{3}$ THF in order to protect the phosphine moiety. Both linear and branched $\mathrm{BH}_{3}-$ products 106 and 107, respectively, were isolated as a brown solid in an 11:1 mixture in $63 \%$ yield (Scheme 4.7 ). The ratio of regioisomers isolated was slightly reduced relative to starting material composition. The mixture is air and moisture stable, allowing subsequent functionalization to occur under ambient conditions. The ${ }^{31} \mathrm{P}\left\{{ }^{1} \mathrm{H}\right\} \mathrm{NMR}$ spectrum shows that the major product 107 undergoes a downfield shift from $\delta-4.6$ ppm $\left(102^{\text {pin }}\right)$ to $\delta 23.0 \mathrm{ppm}$ upon addition of $\mathrm{BH}_{3} \cdot \mathrm{THF}$ (Figure 4.7). The chemical shift change and the resulting complex coupling pattern are indicative of a quadrupolar ${ }^{11} \mathrm{~B}$ nucleus interacting with a ${ }^{31} \mathrm{P}$ nucleus. A new relatively sharp resonance at $\delta-39 \mathrm{ppm}$, 
appearing as a doublet with ${ }^{1} \mathbf{J}_{\mathrm{P}-\mathrm{B}}=65 \mathrm{~Hz}$, is also observed, which is consistent with literature-reported spectra for borane-protected phosphines. ${ }^{28}$ There is no change in the chemical shift of the signal assigned to the BPin moiety upon treatment with $\mathrm{BH}_{3}-\mathrm{THF}$.

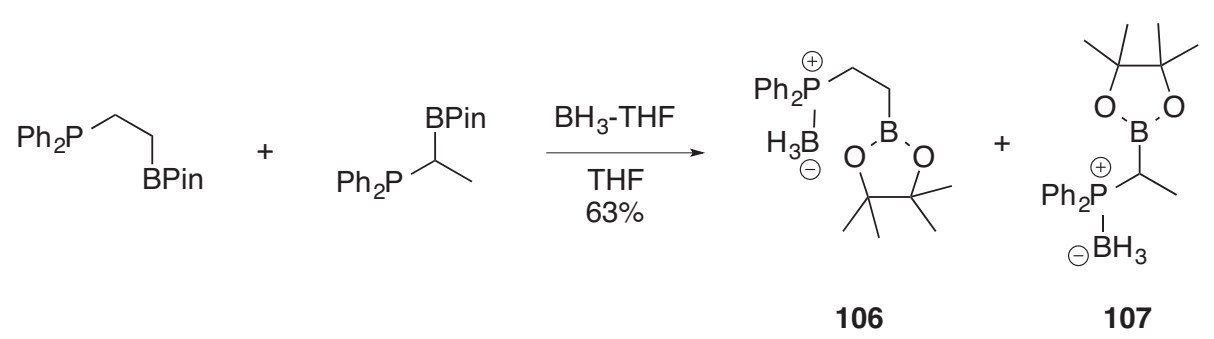

Scheme 4.7. Protection of the vinylphosphine hydroboration products with $\mathrm{BH}_{3}-\mathrm{THF}$ to yield the air- and water-stable $\mathrm{BH}_{3}$-phosphine adducts.

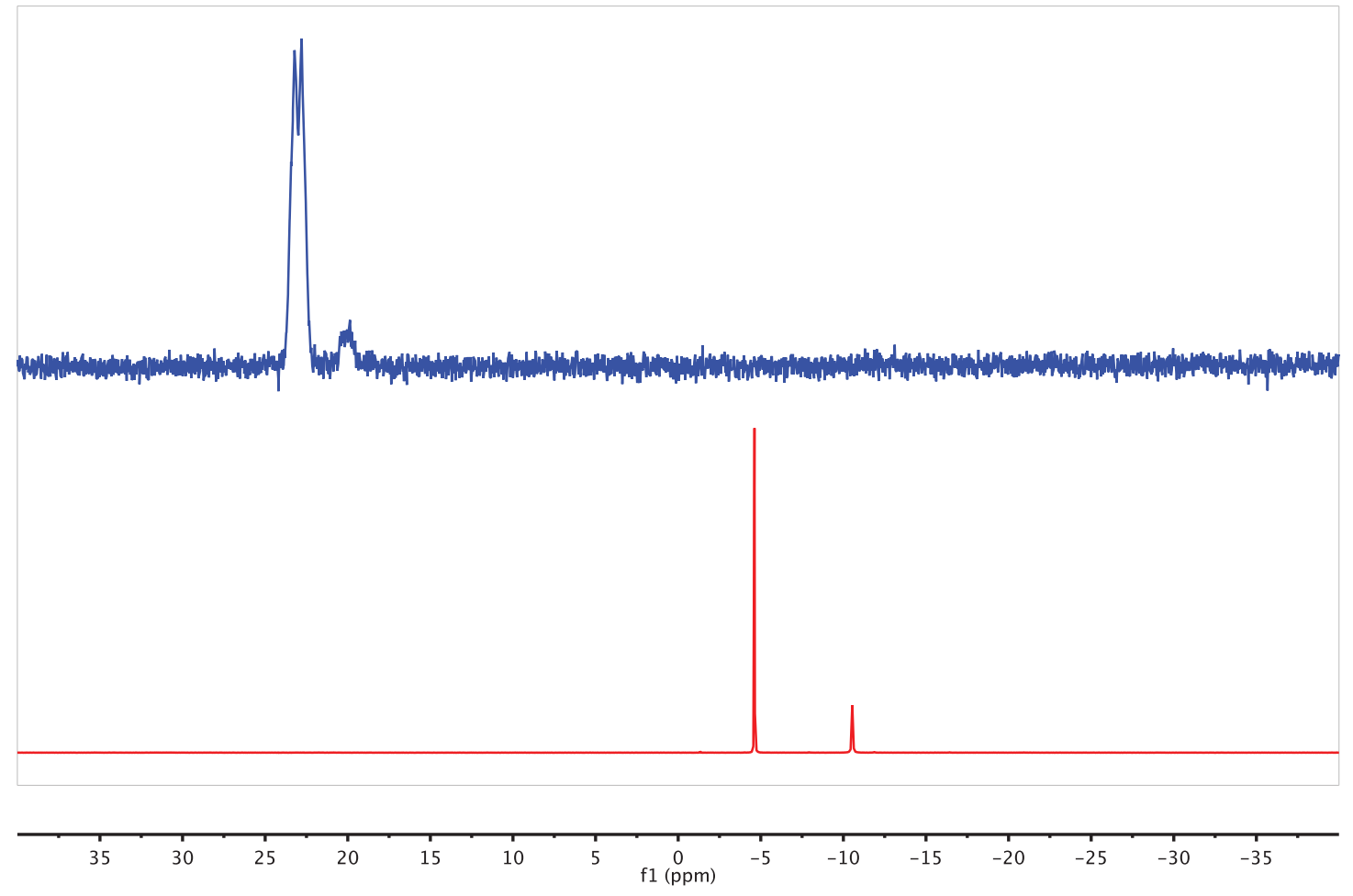

Figure 4.7. Products of the hydroboration reaction of diphenylvinylphosphine with pinacolborane before protection with $\mathrm{BH}_{3}-\mathrm{THF}$ (borttom) and after addition of $\mathrm{BH}_{3}-\mathrm{THF}$ (top).

The mixture of $\mathrm{BH}_{3}$-protected regioisomers was subsequently treated with potassium hydrogen difluoride $\left(\mathrm{KHF}_{2}\right)$ in a water/tetrahydrofuran solvent mixture 
(Scheme 4.8). The resulting crude white solid was shown by NMR spectroscopy to be a 17:1 mixture of air- and moisture-stable linear (108) and branched (109) potassium trifluoroborate salts. Recrystallization by vapor diffusion of pentane into a concentrated acetone solution at $-20{ }^{\circ} \mathrm{C}$ yielded exclusively branched 109 in $69 \%$ yield. The major branched potassium trifluoroborate salt crystallizes in a monoclinic $\mathrm{P} 2{ }_{1} / \mathrm{c}$ space group with each potassium atom interacting with the trifluoroborate group of three different molecules within the unit cell to form an extended network. Each potassium atom is also bound by one molecule of acetone, which is situated in the central cavity of each unit cell. The $\mathrm{BH}_{3}$ groups on the phosphine appear to lie directly over the potassium atoms but are free of interaction. The ${ }^{11} \mathrm{~B}\left\{{ }^{1} \mathrm{H}\right\}$ NMR signal of 101 and 102 shifts upfield from $\delta$ $33 \mathrm{ppm}$ to $\delta 3.5 \mathrm{ppm}$, which is consistent with the formation of a potassium trifluoroborate salt. ${ }^{70}$ This change in the ${ }^{11} \mathrm{~B}\left\{{ }^{1} \mathrm{H}\right\}$ NMR spectra (Figure 4.8) is accompanied by the appearance of a ${ }^{19} \mathrm{~F}$ NMR signal at $\delta-138 \mathrm{ppm}$, which is also consistent with the literature for the formation of a potassium trifluoroborate salt. ${ }^{70}$

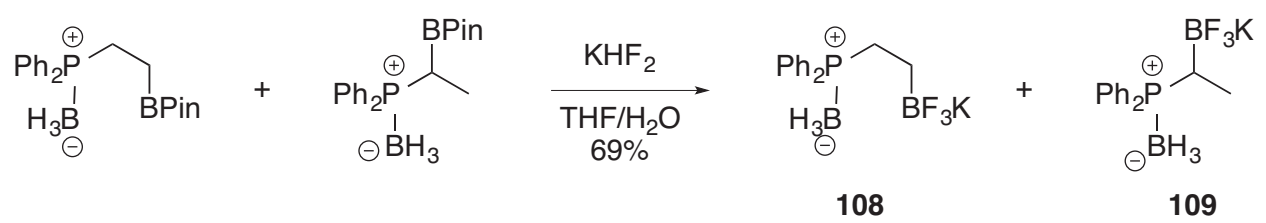

Scheme 4.8. Synthesis of the potassium trifluoroborate salt by reaction of the phosphine-protected pinacol boronic ester with potassium hydrogen difluoride. 

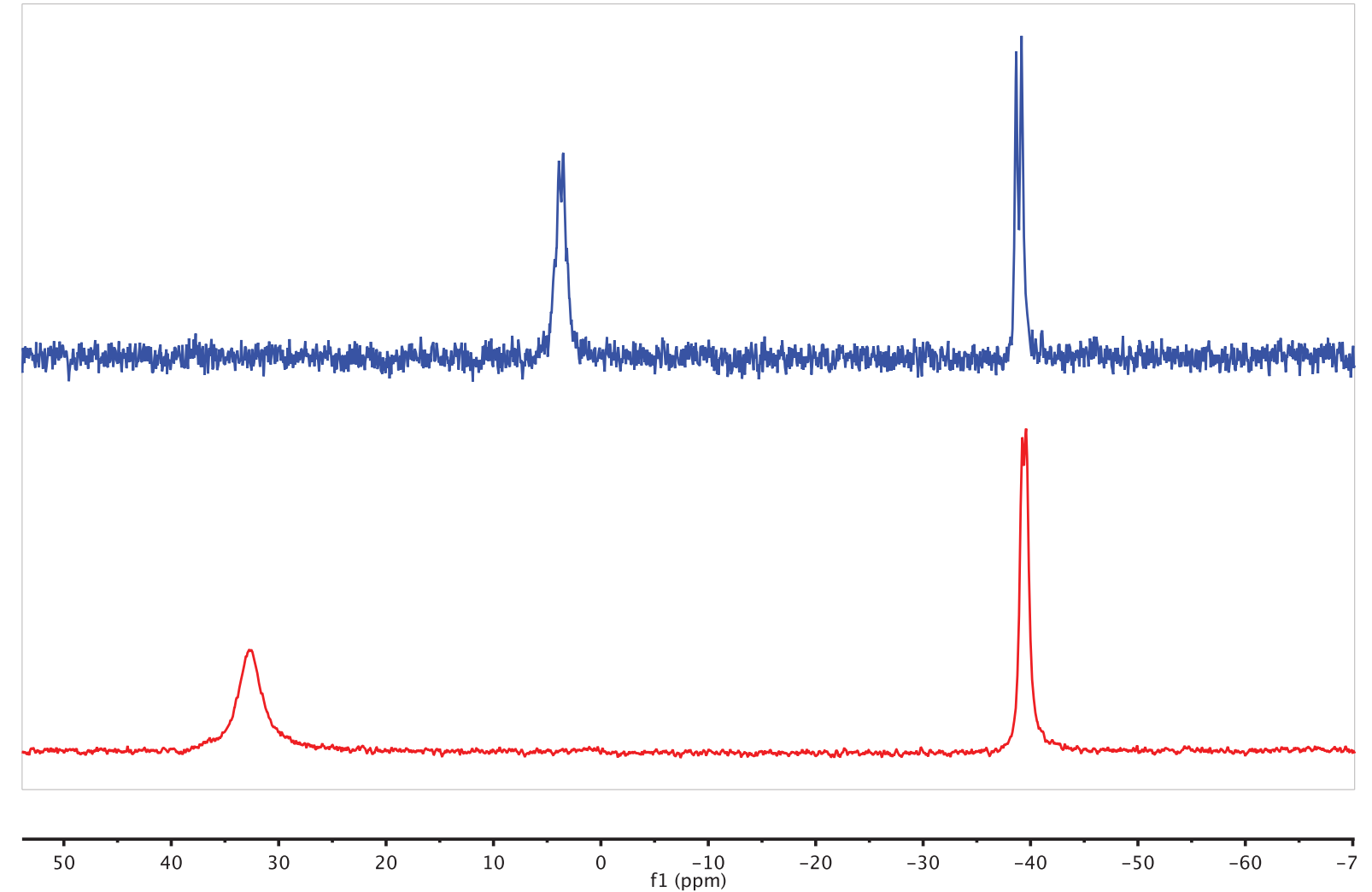

Figure 4.8. ${ }^{11} \mathrm{~B}\left\{{ }^{1} \mathrm{H}\right\}$ NMR spectra of $\mathrm{BH}_{3}$-protected 109 and 110 (bottom) and the potassium trifluoroborate salts 111 and 112 (top). 

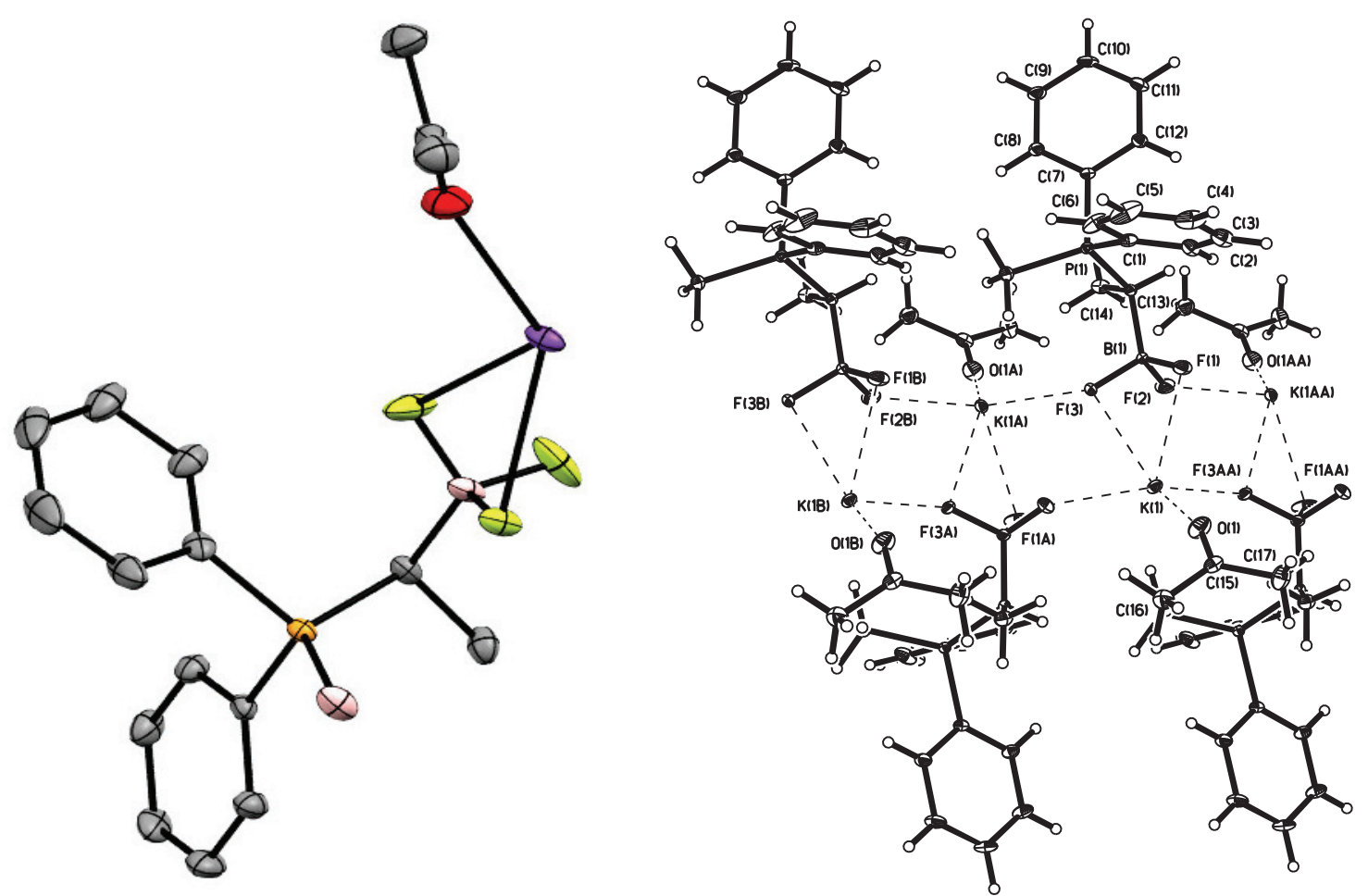

Figure 4.9. X-ray crystallographic structure of $\mathrm{K}\left[\mathrm{Ph}_{2} \mathrm{P}\left(\mathrm{BH}_{3}\right) \mathrm{CH}\left(\mathrm{CH}_{3}\right) \mathrm{BF}_{3}\right]$ (109) (thermal ellipsoids at $30 \%$ probability) with hydrogens removed for clarity. The asymmetric unit of each individual molecule (left) and the perspective view of the molecular arrangement of four units in the lattice (right) are shown. The dashed lines indicate the close contacts between the $\mathrm{K}^{+}$cations and the fluorine atoms of the neighboring anions and the $\mathrm{O}$ of the closest acetone molecule of solvation. Selected bond lengths $[\AA]$ and angles $\left[{ }^{\circ}\right]$ for $\mathrm{K}\left[\mathrm{Ph}_{2} \mathrm{P}\left(\mathrm{BH}_{3}\right) \mathrm{CH}\left(\mathrm{CH}_{3}\right) \mathrm{BF}_{3}\right] \square \mathrm{OC}\left(\mathrm{CH}_{3}\right)_{2}: \mathrm{K}(1)---\mathrm{F}\left(2^{\prime}\right)$ 2.562(1), $\mathrm{K}(1)---\mathrm{F}\left(3^{*}\right)$ 2.562(1), $\mathrm{K}(1)--$ -F(1) 2.767(1), K(1)---F(2) 3.3120(12), K(1)---F(3) 2.7949(8), K(1)---O(1) 2.636(1), P(1)$B(2)$ 1.933(2), $B(1)-F(1)$ 1.395(2), B(1)-F(2) 1.419(2), B(1)-F(3) 1.416(2), $C(13)-B(1)$ 1.623, $\quad \mathrm{C}(13)-\mathrm{P}(1)-\mathrm{B}(2) \quad 116.99(6), \quad \mathrm{B}(1)-\mathrm{C}(13)-\mathrm{P}(1) \quad 116.07(9), \quad \mathrm{C}(15)-\mathrm{O}(1)--\mathrm{K}(1)$ 159.47(12), $F(1)-B(1)-C(13)$ 114.59(11), $F(2)-B(1)-C(13)$ 109.73(12), $F(3)-B(1)-C(13)$ 113.39(10), $\quad F(1)-B(1)-F(3) \quad 106.94(12), \quad F(1)-B(1)-F(2) \quad 106.32(12), \quad F(3)-B(1)-F(2)$ 105.23(11). 


\subsection{Conclusion}

We sought to understand the role of ligand environment on the transition-metalcatalyzed hydroboration of a problematic class of strongly Lewis basic olefins. While our hypothesis that the Lewis basicity could be tempered with pendant Lewis acidic ligand scaffolds proved false, further studies into the reaction lead us to find that the branched regioisomer $1 \mathbf{1 0 2}^{\text {pin }}$ could be synthesized in high selectivity using synthetically convenient HBPin. Under low temperature in the presence of an excess of vinylphosphine, the regioselectivity was inverted to favor the linear isomer $101^{\text {pin }}$. To the best of our knowledge, this is the first example of regioselective control over hydroboration with Lewis basic substrates. Based on these results, a mechanism was proposed that provides a foundation for how to approach the utilization of these Lewis basic substrates.

Lastly, we demonstrated applications of the newly prepared $102^{\text {pin }}$ by synthesizing and isolating $\mathrm{Rh}(\mathrm{COD})\left[102^{\text {pin }}\right] \mathrm{Cl}$ complex 105 , as well as converting the pinacol boronic ester to a potassium trifluoroborate salt 109 . While no crystal structure was of the rhodium(I) complex was obtained, the NMR characterization demonstrates that there is no interaction between the pinacol boronic ester with the chloride, which is in agreement with expected results. Given the synthetic utility of trifluoroborate salts in cross-coupling ${ }^{71-74}$ and the ability to exploit these phosphine-trifluoroborate salts for their coordination to transition metals ${ }^{70,75,76}$, we are currently exploring new routes to broaden these reactions via synthetic and mechanistic studies. 


\subsection{Methods}

\subsubsection{General Considerations}

The manipulation of air- and moisture-sensitive compounds was conducted and performed under a nitrogen atmosphere utilizing either standard Schlenk or glove box techniques, employing dry solvent and glassware. Glovebox experiments were carried out in a MBraun 200B dual-port inert atmosphere glovebox equipped with a $-40^{\circ} \mathrm{C}$ freezer. Dry solvents were obtained utilizing a glass contour solvent purification system and stored in the glovebox over $4 \AA$ molecular sieves. Deuterated solvents were obtained from Cambridge Isotope Laboratories, Inc. and passed through neutral alumina and stored over $4 \AA$ molecular sieves. In the event that NMR data was recorded in non-deuterated NMR solvent, an internal capillary was used that was charged with $d_{6}$-benzene and sealed by flame. High-resolution mass spectra were recorded on a Thermo-Finnigan LTQ MS equipped with an ICR FTMS. NMR spectra were recorded on either a $400 \mathrm{MHz}$ Agilent or a $600 \mathrm{MHz}$ Varian Inova NMR. Spectra were referenced to residual protio-solvent peaks as an internal standard for ${ }^{1} \mathrm{H}$ and ${ }^{13} \mathrm{C}$.

The ${ }^{31} \mathrm{P}$ NMR was referenced to an external $\mathrm{H}_{3} \mathrm{PO}_{4}$ standard and the ${ }^{11} \mathrm{~B}$ and ${ }^{19} \mathrm{~F}$ NMR was referenced to an external $\mathrm{BF}_{3} \cdot \mathrm{OEt}_{2}$ standard. The phosphinoborane ligand ${ }^{56,77}$, $\left[\mathrm{Rh}(\mathrm{COD}) \mathrm{Cl}_{2}{ }^{78}\right.$ and $\left[\mathrm{Rh}(\mathrm{COE})_{2} \mathrm{Cl}\right]_{2}{ }^{79}$ were prepared according to previously published methods. The $\mathrm{Rh}(\mathrm{COD})\left[\mathrm{Ph}_{2} \mathrm{PCH}_{2} \mathrm{CH}_{2} \mathrm{~B}^{\mathrm{BBN}}\right] \mathrm{Cl}$ and $\mathrm{Rh}(\mathrm{CO})\left[\mathrm{Ph}_{2} \mathrm{PCH}_{2} \mathrm{CH}_{2} \mathrm{~B}^{\mathrm{BBN}}\right]_{2} \mathrm{Cl}$ were prepared by modification of literature procedures. ${ }^{57}$

\subsubsection{General Procedure for Hydroboration of Vinyl Diphenylphosphine}

A sample of 0.5 mol\% loading for the $\mathrm{Rh}(\mathrm{COD})$ complex is dissolved in THF, along with the internal standard 1,3,5-trimethoxybenzene, in a small vial equipped with 
a Teflon cap. One equivalent of silver $(\mathrm{I})$ triflate per rhodium is added and the sample is stirred for $30-40$ minutes. To this sample, the vinyl diphenylphosphine is added. This sample is treated with pinacolborane, where the limiting reagent is at a $100 \mathrm{mM}$ concentration, and allowed to stir at the selected temperature. Once complete, the solvent is removed in vacuo resulting in the formation of a yellow oil. This sample can be taken up in benzene and filtered and dried in vacuo. The residual solvent and HBPin were removed by applying a 20 Torr vacuum overnight.

$\mathrm{Ph}_{2} \mathrm{PCH}\left(\mathrm{CH}_{3}\right)$ Bpin (102 $\left.{ }^{\mathrm{pin}}\right)$ : ${ }^{1} \mathrm{H}$ NMR (400 MHz, $\left.\mathrm{C}_{6} \mathrm{D}_{6}\right): \delta 7.34-7.45(\mathrm{~m}, 2 \mathrm{H}, \mathrm{Ph}), \delta$ $7.00-7.14(\mathrm{~m}, 8 \mathrm{H}, P h), \delta 2.02-2.17\left(\mathrm{dq}, 1 \mathrm{H},{ }^{1} \mathrm{~J}_{\mathrm{PH}}=5 \mathrm{~Hz},{ }^{3} \mathrm{~J}_{\mathrm{HH}}=7.3 \mathrm{~Hz}, \mathrm{PCH}\left(\mathrm{CH}_{3}\right) \mathrm{B}\right)$, $\delta 1.22-1.34\left(\mathrm{dd}, 3 \mathrm{H},{ }^{3} \mathrm{~J}_{\mathrm{PH}}=16.4 \mathrm{~Hz},{ }^{3} \mathrm{~J}_{\mathrm{HH}}=7.3 \mathrm{~Hz}, \mathrm{PCH}\left(\boldsymbol{C H}_{3}\right) \mathrm{B}\right), 0.93(6 \mathrm{H}, \mathrm{Me}-$ Pinacol), 0.90 (6H, Me-Pinacol). ${ }^{31} \mathrm{P}\left\{{ }^{1} \mathrm{H}\right\} \mathrm{NMR}\left(162 \mathrm{MHz}, \mathrm{C}_{6} \mathrm{D}_{6}\right): \delta-4.6$ (s). ${ }^{11} \mathrm{~B}\left\{{ }^{1} \mathrm{H}\right\} \mathrm{NMR}$ (128 MHz, $\left.\mathrm{C}_{6} \mathrm{D}_{6}\right): \delta 28.3$ (br. s).

$\mathrm{Ph}_{2} \mathrm{PCH}_{2} \mathrm{CH}_{2}$ Bpin (101 $\left.{ }^{\mathrm{pin}}\right)$ : ${ }^{1} \mathrm{H}$ NMR (400 MHz, $\left.\mathrm{C}_{6} \mathrm{D}_{6}\right): \delta 7.5-7.66(\mathrm{~m}, 10 \mathrm{H}, \mathrm{Ph}), \delta 2.18$ - 2.30 (br. t, $2 \mathrm{H}, \mathrm{PCH}_{2} \mathrm{CH}_{2} \mathrm{~B}$ ), $\delta 1.03-1.09$ (dt, $2 \mathrm{H},{ }^{3} \mathrm{~J}_{\mathrm{HP}}=8.5 \mathrm{~Hz}, \mathrm{PCH}_{2} \mathrm{CH}_{2} \mathrm{~B}$ ), 1.056 (12H, Me-Pinacol). ${ }^{31} \mathrm{P}\left\{{ }^{1} \mathrm{H}\right\} \operatorname{NMR}\left(162 \mathrm{MHz}, \mathrm{C}_{6} \mathrm{D}_{6}\right): \delta-10.5$ (s). ${ }^{11} \mathrm{~B}\left\{{ }^{1} \mathrm{H}\right\} \mathrm{NMR}(128 \mathrm{MHz}$, $\left.\mathrm{C}_{6} \mathrm{D}_{6}\right): \delta 21.7$ (br. s).

\subsubsection{NMR Characterization of Vinylphosphine Hydroboration Products}

The vinylphosphine hydroboration products were characterized by ${ }^{1} \mathrm{H},{ }^{13} \mathrm{C}$, ${ }^{31} \mathrm{P}\left\{{ }^{1} \mathrm{H}\right\}$ and ${ }^{11} \mathrm{~B}\left\{{ }^{1} \mathrm{H}\right\}$ NMR experiments. The products were also characterized by $\mathrm{gHSQC}$ and $\mathrm{gHMBC}^{80}$ experiments with the following parameters. For $\mathrm{gHSQC}$, the parameters were at $=0.150 \mathrm{~s}, \mathrm{nt}=16, \mathrm{ss}=32, \mathrm{~d} 1=1.0 \mathrm{~s}, \mathrm{ni}=128, \mathrm{j} 1 \mathrm{xh}=146, \mathrm{temp}=$ $25^{\circ} \mathrm{C}$. For $\mathrm{gHMBC}$, the parameters were at $=0.150 \mathrm{~s}, \mathrm{nt}=16, \mathrm{ss}=32, \mathrm{~d} 1=1.0 \mathrm{~s}, \mathrm{ni}=$ $200, \mathrm{j} 1 \mathrm{xh}=146, \mathrm{jnxh}=8.0$, temp $=25^{\circ} \mathrm{C}$. 


\subsubsection{General Procedure for the Synthesis of $\mathrm{Rh}(\mathrm{COD})\left[\mathrm{Ph}_{2} \mathrm{PCH}\left(\mathrm{CH}_{3}\right) \mathrm{BPin}\right] \mathrm{Cl}$ Complex 105}

A sample of $[\mathrm{Rh}(\mathrm{COD}) \mathrm{Cl}]_{2}(247 \mathrm{mg}, 0.5 \mathrm{mmols})$ was dissolved in toluene in a 20 $\mathrm{mL}$ vial equipped with stirring. A mixture of isomers, $\mathrm{Ph}_{2} \mathrm{PCH}\left(\mathrm{CH}_{3}\right) \mathrm{BPin}$ and $\mathrm{Ph}_{2} \mathrm{PCH}_{2} \mathrm{CH}_{2} \mathrm{BPin}$ (340.2 mg, $1.0 \mathrm{mmols}$ ), was added as a solution in benzene. The sample was stirred for 21 hours. The sample was dried in vacuo and pentane was added. The yellow solution was isolated and the brown solid was again dissolved in toluene and then dried in vacuo and the pentane extraction was repeated. The yellow solution was dried in vacuo (234 $\mathrm{mg}, 40 \%)$.

${ }^{1} \mathrm{H}$ NMR $\left(400 \mathrm{MHz}, \mathrm{C}_{6} \mathrm{D}_{6}\right): \delta 7.83-7.94(\mathrm{~m}, 4 \mathrm{H}, \mathrm{Ph}), \delta 6.98-7.08(\mathrm{~m}, 6 \mathrm{H}, \mathrm{Ph}), \delta 5.59$ - 5.80 (m, 2H, COD-CH trans P), $\delta 2.90-3.24$ (br. d, 2H, COD-CH trans Cl), $\delta 2.70-$ $2.89(\mathrm{dq}, \mathrm{J}=15.0,7.6 \mathrm{~Hz}, 1 \mathrm{H}, \mathrm{PCH}), \delta 2.01-2.22\left(\mathrm{~m}, 5 \mathrm{H}, \mathrm{COD}-\mathrm{CH}_{2}\right), \delta 1.25-1.98$ $\left(\mathrm{m}, 4 \mathrm{H}, \mathrm{COD}-\mathrm{CH}_{2}\right), \delta 1.61-1.74\left(\mathrm{~m}, 2 \mathrm{H}, \mathrm{COD}-\mathrm{CH}_{2}\right), \delta 1.48-1.56(\mathrm{dd}, \mathrm{J}=15.0,7.6$ $\mathrm{Hz}, 5 \mathrm{H}, \mathrm{PCH}(\mathrm{BPin}) \mathrm{CH}_{3}, \mathrm{COD}-\mathrm{CH}_{2}$ ), $\delta 1.11$ (s, 6H, BPin-Me), $\delta 1.07$ (s, 6H, BPin-Me). ${ }^{13} \mathrm{C}\left\{{ }^{1} \mathrm{H}\right\}$ NMR (100 MHz, $\left.\mathrm{C}_{6} \mathrm{D}_{6}\right): \delta 133.7\left(\mathrm{~d}, 2 \mathrm{C},{ }^{1} \mathrm{~J}_{\mathrm{P}-\mathrm{C}}=36.2 \mathrm{~Hz}\right.$, ipso-Ph), 134.6 (d, 4C, $\left.{ }^{3} \mathrm{~J}_{\mathrm{P}-\mathrm{C}}=14.0 \mathrm{~Hz}, m-P h\right), \delta 134.6\left(\mathrm{~d}, 4 \mathrm{C},{ }^{2} \mathrm{~J}_{\mathrm{P}-\mathrm{C}}=14.0 \mathrm{~Hz}, o-P h\right), \delta 130.1\left(\mathrm{~d}, 2 \mathrm{C},{ }^{4} \mathrm{~J}_{\mathrm{P}-\mathrm{C}}=7.0\right.$ $\mathrm{Hz}, \mathrm{p}-\mathrm{Ph}), \delta 102.2\left(\mathrm{~m}, 2 \mathrm{C}, \mathrm{COD}-\mathrm{CH}\right.$, trans-P), $\delta 83.5$ (s, BPin), $\delta 63.35$ (dd, 2C, ${ }^{1} \mathrm{~J}_{\mathrm{Rh}-\mathrm{C}}=$ $72.1 \mathrm{~Hz},{ }^{2} \mathrm{~J}_{\mathrm{Rh}-\mathrm{P}}=13.4 \mathrm{~Hz}, C O D-C H$, trans-P), $\delta 33.1\left(\mathrm{~d}, 2 \mathrm{C},{ }^{3} \mathrm{~J}_{\mathrm{P}-\mathrm{C}}=2.0 \mathrm{~Hz}, C O D-C H_{2}\right.$, trans-P), $\delta 32.9\left(\mathrm{~d}, 2 \mathrm{C},{ }^{3} \mathrm{~J}_{\mathrm{P}-\mathrm{C}}=3.02 \mathrm{~Hz}, \mathrm{COD}-\mathrm{CH}_{2}\right.$, trans- $\left.\mathrm{P}\right), \delta 24.8$ (s, 4C, BPin-Me), $\delta$ 17.4 (br. m, $\left.\mathrm{PCH}\left(\mathrm{CH}_{3}\right)\right)$, $\delta 13.3$ (s, $\left.\mathrm{PCH}\left(\mathrm{CH}_{3}\right)\right) .{ }^{31} \mathrm{P}\left\{{ }^{1} \mathrm{H}\right\} \mathrm{NMR}\left(162 \mathrm{MHz}, \mathrm{C}_{6} \mathrm{D}_{6}\right): \delta 34.7$ (d, $\left.{ }^{1} \mathrm{~J}_{\mathrm{Rh}-\mathrm{P}}=148.6 \mathrm{~Hz}, \mathrm{Rh}(\mathrm{COD})\left[\mathrm{Ph}_{2} \mathrm{PCH}\left(\mathrm{CH}_{3}\right) \mathrm{BPin}\right] \mathrm{Cl}\right) .{ }^{11} \mathrm{~B}\left\{{ }^{1} \mathrm{H}\right\} \mathrm{NMR}\left(128 \mathrm{MHz}, \mathrm{C}_{6} \mathrm{D}_{6}\right): \delta$ 33.4 (br. s, BPin). HRMS: m/z $551.17524\left[\mathrm{C}_{30} \mathrm{H}_{41} \mathrm{BNO}_{2} \mathrm{PRh}-(\mathrm{M}-\mathrm{Cl})^{+}\right.$requires 551.17525]. 


\subsubsection{General Procedure for the Protection of Vinylphosphine Hydroboration Products with $\mathrm{BH}_{3}$-THF (106 and 107)}

A sample of $\left[\mathrm{Ph}_{2} \mathrm{PCH}(\mathrm{BPin}) \mathrm{CH}_{3}\right]$ and $\left[\mathrm{Ph}_{2} \mathrm{PCH}_{2} \mathrm{CH}_{2} \mathrm{BPin}\right]$ (340 mg, 0.999 mmols) was dissolved in THF in a $25 \mathrm{~mL}$ round bottom flask equipped with a magnetic stir bar and a septum. The $\mathrm{BH}_{3}$-THF, (128.8 mg, $\left.1.499 \mathrm{mmols}\right)$, was added as a $1.0 \mathrm{M}$ solution in THF and the reaction was allowed to stir overnight. The sample was filtered through Celite and the solvent was removed in vacuo. The sample was taken up in benzene and filtered through Celite and the solvent was removed in vacuo. The sample was precipitated by addition of pentane and cooled to $-40^{\circ} \mathrm{C}$. The brown/tan solid was isolated (241 $\mathrm{mg}, 68 \%)$.

$\left[\mathrm{BH}_{3}\right]\left[\mathrm{Ph}_{2} \mathrm{PCH}\left(\mathrm{CH}_{3}\right) \mathrm{BPin}\right]$ (107): ${ }^{1} \mathrm{H} \mathrm{NMR}\left(400 \mathrm{MHz}, \mathrm{C}_{6} \mathrm{D}_{6}\right): \delta 7.93(\mathrm{~m}, 2 \mathrm{H}, \mathrm{Ph}), \delta 7.78$

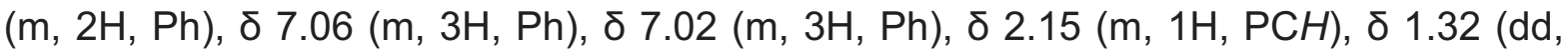
$3 \mathrm{H}, \mathrm{J}=17.5 \mathrm{~Hz}, \mathrm{~J}=7.3 \mathrm{~Hz}, \mathrm{CH}_{3}$ ), $\delta 0.95$ (s, 6H, Me-BPin), $\delta 0.91$ (s, 6H, Me-BPin), $\delta$ $0.87\left(\mathrm{t}, 3 \mathrm{H}, \mathrm{J}=7.1 \mathrm{~Hz}, \mathrm{BH}_{3}\right) .\left[\mathrm{BH}_{3}\right]\left[\mathrm{Ph}_{2} \mathrm{PCH}_{2} \mathrm{CH}_{2} \mathrm{BPin}\right](106): \delta 7.61(\mathrm{~m}, 5 \mathrm{H}, \mathrm{Ph}), \delta$ $6.96(\mathrm{~m}, 5 \mathrm{H}, \mathrm{Ph}), \delta 2.38\left(\mathrm{~m}, 2 \mathrm{H}, \mathrm{PCH}_{2}\right), \delta 1.24$ (br. dt, 2H, $\left.\mathrm{CH}_{2} \mathrm{~B}\right), \delta 1.01$ (s, 12H, MeBPin). ${ }^{13} \mathrm{C}\left\{{ }^{1} \mathrm{H}\right\}$ NMR (100 MHz, $\left.\mathrm{C}_{6} \mathrm{D}_{6}\right): \delta 133.4$ (d, J = 9.1 Hz, m-Ph), $\delta 132.9$ (d, J = 8.9 Hz, m-Ph), $\delta 131.3$ (d, J = 12.3 Hz, ipso-Ph), $\delta 133.8$ (d, J = 10.1 Hz, ipso-Ph), $\delta 130.8$ (d, J = 6.04 Hz, p-Ph), $\delta 130.7$ (d, J = 6.04 Hz, p-Ph), $\delta 128.7$ (d, J = 9.8 Hz, o-Ph), $\delta$ 128.4 (d, J = 10.0 Hz, o-Ph), $\delta 83.1$ (s, BPin, $\delta 18.6$ (br. m, PCH(CH$\left.{ }_{3}\right)$ ), $\delta 24.8$ (s, BPinMe), $\delta 24.8$ (s, BPin-Me), $\delta 14.2$ (s, $\mathrm{PCH}\left(\mathrm{CH}_{3}\right)$ ), $\delta 10.7$ (br. m, $\left.\mathrm{PCH}\left(\mathrm{CH}_{3}\right)\right) .{ }^{31} \mathrm{P}\left\{{ }^{1} \mathrm{H}\right\} \mathrm{NMR}$ (162 $\left.\mathrm{MHz}, \quad \mathrm{C}_{6} \mathrm{D}_{6}\right): \quad \delta \quad 23.0 \quad\left(\mathrm{~m}, \quad\left[\mathrm{BH}_{3}\right]\left[\mathrm{Ph}_{2} \mathrm{PCH}(\mathrm{BPin}) \mathrm{CH}_{3}\right]\right), \quad \delta \quad 20.1 \quad(\mathrm{~m}$, $\left.\left[\mathrm{BH}_{3}\right]\left[\mathrm{Ph}_{2} \mathrm{PCH}_{2} \mathrm{CH}_{2}(\mathrm{BPin})\right]\right) . \quad{ }^{11} \mathrm{~B}\left\{{ }^{1} \mathrm{H}\right\} \quad \mathrm{NMR} \quad\left(128 \mathrm{MHz}, \quad \mathrm{C}_{6} \mathrm{D}_{6}\right): \quad \delta \quad 32.8$ (br. $\quad \mathrm{s}$, $\left.\left[\mathrm{BH}_{3}\right]\left[\mathrm{Ph}_{2} \mathrm{PCH}(\mathrm{BPin}) \mathrm{CH}_{3}\right]\right), \quad \delta 22.9$ (br. s, $\left.\left[\mathrm{BH}_{3}\right]\left[\mathrm{Ph}_{2} \mathrm{PCH}_{2} \mathrm{CH}_{2}(\mathrm{BPin})\right]\right), \delta$-39.6 (d, $\left[\mathrm{BH}_{3}\right]\left[\mathrm{Ph}_{2} \mathrm{PCH}(\mathrm{BPin}) \mathrm{CH}_{3}\right], \quad\left[\mathrm{BH}_{3}\right]\left[\mathrm{Ph}_{2} \mathrm{PCH}_{2} \mathrm{CH}_{2}\right.$ (BPin)]). ${ }^{11} \mathrm{~B}$ NMR (128 MHz, $\left.\mathrm{C}_{6} \mathrm{D}_{6}\right): \delta$ 
32.8 (br. s, $\left.\left[\mathrm{BH}_{3}\right]\left[\mathrm{Ph}_{2} \mathrm{PCH}(\mathrm{BPin}) \mathrm{CH}_{3}\right]\right)$, $\delta 22.9$ (br. s, $\left[\mathrm{BH}_{3}\right]\left[\mathrm{Ph}_{2} \mathrm{PCH}_{2} \mathrm{CH}_{2}(\mathrm{BPin})\right]$ ), $\delta$-39.6 (m, $\left[\mathrm{BH}_{3}\right]\left[\mathrm{Ph}_{2} \mathrm{PCH}(\mathrm{BPin}) \mathrm{CH}_{3}\right],\left[\mathrm{BH}_{3}\right]\left[\mathrm{Ph}_{2} \mathrm{PCH}_{2} \mathrm{CH}_{2}\right.$ (BPin)]). $\mathrm{BH}_{3}$ groups appear as broad signals that overlap with the alkyl region of the ${ }^{1} \mathrm{H}$ NMR spectra. Minor impurities in ${ }^{13} \mathrm{C}$ NMR spectra correspond to linear isomer of protected phosphine.

\subsubsection{General Procedure for the Transformation of Pinacolboronic Ester into Potassium Trifluoroborate Salt (109)}

A sample of $\left[\mathrm{BH}_{3}\right]\left[\mathrm{Ph}_{2} \mathrm{PCH}(\mathrm{BPin}) \mathrm{CH}_{3}\right]$ and $\left[\mathrm{BH}_{3}\right]\left[\mathrm{Ph}_{2} \mathrm{PCH}_{2} \mathrm{CH}_{2} \mathrm{BPin}\right]$ (90 mg, 0.254 mmols) was dissolved in $4 \mathrm{~mL}$ of THF in a small plastic bottle equipped with a magnetic stir bar and a cap. The $\mathrm{KHF}_{2}$, (130.9 mg, 1.678 mmols), was added as a solid, followed by $4 \mathrm{~mL}$ of de-ionized water. The reaction was allowed to stir for 2 hours. The sample was transferred to a round bottom and the solvent removed in vacuo. The sample was taken up in acetone and filtered through cotton. The solid residue was washed with additional acetone. The sample was dried in vacuo and then washed with diethyl ether. The sample was purified to provide a white solid by layering an acetone solution with pentane at $-20^{\circ} \mathrm{C}(59 \mathrm{mg}, 70 \%)$. X-Ray quality crystals of the branched isomer can be obtained by vapor diffusion of pentane into a concentrated acetone solution of the isomeric mixture at $-20^{\circ} \mathrm{C}$.

$\mathrm{Ph}_{2} \mathrm{P}\left(\mathrm{BH}_{3}\right) \mathrm{CH}\left(\mathrm{CH}_{3}\right) \mathrm{BF}_{3} \mathrm{~K}$ (109): ${ }^{1} \mathrm{H}$ NMR (600 MHz, $\mathrm{d}_{6}$-acetone): $\delta 7.84(\mathrm{~m}, 2 \mathrm{H}, \mathrm{Ph}), \delta$

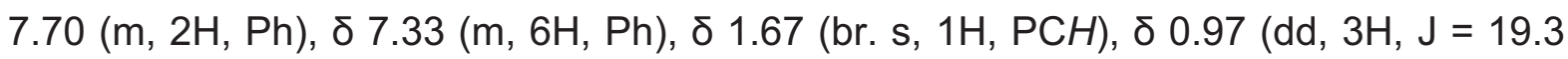
$\mathrm{Hz}, \mathrm{J}=7.4 \mathrm{~Hz}, \mathrm{CH}_{3}$ ), $\delta 0.4-1.4$ (br. m, 3H, BH $\left.{ }_{3}\right) .{ }^{13} \mathrm{C}$ NMR (151 MHz, d $\mathrm{d}^{6}$-acetone): $\delta$

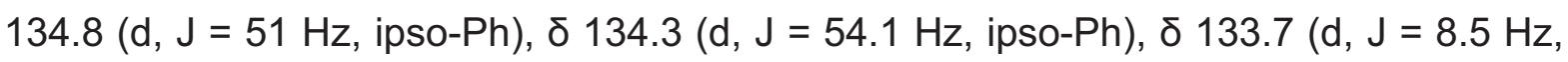

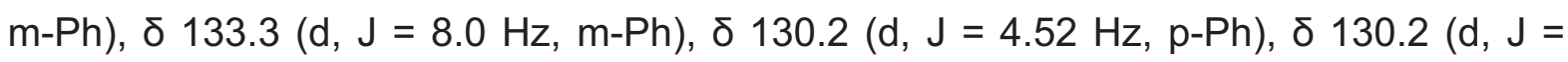
$4.52 \mathrm{~Hz}, \mathrm{p}-\mathrm{Ph}$ ), $\delta 128.6$ (d, J = 9.2 Hz, o-Ph), $\delta 128.3$ (d, J = $9.3 \mathrm{~Hz}, \mathrm{o}-\mathrm{Ph}$ ), $\delta 18.57$ (br. $\left.\mathrm{m}, \mathrm{PCH}\left(\mathrm{CH}_{3}\right)\right), \delta 11.6$ (s, $\left.\mathrm{PCH}\left(\mathrm{CH}_{3}\right)\right) .{ }^{31} \mathrm{P}\left\{{ }^{1} \mathrm{H}\right\} \mathrm{NMR}\left(162 \mathrm{MHz}, \mathrm{d}_{6}\right.$-acetone): $\delta 22.2(\mathrm{~m}$, 
$\left.\left[\mathrm{BH}_{3}\right]\left[\mathrm{Ph}_{2} \mathrm{PCH}(\mathrm{BPin}) \mathrm{CH}_{3}\right]\right) .{ }^{11} \mathrm{~B}\left\{{ }^{1} \mathrm{H}\right\}$ NMR (128 MHz, d $\mathrm{d}_{6}$-acetone): $\delta 4.1$ (br. s, 1B, $\left.\left[\mathrm{BH}_{3}\right]\left[\mathrm{Ph}_{2} \mathrm{PCH}\left(\mathrm{BF}_{3} \mathrm{~K}\right) \mathrm{CH}_{3}\right]\right), \delta-38.9\left(\mathrm{~d}, \mathrm{~J}=64.7 \mathrm{~Hz},\left[\mathrm{BH}_{3}\right]\left[\mathrm{Ph}_{2} \mathrm{PCH}\left(\mathrm{BF}_{3} \mathrm{~K}\right) \mathrm{CH}_{3}\right]\right) .{ }^{11} \mathrm{~B} \mathrm{NMR}$ (128 MHz, $\mathrm{d}_{6}$-acetone): $\delta \quad 4.1$ (br. $\left.\mathrm{s}, \quad\left[\mathrm{BH}_{3}\right]\left[\mathrm{Ph}_{2} \mathrm{PCH}\left(B F_{3} K\right) \mathrm{CH}_{3}\right]\right), \quad \delta \quad-38.9 \quad(\mathrm{~m}$, $\left.\left[\mathrm{BH}_{3}\right]\left[\mathrm{Ph}_{2} \mathrm{PCH}\left(\mathrm{BF}_{3} \mathrm{~K}\right) \mathrm{CH}_{3}\right]\right) .{ }^{19} \mathrm{~F} \quad \mathrm{NMR} \quad\left(376 \mathrm{MHz}, \mathrm{d}_{6}\right.$-acetone): $\delta$-138.2 (br. $\mathrm{s}$, $\left.\left[\mathrm{BH}_{3}\right]\left[\mathrm{Ph}_{2} \mathrm{PCH}\left(\mathrm{BF}_{3} \mathrm{~K}\right) \mathrm{CH}_{3}\right]\right)$.

\subsection{References}

(1) Burgess, K.; Ohlmeyer, M. J. Chem. Rev. 1991, 91, 1179.

(2) Crudden, C. M.; Edwards, D. Eur. J. Org. Chem. 2003, 4695.

(3) Geier, M. J.; Vogels, C. M.; Decken, A.; Westcott, S. A. J. Organomet. Chem. 2009, 694, 3154.

(4) Goralski, C. T.; Singaram, B. Arkivoc 2012, 88.

(5) Singaram, B.; Goralski, C. T.; Rangaishenvi, M. V.; Brown, H. C. J. Am. Chem. Soc. $1989,111,384$.

(6) Zhang, L.; Zuo, Z.; Leng, X.; Huang, Z. Angew. Chem. Int. Ed. Engl. 2014, 53, 2696.

(7) Colin, S.; Vaysse-Ludot, L.; Lecouve, J-P.; Maddaluno, J. J. Chem. Soc. Perk. T. $12000,4505$.

(8) Bungard, C. J.; Hartman, G. D.; Manikowski, J. J.; Perkins, J. J.; Bai, C.; Brandish, P. E.; Euler, D. H.; Hershey, J. C.; Schmidt, A.; Fang, Y.; Norcross, R. T.; Rushmore, T. H.; Thompson, C. D.; Meissner, R. S. Bioorg. Med. Chem. 2011, 19, 7374 .

(9) Horino, Y.; Aimono, A.; Abe, H. Org. Lett. 2015, 17, 2824.

(10) Yu, S.; Wu, C.; Ge, S. J. Am. Chem. Soc. 2017, 139, 6526.

(11) Xi, T.; Lu, Z. ACS Catal. 2017, 7, 1181. 
(12) Ibrahim, A. D.; Entsminger, S. W.; Fout, A. R. ACS Catal. 2017, 7, 3730.

(13) Obligacion, J. V.; Chirik, P. J. Org. Lett. 2013, 15, 2680.

(14) Zhang, L.; Peng, D.; Leng, X.; Huang, Z. Angew. Chem. Int. Ed. Engl. 2013, 52, 3676.

(15) Lee, H.; Lee, B. Y.; Yun, J. Org. Lett. 2015, 17, 764.

(16) Obligacion, J. V.; Chirik, P. J. J. Am. Chem. Soc. 2013, 135, 19107.

(17) Molander, G. A.; Yun, C-S.; Ribagorda, M.; Biolatto, B. J. Org. Chem. 2003, 68, 5534 .

(18) Zhu, G.; Kong, W.; Feng, H.; Qian, Z. J. Org. Chem. 2014, 79, 1786.

(19) Webb, J. D.; Harrison, D. J.; Norman, D. W.; Blacquiere, J. M.; Vogels, C. M.; Decken, A.; Bates, C. G.; Venkataraman, D.; Baker, R. T.; Westcott, S. A. J. Mol. Catal. A Chem. 2007, 275, 91.

(20) Haberberger, M.; Enthaler, S. Chem. Asian J. 2013, 8, 50.

(21) Gorgas, N.; Alves, L. G.; Stöger, B.; Martins, A. M.; Veiros, L. F.; Kirchner, K. J. Am. Chem. Soc. 2017, 139, 8130.

(22) Zuo, Z.; Huang, Z. Org. Chem. Front. 2016, 3, 434.

(23) Obligacion, J. V.; Neely, J. M.; Yazdani, A. N.; Pappas, I.; Chirik, P. J. J. Am. Chem. Soc. 2015, 137, 5855.

(24) Gunanathan, C.; Hölscher, M.; Pan, F.; Leitner, W. J. Am. Chem. Soc. 2012, $134,14349$.

(25) Bidal, Y. D.; Lazreg, F.; Cazin, C. S. J. ACS Catal. 2014, 4, 1564.

(26) Ben-Daat, H.; Rock, C. L.; Flores, M.; Groy, T. L.; Bowman, A. C.; Trovitch, R. J. Chem. Commun. 2017, 53, 7333. 
(27) Garon, C. N.; Mclsaac, D. I.; Vogels, C. M.; Decken, A.; Williams, I. D.; Kleeberg, C.; Marder, T. B.; Westcott, S. A. Dalton Trans. 2009, 1624.

(28) Hornillos, V.; Vila, C.; Otten, E.; Feringa, B. L. Angew. Chem. Int. Edit. 2015, 54, 7867.

(29) Thangavelu, S. G.; Hocker, K. E.; Cooke, S. R.; Muhoro, C. N. J. Organomet. Chem. 2008, 693, 562.

(30) Chakrabarty, S.; Takacs, J. M. J. Am. Chem. Soc. 2017, 139, 6066.

(31) Coles, S. J.; Faulds, P.; Hursthouse, M. B.; Kelly, D. G.; Ranger, G. C.; Toner, A. J.; Walker, N. M. J. Organomet. Chem. 1999, 586, 234.

(32) Miller, A. J. M.; Labinger, J. A.; Bercaw, J. E. Organometallics 2010, 29, 4499.

(33) Ostapowicz, T. G.; Merkens, C.; Hölscher, M.; Klankermayer, J.; Leitner, W. J. Am. Chem. Soc. 2013, 135, 2104.

(34) Song, L-C.; Gai, B.; Feng, Z-H.; Du, Z-Q.; Xie, Z-J.; Sun, X-J.; Song, H-B. Organometallics 2013, 32, 3673.

(35) Chen, S.; Ng, J. K-P.; Pullarkat, S. A.; Liu, F.; Li, Y.; Leung, P-H. Organometallics 2010, 29, 3374.

(36) Weiner, B.; Baeza, A.; Jerphagnon, T.; Feringa, B. L. J. Am. Chem. Soc. 2009, $131,9473$.

(37) Aggarwal, V. K.; Fang, G. Y.; Meek, G. Org. Lett. 2003, 5, 4417.

(38) Vogels, C. M.; O'Connor, P. E.; Phillips, T. E.; Watson, K. J.; Shaver, M. P.; Hayes, P. G.; Westcott, S. A. Can. J. Chem. 2001, 79, 1898.

(39) Westcott, S. A.; Blom, H. P.; Marder, T. B.; Baker, R. T.; Calabrese, J. C. Inorg. Chem. 1993, 32, 2175. 
(40) Bouhadir, G.; Bourissou, D. Chem. Soc. Rev. 2016, 45, 1065.

(41) Bouhadir, G.; Amgoune, A.; Bourissou, D. In Adv Organomet Chem; Hill, A. F., Fink, M. J., Eds. 2010; Vol. 58, p 1.

(42) Spies, P.; Kehr, G.; Bergander, K.; Wibbeling, B.; Fröhlich, R.; Erker, G. Dalton Trans. 2009, 1534.

(43) Spies, P.; Fröhlich, R.; Kehr, G.; Erker, G.; Grimme, S. Chem. Eur. J. 2008, 14, 333.

(44) Schmidbaur, H.; Sigl, M.; Schier, A. J. Organomet. Chem. 1997, 529, 323.

(45) Xu, B-H.; Kehr, G.; Fröhlich, R.; Wibbeling, B.; Schirmer, B.; Grimme, S.; Erker, G. Angew. Chem. Int. Edit. 2011, 50, 7183.

(46) Wang, L.; Zhang, S.; Hasegawa, Y.; Daniliuc, C. G.; Kehr, G.; Erker, G. Chem. Commun. 2017, 53, 5499.

(47) Wang, L.; Samigullin, K.; Wagner, M.; McQuilken, A. C.; Warren, T. H.; Daniliuc, C. G.; Kehr, G.; Erker, G. Chem. Eur. J. 2016, 22, 11015.

(48) Stute, A.; Kehr, G.; Fröhlich, R.; Erker, G. Chem. Commun. 2011, 47, 4288.

(49) Sajid, M.; Klose, A.; Birkmann, B.; Liang, L.; Schirmer, B.; Wiegand, T.; Eckert, H.; Lough, A. J.; Frohlich, R.; Daniliuc, C. G.; Grimme, S.; Stephan, D. W.; Kehr, G.; Erker, G. Chem. Sci. 2013, 4, 213.

(50) Liedtke, R.; Scheidt, F.; Ren, J.; Schirmer, B.; Cardenas, A. J. P.; Daniliuc, C. G.; Eckert, H.; Warren, T. H.; Grimme, S.; Kehr, G.; Erker, G. J. Am. Chem. Soc. 2014, 136, 9014.

(51) Hasegawa, Y.; Kehr, G.; Ehrlich, S.; Grimme, S.; Daniliuc, C. G.; Erker, G. Chem. Sci. 2014, 5, 797. 
(52) Frömel, S.; Kehr, G.; Fröhlich, R.; Daniliuc, C. G.; Erker, G. Dalton Trans. 2013, $42,14531$.

(53) Frömel, S.; Daniliuc, C. G.; Bannwarth, C.; Grimme, S.; Bussmann, K.; Kehr, G.; Erker, G. Dalton Trans. 2016, 45, 19230.

(54) Erdmann, M.; Rösener, C.; Holtrichter-Rößmann, T.; Daniliuc, C. G.; Fröhlich, R.; Uhl, W.; Wurthwein, E-U.; Kehr, G.; Erker, G. Dalton Trans. 2013, 42, 709.

(55) Miller, A. J. M.; Labinger, J. A.; Bercaw, J. E. J. Am. Chem. Soc. 2008, 130, 11874.

(56) Fischbach, A.; Bazinet, P. R.; Waterman, R.; Tilley, T. D. Organometallics 2008, $27,1135$.

(57) Greenacre, V. K.; Ansell, M. B.; Roe, S. M.; Crossley, I. R. Eur. J. Inorg. Chem. 2014, 5053.

(58) Burgess, K.; van der Donk, W. A.; Westcott, S. A.; Marder, T. B.; Baker, R. T.; Calabrese, J. C. J. Am. Chem. Soc. 1992, 114, 9350.

(59) Hirata, G.; Satomura, H.; Kumagae, H.; Shimizu, A.; Onodera, G.; Kimura, M. Org. Lett. 2017, 19, 6148.

(60) Weliange, N. M.; McGuinness, D. S.; Patel, J. Organometallics 2014, 33, 4251.

(61) Brown, H. C.; Joshi, N. N. J. Org. Chem. 1988, 53, 4059.

(62) Morrill, T. C.; D'Souza, C. A.; Yang, L.; Sampognaro, A. J. J. Org. Chem. 2002, 67, 2481.

(63) Lata, C. J.; Crudden, C. M. J. Am. Chem. Soc. 2010, 132, 131.

(64) Endo, K.; Hirokami, M.; Takeuchi, K.; Shibata, T. Synlett 2008, 3231. 
(65) Kessler, J. M.; Nelson, J. H.; Frye, J. S.; Decian, A.; Fischer, J. Inorg. Chem. 1993, 32, 1048.

(66) Hartley, F. R.; Murray, S. G.; Nicholson, P. N. Inorg. Chim. A Lett. 1983, 76, L51.

(67) Clark, P. W.; Hartwell, G. E. J. Organomet. Chem. 1977, 139, 385.

(68) Widauer, C.; Grutzmacher, H.; Ziegler, T. Organometallics 2000, 19, 2097.

(69) Evans, D. A.; Fu, G. C.; Anderson, B. A. J. Am. Chem. Soc. 1992, 114, 6679.

(70) Kim, Y.; Jordan, R. F. Organometallics 2011, 30, 4250.

(71) Molander, G. A.; Yun, C-S.; Ribagorda, M.; Biolatto, B. J. Org. Chem. 2003, 68, 5534.

(72) Molander, G. A.; Sandrock, D. L. Curr. Opin. Drug Disc. 2009, 12, 811.

(73) Ding, S.; Xu, L.; Li, P. ACS Catal. 2016, 6, 1329.

(74) Bayardon, J.; Bernard, J.; Rémond, E.; Rousselin, Y.; Malacea-Kabbara, R.; Jugé, S. Org. Lett. 2015, 17, 1216.

(75) Gott, A. L.; Piers, W. E.; Dutton, J. L.; McDonald, R.; Parvez, M. Organometallics 2011, 30, 4236 .

(76) Gutsulyak, D. V.; Gott, A. L.; Piers, W. E.; Parvez, M. Organometallics 2013, 32, 3363.

(77) Vergnaud, J.; Grellier, M.; Bouhadir, G.; Vendier, L.; Sabo-Etienne, S.; Bourissou, D. Organometallics 2008, 27, 1140.

(78) Giordano, G.; Crabtree, R. H. Inorg. Syn. 1990, 28, 88.

(79) van der Ent, A.; Onderdelinden, A. L. Inorg. Syn. 1990, 28, 90.

(80) Bax, A.; Summers, M. F. J. Am. Chem. Soc. 1986, 108, 2093. 
CHAPTER 5

\section{Influence of Second Coordination Sphere Boranes on Rhodium(I) Oxidative Addition of Aldehydes}




\subsection{Introduction}

The hydroacylation of vinylic substrates represents a powerful method for the synthesis of ketone products from aldehyde precursors. The simpler of the hydroacylation reactions is the intramolecular method that was first described in 1972 by Sakai and coworkers (Scheme 5.1). ${ }^{1,2}$ Sakai and coworkers reported that this reaction occurs at room temperature with stoichiometric rhodium yielding both the desired cyclic hydroacylation product and the undesired decarbonylation side-product. This reaction was later conducted catalytically by Miller and coworkers by employing 10 mol\% $\mathrm{Rh}\left(\mathrm{PPh}_{3}\right)_{3} \mathrm{Cl}$ and ethylene-saturated $\mathrm{CHCl}_{3}$ as the solvent. ${ }^{3}$

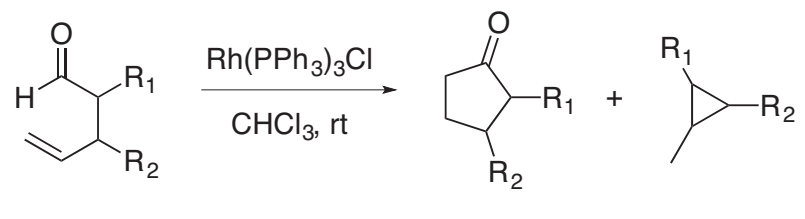

Scheme 5.1. Stoichiometric intramolecular hydroacylation with Wilkinson's complex.

Hydroacylation proceeds via an initial oxidative addition of the aldehyde $\mathrm{C}-\mathrm{H}$ bond to yield the rhodium(III) acyl hydride complex (Scheme 5.2). ${ }^{4-9}$ This step is followed by coordination and either a 2,1- or a 1,2-insertion of alkene into rhodium hydride to produce branched and linear product, respectively. The catalytic cycle is closed by reductive elimination to regenerate the rhodium(I) catalyst and the desired ketone product. While alkene insertion can lead to selectivity problems by providing either the branched or linear products, the challenge of achieving catalytic hydroacylation is preventing decarbonylation from occurring at the rhodium(III)-acyl hydride complex. ${ }^{10}$ In the case of the intramolecular reaction, the chelation of the alkene to the rhodium(III)-acyl hydride facilitates the insertion of the alkene into the hydride. 
However, overcoming the decarbonylation in intermolecular (Scheme 5.2) reactions is more problematic. One common method of preventing decarbonylation is the use of cationic rhodium(I) metal centers bearing chelating bis(phosphine) ligands. ${ }^{4,11,12}$

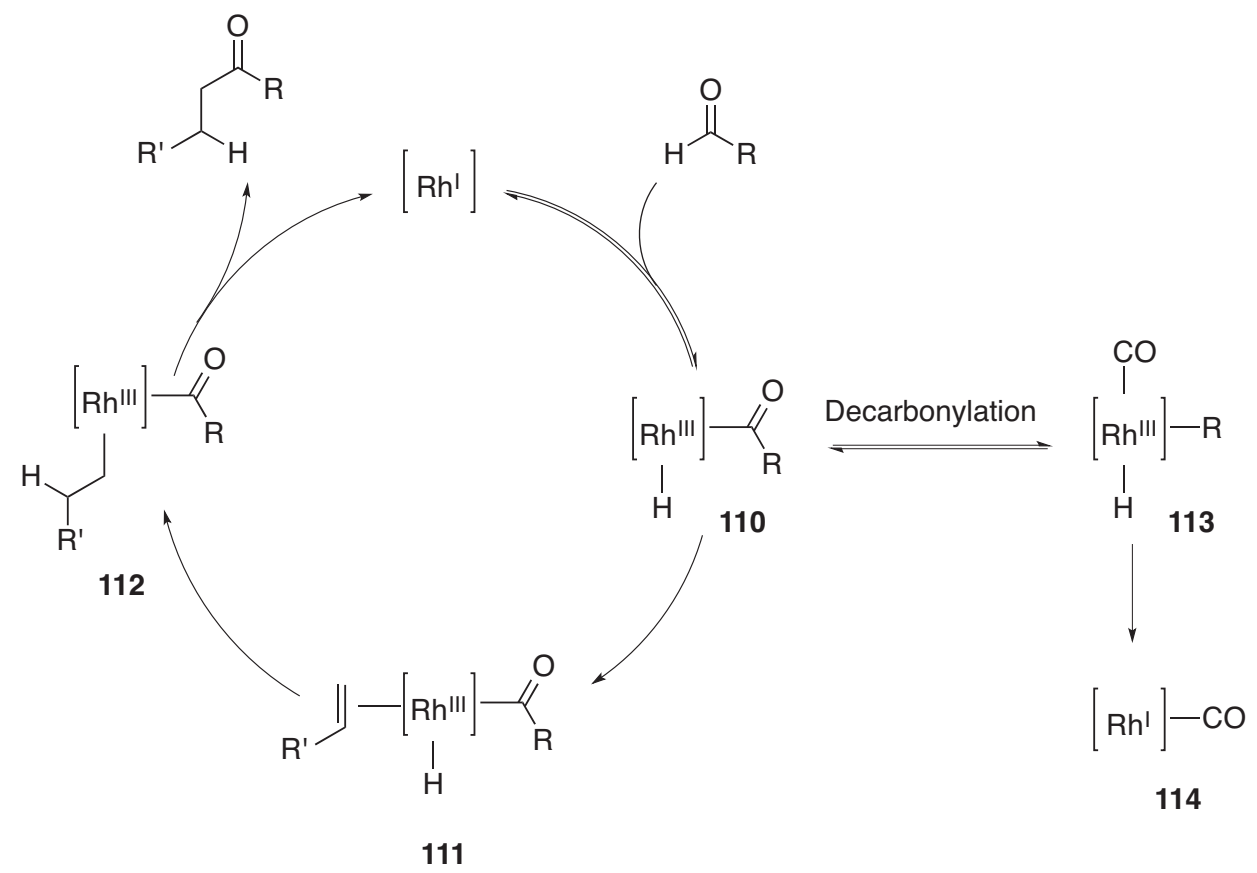

Scheme 5.2. Mechanism for the intermolecular hydroacylation catalyzed by a $\mathrm{Rh}^{1}$ complex.

After oxidative addition of aldehyde to the rhodium(I) complex, the rhodium(III)acyl hydride complex $\mathbf{1 1 0}$ undergoes one of two different pathways. The first pathway is coordination and insertion of alkene, while the second pathway leads to unproductive decarbonylation and ultimately loss of catalytic activity through formation of catalytically inactive rhodium(I)-CO species (118). The acyl-rhodium(III)-hydride (114) was first isolated by Suggs using a 8-quinolinecarbaldehyde capable of generating a stable fivemembered rhodium(III) metallacycle (Scheme 5.3). ${ }^{7}$ Upon treatment of the cationic analog of this complex with 1-octene, the desired ketone product was obtained in 55\% yield. 


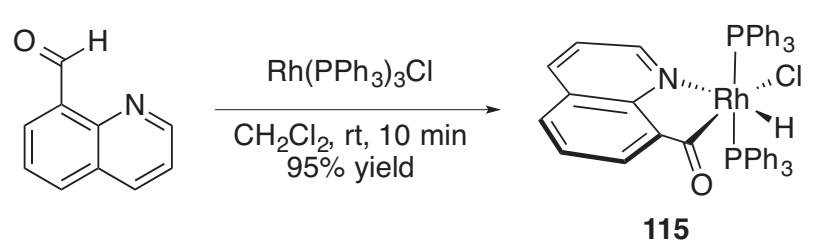

Scheme 5.3. Isolation of an acyl rhodium(III)-hydride complex as a key intermediate in hydroacylation.

In an effort to prevent decarbonylation, several methodologies have been employed in order to drive the reaction to completion. Milstein and coworkers demonstrated that by conducting the reaction under 1000 psi of ethylene pressure with $3.6 \mathrm{~mol} \%$ catalyst loading, the reaction could be driven to the ketone product (Scheme 5.4A). ${ }^{13}$ Presumably ethylene acts as an ancillary ligand and blocks an open coordination side on the rhodium complex to prevent decarbonylation.

In addition to increasing ethylene pressure, several methods adopt a directed hydroacylation approach to stabilize intermediates by utilizing chelation effects (Scheme 5.4B). The incorporation of Lewis basic moieties increases the binding affinity of the aldehyde or the alkene to the metal center and occupies a binding site on the metal that would otherwise be vacant. ${ }^{14,15}$ The substitution of the ortho-position of a ring or the $\beta$ position of an alkyl chain with Lewis basic functionalities allows for the formation of stable 5-membered metallacycle acyl-rhodium(III)-hydride intermediates. Fourmembered metallacycles formed via decarbonylation are energetically unfavorable. In addition, the length of the linker between the directing group and the alkene can affect regioselectivity (Scheme 5.4B). Shorter linkers lead to higher selectivity for the 1,2insertion, whereas longer linkers leads to higher selectivity for the 2,1 -insertion. ${ }^{14}$ While this directing group approach is successful, the use of removable directing groups is desired. In the case of hydroiminoacylation, the aldehyde is condensed with 2- 
aminopyridines to produce the imino-aldehyde (Scheme $5.4 \mathrm{C}) .{ }^{16}$ This substrate undergoes a typical hydroacylation, where the pyridine acts as a chelating ligand to help stabilize rhodium(III) intermediates.

(A)

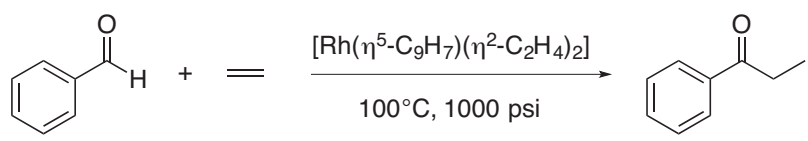

(B)

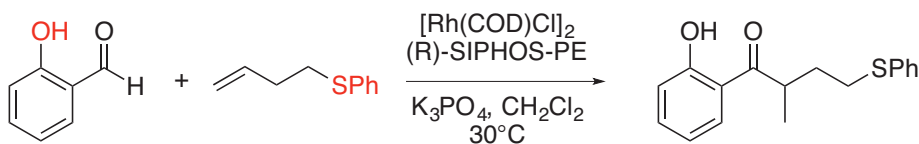

$$
97 \% \text { yield, } 93 \% \text { ee }
$$
$>20: 1$ selectivity

(B)

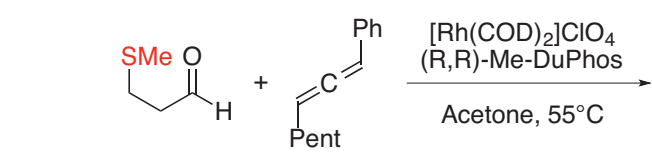
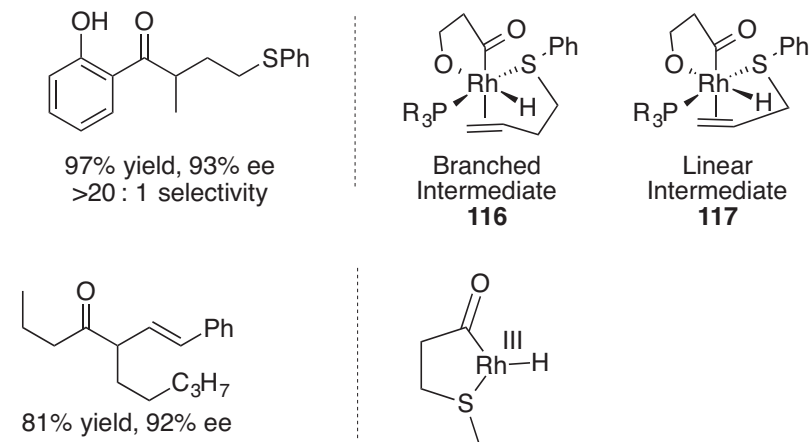
$81 \%$ yield, $92 \%$ ee<smiles>C[SH]1CCC(=O)[In]1C</smiles>

118

(C)
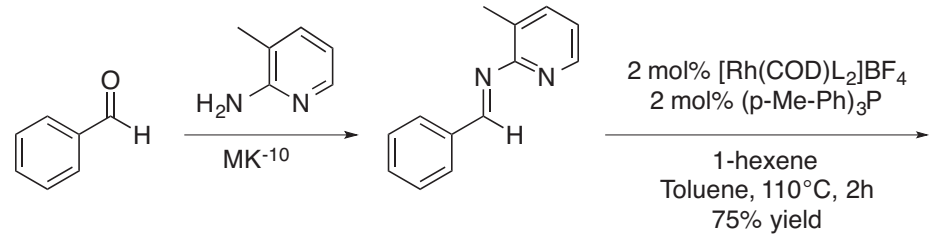

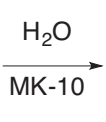<smiles>CC(C)(C)C(=O)c1ccccc1</smiles>

Scheme 5.4. Methods employed for the prevention of decabonylation. (A) Utilization of high pressure of ethylene, (B) use of chelating substrates (chelating groups shown in red) and (C) the condensation of 2-amino-3-picoline onto aldehydes for hydroiminoacylation.

The preferred method of modification to any catalyst system involves altering the ligand environment rather than substrate. Peters and coworkers demonstrated that zwitterionic rhodium(I) complexes bearing a bis(phosphinoborate) ligand had TON values that were much larger than the cationic rhodium(I) with chelating bis(phosphine) ligands (Scheme 5.5). ${ }^{17,18}$ The use of the zwitterionic bis(phosphinoborate) complex (entry 1) gave a high yield and TOF with the reaction reaching completion after 5 minutes. When the phosphine is replaced by an amine (entry 2), the yield was still quite 
high but, the TOF decreased dramatically and the reaction reached completion after 30 minutes. When the cationic complex bearing the silane was used (entry 3 ), both the yield and the TOF were lowered significantly and similar to the dppb complex (entry 4).

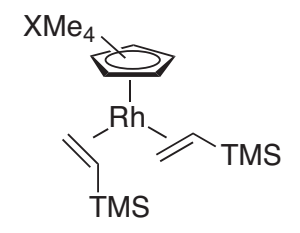

Brookhart Neutral Rhodium(I) Complex

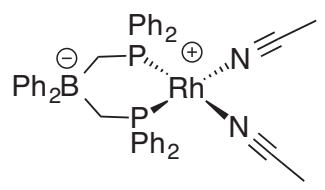

Peters Zwitterionic Rhodium(I) Catalyst

Scheme 5.5. Structures of Brookhart's and Peters' rhodium complexes for hydroacylation $\left(\mathrm{X}=\mathrm{CH}_{3}\right.$ or $\left.\mathrm{CF}_{3}\right)$.

Table 5.1. Catalytic hydroacylation with the use of chelating bis(phosphine) rhodium(I) complexes.

\begin{tabular}{|c|c|c|c|}
\hline Entry & Catalyst & Yield $(\%)$ & $\mathrm{TOF}\left(\mathrm{h}^{-1}\right)$ \\
\hline 1 & {$\left[\left\{\mathrm{Ph}_{2} \mathrm{~B}\left(\mathrm{CH}_{2} \mathrm{PPh}_{2}\right)_{2}\right\} \mathrm{Rh}\left(\mathrm{CH}_{3} \mathrm{CN}\right)_{2}\right](\mathbf{1 2 5})$} & 99 & 2400 \\
\hline 2 & {$\left[\left\{\mathrm{Ph}_{2} \mathrm{~B}\left(\mathrm{CH}_{2} \mathrm{NMe}_{2}\right)_{2}\right\} \mathrm{Rh}\left(\mathrm{CH}_{3} \mathrm{CN}\right)_{2}\right](\mathbf{1 2 6})$} & 95 & 380 \\
\hline 3 & {$\left[\left\{\mathrm{Ph}_{2} \mathrm{Si}\left(\mathrm{CH}_{2} \mathrm{PPh}_{2}\right)_{2}\right\} \mathrm{Rh}\left(\mathrm{CH}_{3} \mathrm{CN}\right)_{2}\right][\mathrm{PF} 6](\mathbf{1 2 7})$} & 78 & 52 \\
\hline 4 & {$\left[\{\mathrm{dppp}\} \mathrm{Rh}\left(\mathrm{CH}_{3} \mathrm{CN}\right)_{2}\right]\left[\mathrm{PF}_{6}\right](\mathbf{1 2 8})$} & 70 & 47 \\
\hline
\end{tabular}

Zwitterionic complexes have been shown to be more effective catalysts by improving the half-life of the rhodium(III) intermediate compared to the cationic analog (Table 5.2). ${ }^{12}$ In the case of these complexes, the use of a stronger donor solvent dramatically stabilizes the rhodium(III) complex, as seen in the half-life, and limits the degree of decarbonylation. However, the zwitterionic complex greatly reduces the degree at which the rhodium(III) intermediate decomposes, as seen in the rate constant 
and the half-life. A longer half-life allows for the coordination and the insertion of the alkene to occur prior to decarbonylation.

Table 5.2. Effect of zwitterionic complexes on stability of rhodium(III) hydroacylation intermediates.

\begin{tabular}{|c|c|c|c|}
\hline Entry & $\begin{array}{c}\text { Rhodium(III) Acyl Complex } \\
\left(\mathrm{R}={ }^{\mathrm{t}} \mathrm{Bu}\right)\end{array}$ & $\begin{array}{c}\text { Decarbonylation Rate } \\
\text { Constant } / 10^{-6} \mathrm{~s}^{-1}\end{array}$ & Half Life / hr \\
\hline 1 & 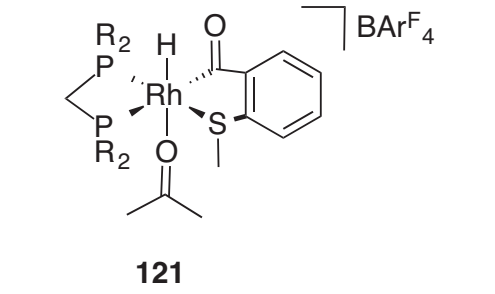 & $108 \pm 4$ & $1.79 \pm 0.06$ \\
\hline 2 & $\mathrm{R}_{2}$ & $5.1 \pm 0.3$ & $38 \pm 2$ \\
\hline 3 & 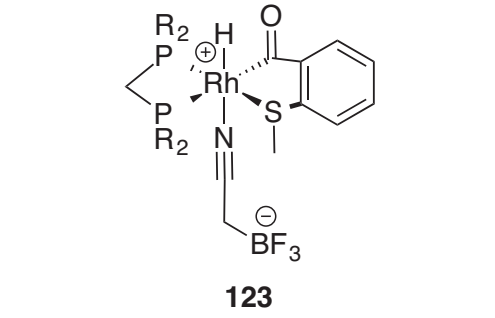 & $2.7 \pm 0.3^{a}$ & $73 \pm 9$ \\
\hline
\end{tabular}

${ }^{a}$ Rate of $\mathrm{Rh}^{\mathrm{III}}$ acyl hydride decomposition

In another case, Brookhart and coworkers showed that the application of $\eta^{5}-\mathrm{Cp}$ type complexes of rhodium proceeded via a mechanism (Scheme 5.6) that, opposed to traditional hydroacylation, favored decarbonylation. ${ }^{19}$ In fact, the decarbonylated species was determined to be the resting state of the catalytic cycle. 


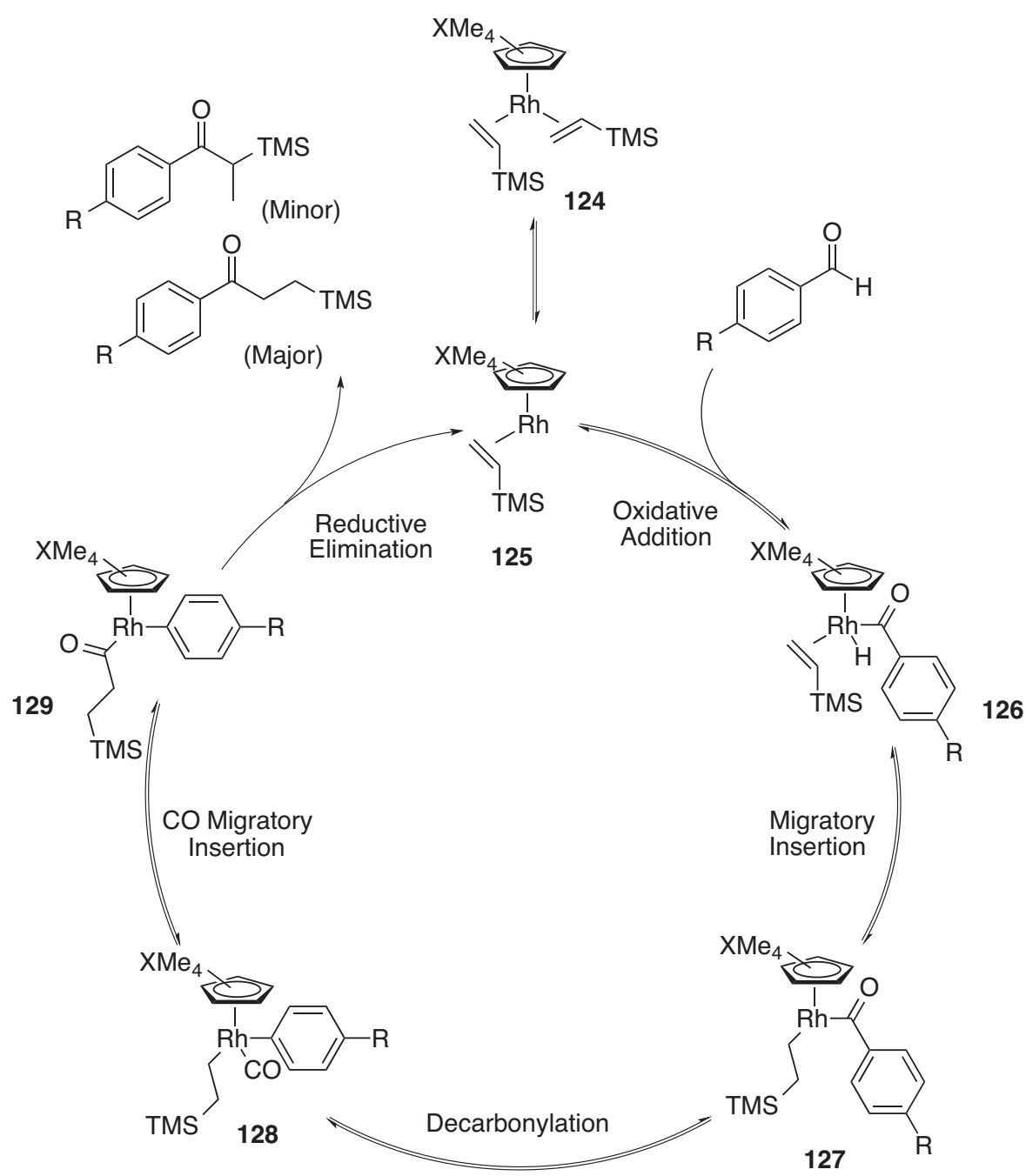

Scheme 5.6. Rh-Cp type complexes utilized for the intermolecular hydroacylation.

Weller and coworkers were able to utilize large-bite angle bis(phosphine) ligands with hemi-labile coordination environments to control the decarbonylation (Scheme 5.7). ${ }^{20,21}$ In order for decarbonylation to occur, there needs to be a vacant coordination site that is cis- to the acyl group. By utilizing a hemi-labile ligand, the site cis- to the acyl can be occupied until alkene coordination and as a result bypass decarbonylation. 


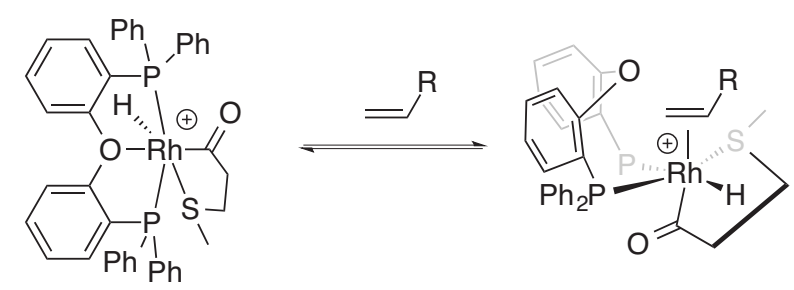

130

Scheme 5.7. Use of hemi-labile coordination environment for the prevention of decarbonylation.

Given the prior work on the stabilization of acyl-rhodium(III)-hydride complexes and their subsequent ability to undergo hydroacylation, we sought a method to utilize rhodium(I) complexes with pendant Lewis acids to stabilize the rhodium(III)-acyl intermediate (Scheme 5.8). Recently, it was shown experimentally and computationally by Dobereiner and coworkers that Lewis acidic $\mathrm{BF}_{3}$ was able to form adducts with the oxygen of platinum(II) acyl complexes. ${ }^{22}$ This work, among others, found that coordination of Lewis acids to M-acyl complexes leads to an increase in the electrophilicity of the acyl ligand. ${ }^{23-26}$
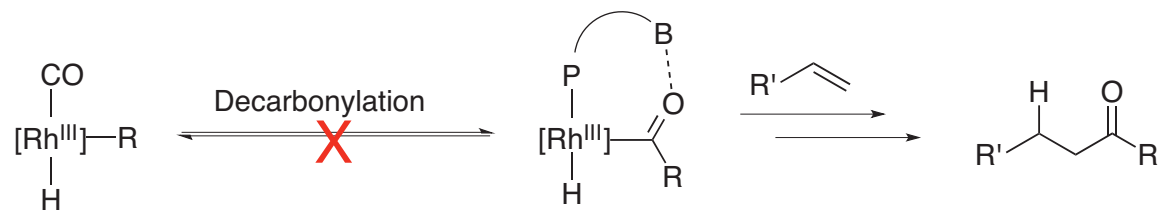

Scheme 5.8. Proposed stabilization of $\mathrm{Rh}^{\mathrm{III}}$ acyl complexes by use of pendant Lewis acids.

In order to facilitate catalytic hydroacylation, we reasoned that decarbonylation could be prevented by using complexes bearing pendant Lewis acids. The working hypothesis is that coordination of second coordination sphere Lewis acids to acyl ligands can prevent decarbonylation by stabilizing acyl-rhodium(III)-hydride complexes. 


\subsection{Results and Discussion}

\subsubsection{Reactivity of 8-Quinolinecarbaldehyde with Rhodium(I) Complexes Featuring a Phosphinoborane Ligand}

The previous work of Suggs demonstrated the use of quinoline as a suitable directing group for the generation of a stable acyl-rhodium(III)-hydride complex. ${ }^{7}$ Therefore, we reacted the cationic $\mathrm{Rh}(\mathrm{COD})$ phosphinoborane complex 66 with 8quinolinecarbaldehyde (Scheme 5.9). While the reaction lead to oxidative addition, as shown by the formation of hydride signals in the upfield shifted ${ }^{1} \mathrm{H}$ NMR spectrum (Figure 5.1), the multitude of hydride resonances lead us to choose a better rhodium(I) precursor to study the reaction. Since alkenes are known to insert into rhodium hydride ligands to generate Rh-alkyl species, a complex that was free of cyclooctadiene ligand was desired.

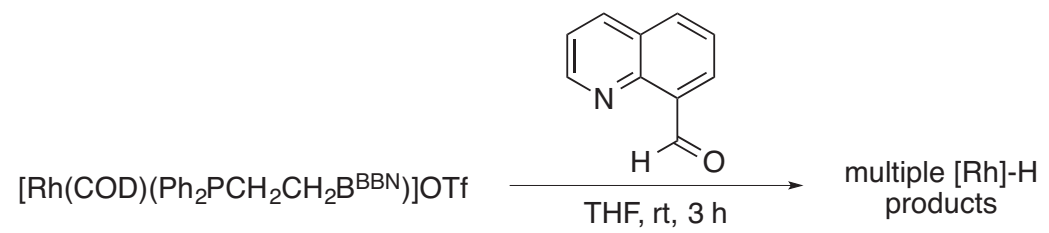

Scheme 5.9. Reaction of cationic rhodium(I) complex with 8-quinolinecarbaldehyde along with desired octahedral rhodium(III) acyl complex. 


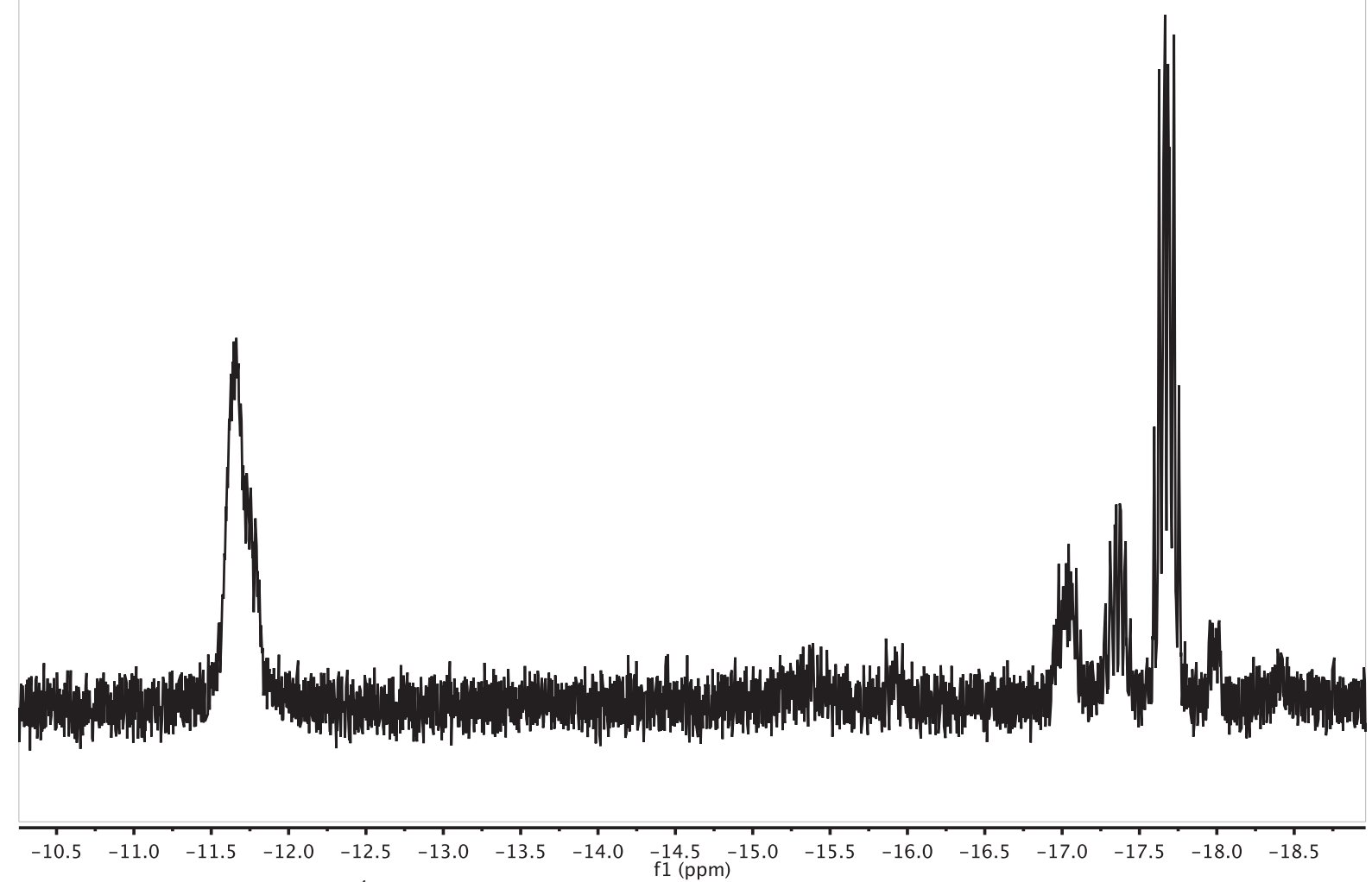

Figure 5.1. Upfield ${ }^{1} \mathrm{H}$ NMR spectra demonstrating the formation of hydrides by oxidative addition to the rhodium(I) precursor.

When Suggs conducted the reaction, Wilkinson's complex was utilized as the rhodium(I) precursor. As a result, one equivalent of 8-quinolinecarbaldehyde was added to the tris(phosphinoborane) rhodium(I) complex 75 (Scheme 5.10). When the reaction was conducted at $60^{\circ} \mathrm{C}$ in THF, a new doublet by ${ }^{31} \mathrm{P}\left\{{ }^{1} \mathrm{H}\right\}$ NMR spectroscopy confirmed the formation of a new complex. The doublet was accompanied by the presence of free phosphinoborane ligand. Due to the formation of free ligand and the presence of a doublet in the ${ }^{31} \mathrm{P}\left\{{ }^{1} \mathrm{H}\right\}$ NMR, the structure was known to contain symmetrical phosphine ligands. In addition, there was one major hydride signal observed that appeared as a slightly broadened doublet of triplets. Once again, the doublet of triplets is in agreement 
with symmetric phosphine ligands. We hypothesized that broadening of the signals was due to the interaction of an ${ }^{11} \mathrm{~B}$ quadripolar nucleus with the hydride ligand.

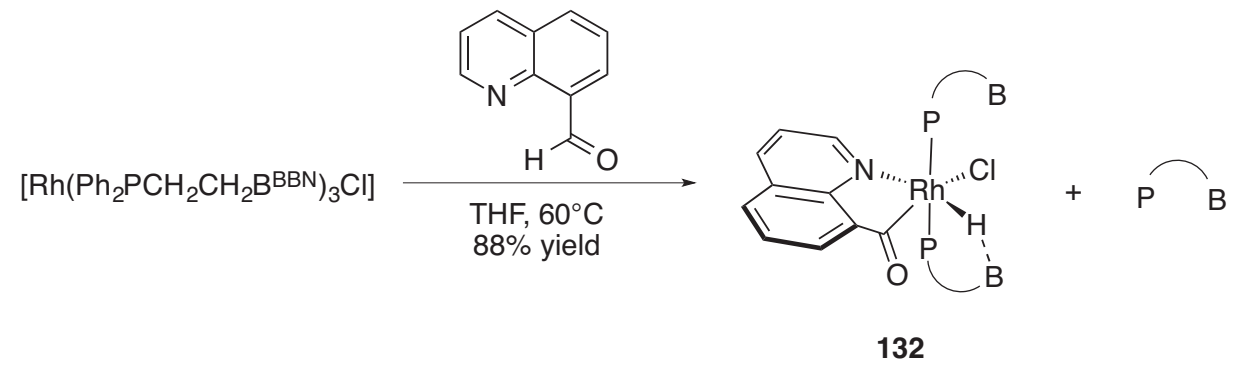

Scheme 5.10. Reaction of tris(phosphinoborane) rhodium(I) complex with 8quinolinecarbaldehyde.

Since free ligand was observed, we reasoned that a cleaner reaction might be obtained by utilizing the bis(phosphinoborane) rhodium(I) dimer 74 as the rhodium(I) precursor (Scheme 5.11). When this reaction was carried out, no free ligand was observed and the same hydride signal was visible in the upfield region of the ${ }^{1} \mathrm{H} N \mathrm{NR}$ (Figure 5.2).
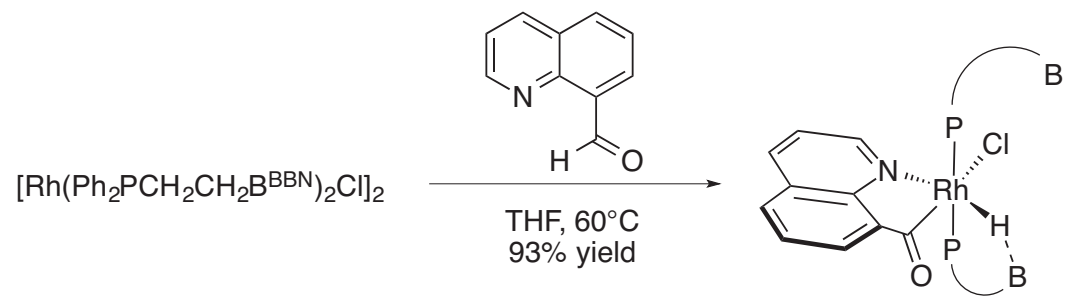

132

Scheme 5.11. Reaction of bis(phosphinoborane) rhodium(I) dimer 74 with 8quinolinecarbaldehyde. 


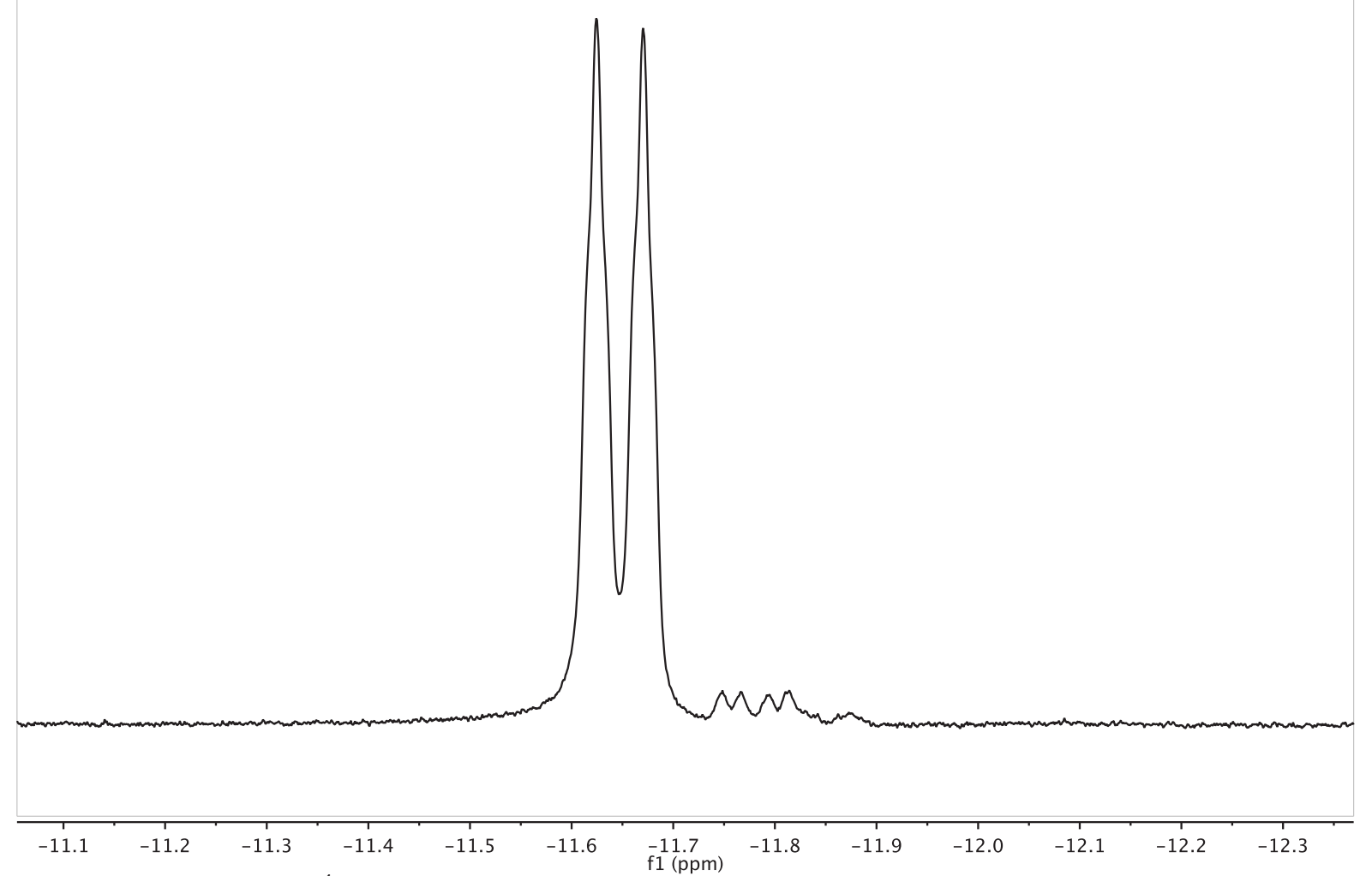

Figure 5.2. Upfield ${ }^{1} \mathrm{H}$ NMR spectra of the reaction of bis(phosphinoborane) rhodium(I) dimer $\mathbf{7 4}$ with 8-quinolinecarbaldehyde.

The hydride signal is significantly broadened, which was postulated to be a result of interactions with a quadrupolar ${ }^{11} \mathrm{~B}$ nucleus. When the reaction was heated for a longer period of time, the minor hydride signal centered at $-11.8 \mathrm{ppm}$ became more prominent. Suggs observed the $\alpha$-quinoline proton at $8.5 \mathrm{ppm}$ in the ${ }^{1} \mathrm{H}$ NMR spectra, along with IR signals at 1660 and $2020 \mathrm{~cm}^{-1}$, which are assigned to the $\eta^{1}$-acyl and the Rh-hydride respectively. ${ }^{7,27}$ For the reaction of the bis(phosphinoborane) rhodium(I) dimer $\mathbf{7 4}$ with 8-quinolinecarbaldehyde, the $\alpha$-quinoline proton appears at $9.11 \mathrm{ppm}$ as a doublet resonance with a coupling constant of $5 \mathrm{~Hz}$, which is consistent with the results discussed by Suggs. ${ }^{7}$ In addition, the FTIR spectrum reveals the presence of a $\eta^{1}$-acyl at 1655 and $1634 \mathrm{~cm}-1$ and a hydride at 1970 and $2043 \mathrm{~cm}^{-1}$ (Figure 5.3). The 
presence of an IR stretch at $1970 \mathrm{~cm}^{-1}$ is consistent with the interaction of a Lewis acidic borane with the hydride, which would ultimately result in a weakening of the Rh-H and a lower Rh-H absorption band.

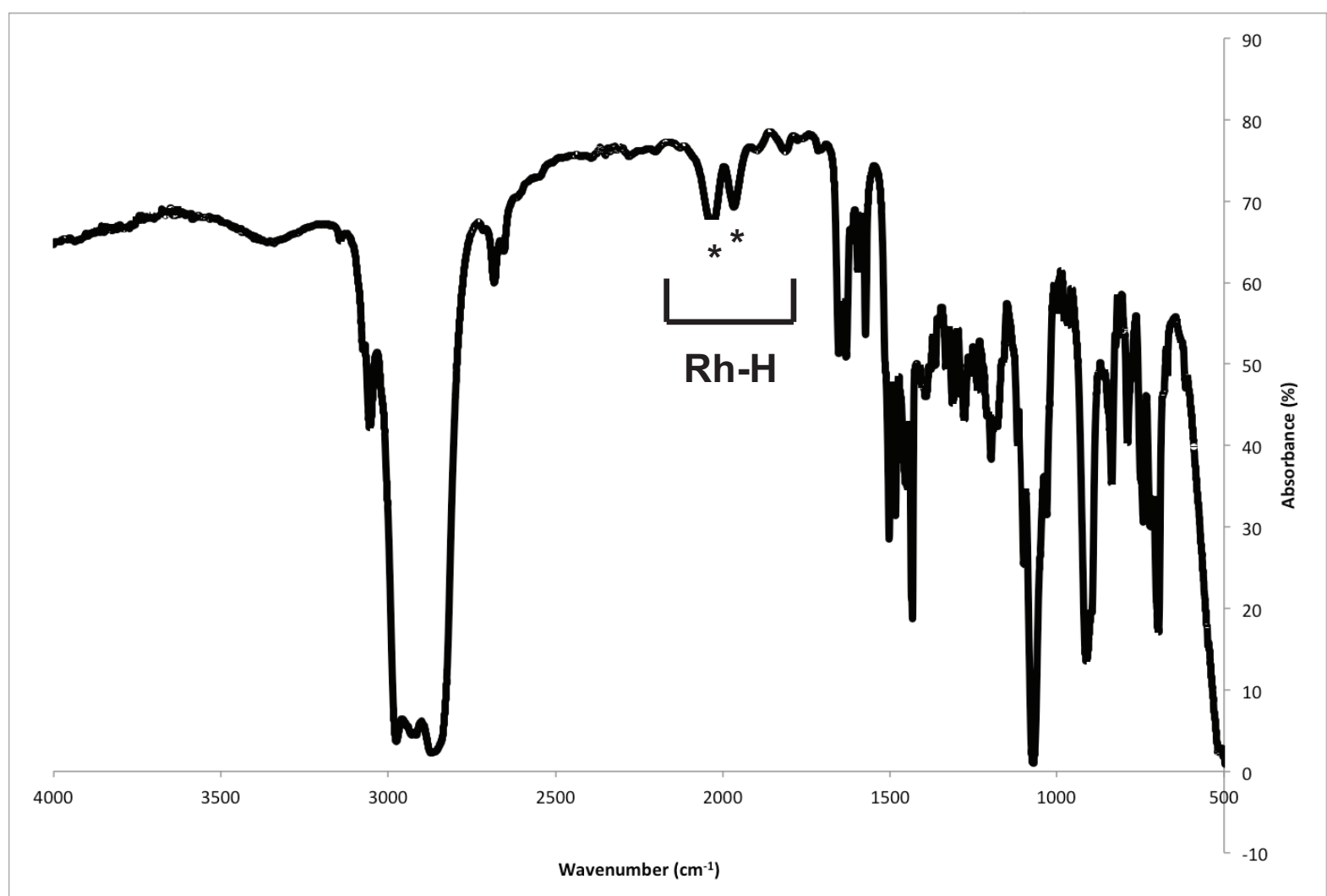

Figure 5.3. Infrared Spectra of acyl-rhodium(III)-hydride phosphineborane complex (Rh$\mathrm{H}$ absorption bands are marked with $\mathrm{a}^{*}$ ).

\subsubsection{Reactivity of Pyridinecarboxaldehydes with Rh(COD) Complex Featuring a Phosphinoborane Ligand}

Given that a hydride was generated by the reaction of $\mathrm{Rh}(\mathrm{COD})$ phosphinoborane with 8-quinolinecarbaldehyde, we sought to explore other potential chelating aldehydes to test their reactivity and stability. As a result, we began by reacting the cationic triflate $\mathrm{Rh}(\mathrm{COD})$ phosphinoborane complex with 2pyridinecarboxaldehyde in THF at room temperature (Scheme 5.12). The upfield portion 
of the ${ }^{1} \mathrm{H}$ NMR spectra revealed the presence of no hydride signals. The ${ }^{31} \mathrm{P}\left\{{ }^{1} \mathrm{H}\right\}$ NMR showed only one doublet situated at $24.1 \mathrm{ppm}$, with a ${ }^{1} \mathrm{~J}_{\mathrm{Rh}-\mathrm{P}}$ coupling constant of 151.2 $\mathrm{Hz}$. The ${ }^{11} \mathrm{~B}\left\{{ }^{1} \mathrm{H}\right\}$ NMR displayed a signal resonance at $12.7 \mathrm{ppm}$, which has an upfield shift that is consistent with the formation of a Lewis acid-base adduct. There was a single resonance observed in the ${ }^{19} \mathrm{~F}$ NMR at $-78.9 \mathrm{ppm}$. When the reaction was monitored by ${ }^{1} \mathrm{H}$ NMR spectroscopy as a function of time at both room temperature and at $-35^{\circ} \mathrm{C}$, there was no evidence of the formation of a rhodium hydride. Despite there literature precedence for the formation of agostic $\mathrm{C}-\mathrm{H}$ interactions between $\mathrm{BBN}$ and rhodium(I) metal centers in more conformationally rigid systems ${ }^{28,29}$, there is no evidence of this interaction being present, which is likely a result of the flexibility of the ligand. However, this does not rule out the possibility of there being a transient rhodium hydride species.

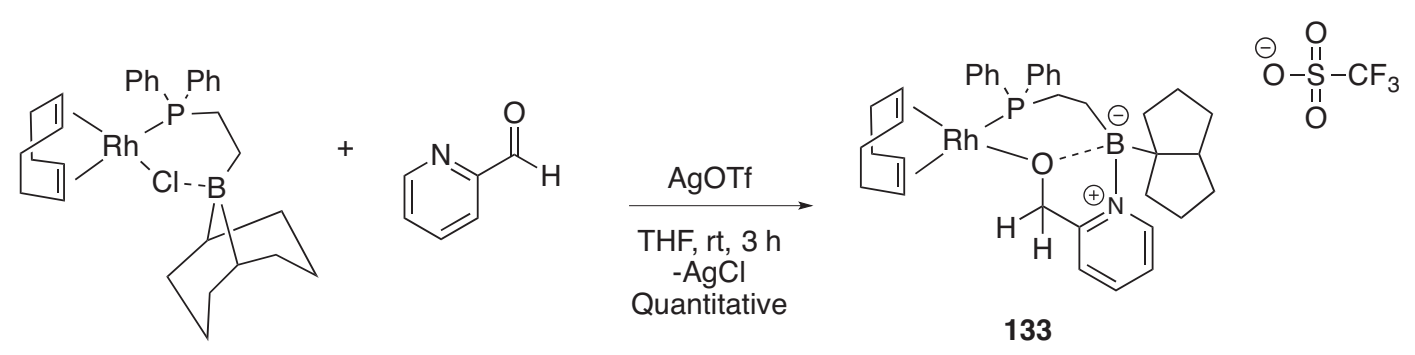

Scheme 5.12. Reaction of the cationic rhodium(I) phosphinoborane complex with 2pyridinecarboxaldehyde.

The structure of product 152 that arose from $\mathrm{Csp}^{3}-\mathrm{H}$ bond cleavage and subsequent $\mathrm{C}-\mathrm{C}$ bond formation was fully characterized by NMR spectroscopy. As shown in Figure 5.4A, the formation of the ring structure in the product involving the phosphinoborane ligand resulted in four distinct signals, as shown in the 1D TOCSY NMR. The ${ }^{11} \mathrm{~B}\left\{{ }^{1} \mathrm{H}\right\}$ NMR spectrum (Figure 5.4B) shows a shift to $13 \mathrm{ppm}$ and is a relatively signal, indicative of a tetra-coordinate borate. The coordination of product 152 
was confirmed by HMBC NMR spectroscopy, which showed coupling between the methylene next to the oxygen atom, the methylene next to the borane, and the quaternary carbon attached to the borane in the OHP (octahydropentalene) ring (Figure $5.4 \mathrm{C})$.
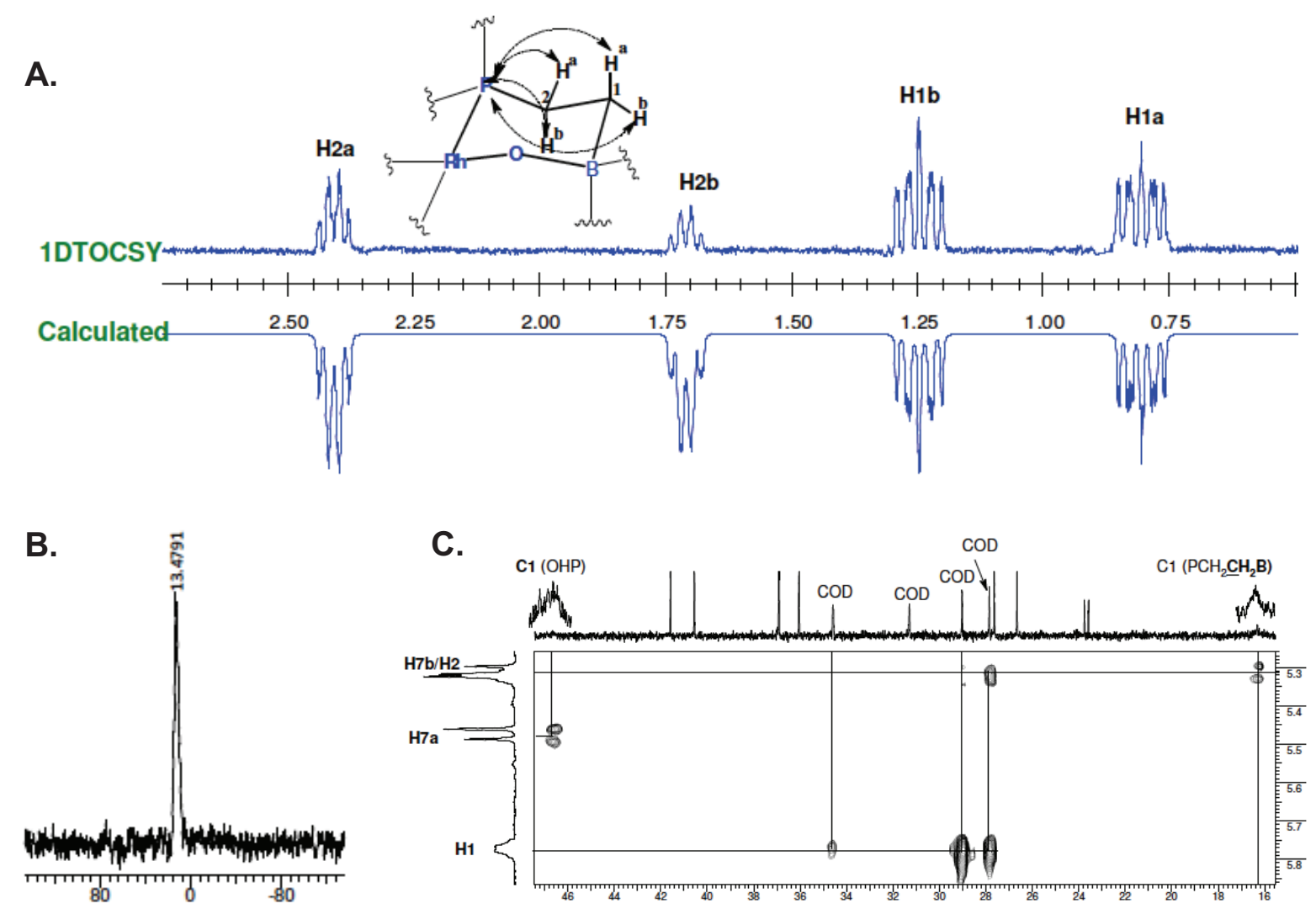

Figure 5.4. NMR spectra of the obtained hydroboration products. A) Experimental and calculated 1D TOCSY NMR spectra, B) ${ }^{11} \mathrm{~B}\left\{{ }^{1} \mathrm{H}\right\}$ NMR spectrum, C) ${ }^{4} \mathrm{~J}_{\mathrm{HC}}$ correlations using HMBC NMR spectrum.

A signal crystal could be obtained and the resulting structure was determined by X-ray diffraction (Figure 5.5). It was discovered that the observed product, obtained in quantitative yield, was the ring migration product, where a new $\mathrm{C}-\mathrm{C}$ bond is formed in the 9-BBN ring. The resulting ring migration produced a hydride that subsequently reduced the aldehyde, while the borane was bound to the pyridine of the substrate. 


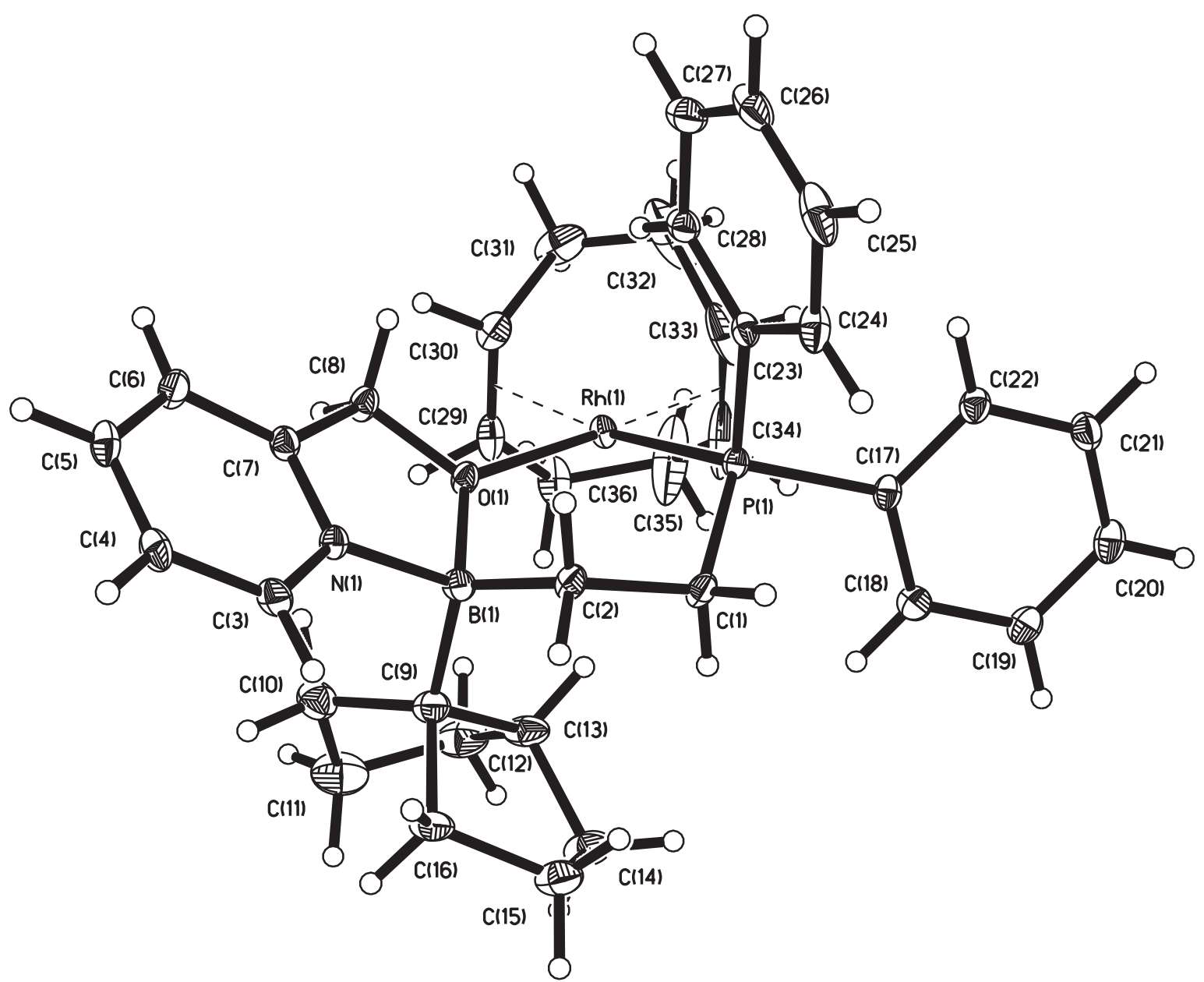

Figure 5.5. X-ray crystallographic structure $\mathrm{Rh}(\mathrm{COD})\left[\mathrm{Ph}_{2} \mathrm{PCH}_{2} \mathrm{CH} 2 \mathrm{~B}\left(\mathrm{C}_{8} \mathrm{H}_{13}\right)\right][2-$ pyridine $-\mathrm{CH}_{2} \mathrm{O}$ ]OTf (133) (thermal ellipsoids at $50 \%$ probability). ${ }^{30}$

While this result was unexpected, it is not unprecedented. Brown and coworkers saw similar reactivity with $9-\mathrm{BBN}$ in the absence of a transition metal (Scheme $5.13) .{ }^{31,32}$ In this case, the treatment of the 2 equivalents of 9 -BBN borate salt with one equivalent of an acid chloride results in the formation of an ethoxide anion. This ethoxide then reacts with the remaining equivalent of acid chloride to produce the corresponding ester. ${ }^{31} \mathrm{~A}$ variety of different substituted 9-BBN groups were subjected to these conditions and the desired product was obtained in over $90 \%$ yield in all cases. ${ }^{31}$ 
In addition to this example of the ring rearrangement, this was also observed by Vedernikov and coworkers for a platinum(II) complex (Scheme 5.13). ${ }^{33}$
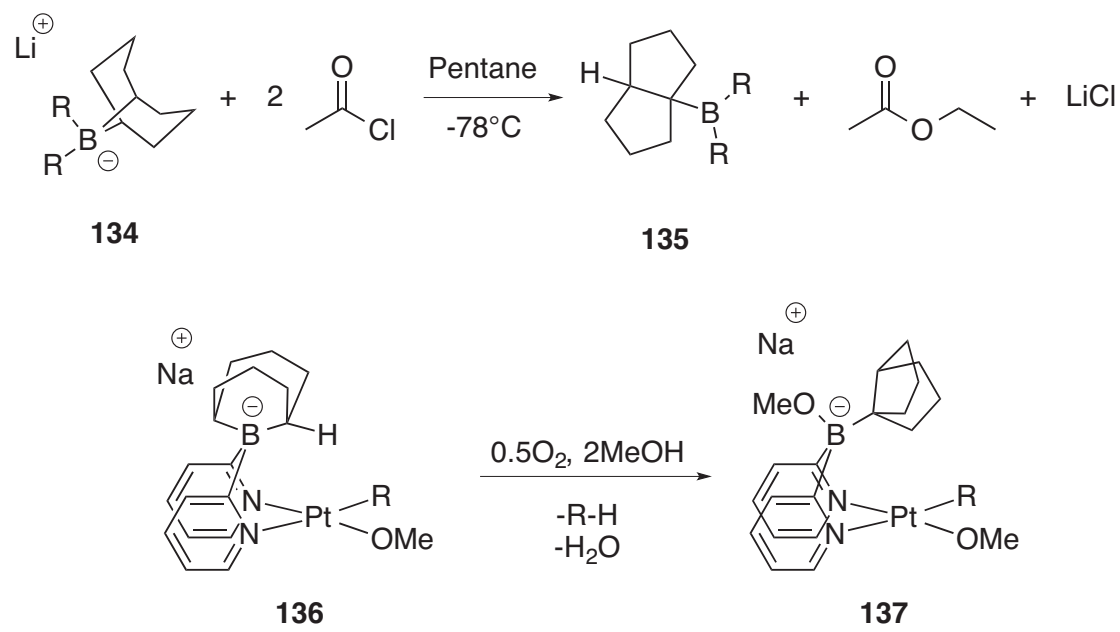

Scheme 5.13. Reaction of (top) 9-BBN borate salts with acid chlorides resulting in ring migration to form a new $\mathrm{C}-\mathrm{C}$ bond within 9-BBN and (bottom) platinum(II) complex resulting in a 9-BBN ring rearrangement.

In the case of this reaction, the mechanism was proposed to proceed, under oxidizing conditions, through an agostic $\mathrm{C}-\mathrm{H}$ interaction at a platinum(IV) metal center. Complexes of cyclooctadiene [bis(pyrazolyl\}borato]rhodium(I) that feature a BBN-based ligand scaffold are known to bear weak $\mathrm{C}-\mathrm{H}$ agostic interactions between the BBN fragment and the rhodium(I) metal center. ${ }^{28,29}$ The formation of the $\mathrm{C}-\mathrm{H}$ agostic interaction then resulted in the ring rearrangement and the generation of a platinum(IV) hydride complex. While the platinum(IV) hydride complex was proposed to form after the ring rearrangement, there was no direct observation of a metal hydride from the reaction. Further oxidation of the product complex in the bottom of Scheme 5.13 resulted in the quantitative formation of bicyclo[3.3.0]oct-1(5)-ene, which is the organic component of the $\mathrm{BBN}$ ring following ring migration. ${ }^{33}$ The oxidation of deuterated complexes $\left(\mathrm{Me}=\mathrm{CD}_{3}, \mathrm{R}=\mathrm{C}_{6} \mathrm{D}_{5}\right)$ in $\mathrm{CD}_{3} \mathrm{OD}$ results in the formation of $\mathrm{CD}_{3} \mathrm{H}$ and 
$\mathrm{C}_{6} \mathrm{D}_{5} \mathrm{H}$, along with the rearrangement product. While there is no direct evidence for a hydride, the protium in the $\mathrm{CD}_{3} \mathrm{H}$ and $\mathrm{C}_{6} \mathrm{D}_{5} \mathrm{H}$ is proposed to originate from the $\mathrm{BBN}$-ring as a result of the rearrangement of the ring. ${ }^{33}$

In addition to the cationic rhodium(I) complex that undergoes this reaction, the cationic iridium(I) complex also undergoes similar reactivity. Based on the literature, it is known that pyridine successfully binds and forms direct Lewis adducts with B-alkyl borabicyclo[3.3.1]nonane.$^{34-37}$ Upon treatment of the cationic phosphinoborane iridium(I) cyclooctadiene complex with pyridine, there was a significant shift in the ${ }^{11} \mathrm{~B}\left\{{ }^{1} \mathrm{H}\right\} \mathrm{NMR}$ spectrum from $87 \mathrm{ppm}$ to $0.5 \mathrm{ppm}$, which is consistent with previously known 9-BBNpyridine adducts. ${ }^{37}$ Therefore, it is known that pyridine is capable of binding to the 9BBN fragment of the ligand.

The control experiment was conducted by reacting complex 66 with 2pyridinecarboxaldehyde in the absence of silver $(\mathrm{I})$ triflate. The ${ }^{1} \mathrm{H}$ NMR and ${ }^{31} \mathrm{P}\left\{{ }^{1} \mathrm{H}\right\}$ NMR spectra of this reaction revealed that there was no rearrangement or oxidative addition product. This confirms that silver(I) salts are necessary for the rearrangement reaction to occur.

As a control experiment, the $\left[\mathrm{Rh}(\mathrm{COD})\left(\mathrm{PPh}_{3}\right)\right] \mathrm{OTf}$ was reacted with 2pyridinecarboxaldehyde. The ${ }^{1} \mathrm{H}$ NMR spectrum of this reaction showed no formation of acyl-rhodium(III)-hydride complex, which means that the rearrangement of the borane is not occurring preferentially over the oxidative addition reaction. The lack of oxidative addition implies that while 8-quinolinecarbaldehyde is a suitable aldehyde partners in hydroacylation, the use of pyridine aldehyde substrates are not comparable. While 3and 4-pyridinecarboxaldehyde work well for hydroiminoacylation with alkenes and 
alkynes, ${ }^{38,39}$ there are no reported examples of their use in transition-metal catalyzed hydroacylation. Only one example of hydroacylation with 3-pyridinecarboxaldehyde and alkenes in the presence of an NHC-catalyst is presented in the literature.$^{40}$ In addition, 2-pyridinecarboxaldehyde is not a competent substrate for the hydroiminoacylation with alkynes but works moderately well for alkenes. ${ }^{38,39}$

Since 2-pyridinecarboxaldehyde reacts to result in the ring rearrangement product, we wanted to explore other pyridinecarboxaldehyde substrates by repeating the reaction in Scheme 5.12 with 3-pyridinecarboxaldehyde. The resulting rhodium(III) oxidative addition product would contain a 4-membered metallacycle for the 2pyridinecarboxaldehyde, whereas the more stable 5-membered metallacycle would form from the 3-pyridinecarboxaldehyde. This experiment will reveal whether the generation the more stable metallacycle will drive oxidative addition over the rearrangement product. However upon conducting this reaction, it was determined that not only was no hydride formed in the reaction, but all of the aldehyde remained. This result indicated that the size of the metallacycle does not drive oxidative addition and the proximity of the aldehyde to the pyridine affects reactivity toward rearrangement. The aldehyde in 3pyridinecarboxaldehyde would be farther from the metal center than the 2pyridinecarboxaldehyde, which could explain the lack of reaction from the 3pyridinecarboxaldehyde.

Based on experimental results and literature precedence, the proposed mechanism for this reaction is shown in Scheme 5.14. The reaction begins by abstraction of the halide from the rhodium to form $\mathrm{AgCl}$, which precipitated from solution and is removed by filtration prior to the addition of 2-pyridinecarboxaldehyde. The 
addition of 2-pyridinecarboxaldehyde results in the binding of the pyridine to the borane to generate the borate complex and the agostic rhodium $\mathrm{B}-\mathrm{H}$ interaction, which then triggers the rearrangement to occur. The rearrangement would then result in the formation of a transient rhodium hydride and the new $\mathrm{C}-\mathrm{C}$ bond in the $\mathrm{B}^{\mathrm{BBN}}$ moiety. This resulting rhodium hydride species could rapidly undergo insertion of the aldehyde carbonyl to furnish the desired product in near quantitative yields.

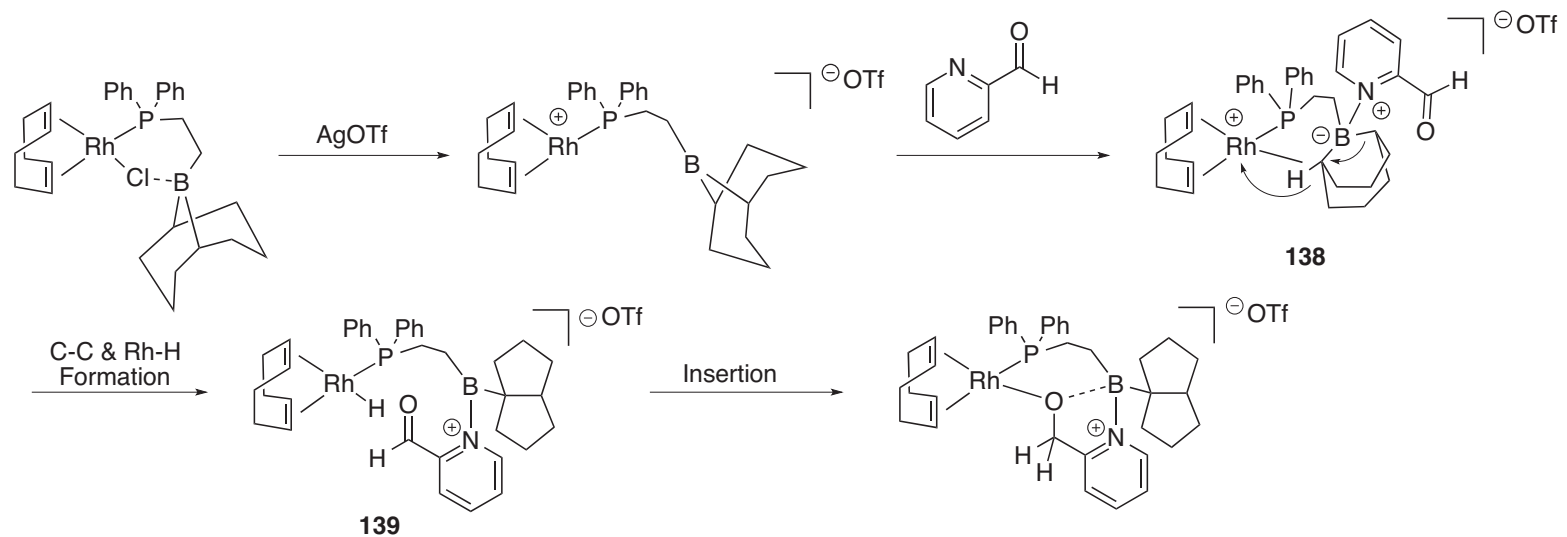

Scheme 5.14. Proposed mechanism for the formation of the ring migration product upon reaction of rhodium(I) phosphinoborane complex 66 with 2pyridiencarboxaldehyde.

\subsection{Conclusion}

The oxidative addition of aldehydes to rhodium(I) complexes represents a critical step in the catalytic hydroacylation reaction. While other methods have been shown to prevent the side-reaction of decarbonylation from occurring, the use of a catalytic pendant borane that can serve as a chelating ligand could represent a strategy to achieve high reaction control. We described the attempted oxidative addition of two chelating aldehydes to study the oxidative addition portion of the mechanism. In one case, the oxidative addition occurred to yield the desired rhodium(III) quinoline complex. Its molecular structure is in agreement with the previous work of Suggs ${ }^{7}$, but it is believed that the borane is interacting with the hydride ligand in the primary coordination 
sphere of the rhodium(III) complex. Alternatively for the reaction involving pyridine carboxaldehydes, the observed product involves a ring migration within the $\mathrm{B}^{\mathrm{BBN}}$ fragment and a subsequent reduction of the aldehyde to the alcohol equivalent. While there was no hydride observed, we cannot rule out the presence of a transient hydride species in the catalytic cycle, which was observed in other $\mathrm{B}^{\mathrm{BBN}}$ based reactions. The application of these systems to the hydroacylation reaction is still a work in progress, where more studies are necessary to understand the effect of the aldehyde structure on reactivity. While the original hypothesis was to study acyl-borane interactions with model compounds, we need to evaluate this reactivity with phosphinoborane ligands other than 9-borabicyclo[3.3.1]nonane as the borane.

\subsection{Methods}

\subsubsection{General Considerations}

The manipulation of air- and moisture-sensitive compounds was conducted and performed under a nitrogen atmosphere utilizing either standard Schlenk or glove box techniques, employing dry solvent and glassware. Glovebox experiments were carried out in a MBraun 200B dual-port inert atmosphere glovebox equipped with a $-40^{\circ} \mathrm{C}$ freezer. Dry solvents were obtained utilizing a glass contour solvent purification system and stored in the glovebox over $4 \AA$ molecular sieves. Deuterated solvents were obtained from Cambridge Isotope Laboratories, Inc. and passed through neutral alumina and stored over $4 \AA$ molecular sieves. In the event that NMR data was recorded in non-deuterated NMR solvent, an internal capillary was used that was charged with $d_{6}$-benzene and sealed by flame. Electrospray ionization (ESI) mass spectra were recorded on a Thermo-Finnigan LCQ DECA XP. High-resolution mass spectra were recorded on a Thermo-Finnigan LTQ MS equipped with an ICR FTMS. 
Infrared spectra were recorded using either a standard salt plate method or on a universal ATR assembly on a Perkin-Elmer Spectrum 100 FTIR. NMR spectra were recorded on either a $400 \mathrm{MHz}$ Agilent or a $600 \mathrm{MHz}$ Varian Inova NMR. Spectra were referenced to residual protio-solvent peaks as an internal standard for ${ }^{1} \mathrm{H}$ and ${ }^{13} \mathrm{C}$. The ${ }^{31} \mathrm{P}$ NMR was referenced to an external $\mathrm{H}_{3} \mathrm{PO}_{4}$ standard and the ${ }^{11} \mathrm{~B}$ and ${ }^{19} \mathrm{~F}$ NMR was referenced to an external $\mathrm{BF}_{3} \cdot \mathrm{OEt}_{2}$ standard. X-Ray crystallography instrumental information can be found in Appendix 1. The phosphinoborane ligand ${ }^{41,42}$, $\left[\mathrm{Rh}(\mathrm{COD}) \mathrm{Cl}_{2}{ }_{2}^{43}\right.$ and $\left[\mathrm{Rh}(\mathrm{COE})_{2} \mathrm{Cl}\right]_{2}{ }^{44}$ were prepared according to previously published methods. The $\mathrm{Rh}(\mathrm{COD})\left[\mathrm{Ph}_{2} \mathrm{PCH}_{2} \mathrm{CH}_{2} \mathrm{~B}^{\mathrm{BBN}}\right] \mathrm{Cl}$ complex was prepared by modification of literature procedures. ${ }^{45}$

\subsubsection{Procedure for Synthesis of $\left[\mathrm{Rh}(\mathrm{COD})\left[\mathrm{Ph}_{2} \mathrm{PCH}_{2} \mathrm{CH}_{2} \mathrm{~B}\left(\mathrm{C}_{8} \mathrm{H}_{13}\right)\right][2-\mathrm{pyridine}\right.$ - $\mathrm{CH}_{2} \mathrm{O}$ OTf Complex 133}

A sample of $\mathrm{Rh}(\mathrm{COD}) \mathrm{PBCl}$ (45 mg, $0.077 \mathrm{mmols}$ ) was dissolved in THF in a 20 $\mathrm{mL}$ scintillation vial equipped with a magnetic stir bar and a cap. A sample of AgOTf, (20 mg, $0.077 \mathrm{mmols}$ ), was added and the sample was stirred for an hour and filtered through Celite. The sample was then treated with 2-pyridinecarboxaldehyde ( $8.3 \mathrm{mg}$, $7.5 \mu \mathrm{L}, 0.77 \mathrm{mmols}$ ) and stirred for an additional 3 hours. The yellow crystals were isolated by recrystallization from $\mathrm{DCM} / \mathrm{Et}_{2} \mathrm{O}$ or toluene (yield $=62 \mathrm{mg}, 99.8 \%$ ). ${ }^{1} \mathrm{H}$ NMR $\left(600 \mathrm{MHz}, \mathrm{CD}_{2} \mathrm{Cl}_{2}\right): \delta 8.27$ (d, $\left.1 \mathrm{H},{ }^{3} \mathrm{~J}_{\mathrm{H}-\mathrm{H}}=6.17 \mathrm{~Hz}, \mathrm{H} 2-\mathrm{pyr}\right), \delta 8.11\left(\mathrm{dd},{ }^{3} \mathrm{~J}_{\mathrm{H}-\mathrm{H}}=7.9 \mathrm{~Hz}\right.$, $\left.{ }^{3} \mathrm{~J}_{\mathrm{H}-\mathrm{H}}=7.5 \mathrm{~Hz}, 1 \mathrm{H}, \mathrm{H} 4-\mathrm{pyr}\right), \delta 8.02(\mathrm{~m}, 2 \mathrm{H}, \mathrm{o}-\mathrm{Ph}), \delta 7.76\left(\mathrm{~d},{ }^{3} \mathrm{~J}_{\mathrm{H}-\mathrm{H}}=7.9 \mathrm{~Hz}, 1 \mathrm{H}, \mathrm{H} 5-\mathrm{pyr}\right)$, $\delta 7.6\left(\mathrm{dd},{ }^{3} \mathrm{~J}_{\mathrm{H}-\mathrm{H}}=7.5 \mathrm{~Hz},{ }^{3} \mathrm{~J}_{\mathrm{H}-\mathrm{H}}=6.2 \mathrm{~Hz}, 1 \mathrm{H}, \mathrm{H} 3-\mathrm{pyr}\right), \delta 7.54(\mathrm{~m}, 1 \mathrm{H}, \mathrm{p}-\mathrm{Ph}), \delta 7.53(\mathrm{~m}$,

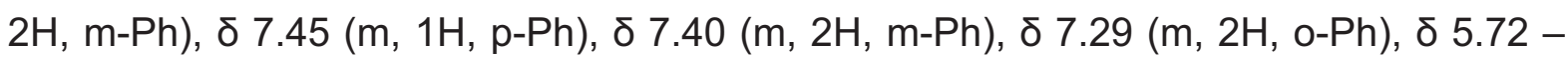
5.78 (br. m, 1H, COD-CH trans-P), $\delta 5.33$ (m., 1H, COD-CH trans-P), $\delta 3.27(\mathrm{~m} ., 1 \mathrm{H}$,

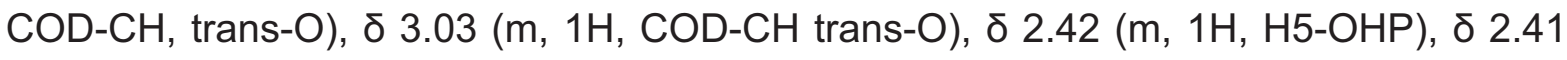


(ddd, $1 \mathrm{H},{ }^{2} \mathrm{~J}_{\mathrm{H}-\mathrm{H}}=14.2 \mathrm{~Hz},{ }^{2} \mathrm{~J}_{\mathrm{P}-\mathrm{H}}=10.3 \mathrm{~Hz},{ }^{3} \mathrm{~J}_{\mathrm{H}-\mathrm{H}}=10.5 \mathrm{~Hz}, \mathrm{PCH}$ ), $\delta 2.25(\mathrm{~m}, 1 \mathrm{H}, \mathrm{OHP})$, $\delta 1.71$ (ddd, $\left.1 \mathrm{H},{ }^{2} \mathrm{~J}_{\mathrm{H}-\mathrm{H}}=14.2 \mathrm{~Hz},{ }^{2} \mathrm{~J}_{\mathrm{P}-\mathrm{H}}=11.5 \mathrm{~Hz},{ }^{3} \mathrm{~J}_{\mathrm{H}-\mathrm{H}}=2.3 \mathrm{~Hz}, \mathrm{PCH}_{2}\right), \delta 1.68(\mathrm{~m}, 2 \mathrm{H}$, OHP), $\delta 1.60$ (m, 1H, OHP), 1.59 (m, 1H, OHP), 1.50 (m, 1H, OHP), 1.45 (m, 2H, OHP), $1.44(\mathrm{~m}, 1 \mathrm{H}, \mathrm{OHP}), 1.42(\mathrm{~m}, 1 \mathrm{H}, \mathrm{OHP}), 1.41(\mathrm{~m}, 1 \mathrm{H}, \mathrm{OHP}), 1.38$ (m, 1H, OHP), $\delta 1.25$ (ddd, $1 \mathrm{H},{ }^{2} \mathrm{~J}_{\mathrm{H}-\mathrm{H}}=15.5 \mathrm{~Hz},{ }^{3} \mathrm{~J}_{\mathrm{P}-\mathrm{H}}=28.3 \mathrm{~Hz},{ }^{3} \mathrm{~J}_{\mathrm{H}-\mathrm{H}}=2.3 \mathrm{~Hz}, \mathrm{PCH}$ ), $\delta 0.81$ (ddd, $1 \mathrm{H},{ }^{2} \mathrm{~J}_{\mathrm{H}-\mathrm{H}}$ $\left.=15.5 \mathrm{~Hz},{ }^{3} \mathrm{~J}_{\mathrm{P}-\mathrm{H}}=26.7 \mathrm{~Hz},{ }^{3} \mathrm{~J}_{\mathrm{H}-\mathrm{H}}=11.5 \mathrm{~Hz}, \mathrm{PCH}\right) .{ }^{13} \mathrm{C}\left\{{ }^{1} \mathrm{H}\right\} \mathrm{NMR}\left(151 \mathrm{MHz}, \mathrm{CD}_{2} \mathrm{Cl}_{2}\right): \delta$

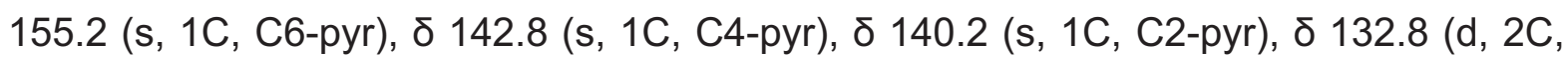
${ }^{2} \mathrm{~J}_{\mathrm{P}-\mathrm{C}}=11.5 \mathrm{~Hz}, \mathrm{o}-\mathrm{Ph}$ ), $\delta 132.5$ (d, 2C, ${ }^{1} \mathrm{~J}_{\mathrm{P}-\mathrm{C}}=43.9 \mathrm{~Hz}$, ipso-Ph), $\delta 132.3$ (d, 2C, ${ }^{2} \mathrm{~J}_{\mathrm{P}-\mathrm{C}}=$ $9.4 \mathrm{~Hz}$, o-Ph), $\delta 132.0$ (d, 2C, $\left.{ }^{4} \mathrm{~J}_{\mathrm{P}-\mathrm{C}}=1.8 \mathrm{~Hz}, \mathrm{p}-\mathrm{Ph}\right), \delta 131.7$ (d, 2C, ${ }^{1} \mathrm{~J}_{\mathrm{P}-\mathrm{C}}=42.1 \mathrm{~Hz}$, ipso-Ph), $\delta 131.0$ (d, 2C, $\left.{ }^{4} \mathrm{JP}_{\mathrm{P}-\mathrm{C}}=1.9 \mathrm{~Hz}, \mathrm{p}-\mathrm{Ph}\right), \delta 130.0$ (d, 2C, $\left.{ }^{3} \mathrm{~J}_{\mathrm{P}-\mathrm{C}}=10.4 \mathrm{~Hz}, \mathrm{~m}-\mathrm{Ph}\right), \delta$ 129.3 (d, 2C, ${ }^{3} \mathrm{~J}_{\mathrm{P}-\mathrm{C}}=9.5 \mathrm{~Hz}, \mathrm{~m}-\mathrm{Ph}$ ), $\delta 125.8$ (s, 1C, C3-pyr), $\delta 121.6$ (s, 1C, C5-pyr), $\delta$ $121.5\left(\mathrm{q}, 1 \mathrm{C},{ }^{1} \mathrm{~J}_{\mathrm{C}-\mathrm{F}}=321.0 \mathrm{~Hz}, \mathrm{O}_{3} \mathrm{SCF}_{3}\right), \delta 107.9\left(\mathrm{dd}, 1 \mathrm{C},{ }^{2} \mathrm{~J}_{\mathrm{P}-\mathrm{C}}=9.2 \mathrm{~Hz},{ }^{1} \mathrm{~J}_{\mathrm{Rh}-\mathrm{C}}=6.5 \mathrm{~Hz}\right.$, COD-CH trans-P), $\delta 105.5$ (dd, $1 \mathrm{C},{ }^{2} \mathrm{~J}_{\mathrm{P}-\mathrm{C}}=11.4 \mathrm{~Hz},{ }^{1} \mathrm{~J}_{\mathrm{Rh}-\mathrm{C}}=7.1 \mathrm{~Hz}, \mathrm{COD}-\mathrm{CH}$ trans-P), $\delta$ $73.2\left(\mathrm{~s}, 1 \mathrm{C}, \mathrm{OCH}_{2}\right), \delta 70.7\left(\mathrm{~d}, 1 \mathrm{C},{ }^{2} \mathrm{~J}_{\mathrm{P}-\mathrm{C}}=15.1 \mathrm{~Hz}, \mathrm{COD}-\mathrm{CH}\right.$ trans-O), $\delta 70.3\left(\mathrm{~d}, 1 \mathrm{C},{ }^{2} \mathrm{~J}_{\mathrm{P}-}\right.$ $c=15.8 \mathrm{~Hz}, \mathrm{COD}-\mathrm{CH}$ trans-O), $\delta 47.7$ (s, 1C, C5-OHP), $\delta 46.7$ (br. s, 1C, C1-OHP), $\delta$ 41.6 (s, 1C, OHP), $\delta 40.5$ (s, 1C, OHP), $\delta 36.9$ (s, 1C, OHP), $\delta 36.0$ (s, 1C, OHP), $\delta$

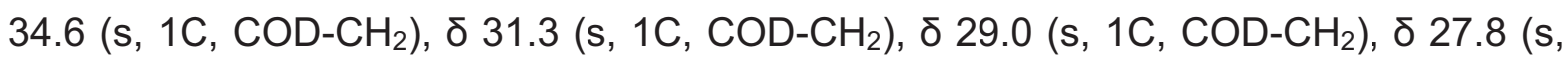

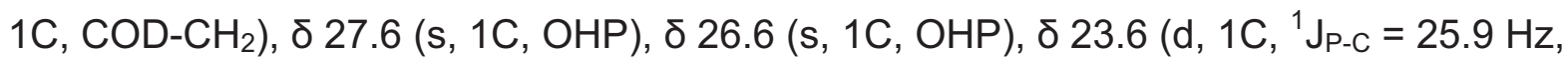
$\mathrm{PCH}_{2}$ ), $\delta 16.3$ (br. s, $\left.1 \mathrm{C}, \mathrm{CH}_{2} \mathrm{~B}\right) .{ }^{11} \mathrm{~B}\left\{{ }^{1} \mathrm{H}\right\} \mathrm{NMR}\left(128 \mathrm{MHz}, \mathrm{CD}_{2} \mathrm{Cl}_{2}\right.$ ): $\delta 13.5$ (br. s). ${ }^{31} \mathrm{P}\left\{{ }^{1} \mathrm{H}\right\}$ $\operatorname{NMR}\left(162 \mathrm{MHz}, \mathrm{CD}_{2} \mathrm{Cl}_{2}\right): \delta 24.1$ (d, $\left.{ }^{1} \mathrm{~J}_{\mathrm{Rh}-\mathrm{P}}=151.4 \mathrm{~Hz}\right) .{ }^{19} \mathrm{~F} \mathrm{NMR}\left(376 \mathrm{MHz}, \mathrm{CD}_{2} \mathrm{Cl}_{2}\right): \delta$ $78.9(\mathrm{~s})$. 


\subsubsection{Procedure for Reaction of $\left[\mathrm{Rh}\left(\mathrm{Ph}_{2} \mathrm{PCH}_{2} \mathrm{CH}_{2} \mathrm{~B}^{\mathrm{BBN}}\right)_{2} \mathrm{Cl}\right]_{2}$ with 8- Quinolinecarboxaldehyde to Yield Complex 132}

A sample of $\left[\mathrm{Rh}\left(\mathrm{Ph}_{2} \mathrm{PCH}_{2} \mathrm{CH}_{2} \mathrm{~B}^{\mathrm{BBN}}\right)_{2} \mathrm{Cl}\right]_{2} \quad(50 \mathrm{mg}, \quad 0.031 \mathrm{mmols})$ and 8quinolinecarboxaldehyde $(9.7 \mathrm{mg}, 0.062 \mathrm{mmols})$ were dissolved in THF in a $50 \mathrm{~mL}$ round bottom equipped with a magnetic stir bar and a septum. The sample was heated to $50^{\circ} \mathrm{C}$ for 48 hours. The solvent was removed in vacuo and the NMR recorded. ${ }^{1} \mathrm{H}$ NMR (400 MHz, $\left.\mathrm{CD}_{2} \mathrm{Cl}_{2}\right): \delta 9.00-9.28\left(\mathrm{~d}, 1 \mathrm{H},{ }^{3} \mathrm{~J}_{\mathrm{Rh}-\mathrm{H}}=4.8 \mathrm{~Hz}, \alpha-\mathrm{H}\right.$ Quinoline), $\delta 2.54-$ $2.88\left(\mathrm{~m}, 4 \mathrm{H}, \mathrm{PCH}_{2}\right), \delta-11.63$ (br. dt, $\left.1 \mathrm{H},{ }^{1} \mathrm{~J}_{\mathrm{Rh}-\mathrm{H}}=18.0 \mathrm{~Hz}, \mathrm{Rh}-\mathrm{H}\right) .{ }^{11} \mathrm{~B}\left\{{ }^{1} \mathrm{H}\right\} \mathrm{NMR}(128$ $\mathrm{MHz}, \mathrm{CD}_{2} \mathrm{Cl}_{2}$ ): $\delta 12.44$ (br. s), $\delta 60.7$ (br. s), $\delta 9.9$ (s). ${ }^{31} \mathrm{P}\left\{{ }^{1} \mathrm{H}\right\} \mathrm{NMR}\left(162 \mathrm{MHz}, \mathrm{CD}_{2} \mathrm{Cl}_{2}\right.$ ): $\delta 39.7\left(\mathrm{~d},{ }^{1} \mathrm{~J}_{\mathrm{Rh}-\mathrm{P}}=118.7 \mathrm{~Hz}\right)$. FTIR: 2044, 1976, 1656.

\subsection{References}

(1) Sakai, K.; Ide, J.; Oda, O.; Nakamura, N. Tetrahedron Lett. 1972, 1287.

(2) Sakai, K.; Oda, O. Tetrahedron Lett. 1972, 4375.

(3) Lochow, C. F.; Miller, R. G. J. Am. Chem. Soc. 1976, 98, 1281.

(4) Fairlie, D. P.; Bosnich, B. Organometallics 1988, 7, 936.

(5) González-Rodríguez, C.; Pawley, R. J.; Chaplin, A. B.; Thompson, A. L.; Weller, A. S.; Willis, M. C. Angew. Chem. Int. Ed. Engl. 2011, 50, 5134.

(6) Barnhart, R. W.; McMorran, D. A.; Bosnich, B. Chem. Commun. 1997, 589.

(7) Suggs, J. W. J. Am. Chem. Soc. 1978, 100, 640.

(8) Suggs, J. W. J. Am. Chem. Soc. 1979, 101, 489.

(9) Suggs, J. W.; Wovkulich, M. J.; Cox, S. D. Organometallics 1985, 4, 1101.

(10) Hartwig, J. F. Organotransition Metal Chemistry: From Bonding to Catalysis; University Science Books, 2010. 
(11) Pernik, I.; Hooper, J. F.; Chaplin, A. B.; Weller, A. S.; Willis, M. C. ACS Catal. 2012, 2, 2779.

(12) Chaplin, A. B.; Hooper, J. F.; Weller, A. S.; Willis, M. C. J. Am. Chem. Soc. 2012, 134,4885 .

(13) Marder, T. B.; Roe, D. C.; Milstein, D. Organometallics 1988, 7, 1451.

(14) Coulter, M. M.; Kou, K. G. M.; Galligan, B.; Dong, V. M. J. Am. Chem. Soc. 2010, 132, 16330.

(15) González-Rodríguez, C.; Willis, M. C. Pure Appl. Chem. 2011, 83, 577.

(16) Marcé, P.; Godard, C.; Feliz, M.; Yañez, X.; Bo, C.; Castillón, S. Organometallics 2009, 28, 2976.

(17) Thomas, J. C.; Peters, J. C. Inorg. Chem. 2003, 42, 5055.

(18) Betley, T. A.; Peters, J. C. Angew. Chem. Int. Ed. Engl. 2003, 42, 2385.

(19) Roy, A. H.; Lenges, C. P.; Brookhart, M. J. Am. Chem. Soc. 2007, 129, 2082.

(20) Pawley, R. J.; Moxham, G. L.; Dallanegra, R.; Chaplin, A. B.; Brayshaw, S. K.; Weller, A. S.; Willis, M. C. Organometallics 2010, 29, 1717.

(21) Dallanegra, R.; Chaplin, A. B.; Weller, A. S. Organometallics 2012, 31, 2720.

(22) Chen, D. M.; Gau, M. R.; Dobereiner, G. E. Organometallics 2015, 34, 4069.

(23) Vummaleti, S. V. C.; Al-Ghamdi, M.; Poater, A.; Falivene, L.; Scaranto, J.; Beetstra, D. J.; Morton, J. G.; Cavallo, L. Organometallics 2015, 34, 5549.

(24) Nolan, S. P.; de la Vega, R. L.; Hoff, C. D. J. Am. Chem. Soc. 1986, 108, 7852.

(25) Llewellyn, S. A.; Green, M. L. H.; Cowley, A. R. Dalton Trans. 2006, 1776.

(26) Smeltz, J. L.; Lilly, C. P.; Boyle, P. D.; Ison, E. A. J. Am. Chem. Soc. 2013, 135, 9433. 
(27) Ko, S.; Kang, B.; Chang, S. Angew. Chem. Int. Ed. Engl. 2005, 44, 455.

(28) Trofimenko, S.; Calabrese, J. C.; Thompson, J. S. Inorg. Chem. 1992, 31, 974.

(29) Bortolin, M.; Bucher, U. E.; Rüegger, H.; Venanzi, L. M.; Albinati, A.; Lianza, F.; Trofimenko, S. Organometallics 1992, 11, 2514.

(30) The R-factor of the complex is too high. The crystal structure establishes connectivity amongst the atoms in the complex.

(31) Kramer, G. W.; Brown, H. C. J. Am. Chem. Soc. 1976, 98, 1964.

(32) Sikorski, J. A.; Bhat, N. G.; Cole, T. E.; Wang, K. K.; Brown, H. C. J. Org. Chem. $1986,51,4521$.

(33) Pal, S.; Zavalij, P. Y.; Vedernikov, A. N. Chem. Commun. 2014, 50, 5376.

(34) Seidel, G.; Fürstner, A. Organometallics 2014, 33, 4336.

(35) Guennouni, N.; Lhermitte, F.; Cochard, S.; Carboni, B. Tetrahedron 1995, 51, 6999.

(36) Miller, A. J. M.; Labinger, J. A.; Bercaw, J. E. Organometallics 2011, 30, 4308.

(37) Miller, A. J. M.; Labinger, J. A.; Bercaw, J. E. Organometallics 2010, 29, 4499.

(38) Jun, C-H.; Lee, D-Y.; Hong, J-B. Tetrahedron Lett. 1997, 38, 6673.

(39) Jun, C-H.; Lee, H.; Hong, J-B.; Kwon, B-I. Angew. Chem. Int. Ed. Engl. 2002, 41, 2146.

(40) Bugaut, X.; Liu, F.; Glorius, F. J. Am. Chem. Soc. 2011, 133, 8130.

(41) Fischbach, A.; Bazinet, P. R.; Waterman, R.; Tilley, T. D. Organometallics 2008, 27, 1135.

(42) Vergnaud, J.; Grellier, M.; Bouhadir, G.; Vendier, L.; Sabo-Etienne, S.; Bourissou, D. Organometallics 2008, 27, 1140. 
(43) Giordano, G.; Crabtree, R. H. Inorg. Syn. 1990, 28, 88.

(44) van der Ent, A.; Onderdelinden, A. L. Inorg. Syn. 1990, 28, 90.

(45) Greenacre, V. K.; Ansell, M. B.; Roe, S. M.; Crossley, I. R. Eur. J. Inorg. Chem. 2014, 5053. 
CHAPTER 6

Summary and Perspective 


\subsection{Summary}

The previous chapters have described studies with the goal of understanding the effect of pendant, second-coordination sphere Lewis acids on both the structure and catalytic activity of late transition metal complexes. These studies attempted to bridge the gap between the solid and solution state structures and catalytic activity. The use of model catalytic systems and experimental techniques, such as ${ }^{11} B\left\{{ }^{1} H\right\} N M R$ spectroscopy, lead to an improved understanding of the synergistic behavior of these late transition metal complexes bearing Lewis acids, which are summarized below.

Chapter 2: The synthesis of a variety of rhodium and iridium complexes featuring the conformationally flexible $\beta$-phosphinoethylborane ligand lead to complexes reported previously by Crossley and coworkers. ${ }^{1}$ Crossley and coworkers reported that the borane was free of interactions based on ${ }^{11} \mathrm{~B}\left\{{ }^{1} \mathrm{H}\right\}$ NMR spectroscopy. ${ }^{1}$ However, the solid-state structure of these rhodium and iridium phosphinoborane complexes showed a weak borane-chloride interaction visible in the solid-state structure. An NMR spectroscopic investigation into the solution-phase structure determined that this same interaction was dependent on a variety of factors. Firstly, the interaction was dependent on the solvent, for which there were two visible regimes. The first regime was for low polarity solvents, where the interaction increased as the solvent polarity decreased. The second regime applied to higher polarity solvents, where there was a competition between the solvent-bound borane and the borane-chloride interaction. Next, as the electronegativity of the group interacting with the borane increases, the ${ }^{11} B\left\{{ }^{1} H\right\} N M R$ resonance shifts upfield, corresponding to an increase in Lewis acid-base pairing. Low- 
temperature analysis revealed that the rhodium complex 66 exhibits fluxional solution phase dynamics, which approaches a coalescence point at $-80^{\circ} \mathrm{C}$.

Chapter 3: In order to investigate the effect of pendant Lewis acids on catalysis, we sought to use the work of Crudden and coworkers ${ }^{2,3}$ as a model system to study the effect of the Lewis acid on hydroboration. During the screening of the reaction conditions, it was determined that the hydroboration of vinyl arenes worked best in THF with the addition of silver (I) triflate. While there were a number of by-products occurring from side-reactions, these could be minimized by the use of excess exogenous phosphinoborane ligand. ${ }^{4}$ Stoichiometric reactions between the rhodium(I) dimer 74 and HBPin revealed the presence of a weak borane hydride interaction in the five-coordinate oxidative addition product. The control study using triphenylphosphine in place of phosphinoborane was conducted and revealed that the interaction was due to the 9BBN moiety.

Chapter 4: The substrate screen in Chapter 3 led to the discovery that rhodium(I) complex 66 catalyzed the hydroboration of diphenylvinylphosphine..$^{5-7}$ It was subsequently determined that $[\mathrm{Rh}(\mathrm{COD}) \mathrm{Cl}]_{2}$ catalyzed the reaction just as effectively, as the addition of exogenous phosphine was not necessary. After further optimization, the phosphine-limiting reaction at elevated temperatures yielded the branched-product over the linear product in a 93:7 ratio, while the borane-limiting reaction at low temperature yielded the linear product over the branched product in a 90:10 ratio. To the best of our knowledge, this was the first reported example of the hydroboration of a vinylic Lewis basic substrate that provided regioselective control over the products. The branched product was converted into the corresponding rhodium $(\mathrm{I})$ complex 105 . The ${ }^{11} \mathrm{~B}\left\{{ }^{1} \mathrm{H}\right\}$ 
NMR spectra confirmed that the boronic ester does not interact with the chloride, as a result of a combination of the steric bulk and the reduced Lewis acidity of the pinacol boronic ester moiety. The phosphinoborane product was additionally protected with $\mathrm{BH}_{3}$-THF and converted into the phosphine-protected Molander salt 109, which was characterized by X-ray crystallography and NMR spectroscopy.

Chapter 5: We sought to explore the hydroacylation reaction with the ultimate goal of utilizing the pendant borane to stabilize rhodium(III)-acyl hydride complexes. It was determined through stoichiometric reactivity that one of two different reactions occurred. When using 8-quinolinecarboxaldehyde ${ }^{8}$ as an aldehyde equivalent, traditional oxidative addition occurred yielding the formation of the expected acylrhodium(III)-hydride complex 132. When 2-pyridinecarbaldehyde was used, product 133 resulted from ring-migration ${ }^{9,10}$ within the $\mathrm{B}^{\mathrm{BBN}}$ moiety and an ultimate reduction of the aldehyde. This latter reactivity represents a rare example of $\mathrm{C}\left(\mathrm{sp}^{3}\right)-\mathrm{H}$ bond cleavage and subsequent $\mathrm{C}-\mathrm{C}$ bond formation.

The studies conducted provide a better understanding of the role of second coordination sphere Lewis acids. Experimental evidence suggests that these boranes exhibit dynamic behavior involving primary coordination sphere ligands. Through the use of hydroboration as a model reaction for other hydrofunctionalizations, we were able to probe the effect of pendant boranes on late transition metal catalytic activity and the stabilization of reactive intermediates. Herein, we demonstrated the application of FLP-type molecules as ligands for late transition metal complexes.

The future goals of this project are to expand upon our understanding of the observed reactivity trends through mechanistic studies and apply this knowledge to 
other reactions. Another future goal is to expand on the types of Lewis acids utilized in these ligand scaffolds. The use of more or less Lewis acidic boranes can expand on the reactivity currently known for the 9-BBN ligand scaffold. The use of chiral boranes, such as diisopinocampheylborane, could potentially be utilized to impart chirality on the products of hydrofunctionalization reactions through the observed weak interactions with the metal-hydride ligand. In the case of hydroacylation, studies are on going to investigate catalytic hydroacylation using these pendant borane catalysts.

\subsection{References}

(1) Greenacre, V. K.; Ansell, M. B.; Roe, S. M.; Crossley, I. R. Eur. J. Inorg. Chem. 2014, 5053.

(2) Lata, C. J.; Crudden, C. M. J. Am. Chem. Soc. 2010, 132, 131.

(3) Crudden, C. M.; Hleba, Y. B.; Chen, A. C. J. Am. Chem. Soc. 2004, 126, 9200.

(4) Evans, D. A.; Fu, G. C.; Anderson, B. A. J. Am. Chem. Soc. 1992, 114, 6679.

(5) Hornillos, V.; Vila, C.; Otten, E.; Feringa, B. L. Angew. Chem. Int. Edit. 2015, 54, 7867.

(6) Garon, C. N.; McIsaac, D. I.; Vogels, C. M.; Decken, A.; Williams, I. D.; Kleeberg, C.; Marder, T. B.; Westcott, S. A. Dalton Trans. 2009, 1624.

(7) Thangavelu, S. G.; Hocker, K. E.; Cooke, S. R.; Muhoro, C. N. J. Organomet. Chem. 2008, $693,562$.

(8) Suggs, J. W. J. Am. Chem. Soc. 1978, 100, 640.

(9) Sikorski, J. A.; Bhat, N. G.; Cole, T. E.; Wang, K. K.; Brown, H. C. J. Org. Chem. 1986, 51, 4521.

(10) Pal, S.; Zavalij, P. Y.; Vedernikov, A. N. Chem. Commun. 2014, 50, 5376. 
Appendix One

\section{X-Ray Crystallography Data Tables} and Instrumental Information 


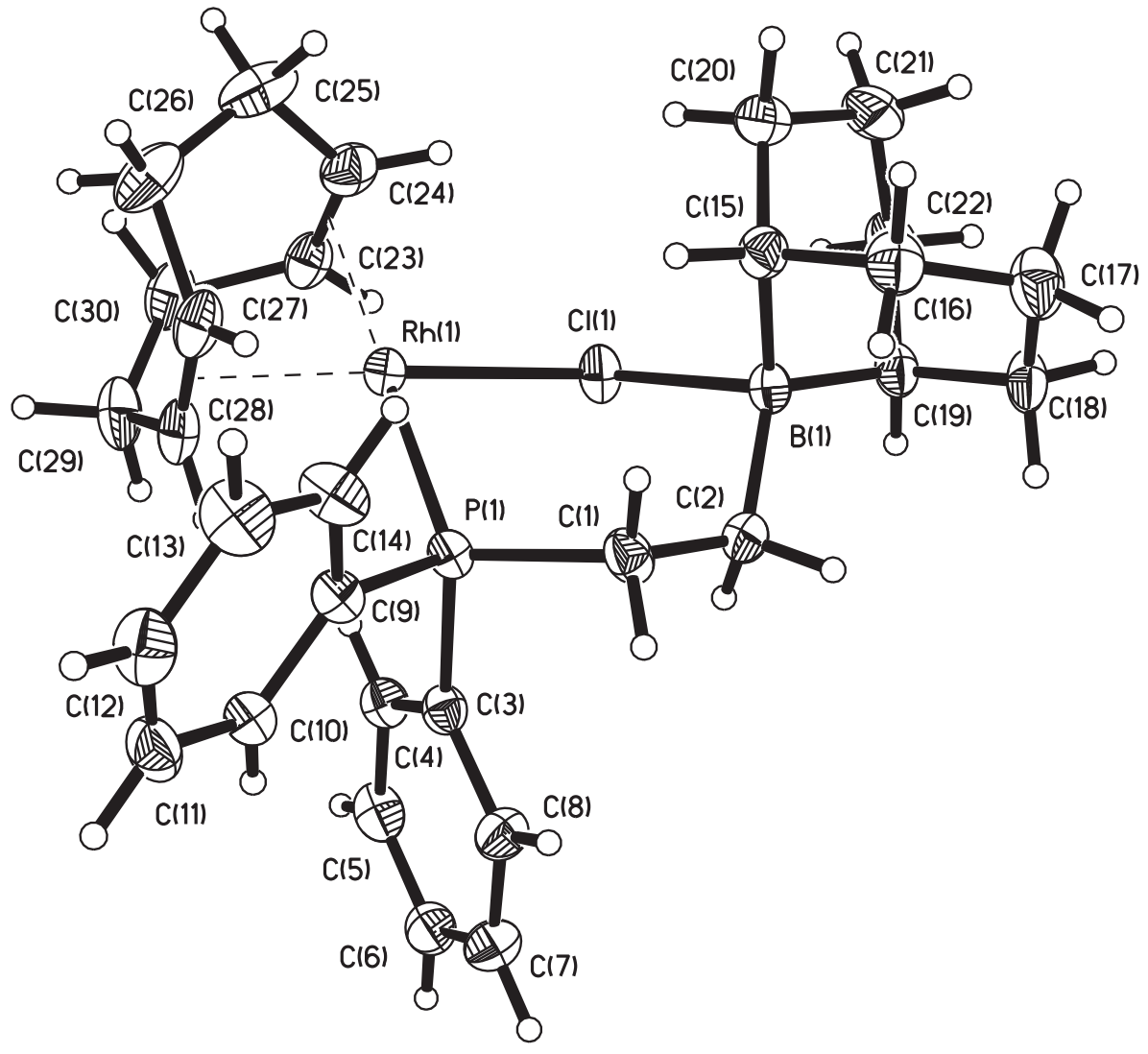

Figure A1.1. Perspective view of the molecular structure of $\mathrm{RhCl}(\mathrm{COD})\left[\mathrm{PPh}_{2} \mathrm{CH}_{2} \mathrm{CH}_{2} \mathrm{~B}\left(\mathrm{C}_{8} \mathrm{H}_{14}\right)\right]$ with the atom labeling scheme for the independent non-hydrogen atoms. The thermal ellipsoids are scaled to enclosed $30 \%$ probability. 


\section{Description of the X-ray Structural Analysis of $\mathrm{RhCl}(\mathrm{COD})\left[\mathrm{PPh}_{2} \mathrm{CH}_{2} \mathrm{CH}_{2} \mathrm{~B}\left(\mathrm{C}_{8} \mathrm{H}_{14}\right)\right]$}

A yellow crystal of $\mathrm{RhCl}(\mathrm{COD})\left[\mathrm{PPh}_{2} \mathrm{CH}_{2} \mathrm{CH}_{2} \mathrm{~B}\left(\mathrm{C}_{8} \mathrm{H}_{14}\right)\right]$ was washed with the perfluoropolyether PFO-XR75 (Lancaster) and sealed under a nitrogen atmosphere in a glass capillary. The sample was optically aligned on the four-circle of a Siemens P4 diffractometer equipped with a graphite monochromator, a monocap collimator, a Mo Ka radiation source $(\lambda=0.71073 \AA)$, and a SMART CCD detector held at $5.050 \mathrm{~cm}$ from the crystal. Four sets of 20 frames each were collected using the $\omega$ scan method and with a $10 \mathrm{~s}$ exposure time. Integration of these frames followed by reflection indexing and least-squares refinement produced a crystal orientation matrix for the triclinic crystal lattice.

Data collection consisted of the measurement of a total of 1650 frames in five different runs covering a hemisphere of data. Frame scan parameters are summarized below:

\begin{tabular}{|c|c|c|c|c|c|c|c|c|}
\hline Run & $2 \theta$ & $\omega$ & $\phi$ & $X$ & $\begin{array}{r}\text { Scan } \\
\text { axis }\end{array}$ & $\begin{array}{l}\text { Scan } \\
\text { width }\left(^{\circ}\right)\end{array}$ & $\begin{array}{l}\text { Frames } \\
)(\#)\end{array}$ & $\begin{array}{l}\text { Exposure } \\
\text { time (sec.) }\end{array}$ \\
\hline 1 & 28 & 43.00 & 0.00 & 280.00 & 2 & -0.3 & 100 & 40 \\
\hline 2 & 28 & 43.00 & 90.00 & 280.00 & 2 & -0.3 & 100 & 40 \\
\hline 3 & 28 & 43.00 & 180.00 & 280.00 & 2 & -0.3 & 100 & 40 \\
\hline 4 & 28 & 43.00 & 270.00 & 280.00 & 2 & -0.3 & 100 & 40 \\
\hline 5 & 28 & 28.00 & 0.00 & 30.00 & 3 & 0.3 & 1250 & 40 \\
\hline
\end{tabular}

The program SMART (version 5.6) ${ }^{1}$ was used for diffractometer control, frame scans, indexing, orientation matrix calculations, least-squares refinement of cell parameters, and the data collection. All 1650 crystallographic raw data frames were 
read by the program SAINT (version $5 / 6.0)^{1}$ and integrated using 3D profiling algorithms. The resulting data were reduced to produce a total of 9378 reflections and their intensities and estimated standard deviations. An absorption correction was applied using the SADABS routine available in SAINT. ${ }^{1}$ The data were corrected for Lorentz and polarization effects. No evidence of crystal decomposition was observed. Data preparation was carried out by using the program XPREP, ${ }^{1}$ which gave 5969 unique reflections $\left(R_{\text {int }}=3.84 \%\right)$ with indices $-14 \leq h \leq 14,-13 \leq k \leq 15,-16 \leq \mathrm{I} \leq 16$. The triclinic space group was determined to be $\mathrm{P}^{\overline{1}}$ (No. 2).

The structure was solved by a combination of direct methods and difference Fourier analysis with the use of SHELXTL $6.1 .^{2}$ Idealized positions for the hydrogen atoms were included as fixed contributions using a riding model with isotropic temperature factors set at 1.2 times that of the adjacent carbon atom. Full-matrix leastsquares refinement, based upon the minimization of $\Sigma w_{i}\left|F_{o}{ }^{2}-F_{c}{ }^{2}\right|^{2}$, with weighting $w_{i}^{-1}$ $=\left[\sigma^{2}\left(F_{o}^{2}\right)+(0.0395 P)^{2}+4.503 P\right]$, where $P=\left(\operatorname{Max}\left(F_{o}^{2}, 0\right)+2 F_{c}^{2}\right) / 3$, converged to give final discrepancy indices ${ }^{3}$ of $\mathrm{R} 1=0.0547$, wR2 $^{2} 0.1591$ for 5318 diffraction data with $\mathrm{I}>2 \sigma(\mathrm{I})$. The goodness of fit (GOF) value was 1.098 .

A correction for secondary extinction was not applied. The maximum and minimum residual electron density peaks in the final difference Fourier map were 1.328 and $-0.682 \mathrm{e} / \AA^{3}$, respectively. The linear absorption coefficient, atomic scattering factors, and anomalous dispersion corrections were calculated from values found in the International Tables of X-ray Crystallography. ${ }^{4}$ 


\section{References}

1. SMART, SAINT and XPREP programs are part of Bruker crystallographic software package for single crystal data collection, reduction and preparation.

2. Sheldrick, G. M., SHELXTL6.1 (2000), Crystallographic software package, Bruker AXS, Inc. Madison, Wisconsin, USA.

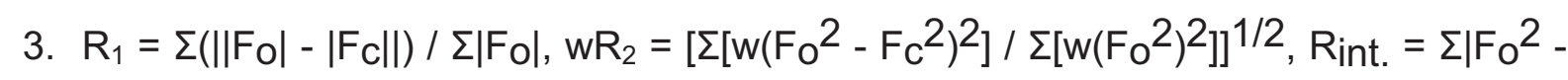
$\left.F_{o}^{2}(\operatorname{mean})\right|^{2} / \Sigma\left[F_{o}^{2}\right]$, and GOF $\left.=\left[\Sigma w\left(F_{o}^{2}-F_{c}^{2}\right)^{2}\right] /(n-p)\right]^{1 / 2}$, where $n$ is the number of reflections and $p$ is the total number of parameters which were varied during the last refinement cycle.

4. International Tables for X-ray Crystallography (1974). Vol. IV, p. 55. Birmingham: Kynoch Press. (Present distributor, D. Reidel, Dordrecht.). 
Table 1. Crystal data and structure refinement for $\mathrm{RhCl}(\mathrm{COD})\left[\mathrm{PPh}_{2} \mathrm{CH}_{2} \mathrm{CH}_{2} \mathrm{~B}\left(\mathrm{C}_{8} \mathrm{H}_{14}\right)\right]$.

Identification code

CCDC Number

Empirical formula

Formula weight

Temperature

Wavelength

Crystal system

Space group

Unit cell dimensions

Volume

Z

Density (calculated)

Absorption coefficient

$\mathrm{F}(000)$

Crystal size

$\theta$ range for data collection

Index ranges

Reflections collected

Independent reflections

Completeness to $\theta=27.59^{\circ}$

Max. and min. transmission

Refinement method

Data / restraints / parameters

Goodness-of-fit on F2

Final $R$ indices $[\mid>2 \sigma(I)]$

$\mathrm{R}$ indices (all data)

Largest diff. peak and hole bp1ccd

CCDC 1833915

$\mathrm{C}_{30} \mathrm{H}_{40} \mathrm{BCIPRh}$

580.76

293(2) K

$0.71073 \AA$

triclinic

$\mathrm{P} \overline{1}$

$a=11.074(1) \AA$

$a=65.811(2)^{\circ}$

$b=11.690(1) \AA$

$\mathrm{b}=75.634(1)^{\circ}$

$c=13.074(1) \AA$

$1367.4(2) \AA^{3}$

2

$1.410 \mathrm{~g} / \mathrm{cm}^{3}$

$7.98 \mathrm{~cm}^{-1}$

604

$0.06 \times 0.24 \times 0.58 \mathrm{~mm}$

1.71 to $27.59^{\circ}$

$-14 \leq h \leq 14,-13 \leq k \leq 15,-16 \leq \mathrm{I} \leq 16$

9378

$5969[R($ int $)=0.0384]$

$94.1 \%$

0.954 and 0.655

Full-matrix least-squares on $\mathrm{F}^{2}$

5969 / 0 / 307

1.098

$\mathrm{R} 1=0.0547, \mathrm{wR} 2=0.1591$

$\mathrm{R} 1=0.0604, \mathrm{wR} 2=0.1632$

1.324 and $-0.682 \mathrm{e} / \AA^{3}$ 


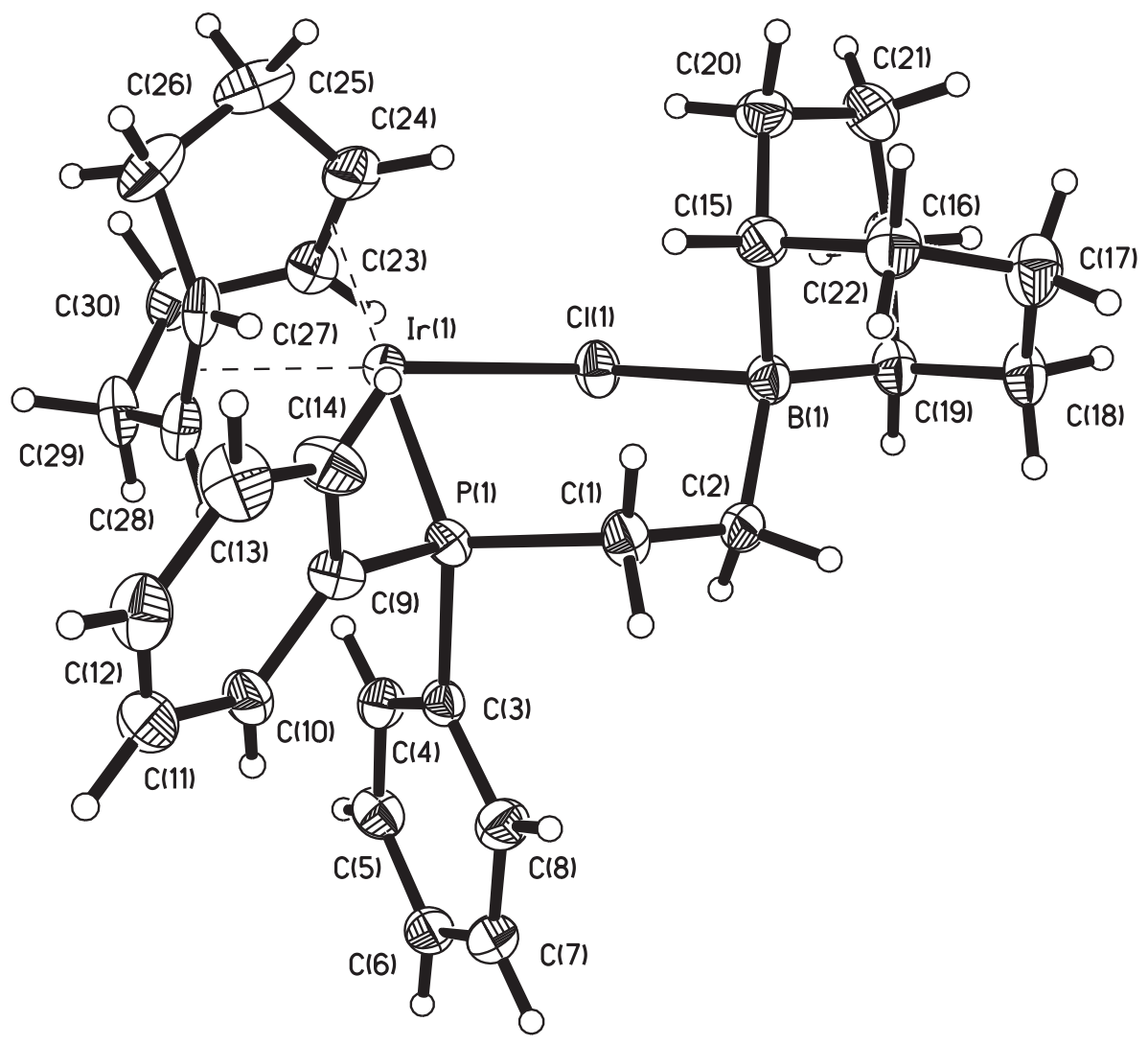

Figure A1.2. Perspective view of the molecular structure of IrCl(COD) $\left[\mathrm{PPh}_{2} \mathrm{CH}_{2} \mathrm{CH}_{2} \mathrm{~B}\left(\mathrm{C}_{8} \mathrm{H}_{14}\right)\right]$ with the atom labeling scheme provided for the non-hydrogen atoms. The thermal ellipsoids are scaled to enclose $30 \%$ probability. 


\section{Description of the X-ray Structural Analysis of $\operatorname{IrCl}(\mathrm{COD})\left[\mathrm{PPh}_{2} \mathrm{CH}_{2} \mathrm{CH}_{2} \mathrm{~B}\left(\mathrm{C}_{8} \mathrm{H}_{14}\right)\right]$}

A yellow irregular crystalline fragment of $\operatorname{IrCl}(\mathrm{COD})\left[\mathrm{PPh}_{2} \mathrm{CH}_{2} \mathrm{CH}_{2} \mathrm{~B}\left(\mathrm{C}_{8} \mathrm{H}_{14}\right)\right]$ was washed with the perfluoropolyether PFO-XR75 (Lancaster) and sealed under dintrogen in a glass capillary. The sample was optically aligned on the four-circle of a Siemens P4 diffractometer equipped with a graphite monochromator, a monocap collimator, a Mo Ka radiation source $(\lambda=0.71073 \AA)$, and a SMART CCD detector held at $5.030 \mathrm{~cm}$ from the crystal. Four sets of 20 frames each were collected using the $\omega$ scan method and with a $10 \mathrm{~s}$ exposure time. Integration of these frames followed by reflection indexing and least-squares refinement produced a crystal orientation matrix for the triclinic crystal lattice.

Data collection consisted of the measurement of a total of 1650 frames in five different runs covering a hemisphere of data. Frame scan parameters are summarized below:

\begin{tabular}{|c|c|c|c|c|c|c|c|c|}
\hline Run & $2 q$ & w & $f$ & c & $\begin{array}{r}\text { Scan } \\
\text { axis }\end{array}$ & $\begin{array}{l}\text { Scan } \\
\text { width }\left({ }^{\circ}\right)\end{array}$ & $\begin{array}{l}\text { Frames } \\
(\#)\end{array}$ & $\begin{array}{l}\text { Exposure } \\
\text { time (sec.) }\end{array}$ \\
\hline 1 & 28 & 43.00 & 0.00 & 280.00 & 2 & -0.3 & 100 & 40 \\
\hline 2 & 28 & 43.00 & 90.00 & 280.00 & 2 & -0.3 & 100 & 40 \\
\hline 3 & 28 & 43.00 & 180.00 & 280.00 & 2 & -0.3 & 100 & 40 \\
\hline 4 & 28 & 43.00 & 270.00 & 280.00 & 2 & -0.3 & 100 & 40 \\
\hline 5 & 28 & 28.00 & 0.00 & 30.00 & 3 & 0.3 & 1250 & 40 \\
\hline
\end{tabular}

The program SMART (version 5.6) ${ }^{1}$ was used for diffractometer control, frame scans, indexing, orientation matrix calculations, least-squares refinement of cell parameters, and the data collection. All 1650 crystallographic raw data frames were 
read by the program SAINT (version $5 / 6.0)^{1}$ and integrated using 3D profiling algorithms. The resulting data were reduced to produce a total of 8497 reflections and their intensities and estimated standard deviations. An absorption correction was applied using the SADABS routine available in SAINT. ${ }^{1}$ The data were corrected for Lorentz and polarization effects. No evidence of crystal decomposition was observed. Data preparation was carried out by using the program XPREP, ${ }^{1}$ which gave 5614 unique reflections $\left(R_{\text {int }}=3.54 \%\right)$ with indices $-14 \leq h \leq 14,-14 \leq k \leq 15,-16 \leq \mathrm{I} \leq 15$. The triclinic space group was determined to be $\mathrm{P}^{\overline{1}}$ (No. 2).

The structure was solved by a combination of the Patterson heavy atom method and difference Fourier analysis with the use of SHELXTL $6.1 .^{2}$ Idealized positions for the hydrogen atoms were included as fixed contributions using a riding model with isotropic temperature factors set at 1.2 times that of the adjacent carbon atom. Fullmatrix least-squares refinement, based upon the minimization of $\Sigma w_{i}\left|F_{o}^{2}-F_{c}^{2}\right|^{2}$, with weighting $\mathrm{w}_{\mathrm{i}}^{-1}=\left[\sigma^{2}\left(\mathrm{~F}_{\mathrm{o}}{ }^{2}\right)+(0.0993 \mathrm{P})^{2}+8.2603 \mathrm{P}\right]$, where $\mathrm{P}=\left(\operatorname{Max}\left(\mathrm{F}_{\mathrm{o}}{ }^{2}, 0\right)+2 \mathrm{~F}_{\mathrm{c}}{ }^{2}\right) / 3$, converged to give final discrepancy indices ${ }^{3}$ of $\mathrm{R} 1=0.0585$, wR2 $=0.1843$ for 5278 diffraction data with $\mathrm{I}>2 \sigma(\mathrm{I})$. The goodness of fit (GOF) value was 1.157.

A correction for secondary extinction was not applied. The maximum and minimum residual electron density peaks in the final difference Fourier map were 1.389 and $-1.773 \mathrm{e} / \AA^{3}$, respectively. The linear absorption coefficient, atomic scattering factors, and anomalous dispersion corrections were calculated from values found in the International Tables of X-ray Crystallography. ${ }^{4}$ 


\section{References}

1. SMART, SAINT and XPREP programs are part of Bruker crystallographic software package for single crystal data collection, reduction and preparation.

2. Sheldrick, G. M., SHELXTL6.1 (2000), Crystallographic software package, Bruker AXS, Inc. Madison, Wisconsin, USA.

3. $R_{1}=\Sigma\left(|| F_{O}|-| F_{c}||\right) / \Sigma\left|F_{o}\right|, w_{2}=\left[\Sigma\left[w\left(F_{o}^{2}-F_{c}^{2}\right)^{2}\right] / \Sigma\left[w\left(F_{o}^{2}\right)^{2}\right]\right]^{1 / 2}$, Rint. $=\Sigma \mid F_{o}{ }^{2}-$

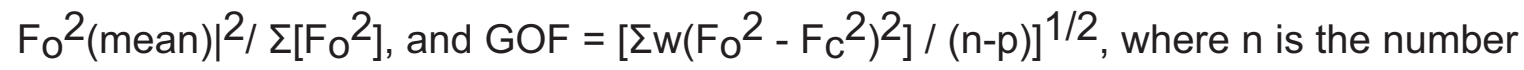
of reflections and $p$ is the total number of parameters which were varied during the last refinement cycle.

4. International Tables for X-ray Crystallography (1974). Vol. IV, p. 55. Birmingham: Kynoch Press. (Present distributor, D. Reidel, Dordrecht.). 
Table 2. Crystal data and structure refinement for $\operatorname{IrCl}(\mathrm{COD})\left[\mathrm{PPh}_{2} \mathrm{CH}_{2} \mathrm{CH}_{2} \mathrm{~B}\left(\mathrm{C}_{8} \mathrm{H}_{14}\right)\right]$.

Identification code

CCDC Number

Empirical formula

Formula weight

Temperature

Wavelength

Crystal system

Space group

Unit cell dimensions

Volume

Z

Density (calculated)

Absorption coefficient

$\mathrm{F}(000)$

Crystal dimensions

$\theta$ range for data collection

Index ranges

Reflections collected

Independent reflections

Completeness to $\theta=27.59^{\circ}$

Max. and min. transmission

Refinement method

Data / restraints / parameters

Goodness-of-fit on F2

Final $R$ indices $[\mid>2 \sigma(I)]$

$\mathrm{R}$ indices (all data)

Largest diff. peak and hole bp18ccd

CCDC 1856222

$\mathrm{C}_{30} \mathrm{H}_{40} \mathrm{BCll} r \mathrm{P}$

670.05

293(2) K

$0.71073 \AA$

triclinic

$\mathrm{P} \overline{1}$

$a=11.0440(9) \AA \quad a=65.590(1)^{\circ}$

$b=11.7061(10) \AA \quad b=75.640(1)^{\circ}$

$c=13.1261(11) \AA \quad g=62.566(1)^{\circ}$

$1368.0(2) \AA^{3}$

2

$1.627 \mathrm{~g} / \mathrm{cm}^{3}$

$50.53 \mathrm{~cm}^{-1}$

668

$0.22 \times 0.34 \times 0.40 \mathrm{~mm}$

2.09 to $27.59^{\circ}$

$-14 \leq h \leq 14,-14 \leq k \leq 15,-16 \leq \mathrm{I} \leq 15$

8497

$5614[R($ int $)=0.0354]$

$88.6 \%$

0.403 and 0.237

Full-matrix least-squares on $\mathrm{F}^{2}$

5614 / 0 / 307

1.157

$\mathrm{R} 1=0.0585, \mathrm{wR} 2=0.1843$

$\mathrm{R} 1=0.0599, \mathrm{wR} 2=0.1849$

1.389 and $-1.773 \mathrm{e} / \AA^{3}$ 


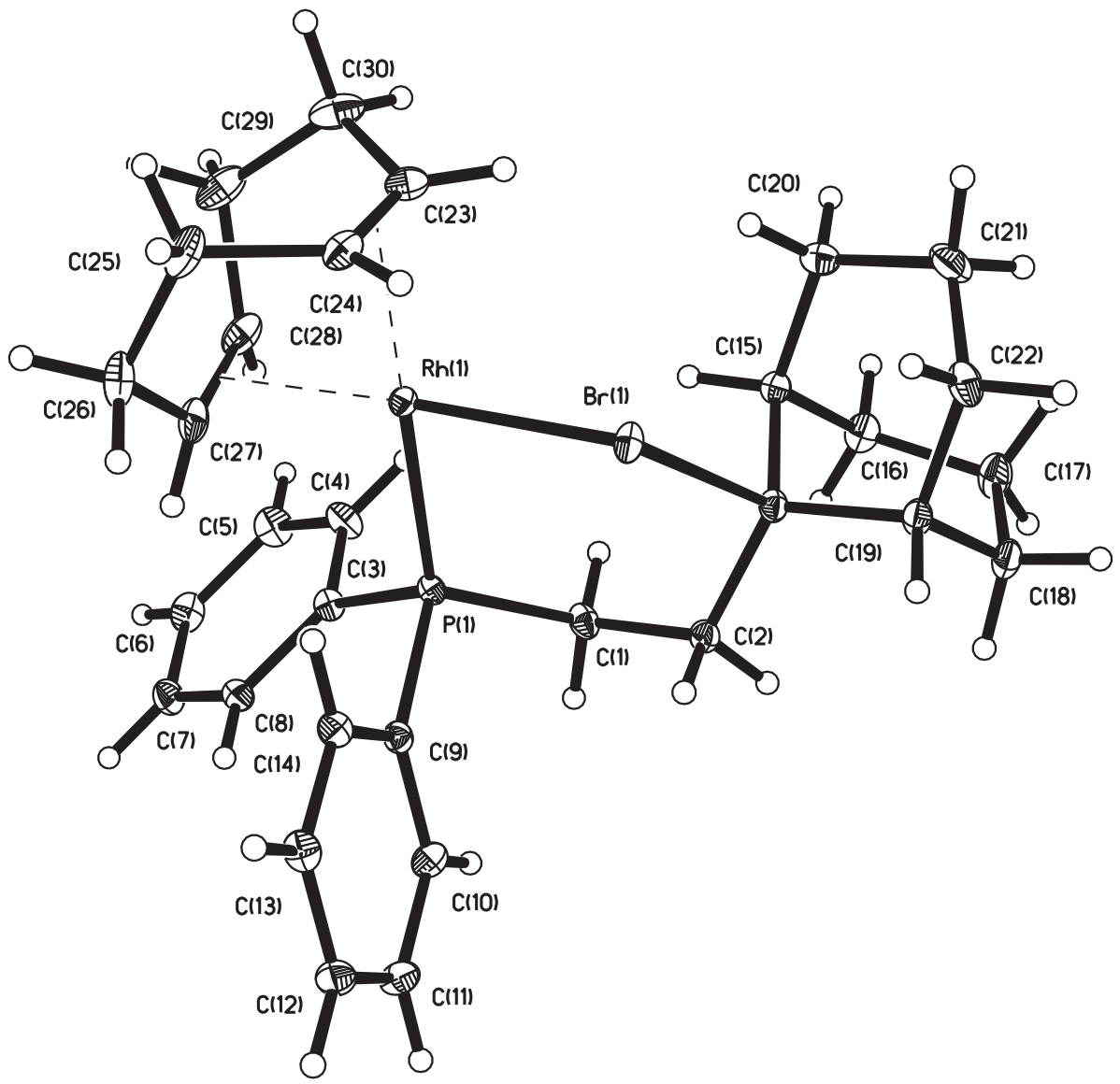

Figure A1.3. Perspective view of the molecular arrangement of (COD)RhBr[PPh $\left.\mathrm{CH}_{2} \mathrm{CH}_{2} \mathrm{~B}\left(\mathrm{C}_{8} \mathrm{H}_{14}\right)\right]$ with the atom labeling scheme for the non-hydrogen atoms. The thermal ellipsoids are scaled to enclose $50 \%$ probability. 


\section{Description of the X-ray Structural Analysis of (COD)RhBr[PPh $\left.{ }_{2} \mathrm{CH}_{2} \mathrm{CH}_{2} \mathrm{~B}\left(\mathrm{C}_{8} \mathrm{H}_{14}\right)\right]$}

A yellow paralellepiped crystal of (COD) $\mathrm{RhBr}\left[\mathrm{PPh}_{2} \mathrm{CH}_{2} \mathrm{CH}_{2} \mathrm{~B}\left(\mathrm{C}_{8} \mathrm{H}_{14}\right)\right]$ was covered in a polybutene oil (Sigma-Aldrich) and placed on the end of a MiTeGen loop. The sample was cooled to $100 \mathrm{~K}$ with an Oxford Cryostream 700 system and optically aligned on a Bruker AXS D8 Venture fixed-chi X-ray diffractometer equipped with a Triumph monochromator, a Mo Ka radiation source $(\lambda=0.71073 \AA)$, and a PHOTON 100 CMOS detector. Three sets of 12 frames each were collected using the omega scan method with a 10 second exposure time. Integration of these frames followed by reflection indexing and least-squares refinement produced a crystal orientation matrix for the triclinic crystal lattice that was used for the structural analysis.

Data collection consisted of the measurement of a total of 925 frames in five runs using omega scans with the detector held at $5.00 \mathrm{~cm}$ from the crystal. Frame scan parameters are summarized below:

\begin{tabular}{|c|c|c|c|c|c|c|c|}
\hline Run & $2 \theta$ & $\omega$ & $\varphi$ & $\chi$ & $\begin{array}{c}\text { Scan } \\
\text { Width }\left({ }^{\circ}\right)\end{array}$ & Frames & $\begin{array}{c}\text { Exposure } \\
\text { Time }(\mathrm{sec})\end{array}$ \\
\hline 1 & 21.65 & -161.04 & -156.00 & 54.74 & 1.00 & 185 & 15.00 \\
\hline 2 & 21.65 & -161.04 & 102.00 & 54.74 & 1.00 & 185 & 15.00 \\
\hline 3 & 21.65 & -161.04 & 0.00 & 54.74 & 1.00 & 185 & 15.00 \\
\hline 4 & 21.65 & -161.04 & 153.00 & 54.74 & 1.00 & 185 & 15.00 \\
\hline 5 & 21.65 & -161.04 & 51.00 & 54.74 & 1.00 & 185 & 15.00 \\
\hline
\end{tabular}

The APEX3 software program (version 2016.9-0) ${ }^{1}$ was used for diffractometer control, preliminary frame scans, indexing, orientation matrix calculations, least-squares refinement of cell parameters, and the data collection. The frames were integrated with the Bruker SAINT software package using a narrow-frame algorithm. The integration of the data using a triclinic unit cell yielded a total of 42250 reflections to a maximum $\theta$ 
angle of $32.65^{\circ}$ (0.66 $\AA$ resolution), of which 9795 were independent (average redundancy 4.313 , completeness $\left.=99.8 \%, R_{\text {int }}=3.10 \%, R_{\text {sig }}=2.82 \%\right)$ and 8377 $(85.52 \%)$ were greater than $2 \sigma\left(F^{2}\right)$. The final cell constants of $\underline{a}=10.8655(4) \AA, \underline{b}=$ 11.6362(4) $\AA, \underline{c}=13.1121(5) \AA, \alpha=65.1401(11)^{\circ}, \beta=75.7848(11)^{\circ}, y=63.0790(10)^{\circ}$, volume $=1338.05(9) \AA^{3}$, are based upon the refinement of the XYZ-centroids of 9779 reflections above $20 \sigma(\mathrm{I})$ with $6.308^{\circ}<2 \theta<65.26^{\circ}$. Data were corrected for absorption effects using the multi-scan method (SADABS). The ratio of minimum to maximum apparent transmission was 0.799 . The calculated minimum and maximum transmission coefficients (based on crystal size) are 0.4710 and 0.8260 .

The structure was solved by direct methods and difference Fourier analysis using the programs provided by SHELXL-2014/7. ${ }^{2}$ The fractional coordinates of the four aromatic hydrogen atoms of the cyclooctadiene ligand were refined with the isotropic thermal factor set at 1.2 times that of the adjacent carbon atom. Idealized positions for the remaining methine, methylene, and aromatic hydrogen atoms were included as fixed contributions using a riding model with isotropic temperature factors set at 1.2 times that of the adjacent carbon atom. Full-matrix least-squares refinement, based upon the minimization of $\Sigma W_{i}\left|F_{o}{ }^{2}-F_{c}{ }^{2}\right|^{2}$, with weighting $w_{i}^{-1}=\left[\sigma^{2}\left(F_{o}{ }^{2}\right)+(0.0190 P)^{2}+\right.$ $0.6568 \mathrm{P}]$, where $P=\left(\operatorname{Max}\left(F_{o}{ }^{2}, 0\right)+2 F_{c}{ }^{2}\right) / 3 .{ }^{2}$ The final anisotropic full-matrix leastsquares refinement on $\mathrm{F}^{2}$ with 319 variables converged at $\mathrm{R} 1=2.20 \%$, for the 8377 observed data with $1>2 \sigma(I)$ and $w R 2=5.02 \%$ for all data. The goodness-of-fit was $1.052 .^{3}$

A correction for secondary extinction was not applied. The largest peak in the final difference electron density synthesis was $0.653 \mathrm{e}^{-} / \AA^{3}$ and the largest hole was - 
$0.829 \mathrm{e}^{-} / \AA^{3}$ with an RMS deviation of $0.085 \mathrm{e}^{-} / \AA^{3}$. The linear absorption coefficient, atomic scattering factors, and anomalous dispersion corrections were calculated from values found in the International Tables of X-ray Crystallography. ${ }^{4}$

\section{References}

1. APEX3 is a Bruker AXS crystallographic software package for single crystal data collection, reduction and preparation.

2. Sheldrick, G. M., SHELXL-2014, Crystallographic software package, Bruker AXS, Inc., Madison, Wisconsin, USA.

3. $R_{1}=a ̊\left(|| F_{o}|-| F_{c}||\right) / a ̊\left|F_{o}\right|, w R_{2}=\left[a ̊\left[w\left(F_{o}^{2}-F_{c}^{2}\right)^{2}\right] / a\left[w\left(F_{o}^{2}\right)^{2}\right]\right]^{1 / 2}, R_{i n t . ~}=a ̊ \mid F_{o}{ }^{2}-$

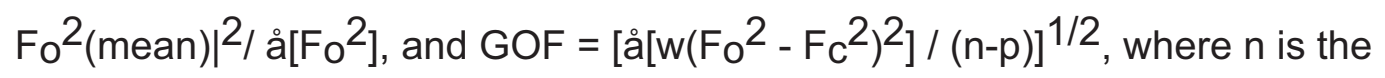
number of reflections and $p$ is the total number of parameters which were varied during the last refinement cycle.

4. International Tables for X-ray Crystallography (1974). Vol. IV, p. 55. Birmingham: Kynoch Press. (Present distributor, D. Reidel, Dordrecht.). 
Table 3. Crystal data for (COD) RhBr[PPh $\left.\mathrm{CH}_{2} \mathrm{CH}_{2} \mathrm{~B}\left(\mathrm{C}_{8} \mathrm{H}_{14}\right)\right]$.

Ident. code bp48cms

CCDC Number CCDC 1856225

Chemical form. $\mathrm{C}_{30} \mathrm{H}_{40} \mathrm{BBrPRh}$

Formula weight $625.22 \mathrm{~g} / \mathrm{mol}$

Temperature $100(2) \mathrm{K}$

Wavelength $\quad 0.71073 \AA$

Crystal size $\quad 0.090 \times 0.186 \times 0.401 \mathrm{~mm}$

Crystal system Triclinic

Space group $\mathrm{P}-1$ (No. 2)

Unit cell $\quad a=10.8655(4) \AA \quad \alpha=65.1401(11)^{\circ}$

$b=11.6362(4) \AA \quad \beta=75.7848(11)^{\circ}$

$c=13.1121(5) \AA \quad Y=63.0790(10)^{\circ}$

Volume, $\AA^{3} \quad 1338.05(9)$

Z 2

Density (calc) $1.552 \mathrm{~g} / \mathrm{cm}^{3}$

Abs. coefficient $2.209 \mathrm{~mm}^{-1}$

$\mathrm{F}(000) \quad 640$

Table 4. Data collection and structure refinement for (COD) RhBr[PPh $\left.\mathrm{CH}_{2} \mathrm{CH}_{2} \mathrm{~B}\left(\mathrm{C}_{8} \mathrm{H}_{14}\right)\right]$.

Theta range

Index ranges

Reflections

Independent refls

Coverage
3.15 to $32.65^{\circ}$

$$
-16 \leq \mathrm{h} \leq 15,-17 \leq \mathrm{k} \leq 17,-19 \leq \mathrm{l} \leq 19
$$

42250

$9795[R($ int $)=0.0310]$

$99.8 \%$

Absorption correction multi-scan

Max. and min. trans. 0.826 and 0.471

Refinement method Full-matrix least-squares on $\mathrm{F}^{2}$

Refinement program SHELXL-2014/7 (Sheldrick, 2014)

Data / restraints /

parameters

$9795 / 0 / 319$

Goodness-of-fit on $\mathrm{F}^{2} 1.052$

Final $R$ indices

8377 data; $I>2 \sigma(\mathrm{I}) \quad \mathrm{R} 1=0.0220, \mathrm{wR} 2=0.0475$

all data

$R 1=0.0321, w R 2=0.0502$

Largest diff. peak

and hole

0.653 and $-0.829 e^{-} / \AA^{3}$ 


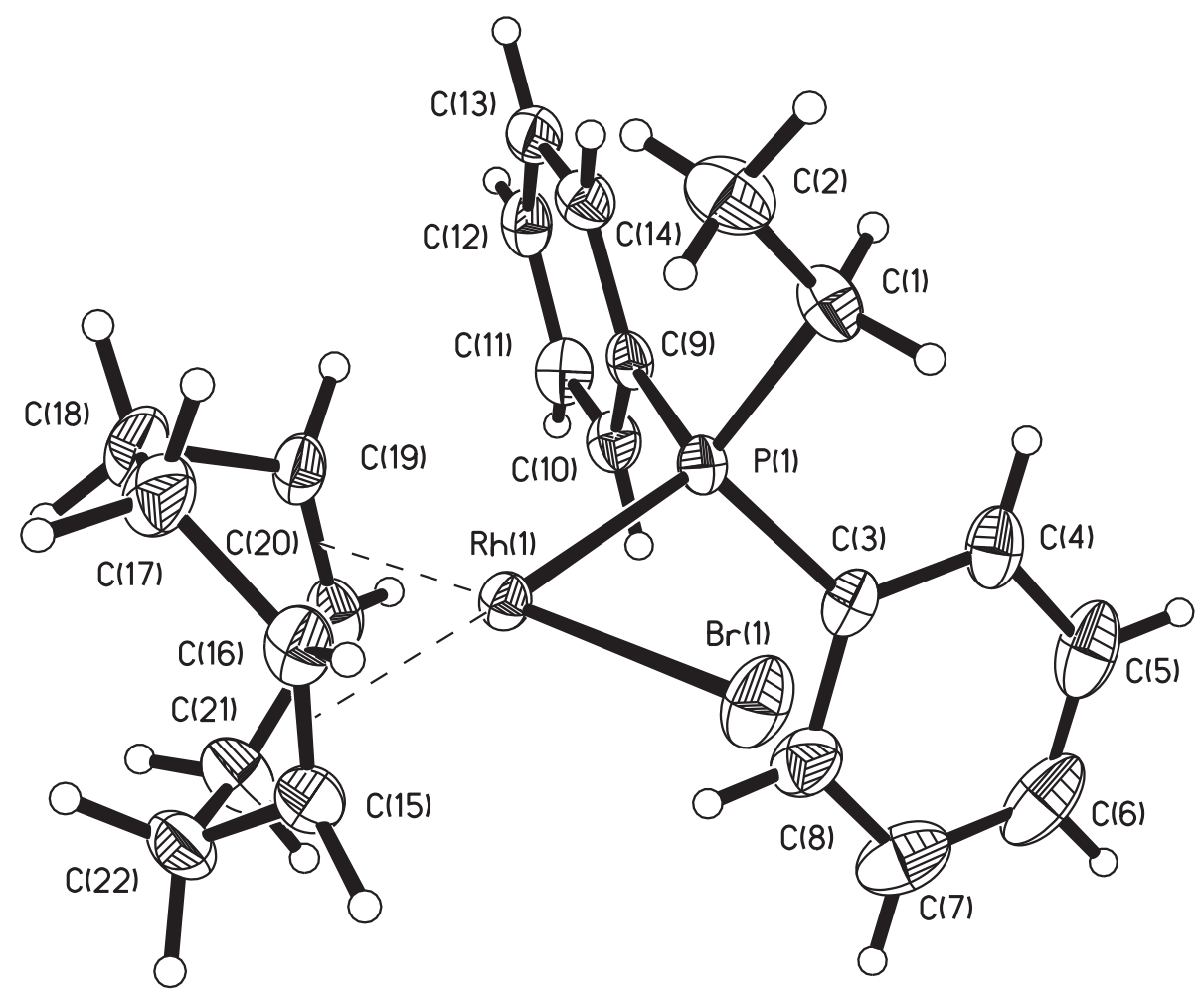

Figure A1.4. Perspective view of the molecular structure of $\operatorname{RhBr}(\mathrm{COD})\left(\mathrm{PPh}_{2} \mathrm{Et}\right)$ with the atom labeling scheme for the non-hydrogen atoms. The thermal ellipsoids are scaled to enclose $30 \%$ probability. 


\section{Description of the X-ray Structural Analysis of $\operatorname{RhBr}(\mathrm{COD})\left(\mathrm{PPh}_{2} \mathrm{Et}\right)$}

An amber crystal of $\mathrm{RhBr}(\mathrm{COD})\left(\mathrm{PPh}_{2} \mathrm{Et}\right)$ was washed with the perfluoropolyether PFO-XR75 (Lancaster) and sealed in a glass capillary under nitrogen. The sample was optically aligned on a Bruker AXS D8 Venture fixed-chi X-ray diffractometer equipped with a Triumph monochromator, a Mo Ka radiation source $(\lambda=0.71073 \AA)$, and a PHOTON 100 CMOS detector. Two sets of 12 frames each were collected using the omega scan method with a $10 \mathrm{~s}$ exposure time. Integration of these frames followed by reflection indexing and least-squares refinement produced a crystal orientation matrix for the tetragonal crystal lattice.

Data collection consisted of the measurement of a total of 744 frames in two run using omega scans with the detector held at $5.00 \mathrm{~cm}$ from the crystal. The frame scan parameters are summarized below:

$\begin{array}{llllllll}\text { Run } & 2 \theta & \omega & \varphi & X & \text { Scan Width }\left(^{\circ}\right) & \text { Frames } & \begin{array}{l}\text { Exposure } \\ \text { Time }(\mathrm{sec})\end{array} \\ 1 & 22.76 & -160.24 & -102.3154 .79 & 0.50 & 372 & 20.00 \\ 2 & 22.76 & -160.24 & 4.33 & 54.79 & 0.50 & 372 & 20.00\end{array}$

The APEX2 software program (version 2014.1-1) ${ }^{1}$ was used for diffractometer control, preliminary frame scans, indexing, orientation matrix calculations, least-squares refinement of cell parameters, and the data collection. The frames were integrated with the Bruker SAINT software package using a narrow-frame algorithm. The frames were integrated with the Bruker SAINT software package using a narrow-frame algorithm. The integration of the data using a tetragonal unit cell yielded a total of 34316 reflections to a maximum $\theta$ angle of $27.50^{\circ}(0.77 \AA$ resolution), of which 4727 were independent (average redundancy 7.260 , completeness $=99.5 \%, R_{\text {int }}=3.29 \%, R_{\text {sig }}=$ 
$1.93 \%)$ and $3931(83.16 \%)$ were greater than $2 \sigma\left(F^{2}\right)$. The final cell constants of $\underline{a}=$ 16.5001(6) $\AA, \underline{b}=16.5001(6) \AA, \underline{c}=15.1817(6) \AA$, volume $=4133.3(3) \AA^{3}$, are based upon the refinement of the XYZ-centroids of 9802 reflections above $20 \sigma(I)$ with $5.908^{\circ}$ $<2 \theta<65.09^{\circ}$. Data were corrected for absorption effects using the multi-scan method (SADABS). The calculated minimum and maximum transmission coefficients are 0.38 and

The structure was solved by the Patterson heavy-atom method and difference Fourier analysis using the programs provided by SHELXL-2014. ${ }^{2}$ Idealized positions for the hydrogen atoms were included as fixed contributions using a riding model with isotropic temperature factors set at 1.2 times (olefinic, methylene, and aromatic hydrogens) or 1.5 (methyl hydrogens) times that of the adjacent carbon atom. The positions of the methyl hydrogen atoms were optimized by a rigid rotating group refinement with idealized angles. Full-matrix least-squares refinement, based upon the minimization of $\Sigma \mathrm{W}_{\mathrm{i}}\left|\mathrm{F}_{\mathrm{o}}{ }^{2}-\mathrm{F}_{\mathrm{c}}{ }^{2}\right|^{2}$, with weighting $\mathrm{w}_{\mathrm{i}}^{-1}=\left[\sigma^{2}\left(\mathrm{~F}_{\mathrm{o}}{ }^{2}\right)+(0.0361 \mathrm{P})^{2}+8.8911 \mathrm{P}\right]$, where $P=\left(\operatorname{Max}\left(F_{o}^{2}, 0\right)+2 F_{c}^{2}\right) / 3 .{ }^{2}$ The final anisotropic full-matrix least-squares refinement on $\mathrm{F}^{2}$ with 227 variables converged at $\mathrm{R} 1=3.45 \%$, for the 3931 observed data with $\mid>2 \sigma(I)$ and $w R 2=9.06 \%$ for all data. The goodness-of-fit was $1.034 .^{3}$

A correction for secondary extinction was not applied. The largest peak in the final difference electron density synthesis was $0.878 \mathrm{e}^{-} / \AA^{3}$ and the largest hole was $0.393 \mathrm{e}^{-/} / \AA^{3}$ with an RMS deviation of $0.082 \mathrm{e}^{-} / \AA^{3}$. The linear absorption coefficient, atomic scattering factors, and anomalous dispersion corrections were calculated from values found in the International Tables of X-ray Crystallography. ${ }^{4}$ 


\section{References}

1. SMART, SAINT and XPREP programs are part of Bruker crystallographic software package for single crystal data collection, reduction and preparation.

2. Sheldrick, G. M., SHELXTL6.1 (2000), Crystallographic software package, Bruker AXS, Inc. Madison, Wisconsin, USA.

3. $R_{1}=\Sigma\left(|| F_{O}|-| F_{c}||\right) / \Sigma\left|F_{o}\right|, w_{2}=\left[\Sigma\left[w\left(F_{o}^{2}-F_{c}^{2}\right)^{2}\right] / \Sigma\left[w\left(F_{o}^{2}\right)^{2}\right]\right]^{1 / 2}$, Rint. $=\Sigma \mid F_{o}{ }^{2}-$

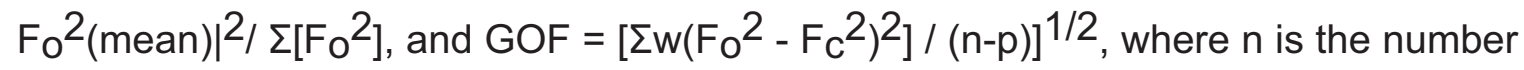
of reflections and $p$ is the total number of parameters which were varied during the last refinement cycle.

4. International Tables for X-ray Crystallography (1974). Vol. IV, p. 55. Birmingham: Kynoch Press. (Present distributor, D. Reidel, Dordrecht.). 
Table 5. Crystal data for $\operatorname{RhBr}(\mathrm{COD})\left(\mathrm{PPh}_{2} \mathrm{Et}\right)$.

\begin{tabular}{|c|c|}
\hline Identification code & $\mathrm{bp} 15 \mathrm{cms}$ \\
\hline CCDC Number & CCDC 1856224 \\
\hline Chemical formula & $\mathrm{C}_{22} \mathrm{H}_{27} \mathrm{BrPRh}$ \\
\hline Formula weight & $505.22 \mathrm{~g} / \mathrm{mol}$ \\
\hline Temperature & 293(2) K \\
\hline Wavelength & $0.71073 \AA$ \\
\hline Crystal size & $0.302 \times 0.357 \times 0.428 \mathrm{~mm}$ \\
\hline Crystal system & tetragonal \\
\hline Space group & $\mathrm{P} 44_{2} / \mathrm{n}(\mathrm{No} .86)$ \\
\hline \multirow{3}{*}{ Unit cell dimensions } & $a=16.5001(6) \AA \quad \alpha=90^{\circ}$ \\
\hline & $\mathrm{b}=16.5001(6) \AA \quad \beta=90^{\circ}$ \\
\hline & $c=15.1817(6) \AA \quad y=90^{\circ}$ \\
\hline Volume & 4133.3(3) $\AA^{3}$ \\
\hline Z & 8 \\
\hline Density (calculated) & $1.624 \mathrm{~g} / \mathrm{cm}^{3}$ \\
\hline Absorption coefficient & $2.839 \mathrm{~mm}^{-1}$ \\
\hline$F(000)$ & 2032 \\
\hline
\end{tabular}

Table 6. Data collection and structure refinement for $\operatorname{RhBr}(\mathrm{COD})\left(\mathrm{PPh}_{2} \mathrm{Et}\right)$.

Theta range for data used in the structural refinement 2.95 to $27.50^{\circ}$

Index ranges

$-17 \leq \mathrm{h} \leq 21,-21 \leq \mathrm{k} \leq 21,-19 \leq \mathrm{l} \leq 19$

Reflections 34316

Independent reflections

$4727[R($ int $)=0.0329]$

Coverage of independent $99.5 \%$ reflections

Absorption correction

multi-scan

Max. and min. transmission

0.48 and 0.38

Refinement method

Full-matrix least-squares on $\mathrm{F}^{2}$

Refinement program

SHELXL-2014 (Sheldrick, 2014)

Data / restraints / parameters 4727 / 0 / 227

Goodness-of-fit on $\mathrm{F}^{2}$

Final $\mathrm{R}$ indices

Largest diff. peak and hole
1.034

3931 data; $I>2 \sigma(I) \quad R 1=0.0345, w R 2=0.0801$

all data 


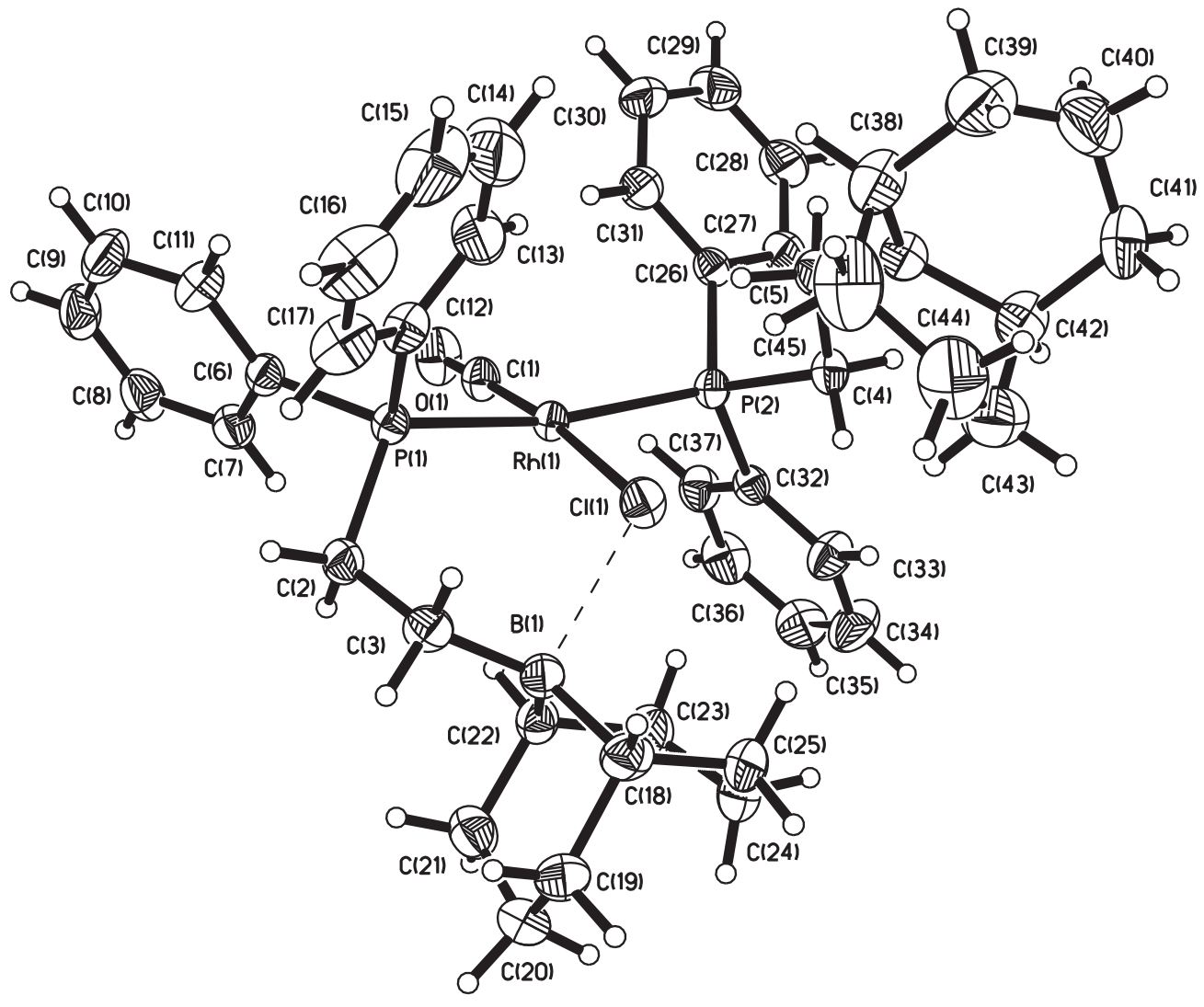

Figure A1.5. Perspective view of the molecular structure of $\mathrm{Rh}(\mathrm{CO}) \mathrm{Cl}\left(\mathrm{PPh}_{2} \mathrm{CH}_{2} \mathrm{CH}_{2}-9-\right.$ $\mathrm{BBN})_{2}$ with the atom labeling scheme. The thermal ellipsoids are scaled to enclose $30 \%$ probability. 


\section{Description of the X-ray Structural Analysis of $\mathrm{Rh}(\mathrm{CO}) \mathrm{Cl}\left(\mathrm{PPh}_{2} \mathrm{CH}_{2} \mathrm{CH}_{2}-9\right.$ - $\mathrm{BBN})_{2} \cdot \mathrm{C}_{4} \mathrm{H}_{10} \mathrm{O}$}

An orange crystal of $\mathrm{Rh}(\mathrm{CO}) \mathrm{Cl}\left(\mathrm{PPh}_{2} \mathrm{CH}_{2} \mathrm{CH}_{2}-9-\mathrm{BBN}\right)_{2} \cdot \mathrm{C}_{4} \mathrm{H}_{10} \mathrm{O}$ was washed with the perfluoropolyether PFO-XR75 (Lancaster) and sealed in a glass capillary under nitrogen. The sample was optically aligned on the four-circle of a Siemens P4 diffractometer equipped with a graphite monochromator, a Mo Ka radiation source $(\lambda=$ $0.71073 \AA$ ), and a SMART CCD detector held at $5.050 \mathrm{~cm}$ from the crystal. Four sets of 20 frames each were collected using the $\omega$ scan method and with a 10 s exposure time. Integration of these frames followed by reflection indexing and least-squares refinement produced a crystal orientation matrix for the monoclinic crystal lattice.

Data collection consisted of the measurement of a total of 1650 frames in five different runs covering a hemisphere of data. Frame scan parameters are summarized below:

$\begin{array}{ccccccccc}\text { Run } & 2 q & \text { w } & f & c & \begin{array}{c}\text { Scan } \\ \text { axis }\end{array} & \begin{array}{c}\text { Scan } \\ \text { width }\left(^{\circ}\right)\end{array} & \begin{array}{c}\text { Frames } \\ (\#)\end{array} & \begin{array}{r}\text { Exposure } \\ \text { time }(\mathrm{sec})\end{array} \\ 1 & 28 & 43.00 & 0.00 & 280.00 & 2 & -0.3 & 100 & 40 \\ 2 & 28 & 43.00 & 90.00 & 280.00 & 2 & -0.3 & 100 & 40 \\ 3 & 28 & 43.00 & 180.00 & 280.00 & 2 & -0.3 & 100 & 40 \\ 4 & 28 & 43.00 & 270.00 & 280.00 & 2 & -0.3 & 100 & 40 \\ 5 & 28 & 28.00 & 0.00 & 30.00 & 3 & 0.3 & 1250 & 40\end{array}$

The program SMART (version 5.6) ${ }^{1}$ was used for diffractometer control, frame scans, indexing, orientation matrix calculations, least-squares refinement of cell parameters, and the data collection. All 1650 crystallographic raw data frames were 
read by program SAINT (version $5 / 6.0)^{1}$ and integrated using 3 D profiling algorithms. The resulting data were reduced to produce a total of 35144 reflections and their intensities and estimated standard deviations. An absorption correction was applied using the SADABS routine available in SAINT. ${ }^{1}$ The data were corrected for Lorentz and polarization effects. Data preparation was carried out by using the program XPREP, ${ }^{1}$ which gave 11231 unique reflections $\left(R_{\text {int }}=5.08 \%\right)$ with indices $-14 \leq h \leq 14$, $30 \leq k \leq 30,-24 \leq 1 \leq 24$. The monoclinic space group was determined to be $P 2{ }_{1} / n$, a nonstandard setting of $\mathrm{P} 2{ }_{1} / \mathrm{c}$ (No. 14).

The structure was solved by a combination of direct methods and difference Fourier analysis with the use of SHELXTL 6.1.2 The crystallographic asymmetric unit contains independent molecules of $\mathrm{Rh}(\mathrm{CO}) \mathrm{Cl}\left(\mathrm{PPh}_{2} \mathrm{CH}_{2} \mathrm{CH}_{2}-9-\mathrm{BBN}\right)_{2} \cdot \mathrm{C}_{4} \mathrm{H}_{10} \mathrm{O}$ and highly disordered molecules of ether. Idealized positions for the hydrogen atoms were included as fixed contributions using a riding model with isotropic temperature factors set at 1.2 (aromatic and $\mathrm{B}-\mathrm{H}$ protons) or 1.5 (methyl protons) times that of the adjacent non-hydrogen atom. The positions of the methyl hydrogen atoms were optimized by a rigid rotating group refinement with idealized tetrahedral angles. The diethyl ether was treated as a diffuse electron density contribution with the aid of the SQUEEZE routine in the program PLATON. ${ }^{3}$ Although specific positions for the independent carbon, hydrogen, and oxygen atoms of the diethyl ether were not determined, the calculated density, absorption coefficient and empirical formula weight reflect their presence within the crystal lattice. Full-matrix least-squares refinement, based upon the minimization of $\Sigma \mathrm{W}_{\mathrm{i}}\left|\mathrm{F}_{\mathrm{o}}{ }^{2}-\mathrm{F}_{\mathrm{c}}{ }^{2}\right|^{2}$, with weighting $\mathrm{W}_{\mathrm{i}}^{-1}=\left[\sigma^{2}\left(\mathrm{~F}_{\mathrm{o}}{ }^{2}\right)+(0.0898 \mathrm{P})^{2}+0.7165 \mathrm{P}\right]$, where $\mathrm{P}=(\mathrm{Max}$ 
$\left.\left(F_{0}^{2}, 0\right)+2 F_{c}^{2}\right) / 3$, converged to give final discrepancy indices ${ }^{4}$ of $R 1=0.0367, w R 2=$ 0.1461 for 6739 data with $\mathrm{I}>2 \sigma(\mathrm{I})$. The goodness of fit (GOF) value was 1.031.

A correction for secondary extinction was not applied. The maximum and minimum residual electron density peaks in the final difference Fourier map were 0.348 and $-0.274 \mathrm{e} / \AA^{3}$, respectively. The linear absorption coefficient, atomic scattering factors, and anomalous dispersion corrections were calculated from values found in the International Tables of X-ray Crystallography. ${ }^{5}$

\section{References}

1. SMART, SAINT and XPREP programs are part of Bruker crystallographic software package for single crystal data collection, reduction and preparation.

2. Sheldrick, G. M., SHELXTL6.1 (2000), Crystallographic software package, Bruker AXS, Inc. Madison, Wisconsin, USA.

3. PLATON, written by Professor Anthony L. Spek, Bijvoet Centre for Biomolecular Research, Utrecht University. Current versions of PLATON for Windows are available from Professor Louis J. Farrugia, Department of Chemistry, University of Glasgow at www.chem.gla.ac.uk/ louis/software/.

4. $\mathrm{R}_{1}=\Sigma\left(|| \mathrm{Fo}_{\mathrm{O}}|-| \mathrm{F}_{\mathrm{C}}||\right) / \Sigma\left|\mathrm{F}_{\mathrm{O}}\right|, \mathrm{wR}_{2}=\left[\Sigma\left[\mathrm{w}\left(\mathrm{Fo}_{\mathrm{o}}^{2}-\mathrm{F}_{\mathrm{C}}{ }^{2}\right)^{2}\right] / \Sigma\left[\mathrm{w}\left(\mathrm{Fo}_{\mathrm{o}}^{2}\right)^{2}\right]\right]^{1 / 2}, \mathrm{R}_{\text {int }}=\Sigma \mid \mathrm{F}_{\mathrm{o}}{ }^{2}-$

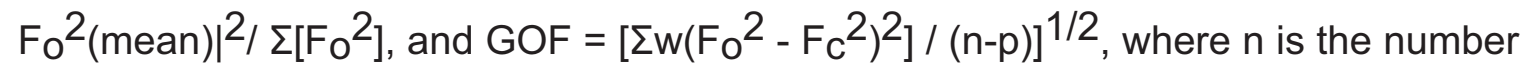
of reflections and $p$ is the total number of parameters which were varied during the last refinement cycle.

5. International Tables for X-ray Crystallography (1974). Vol. IV, p. 55. Birmingham: Kynoch Press. (Present distributor, D. Reidel, Dordrecht.). 
Table 7. Crystal data and structure refinement for $\mathrm{Rh}(\mathrm{CO}) \mathrm{Cl}\left(\mathrm{PPh}_{2} \mathrm{CH}_{2} \mathrm{CH}_{2}-9\right.$ $\mathrm{BBN})_{2} \cdot \mathrm{C}_{4} \mathrm{H}_{10} \mathrm{O}$.

Identification code

CCDC Number

Empirical formula

Formula weight

Temperature

Wavelength

Crystal system

Space group

Unit cell dimensions

Volume

Z

Density (calculated)

Absorption coefficient

$\mathrm{F}(000)$

Crystal size

$\theta$ range for data collection

Index ranges

Reflections collected

Independent reflections

Completeness to $\theta=27.56^{\circ}$

Max. and min. transmission

Refinement method

Data / restraints / parameters

Goodness-of-fit on F2

Final $R$ indices $[\mathrm{I}>2 \sigma(\mathrm{I})]$

$\mathrm{R}$ indices (all data)

Largest diff. peak and hole bp5plt

CCDC 1833916

$\mathrm{C}_{49} \mathrm{H}_{66} \mathrm{~B}_{2} \mathrm{ClO}_{2} \mathrm{P}_{2} \mathrm{Rh}$

908.94

293(2) K

$0.71073 \AA$

monoclinic

$\mathrm{P} 2{ }_{1} / \mathrm{n}$

$a=10.851(1) \AA \quad a=90^{\circ}$

$\mathrm{b}=18.685(2) \AA \quad \mathrm{b}=97.510(2)^{\circ}$

$c=23.362(2) \AA \quad g=90^{\circ}$

4696.1(8) $\AA^{3}$

4

$1.286 \mathrm{~g} / \mathrm{cm}^{3}$

$5.26 \mathrm{~cm}^{-1}$

1912

$0.18 \times 0.30 \times 0.38 \mathrm{~mm}$

2.07 to $27.56^{\circ}$

$-13 \leq \mathrm{h} \leq 14,-23 \leq \mathrm{k} \leq 24,-27 \leq \mathrm{I} \leq 30$

33424

$10790[R($ int $)=0.0384]$

$99.4 \%$

0.9113 and 0.8253

Full-matrix least-squares on $\mathrm{F}^{2}$

10790 / 0 / 469

1.031

$\mathrm{R} 1=0.0367, w R 2=0.1025$

$\mathrm{R} 1=0.0527, \mathrm{wR} 2=0.1085$

0.431 and -0.318 e/A 3 


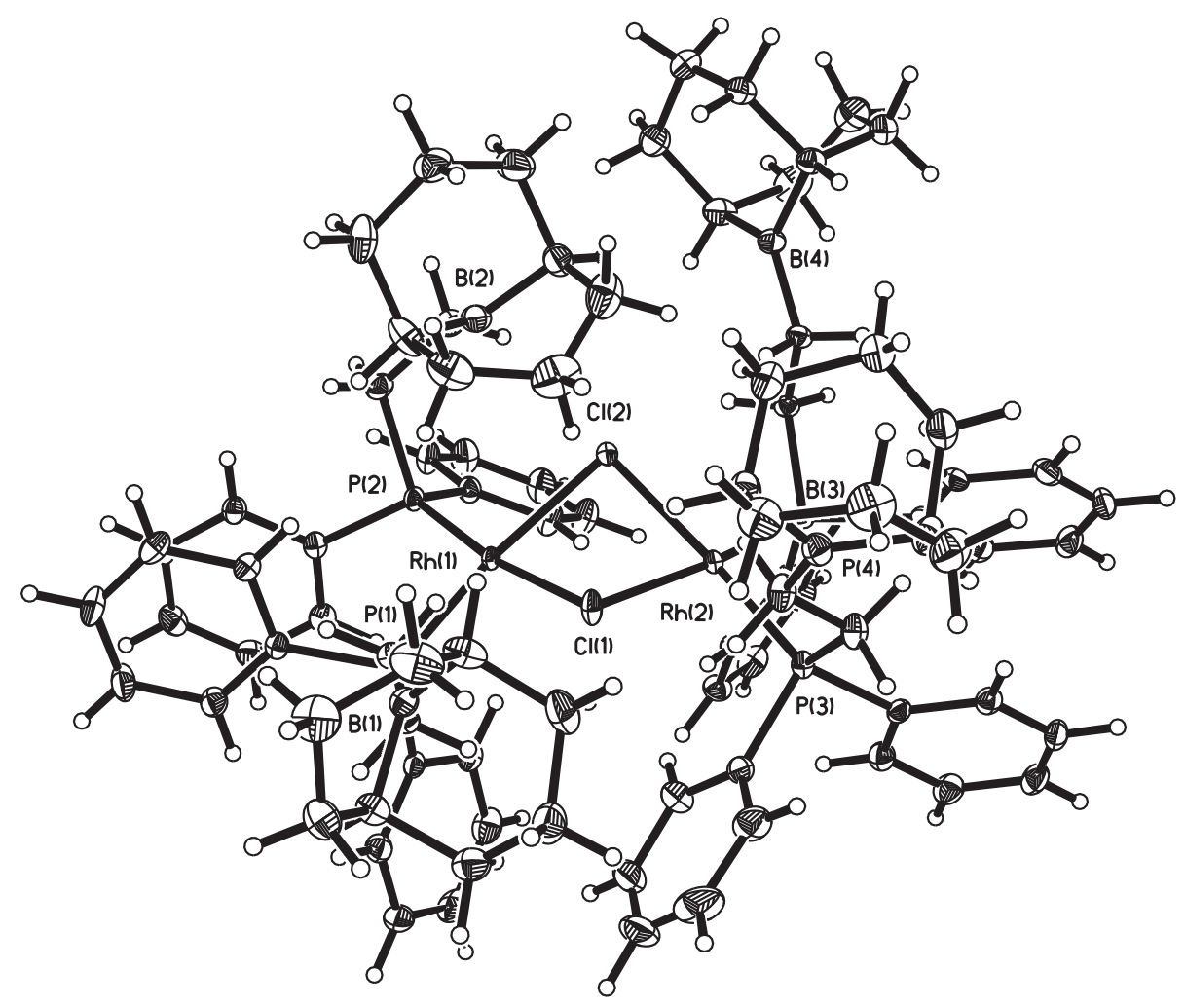

Figure A1.6. Perspective view of the molecular structure of $\left[\left(\mathrm{C}_{44} \mathrm{H}_{56} \mathrm{P}_{2} \mathrm{~B}_{2}\right) \mathrm{Rh}(\mu-\mathrm{Cl})\right]_{2}$ with the atom labeling scheme for the non-hydrogen atoms. The thermal ellipsoids are scaled to enclose $50 \%$ probability. 


\section{Description of the X-ray Structural Analysis of $\left[\left(\mathrm{C}_{44} \mathrm{H}_{56} \mathrm{P}_{2} \mathrm{~B}_{2}\right) \mathrm{Rh}(\mu-\mathrm{Cl})\right]_{2}$}

A pale orange crystal of $\left[\left(\mathrm{C}_{44} \mathrm{H}_{56} \mathrm{P}_{2} \mathrm{~B}_{2}\right) \mathrm{Rh}(\mu-\mathrm{Cl})\right]_{2}$ was covered in a polybutene oil (Sigma-Aldrich) and placed on the end of a MiTeGen loop. The sample was cooled to $100 \mathrm{~K}$ with an Oxford Cryostream 700 system and optically aligned on a Bruker AXS D8 Venture fixed-chi X-ray diffractometer equipped with a Triumph monochromator, a Mo Ka radiation source $(\lambda=0.71073 \AA)$, and a PHOTON 100 CMOS detector. Two sets of 12 frames each were collected using the omega scan method with a $10 \mathrm{~s}$ exposure time. Integration of these frames followed by reflection indexing and least-squares refinement produced a crystal orientation matrix for the triclinic crystal lattice.

Data collection consisted of the measurement of a total of 920 frames in four runs using omega scans with the detector held at $5.00 \mathrm{~cm}$ from the crystal. Frame scan parameters are summarized below:

$\begin{array}{lllllll}\text { Run } 2 \theta & \omega & \varphi & X & \text { Scan Width }\left(^{\circ}\right) & \text { Frames } & \begin{array}{l}\text { Exposure Time } \\ (\mathrm{sec})\end{array} \\ 1 & 16.35 & -165.65-60.00 & 54.74 & 0.80 & 230 & 30.00 \\ 2 & 16.35 & -165.65-180.00 & 54.74 & 0.80 & 230 & 30.00 \\ 3 & 16.35 & -165.6560 .00 & 54.74 & 0.80 & 230 & 30.00 \\ 4 & 16.35 & -165.650 .00 & 54.74 & 0.80 & 230 & 30.00\end{array}$

The APEX2 software program (version 2014.1-7) ${ }^{1}$ was used for diffractometer control, preliminary frame scans, indexing, orientation matrix calculations, least-squares refinement of cell parameters, and the data collection. The frames were integrated with the Bruker SAINT software package using a narrow-frame algorithm. The integration of the data using a triclinic unit cell yielded a total of 88431 reflections to a maximum $\theta$ angle of $30.10^{\circ}(0.71 \AA$ resolution), of which 22711 were independent (average 
redundancy 3.894 , completeness $\left.=99.5 \%, R_{\text {int }}=3.78 \%, R_{\text {sig }}=4.13 \%\right)$ and 18876 $(83.11 \%)$ were greater than $2 \sigma\left(F^{2}\right)$. The final cell constants of $\underline{a}=12.2787(5) \AA, \underline{b}=$ 14.2439(6) $\AA, \underline{c}=25.4195(10) \AA, \alpha=96.1831(12)^{\circ}, \quad \beta=100.4360(11)^{\circ}, \quad Y=$ $114.9881(11)^{\circ}$, volume $=3877.4(3) \AA^{3}$, are based upon the refinement of the $\mathrm{XYZ}$ centroids of 9675 reflections above $20 \sigma(\mathrm{I})$ with $5.983^{\circ}<2 \theta<60.15^{\circ}$. Data were corrected for absorption effects using the multi-scan method (SADABS). The ratio of minimum to maximum apparent transmission was 0.919 . The calculated minimum and maximum transmission coefficients (based on crystal size) are 0.848 and 0.915 .

The structure was solved by direct methods and difference Fourier analysis using the programs provided by SHELXL-2014. ${ }^{2} \quad$ Idealized positions for the hydrogen atoms were included as fixed contributions using a riding model with isotropic temperature factors set at 1.2 times that of the adjacent carbon atom. Full-matrix leastsquares refinement, based upon the minimization of $\Sigma w_{i}\left|F_{o}{ }^{2}-F_{c}{ }^{2}\right|^{2}$, with weighting $w_{i}^{-1}$ $=\left[\sigma^{2}\left(F_{o}{ }^{2}\right)+(0.0342 P)^{2}+5.7918 P\right]$, where $P=\left(\operatorname{Max}\left(F_{o}{ }^{2}, 0\right)+2 F_{c}{ }^{2}\right) / 3 .{ }^{2}$ The final anisotropic full-matrix least-squares refinement on $\mathrm{F}^{2}$ with 901 variables converged at $R 1=4.42 \%$ for 18876 observed data with $I>2 \sigma(I)$ and $w R 2=9.42 \%$ for all data. The goodness-of-fit was $1.075^{3}$

A correction for secondary extinction was not applied. The largest peak in the final difference electron density synthesis was $1.913 \mathrm{e}^{-/} / \AA^{3}$ and the largest hole was $0.717 \mathrm{e}^{-} / \AA^{3}$ with an RMS deviation of $0.102 \mathrm{e}^{-} / \AA^{3}$. The linear absorption coefficient, atomic scattering factors, and anomalous dispersion corrections were calculated from values found in the International Tables of X-ray Crystallography. ${ }^{4}$ 


\section{References}

1. APEX2 is a Bruker AXS crystallographic software package for single crystal data collection, reduction and preparation.

2. Sheldrick, G. M., SHELXL-2014, Crystallographic software package, Bruker AXS, Inc., Madison, Wisconsin, USA.

3. $R_{1}=\Sigma\left(|| F_{o}|-| F_{c}||\right) / \Sigma\left|F_{o}\right|, w R_{2}=\left[\Sigma\left[w\left(F_{o}^{2}-F_{c}^{2}\right)^{2}\right] / \Sigma\left[w\left(F_{o}^{2}\right)^{2}\right]\right]^{1 / 2}$, Rint. $=\Sigma \mid F_{o}{ }^{2}$

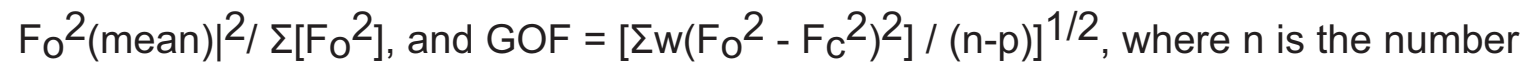
of reflections and $p$ is the total number of parameters which were varied during the last refinement cycle.

4. International Tables for X-ray Crystallography (1974). Vol. IV, p. 55. Birmingham: Kynoch Press. (Present distributor, D. Reidel, Dordrecht.). 
Table 8. Crystal data for $\left[\left(\mathrm{C}_{44} \mathrm{H}_{56} \mathrm{P}_{2} \mathrm{~B}_{2}\right) \mathrm{Rh}(\mu-\mathrm{Cl})\right]_{2}$.

$\begin{array}{lll}\text { Identification code } & \text { bp35cms } & \\ \text { CCDC Number } & \text { CCDC } 1856227 & \\ \text { Chemical formula } & \mathrm{C}_{88} \mathrm{H}_{112} \mathrm{~B}_{4} \mathrm{Cl}_{2} \mathrm{P}_{4} \mathrm{Rh}_{2} & \\ \text { Formula weight } & 1613.61 \mathrm{~g} / \mathrm{mol} & \\ \text { Temperature } & 100(2) \mathrm{K} & \\ \text { Wavelength } & 0.71073 \AA & \\ \text { Crystal size } & 0.146 \times 0.234 \times 0.273 \mathrm{~mm} & \\ \text { Crystal system } & \text { Triclinic } & \\ \text { Space group } & \mathrm{P}-1(\mathrm{No} .2) & \alpha=96.1831(12)^{\circ} \\ \text { Unit cell dimensions } & \mathrm{a}=12.2787(5) \AA & \beta=100.4360(11)^{\circ} \\ & \mathrm{b}=14.2439(6) \AA & \mathrm{Y}=114.9881(11)^{\circ} \\ \text { Volume } & \mathrm{c}=25.4195(10) \AA & \\ Z & 3877.4(3) \AA^{3} & \\ \text { Density (calculated) } & 2 & \\ \text { Absorption coefficient } & 0.382 \mathrm{~g}^{3} \mathrm{~cm}^{3} & \\ \text { F(000) } & 1688 & \end{array}$

Table 9. Data collection and structure refinement for $\left[\left(\mathrm{C}_{44} \mathrm{H}_{56} \mathrm{P}_{2} \mathrm{~B}_{2}\right) \mathrm{Rh}(\mu-\mathrm{Cl})\right]_{2}$.

\begin{tabular}{|c|c|c|}
\hline $\begin{array}{l}\text { Theta range used } \\
\text { refinement }\end{array}$ & 2.99 to $30.10^{\circ}$ & \\
\hline Index ranges & \multicolumn{2}{|c|}{$-17 \leq \mathrm{h} \leq 17,-20 \leq \mathrm{k} \leq 20,-35 \leq \mathrm{I} \leq 35$} \\
\hline Reflections collected & \multicolumn{2}{|l|}{88431} \\
\hline Independent reflections & \multicolumn{2}{|l|}{$22711[R($ int $)=0.0378]$} \\
\hline$\%$ independent reflections & \multicolumn{2}{|l|}{$99.5 \%$} \\
\hline Absorption correction & \multicolumn{2}{|l|}{ multi-scan } \\
\hline Refinement method & \multicolumn{2}{|c|}{ Full-matrix least-squares on $\mathrm{F}^{2}$} \\
\hline Refinement program & \multicolumn{2}{|c|}{ SHELXL-2014 (Sheldrick, 2014) } \\
\hline Data / restraints / parameters & \multicolumn{2}{|l|}{$22711 / 0 / 901$} \\
\hline Goodness-of-fit on $\mathrm{F}^{2}$ & \multicolumn{2}{|l|}{1.075} \\
\hline Final $R$ indices & $\begin{array}{l}18876 \text { data; } \mid>2 \sigma(I) \\
\text { all data }\end{array}$ & $\begin{array}{l}R 1=0.0442, w R 2=0.0890 \\
R 1=0.0592, w R 2=0.0942\end{array}$ \\
\hline $\begin{array}{l}\text {-argest diff. } \\
\text { peak and hole }\end{array}$ & 1.913 and $-0.717 \mathrm{e}^{-} / \AA^{3}$ & \\
\hline
\end{tabular}




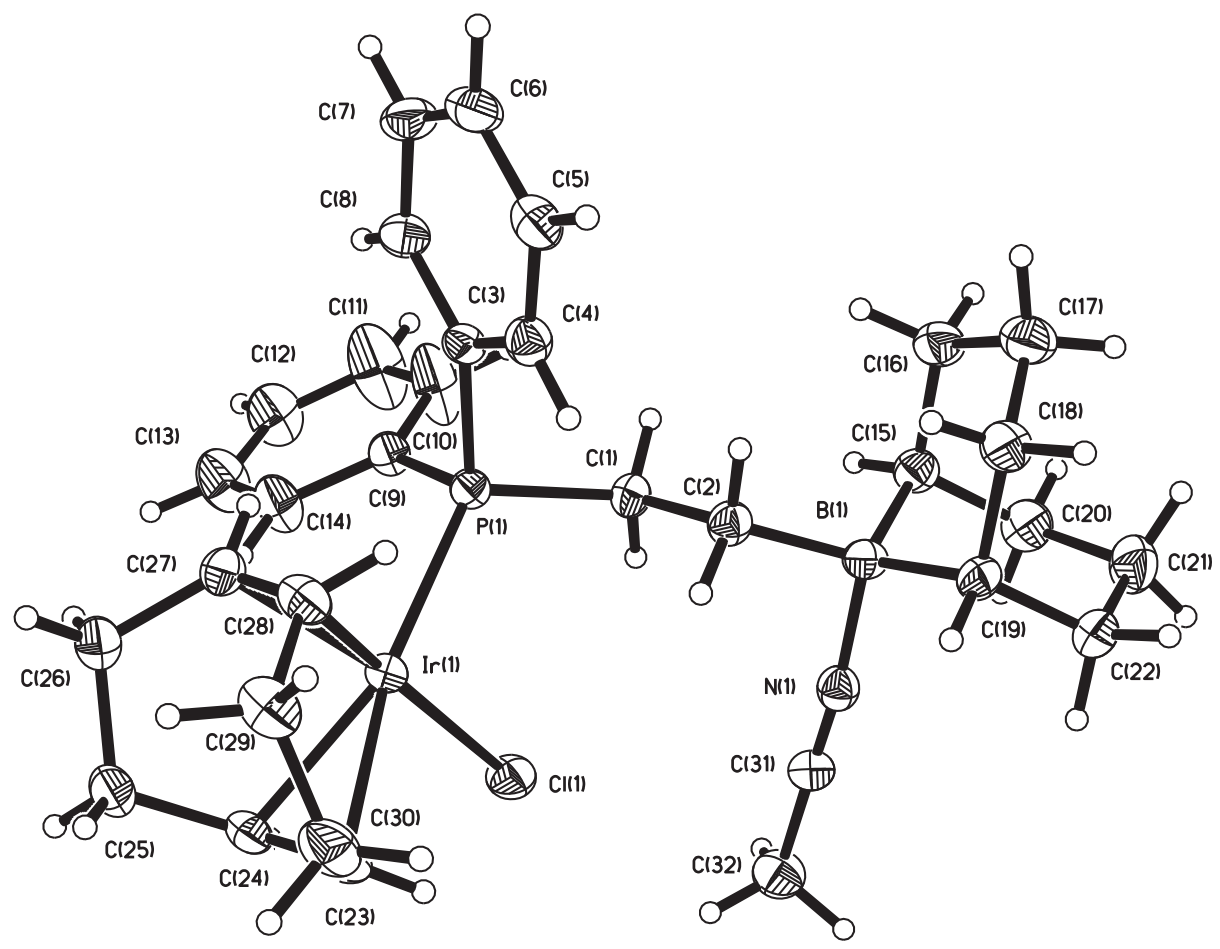

Figure A1.7. Perspective view of the molecular structure of $\operatorname{IrCl}(\mathrm{COD})\left[\mathrm{PPh}_{2} \mathrm{CH}_{2} \mathrm{CH}_{2} \mathrm{~B}\left(\mathrm{C}_{8} \mathrm{H}_{14}\right)(\mathrm{NCMe})\right]$ with the atom labeling scheme provided for the non-hydrogen atoms. The thermal ellipsoids are scaled to enclose $30 \%$ probability. 


\section{Description of the $X$-ray Structural Analysis of $\operatorname{IrCl}(\mathrm{COD})\left[\mathrm{PPh}_{2} \mathrm{CH}_{2} \mathrm{CH}_{2} \mathrm{~B}\left(\mathrm{C}_{8} \mathrm{H}_{14}\right)(\mathrm{NCMe})\right]$}

A yellow crystal of $\operatorname{IrCl}(\mathrm{COD})\left[\mathrm{PPh}_{2} \mathrm{CH}_{2} \mathrm{CH}_{2} \mathrm{~B}\left(\mathrm{C}_{8} \mathrm{H}_{14}\right)(\mathrm{NCMe})\right]$ was washed with the perfluoropolyether PFO-XR75 (Lancaster) and sealed under dintrogen in a glass capillary. The sample was optically aligned on the four-circle of a Siemens P4 diffractometer equipped with a graphite monochromator, a monocap collimator, a Mo Ka radiation source $(\lambda=0.71073 \AA)$, and a SMART CCD detector held at $5.050 \mathrm{~cm}$ from the crystal. Four sets of 20 frames each were collected using the $\omega$ scan method and with a $10 \mathrm{~s}$ exposure time. Integration of these frames followed by reflection indexing and least-squares refinement produced a crystal orientation matrix for the triclinic crystal lattice.

Data collection consisted of the measurement of a total of 1650 frames in five different runs covering a hemisphere of data. Frame scan parameters are summarized below:

\begin{tabular}{|c|c|c|c|c|c|c|c|}
\hline Run & w & $f$ & C & $\begin{array}{r}\text { Scan } \\
\text { axis }\end{array}$ & $\begin{array}{l}\text { Scan } \\
\text { width }\left(^{\circ}\right)\end{array}$ & $\begin{array}{l}\text { Frames } \\
\text { ) (\#) }\end{array}$ & $\begin{array}{r}\text { Exposure } \\
\text { time (sec.) }\end{array}$ \\
\hline 28 & 43.00 & 0.00 & 280.00 & 2 & -0.3 & 100 & 40 \\
\hline 28 & 43.00 & 90.00 & 280.00 & 2 & -0.3 & 100 & 40 \\
\hline 28 & 43.00 & 180.00 & 280.00 & 2 & -0.3 & 100 & 40 \\
\hline 28 & 43.00 & 270.00 & 280.00 & 2 & -0.3 & 100 & 40 \\
\hline 28 & 28.00 & 0.00 & 30.00 & 3 & 0.3 & 1250 & 40 \\
\hline
\end{tabular}

The program SMART (version 5.6) ${ }^{1}$ was used for diffractometer control, frame scans, indexing, orientation matrix calculations, least-squares refinement of cell parameters, and the data collection. All 1650 crystallographic raw data frames were 
read by the program SAINT (version 5/6.0) ${ }^{1}$ and integrated using 3D profiling algorithms. The resulting data were reduced to produce a total of 10597 reflections and their intensities and estimated standard deviations. An absorption correction was applied using the SADABS routine available in SAINT. ${ }^{1}$ The data were corrected for Lorentz and polarization effects. No evidence of crystal decomposition was observed. Data preparation was carried out by using the program XPREP, ${ }^{1}$ which gave 6729 unique reflections $\left(\mathrm{R}_{\mathrm{int}}=3.71 \%\right)$ with indices $-11 \leq \mathrm{h} \leq 12,-16 \leq \mathrm{k} \leq 16,-16 \leq \mathrm{I} \leq 17$. The triclinic space group was determined to be $\mathrm{P}^{\overline{1}}$ (No. 2).

The structure was solved by a combination of the Patterson heavy atom method and difference Fourier analysis with the use of SHELXTL $6.1 .^{2}$ Idealized positions for the hydrogen atoms were included as fixed contributions using a riding model with isotropic temperature factors set at 1.2 (aromatic, methylene, and methine hydrogens) or 1.5 (methyl hydrogens) times that of the adjacent carbon atom. The positions of the methyl hydrogen atoms were optimized by a rigid rotating group refinement with idealized angles. Full-matrix least-squares refinement, based upon the minimization of $\Sigma \mathrm{W}_{\mathrm{i}}\left|\mathrm{F}_{\mathrm{o}}{ }^{2}-\mathrm{F}_{\mathrm{c}}{ }^{2}\right|^{2}$, with weighting $\mathrm{W}_{\mathrm{i}}^{-1}=\left[\sigma^{2}\left(\mathrm{~F}_{\mathrm{o}}{ }^{2}\right)+(0.0575 \mathrm{P})^{2}+0.3738 \mathrm{P}\right]$, where $\mathrm{P}=(\operatorname{Max}$ $\left.\left(F_{o}^{2}, 0\right)+2 F_{c}^{2}\right) / 3$, converged to give final discrepancy indices ${ }^{3}$ of $R 1=0.0400$, wR2 $=$ 0.1012 for 5858 diffraction data with $\mathrm{I}>2 \sigma(\mathrm{I})$. The goodness of fit (GOF) value was 1.032.

A correction for secondary extinction was not applied. The maximum and minimum residual electron density peaks in the final difference Fourier map were 2.206 and $-1.346 \mathrm{e} / \AA^{3}$, respectively. The linear absorption coefficient, atomic scattering 
factors, and anomalous dispersion corrections were calculated from values found in the International Tables of X-ray Crystallography. ${ }^{4}$

\section{References}

1. SMART, SAINT and XPREP programs are part of Bruker crystallographic software package for single crystal data collection, reduction and preparation.

2. Sheldrick, G. M., SHELXTL6.1 (2000), Crystallographic software package, Bruker AXS, Inc. Madison, Wisconsin, USA.

3. $\mathrm{R}_{1}=\Sigma\left(|| \mathrm{Fo}_{\mathrm{o}}|-| \mathrm{F}_{\mathrm{C}}||\right) / \Sigma\left|\mathrm{Fo}_{\mathrm{o}}\right|, \mathrm{wR}_{2}=\left[\Sigma\left[w\left(\mathrm{Fo}_{\mathrm{o}}^{2}-\mathrm{F}_{\mathrm{C}}^{2}\right)^{2}\right] / \Sigma\left[w\left(\mathrm{Fo}_{\mathrm{o}}^{2}\right)^{2}\right]\right]^{1 / 2}$, Rint. $=\Sigma \mid \mathrm{F}_{\mathrm{o}}{ }^{2}-$ $\left.\mathrm{Fo}_{\mathrm{O}}^{2}($ mean $)\right|^{2} / \Sigma\left[\mathrm{Fo}_{\mathrm{o}}{ }^{2}\right]$, and GOF $\left.=\left[\Sigma w\left(F_{o}{ }^{2}-F_{c}{ }^{2}\right)^{2}\right] /(n-p)\right]^{1 / 2}$, where $n$ is the number of reflections and $p$ is the total number of parameters which were varied during the last refinement cycle.

4. International Tables for X-ray Crystallography (1974). Vol. IV, p. 55. Birmingham: Kynoch Press. (Present distributor, D. Reidel, Dordrecht.). 
Table 10. Crystal data and structure refinement for $\operatorname{IrCl}(\mathrm{COD})\left[\mathrm{PPh}_{2} \mathrm{CH}_{2} \mathrm{CH}_{2} \mathrm{~B}\left(\mathrm{C}_{8} \mathrm{H}_{14}\right)(\mathrm{NCMe})\right]$.

Identification code

CCDC Number

Empirical formula

Formula weight

Temperature

Wavelength

Crystal system

Space group

Unit cell dimensions

Volume

Z

Density (calculated)

Absorption coefficient

$\mathrm{F}(000)$

Crystal dimensions

$\theta$ range for data collection

Index ranges

Reflections collected

Independent reflections

Completeness to $\theta=27.50^{\circ}$

Absorption correction

Max. and min. transmission

Refinement method

Data / restraints / parameters

Goodness-of-fit on $\mathrm{F}^{2}$

Final $R$ indices $[l>2 \sigma(I)]$

$R$ indices (all data)

Largest diff. peak and hole bp16ccd

CCDC 1856223

$\mathrm{C}_{32} \mathrm{H}_{43} \mathrm{BCll} r \mathrm{NP}$

711.10

293(2) K

$0.71073 \AA$

triclinic

$\mathrm{P} 1$

$a=9.8906(9) \AA \quad a=114.412(2)^{\circ}$

$\mathrm{b}=12.8325(13) \AA \quad \mathrm{b}=93.805(2)^{\circ}$

$c=13.1400(13) \AA \quad g=92.019(2)^{\circ}$

$1511.7(3) \AA^{3}$

2

$1.562 \mathrm{~g} / \mathrm{cm}^{3}$

$45.79 \mathrm{~cm}^{-1}$

712

$0.05 \times 0.12 \times 0.34 \mathrm{~mm}$

2.56 to $27.50^{\circ}$

$-11 \leq \mathrm{h} \leq 12,-16 \leq \mathrm{k} \leq 16,-16 \leq \mathrm{I} \leq 17$

10597

$6729[\mathrm{R}$ (int) $=0.0371]$

$96.8 \%$

Semi-empirical from equivalents

0.803 and 0.305

Full-matrix least-squares on $\mathrm{F}^{2}$

6729 / 0 / 335

1.032

$\mathrm{R} 1=0.0400, \mathrm{wR} 2=0.1012$

$\mathrm{R} 1=0.0492, \mathrm{wR} 2=0.1074$

2.206 and -1.346 e/A 3 


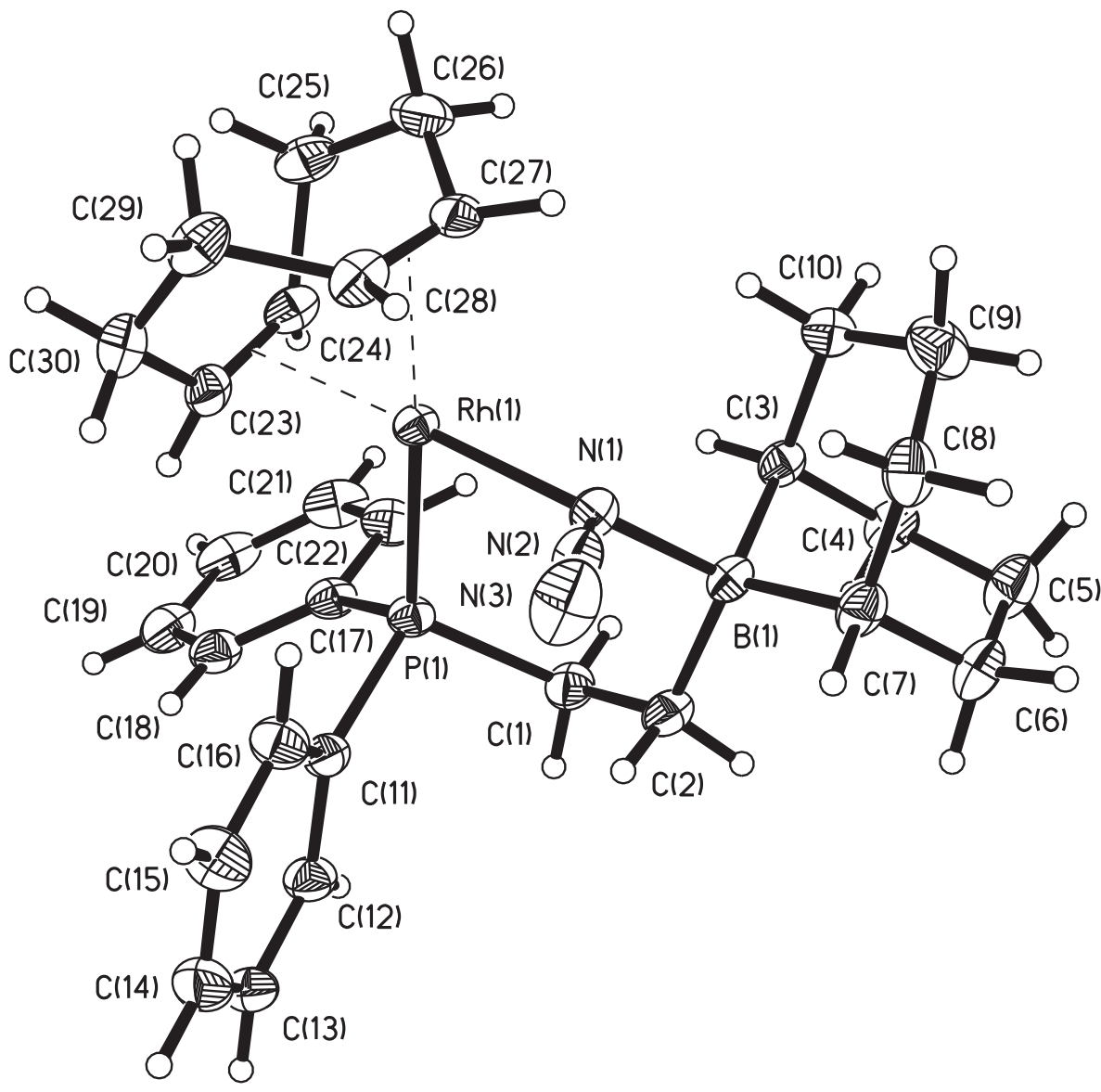

Figure A1.8. Perspective view of the molecular structure of $\mathrm{C}_{30} \mathrm{H}_{40} \mathrm{PBN}_{3} \mathrm{Rh}$ with the atom labeling scheme for the non-hydrogen atoms. The thermal ellipsoids are scaled to enclose $30 \%$ probability. 


\section{Description of the X-ray Structural Analysis of $\mathrm{C}_{30} \mathrm{H}_{40} \mathrm{PBN}_{3} \mathrm{Rh}$}

A yellow crystal of $\mathrm{C}_{30} \mathrm{H}_{40} \mathrm{PBN}_{3} \mathrm{Rh}$ was washed with the perfluoropolyether PFOXR75 (Lancaster) and sealed under nitrogen in a glass capillary. The sample was optically aligned on a Bruker AXS D8 Venture Fixed-Chi X-ray diffractometer equipped with a Triumph monochromator, a Mo Ka radiation source $(\lambda=0.71073 \AA$ ), and a PHOTON 100 CMOS detector held at $5.00 \mathrm{~cm}$ from the crystal. Two sets of 12 frames each were collected using the $\omega$ scan method with a $10 \mathrm{~s}$ exposure time. Integration of these frames followed by reflection indexing and least-squares refinement produced a crystal orientation matrix for the monoclinic crystal lattice.

Data collection consisted of the measurement of a total of 372 frames in one run covering a hemisphere of data using omega scans. The total exposure time was 1.55 hours. Frame scan parameters are summarized below:

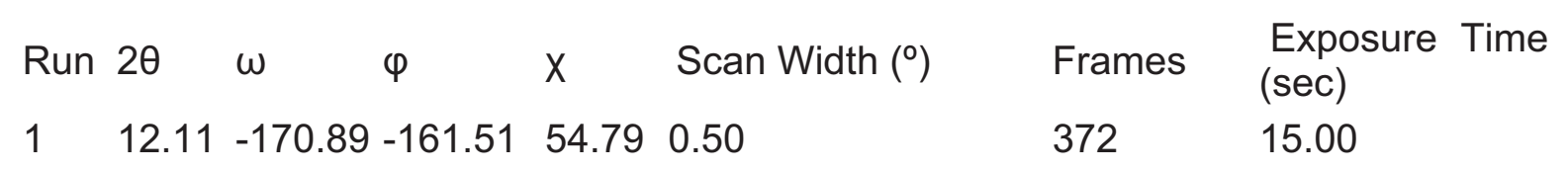

The APEX2 software program (version 2013.10-0) ${ }^{1}$ was used for diffractometer control, preliminary frame scans, indexing, orientation matrix calculations, least-squares refinement of cell parameters, and the data collection. The frames were integrated with the Bruker SAINT software package using a narrow-frame algorithm. The integration of the data using a monoclinic unit cell yielded a total of 13738 reflections to a maximum $\theta$ angle of $27.51^{\circ}(0.77 \AA$ resolution), of which 6264 were independent (average redundancy 2.193, completeness $=98.1 \%, R_{\text {int }}=2.04 \%, R_{\text {sig }}=3.38 \%$ ) and 4946 $(78.96 \%)$ were greater than $2 \sigma\left(F^{2}\right)$. The final cell constants of $\underline{a}=12.0573(5) \AA \underline{b}=$ 
14.1028(6) $\AA, \underline{c}=16.6834(8) \AA, \beta=101.6948(12)^{\circ}$, volume $=2778.0(2) \AA^{3}$, are based upon the refinement of the XYZ-centroids of 8213 reflections above $20 \sigma(I)$ with $6.177^{\circ}$ $<2 \theta<55.02^{\circ}$. Data were corrected for absorption effects using the multi-scan method (SADABS). The ratio of minimum to maximum apparent transmission was 0.743 . The calculated minimum and maximum transmission coefficients (based on crystal size) are 0.770 and 0.862 .

The structure was solved by direct methods and difference Fourier analysis using the programs provided by SHELXL-2013. ${ }^{2} \quad$ Idealized positions for the hydrogen atoms were included as fixed contributions using a riding model with isotropic temperature factors set at 1.2 times that of the adjacent carbon atom. Full-matrix leastsquares refinement, based upon the minimization of $\Sigma w_{i}\left|F_{o}{ }^{2}-F_{c}{ }^{2}\right|^{2}$, with weighting $w_{i}^{-1}$ $=\left[\sigma^{2}\left(F_{o}^{2}\right)+(0.0264 P)^{2}+2.9861 P\right]$, where $P=\left(\operatorname{Max}\left(F_{o}^{2}, 0\right)+2 F_{c}^{2}\right) / 3 .{ }^{2}$ The final anisotropic full-matrix least-squares refinement on $\mathrm{F}^{2}$ with 325 variables converged at $\mathrm{R} 1=3.73 \%$, for the observed data and $\mathrm{wR} 2=8.32 \%$ for all data. The goodness-of-fit was $1.066 .^{3}$

A correction for secondary extinction was not applied. The largest peak in the final difference electron density synthesis was $0.826 \mathrm{e}^{-} / \AA^{3}$ and the largest hole was $0.616 \mathrm{e}^{-} / \AA^{3}$ with an RMS deviation of $0.073 \mathrm{e}^{-} / \AA^{3}$. The linear absorption coefficient, atomic scattering factors, and anomalous dispersion corrections were calculated from values found in the International Tables of X-ray Crystallography. ${ }^{4}$ 


\section{References}

1. APEX2 is a Bruker AXS crystallographic software package for single crystal data collection, reduction and preparation.

2. Sheldrick, G. M., SHELXL-2013, Crystallographic software package, Bruker AXS, Inc., Madison, Wisconsin, USA.

3. $R_{1}=\Sigma\left(|| F_{O}|-| F_{c}||\right) / \Sigma\left|F_{o}\right|, w_{2}=\left[\Sigma\left[w\left(F_{o}^{2}-F_{c}^{2}\right)^{2}\right] / \Sigma\left[w\left(F_{o}^{2}\right)^{2}\right]\right]^{1 / 2}$, Rint. $=\Sigma \mid F_{o}{ }^{2}-$ $\left.\mathrm{Fo}^{2}(\operatorname{mean})\right|^{2} / \Sigma\left[\mathrm{Fo}_{\mathrm{o}}^{2}\right]$, and GOF $\left.=\left[\Sigma \mathrm{w}\left(\mathrm{Fo}_{\mathrm{o}}^{2}-\mathrm{F}_{\mathrm{c}}{ }^{2}\right)^{2}\right] /(n-p)\right]^{1 / 2}$, where $\mathrm{n}$ is the number of reflections and $p$ is the total number of parameters which were varied during the last refinement cycle.

4. International Tables for X-ray Crystallography (1974). Vol. IV, p. 55. Birmingham: Kynoch Press. (Present distributor, D. Reidel, Dordrecht.). 
Table 11. Crystal data for $\mathrm{C}_{30} \mathrm{H}_{40} \mathrm{PBN}_{3} \mathrm{Rh}$.

Identification code

Chemical formula

CCDC Number

Formula weight

Temperature

Wavelength

Crystal size

Crystal system

Space group

Unit cell dimensions

Volume

Z

Density (calculated)

Absorption coefficient $\mathrm{F}(000)$ bp3cms

$\mathrm{C}_{30} \mathrm{H}_{40} \mathrm{BN}_{3} \mathrm{PRh}$

CCDC 1856220

587.34

296(2) K

$0.71073 \AA$

$0.22 \times 0.28 \times 0.40 \mathrm{~mm}$

monoclinic

$P 2_{1} / n$ (non-standard setting of $P 21 / c$, No. 14)

$a=12.0573(5) \AA \quad \alpha=90^{\circ}$

$b=14.1028(6) \AA \quad \beta=101.6948(12)^{\circ}$

$c=16.6834(8) \AA \quad Y=90^{\circ}$
4

$1.404 \mathrm{~g} / \mathrm{cm}^{3}$

$0.696 \mathrm{~mm}^{-1}$

1224

Table 12. Data collection and structure refinement for $\mathrm{C}_{30} \mathrm{H}_{40} \mathrm{BN}_{3} \mathrm{PRh}$.

Theta range for data collection 3.15 to $27.51^{\circ}$

Index ranges

$-15 \leq \mathrm{h} \leq 12,-18 \leq \mathrm{k} \leq 15,-20 \leq \mathrm{I} \leq 21$

Reflections collected

13738

Independent reflections

$6264[R($ int $)=0.0204]$

Coverage of independent $98.1 \%$

reflections

Absorption correction

multi-scan

Max. and min. transmission

0.862 and 0.770

Refinement method

Full-matrix least-squares on $\mathrm{F}^{2}$

Refinement program

SHELXL-2013 (Sheldrick, 2013)

Data / restraints / parameters

Goodness-of-fit on $\mathrm{F}^{2}$

6264 / 0 / 325

1.066

Final $\mathrm{R}$ indices

4946 data; $\mid>2 \sigma(\mathrm{I}) \quad \mathrm{R} 1=0.0373, \mathrm{wR} 2=0.0747$

all data

$\mathrm{R} 1=0.0552, \mathrm{wR} 2=0.0832$

Largest diff. peak and hole

0.826 and $-0.616 e^{-} / \AA^{3}$ 


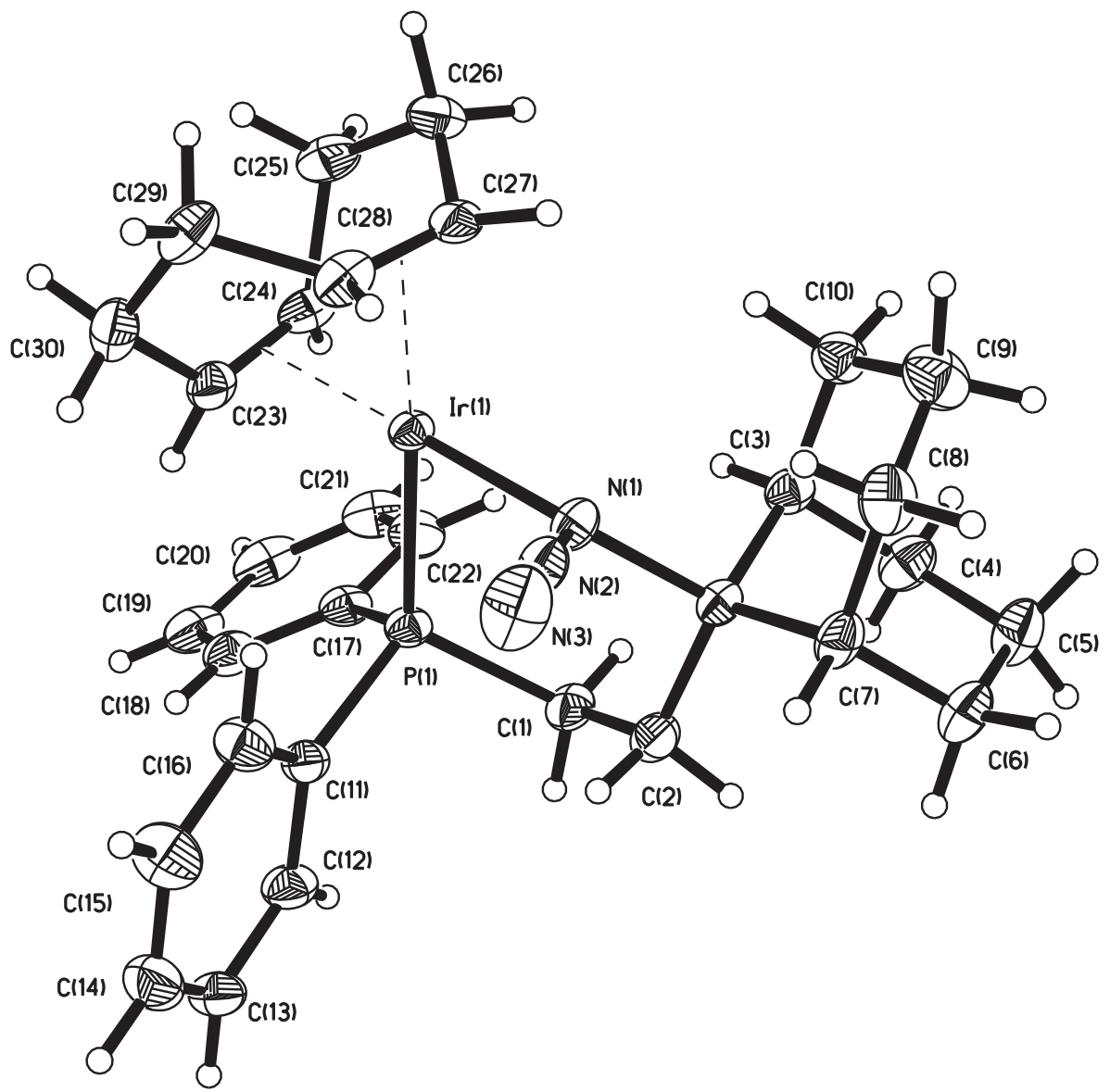

Figure A1.9. Perspective view of the molecular structure of $\mathrm{C}_{30} \mathrm{H}_{40} \mathrm{PBN}_{3} \mathrm{Ir}$ with the atom labeling scheme for the non-hydrogen atoms. The thermal ellipsoids are scaled to enclose $30 \%$ probability. 


\section{Description of the X-ray Structural Analysis of $\mathrm{C}_{30} \mathrm{H}_{40} \mathrm{PBN}_{3} \mathrm{Ir}$}

A light orange crystal of $\mathrm{C}_{30} \mathrm{H}_{40} \mathrm{PBN}_{3}$ Ir was washed with the perfluoropolyether PFO-XR75 (Lancaster) and sealed under nitrogen in a glass capillary. The sample was optically aligned on a Bruker AXS D8 Venture fixed-chi X-ray diffractometer equipped with a Triumph monochromator, a Mo Ka radiation source $(\lambda=0.71073 \AA)$, and a PHOTON 100 CMOS detector. Two sets of 12 frames each were collected using the $\omega$ scan method with a $10 \mathrm{~s}$ exposure time. Integration of these frames followed by reflection indexing and least-squares refinement produced a crystal orientation matrix for the monoclinic crystal lattice.

Data collection consisted of the measurement of a total of 494 frames in two runs using omega scans with the detector held at $5.00 \mathrm{~cm}$ from the crystal. The total exposure time was 2.06 hours. Frame scan parameters are summarized below:

$\begin{array}{lrrrrrrrr}\text { Run } 2 \theta & \omega & \varphi & X & & \text { Scan Width }\left(^{\circ}\right) & & \begin{array}{c}\text { Frames } \\ \begin{array}{c}\text { Exposure } \\ \text { Time } \\ (\mathrm{sec})\end{array}\end{array} \\ 1 & 18.44 & -164.18 & -158.11 & 54.79 & 0.75 & 247 & 15.00 \\ 2 & 18.44 & -164.18 & -40.87 & 54.79 & 0.75 & 247 & 15.00\end{array}$

The APEX2 software program (version 2013.10-0) ${ }^{1}$ was used for diffractometer control, preliminary frame scans, indexing, orientation matrix calculations, least-squares refinement of cell parameters, and the data collection. The frames were integrated with the Bruker SAINT software package using a narrow-frame algorithm. The integration of the data using a monoclinic unit cell yielded a total of 24120 reflections to a maximum $\theta$ angle of $27.50^{\circ}(0.77 \AA$ resolution), of which 6324 were independent (average 
redundancy 3.814 , completeness $\left.=99.0 \%, R_{\text {int }}=2.86 \%, R_{\text {sig }}=2.40 \%\right)$ and 5492 $(86.84 \%)$ were greater than $2 \sigma\left(F^{2}\right)$. The final cell constants of $\underline{a}=12.0583(5) \AA, \underline{b}=$ 14.1410(5) $\AA, \underline{c}=16.6581(6) \AA, \beta=101.6544(11)^{\circ}$, volume $=2781.92(18) \AA^{3}$, are based upon the refinement of the XYZ-centroids of 9841 reflections above $20 \sigma(\mathrm{I})$ with $6.179^{\circ}<2 \theta<61.08^{\circ}$. Data were corrected for absorption effects using the multi-scan method (SADABS). The ratio of minimum to maximum apparent transmission was 0.497. The calculated minimum and maximum transmission coefficients (based on crystal size) are 0.173 and 0.363 .

The structure was solved by direct methods and difference Fourier analysis using the programs provided by SHELXL-2013. ${ }^{2} \quad$ Idealized positions for the hydrogen atoms were included as fixed contributions using a riding model with isotropic temperature factors set at 1.2 times that of the adjacent carbon atom. Full-matrix leastsquares refinement, based upon the minimization of $\Sigma w_{i}\left|F_{o}{ }^{2}-F_{c}{ }^{2}\right|^{2}$, with weighting $w_{i}^{-1}$ $=\left[\sigma^{2}\left(F_{o}{ }^{2}\right)+(0.0115 P)^{2}+9.7602 P\right]$, where $P=\left(\operatorname{Max}\left(F_{o}{ }^{2}, 0\right)+2 F_{c}{ }^{2}\right) / 3 .{ }^{2}$ The final anisotropic full-matrix least-squares refinement on $\mathrm{F}^{2}$ with 325 variables converged at $R 1=3.32 \%$, for the observed data and $w R 2=7.13 \%$ for all data. The goodness-of-fit was $1.166 .^{3}$

A correction for secondary extinction was not applied. The largest peak in the final difference electron density synthesis was $2.166 \mathrm{e}^{-} / \AA^{3}$ and the largest hole was $1.575 \mathrm{e}^{-} / \AA^{3}$ with an RMS deviation of $0.120 \mathrm{e}^{-} / \AA^{3}$. The linear absorption coefficient, atomic scattering factors, and anomalous dispersion corrections were calculated from values found in the International Tables of X-ray Crystallography. ${ }^{4}$ 


\section{References}

1. APEX2 is a Bruker AXS crystallographic software package for single crystal data collection, reduction and preparation.

2. Sheldrick, G. M., SHELXL-2013, Crystallographic software package, Bruker AXS, Inc., Madison, Wisconsin, USA.

3. $\mathrm{R}_{1}=\Sigma\left(|| \mathrm{F}_{\mathrm{O}}|-| \mathrm{F}_{\mathrm{C}}||\right) / \Sigma\left|\mathrm{Fo}_{\mathrm{O}}\right|, \mathrm{wR}_{2}=\left[\Sigma\left[\mathrm{w}\left(\mathrm{Fo}_{\mathrm{o}}^{2}-\mathrm{Fc}^{2}\right)^{2}\right] / \Sigma\left[w\left(\mathrm{Fo}_{\mathrm{o}}^{2}\right)^{2}\right]\right]^{1 / 2}$, Rint. $=\Sigma \mid \mathrm{Fo}_{\mathrm{o}}{ }^{2}-$ $\left.\mathrm{Fo}_{\mathrm{O}}^{2}(\operatorname{mean})\right|^{2} / \Sigma\left[\mathrm{Fo}_{\mathrm{o}}^{2}\right]$, and GOF $\left.=\left[\Sigma \mathrm{w}\left(\mathrm{Fo}_{\mathrm{O}}^{2}-\mathrm{F}_{\mathrm{C}}{ }^{2}\right)^{2}\right] /(\mathrm{n}-\mathrm{p})\right]^{1 / 2}$, where $\mathrm{n}$ is the number of reflections and $p$ is the total number of parameters which were varied during the last refinement cycle.

4. International Tables for X-ray Crystallography (1974). Vol. IV, p. 55. Birmingham: Kynoch Press. (Present distributor, D. Reidel, Dordrecht.). 
Table 13. Crystal data for $\mathrm{C}_{30} \mathrm{H}_{40} \mathrm{PBN}_{3}$ Ir.

Identification code

CCDC Number

Chemical formula

Formula weight

Temperature

Wavelength

Crystal size

Crystal system

Space group

Unit cell dimensions

Volume

Z

Density (calculated)

Absorption coefficient

$\mathrm{F}(000)$ bp4cms

CCDC 1856221

$\mathrm{C}_{30} \mathrm{H}_{40} \mathrm{BN}_{3} \mathrm{PIr}$

676.63

296(2) K

$0.71073 \AA$

$0.260 \times 0.422 \times 0.553 \mathrm{~mm}$

monoclinic

$P 2_{1} /$ n (non-standard setting of $P 2{ }_{1} / c$, No. 14)

$a=12.0583(5) \AA \quad \alpha=90^{\circ}$

$b=14.1410(5) \AA \quad \beta=101.6544(11)^{\circ}$

$c=16.6581(6) \AA \quad Y=90^{\circ}$

$2781.92(18) \AA^{3}$

4

$1.616 \mathrm{~g} / \mathrm{cm}^{3}$

$4.881 \mathrm{~mm}^{-1}$

1352

Table 14. Data collection and structure refinement for $\mathrm{C}_{30} \mathrm{H}_{40} \mathrm{BN}_{3} \mathrm{PIr}$.

Theta range for data collection 3.09 to $27.50^{\circ}$

Index ranges

Reflections collected

Independent reflections
$-15 \leq \mathrm{h} \leq 15,-18 \leq \mathrm{k} \leq 18,-21 \leq \mathrm{I} \leq 21$

24120

$6324[R($ int $)=0.0286]$

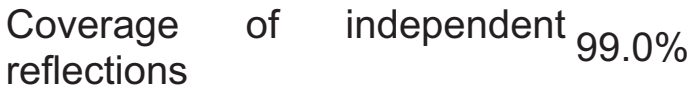

Absorption correction

multi-scan

Max. and min. transmission

0.363 and 0.173

Refinement method

Full-matrix least-squares on $\mathrm{F}^{2}$

Refinement program SHELXL-2013 (Sheldrick, 2013)

Data / restraints / parameters 6324 / 0 / 325

Goodness-of-fit on $\mathrm{F}^{2}$ 1.166

Final $\mathrm{R}$ indices 5492 data; $\mid>2 \sigma(I) \quad R 1=0.0332, w R 2=0.0679$ all data $\mathrm{R} 1=0.0413, w R 2=0.0713$

Largest diff. peak and hole 2.166 and $-1.575 \mathrm{e}^{-} / \AA^{3}$ 


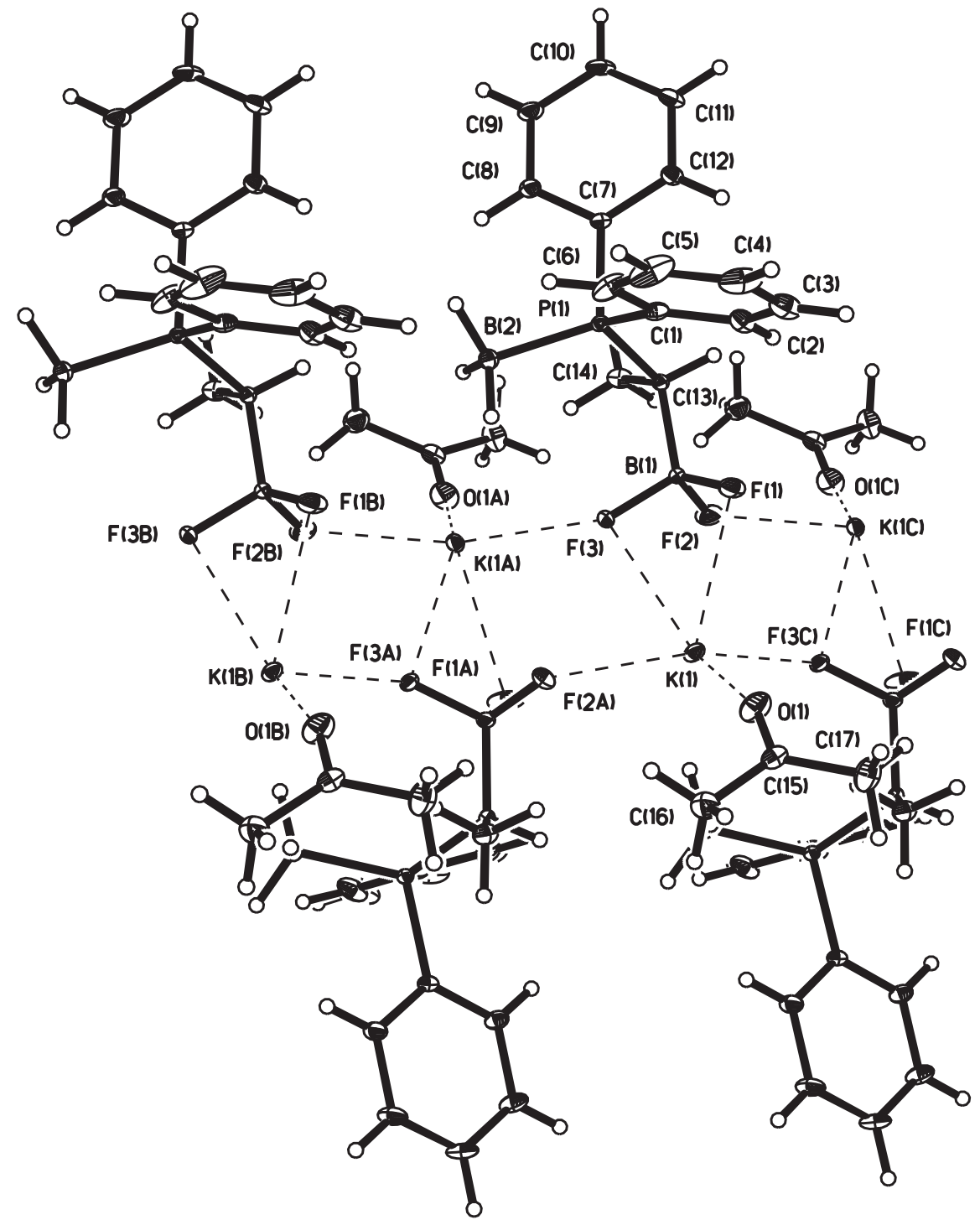

Figure A1.10. Perspective view of the molecular arrangement of four $\mathrm{K}\left[\mathrm{PPh}_{2}\left(\mathrm{BH}_{3}\right)\left(\mathrm{CHMeBF}_{3}\right)\right] \cdot \mathrm{OCMe}_{2}$ units in the lattice with an atom labeling scheme for selected non-hydrogen atoms. The thermal ellipsoids are scaled to enclose $30 \%$ probability. The dashed lines indicate the close contacts between the $\mathrm{K}+$ cations and the fluorine atoms of the neighboring anions and the $\mathrm{O}$ of the closest acetone molecule of solvation. 


\section{Description of the X-ray Structural Analysis of $\mathrm{K}\left[\mathrm{PPh}_{2}\left(\mathrm{BH}_{3}\right)(\mathrm{CHMeBF})\right] \cdot \mathrm{OCMe}_{2}$}

A colorless crystal of $\mathrm{K}\left[\mathrm{PPh}_{2}\left(\mathrm{BH}_{3}\right)\left(\mathrm{CHMeBF}_{3}\right)\right] \cdot \mathrm{OCMe}_{2}$ was covered in a polybutene oil (Sigma-Aldrich) and placed on the end of a MiTeGen loop. The sample was cooled to $100 \mathrm{~K}$ with an Oxford Cryostream 700 system and optically aligned on a Bruker AXS D8 Venture fixed-chi X-ray diffractometer equipped with a Triumph monochromator, a Mo Ka radiation source $(\lambda=0.71073 \AA)$, and a PHOTON 100 CMOS detector. Three sets of 12 frames each were collected using the omega scan method with a $10 \mathrm{~s}$ exposure time. Integration of these frames followed by reflection indexing and least-squares refinement produced a crystal orientation matrix for the monoclinic crystal lattice that was used for the structural analysis.

Data collection consisted of the measurement of a total of 740 frames in four runs using omega scans with the detector held at $5.00 \mathrm{~cm}$ from the crystal. Frame scan parameters are summarized below:

$\begin{array}{cccccccc}\begin{array}{c}\mathrm{Ru} \\ \mathrm{n}\end{array} & 2 \theta & \omega & \Phi & \chi & \begin{array}{c}\text { Scan Width } \\ \left({ }^{\circ}\right)\end{array} & \begin{array}{c}\text { Frame } \\ \mathrm{s}\end{array} & \begin{array}{c}\text { Exposure } \\ \text { Time } \\ (\mathrm{sec})\end{array} \\ & & & & & & & 1.00 \\ 1 & 21.90 & -160.79 & 102.00 & 54.74 & 185 & 15.00 \\ 2 & 21.90 & -160.79 & 0.00 & 54.74 & 1.00 & 185 & 15.00 \\ 3 & 21.90 & -160.79 & 153.00 & 54.74 & 1.00 & 185 & 15.00 \\ 4 & 21.90 & -160.79 & 51.00 & 54.74 & 1.00 & 185 & 15.00\end{array}$

The APEX3 software program (version 2016.9-0) ${ }^{1}$ was used for diffractometer control, preliminary frame scans, indexing, orientation matrix calculations, least-squares refinement of cell parameters, and the data collection. The frames were integrated with the Bruker SAINT software package using a narrow-frame algorithm. The integration of 
the data using a monoclinic unit cell yielded a total of 41036 reflections to a maximum $\theta$ angle of $30.00^{\circ}(0.71 \AA$ resolution), of which 5892 were independent (average redundancy 6.965 , completeness $\left.=99.8 \%, R_{\text {int }}=3.12 \%, R_{\text {sig }}=1.97 \%\right)$ and 5176 $(87.85 \%)$ were greater than $2 \sigma\left(F^{2}\right)$. The final cell constants of $\underline{a}=16.5781(6) \AA, \underline{b}=$ 6.9492(3) $\AA, \underline{c}=17.6391(7) \AA, \beta=96.3164(10)^{\circ}$, volume $=2019.77(14) \AA^{3}$, are based upon the refinement of the XYZ-centroids of 9966 reflections above $20 \sigma(I)$ with $6.363^{\circ}$ $<2 \theta<65.42^{\circ}$. Data were corrected for absorption effects using the multi-scan method (SADABS). The ratio of minimum to maximum apparent transmission was 0.892 . The calculated minimum and maximum transmission coefficients (based on crystal size) are 0.834 and 0.934 .

The structure was solved by direct methods and difference Fourier analysis using the programs provided by SHELXL-2014/7. ${ }^{2}$ The crystallographic asymmetric unit contains a potassium cation, a $\left[\mathrm{PPh}_{2}\left(\mathrm{BH}_{3}\right)\left(\mathrm{CHMeBF}_{3}\right)\right]^{-}$monoanion, and a molecule of acetone. Idealized positions for the hydrogen atoms bound to carbon atoms were included as fixed contributions using a riding model with isotropic temperature factors set at 1.2 (methine and aromatic hydrogens) or 1.5 (methyl hydrogens) times that of the adjacent carbon atom. The fractional coordinates and isotropic thermal parameters of the three hydrogens of the $\mathrm{BH}_{3}$ group bound to the phosphorus atom were refined. The positions of the methyl hydrogen atoms were optimized by a rigid rotating group refinement with idealized angles. Full-matrix least-squares refinement, based upon the minimization of $\Sigma \mathrm{w}_{\mathrm{i}}\left|\mathrm{F}_{\mathrm{o}}{ }^{2}-\mathrm{F}_{\mathrm{c}}{ }^{2}\right|^{2}$, with weighting $\mathrm{w}_{\mathrm{i}}^{-1}=\left[\sigma^{2}\left(\mathrm{~F}_{\mathrm{o}}{ }^{2}\right)+(0.0352 \mathrm{P})^{2}+1.4010 \mathrm{P}\right]$, where $P=\left(\operatorname{Max}\left(F_{o}^{2}, 0\right)+2 F_{c}^{2}\right) / 3 .^{2}$ The final anisotropic full-matrix least-squares 
refinement on $\mathrm{F}^{2}$ with 241 variables converged at $\mathrm{R} 1=3.60 \%$, for the 5176 observed data with $\mid>2 \sigma(I)$ and $w R 2=9.06 \%$ for all data. The goodness-of-fit was $1.073 .^{3}$

A correction for secondary extinction was not applied. The largest peak in the final difference electron density synthesis was $0.529 \mathrm{e}^{-} / \AA^{3}$ and the largest hole was -

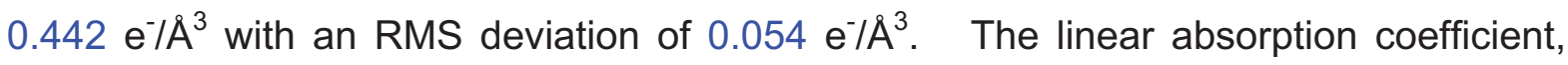
atomic scattering factors, and anomalous dispersion corrections were calculated from values found in the International Tables of X-ray Crystallography. ${ }^{4}$

\section{References}

1. APEX3 is a Bruker AXS crystallographic software package for single crystal data collection, reduction and preparation.

2. Sheldrick, G. M., SHELXL-2014, Crystallographic software package, Bruker AXS, Inc., Madison, Wisconsin, USA.

3. $\mathrm{R}_{1}=\Sigma\left(|| \mathrm{Fo}_{\mathrm{O}}|-| \mathrm{F}_{\mathrm{C}}||\right) / \Sigma\left|\mathrm{Fo}_{\mathrm{o}}\right|, \mathrm{wR}_{2}=\left[\Sigma\left[\mathrm{w}\left(\mathrm{Fo}_{\mathrm{o}}^{2}-\mathrm{F}_{\mathrm{C}}\right)^{2}\right] / \Sigma\left[\mathrm{w}\left(\mathrm{Fo}_{\mathrm{o}}^{2}\right)^{2}\right]\right]^{1 / 2}, \mathrm{R}_{\text {int. }}=\Sigma \mid \mathrm{F}_{\mathrm{o}}{ }^{2}-$

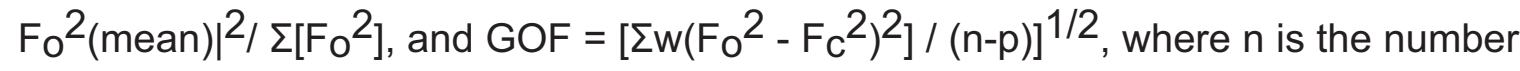
of reflections and $p$ is the total number of parameters which were varied during the last refinement cycle.

4. International Tables for X-ray Crystallography (1974). Vol. IV, p. 55. Birmingham: Kynoch Press. (Present distributor, D. Reidel, Dordrecht.). 
Table 15. Crystal data for $\mathrm{K}\left[\mathrm{PPh}_{2}\left(\mathrm{BH}_{3}\right)\left(\mathrm{CHMeBF}_{3}\right)\right] \cdot \mathrm{OCMe}_{2}$.

$\begin{array}{lll}\text { Ident. code } & \text { bp46cms } \\ \text { CCDC Number } & \text { CCDC } 1833917 & \\ \text { Chemical form. } & \mathrm{C}_{17} \mathrm{H}_{23} \mathrm{~B}_{2} \mathrm{~F}_{3} \mathrm{KOP} & \\ \text { Formula weight } & 392.04 \mathrm{~g} / \mathrm{mol} & \\ \text { Temperature } & 100(2) \mathrm{K} \\ \text { Wavelength } & 0.71073 \AA & \\ \text { Crystal size } & 0.188 \times 0.489 \times 0.509 \mathrm{~mm} \\ \text { Crystal system } & \text { monoclinic } & \\ \text { Space group } & \mathrm{P} 2{ }_{1} / \mathrm{c}(\mathrm{No} .14) & \\ \text { Unit cell } & \mathrm{a}=16.5781(6) \AA & \alpha=90^{\circ} \\ & \mathrm{b}=6.9492(3) \AA & \beta=96.3164(10)^{\circ} \\ & \mathrm{C}=17.6391(7) \AA & \mathrm{Y}=90^{\circ} \\ \text { Volume, } \AA^{3} & 2019.77(14) & \\ Z & 4 & \\ \text { Density (calc) } & 1.289 \mathrm{~g}^{\circ} \mathrm{cm}^{3} & \\ \text { Abs. coefficient } & 0.370 \mathrm{~mm}^{-1} & \\ \text { F(000) } & 816 & \end{array}$

Table 16. Data collection and structure refinement for $\mathrm{K}\left[\mathrm{PPh}_{2}\left(\mathrm{BH}_{3}\right)\left(\mathrm{CHMeBF}_{3}\right)\right] \cdot \mathrm{OCMe}_{2}$.

Theta range

Index ranges

Reflections

Independent refls

Coverage

Absorption correction

Max. and min. trans.

Refinement method

Refinement program

Data / restraints / parameters

Goodness-of-fit on $\mathrm{F}^{2}$

Final $R$ indices

Largest diff. peak and hole
3.15 to $30.00^{\circ}$

$-23 \leq \mathrm{h} \leq 22,-9 \leq \mathrm{k} \leq 9,-19 \leq \mathrm{I} \leq 24$

41036

$5892[R($ int $)=0.0312]$

$99.8 \%$

multi-scan

0.934 and 0.834

Full-matrix least-squares on $\mathrm{F}^{2}$

SHELXL-2014/7 (Sheldrick, 2014)

5892 / 0 / 241

1.073

5176 data; $1>2 \sigma(l)$

$\mathrm{R} 1=0.0360, w R 2=0.0862$

all data

$\mathrm{R} 1=0.0431, \mathrm{wR} 2=0.0906$

0.529 and $-0.442 \mathrm{e}^{-} / \AA^{3}$ 
Appendix Two

Spectroscopic Characterization of Inorganic Complexes and Organic Products 


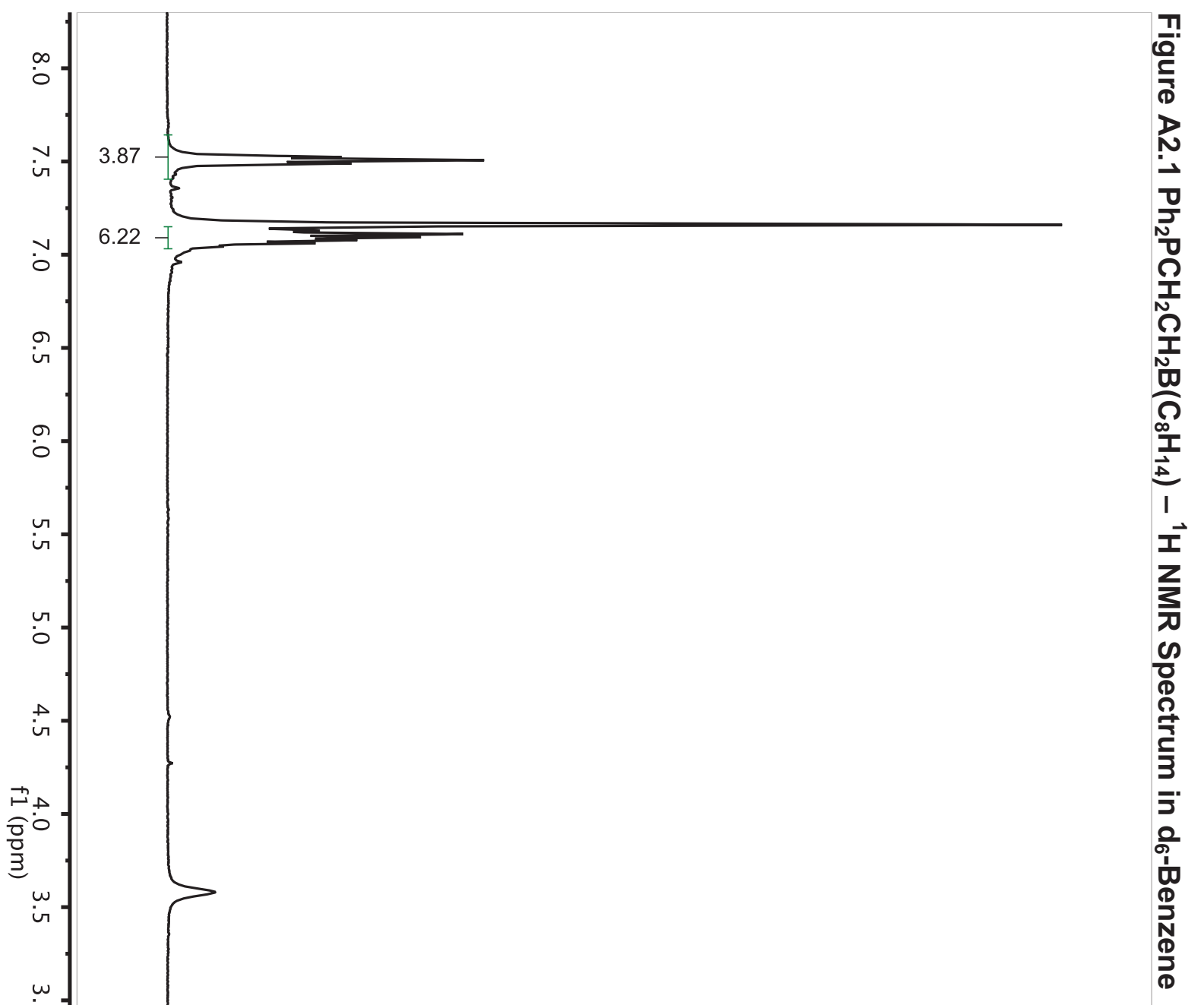



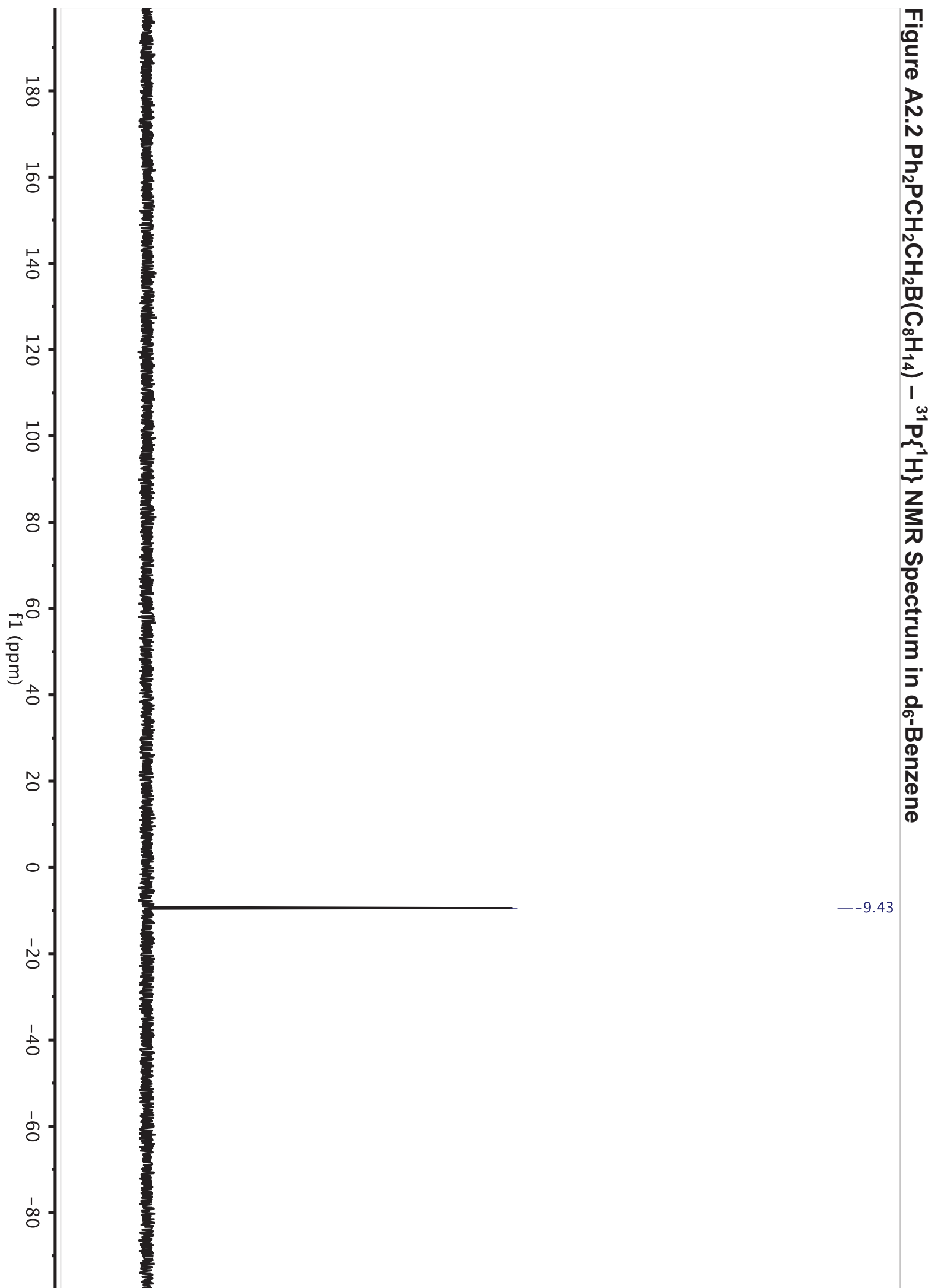
231

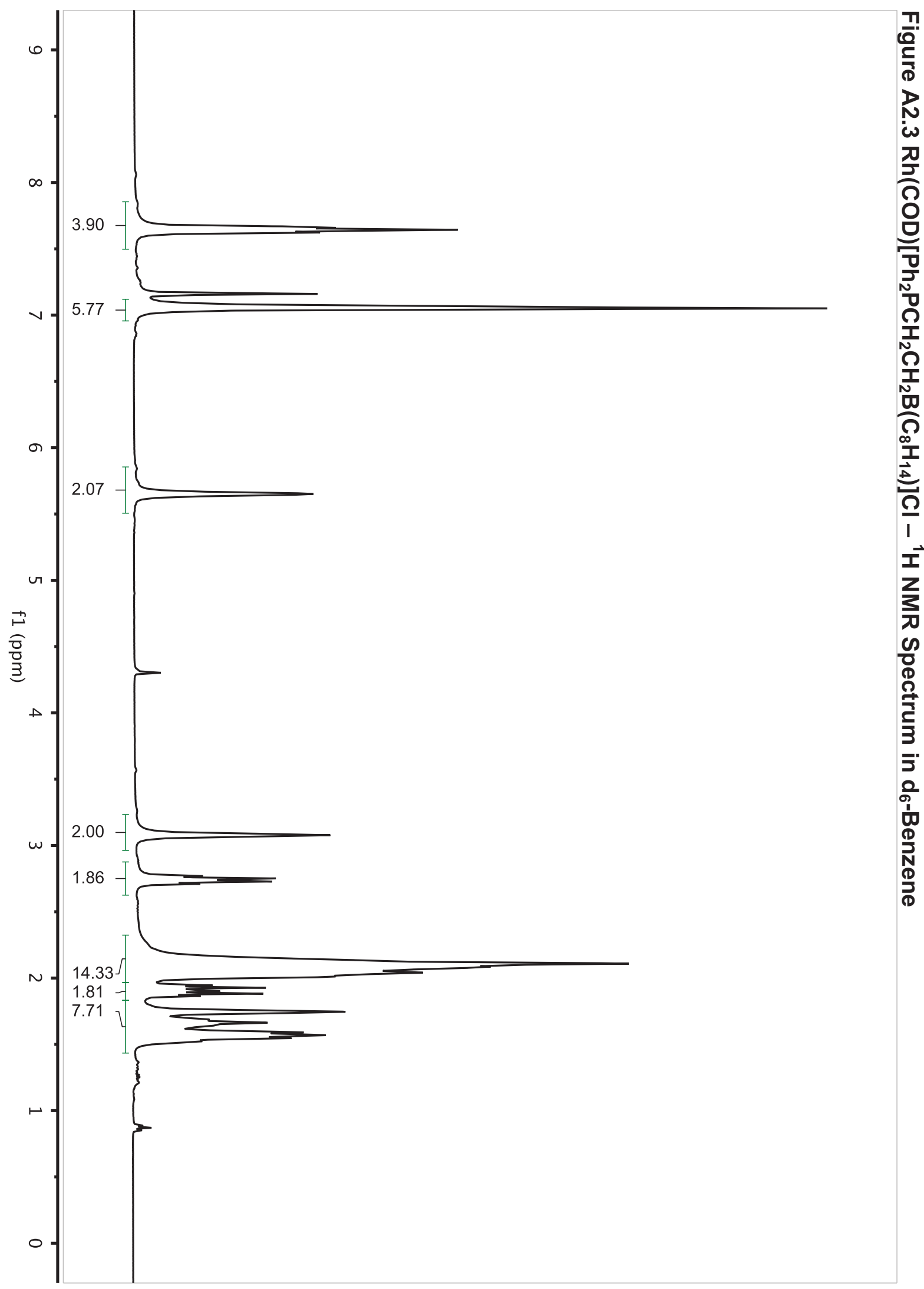




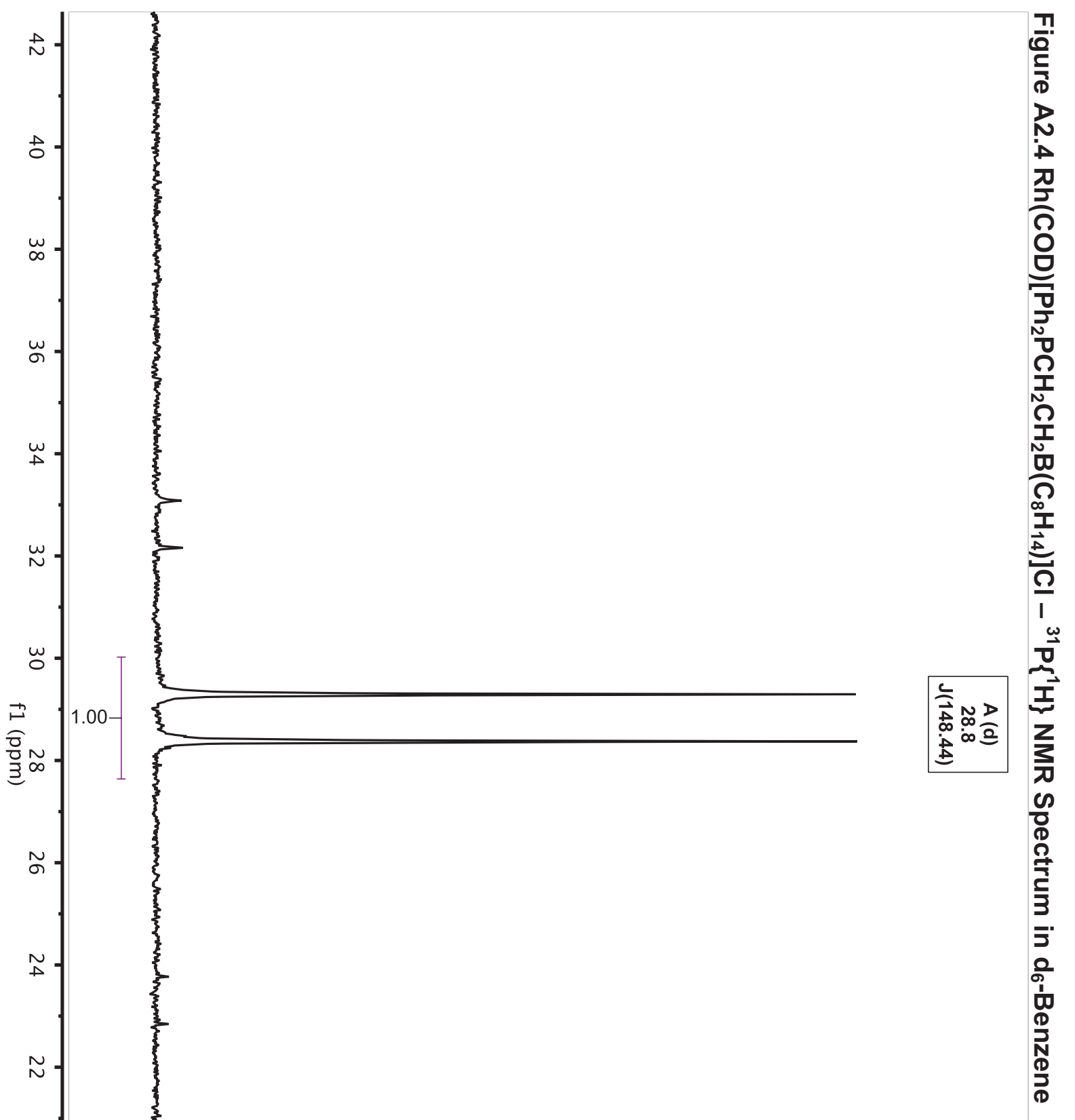



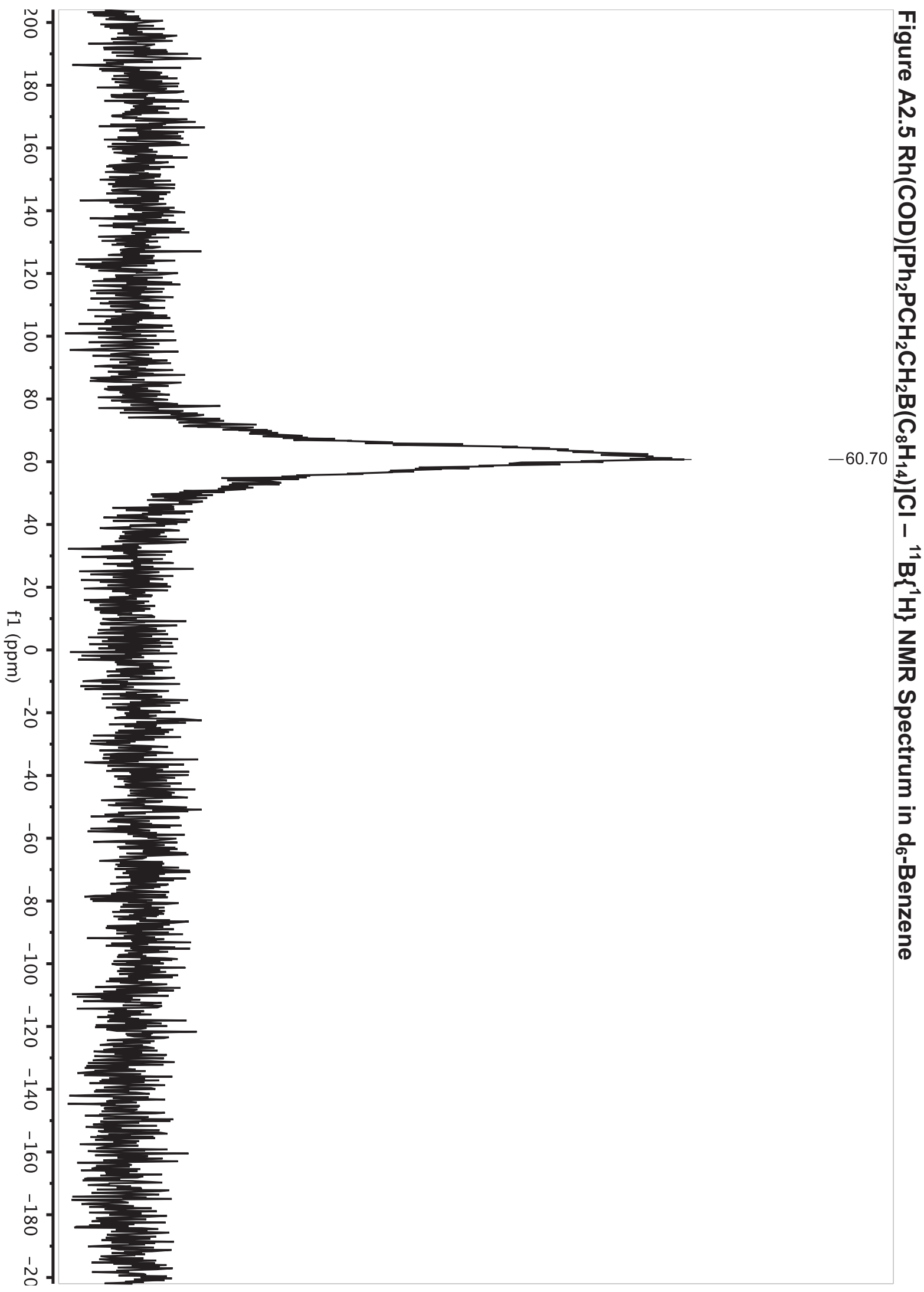


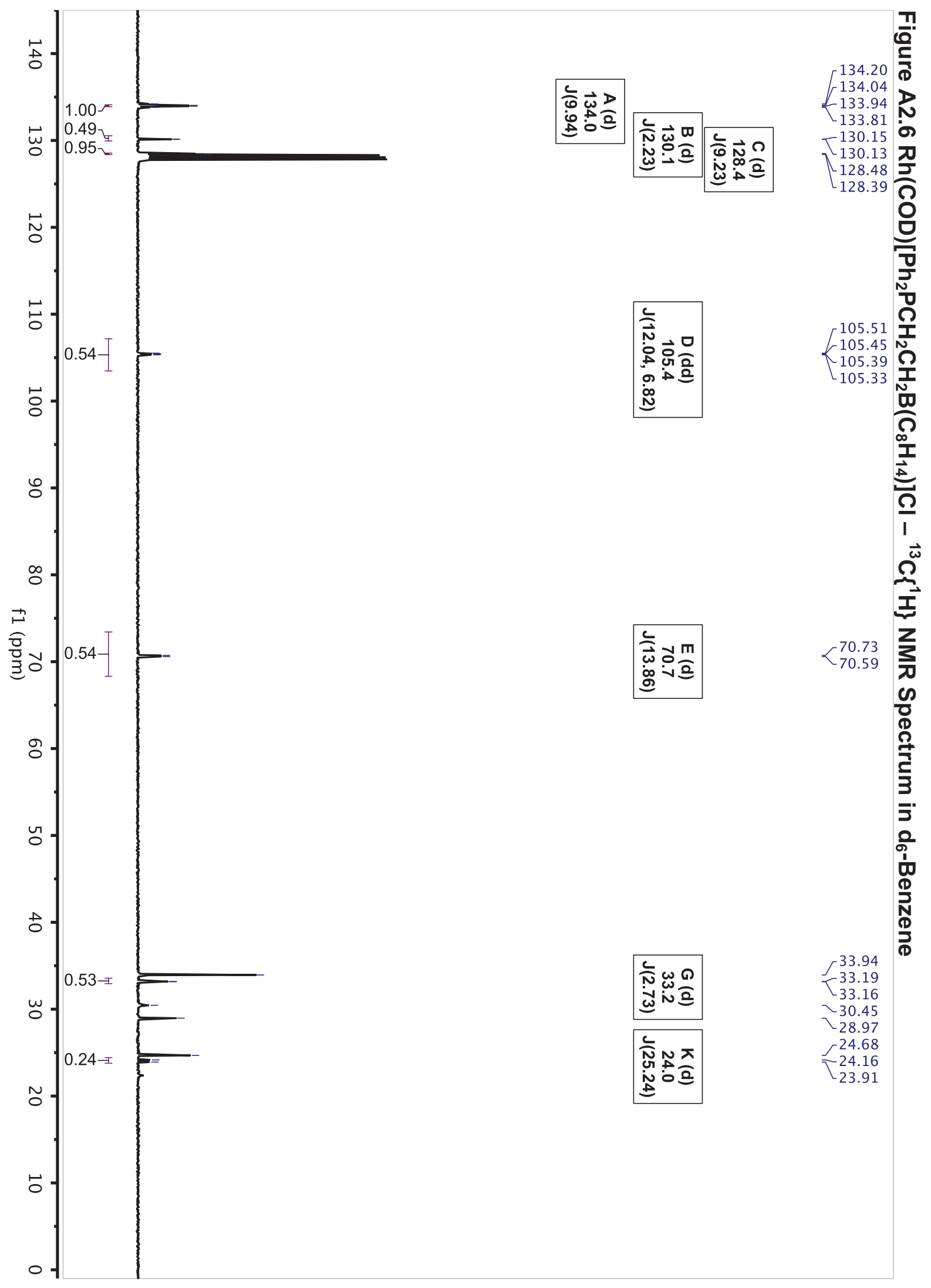




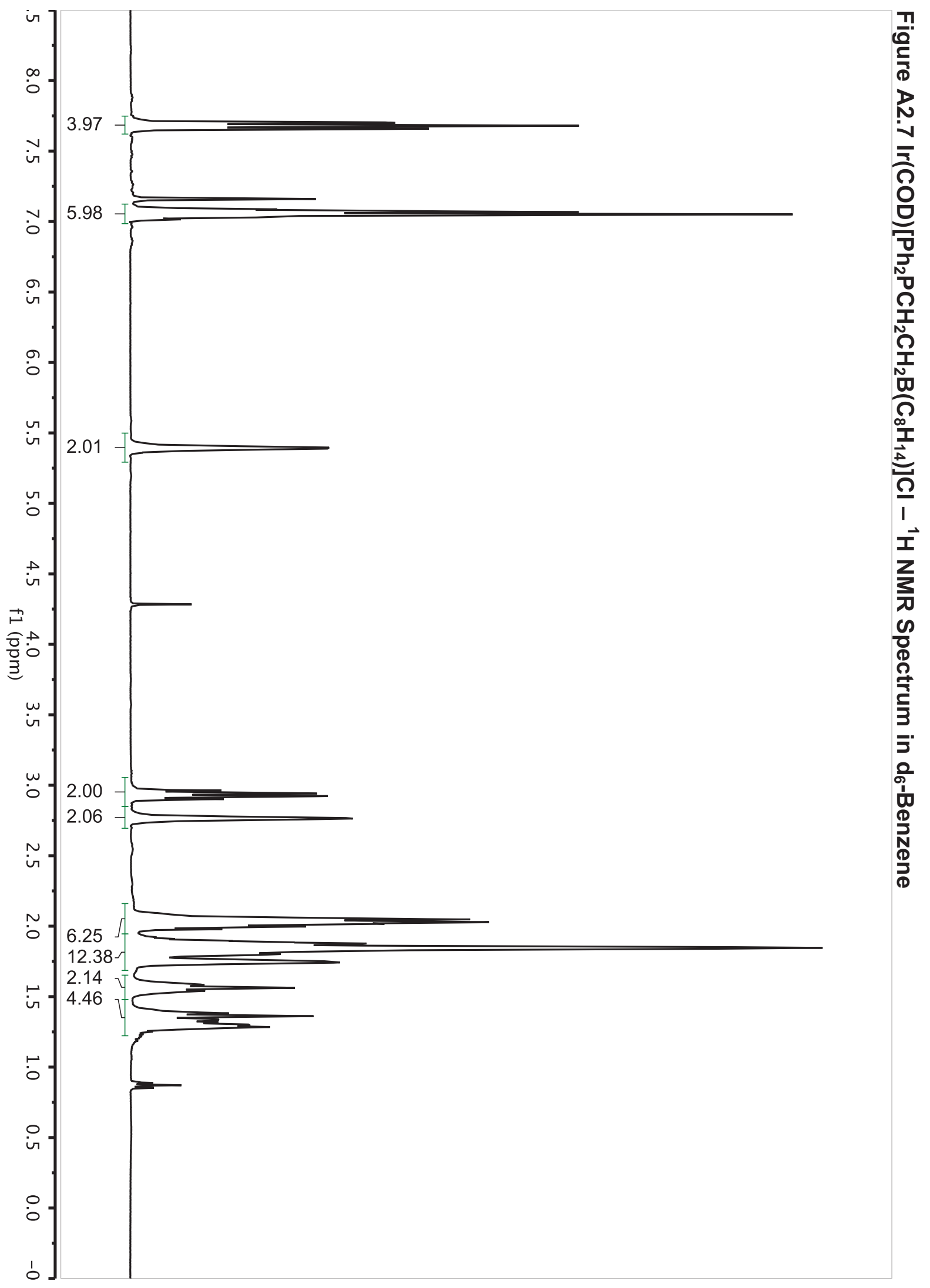




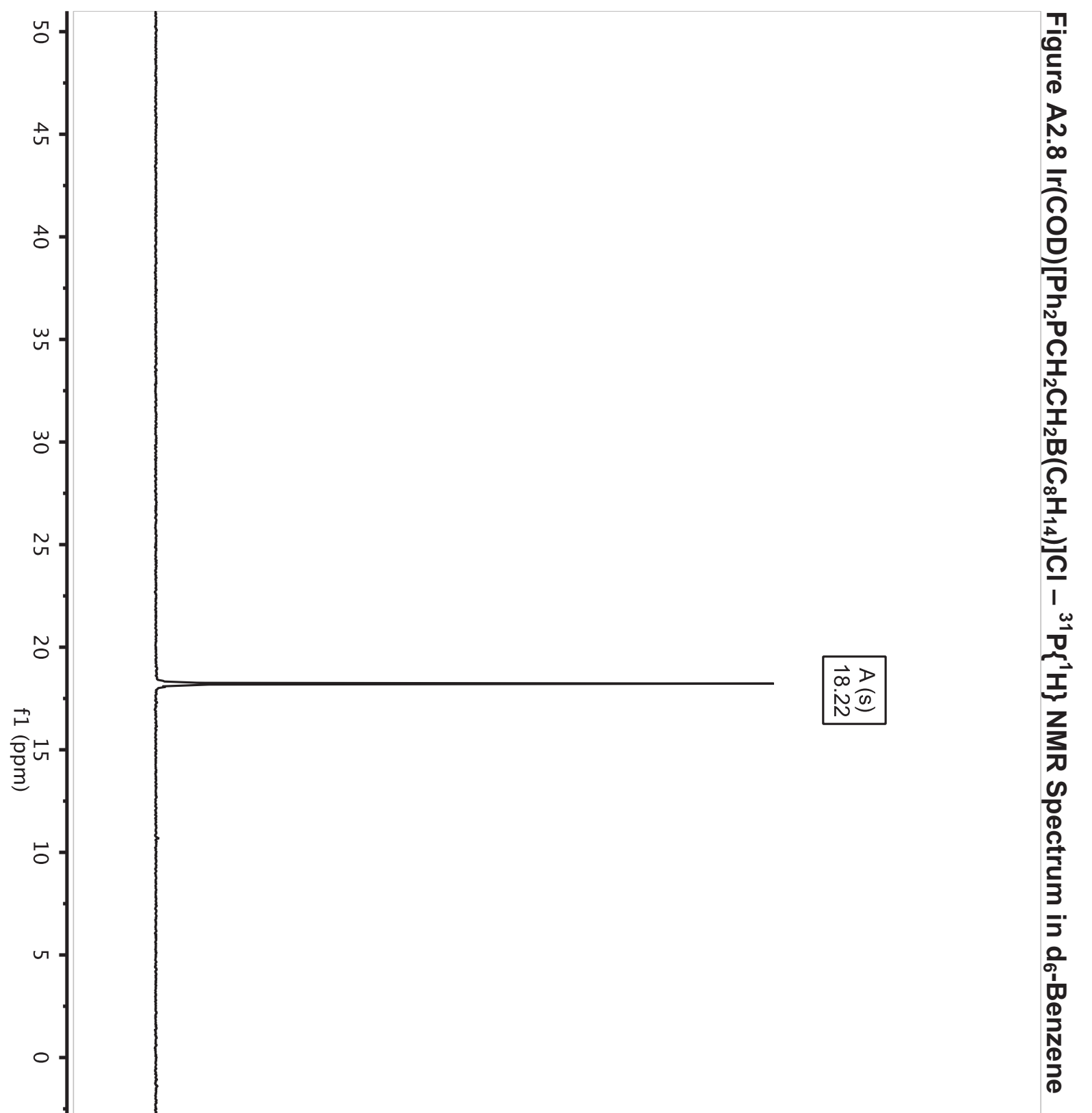



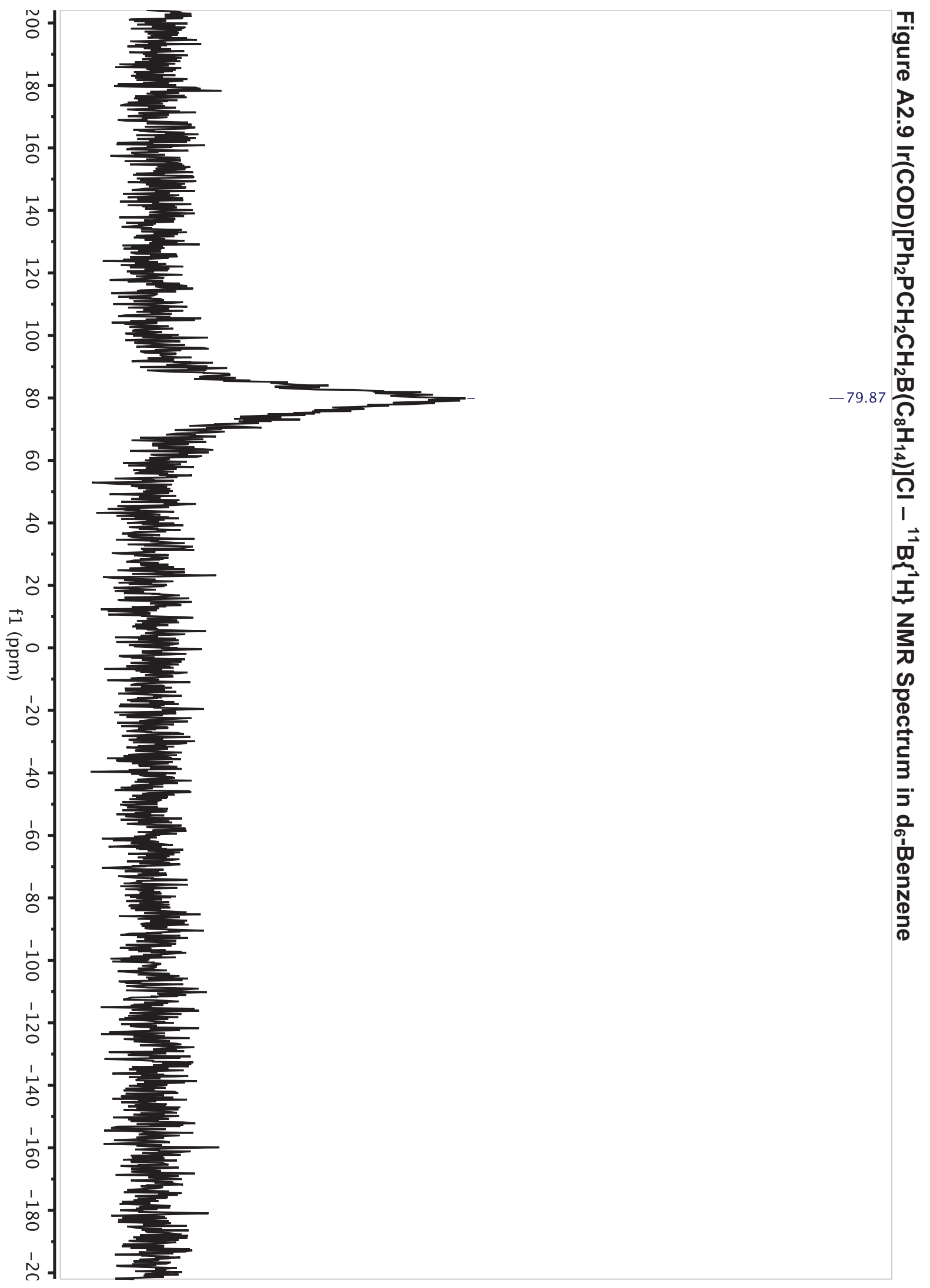


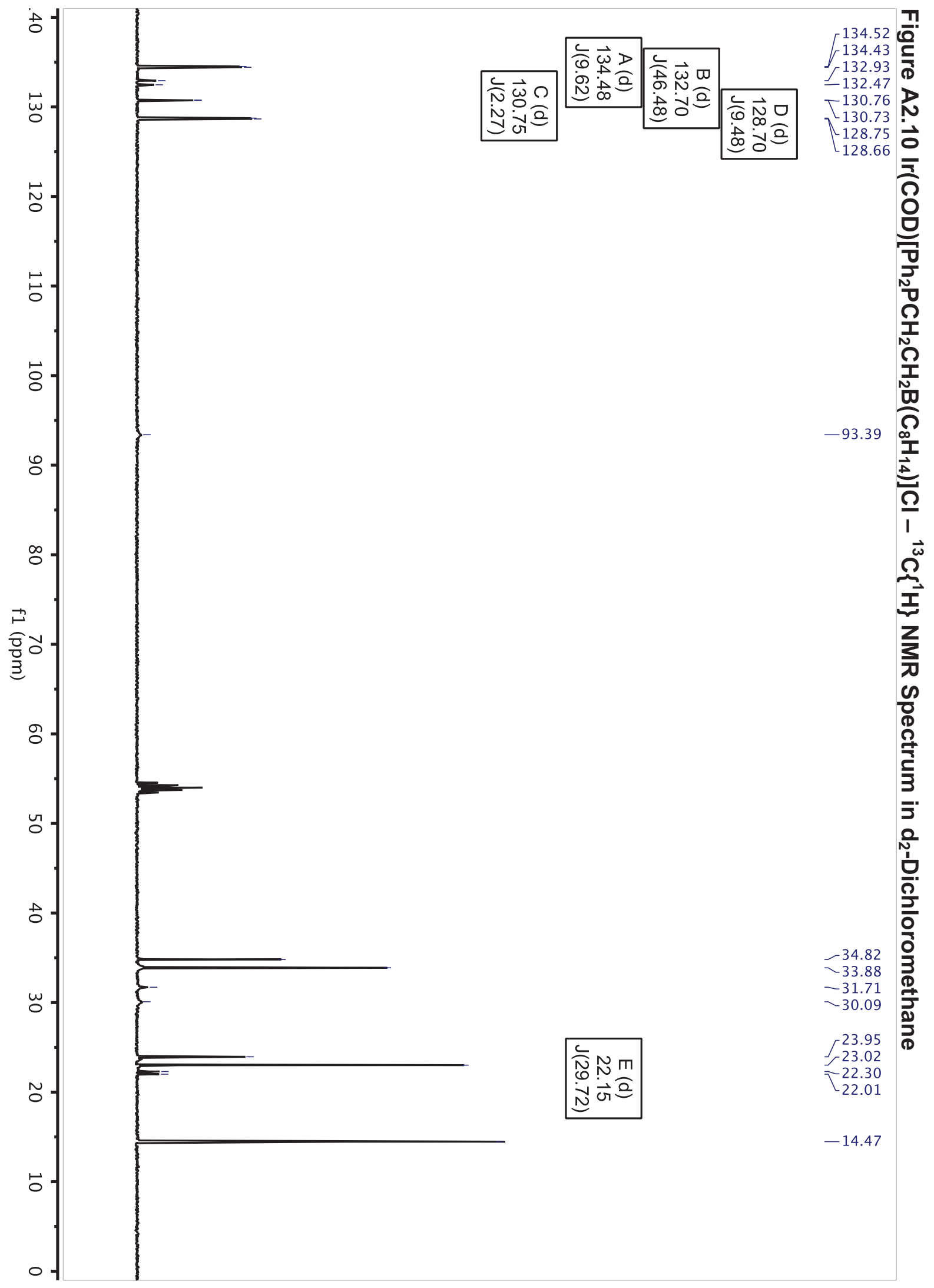




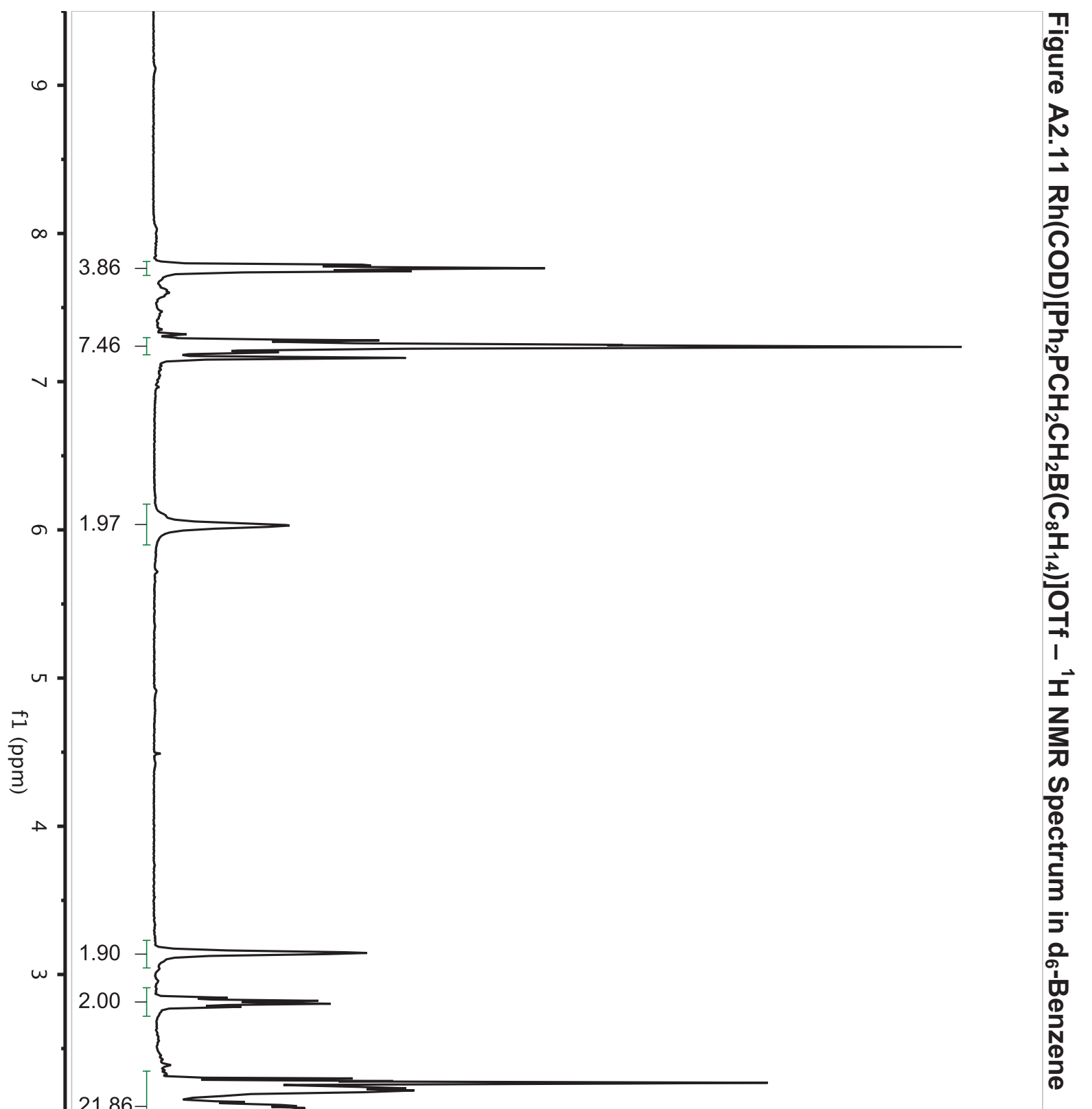




$$
F
$$




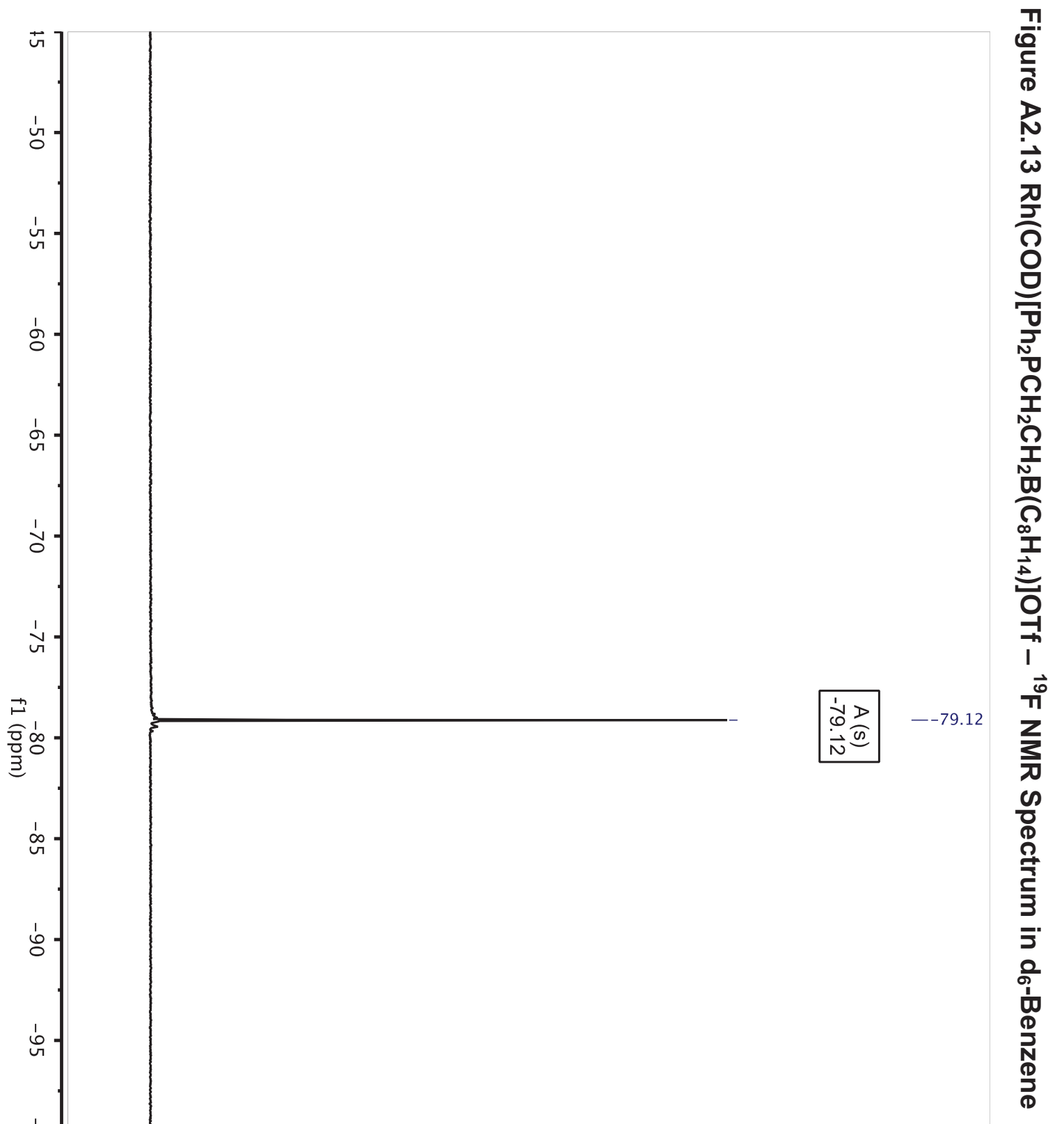




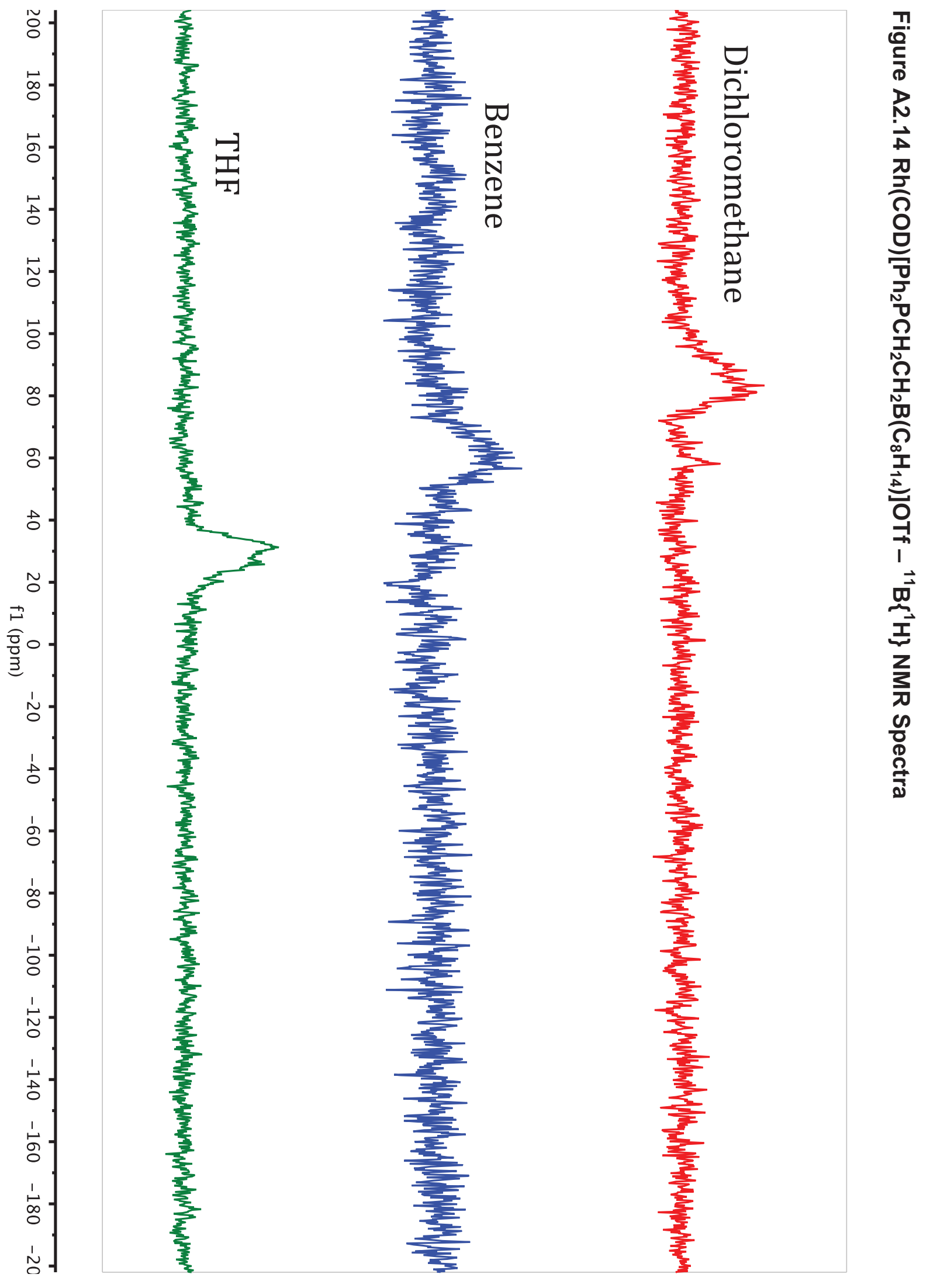




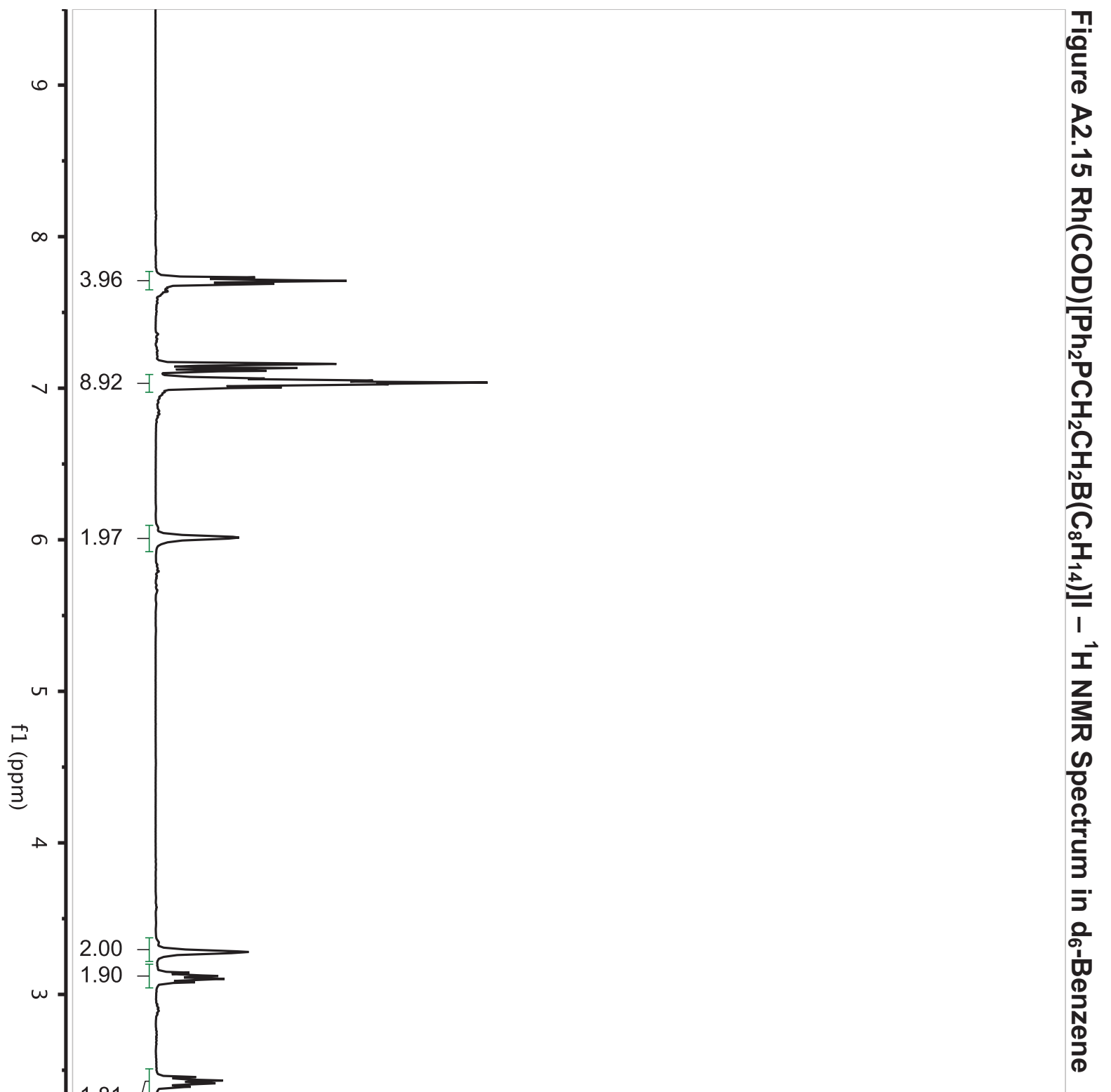




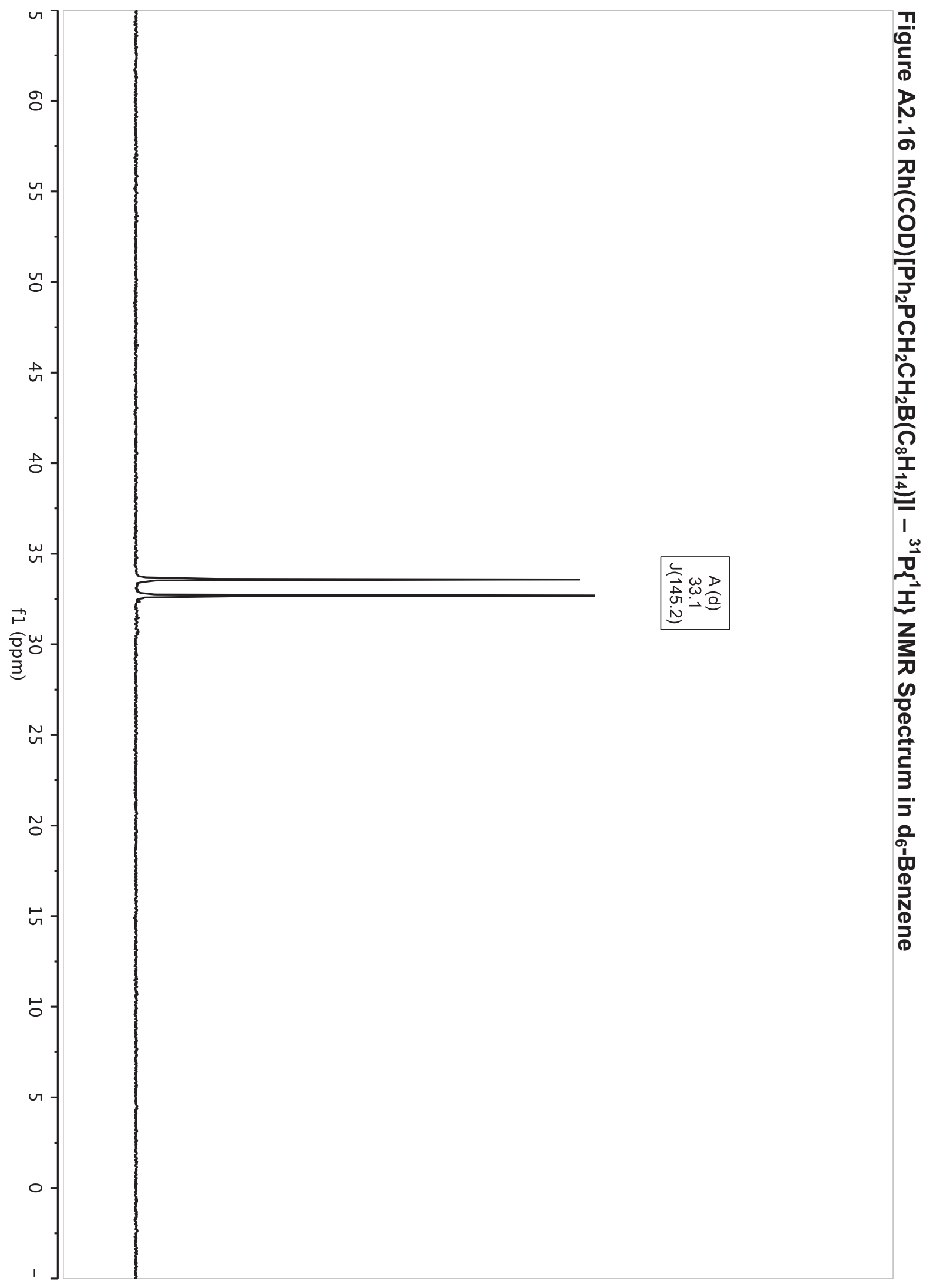




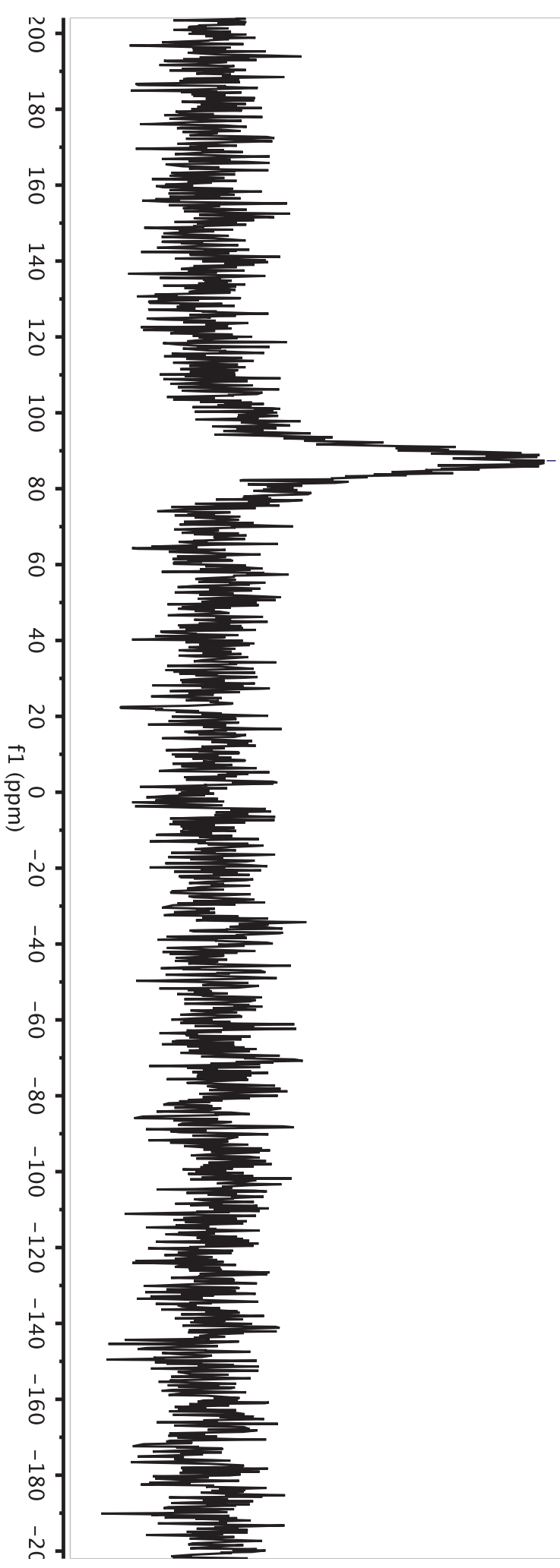

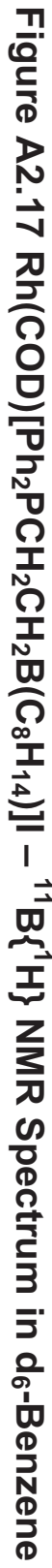




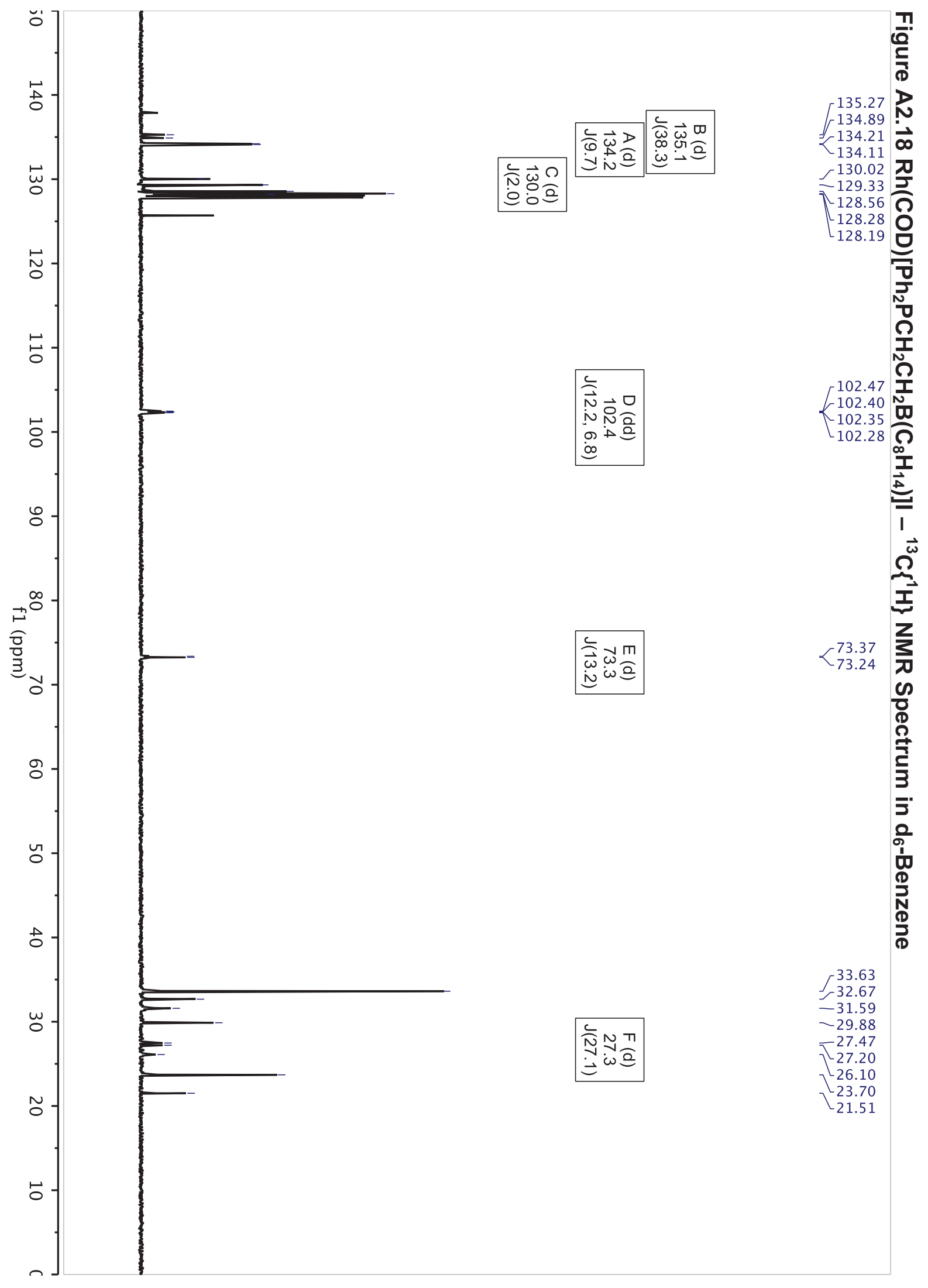




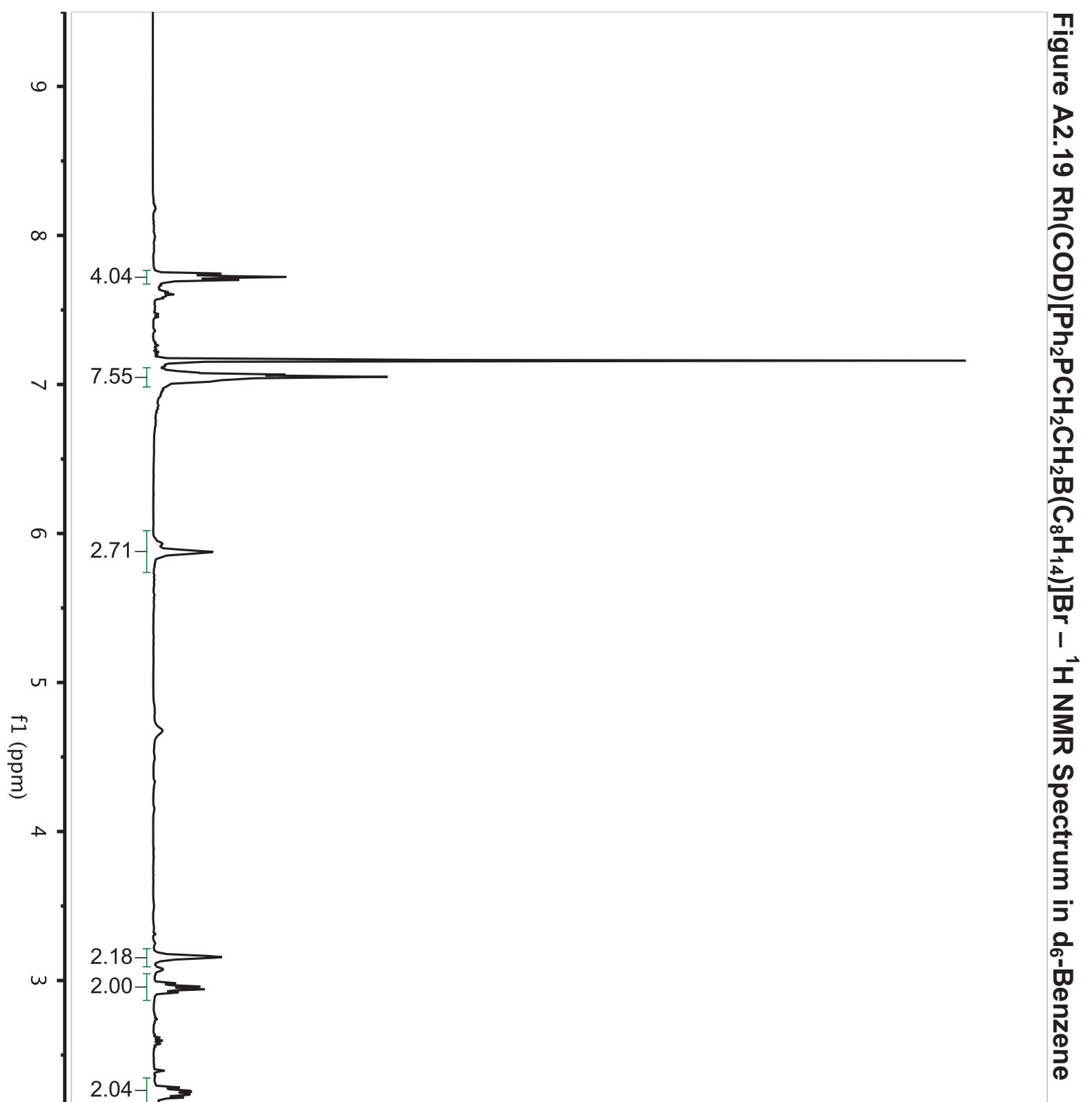




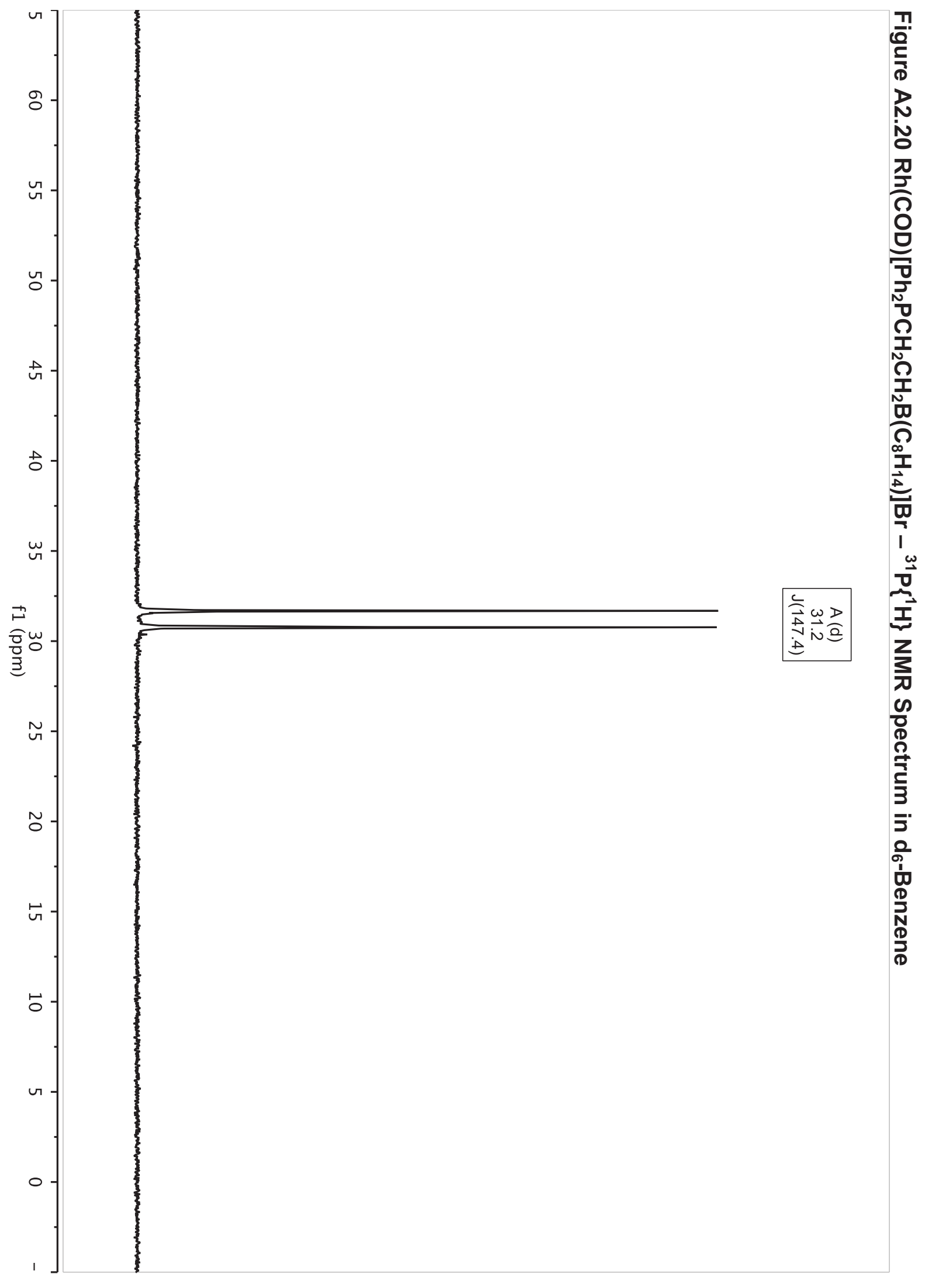




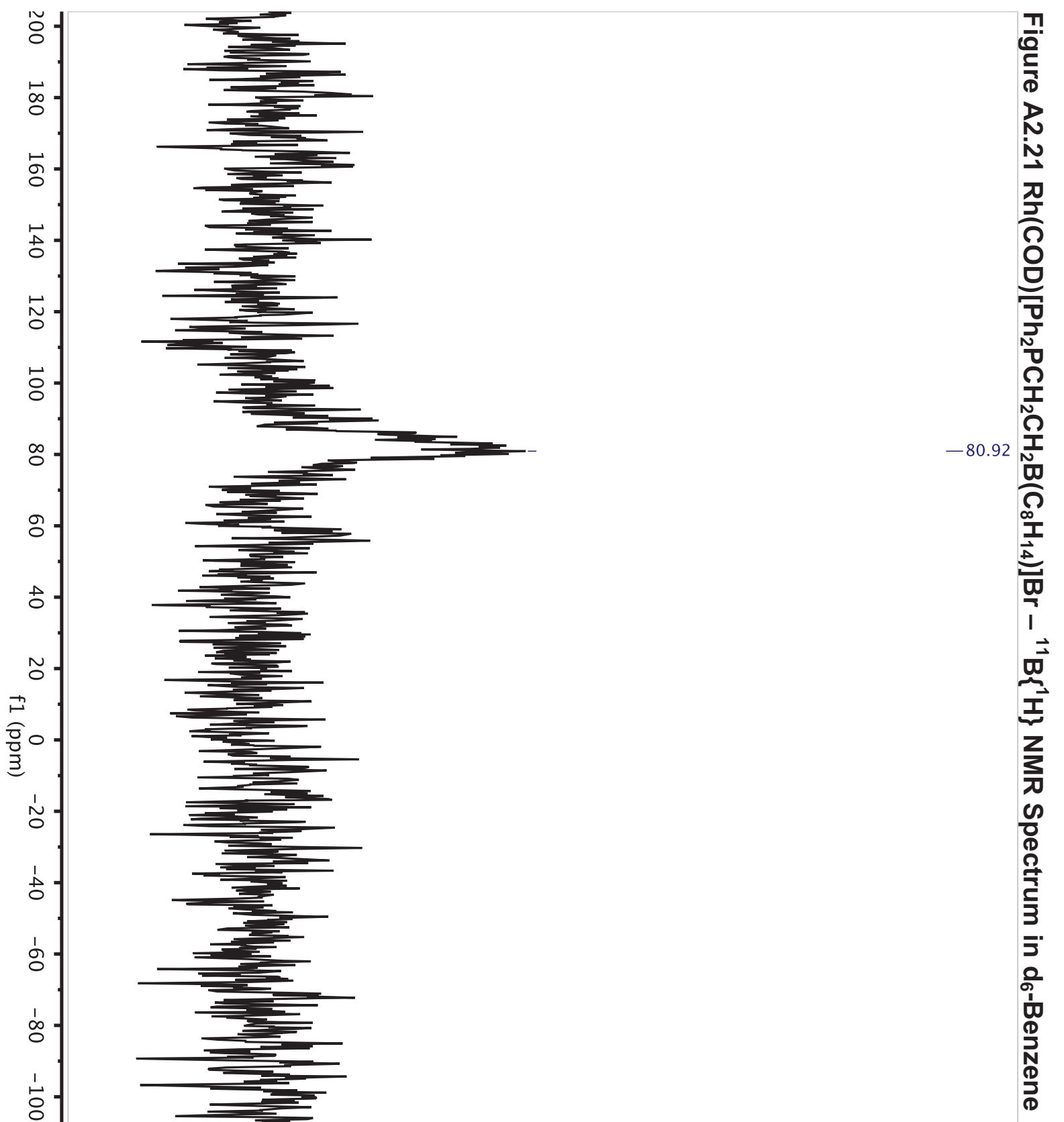




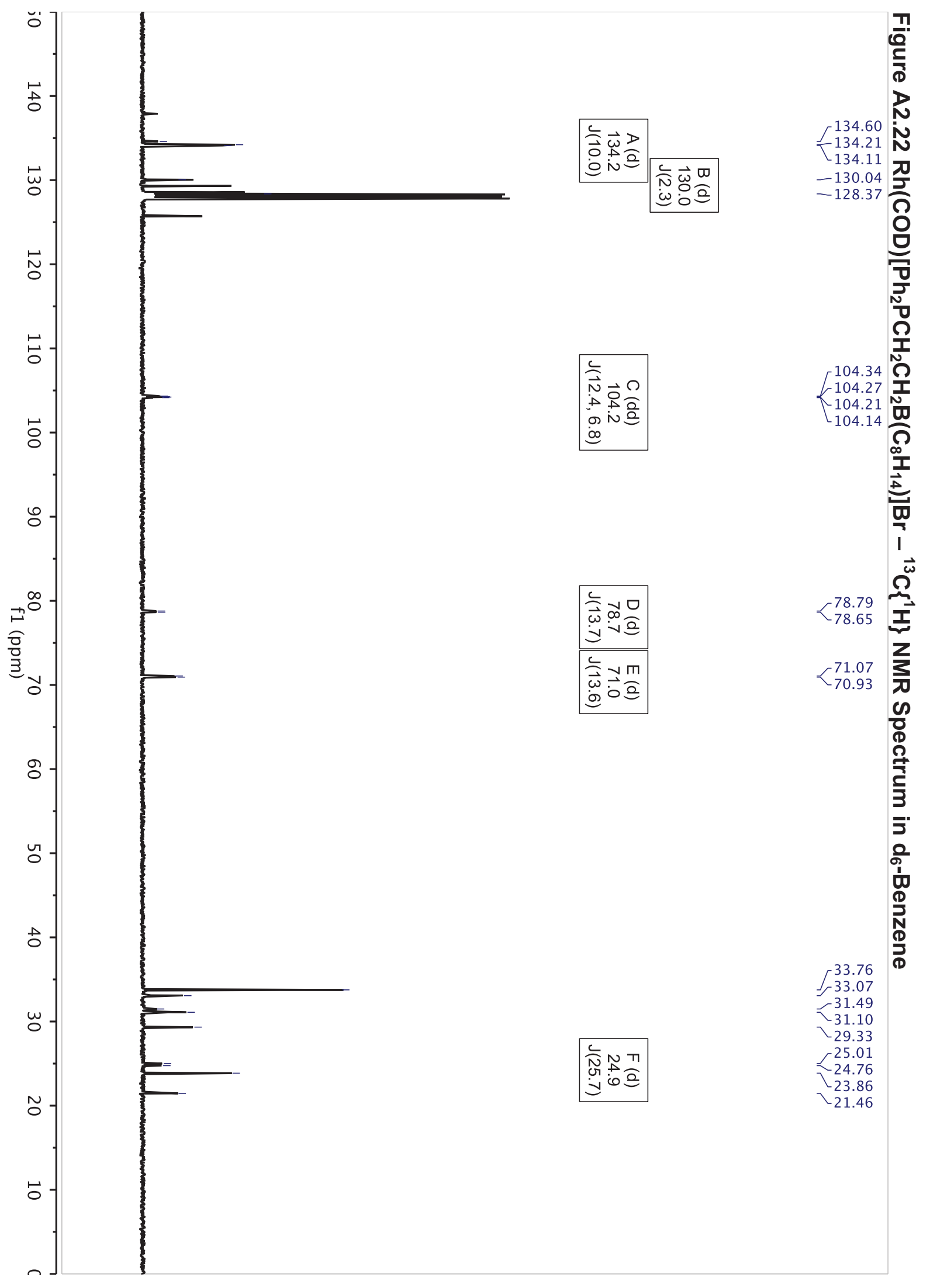


251

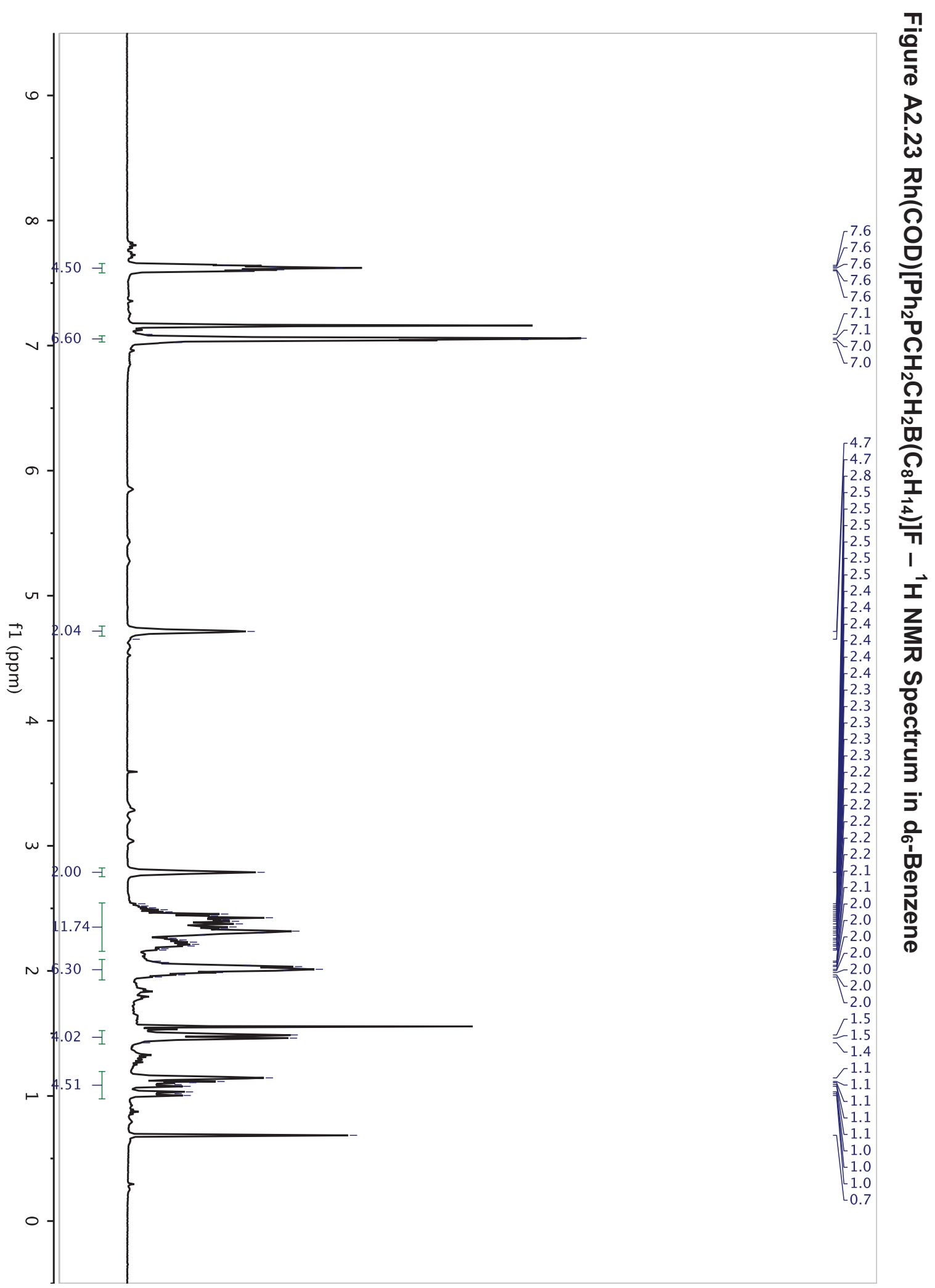




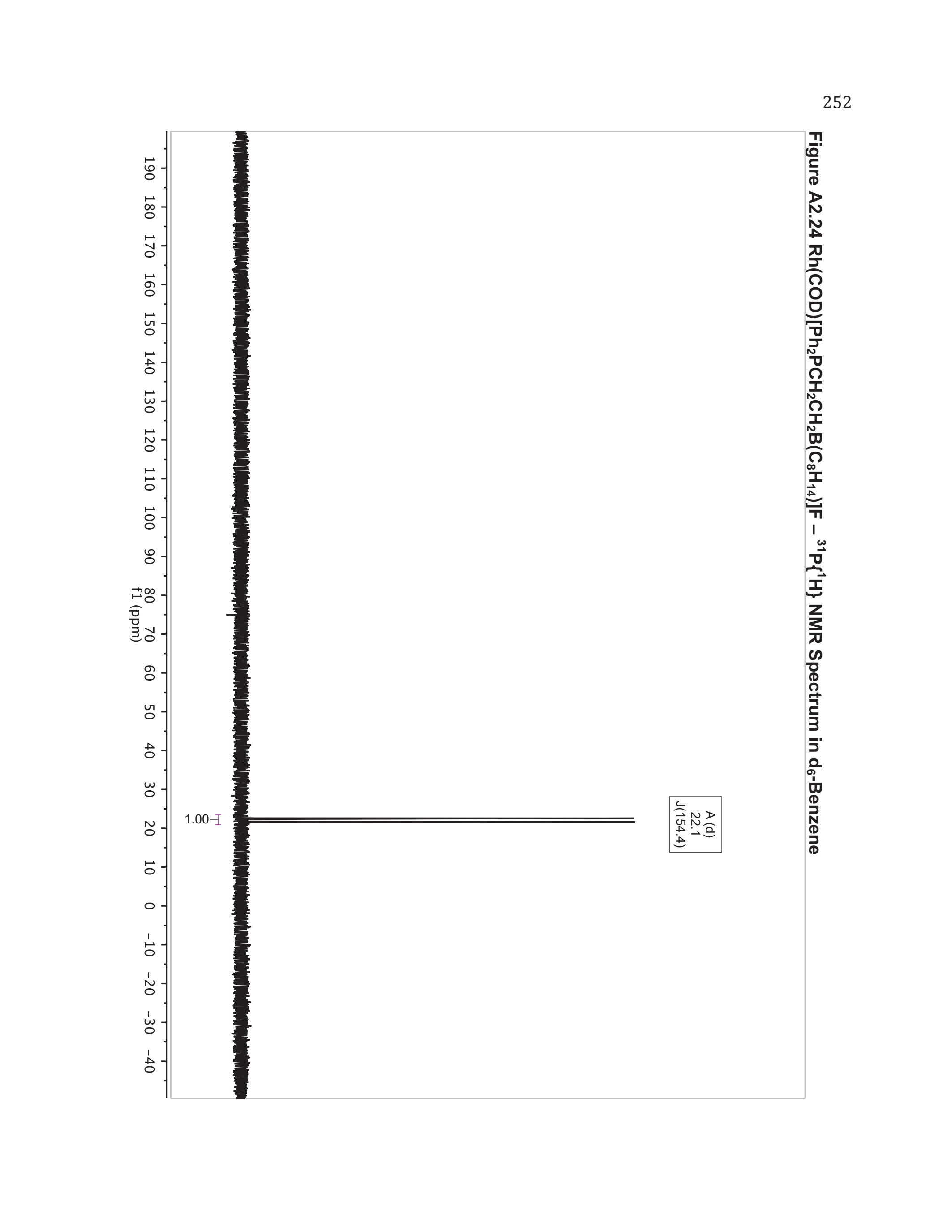




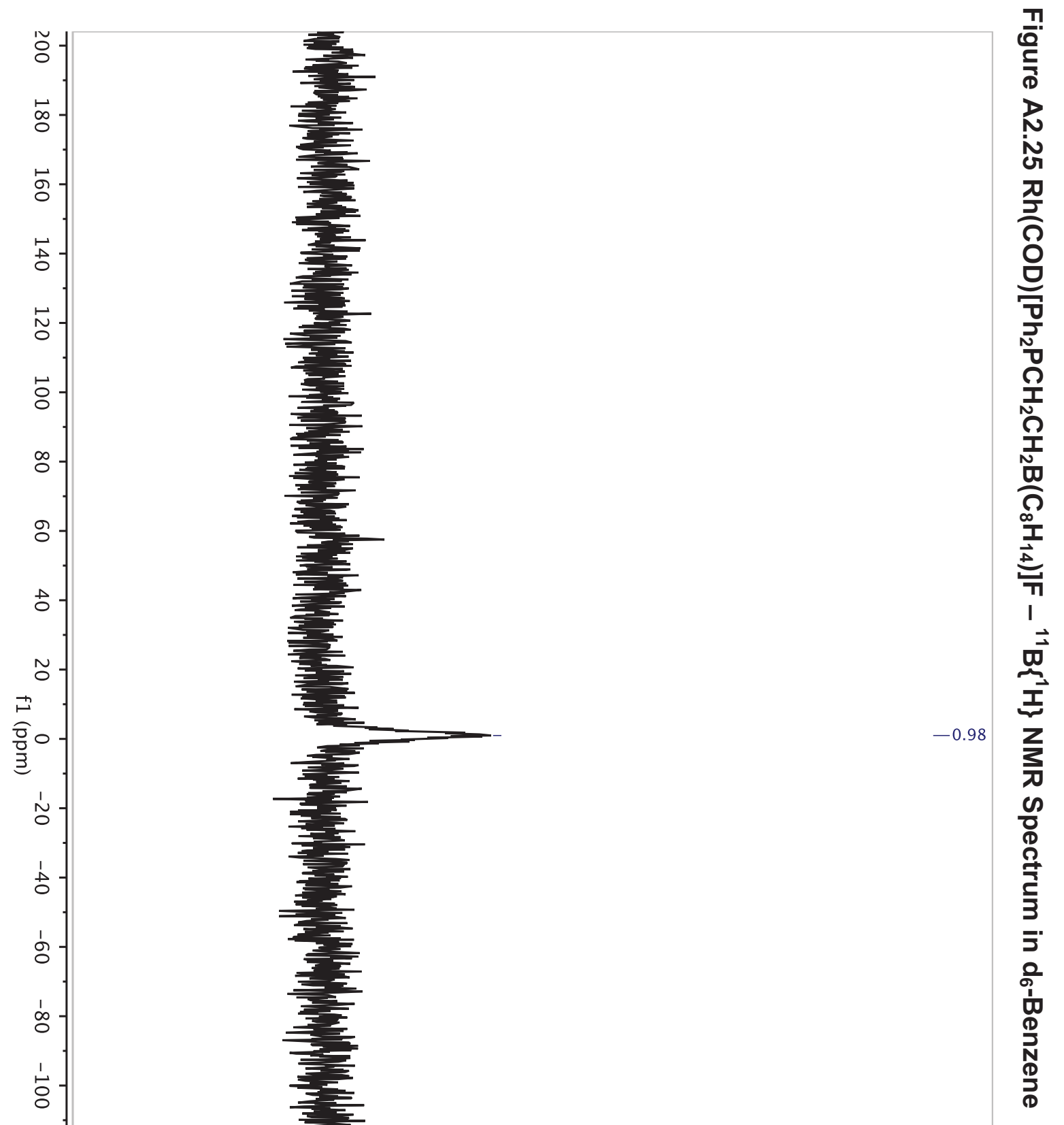




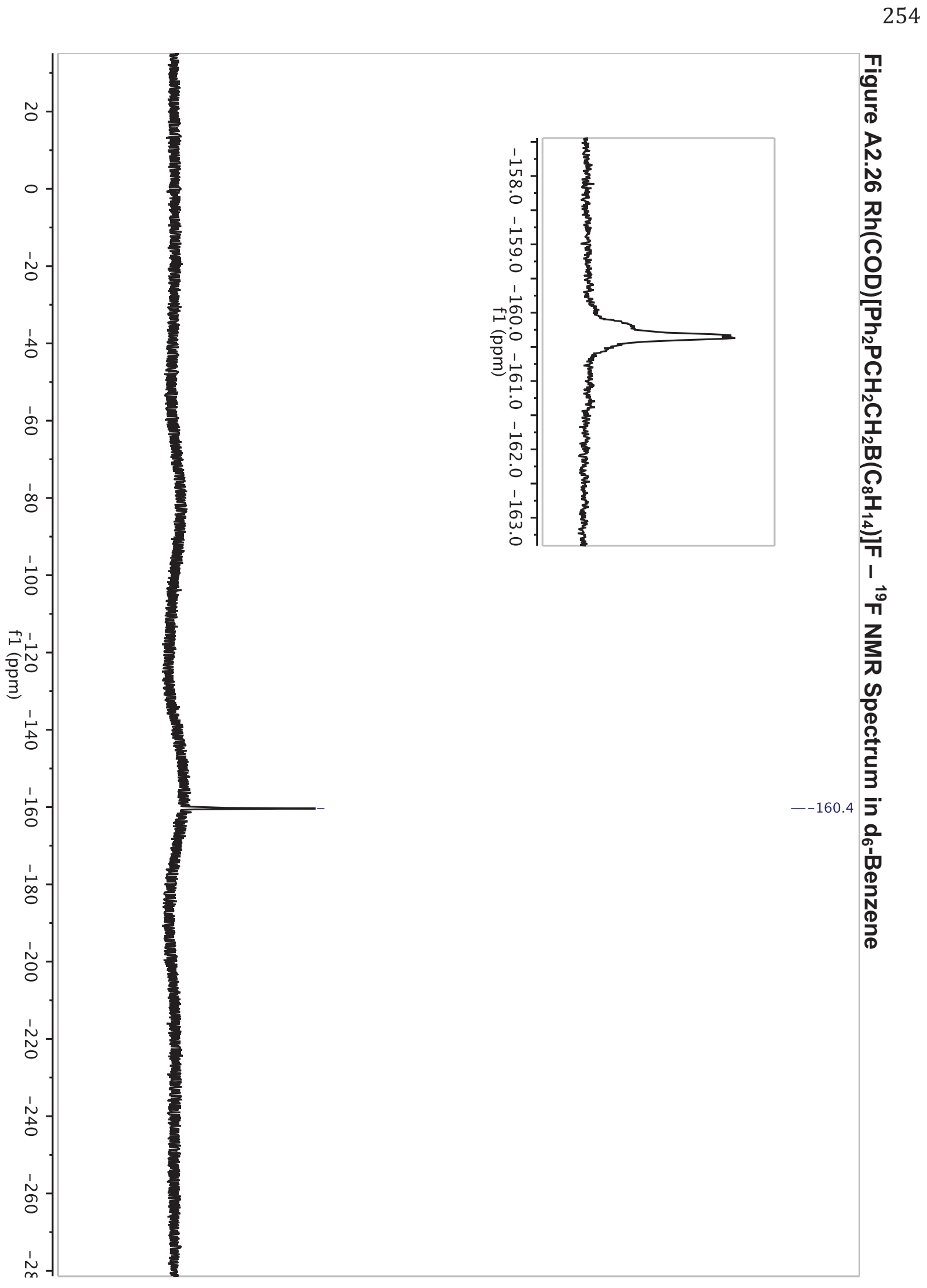




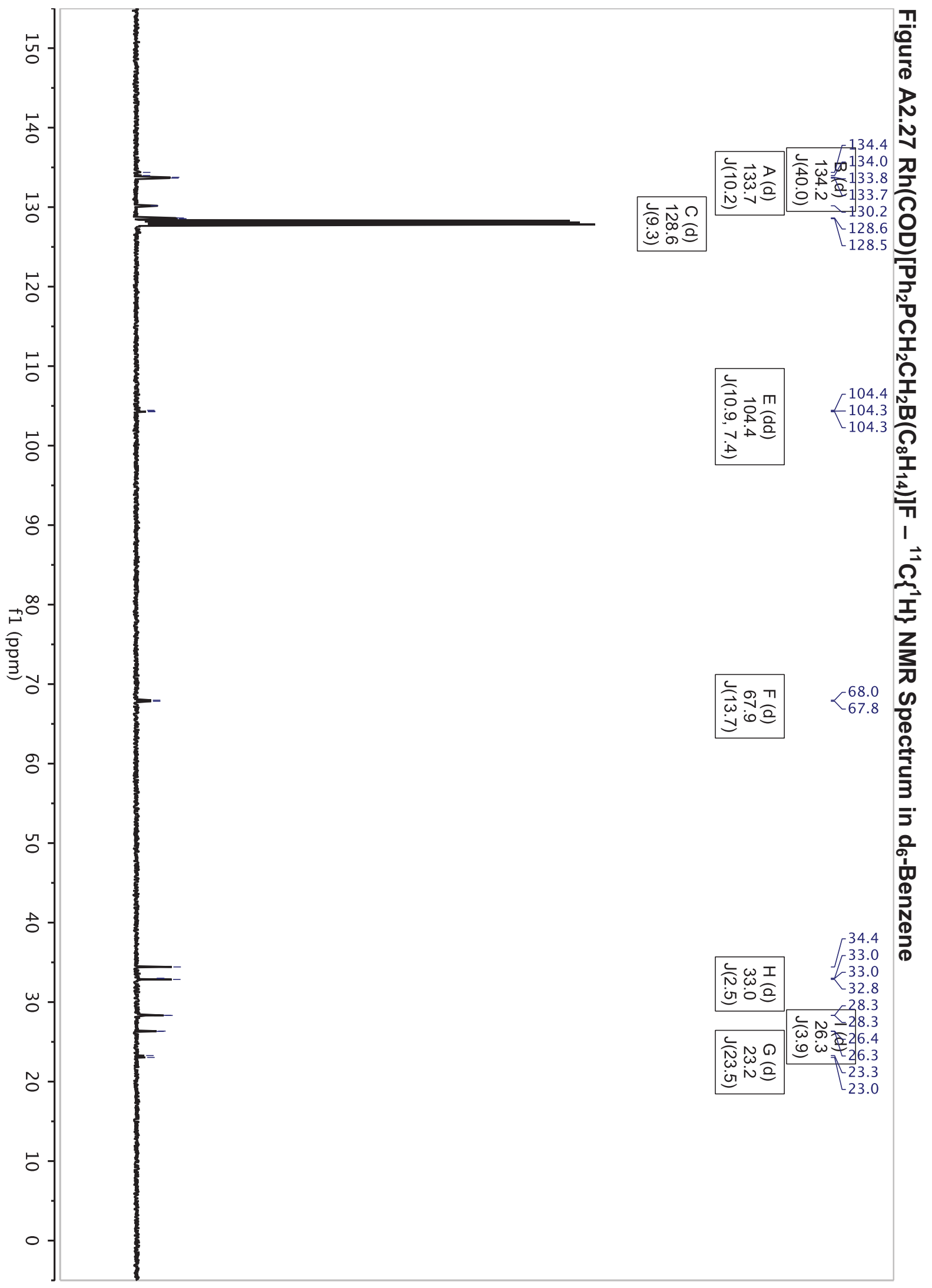




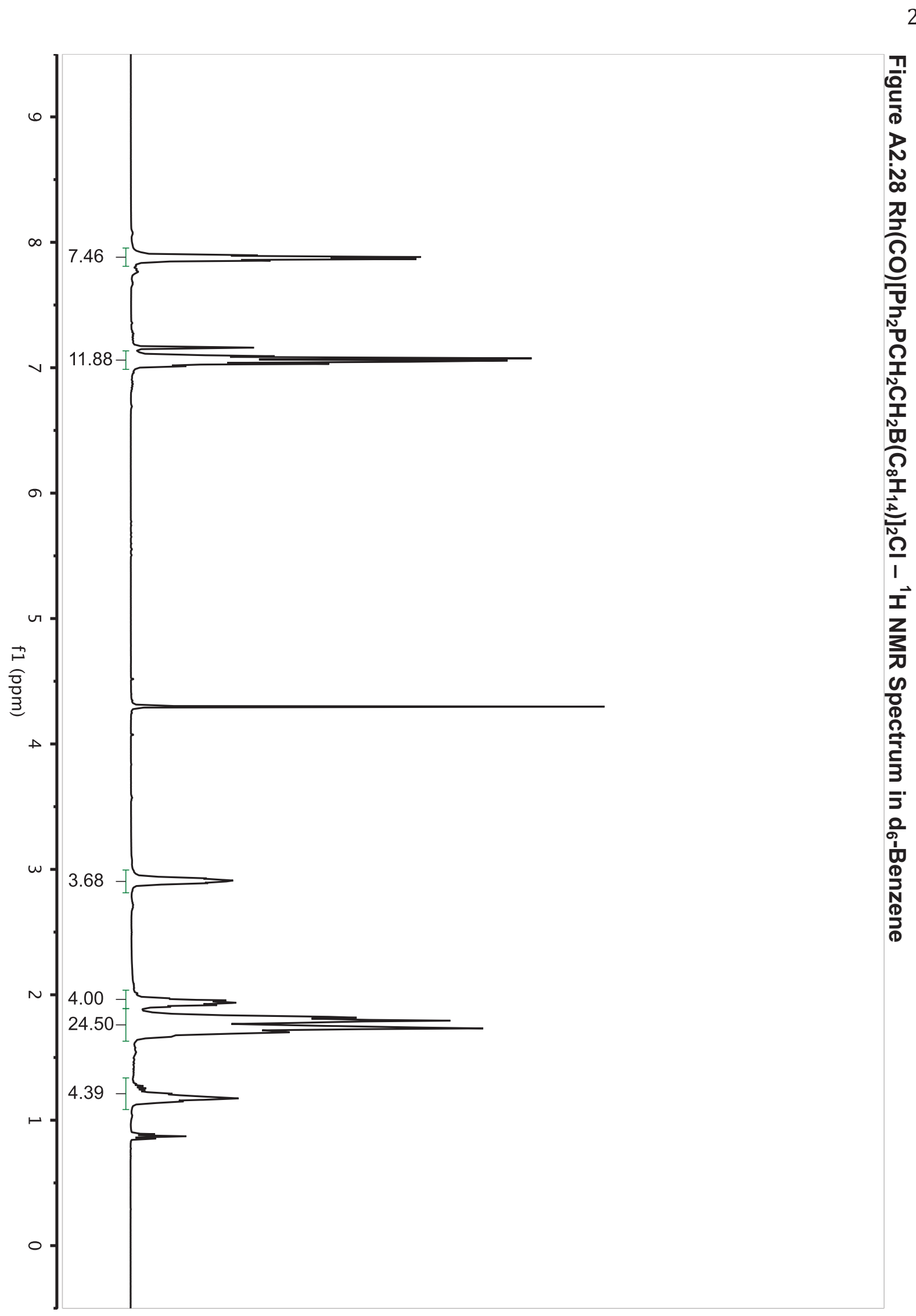




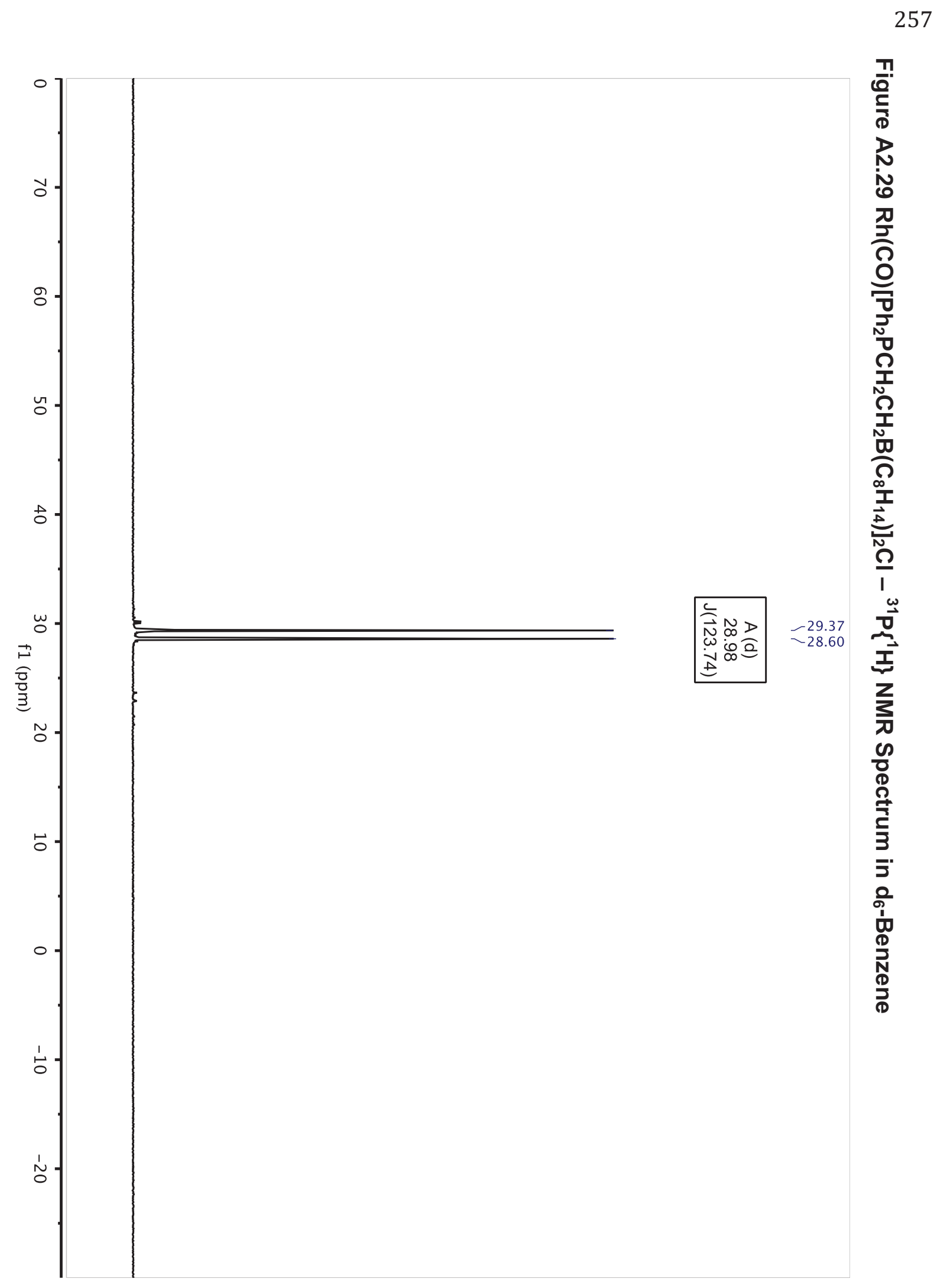




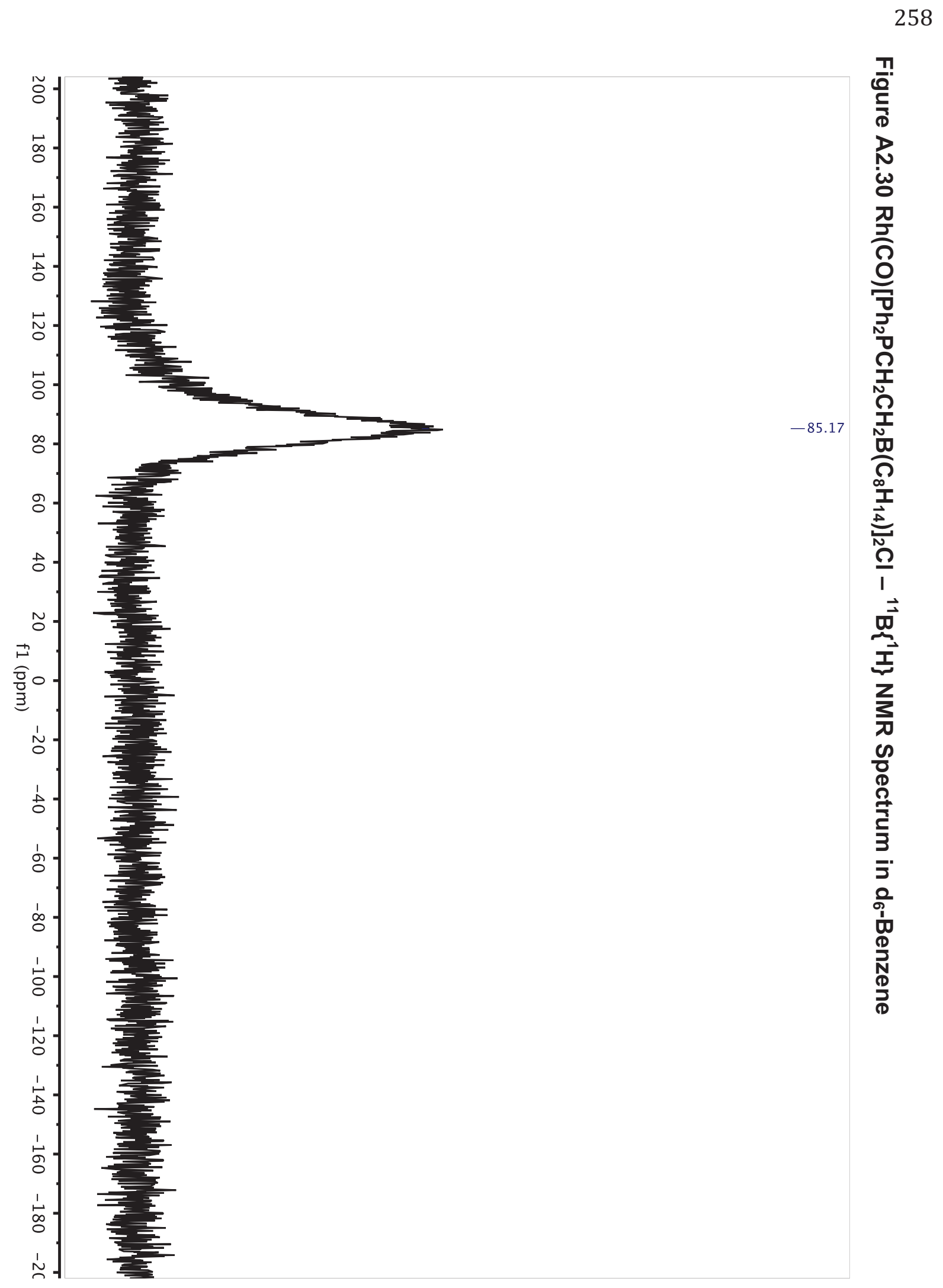




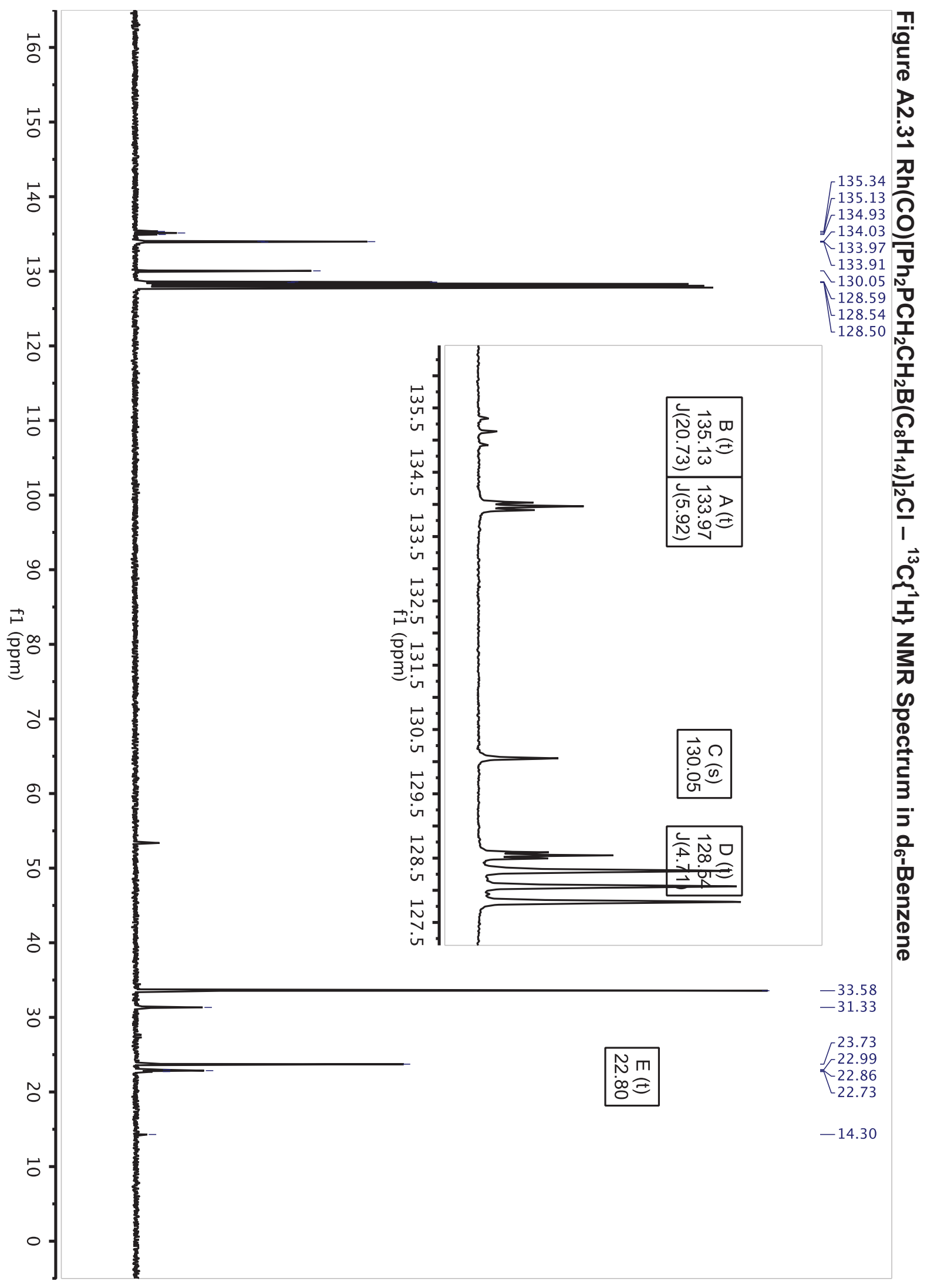




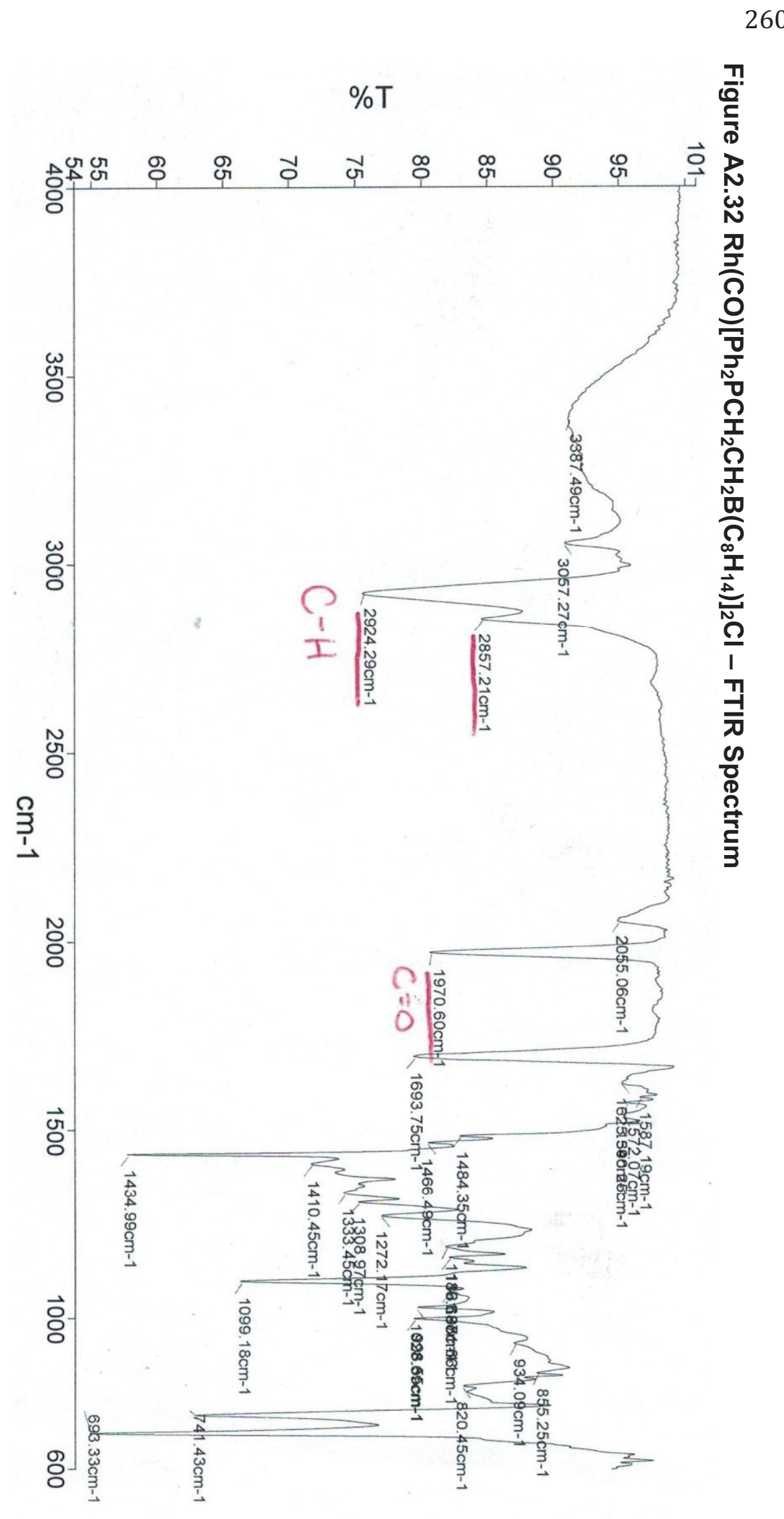




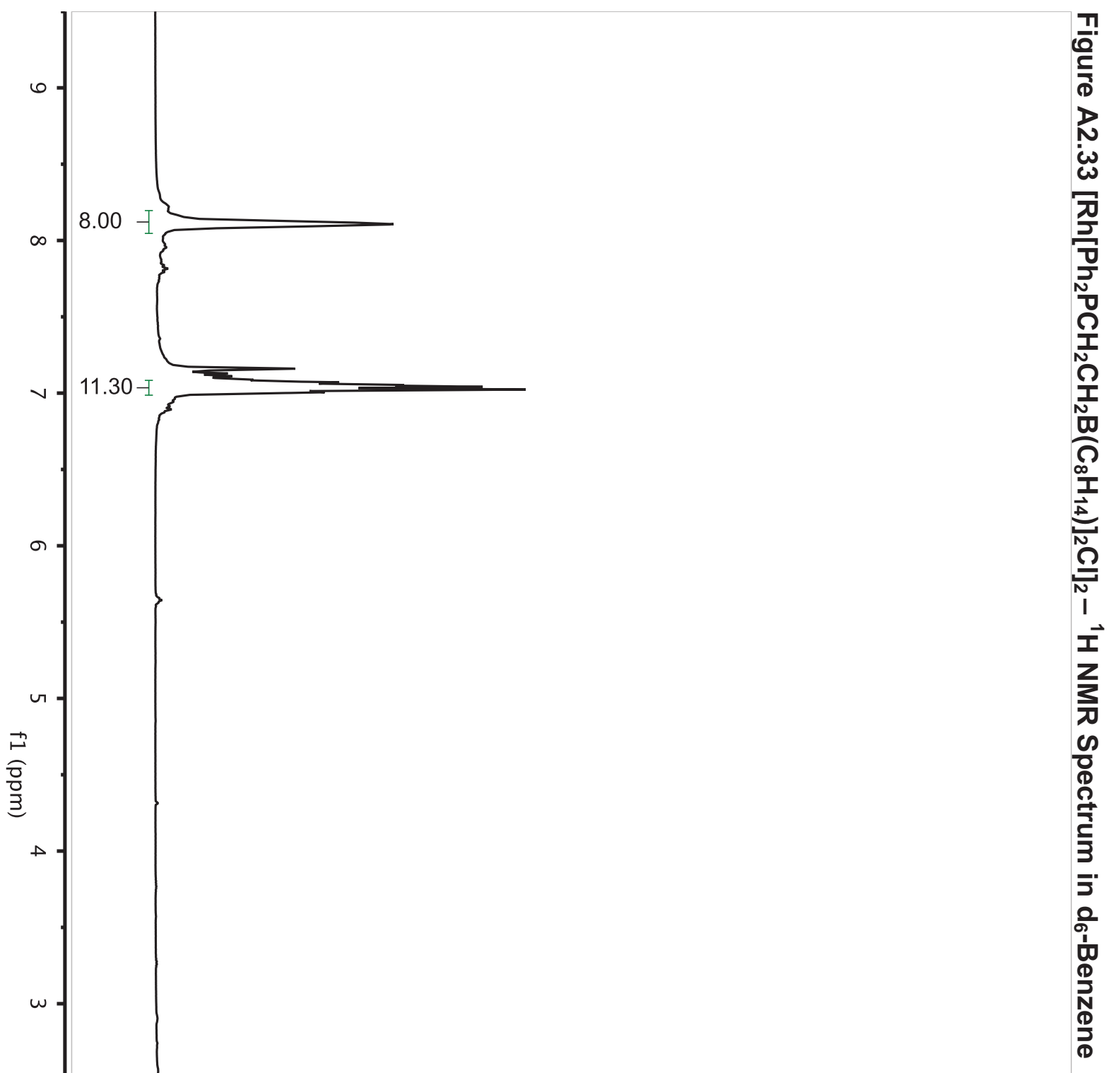




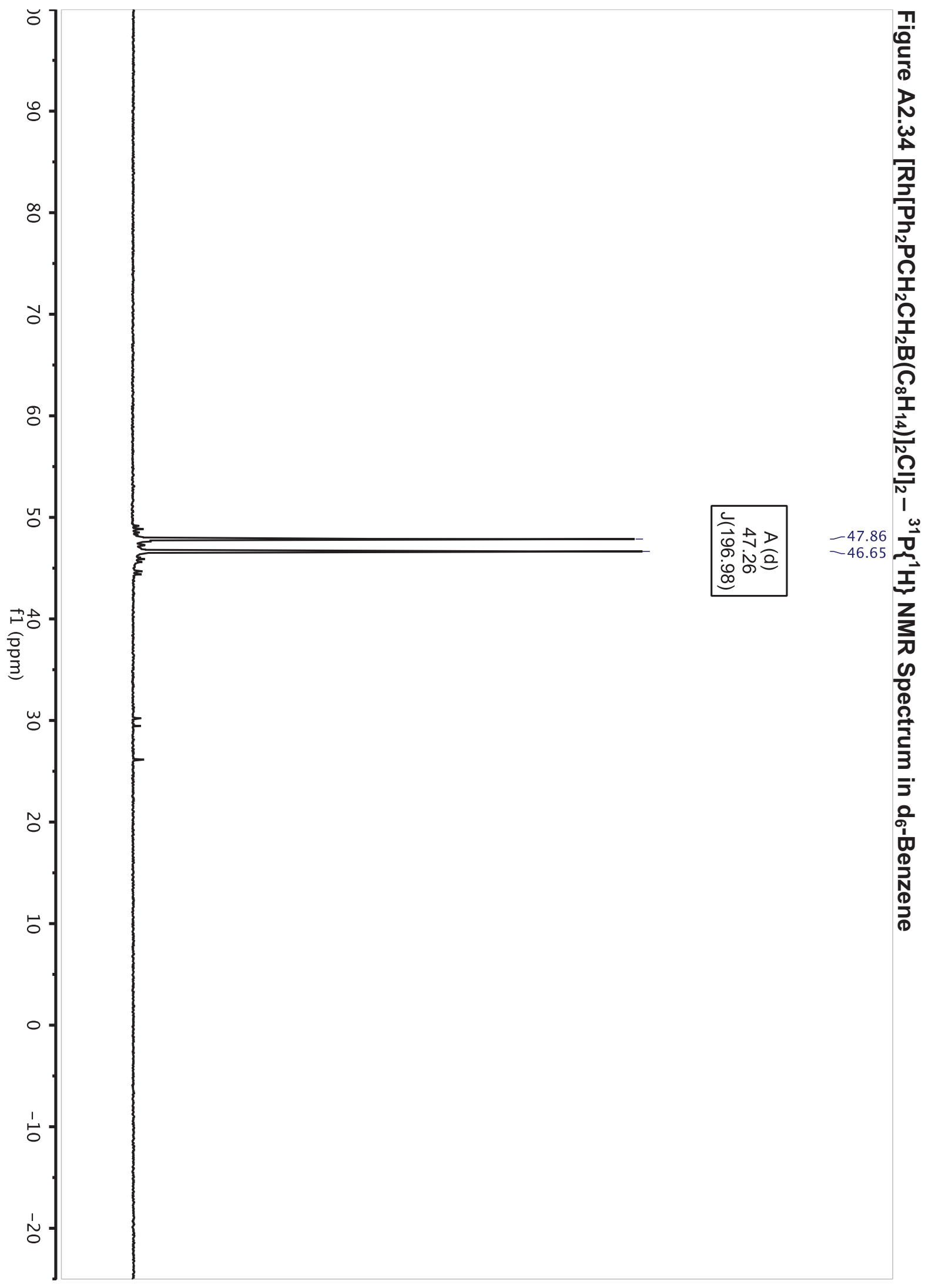




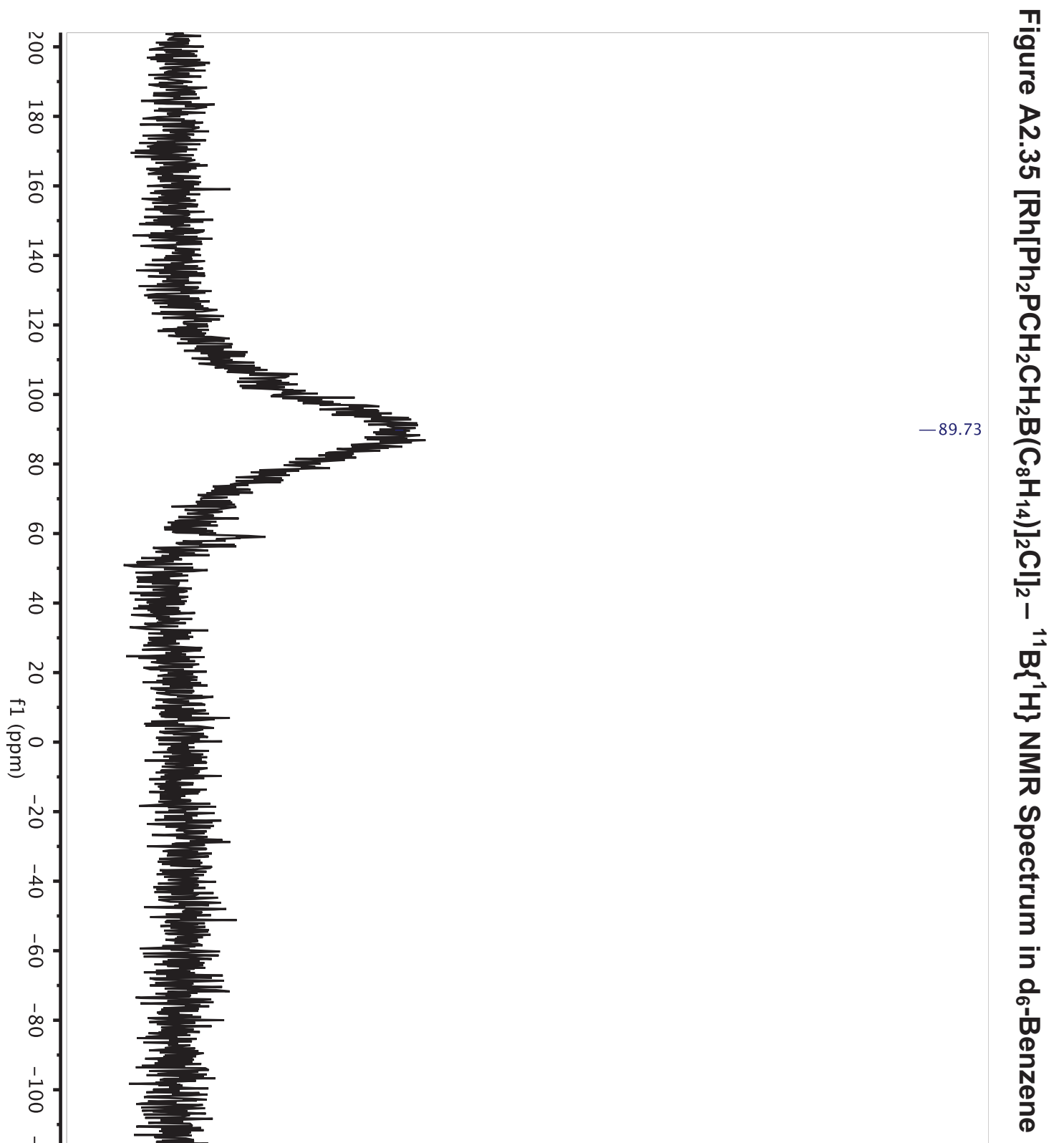




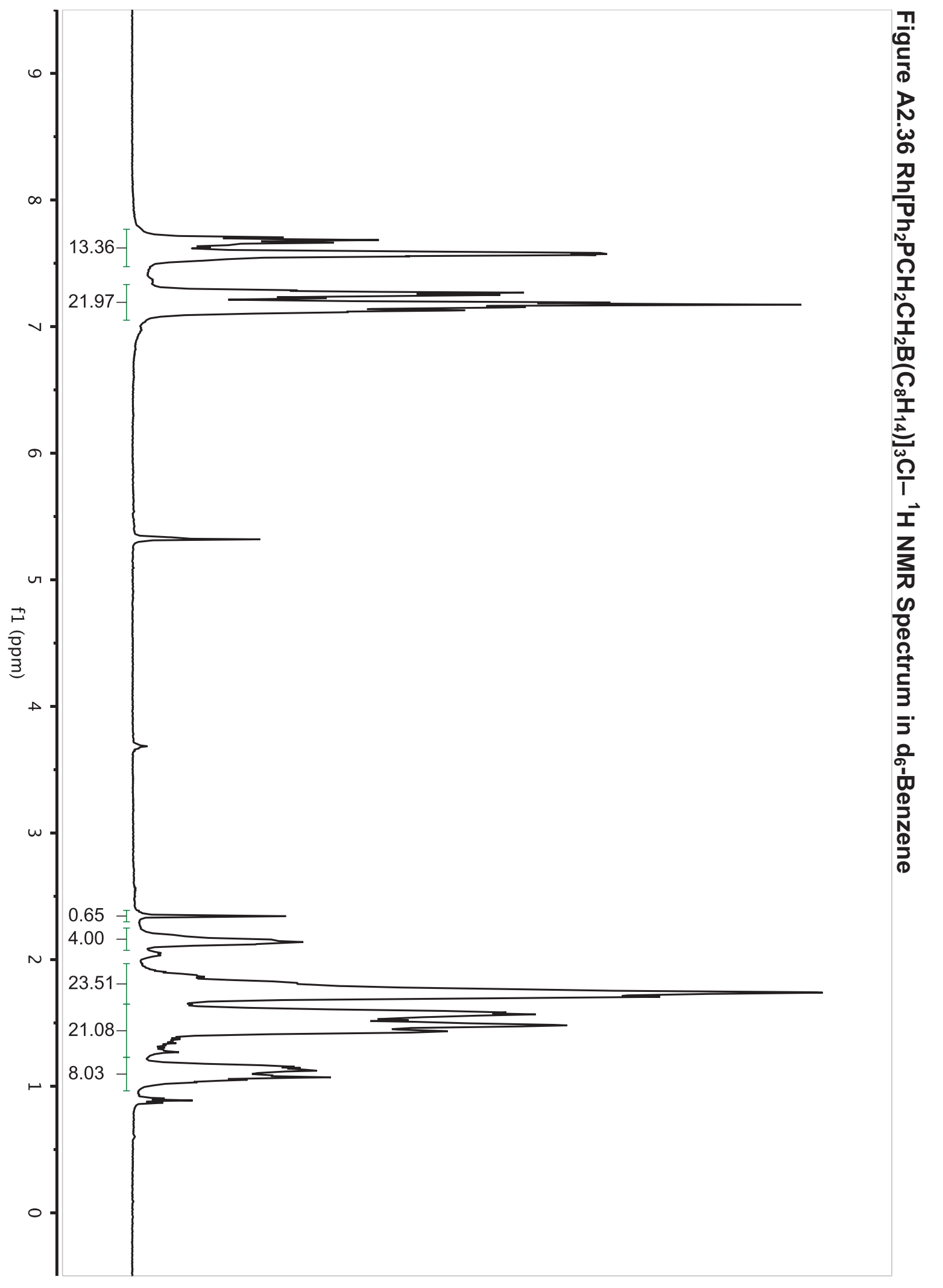




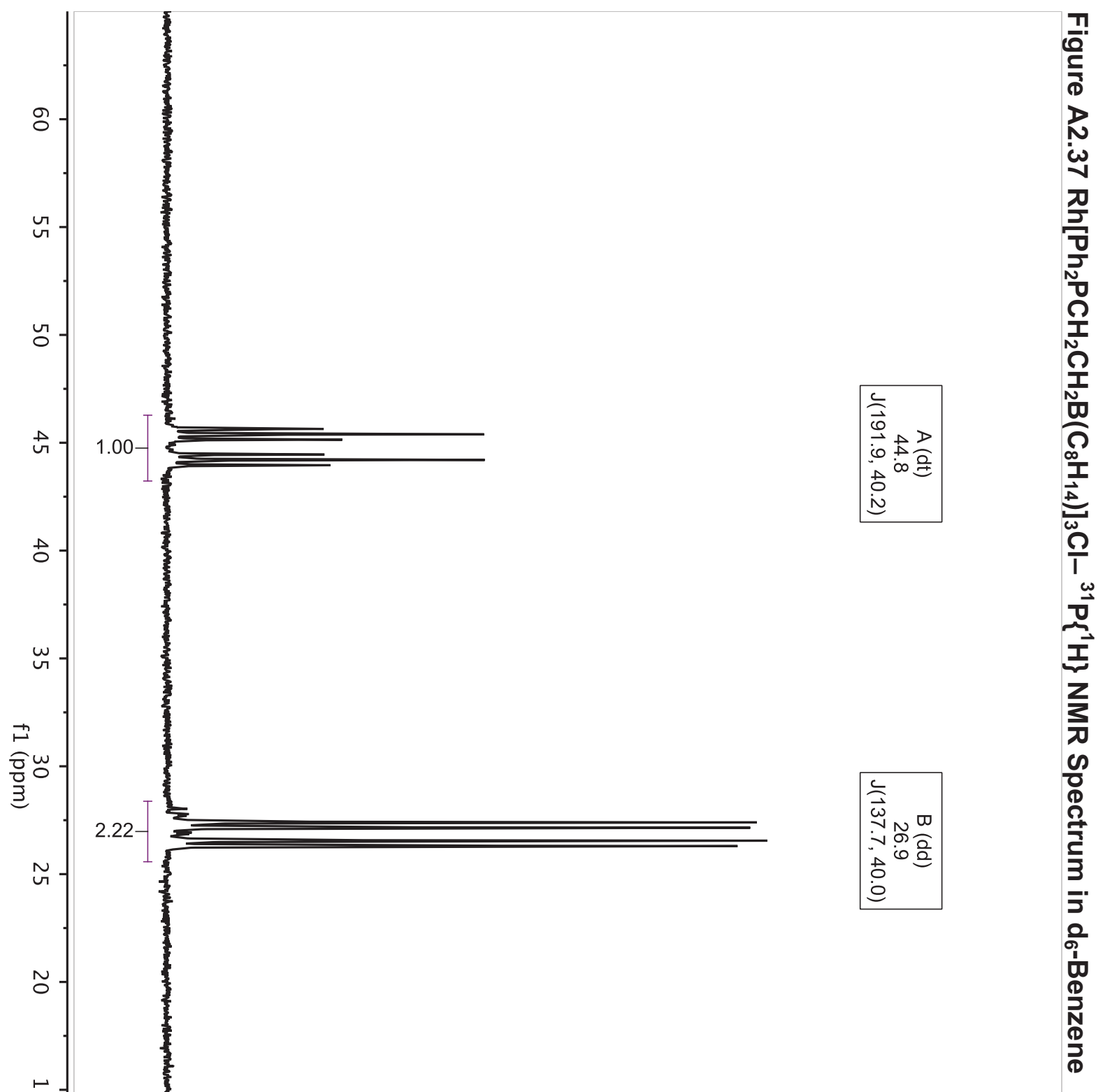




$$
\}
$$




$$
F=
$$




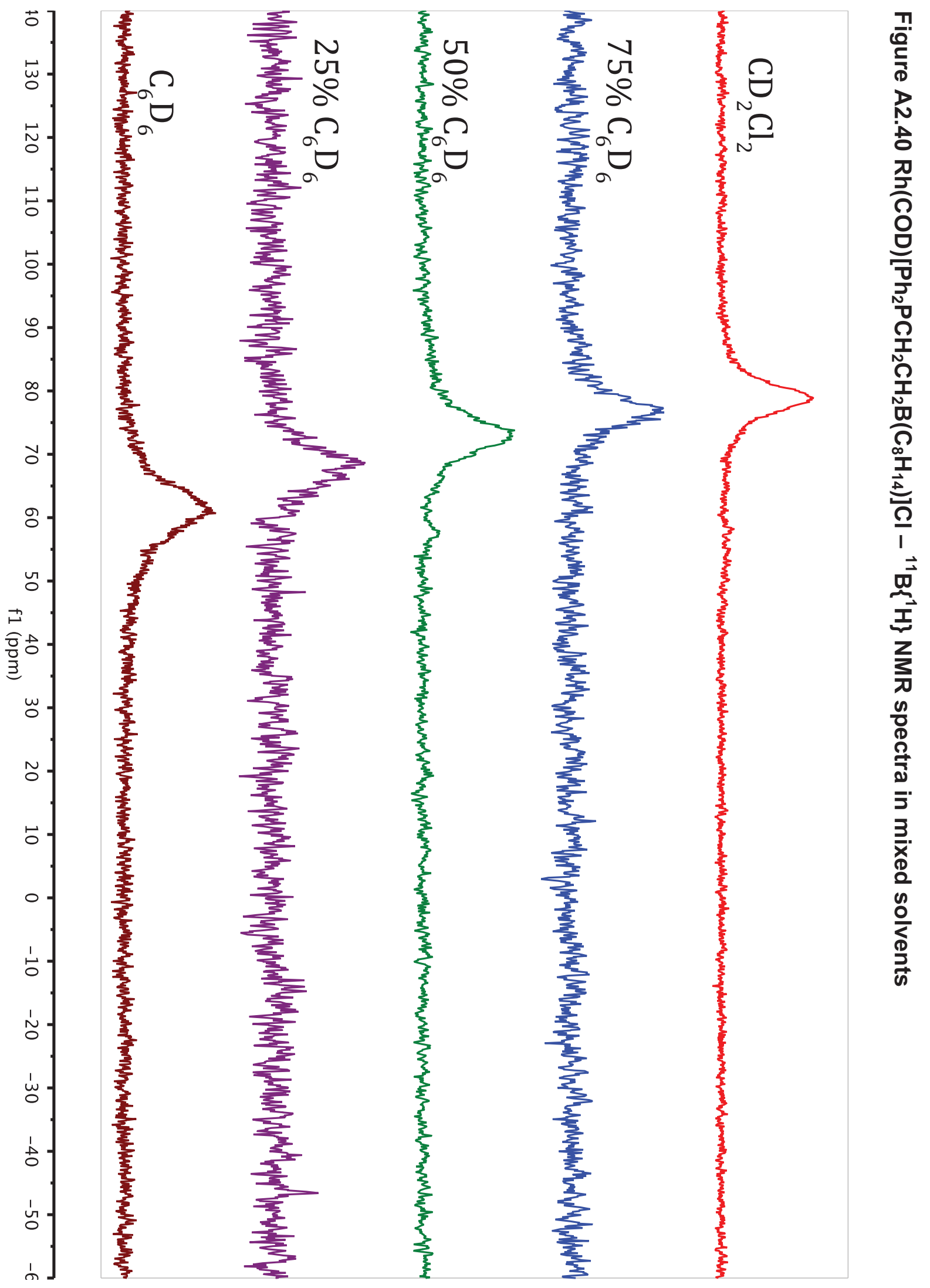




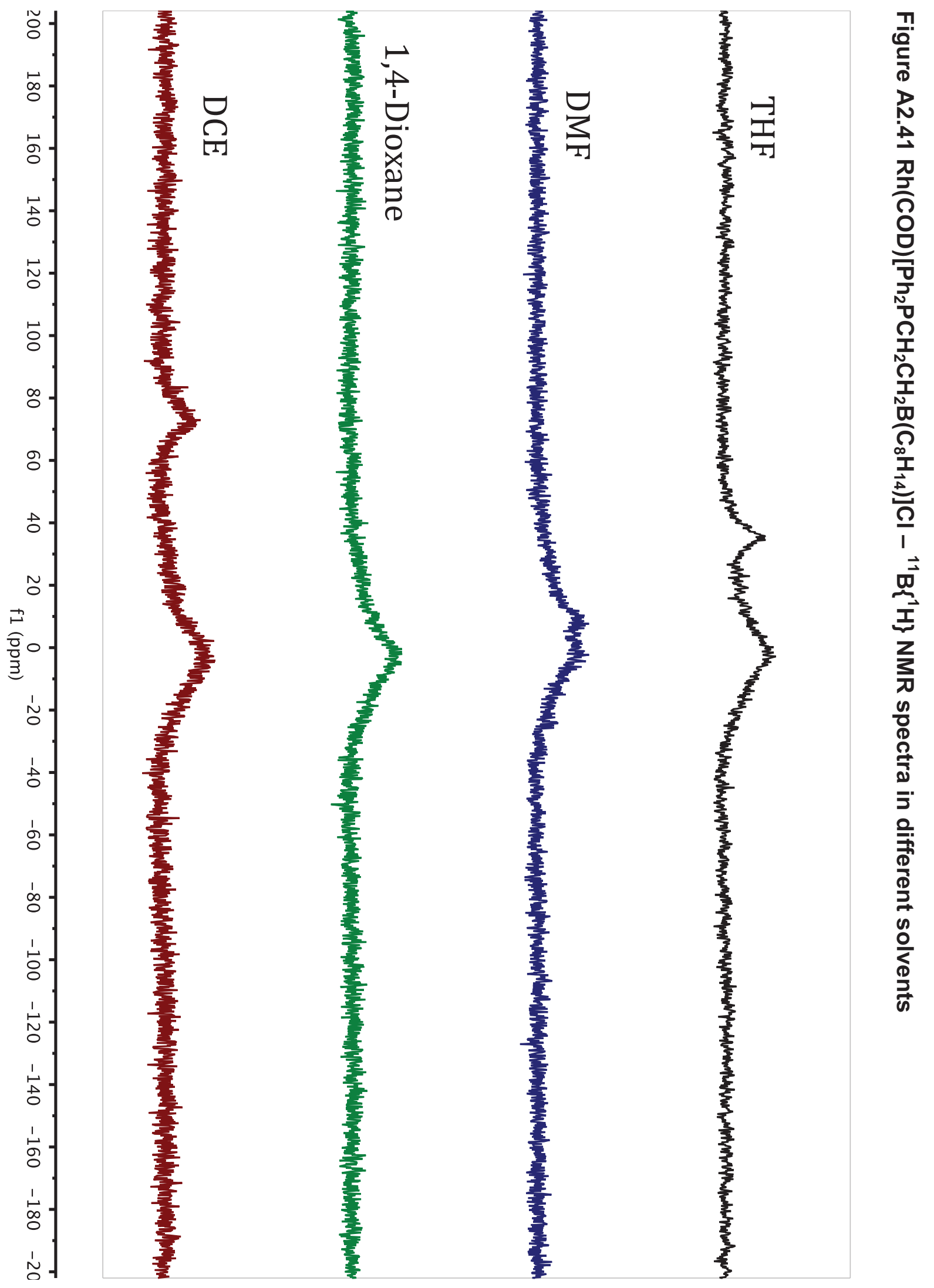


270

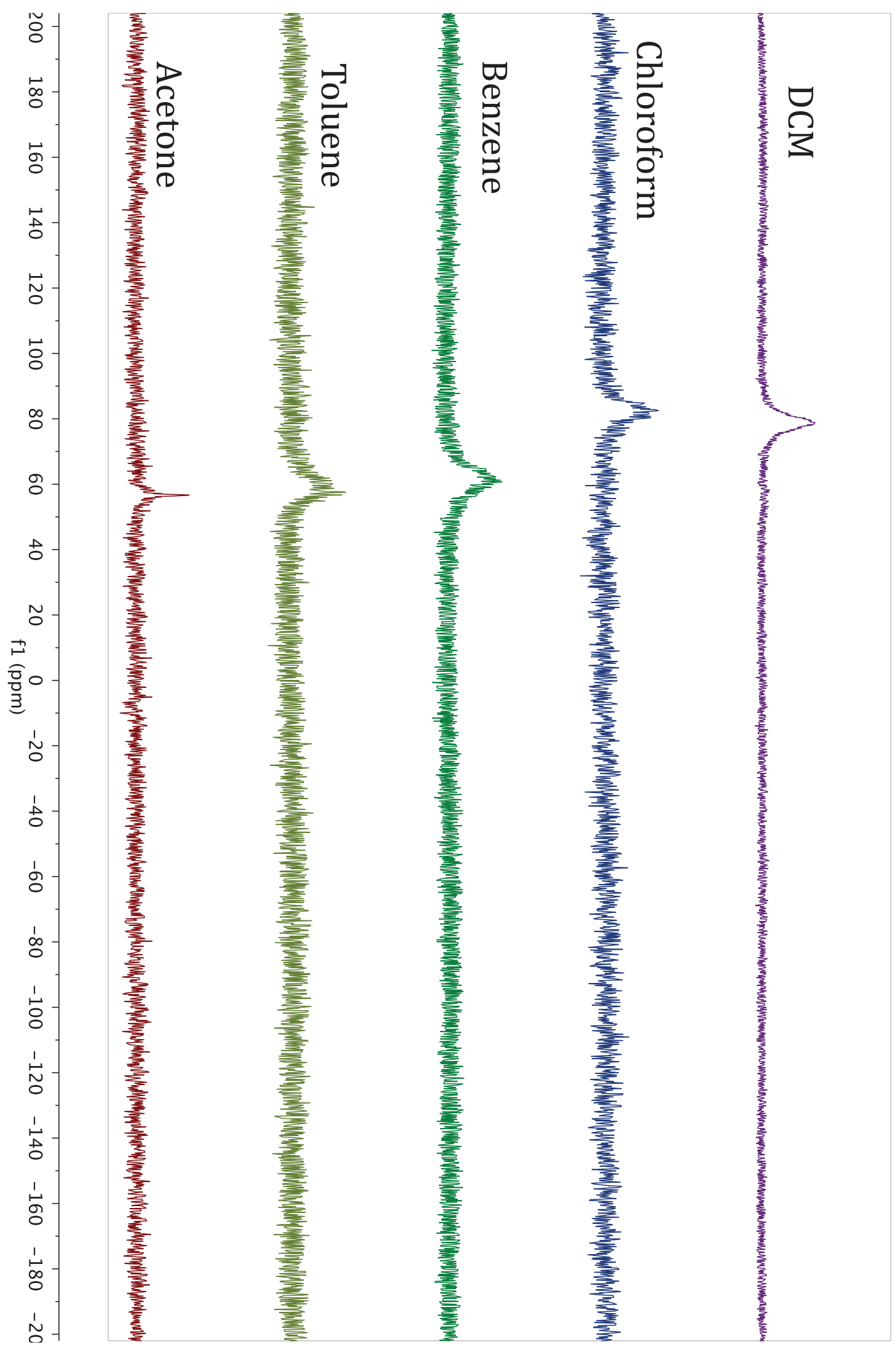




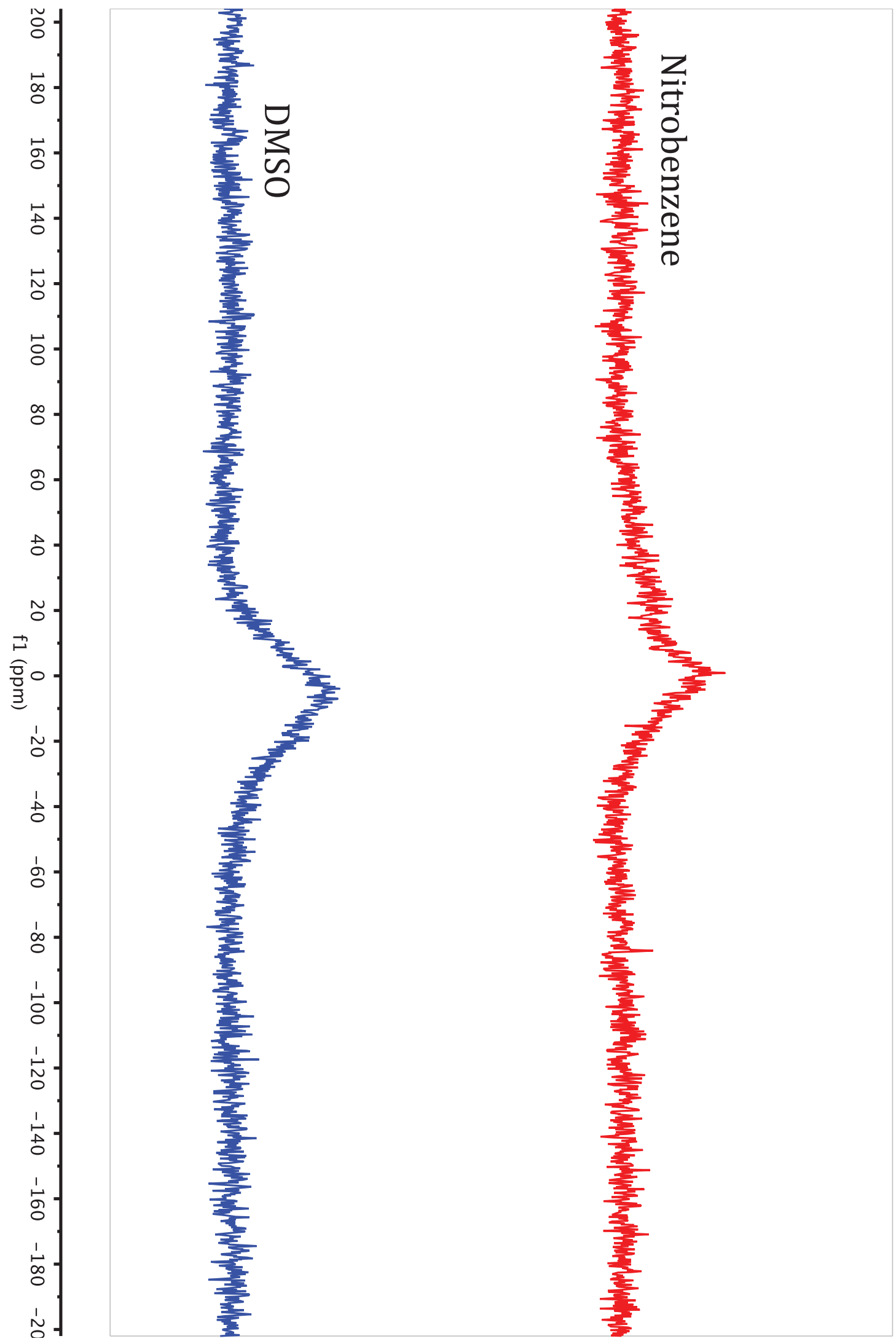




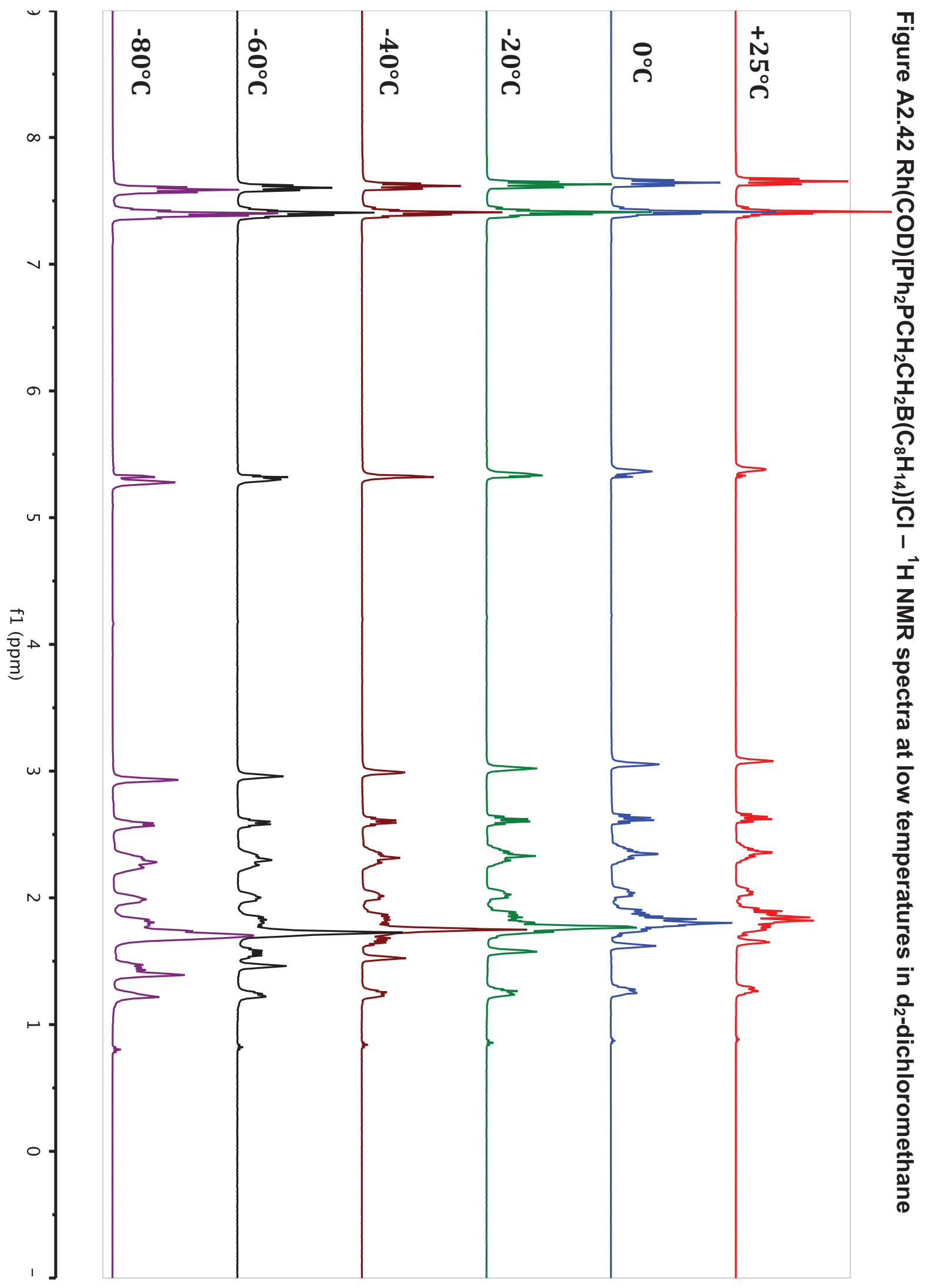




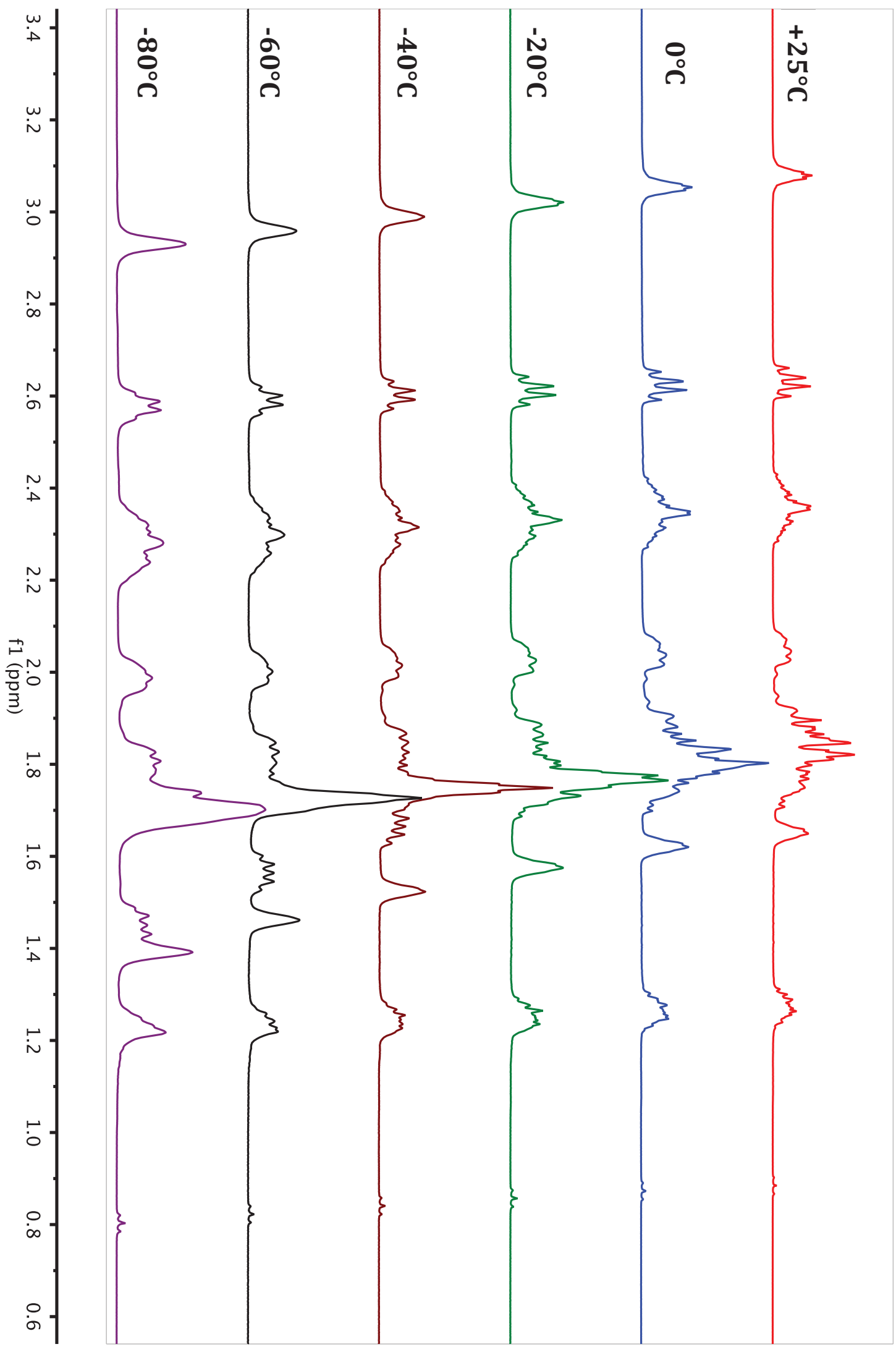




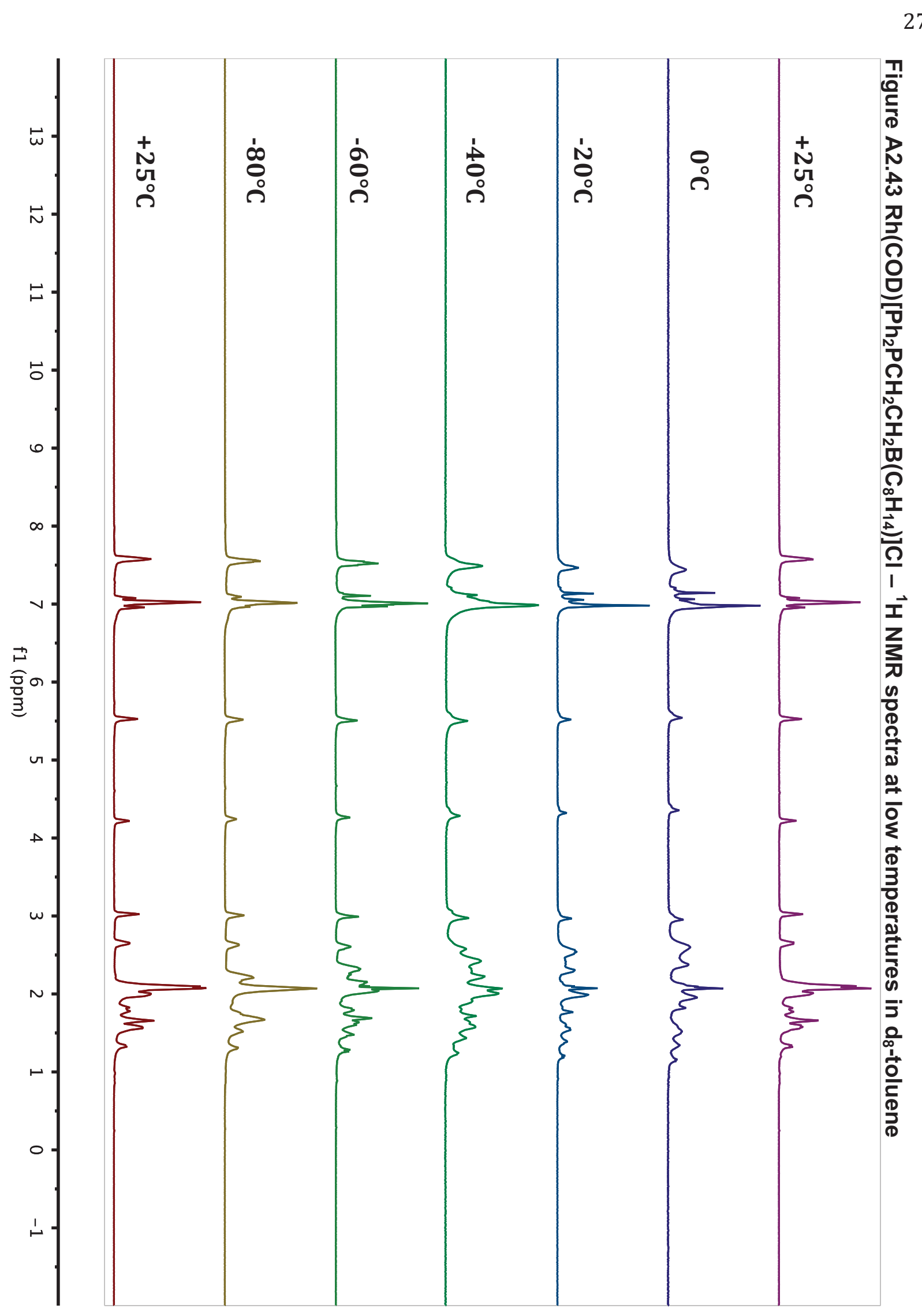




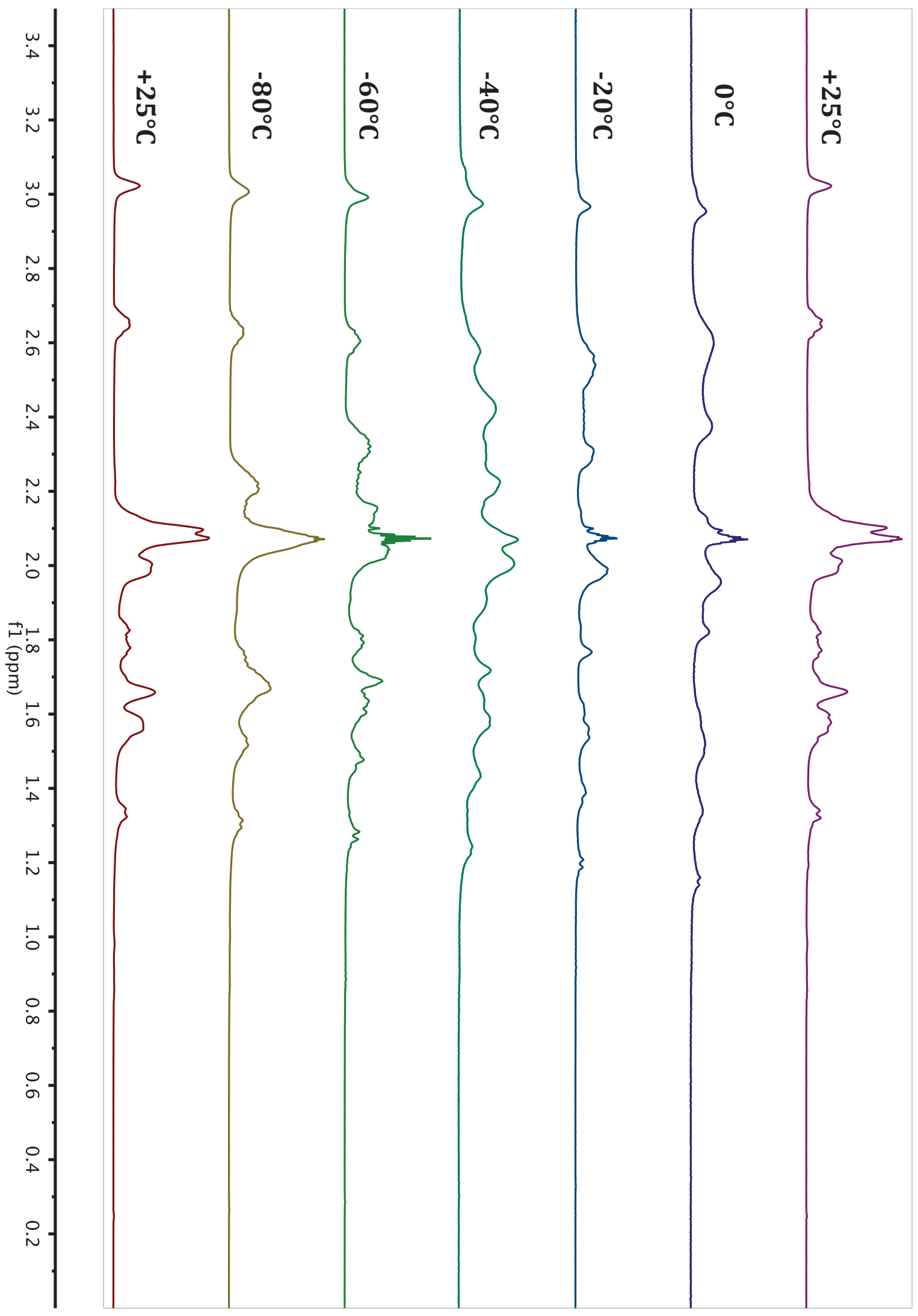




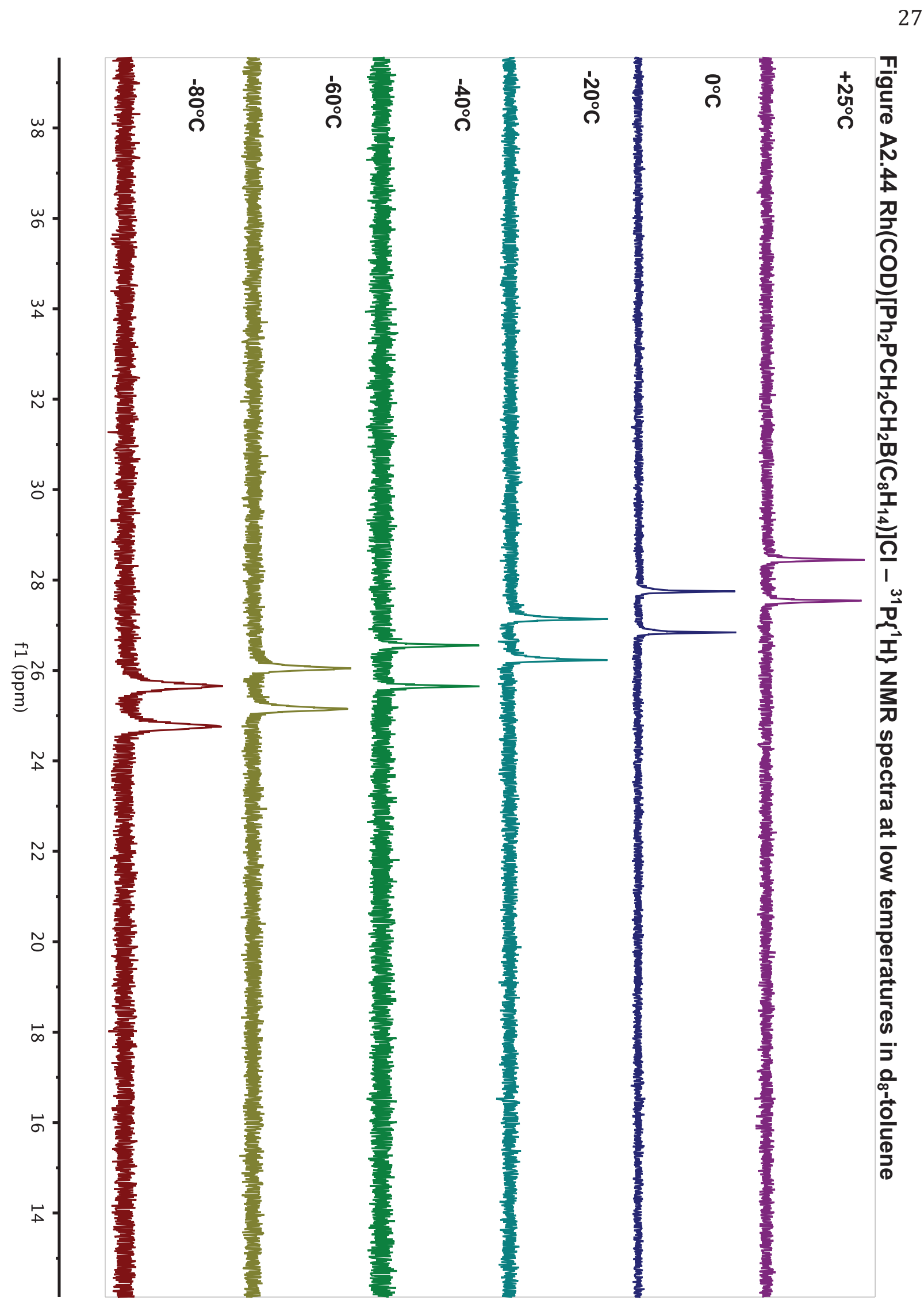




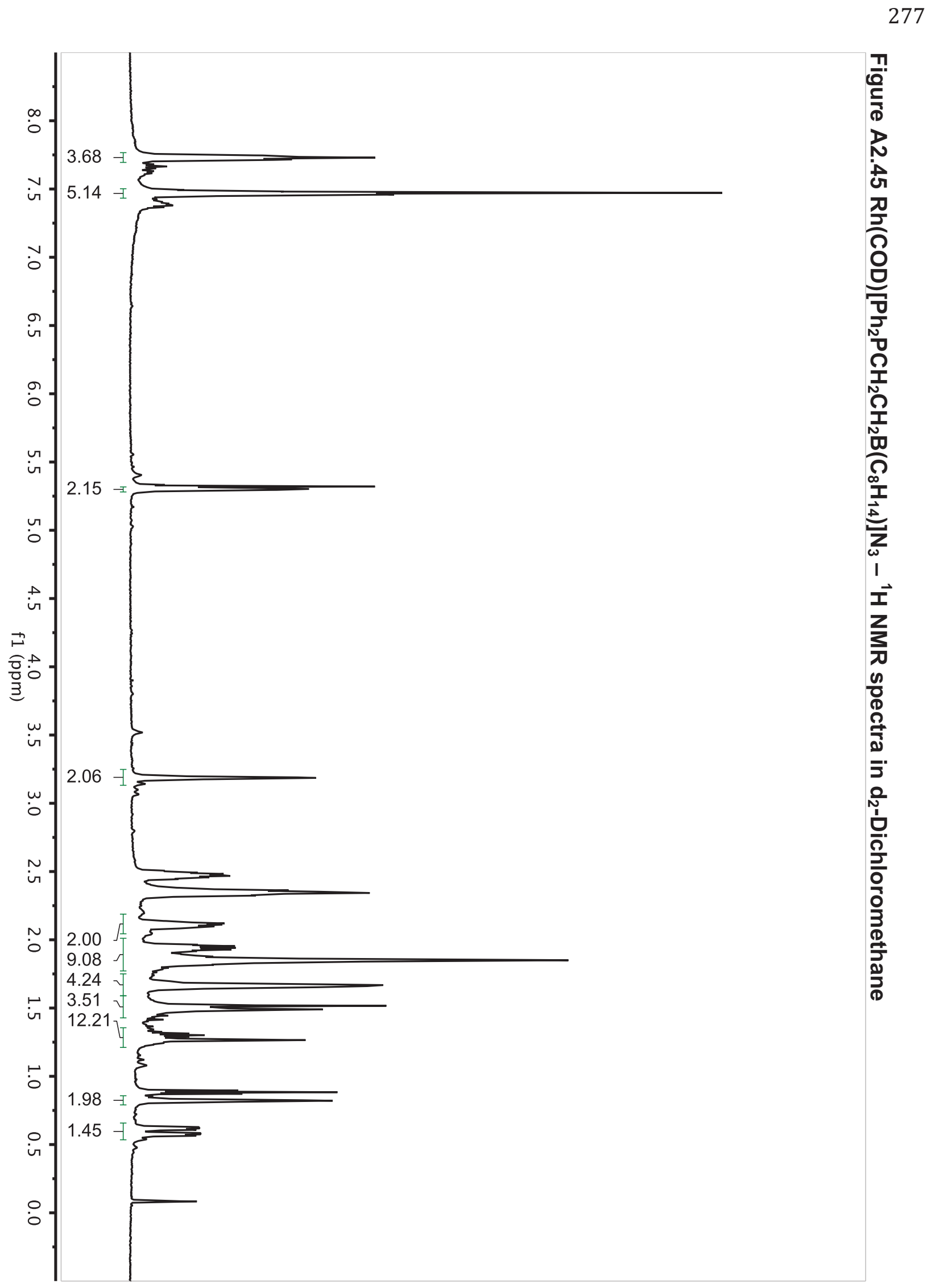



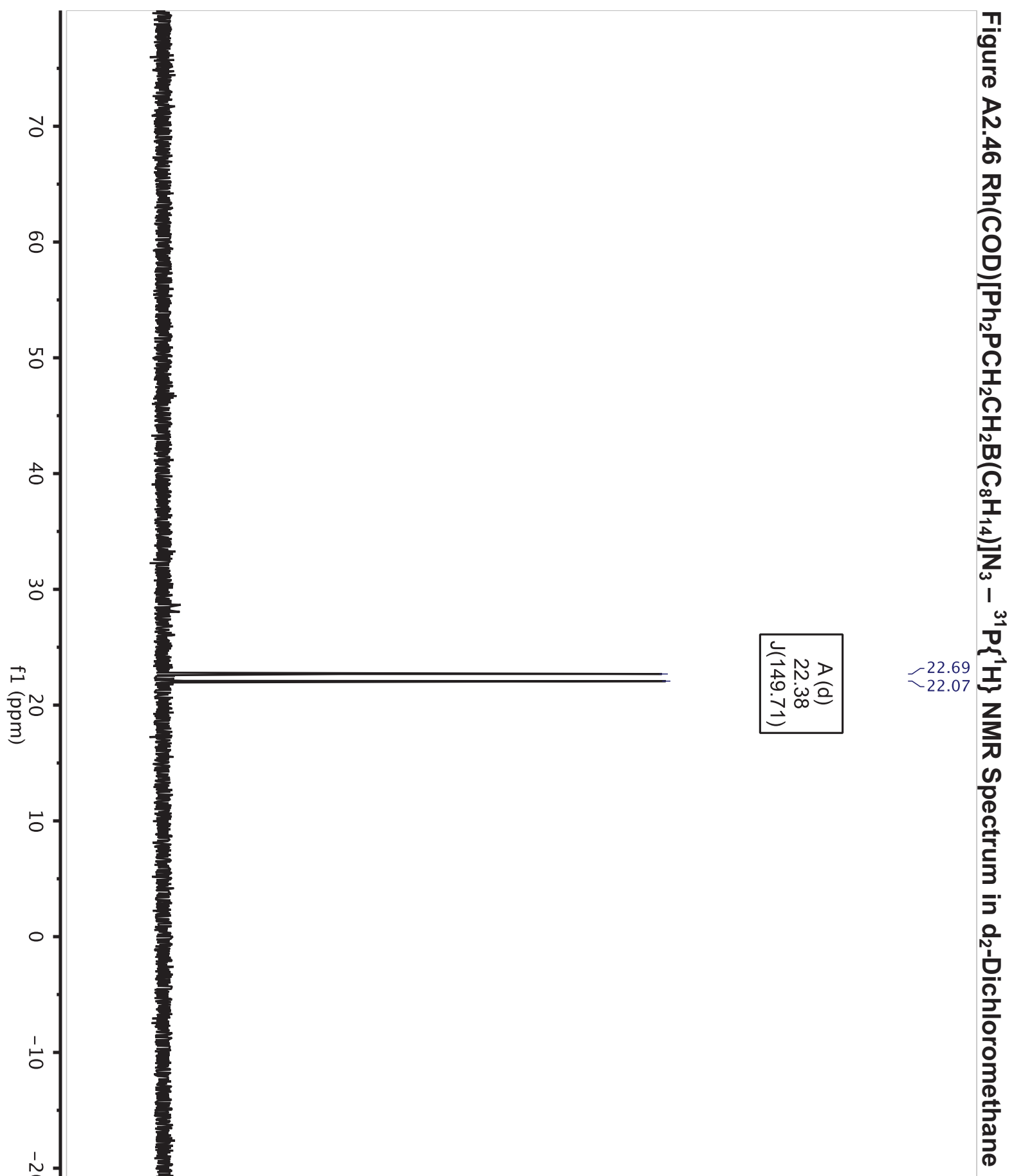


$$
\}
$$




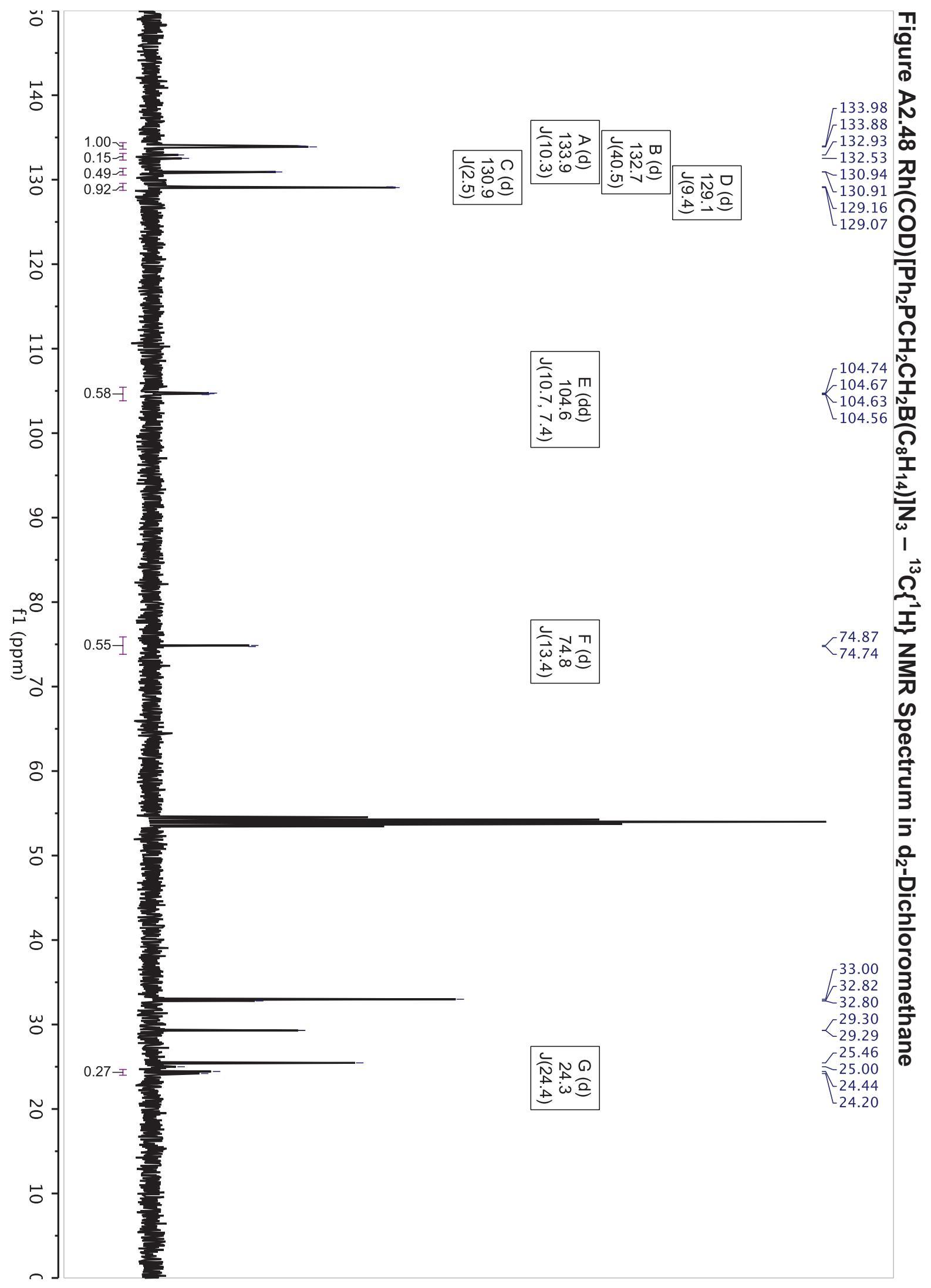




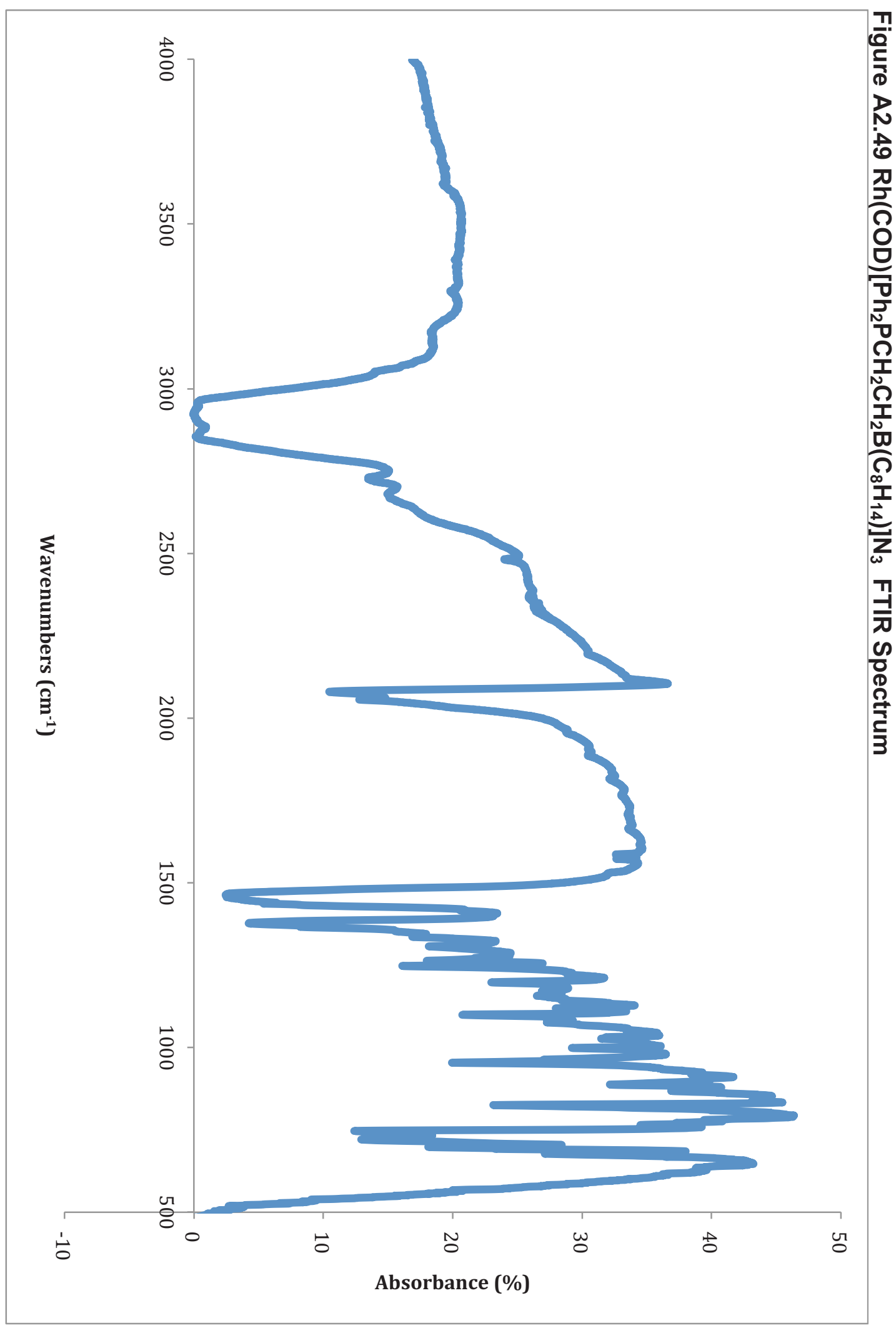




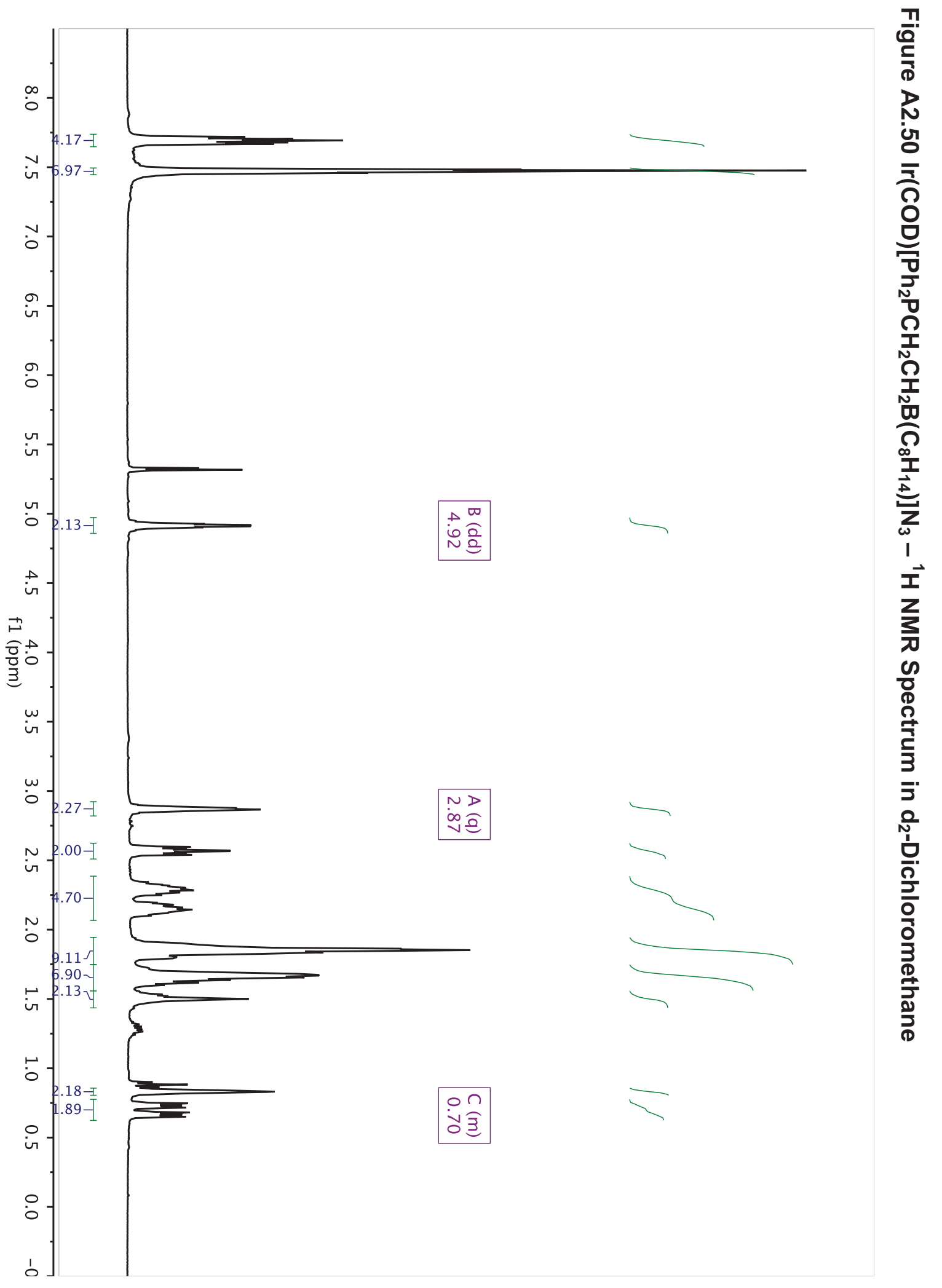




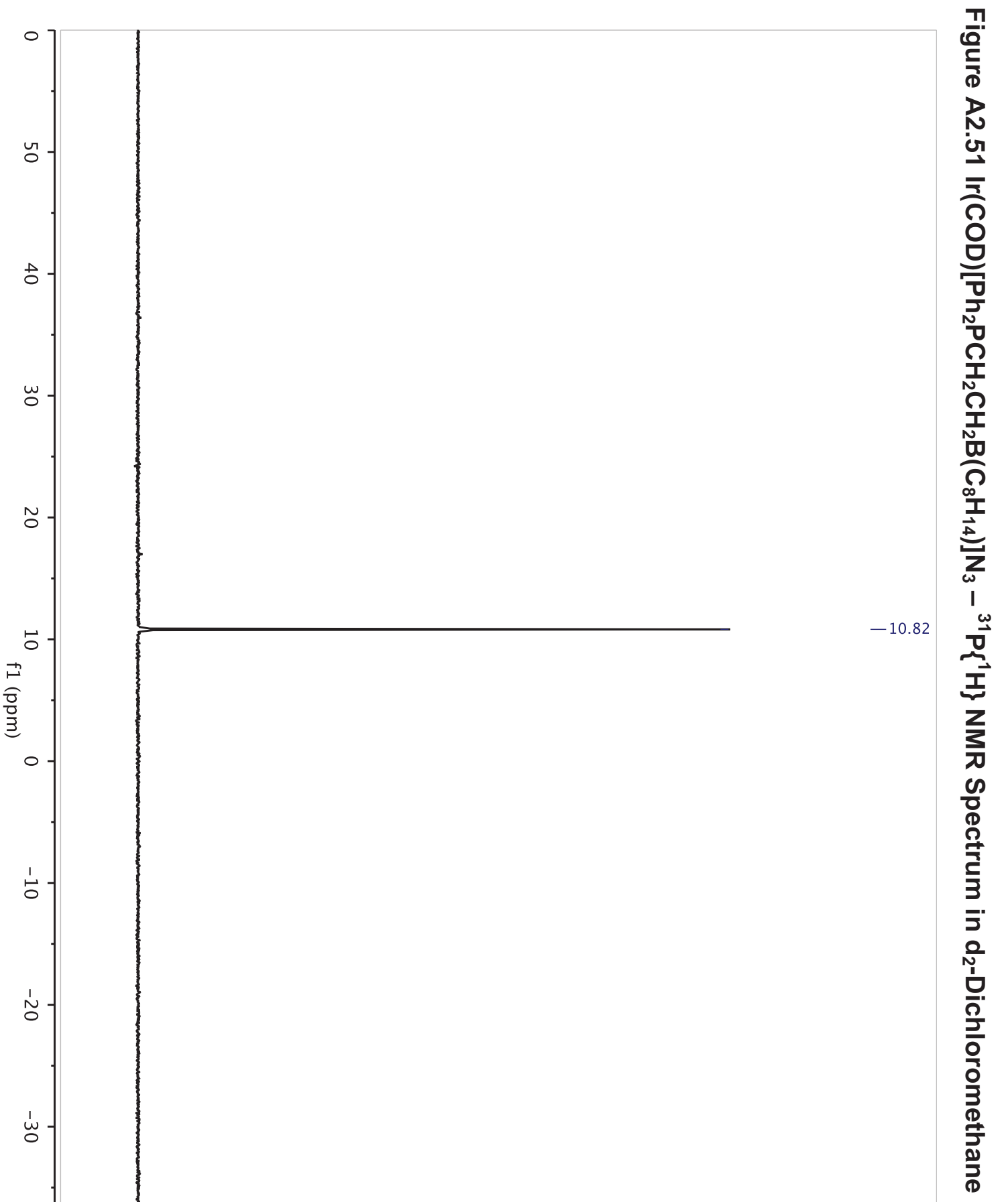




$$
\}
$$




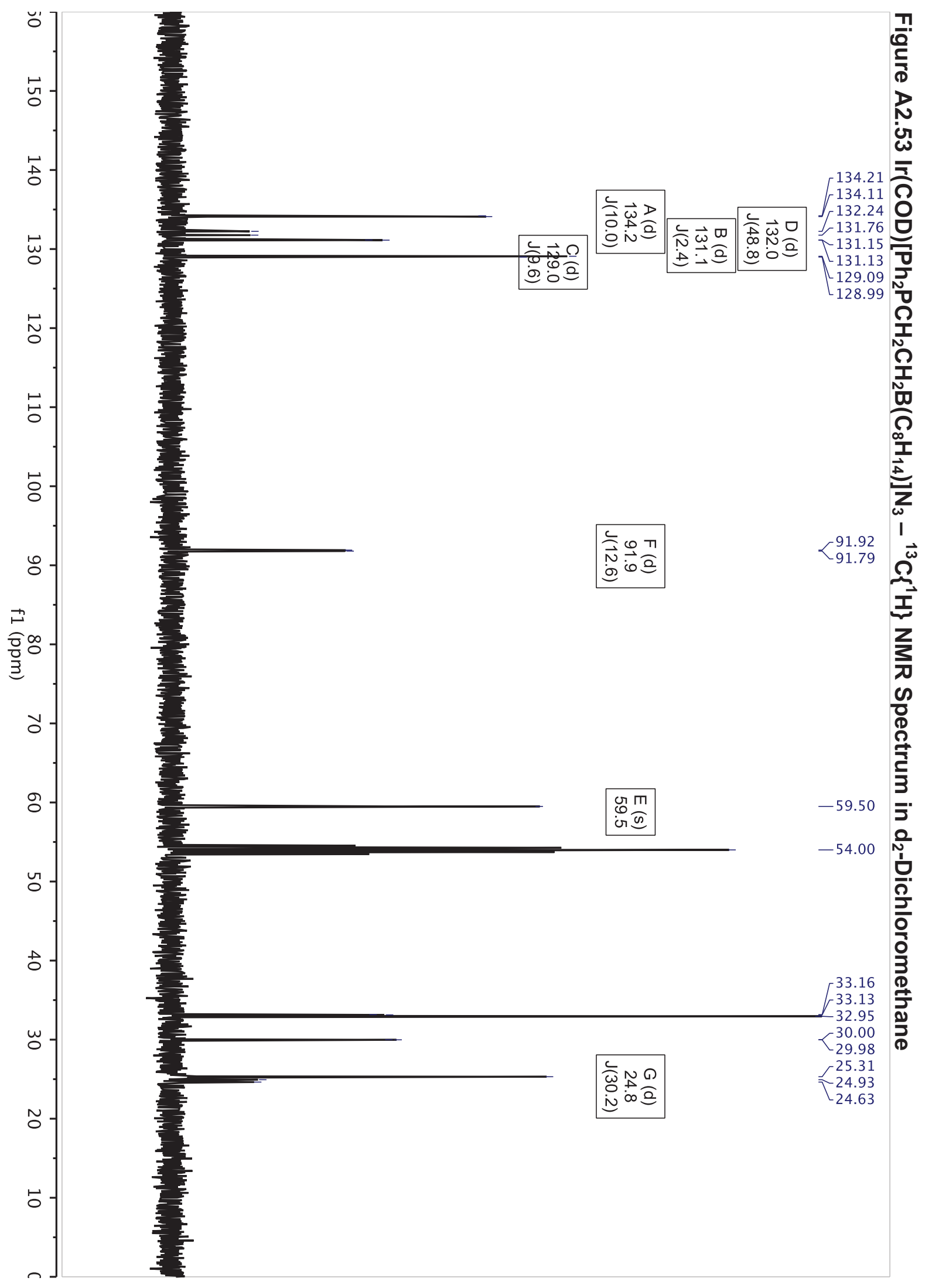




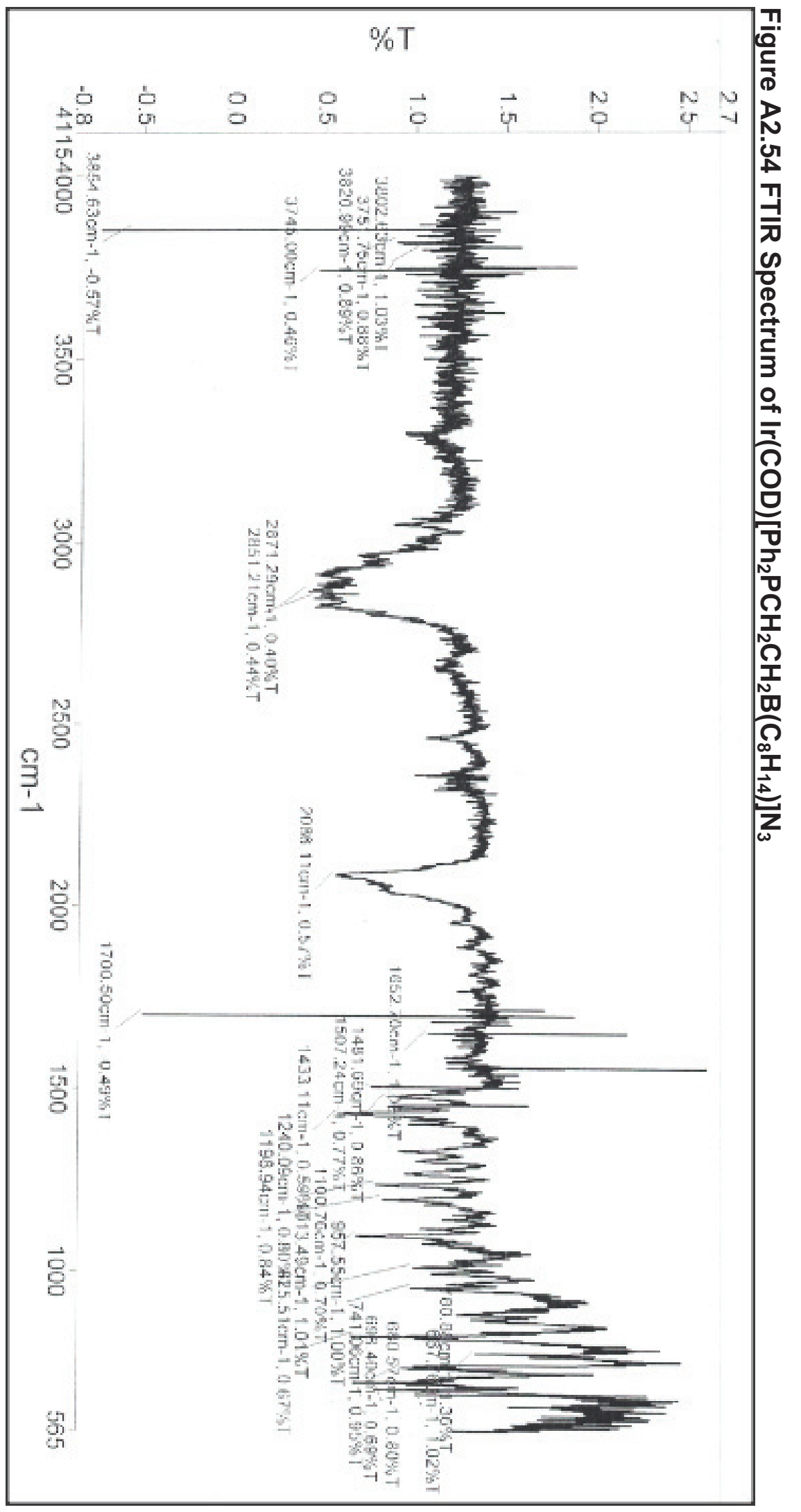


287

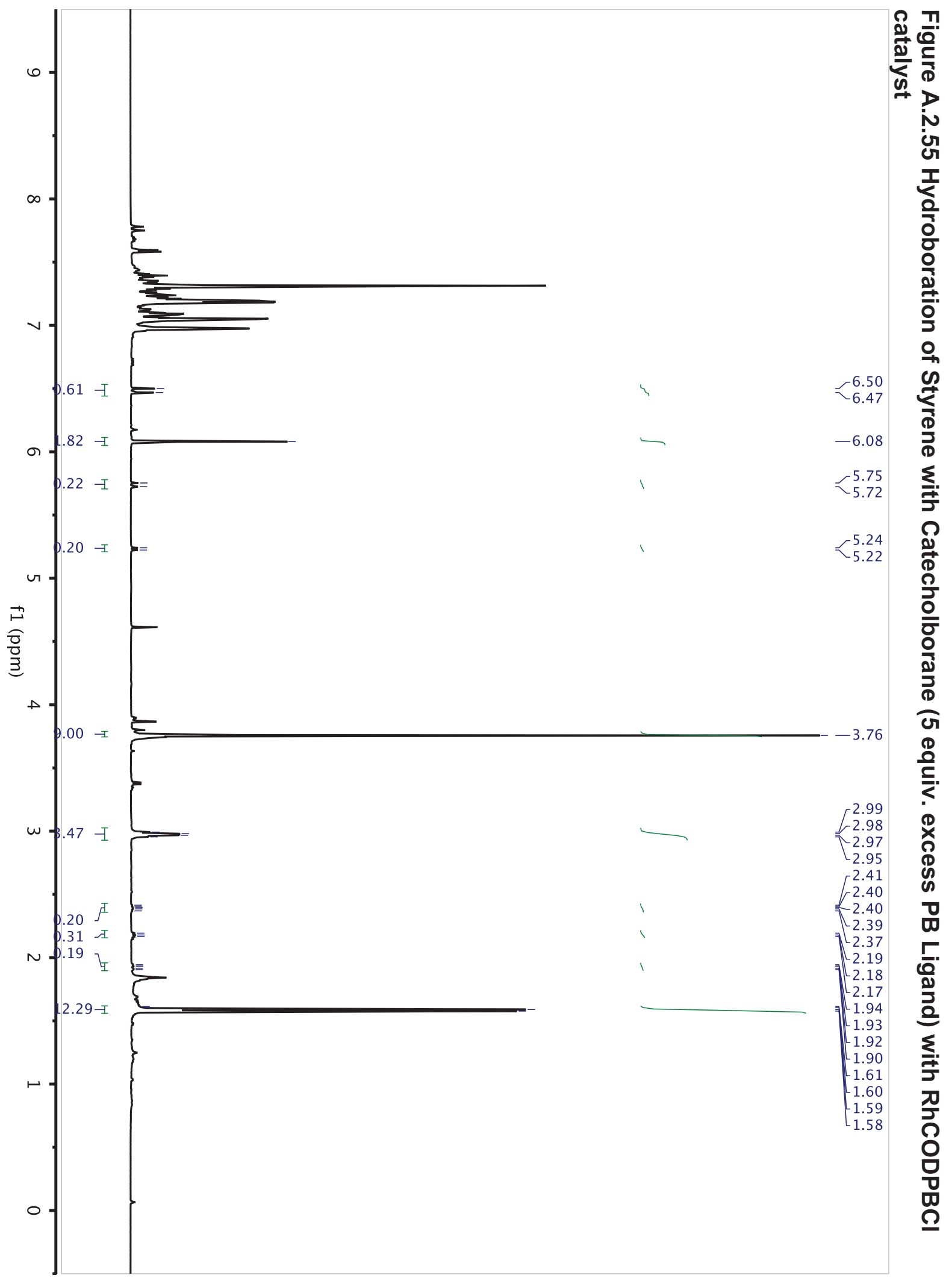




$$
E H
$$



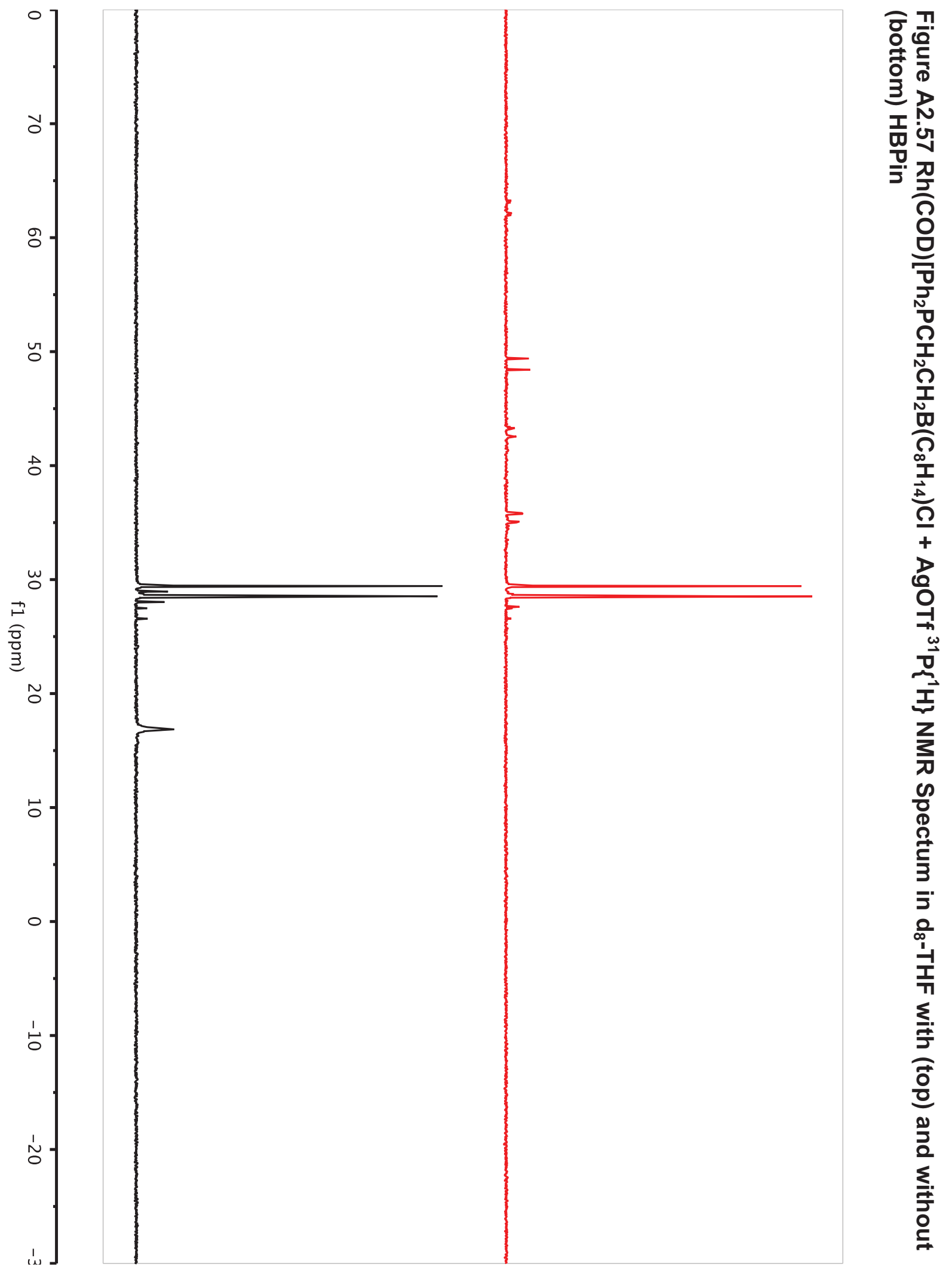


$$
\mid
$$




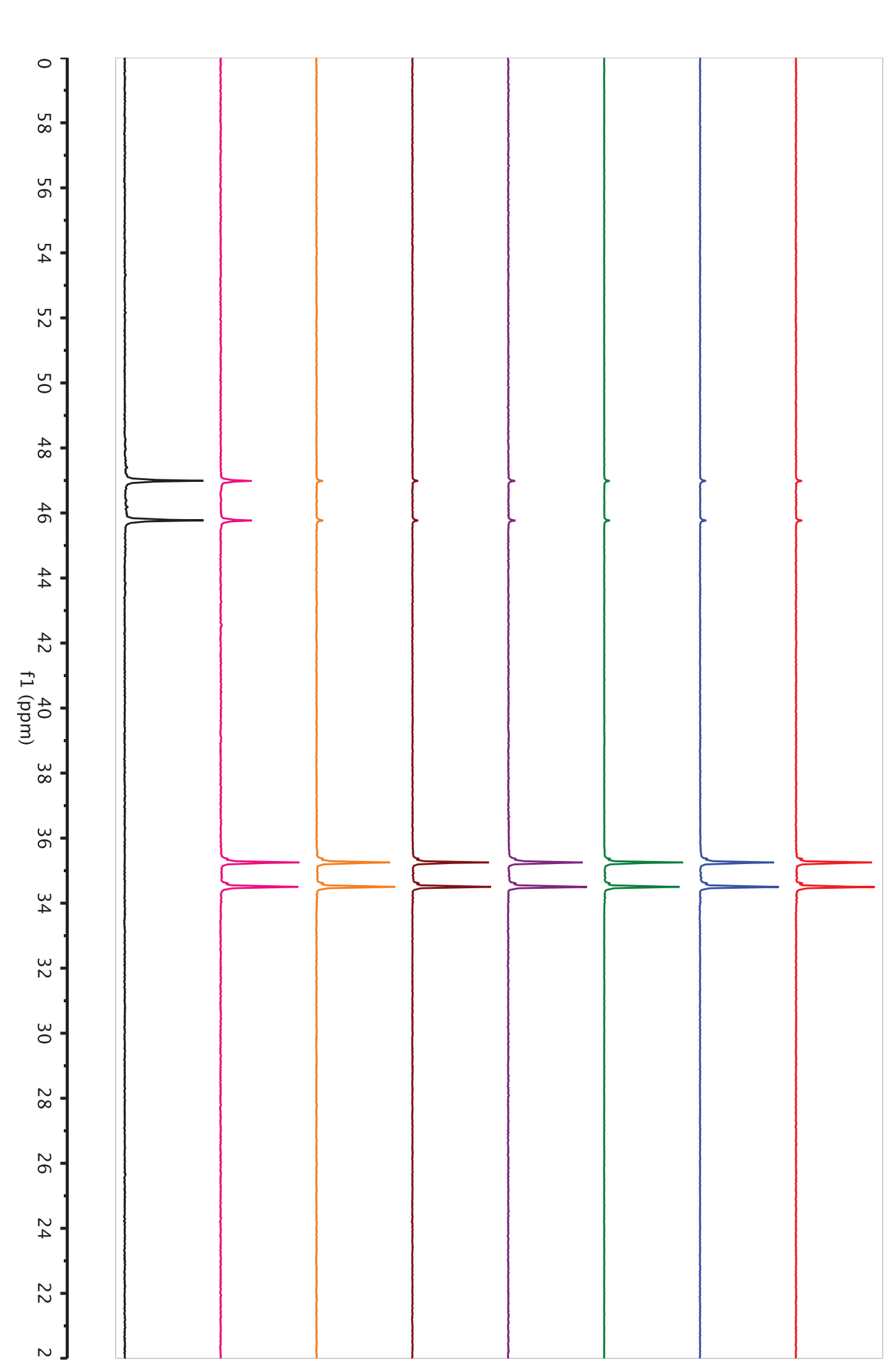

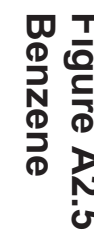

نु

궁

ถุ่

ํㅗㄱ

옥

지

문

N

온

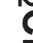

范

م

I

蒙

N

D

올

$\leqslant$

291 


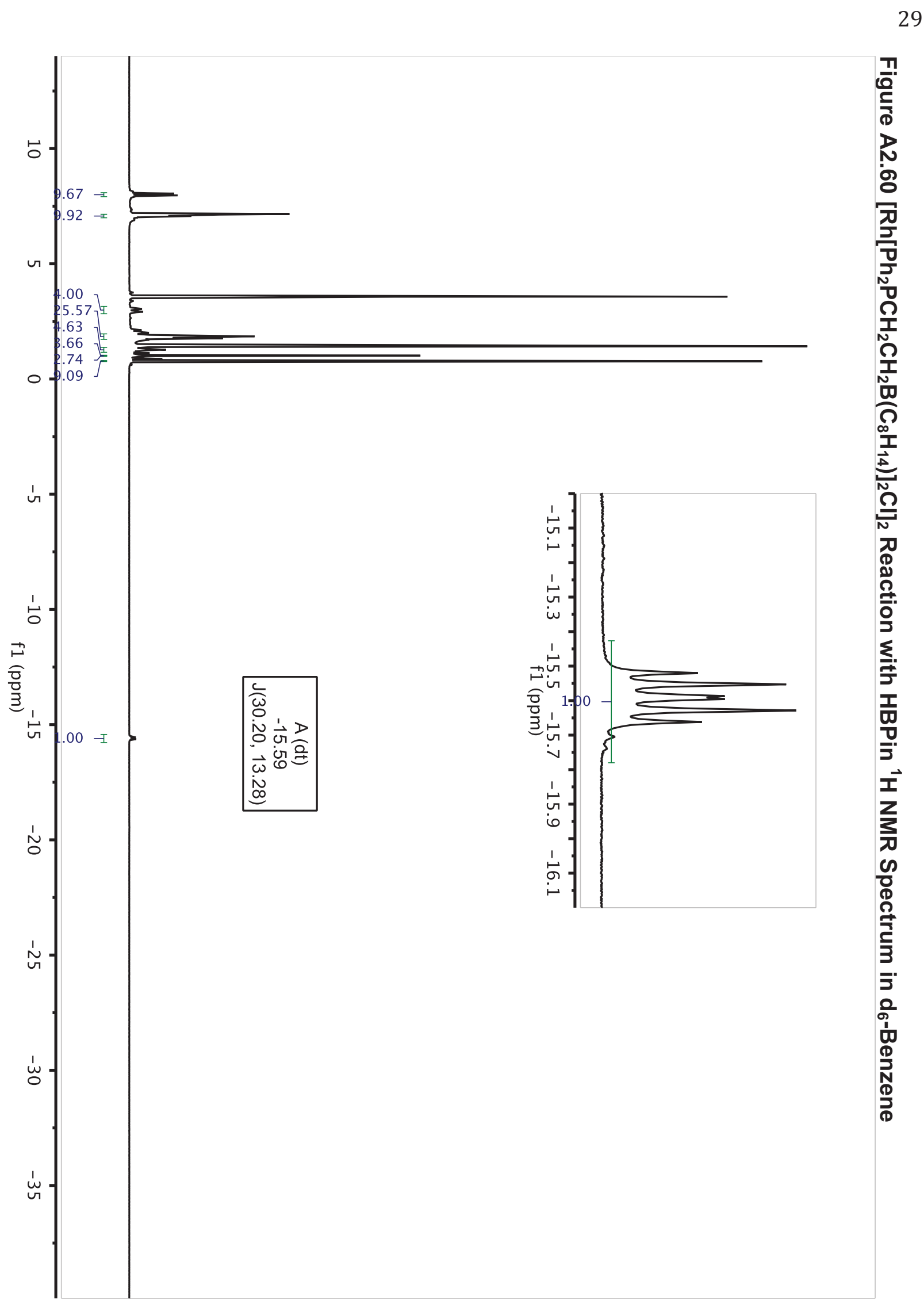




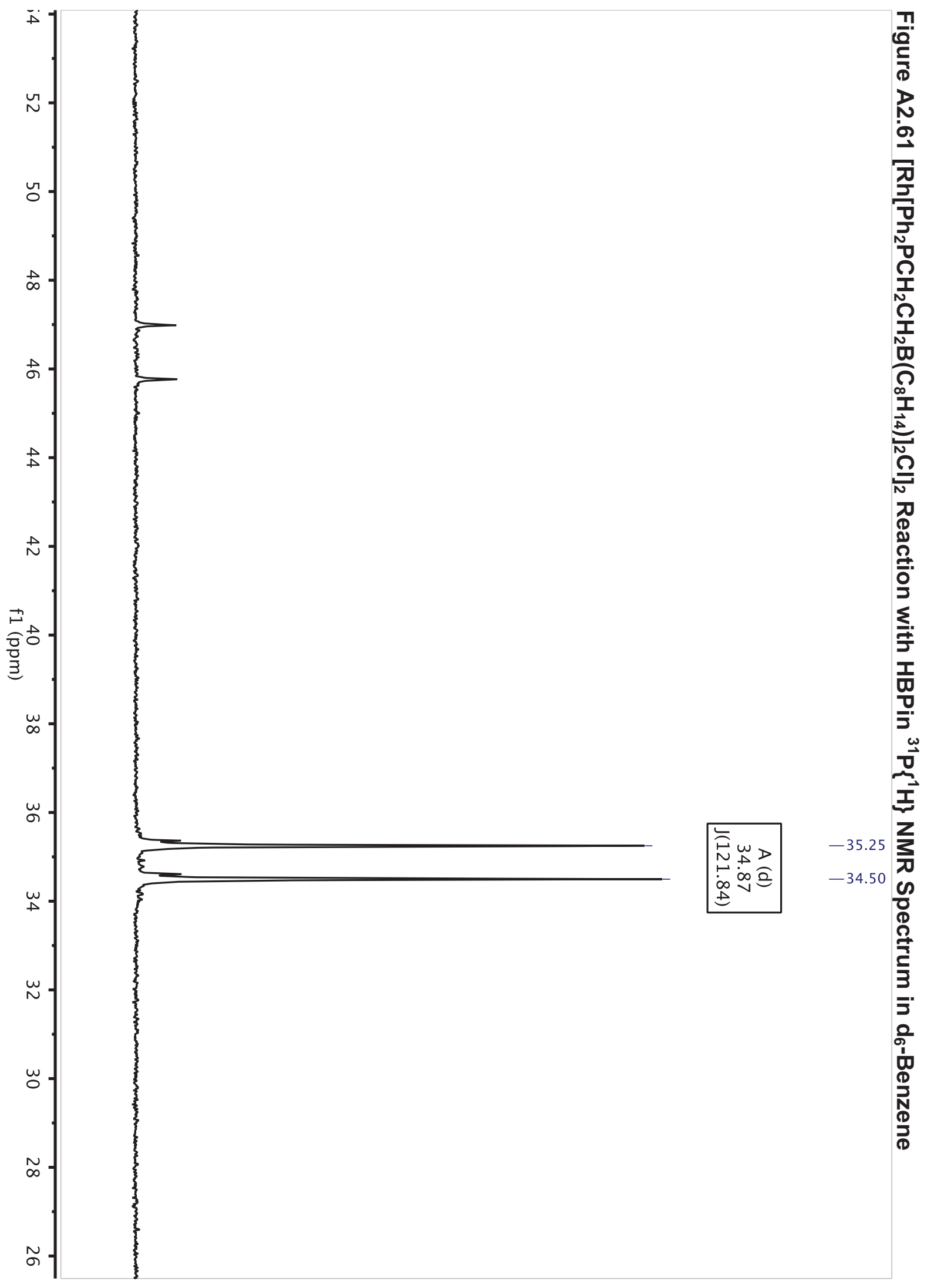




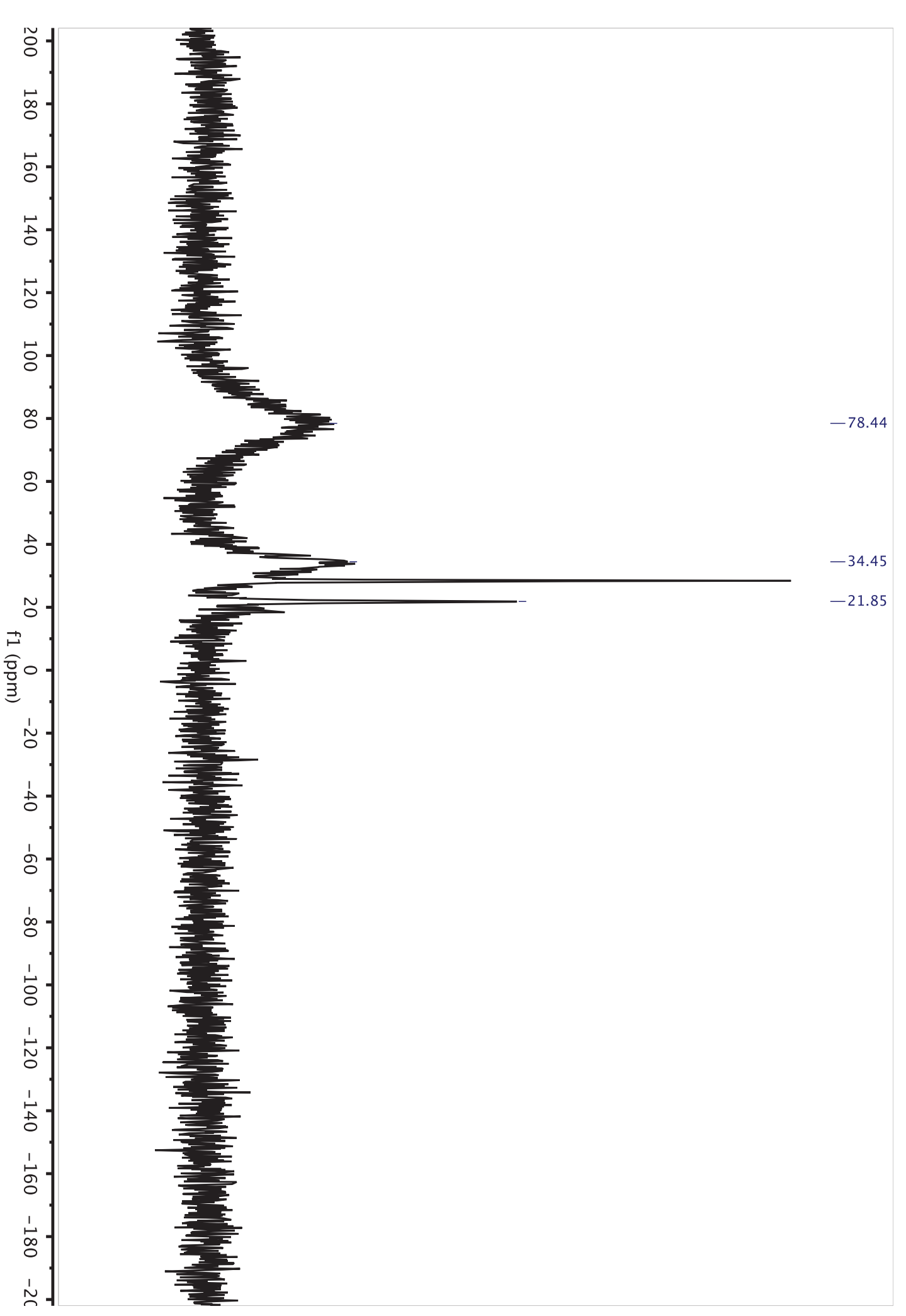



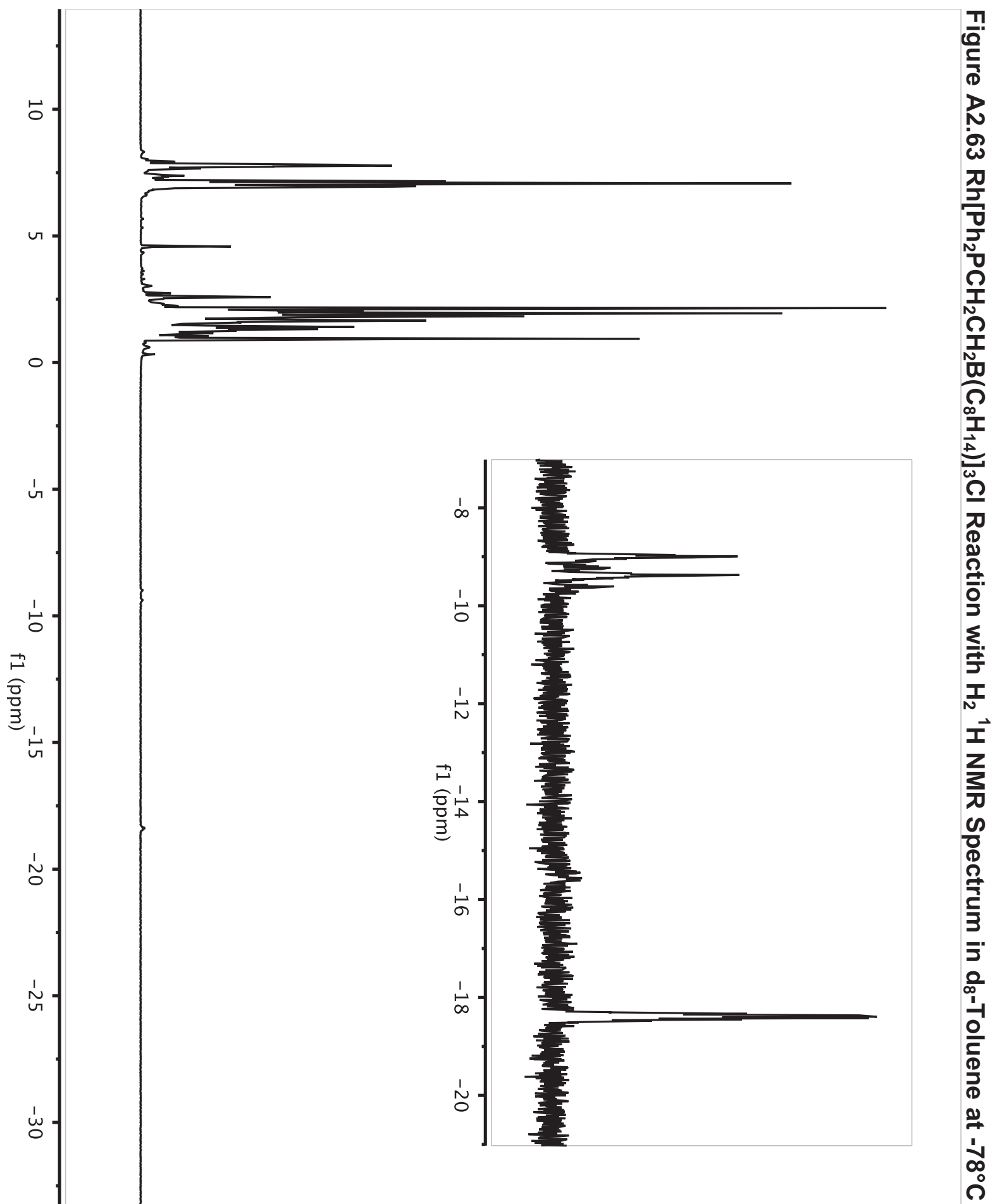


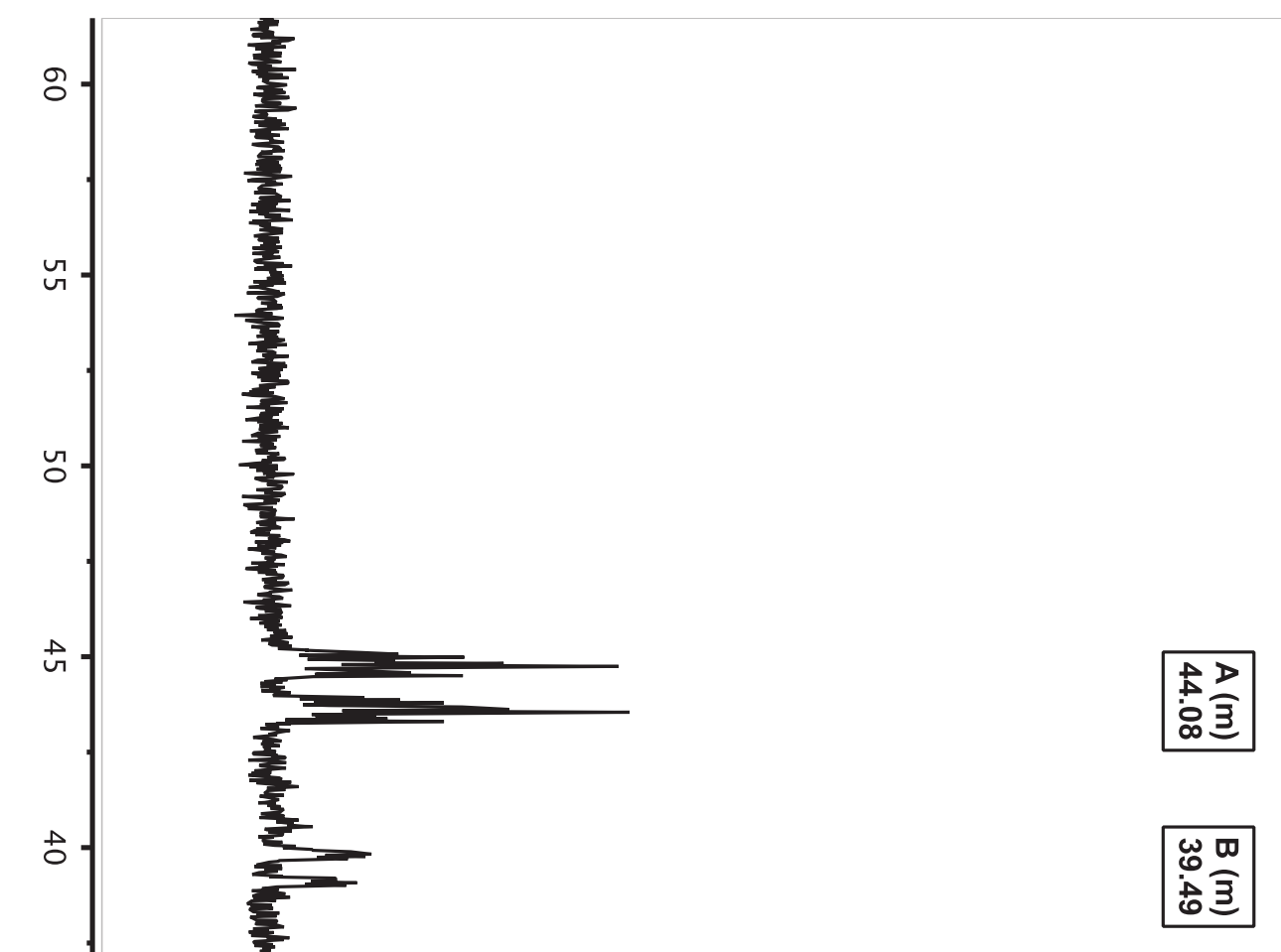

믄

8

지

$\frac{\pi}{2}$

No

을

$\overrightarrow{\nabla u}$

흠

w

N

章豆

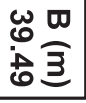

우

$\Omega$

I

س

舟

I

$\stackrel{E}{\varrho}$

D

(1)

일

흔

$\Sigma$

亲

I

$\stackrel{\omega}{0}$

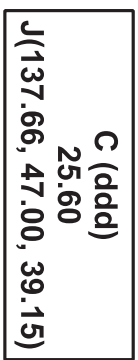

I

C

D

$\stackrel{?}{\frac{7}{7}}$

క

ก 


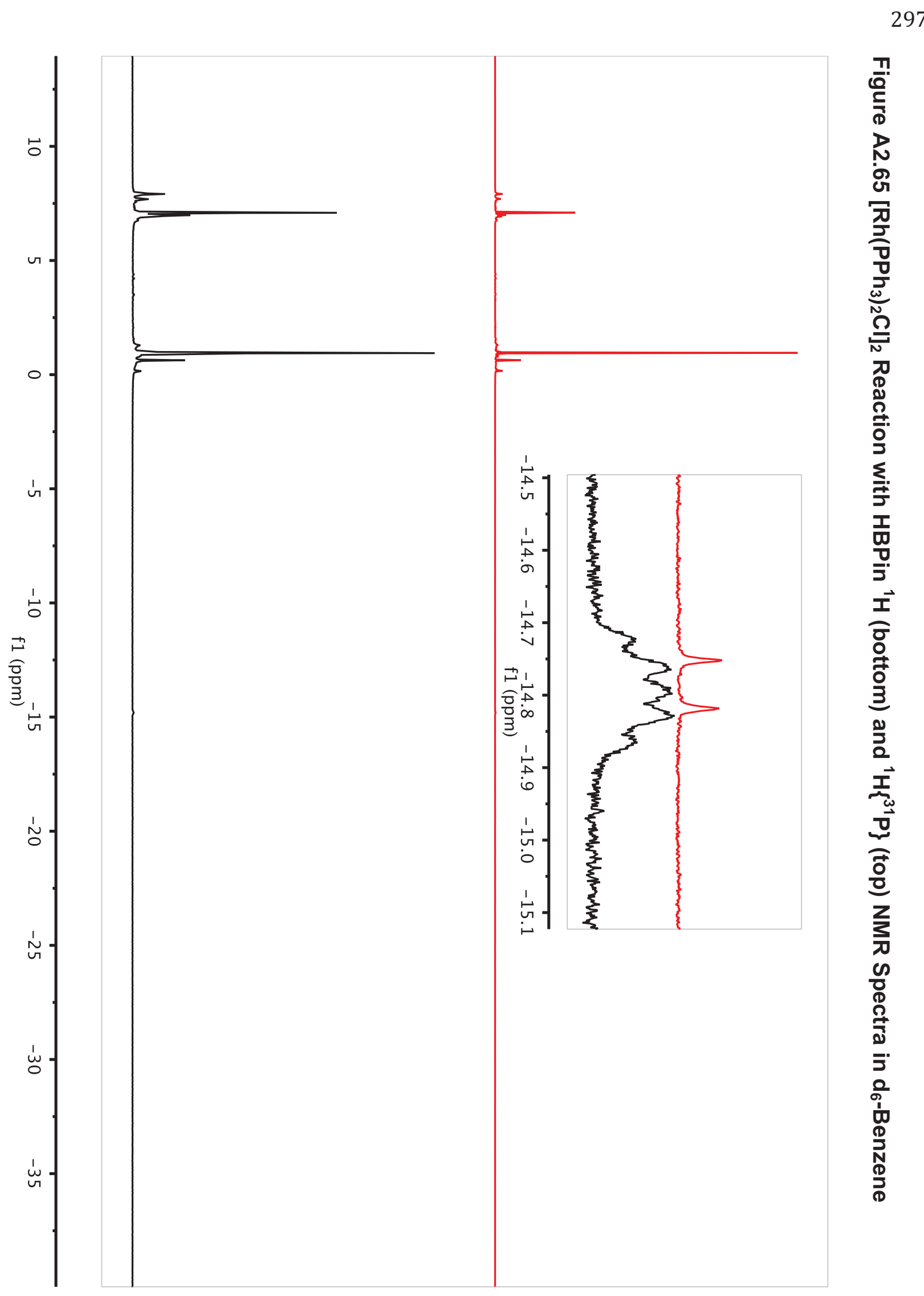


298
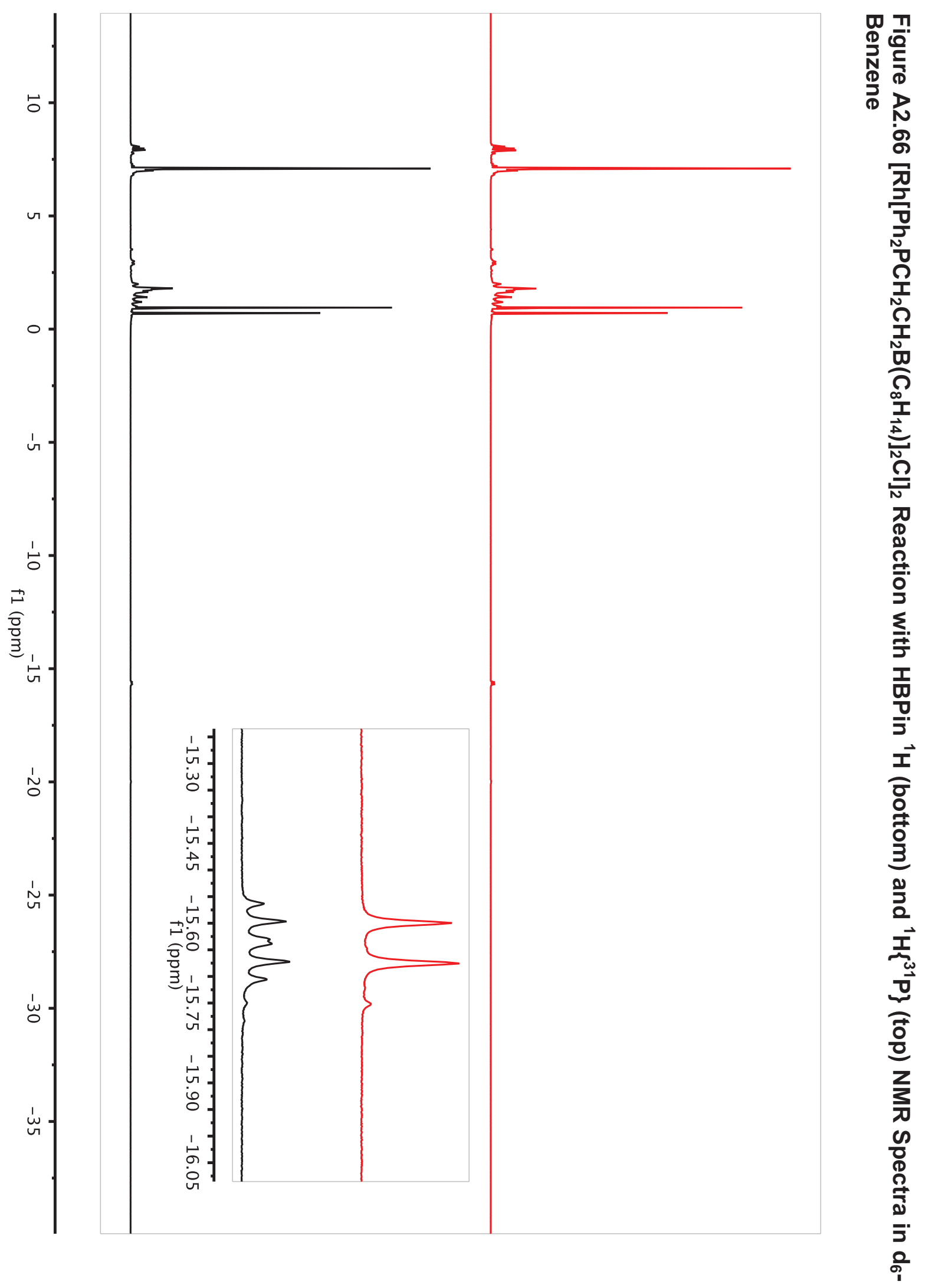


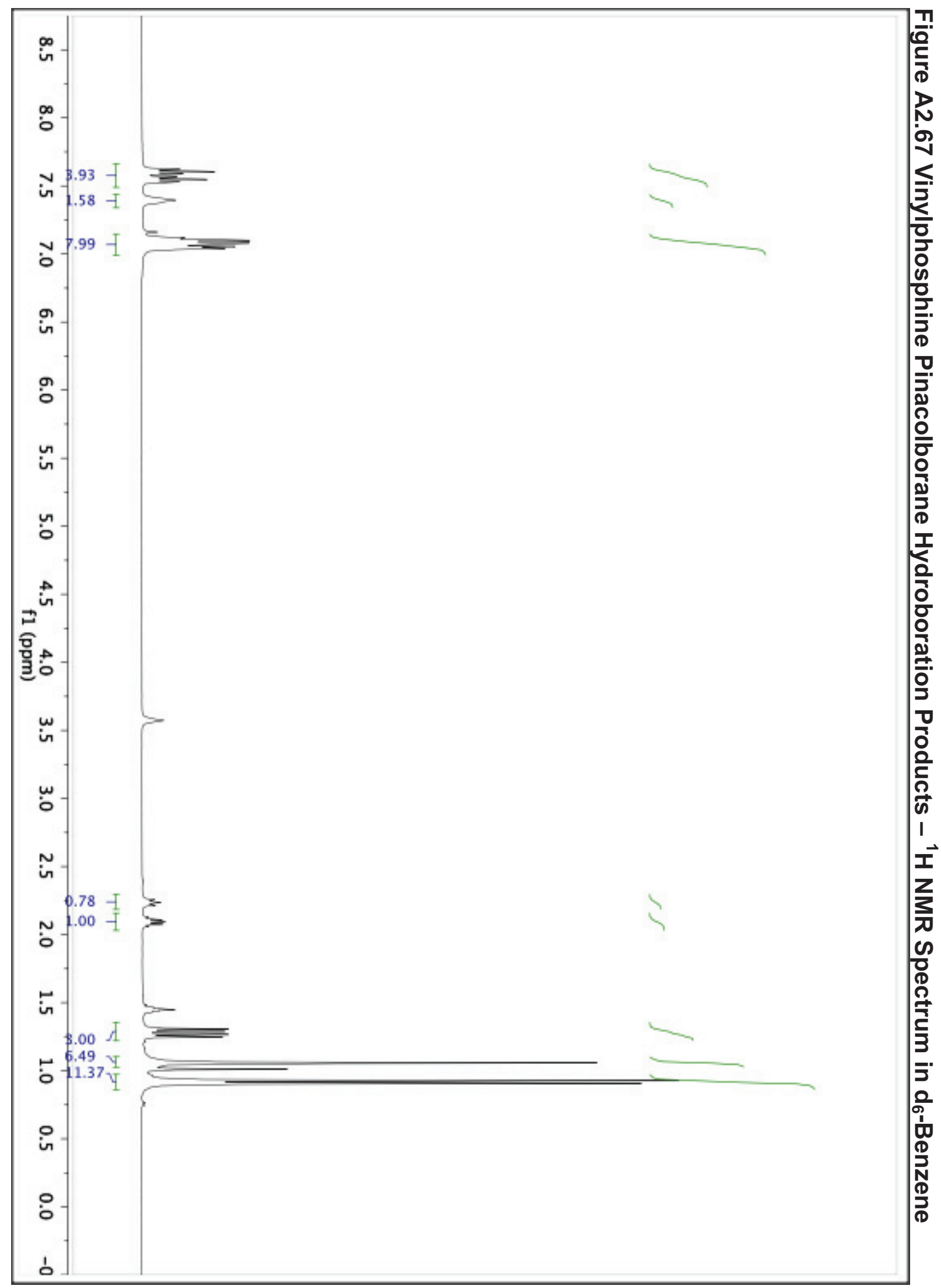




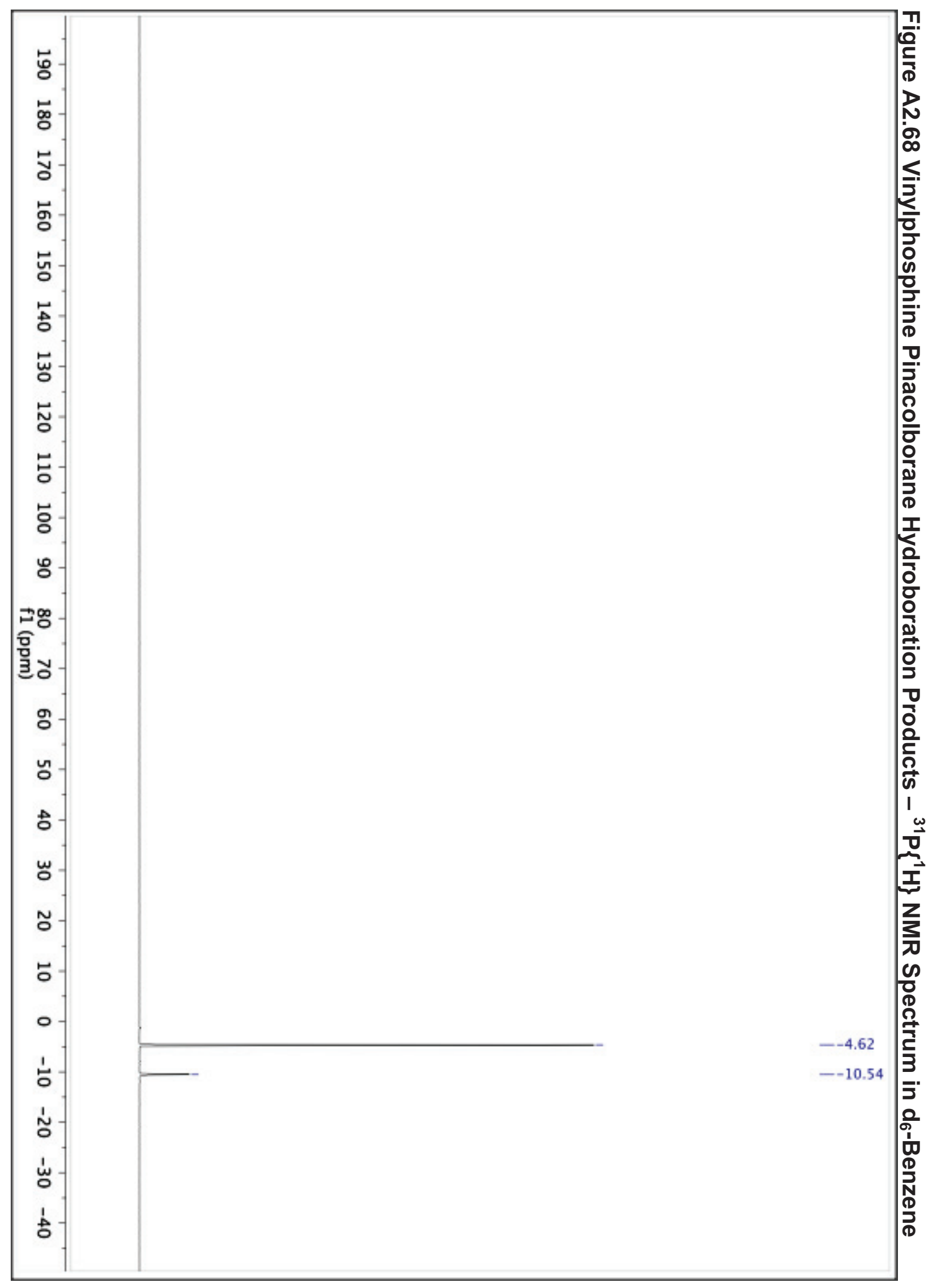




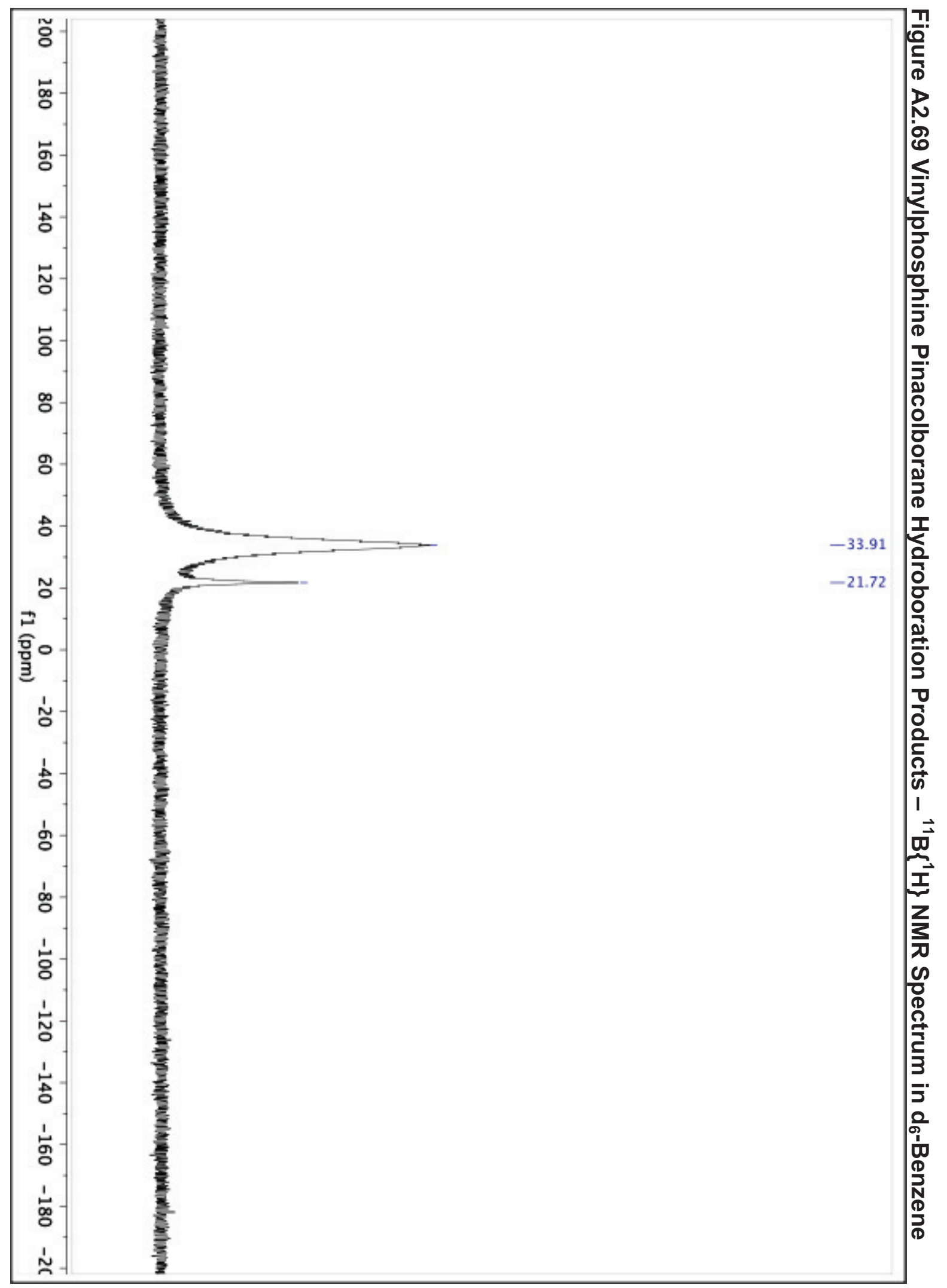




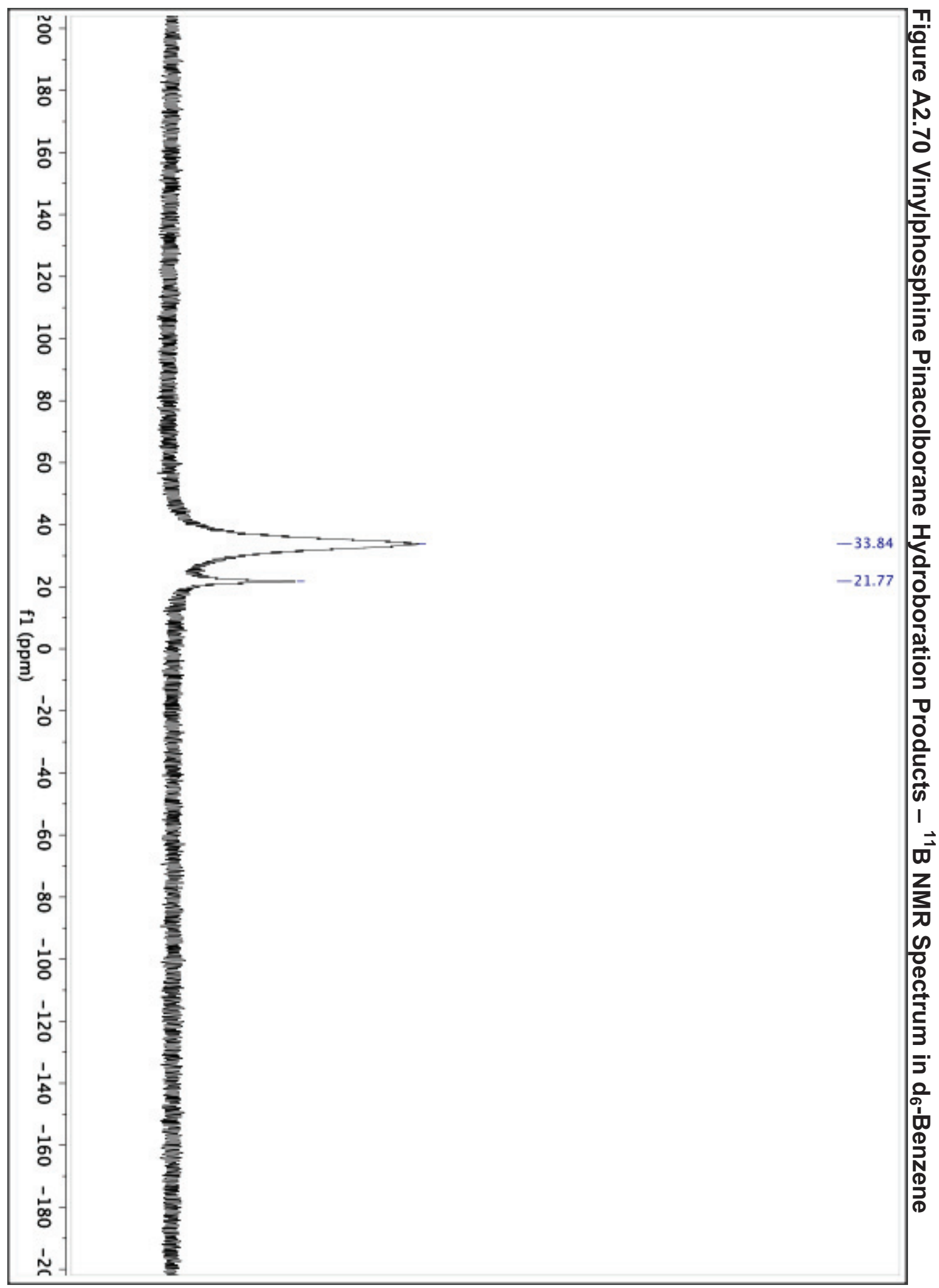




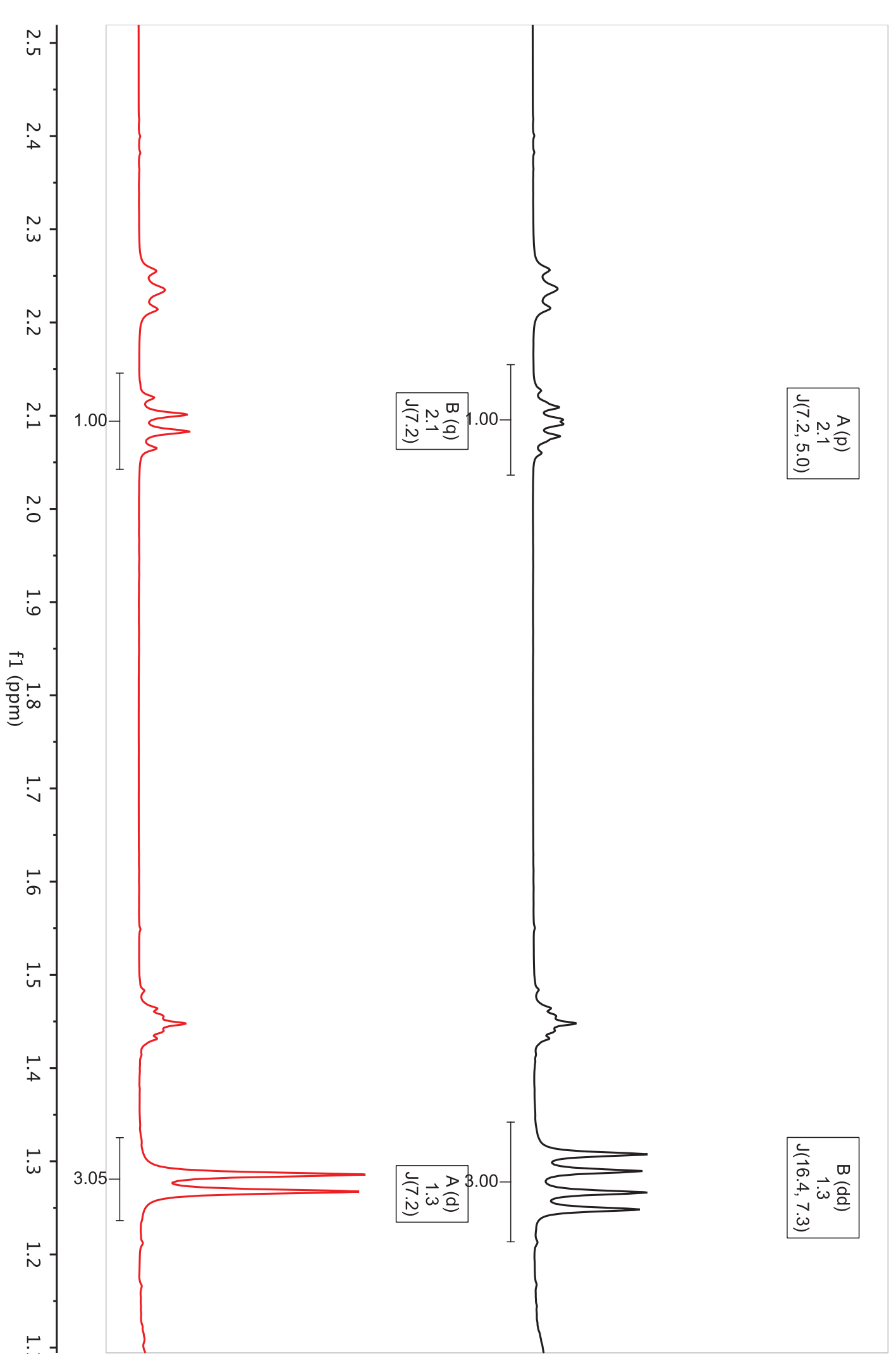

요 $\pi$

훙

옥 들

至

은

$N \leq$

몽

응 흥

ํㅜㅇ

꾸응

象 을

윽 종

ำ

กำ

도 응

응 항

向

ก จ

포

ه

응

웅

훔.

Tㅁ

응

高

I

1

C)

$\frac{\mathbb{D}}{8}$

尽

v

으

ㅇำ

듬

高 


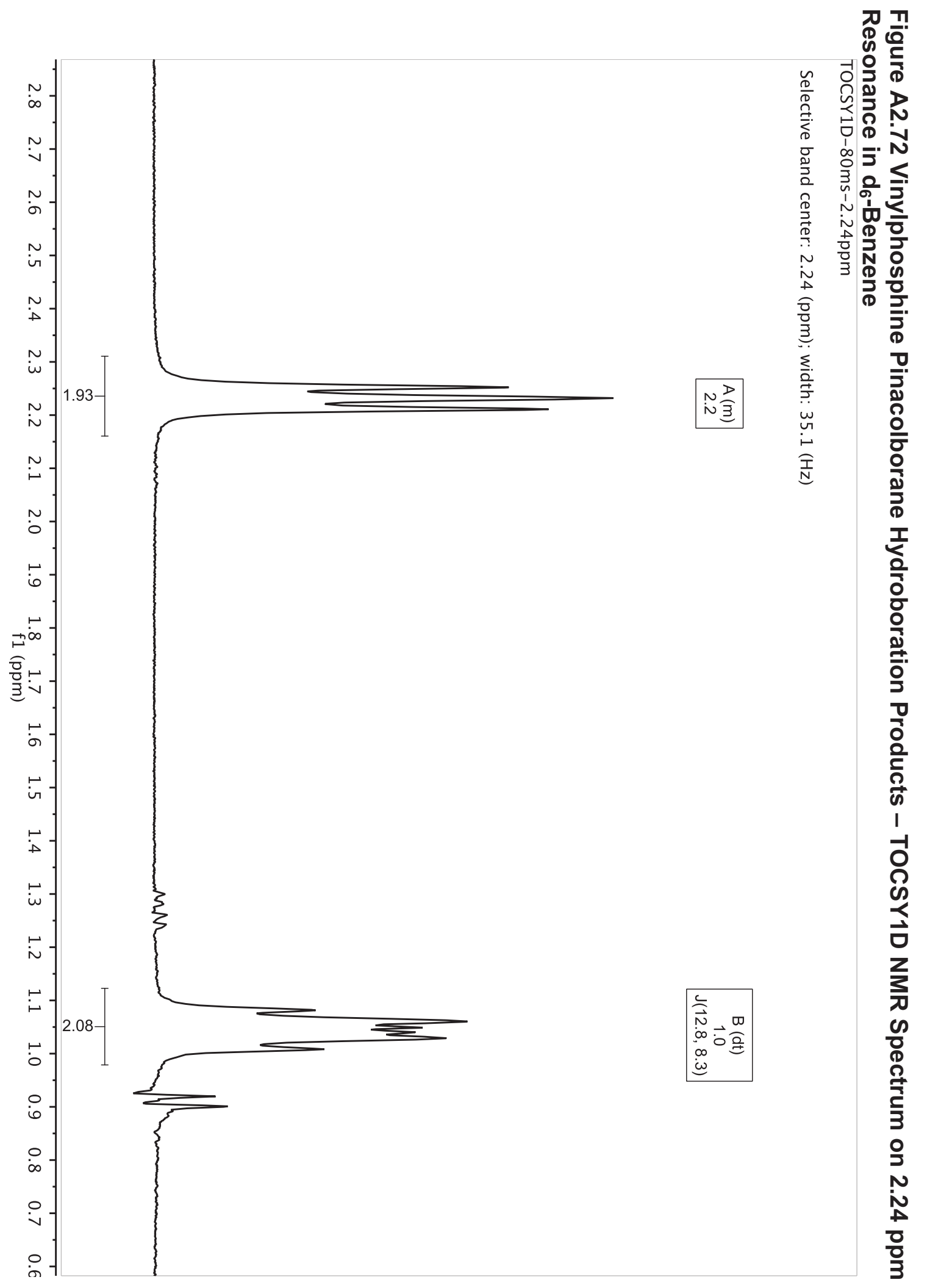




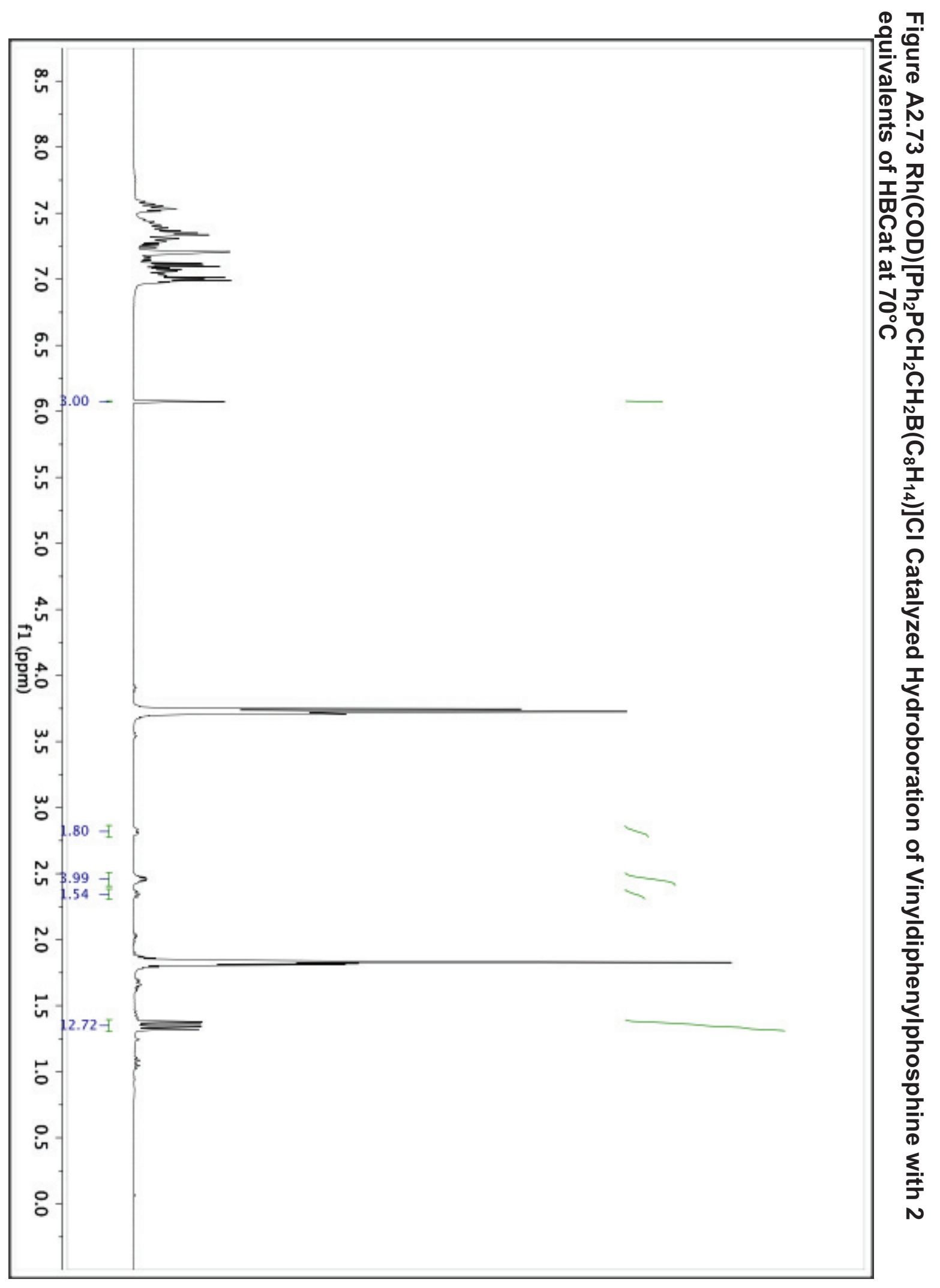




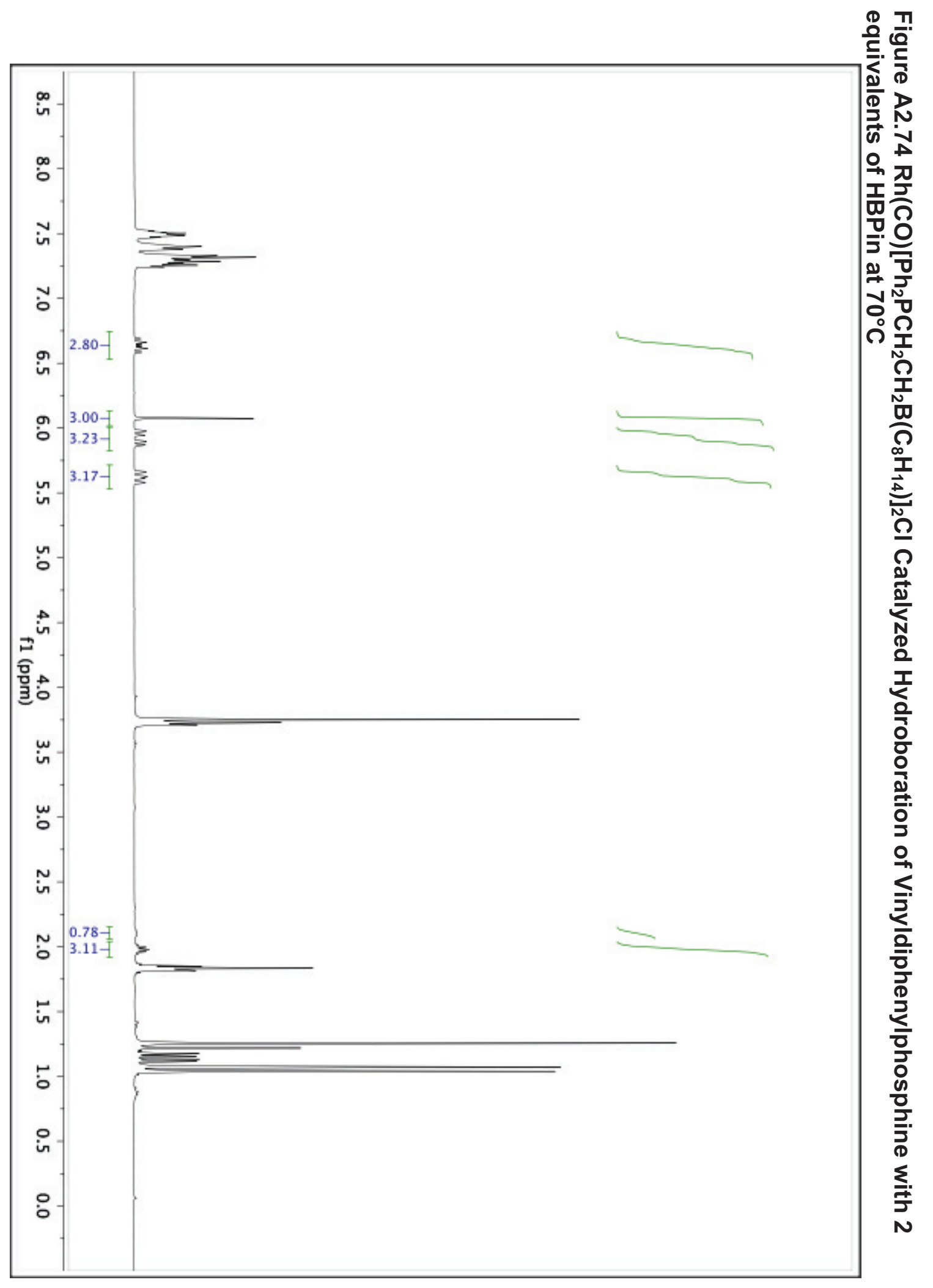




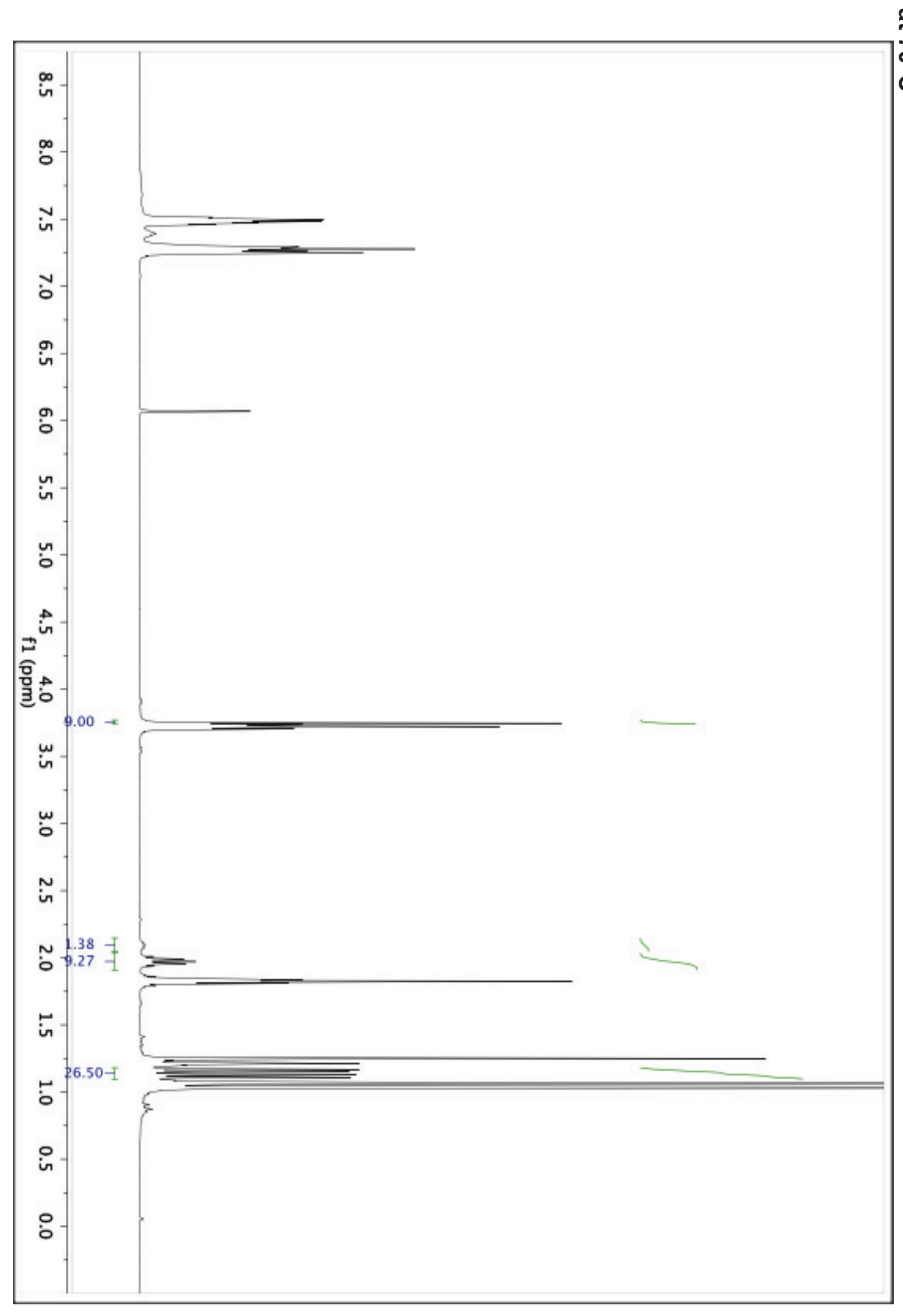

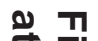
츨 ㅇํㅇ ก जै

즈

วิำ

음

ํํำ

$\frac{0}{\sqrt{2}}$

$\Omega$

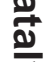

隹

$\stackrel{2}{2}$

I

옥

응

20

웅

욲

군

흥

흠

$\stackrel{\frac{\Phi}{2}}{2}$

후

จ

음

จุ

$\Sigma$

5

N

욜

들

ฏ

要

옥

㽞 


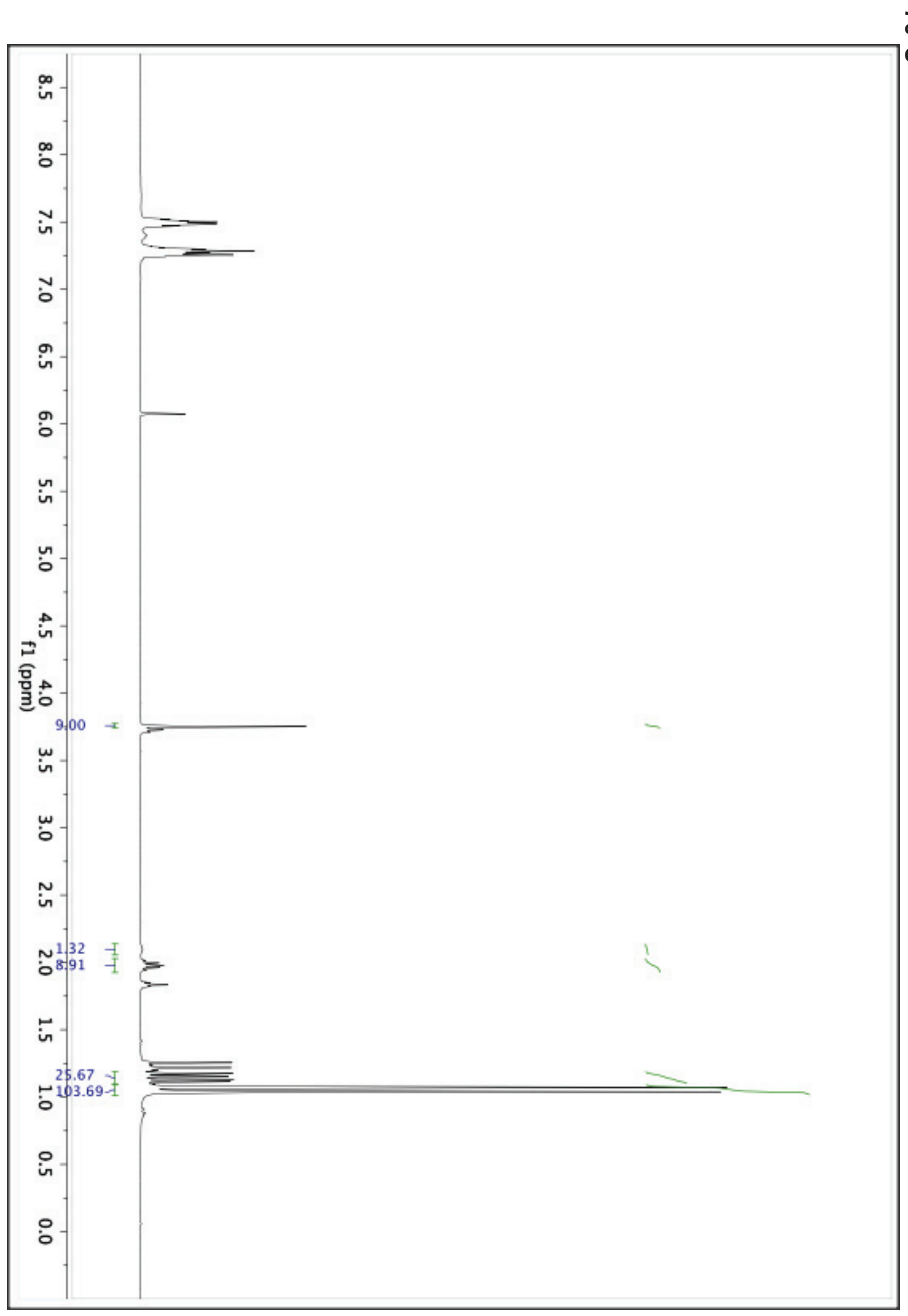

잉ำ




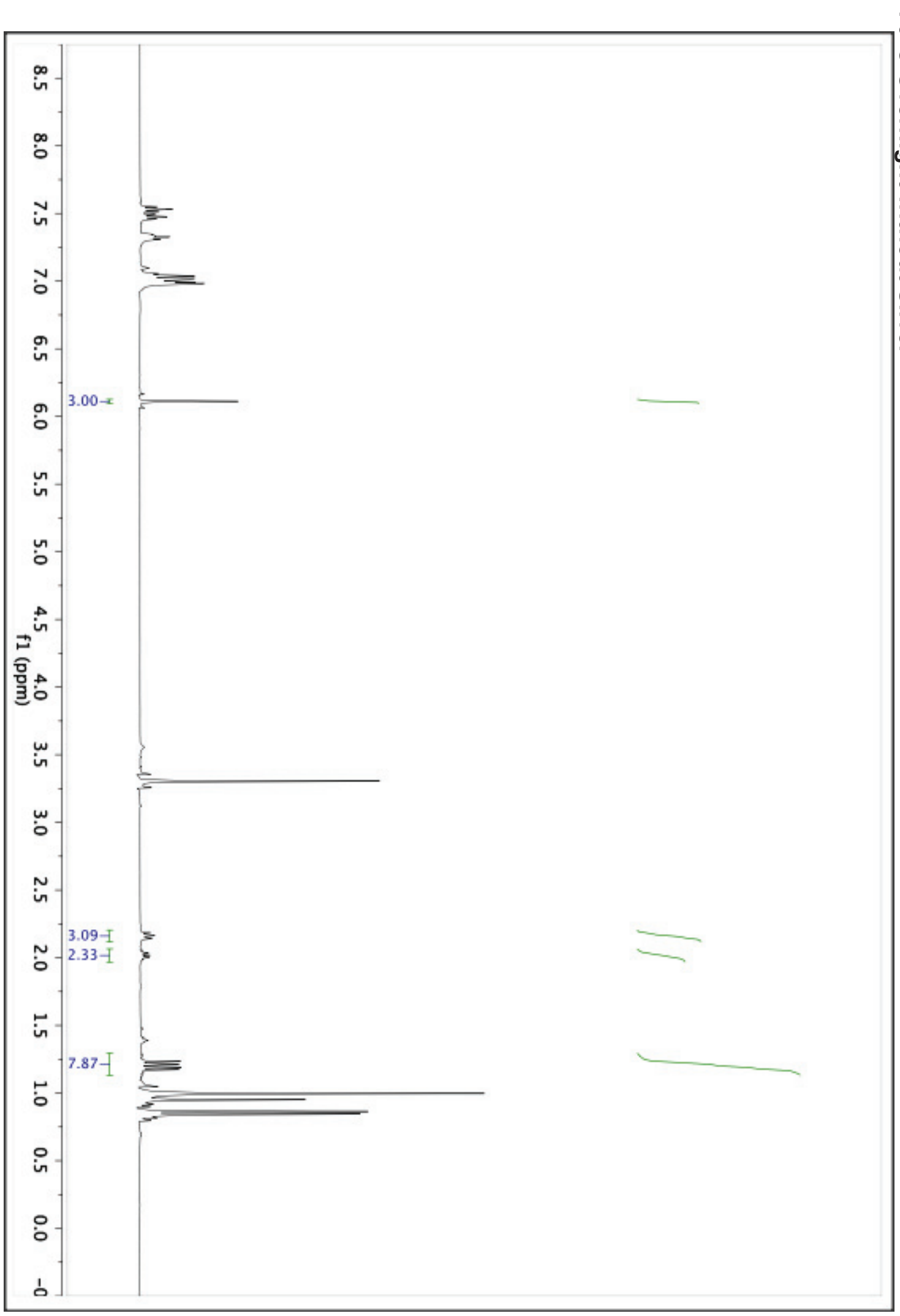




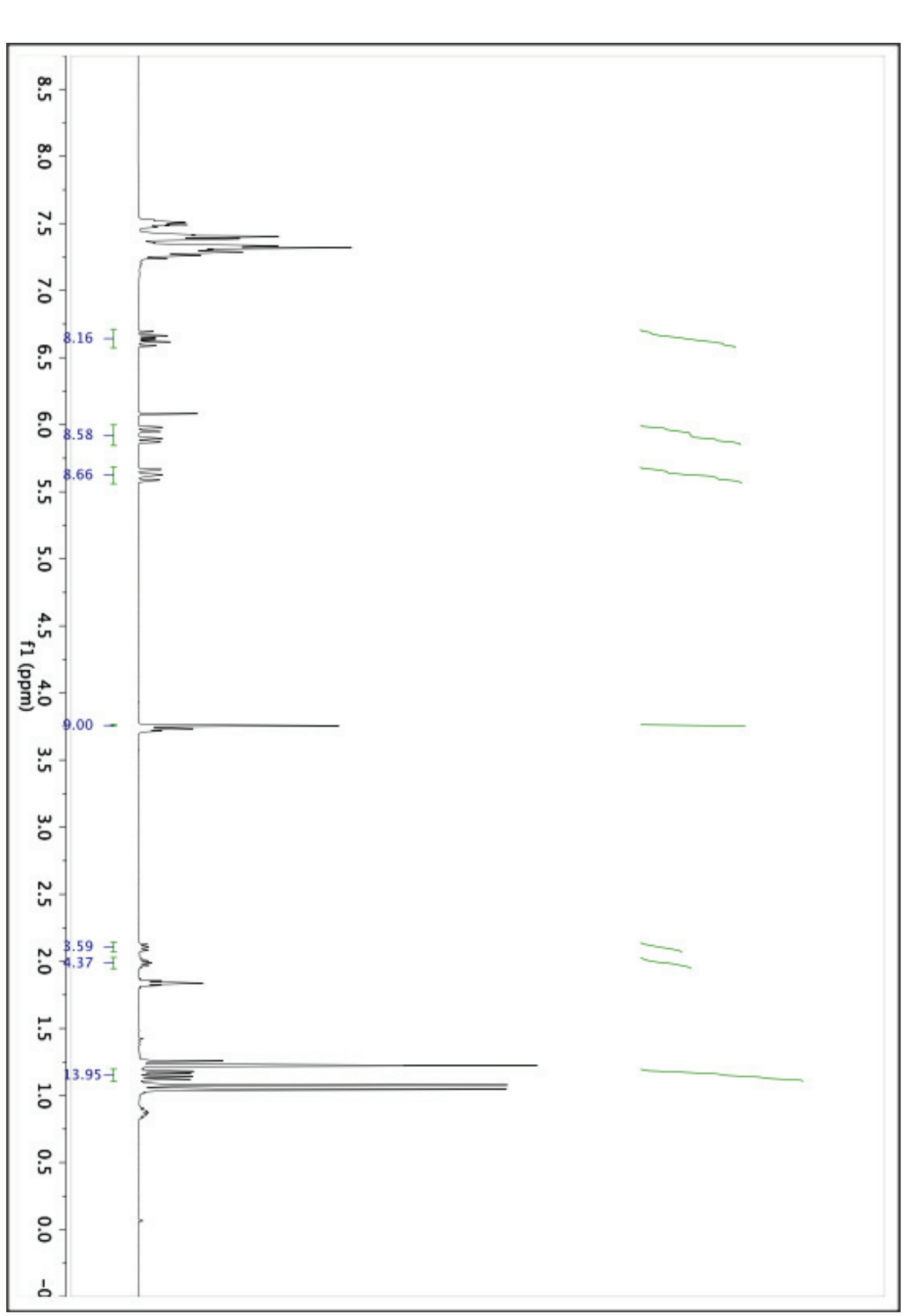

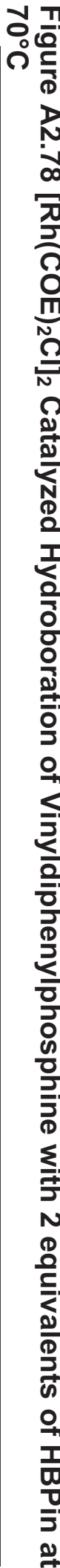




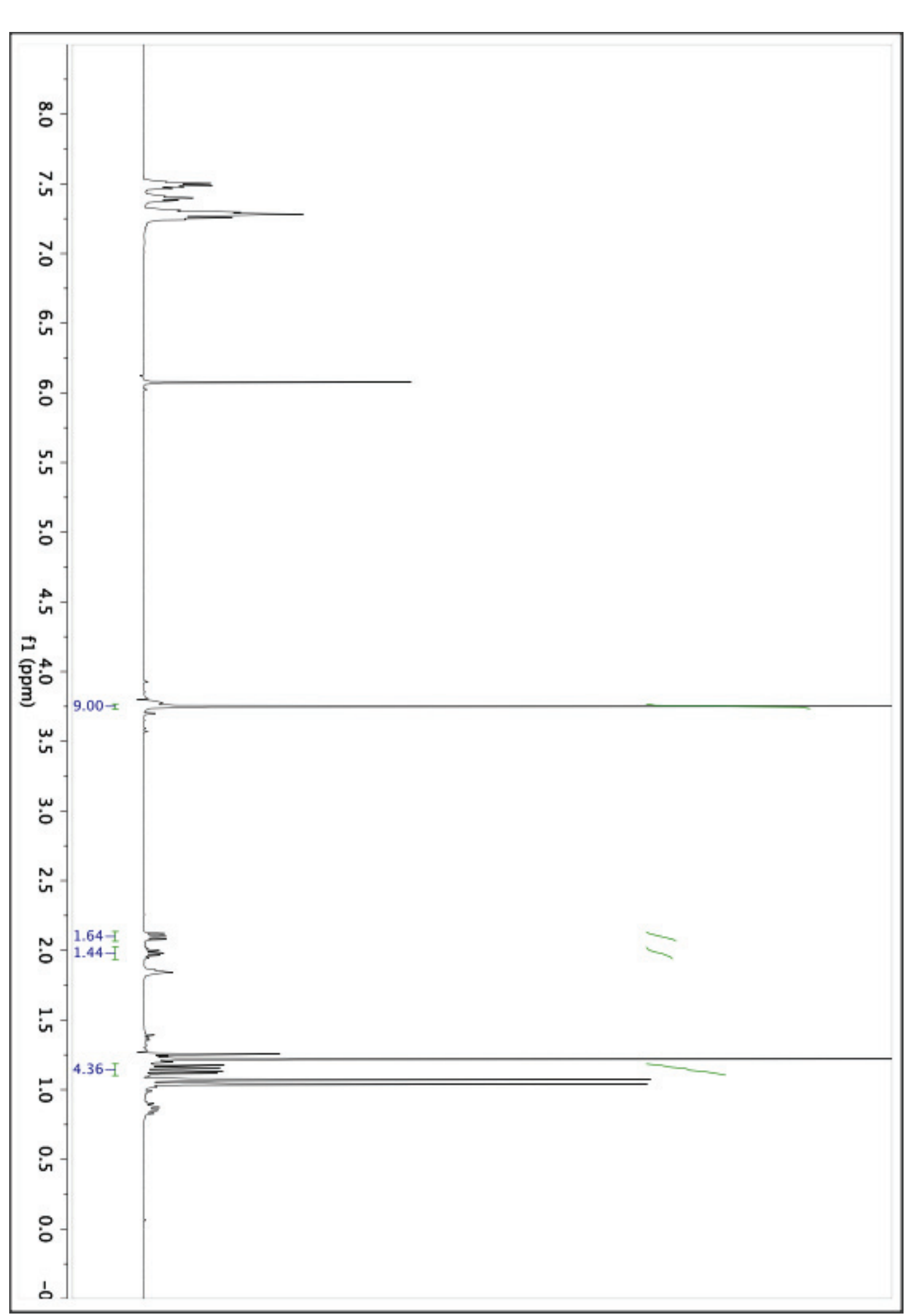

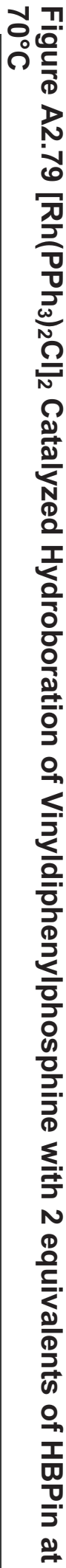




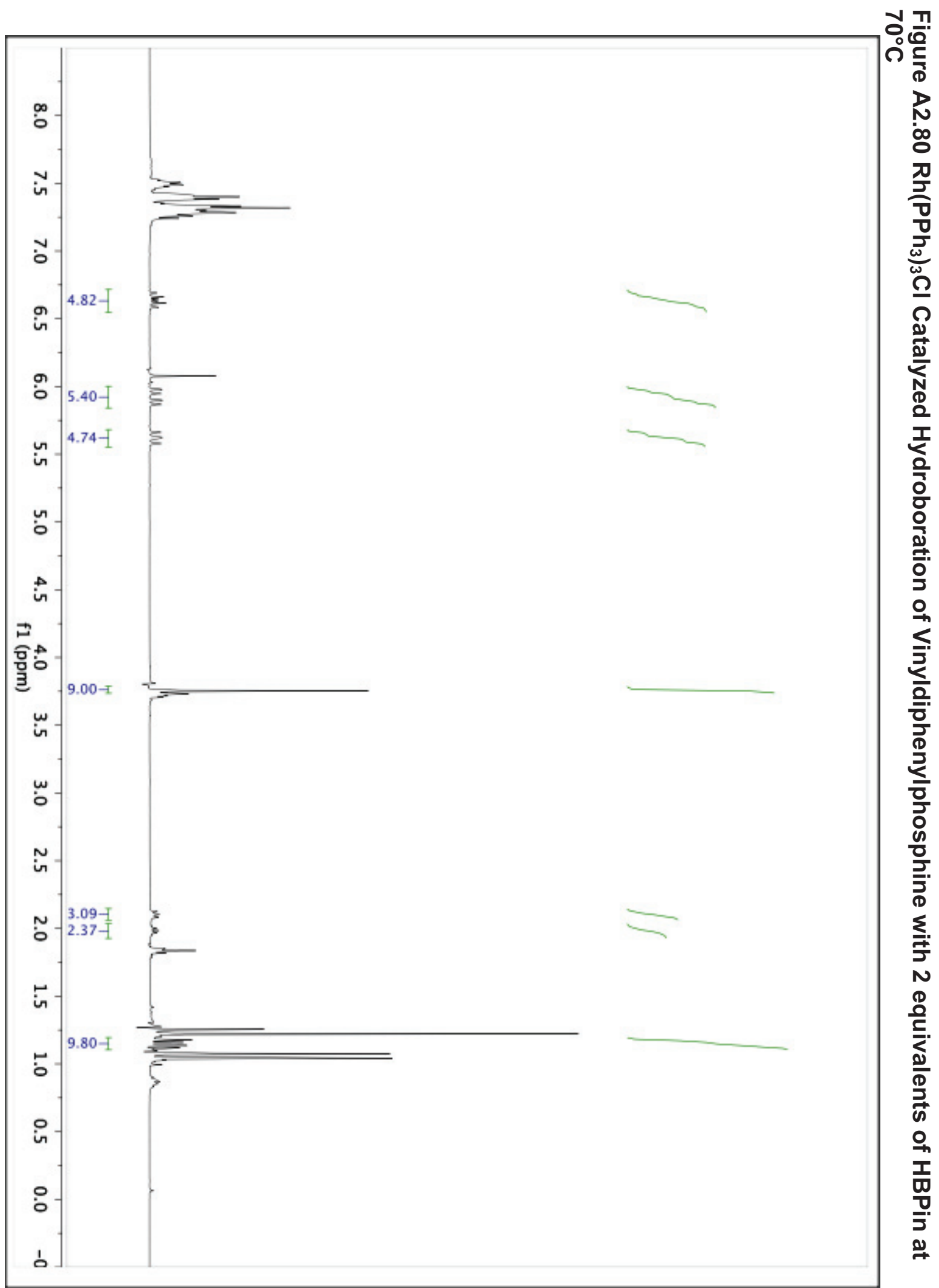


313

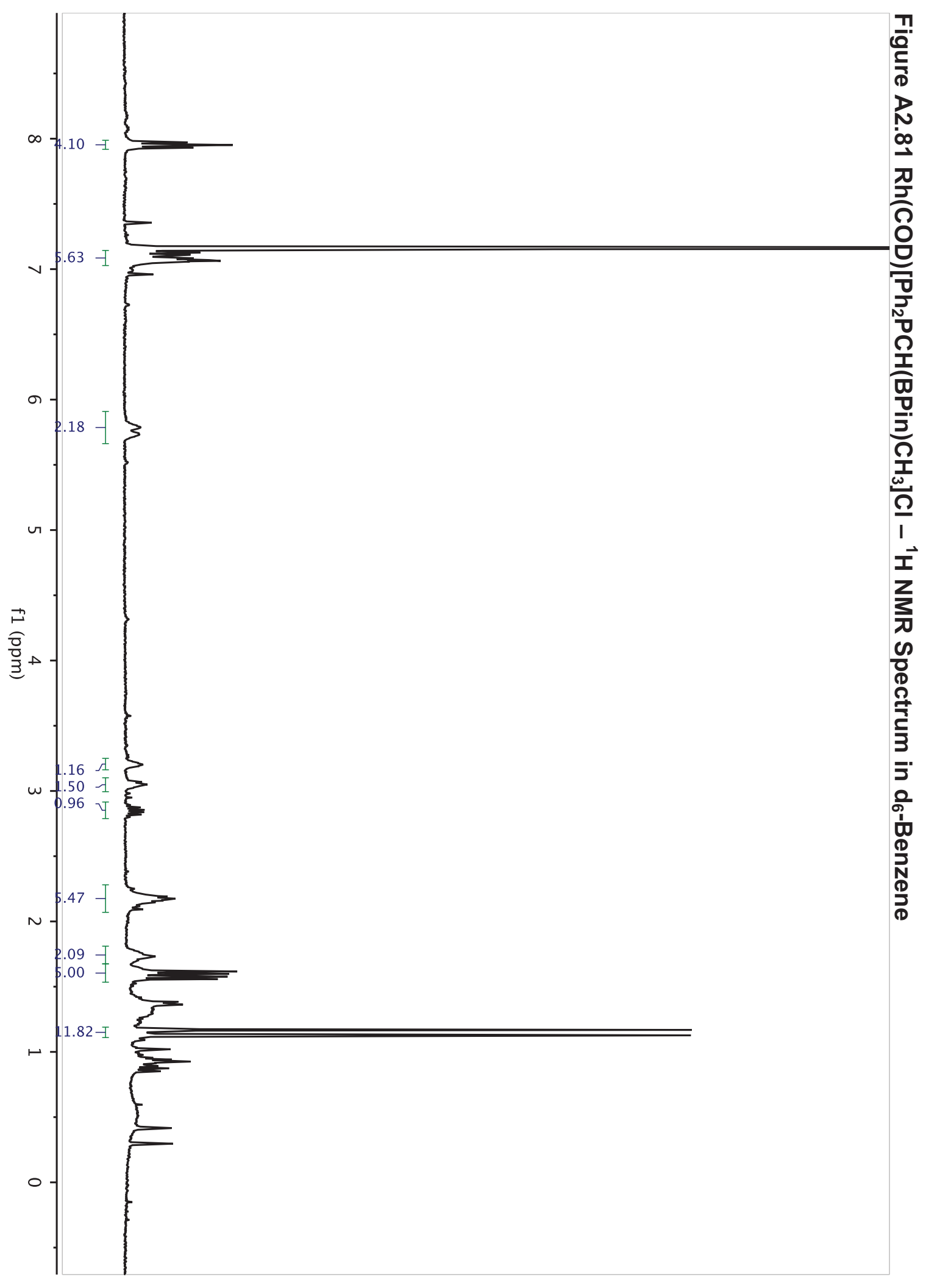




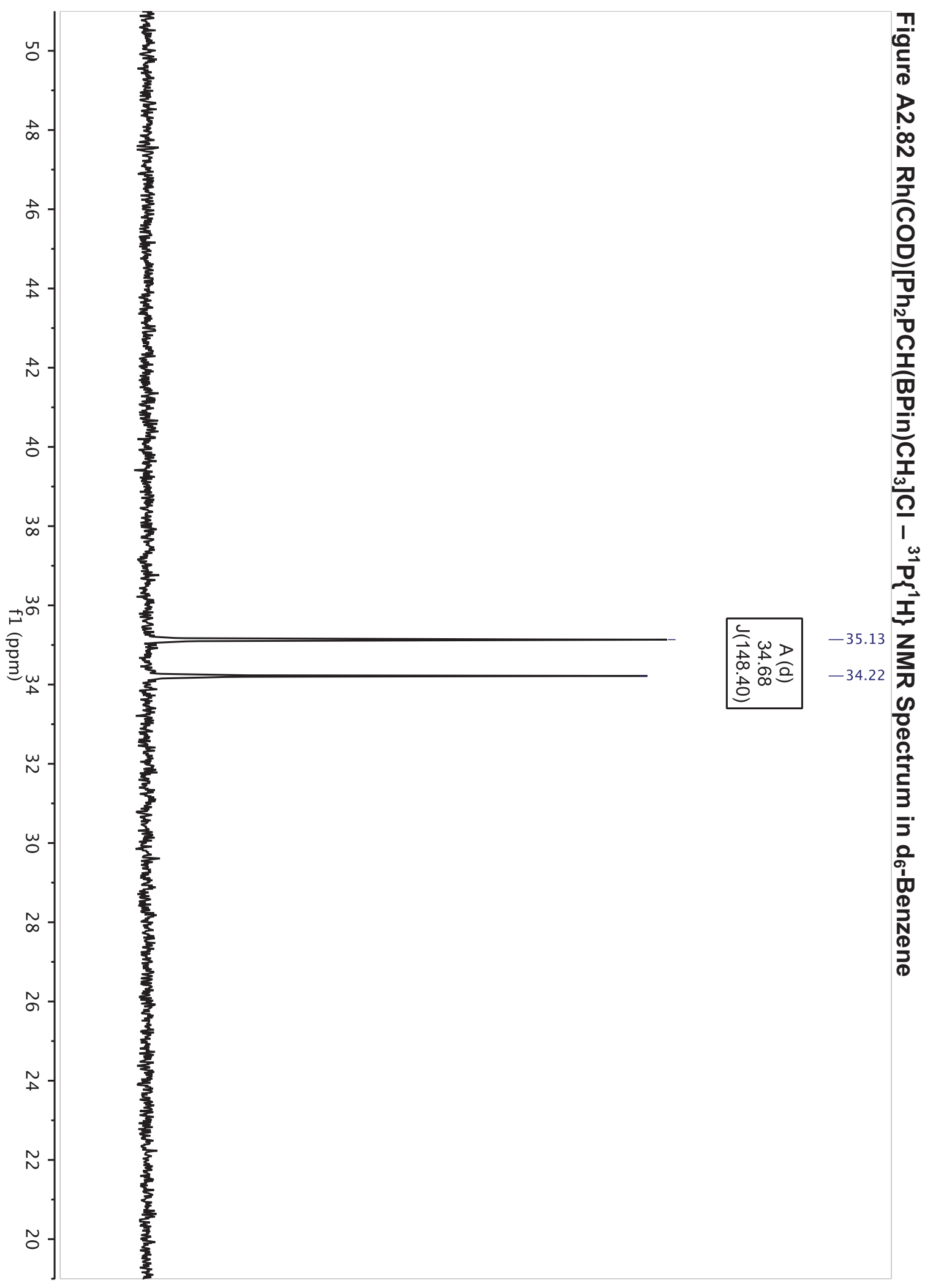




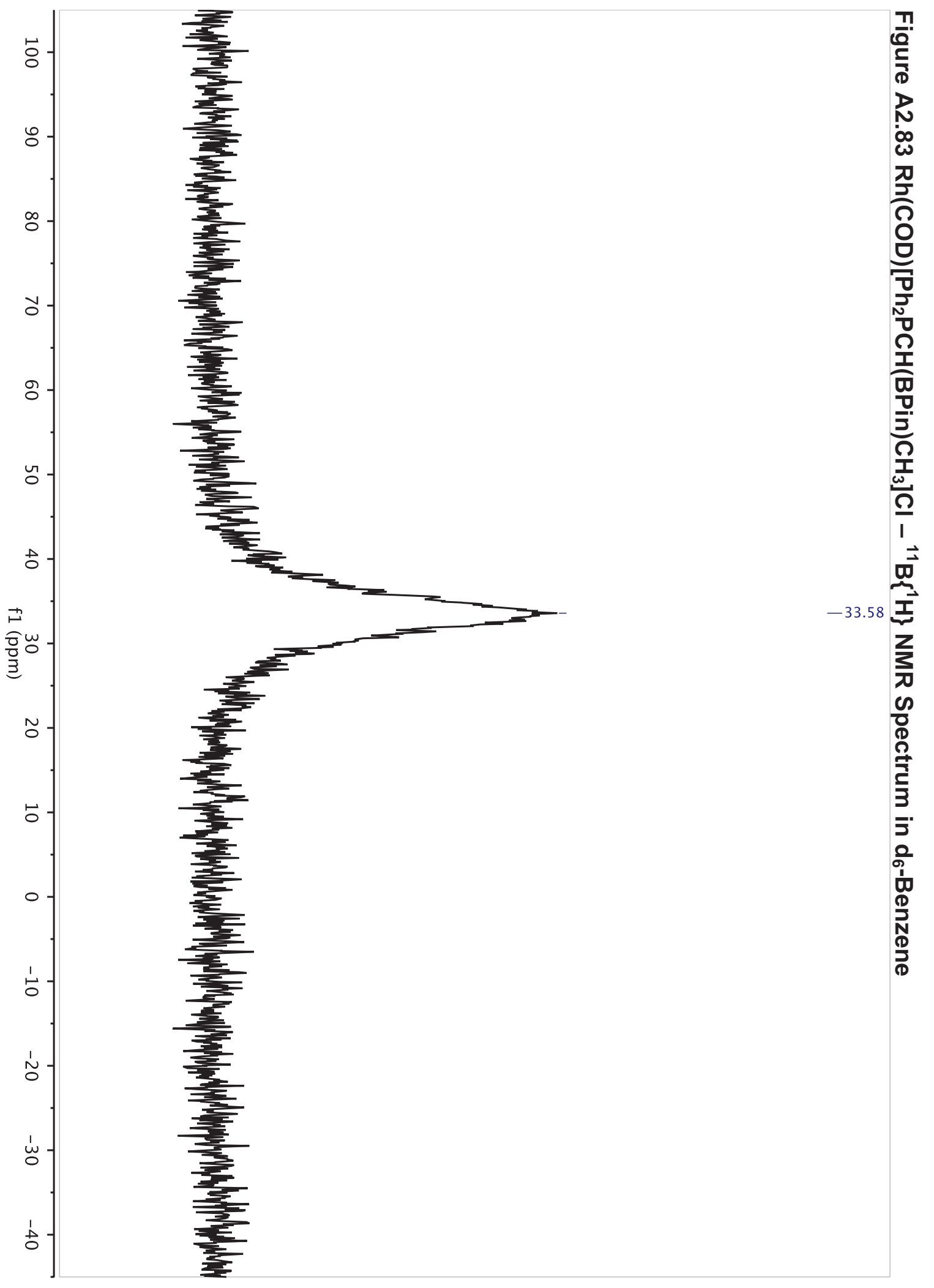




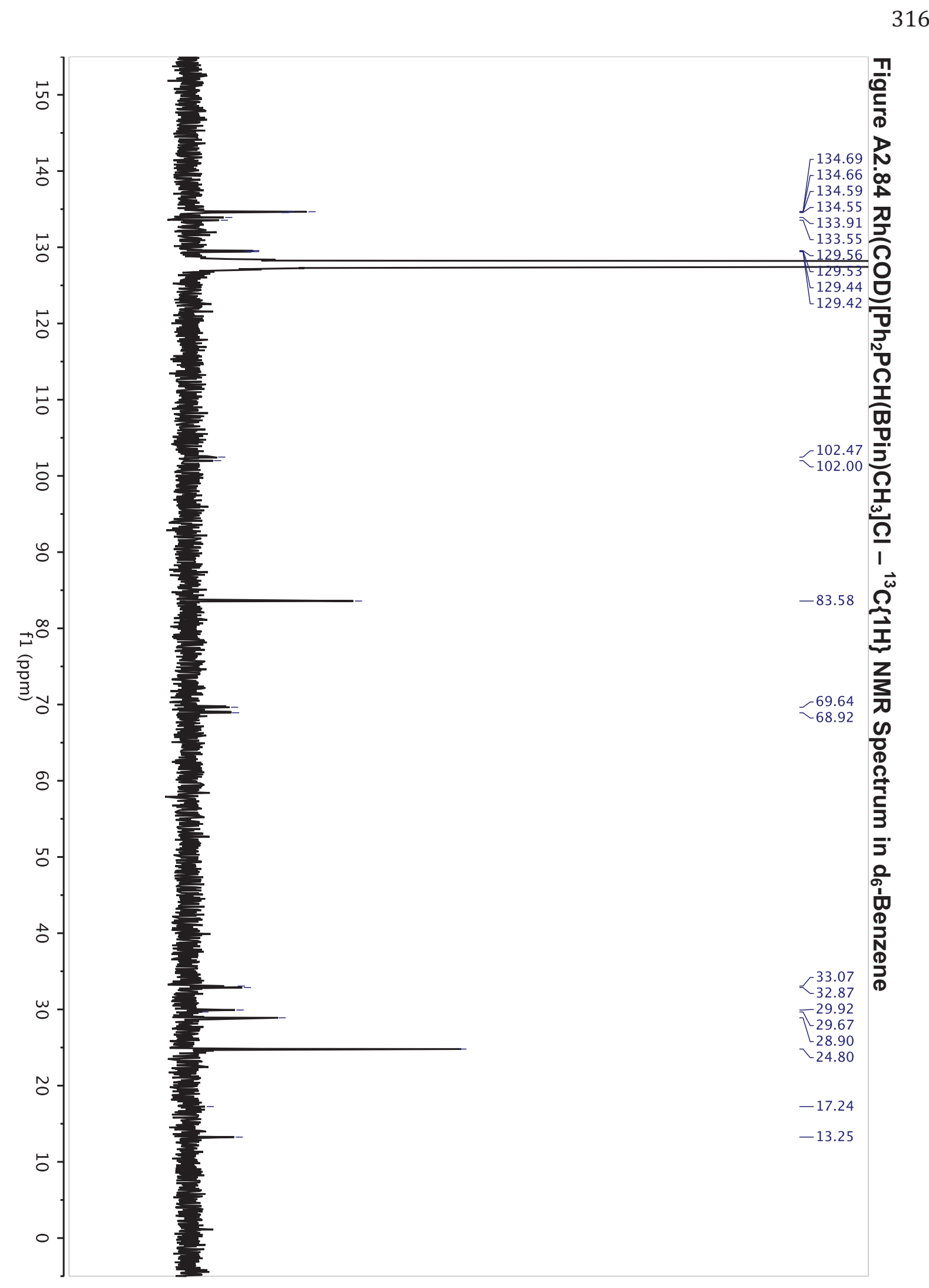




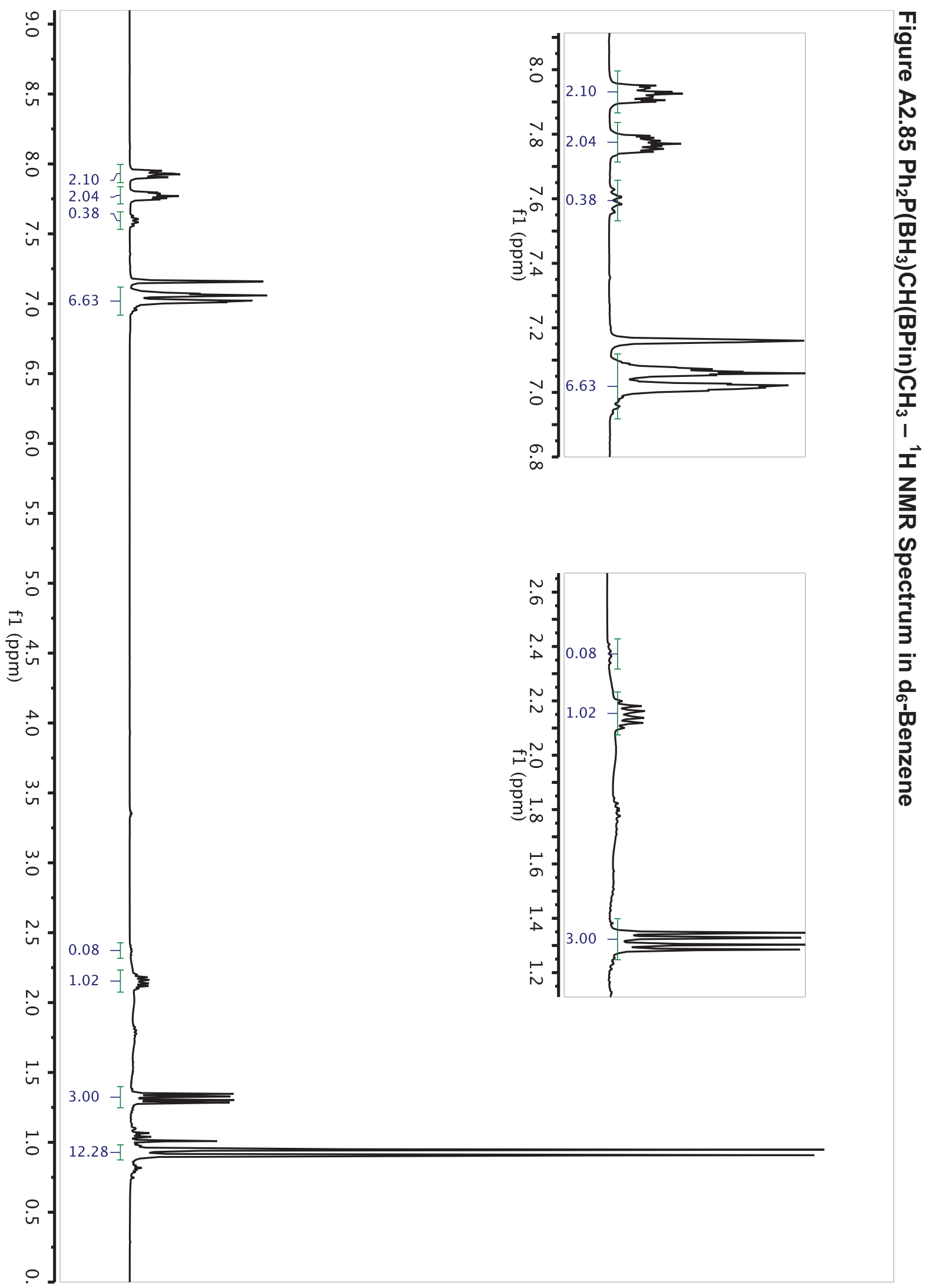




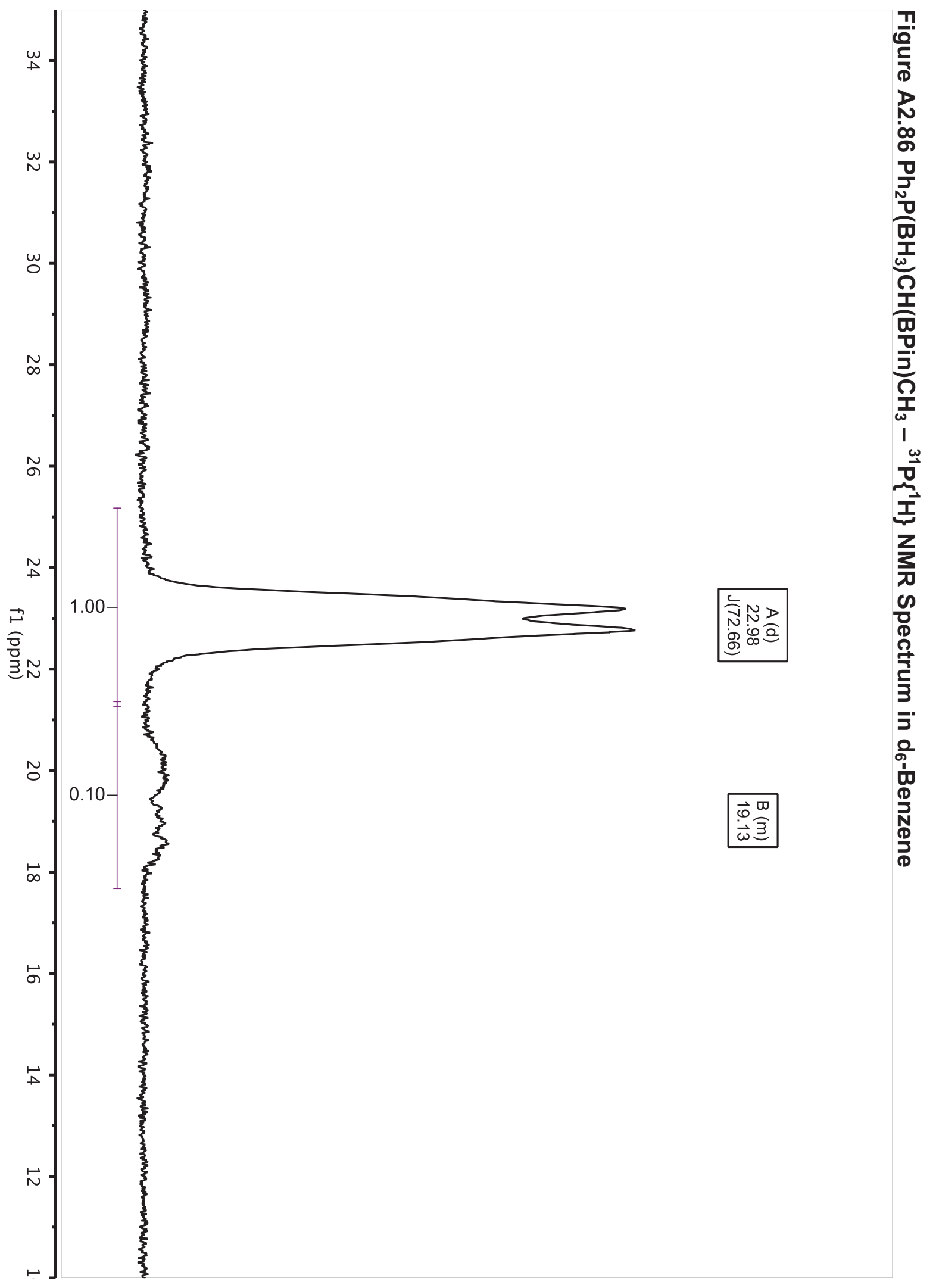



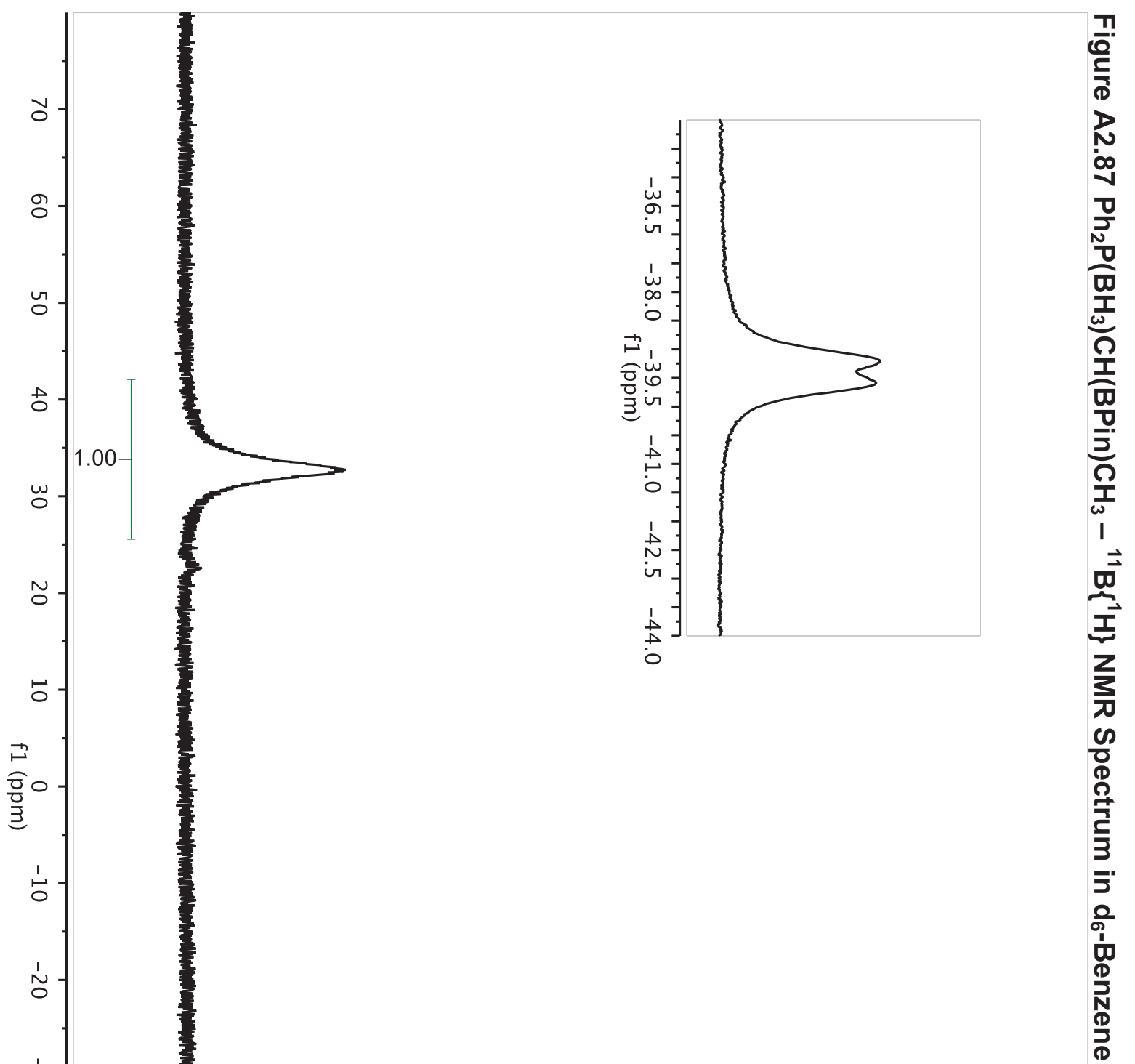


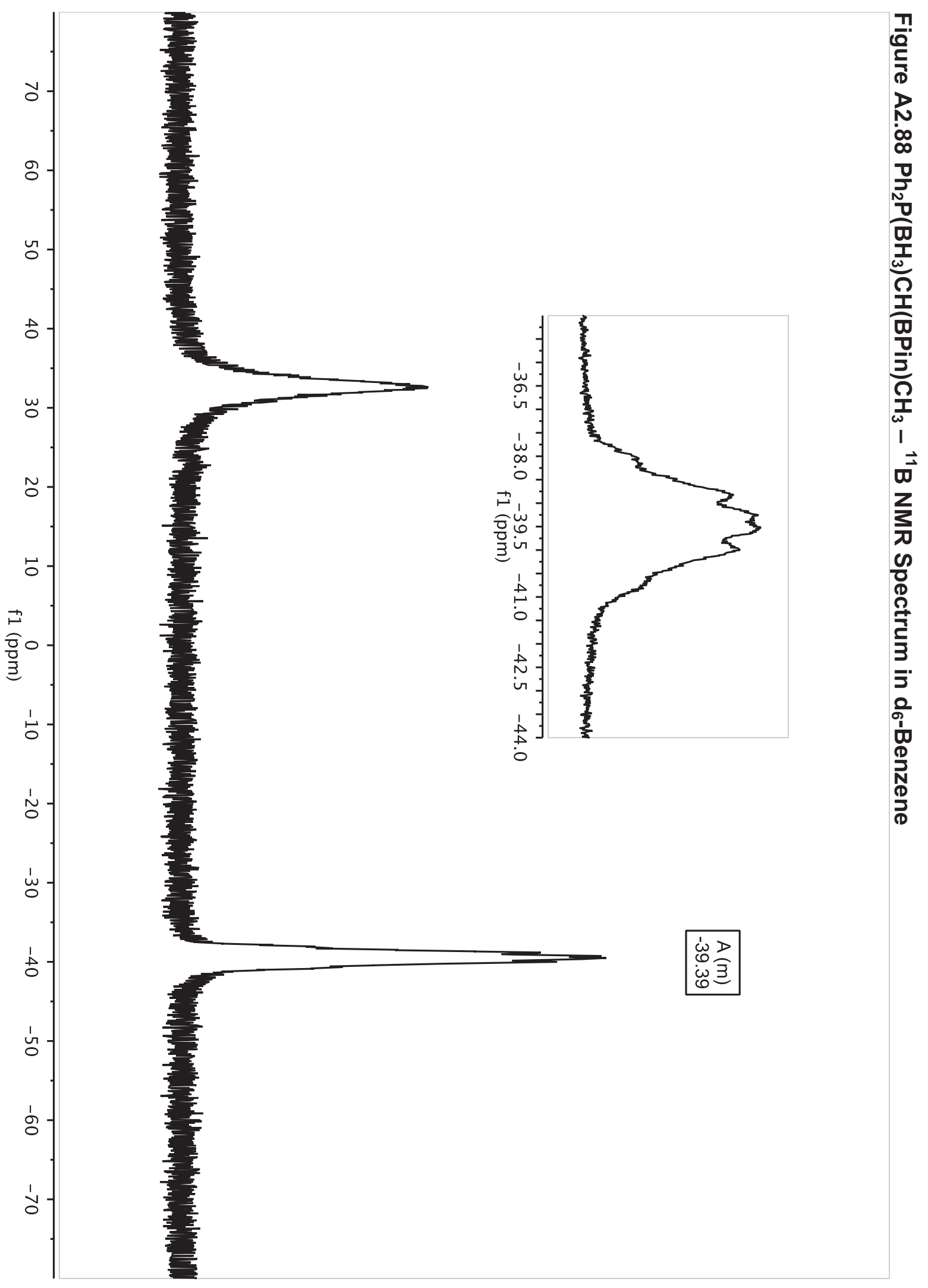




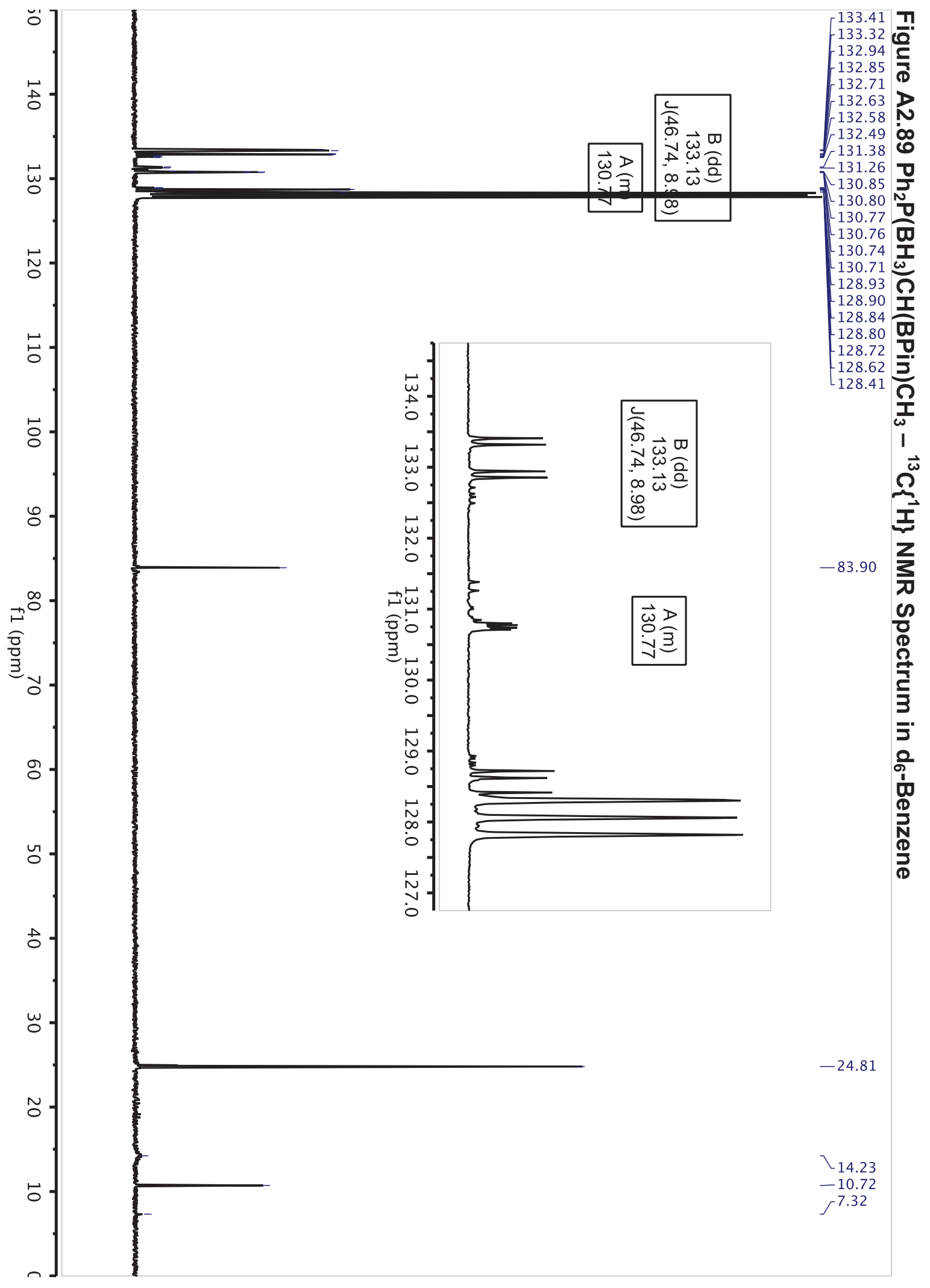




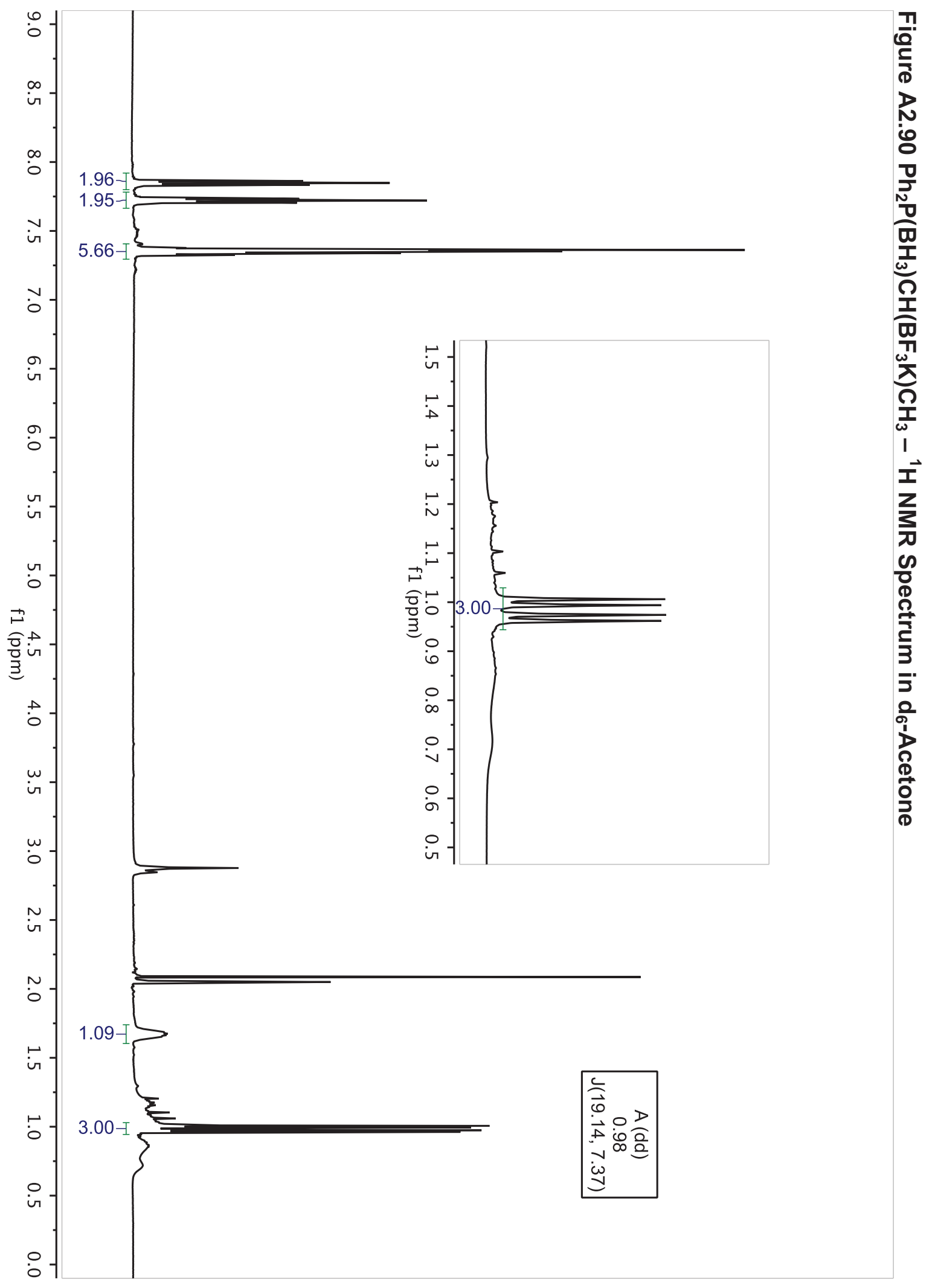




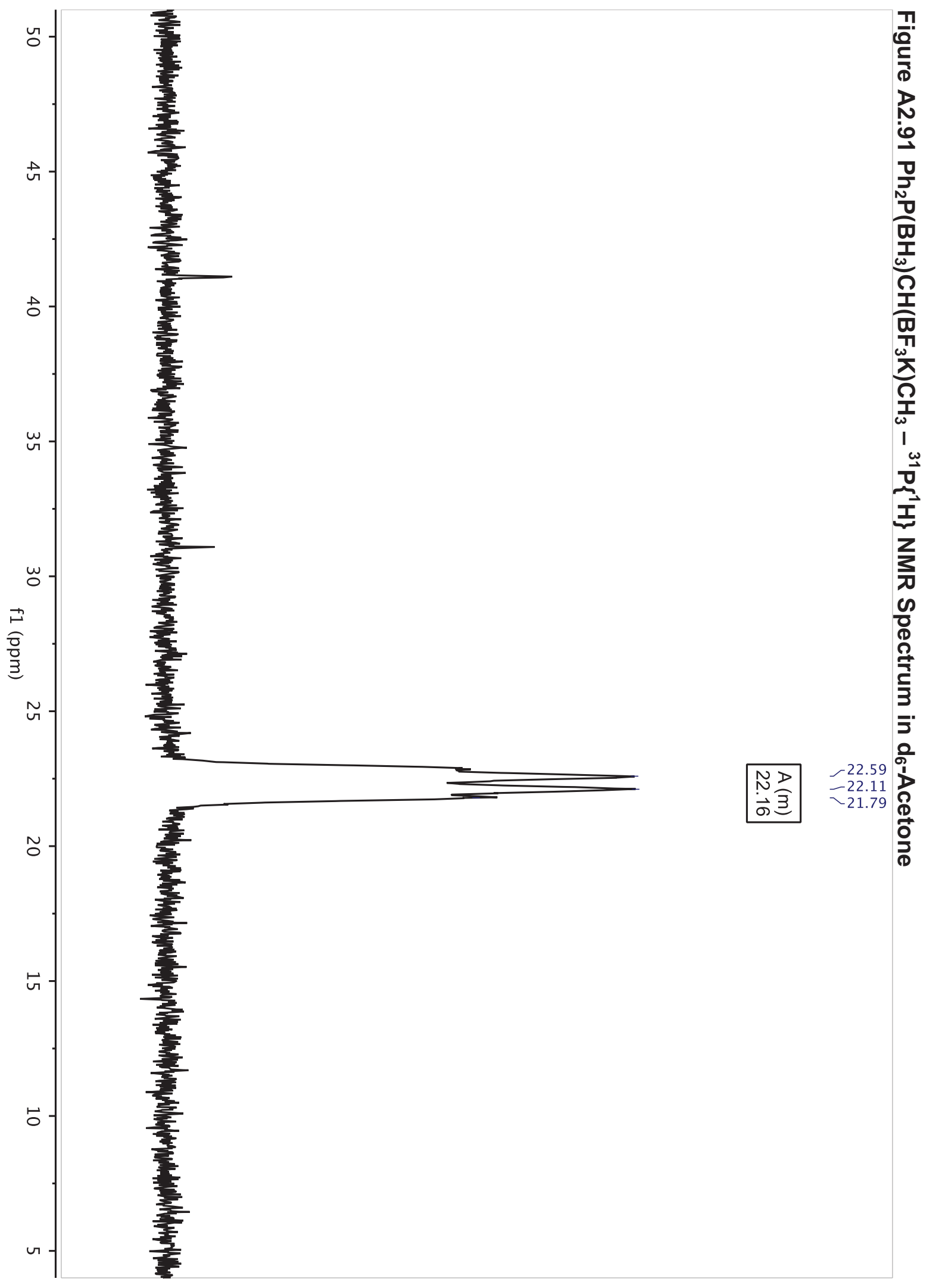




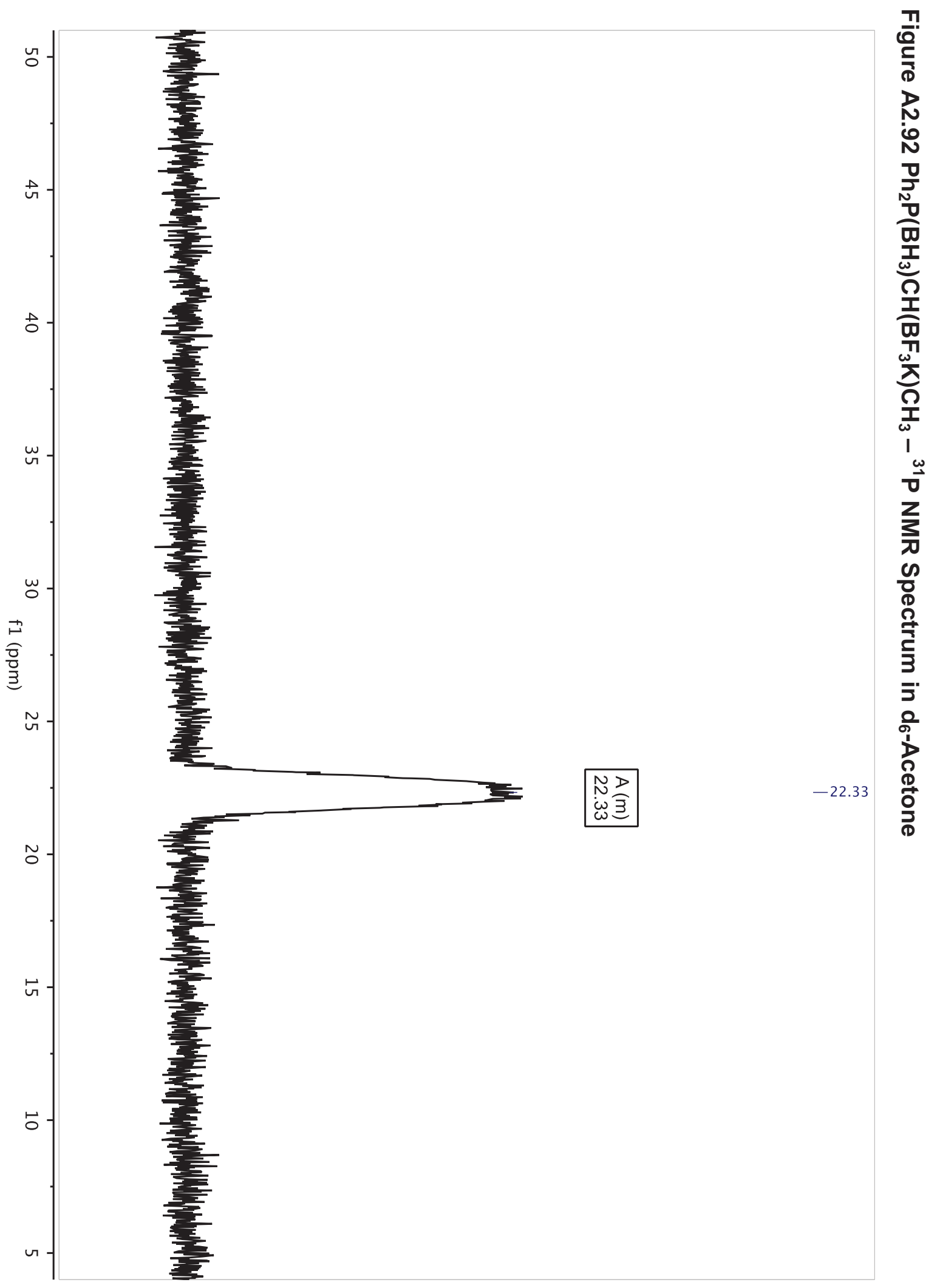




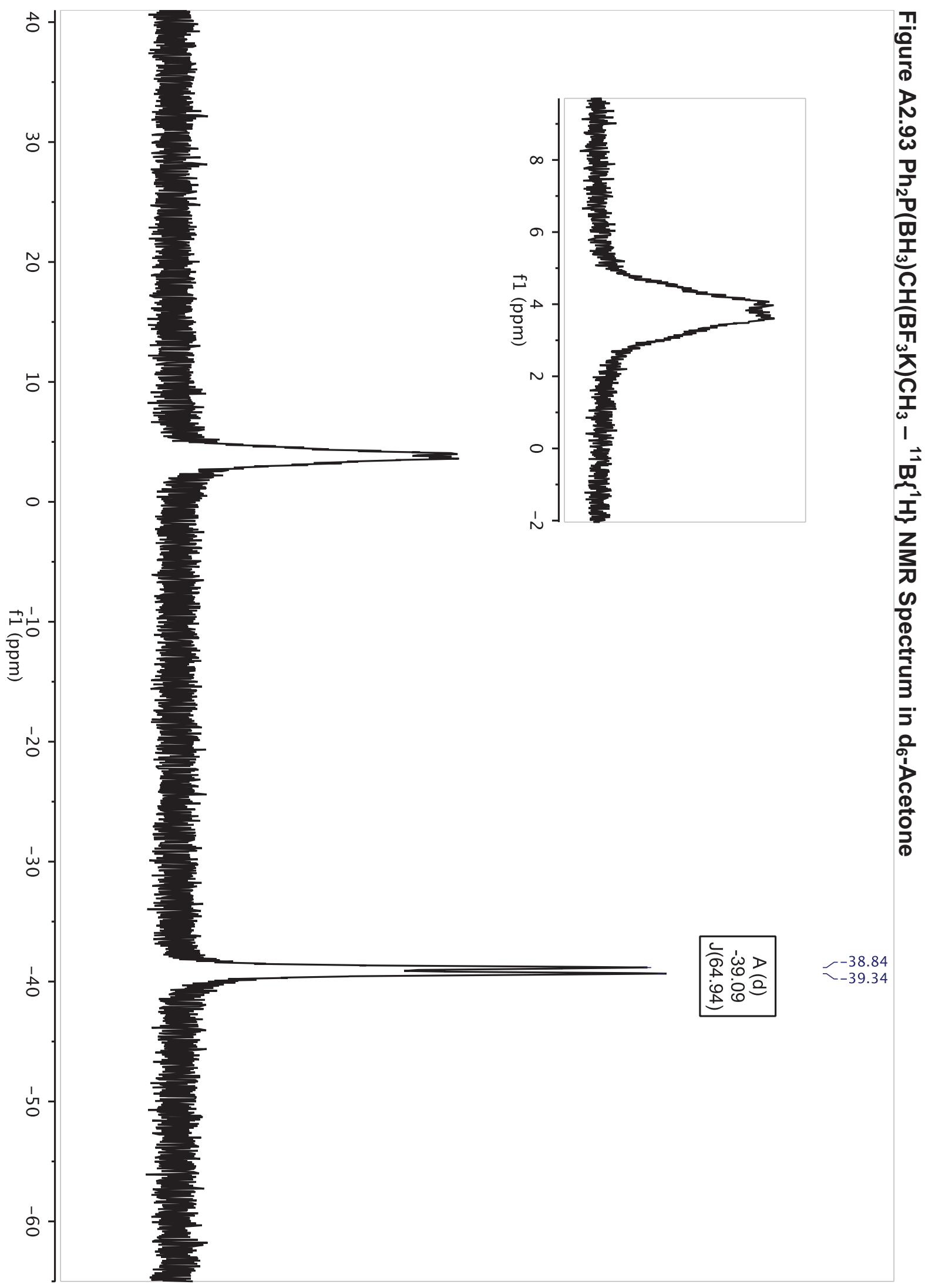




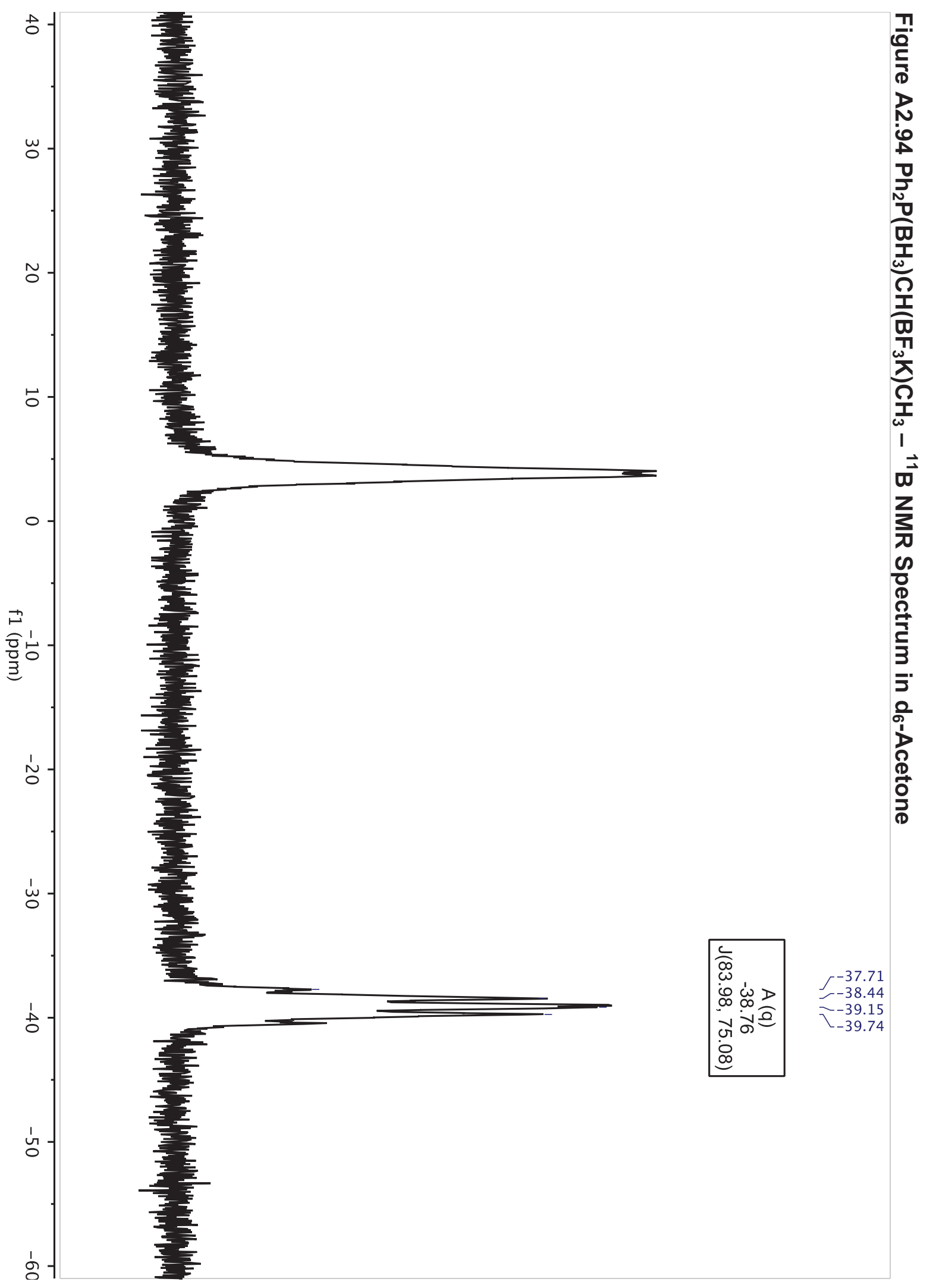




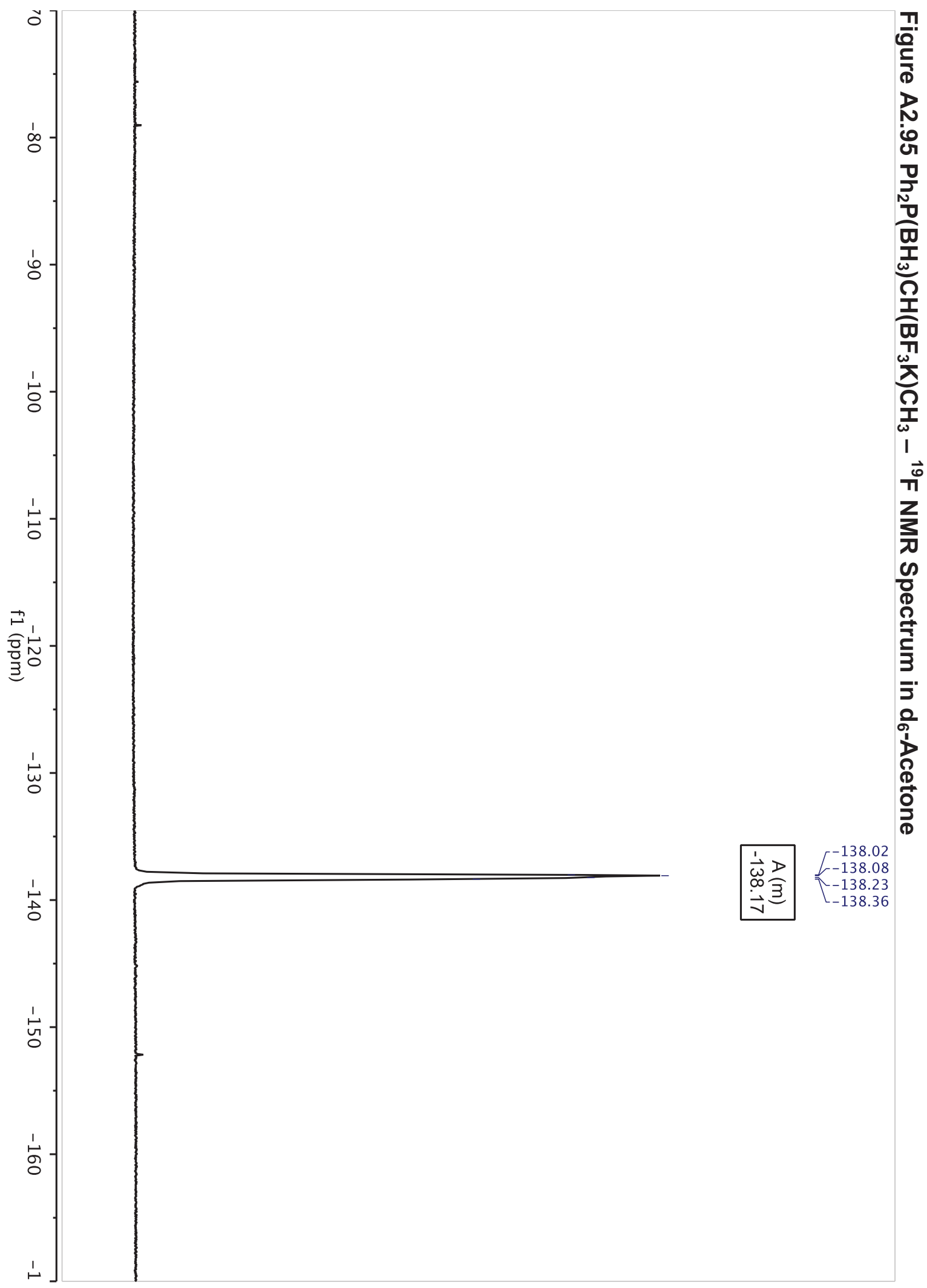




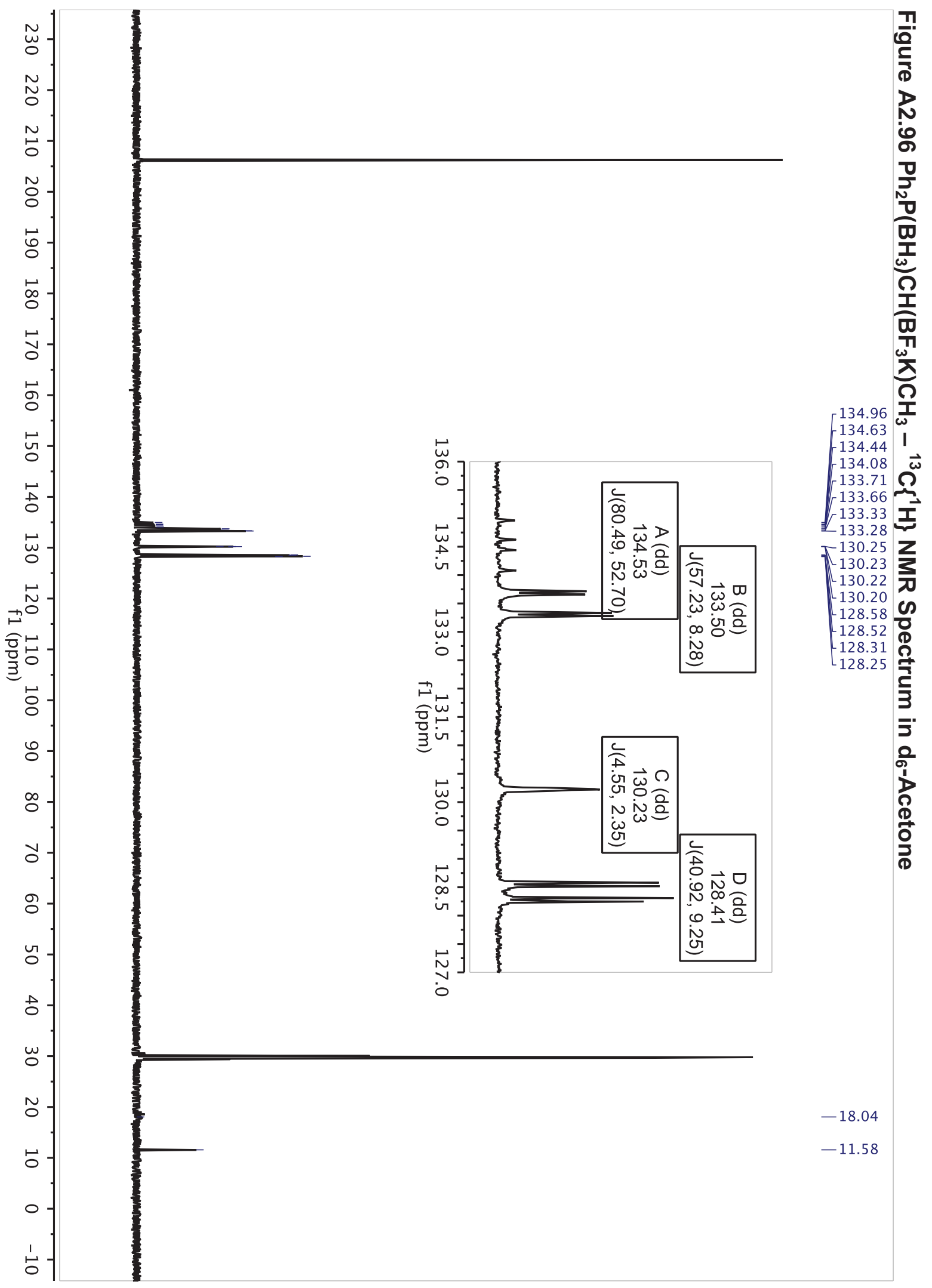




$$
F
$$


330

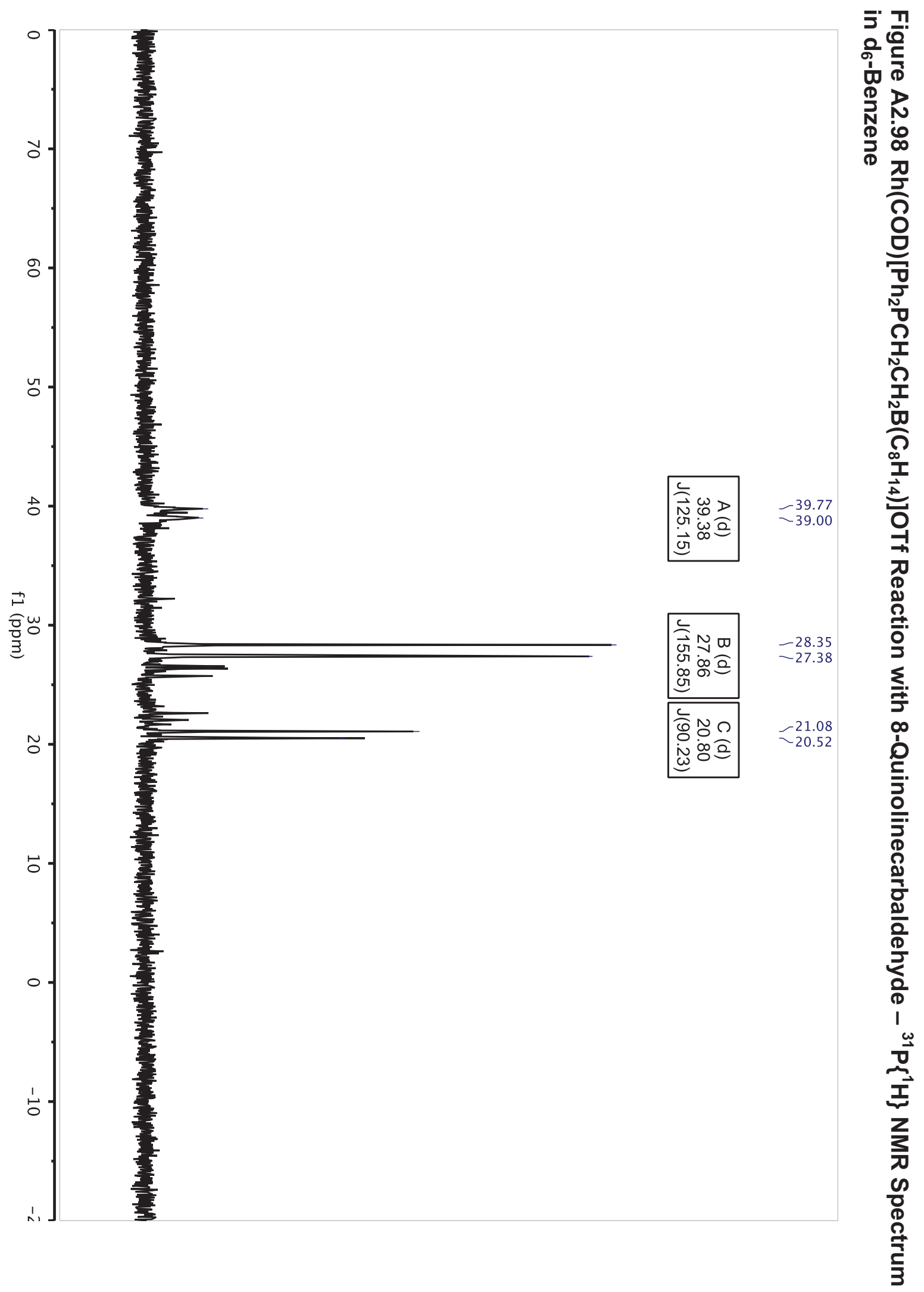




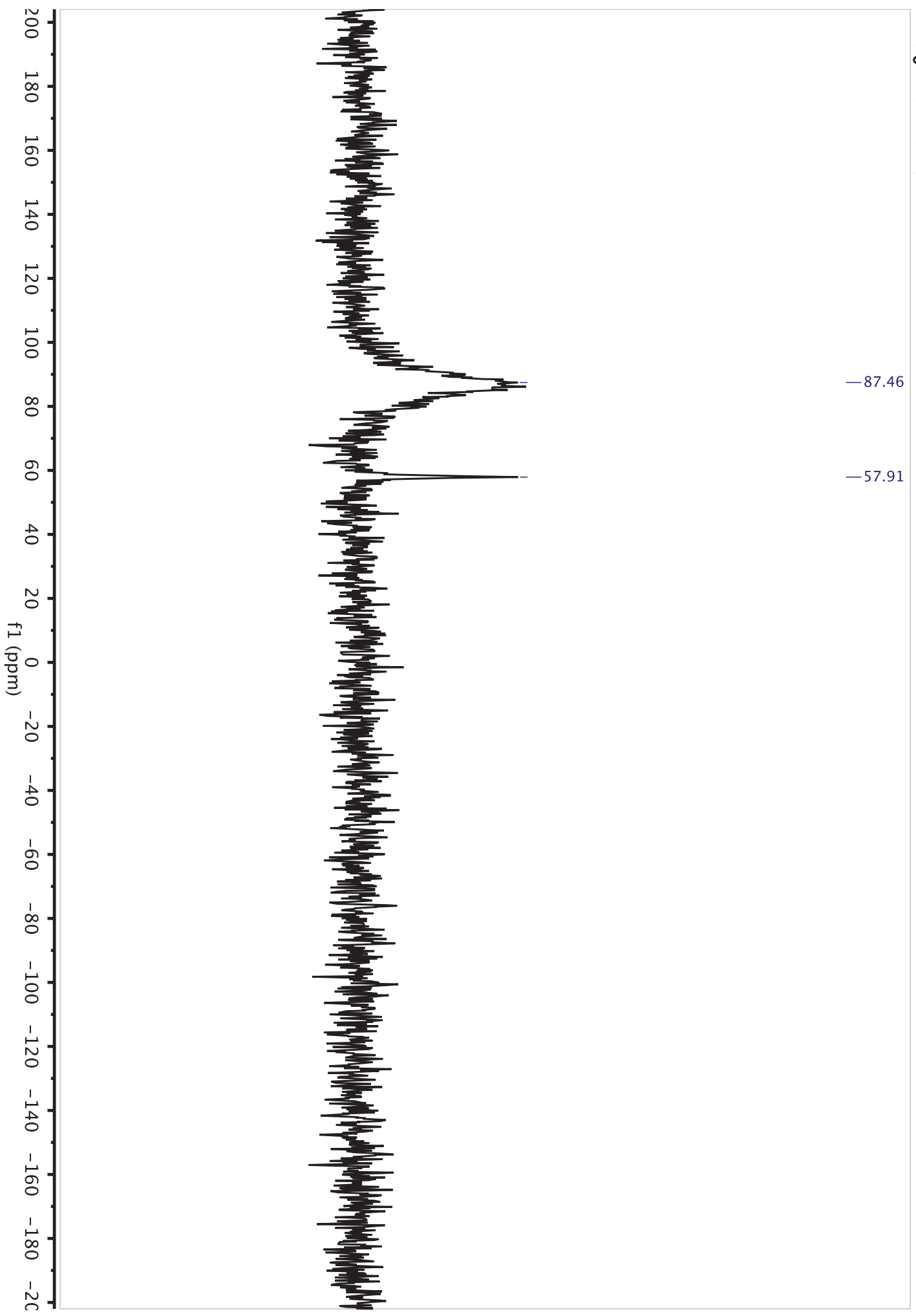

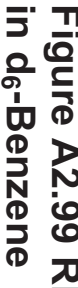

ลิ

음

T

品

I

$\Omega$

空

ก

$\stackrel{\infty}{I}$

옥

D

\%

$\stackrel{7}{\overline{0}}$

군

$\leq$

$\infty$

○

동

윽.

จ

?

긍

Ð

응

응

I

岢

I

紊

용

○

ड 


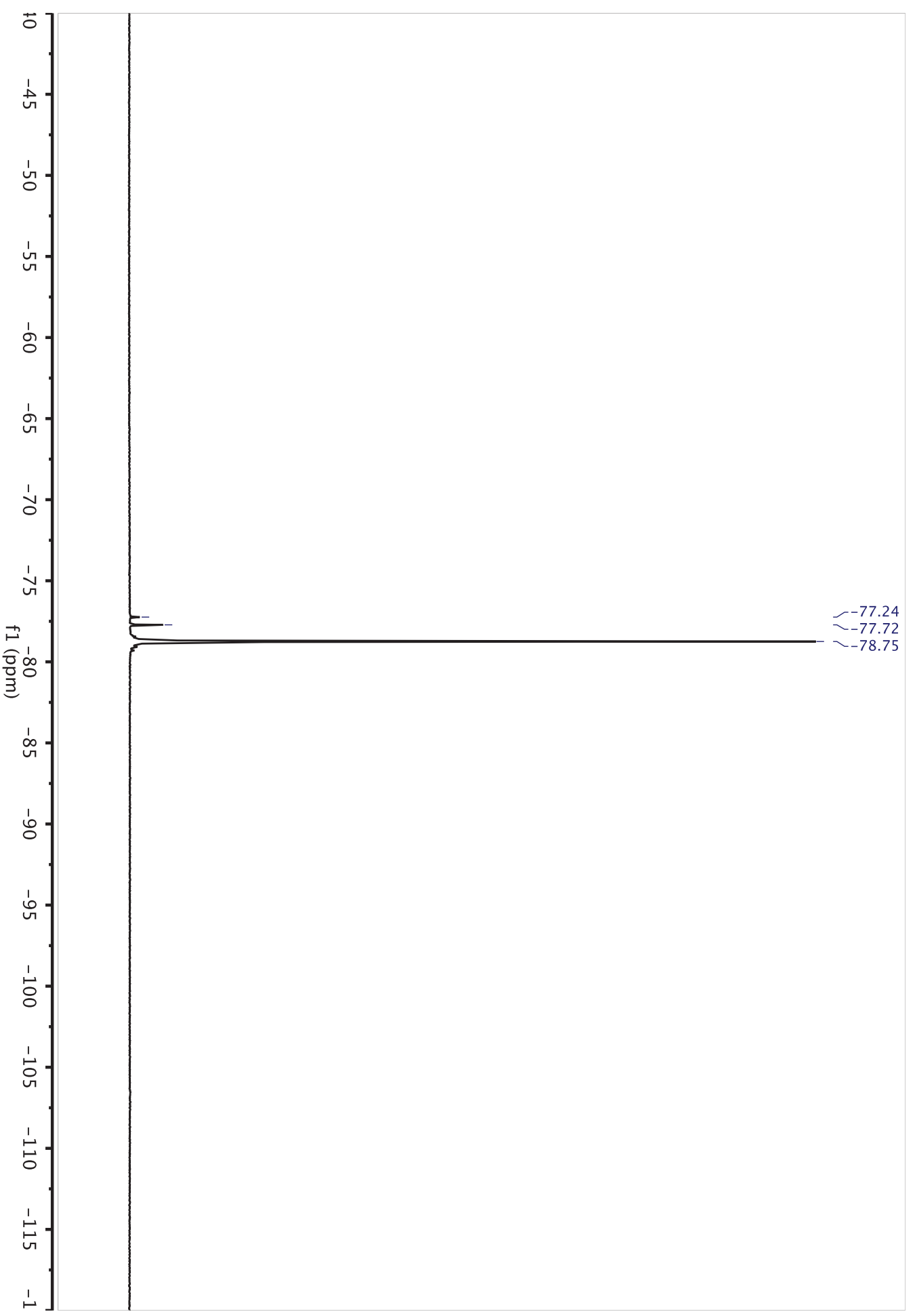




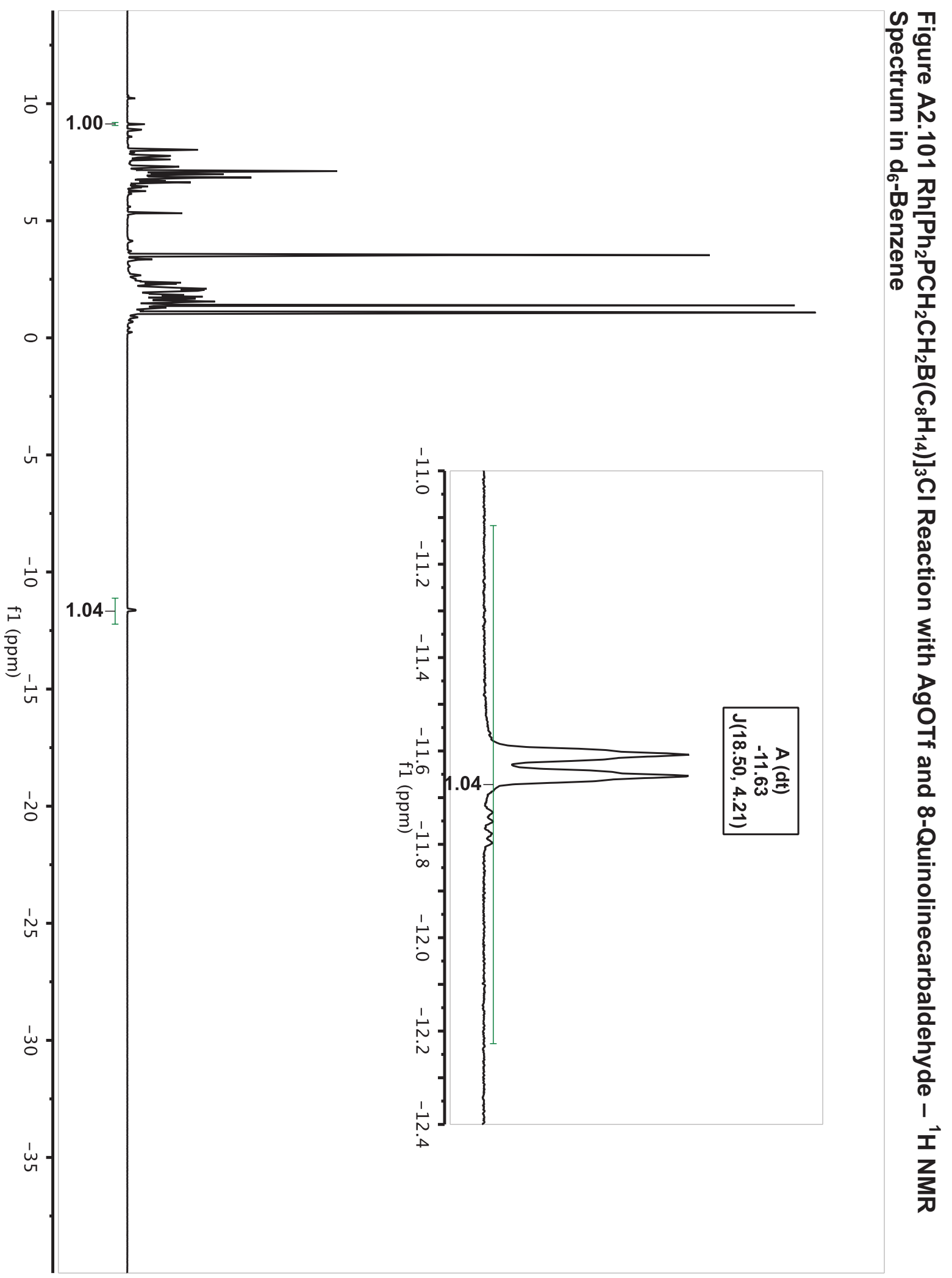




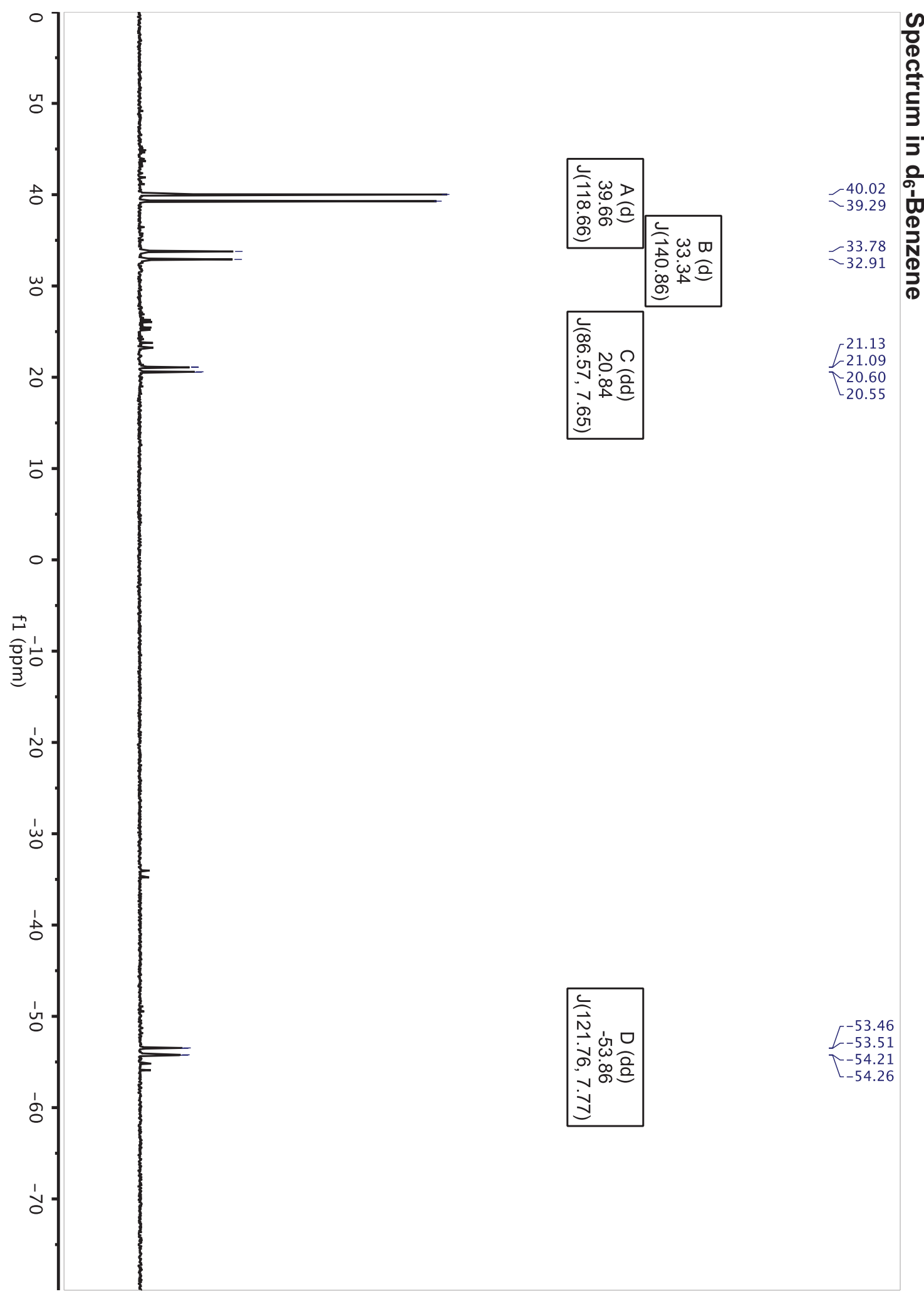

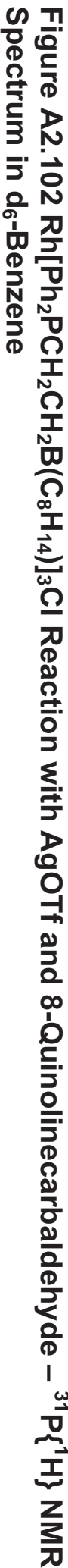




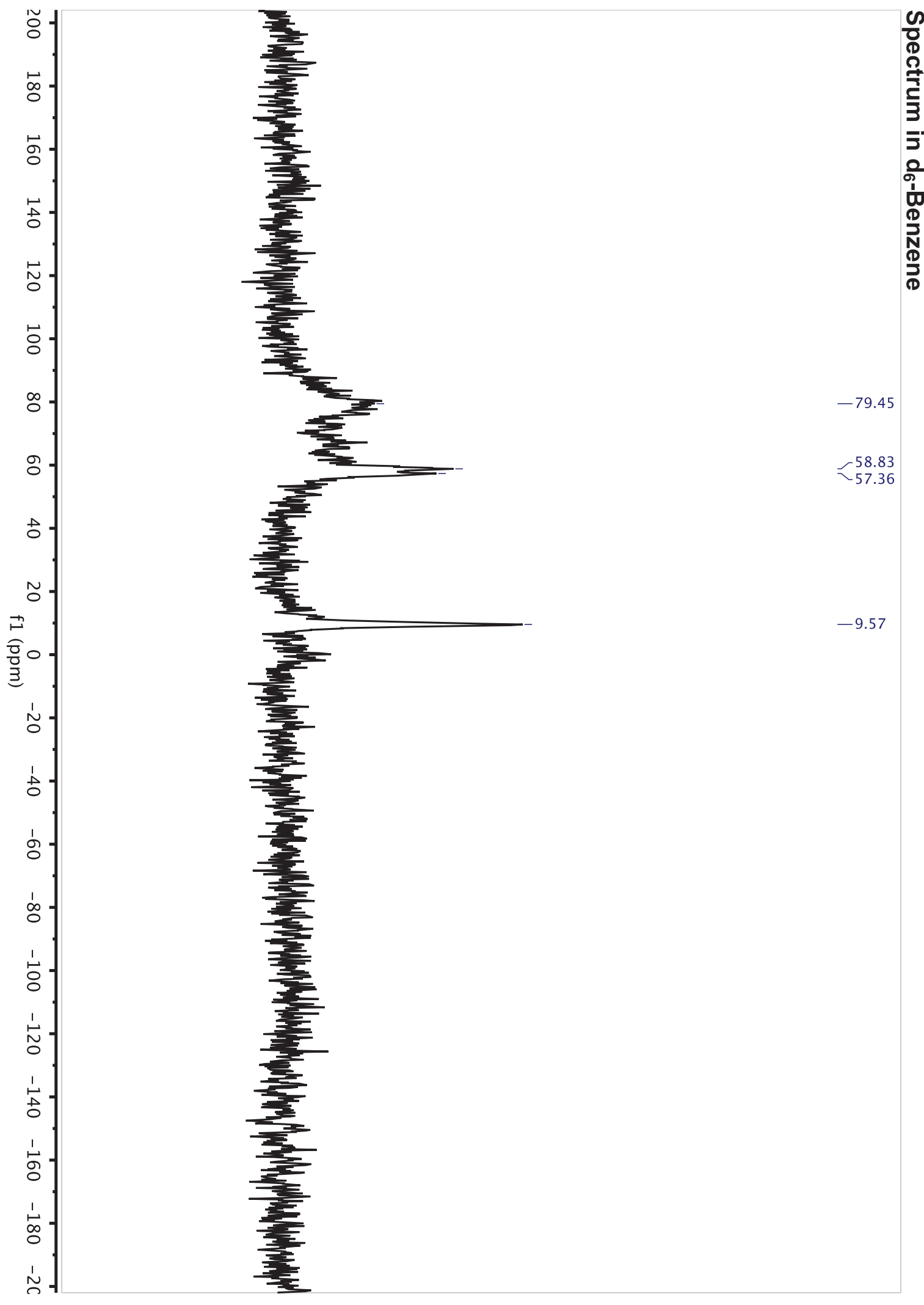

능

옥

ह

$\overline{5} \overrightarrow{0}$

ㅇ

D

Ф

N

T

T

$\Omega$

T

อ

$\infty$

I

E

으

D

叹

ก․

군

$\Sigma$

8

욱

$\stackrel{0}{2}$

$\infty$

อ

ㄷ.ᅳ.

을

จ

ค

궁

임

음

응

I

تِ

ż 

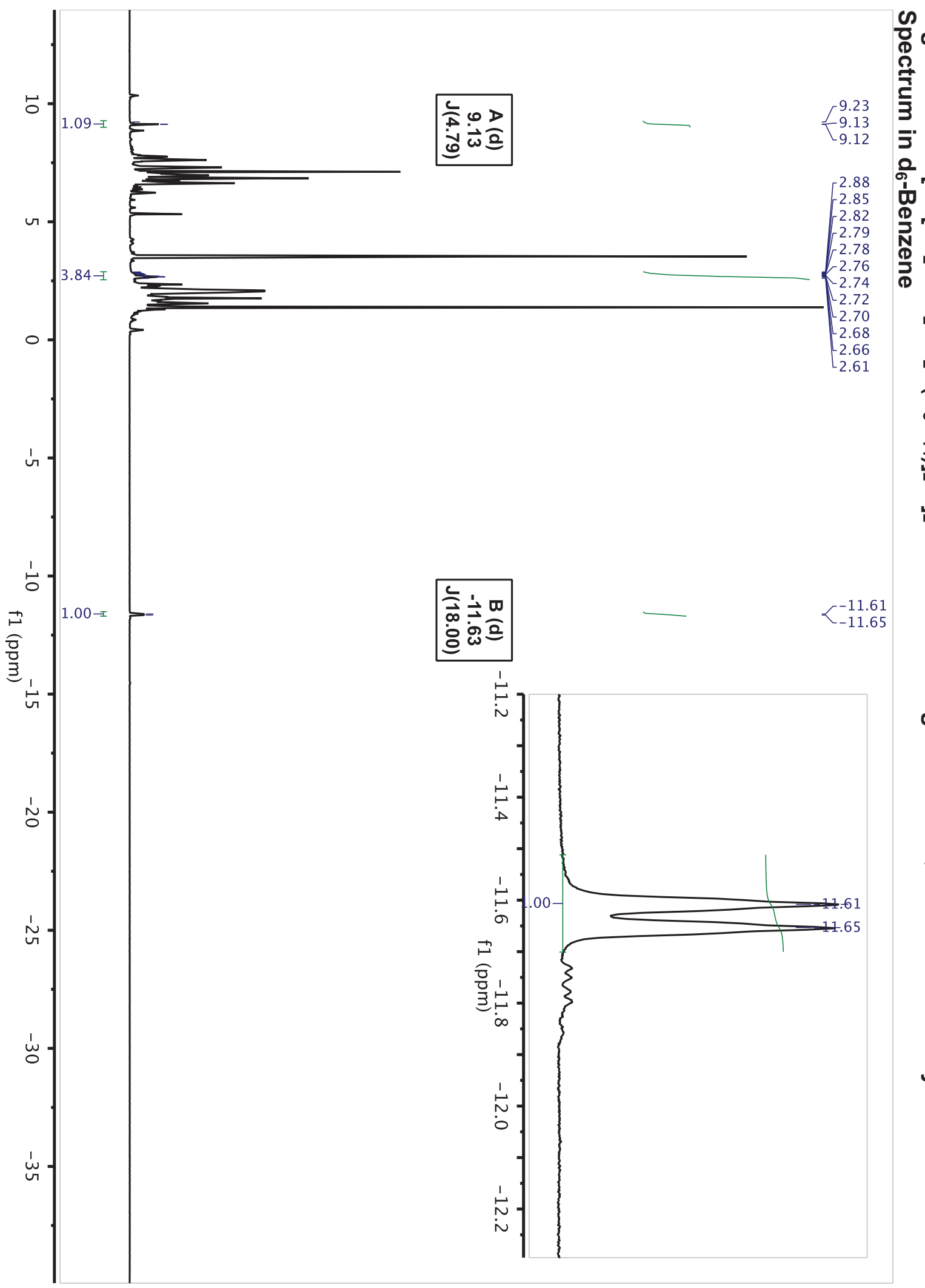

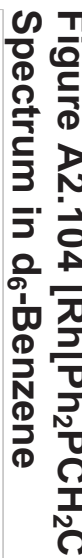

早

$\frac{\infty}{\Omega}$

$\stackrel{\infty}{=}$

E

를

D

禺

$\stackrel{2}{=}$

욱

$\leq$

紊

6

ำ

$\infty$

일

득.

$\overline{\bar{z}}$

๑

국

อ

응

ํㅏㄴ

(D)

$\frac{\vec{I}}{z}$ 

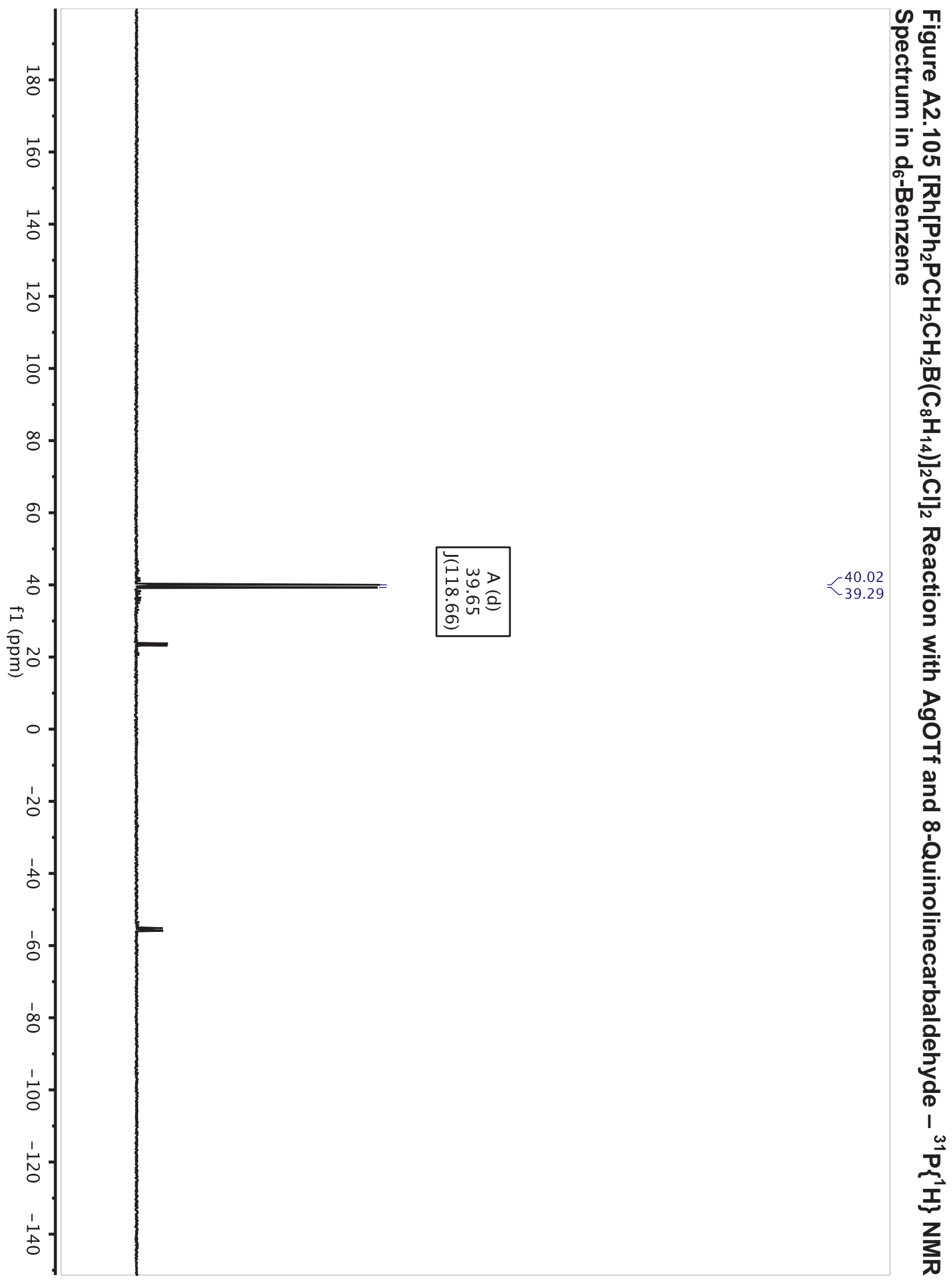


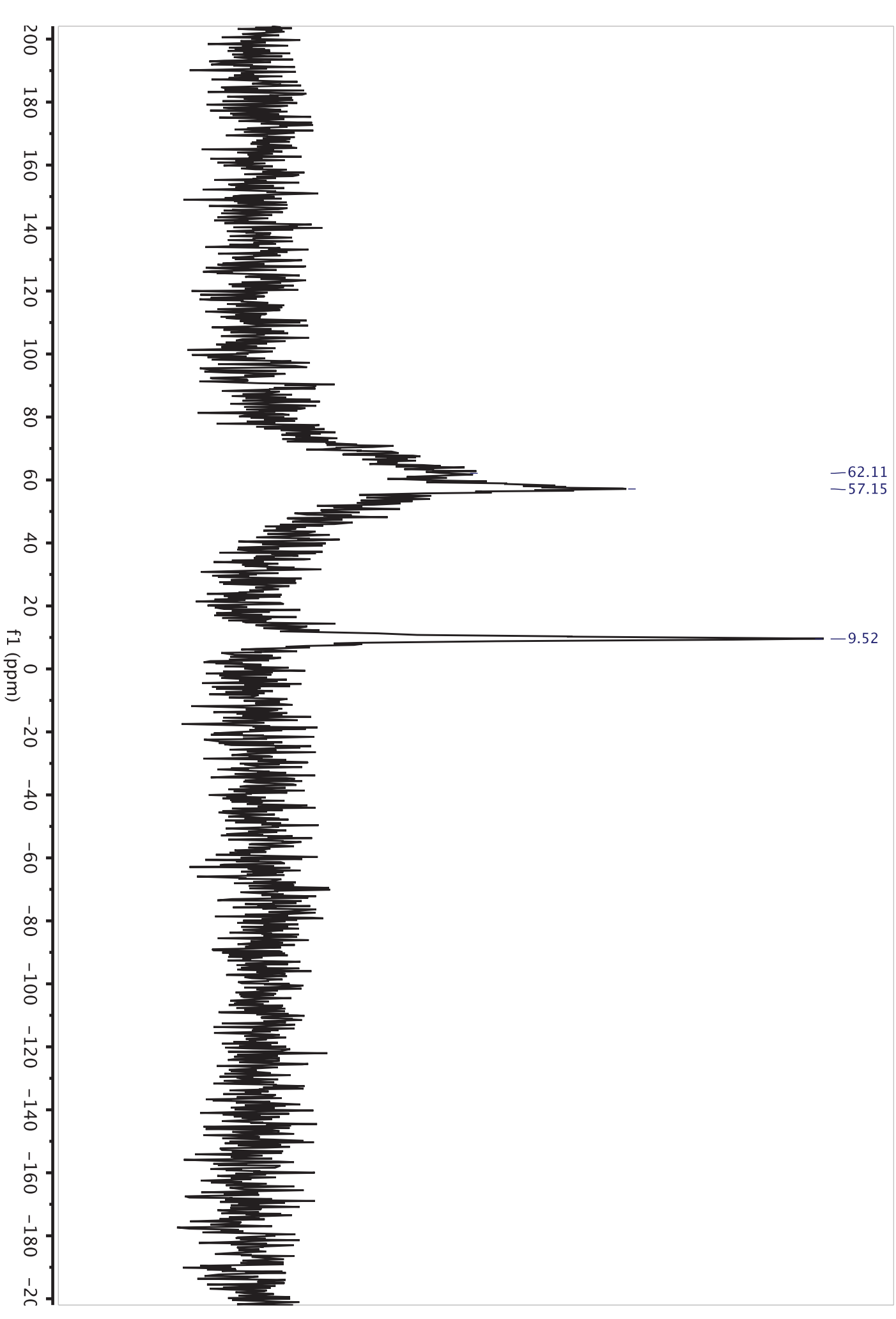


339

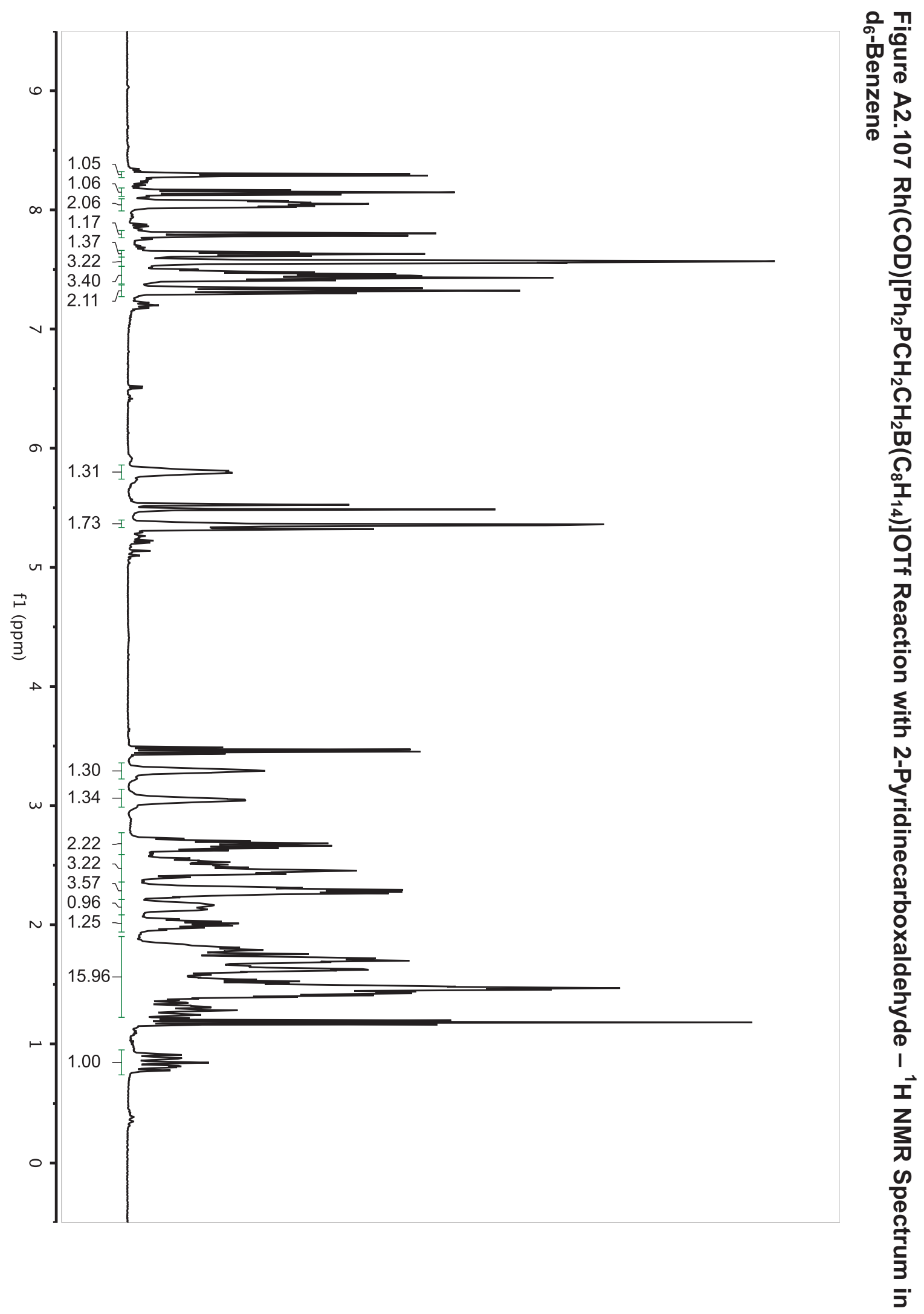



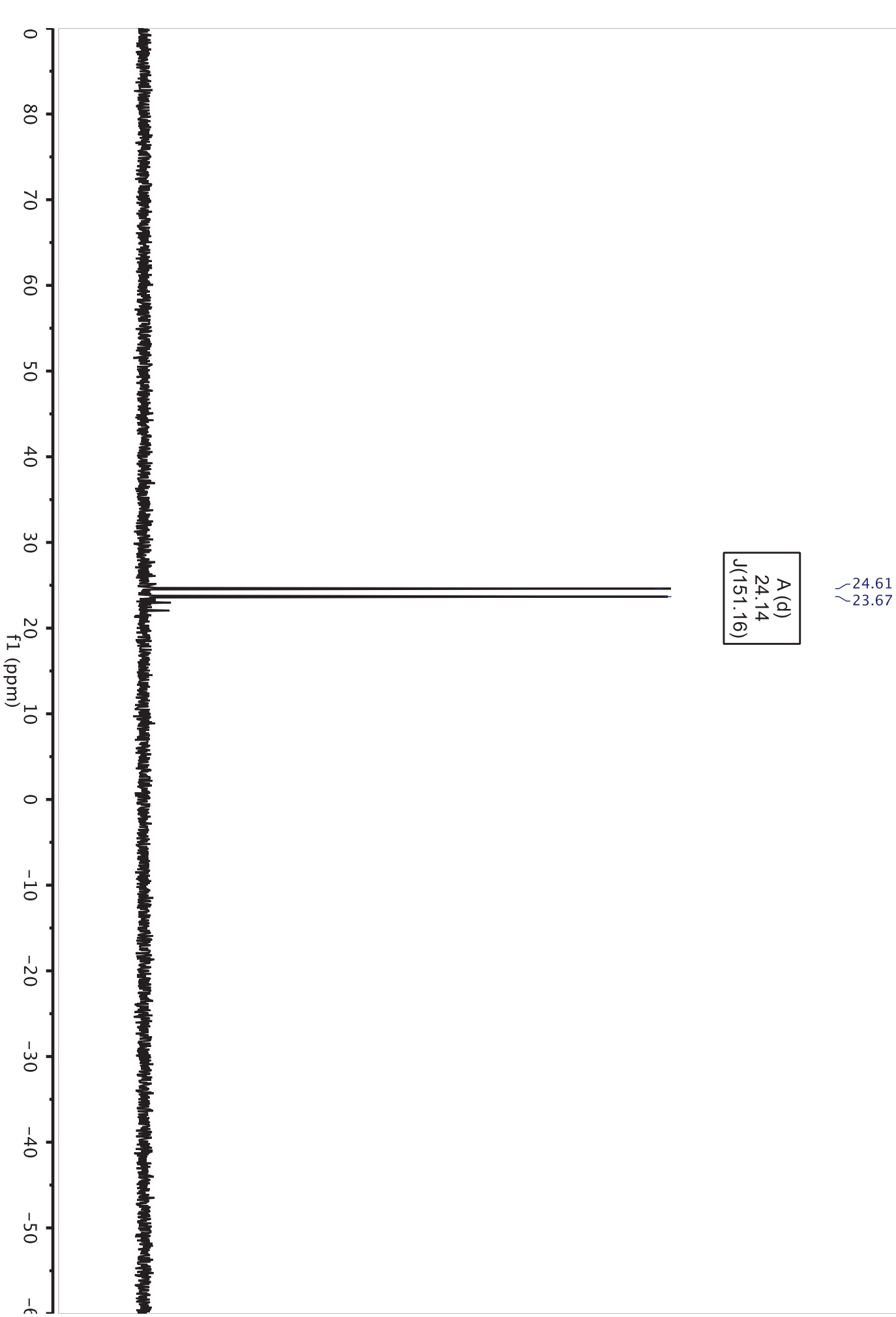

กำ

음

$\Sigma$

F

N

\.

흘

จ

ำำ

움

음

$\frac{\frac{0}{10}}{\frac{0}{10}}$

I

$\stackrel{\omega}{\square}$

章

紊 


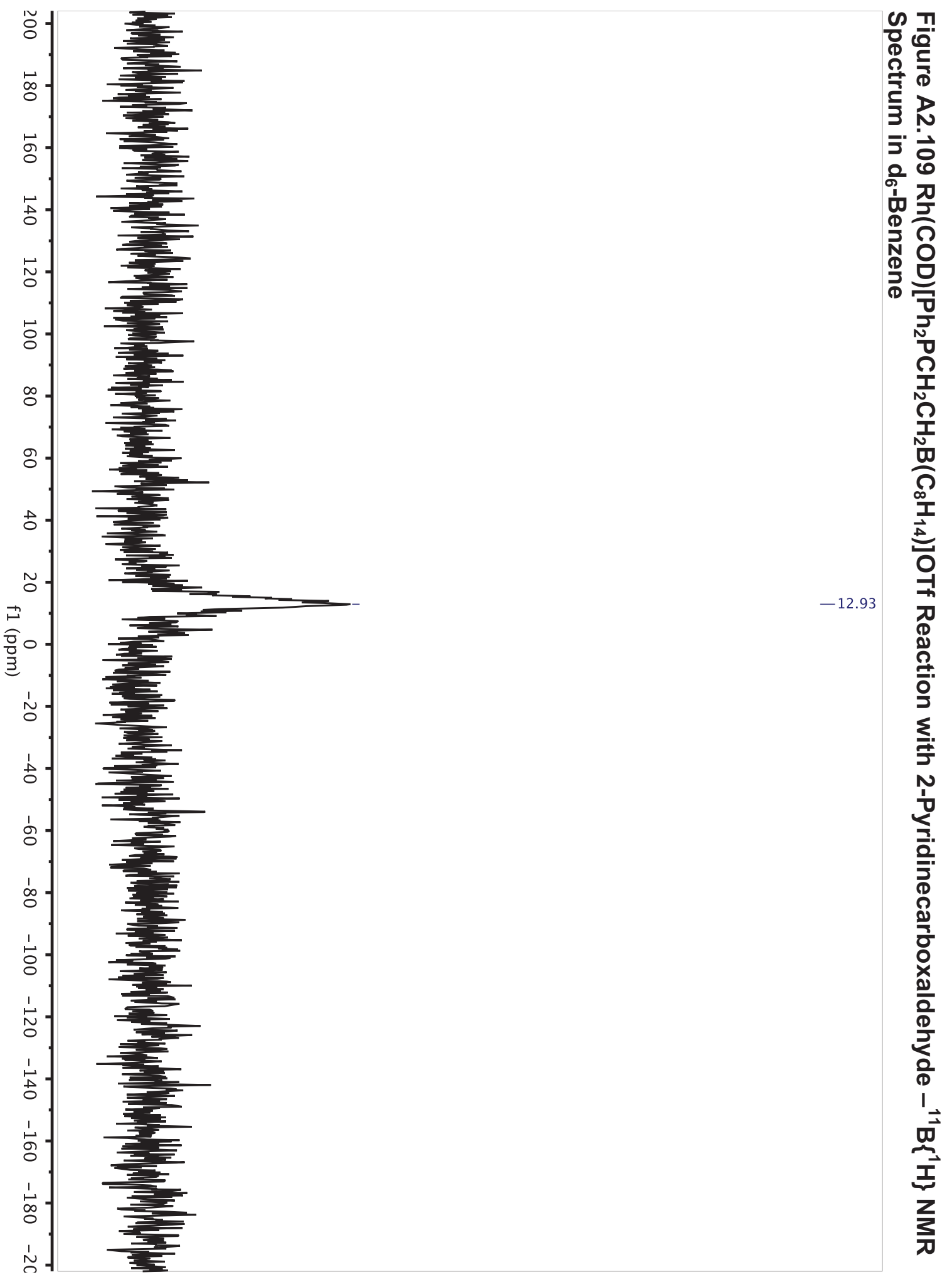



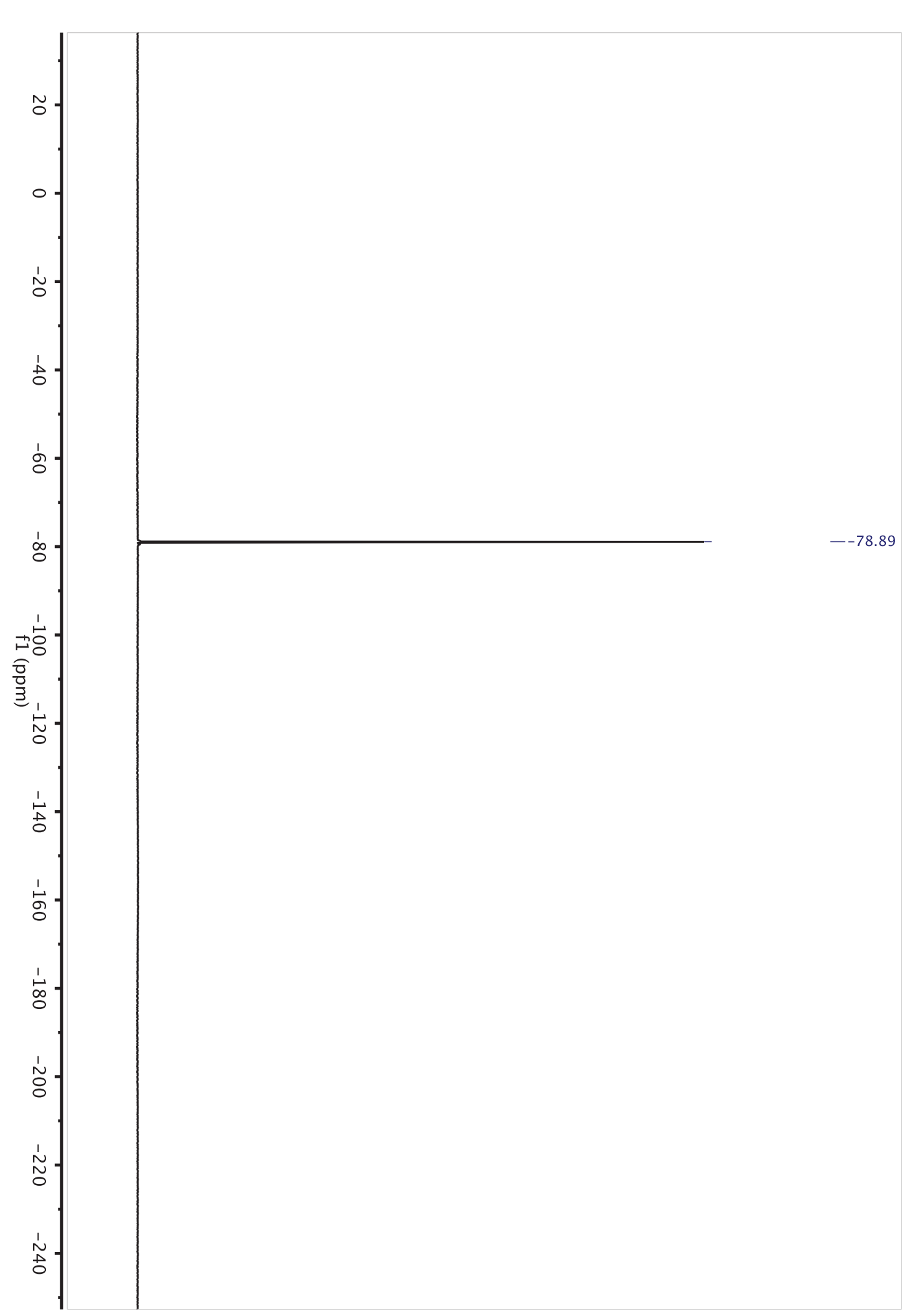

$\infty$

T

윽

D

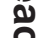

웅

$\Sigma$

章

N

들.

을

긍

ำ

음

$\frac{\frac{1}{2}}{\frac{0}{10}}$

I

$\vec{T}$

紊

c)

유

올

5 

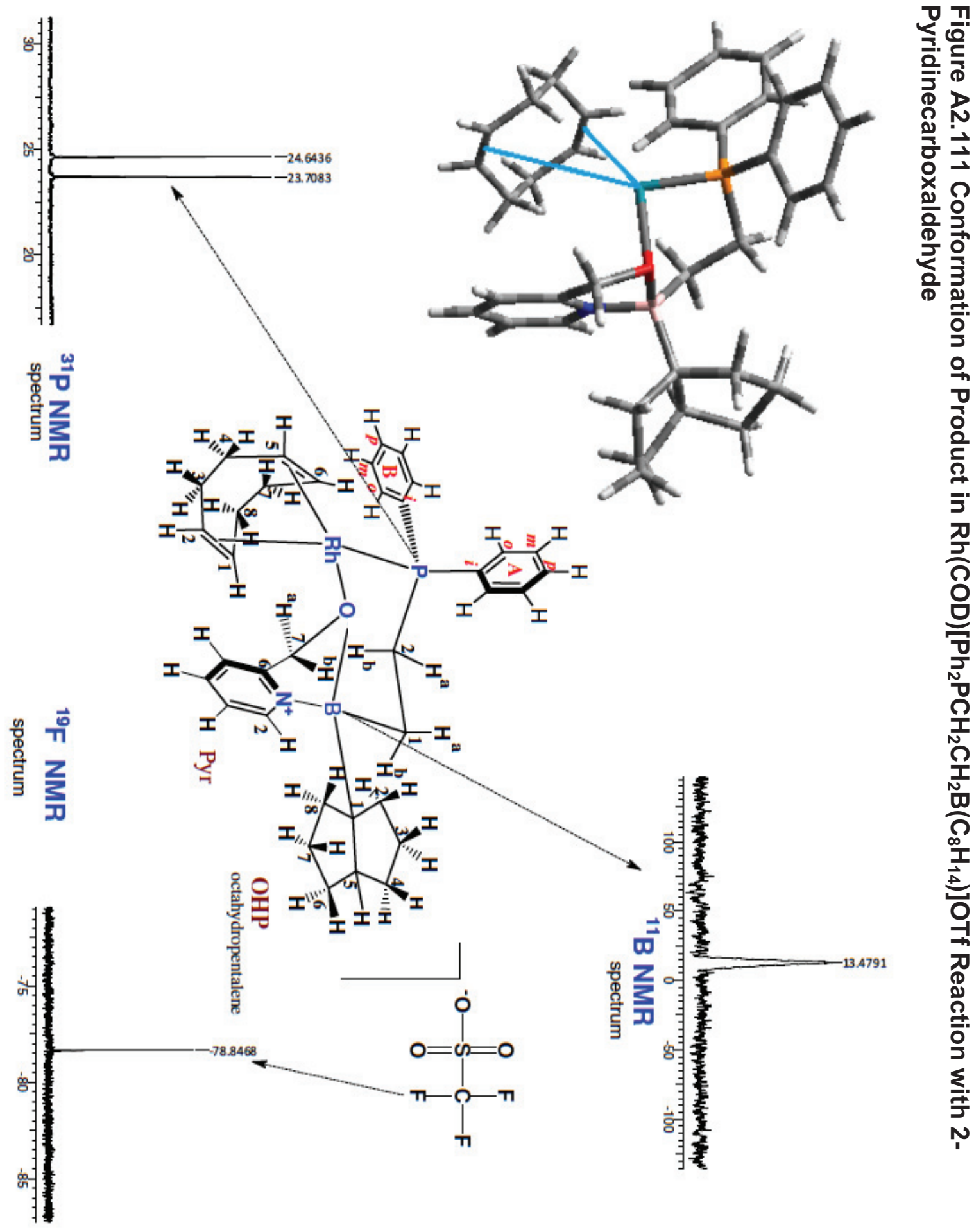

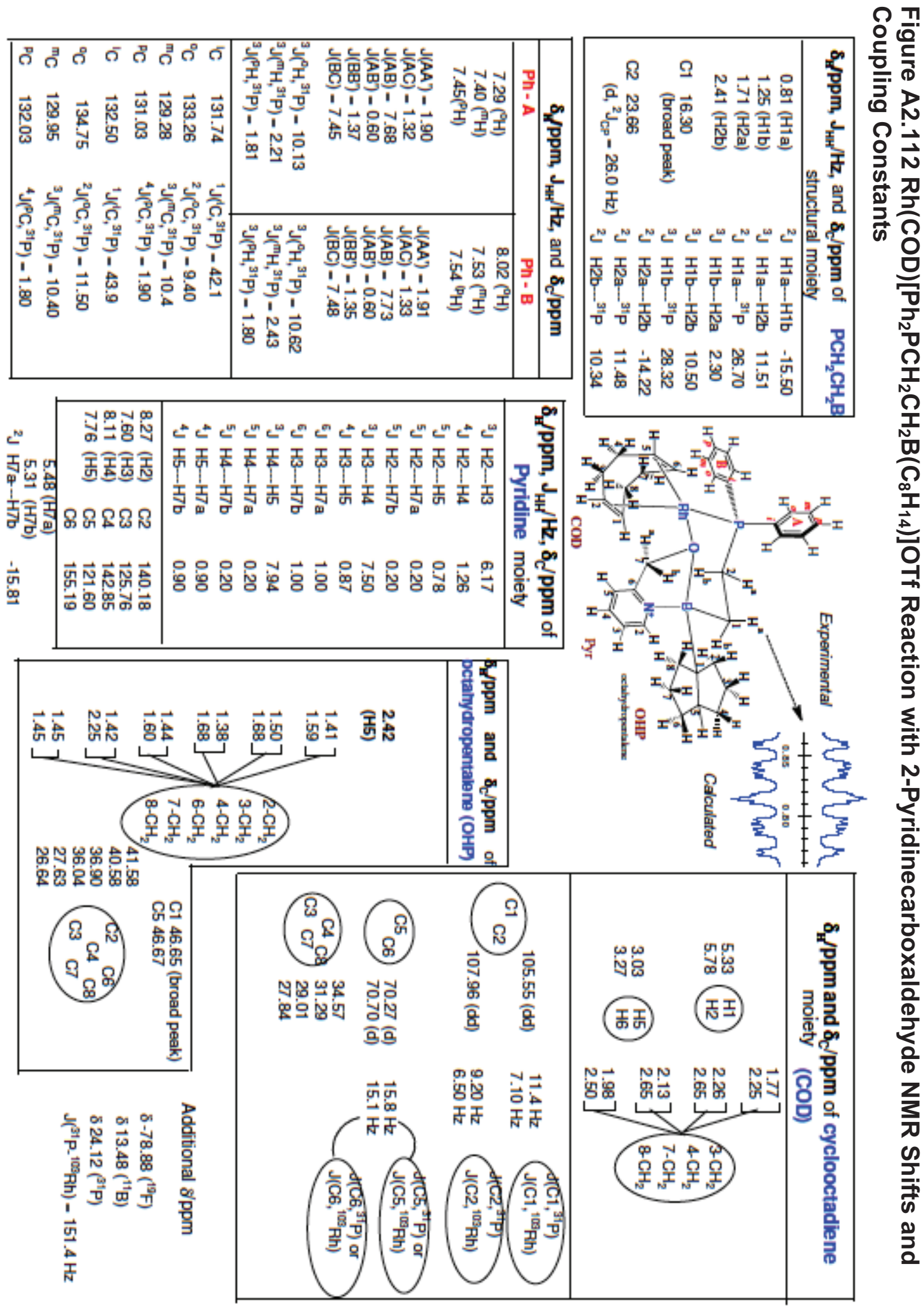

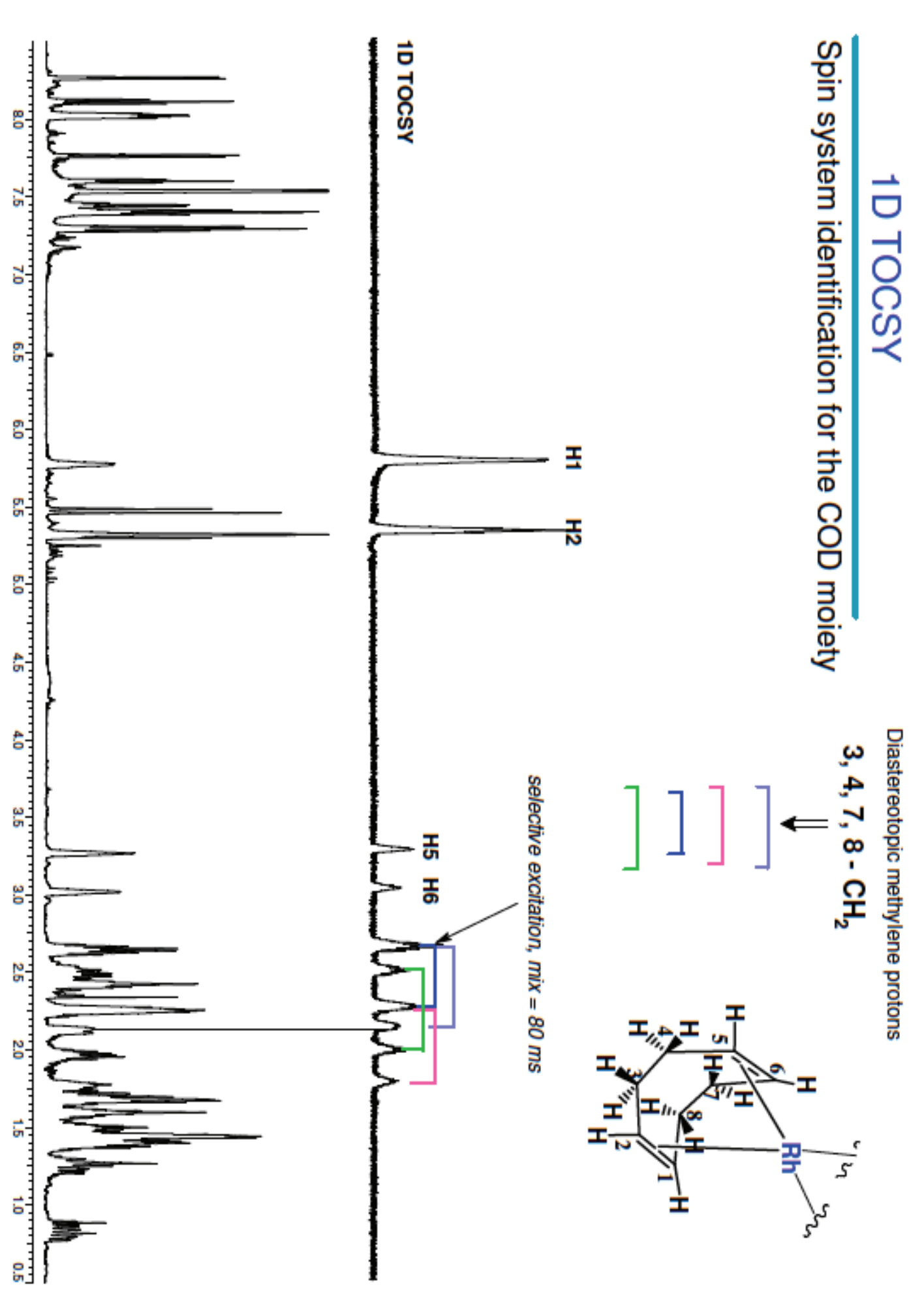

끼 꾸

\&

을

品

思 $\overrightarrow{\vec{c}}$

즘

อ

음

T

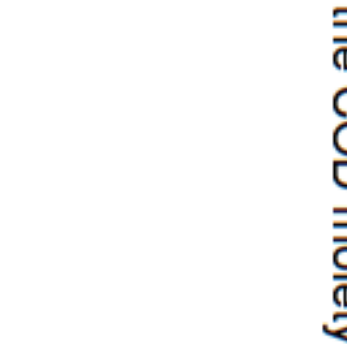



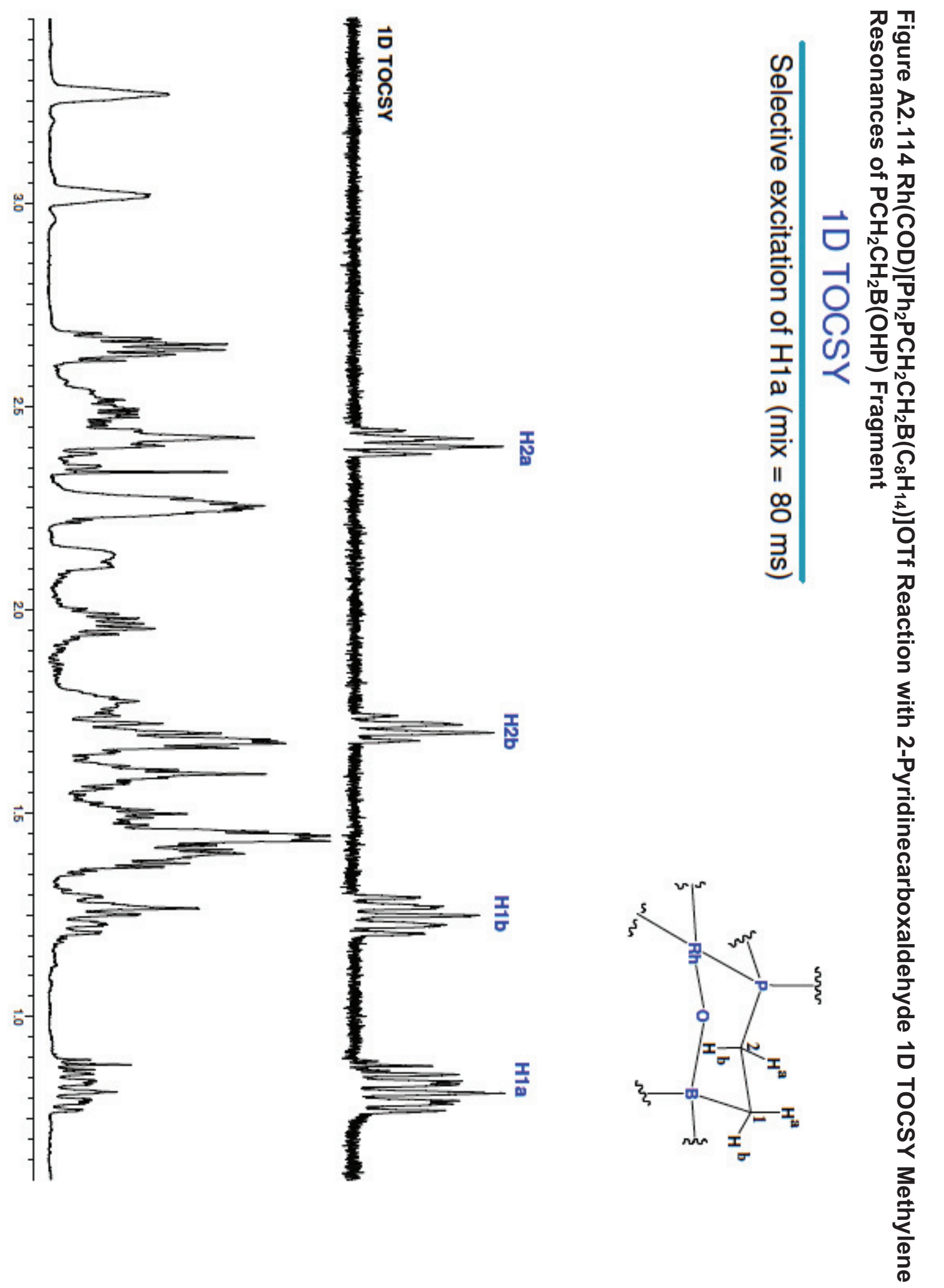

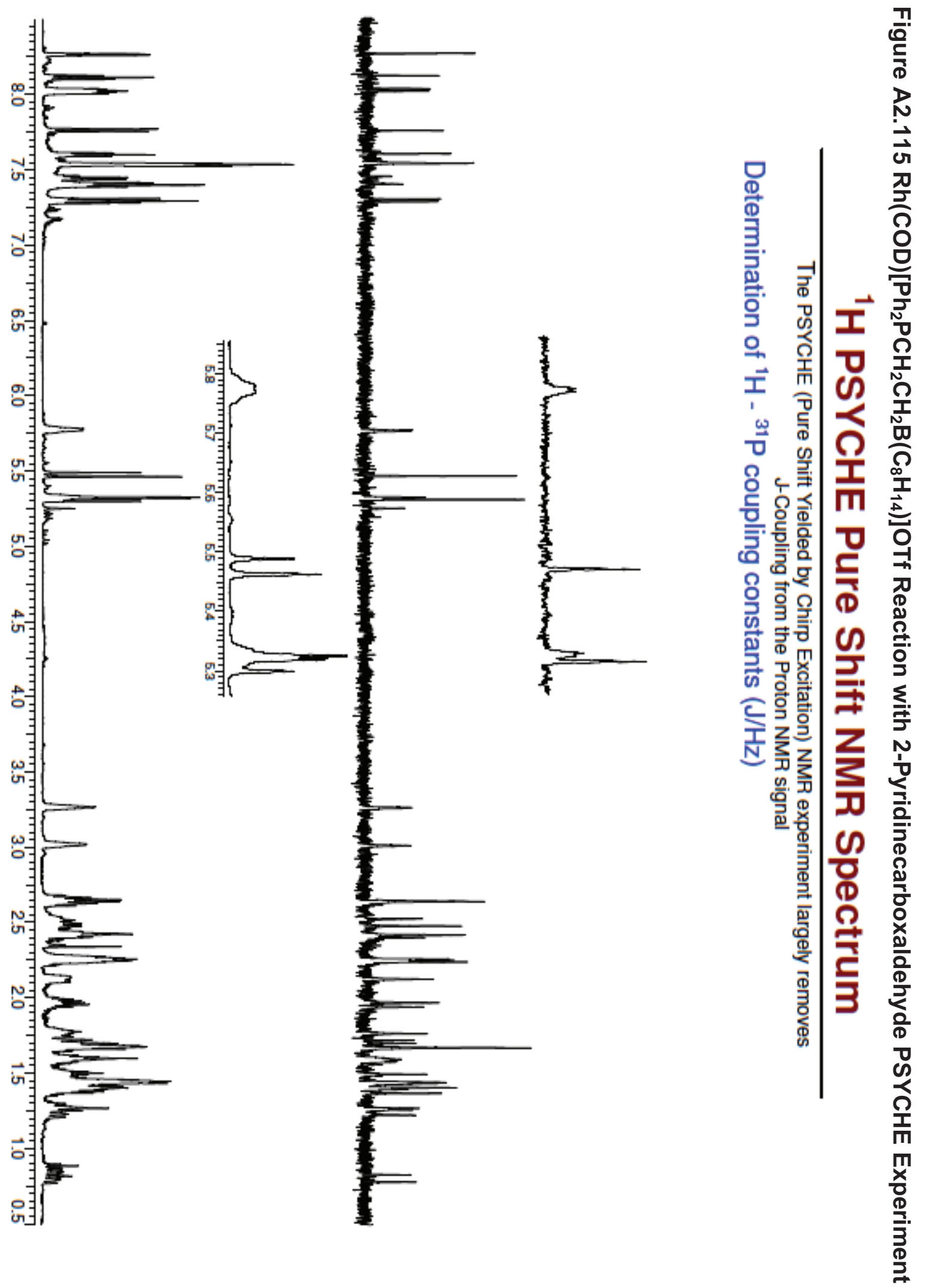


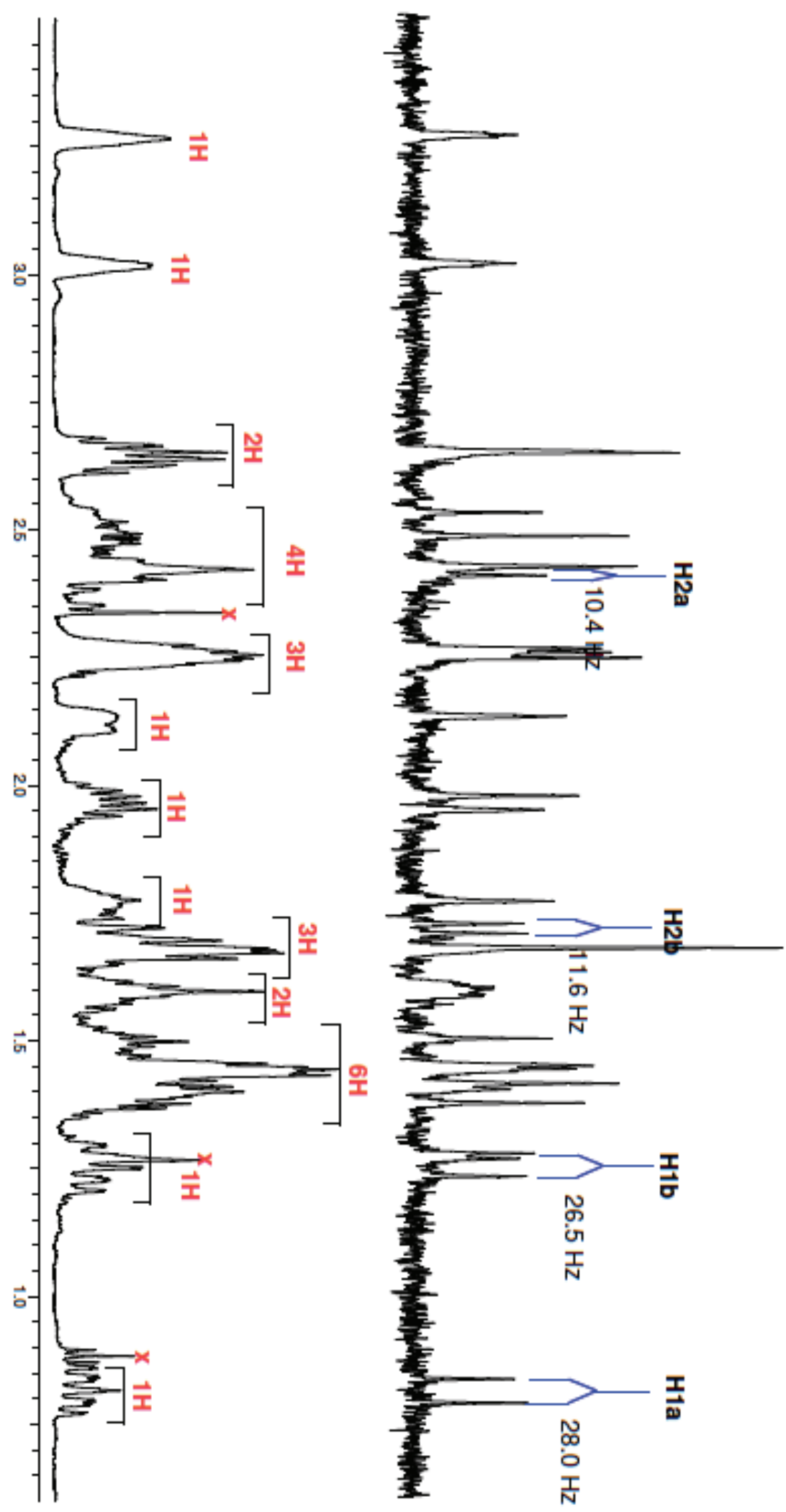




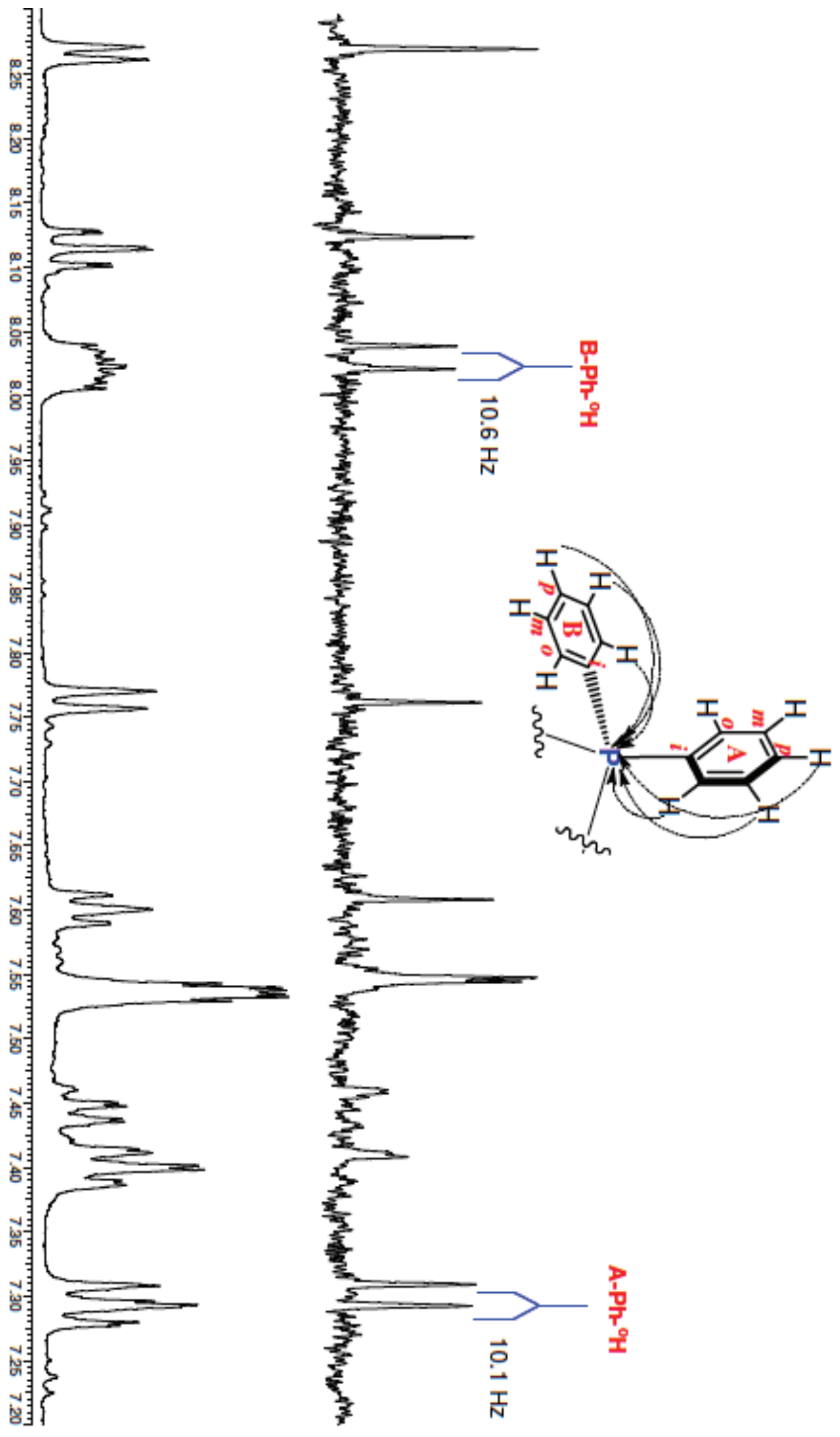




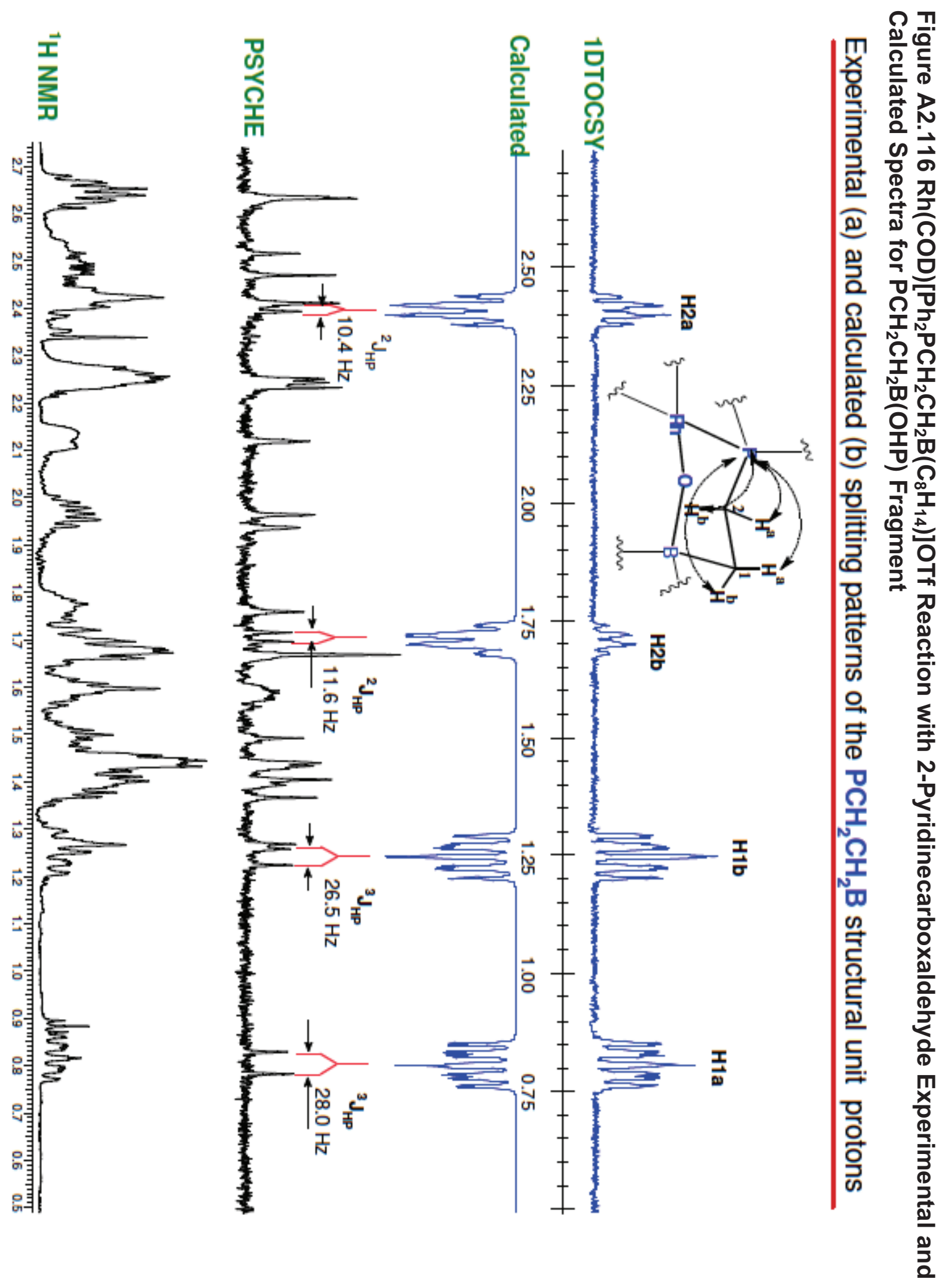




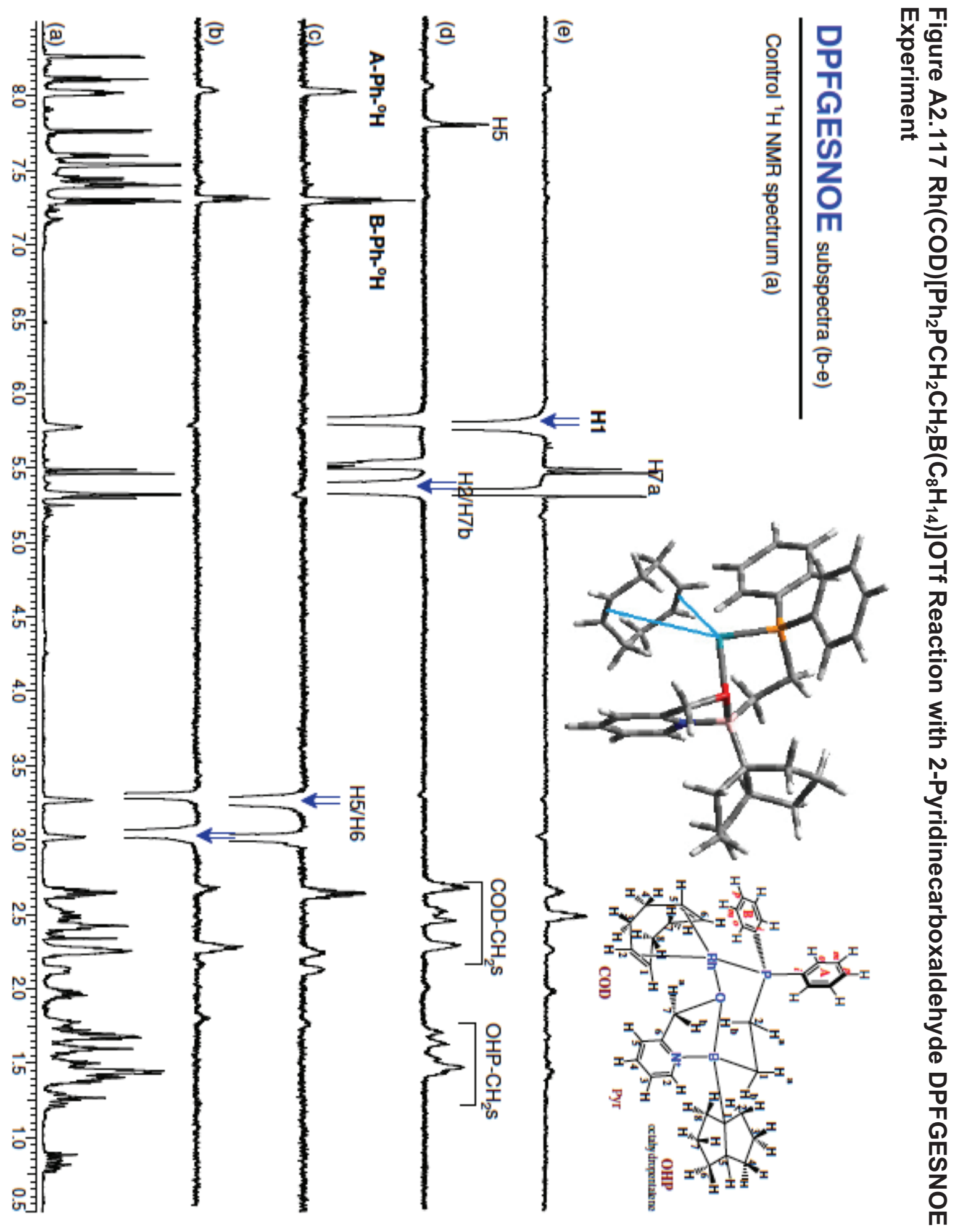




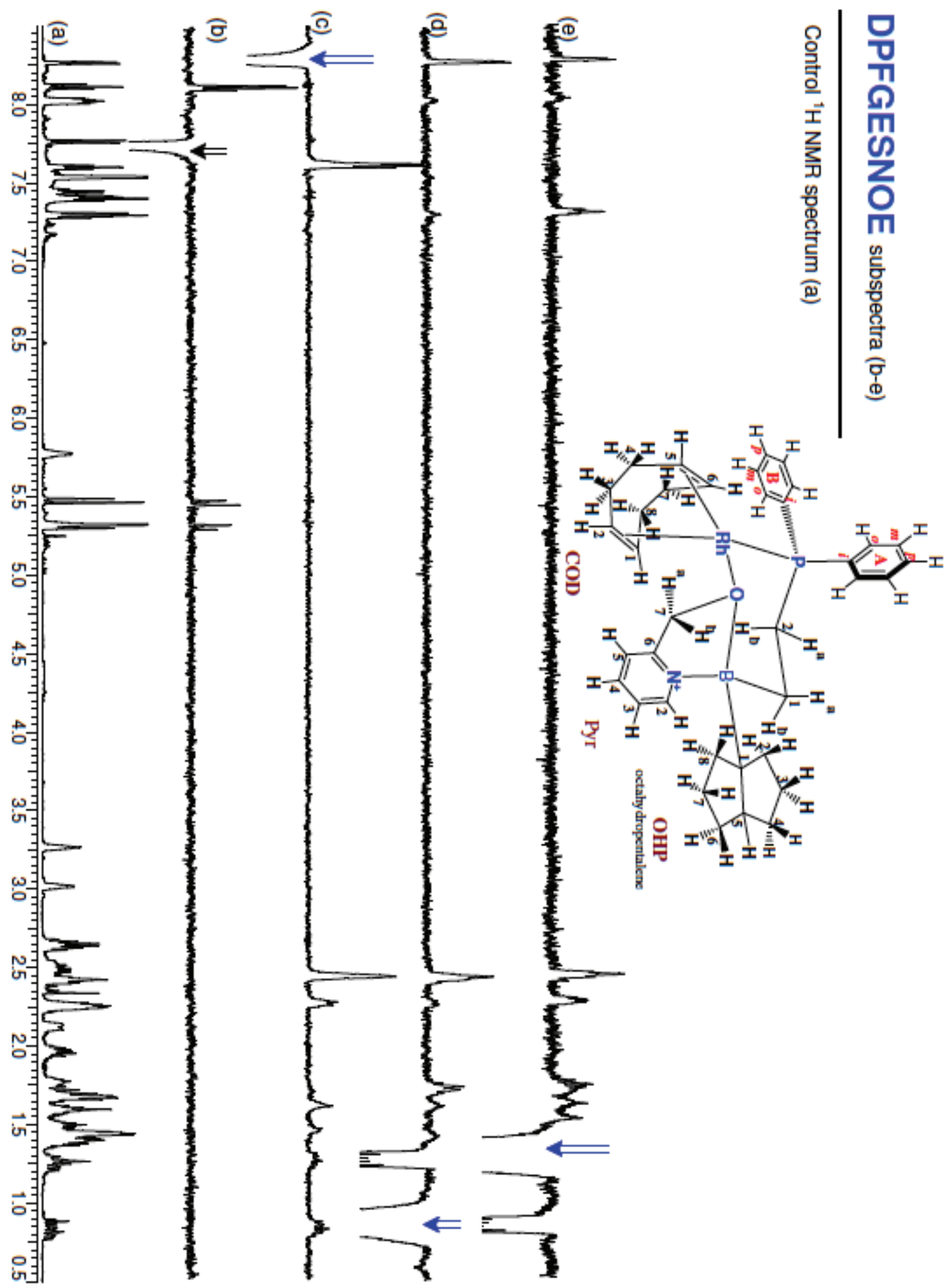




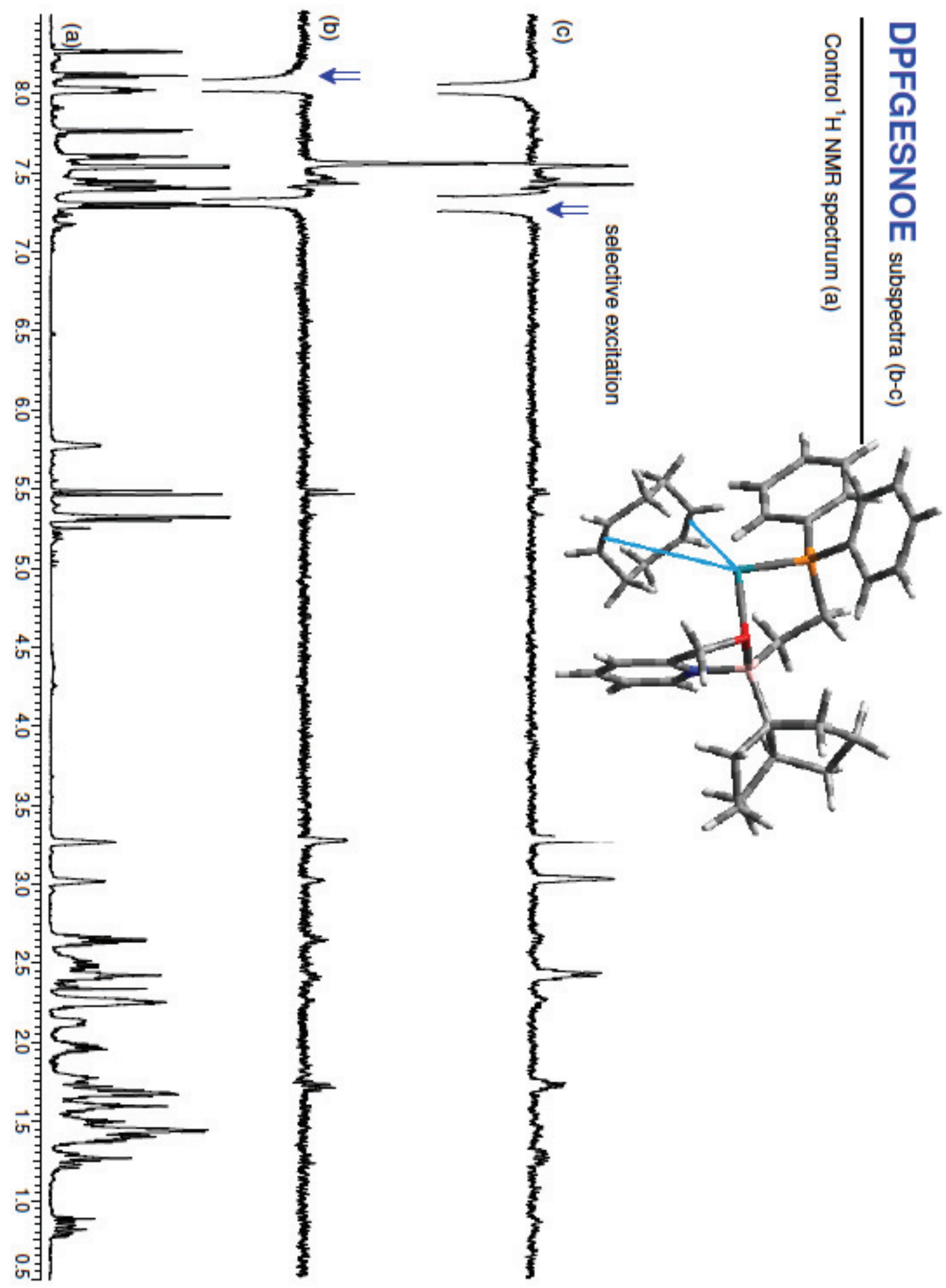




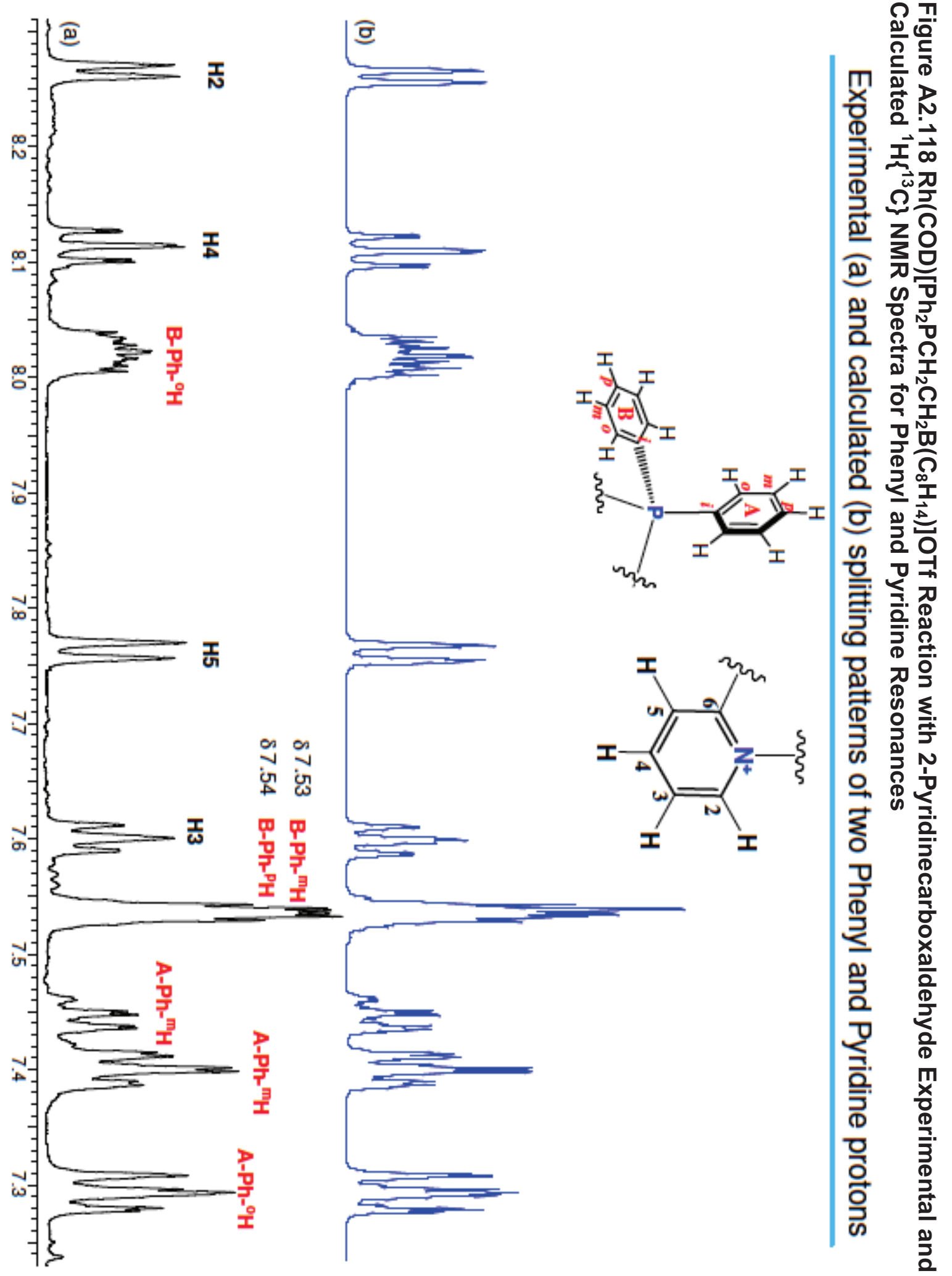




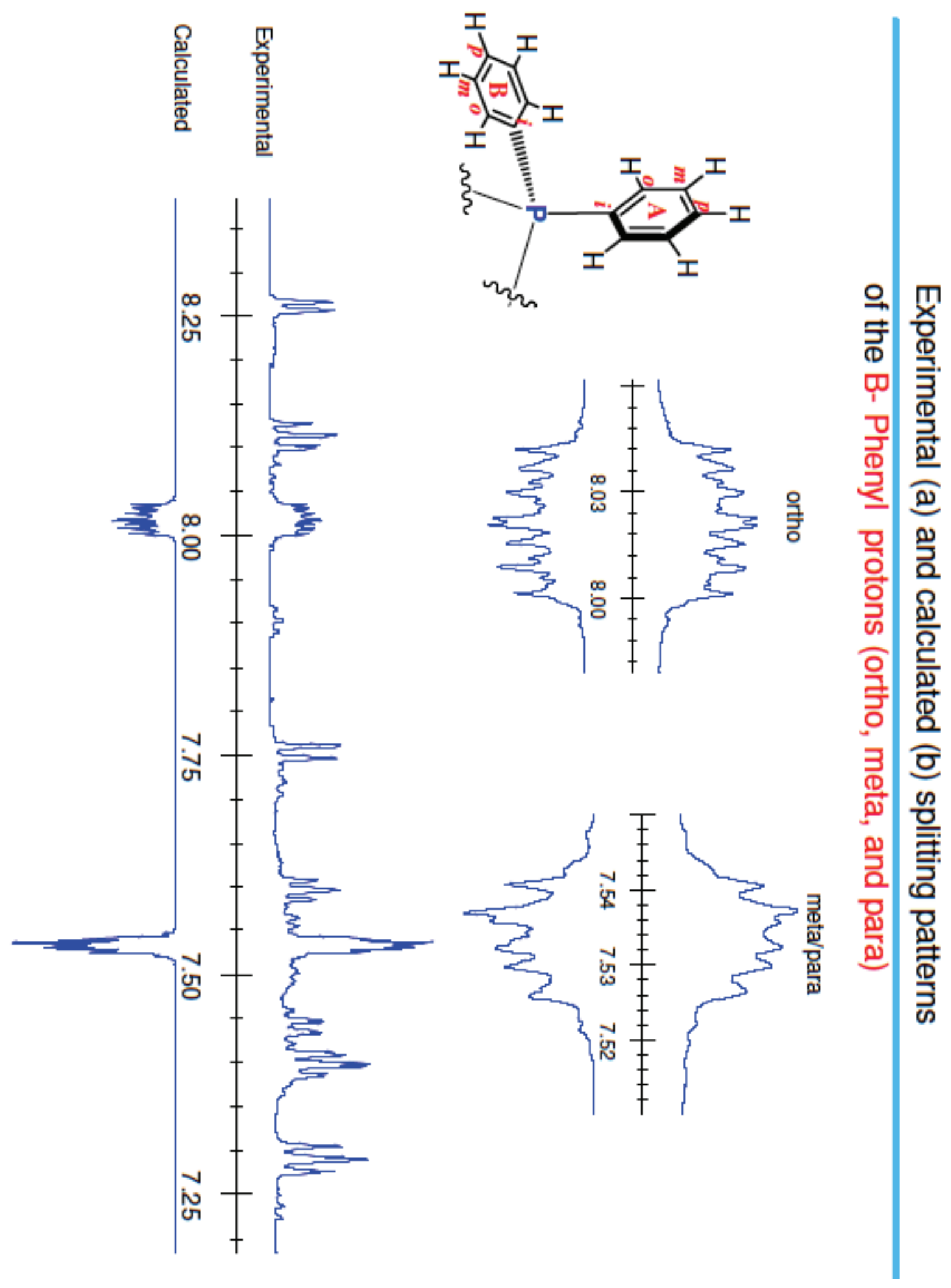




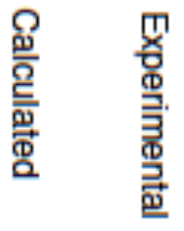
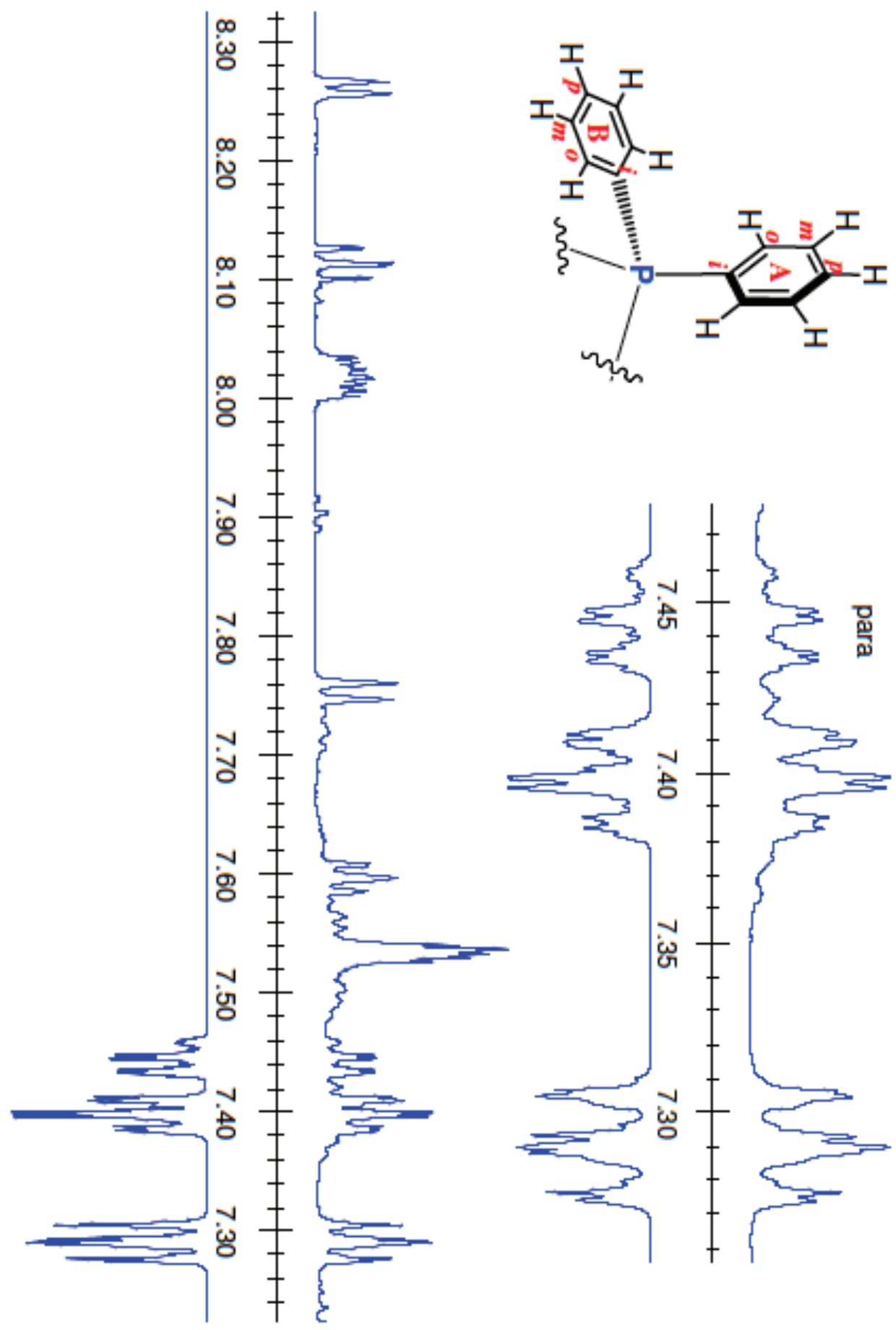

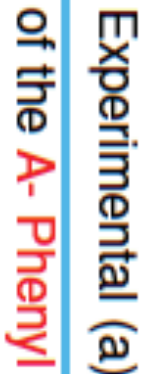

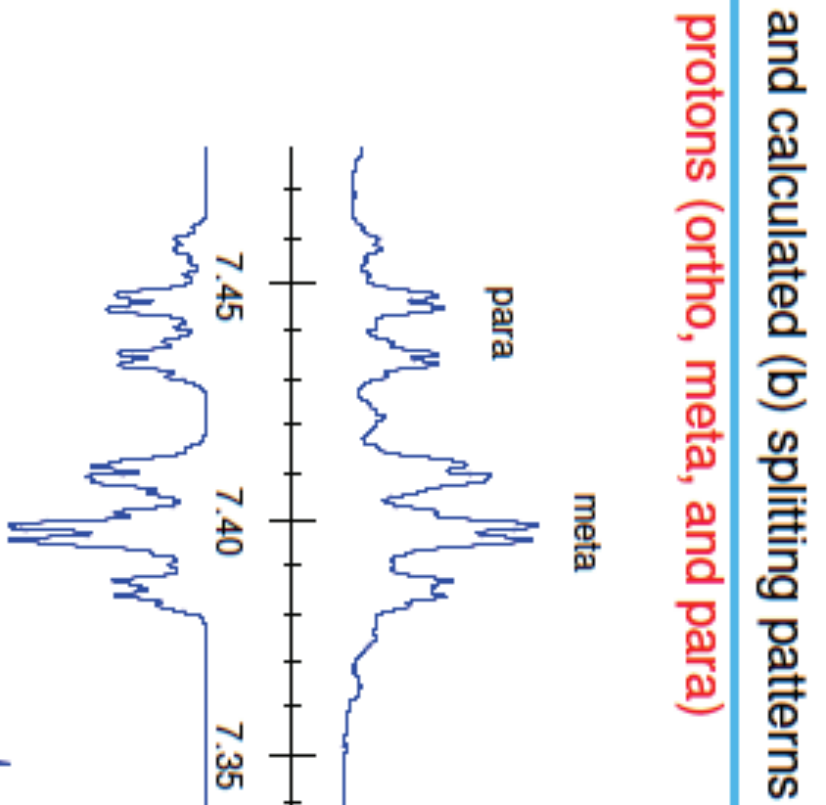




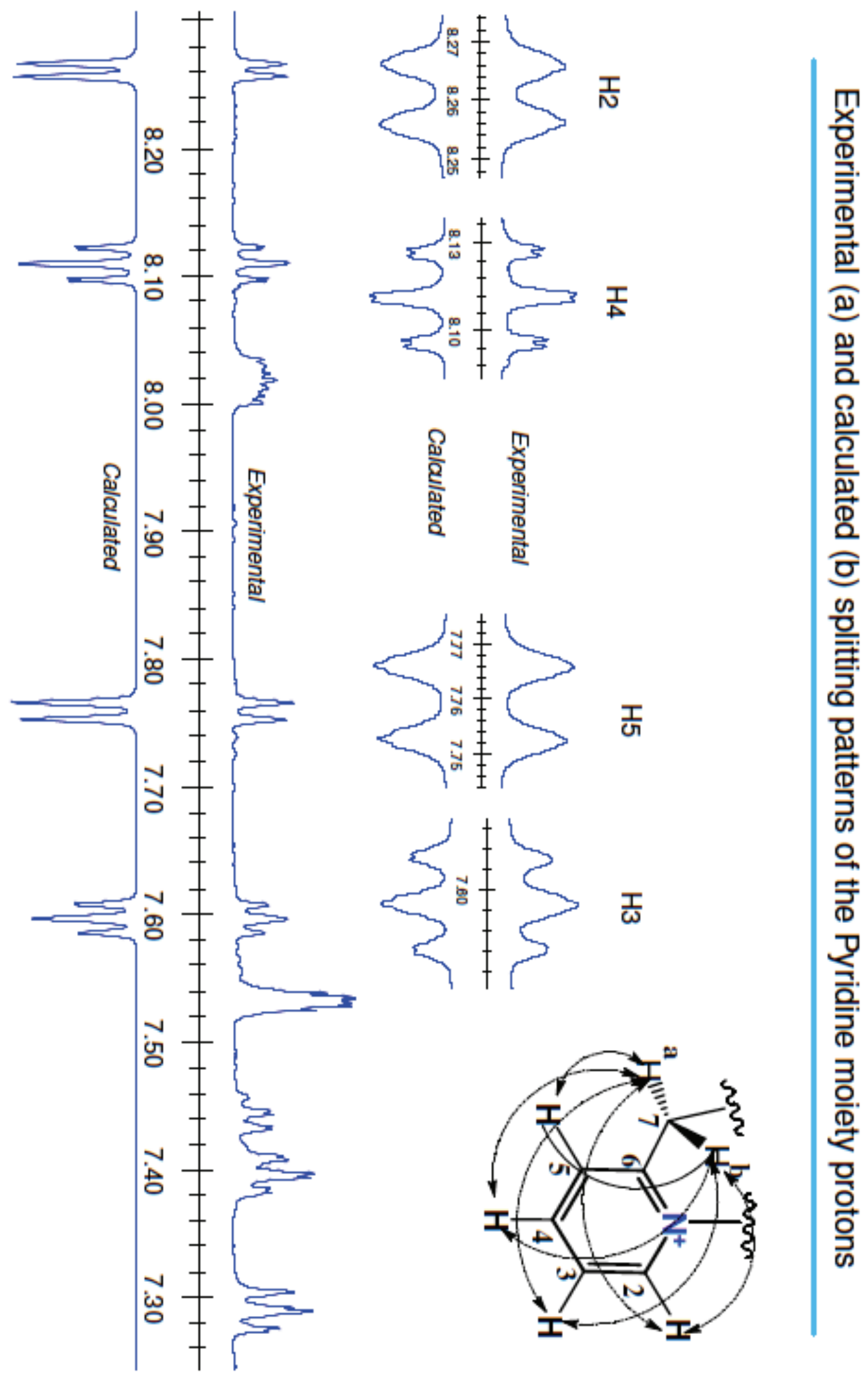




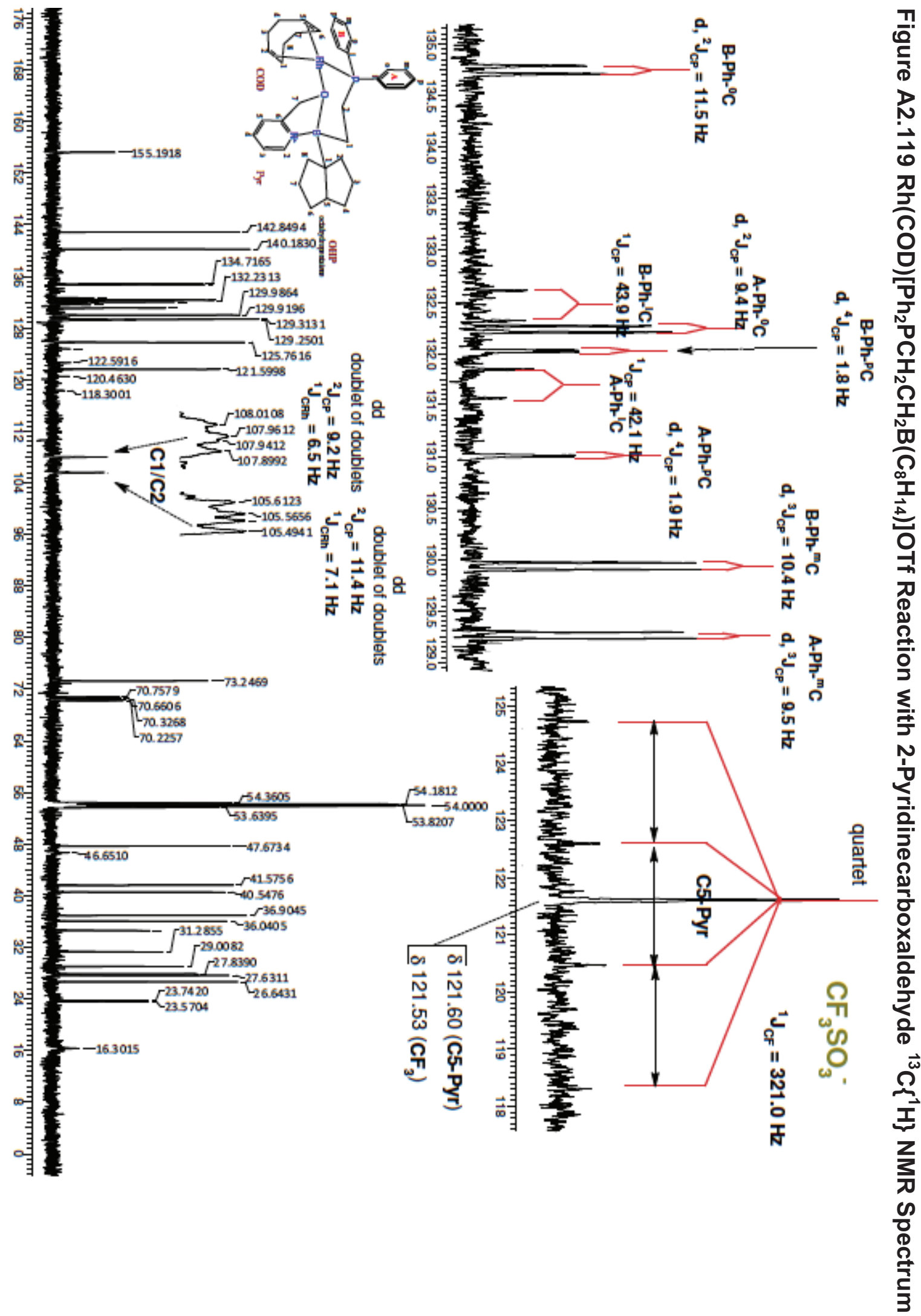



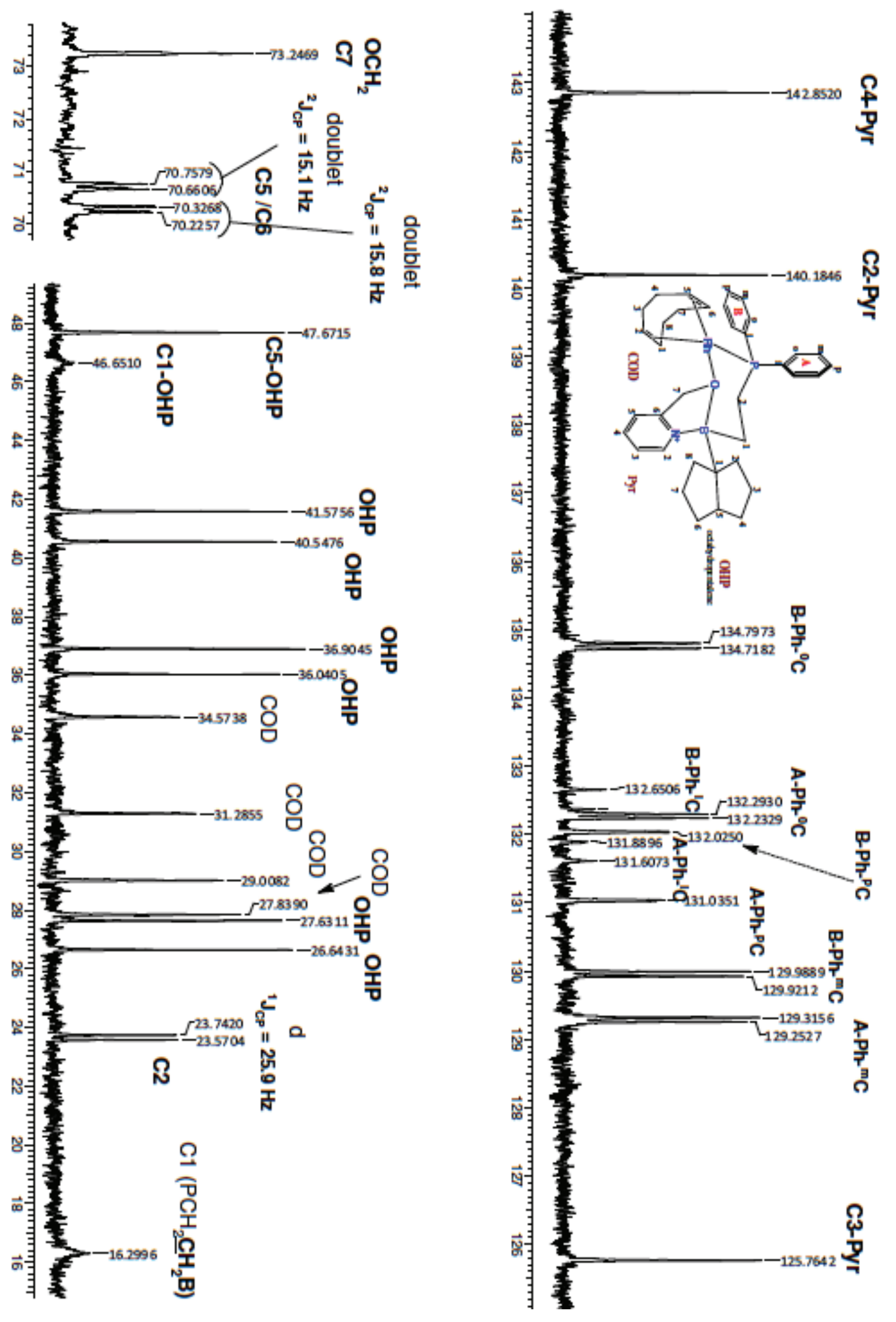


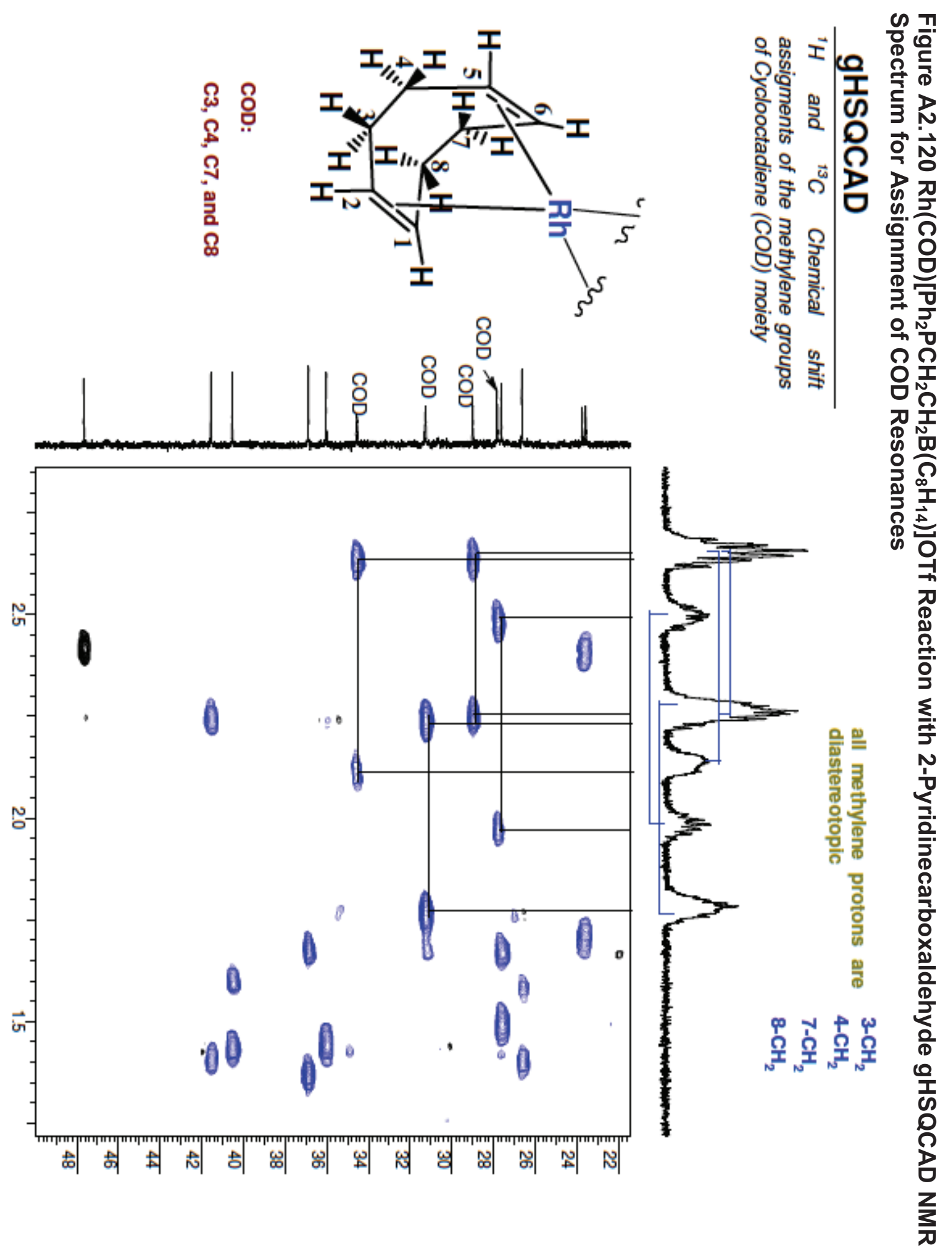



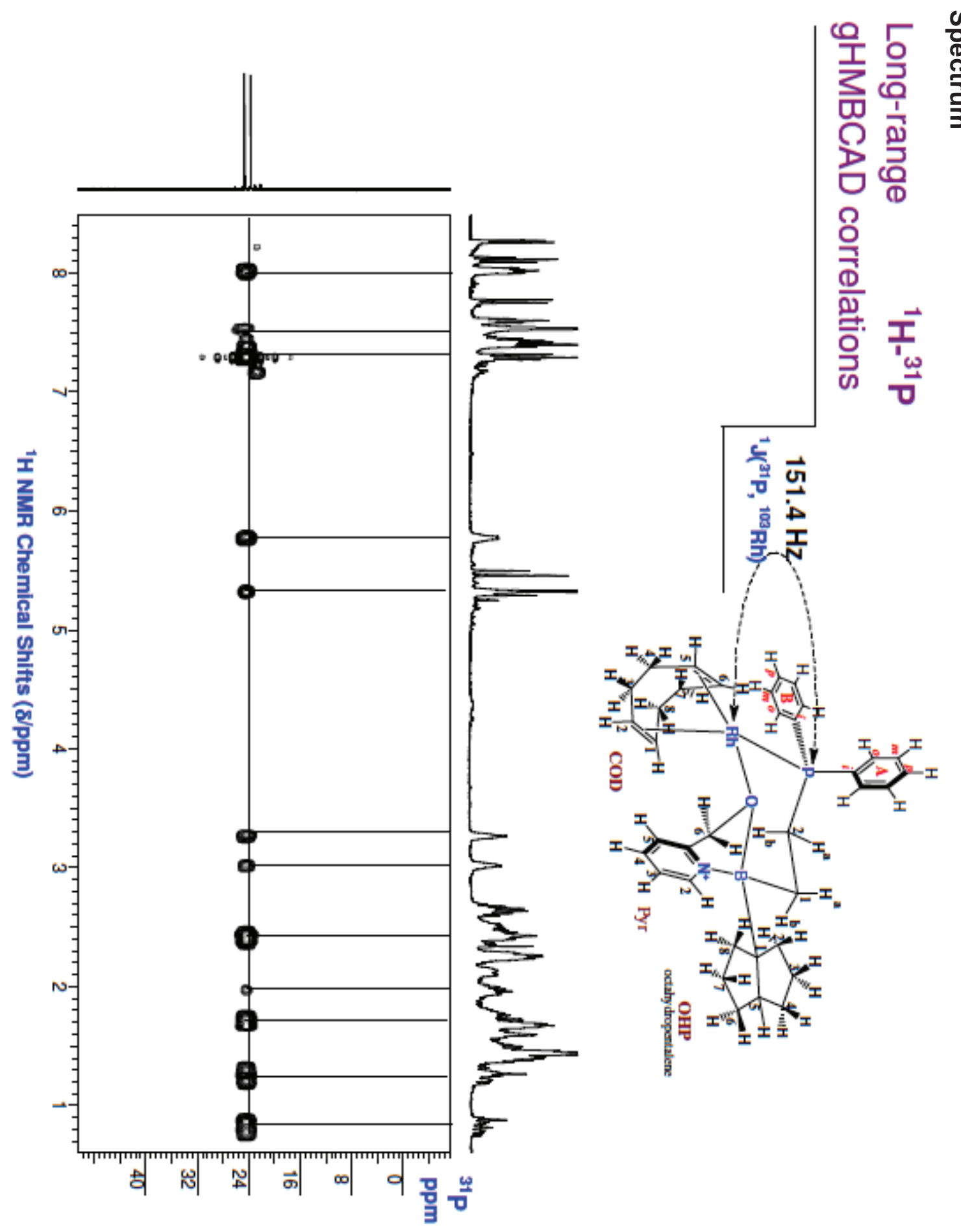

오끄

ํㅡㄹ

록

N

중

음

ํํำ

克

ก

$\stackrel{\infty}{I}$

옥

D

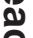

흠

$\underline{5}$

N

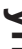

을

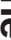

ำ

긍

x

음

은

$\vec{I}$

ర

으

ฉ

$\frac{z}{3}$ 

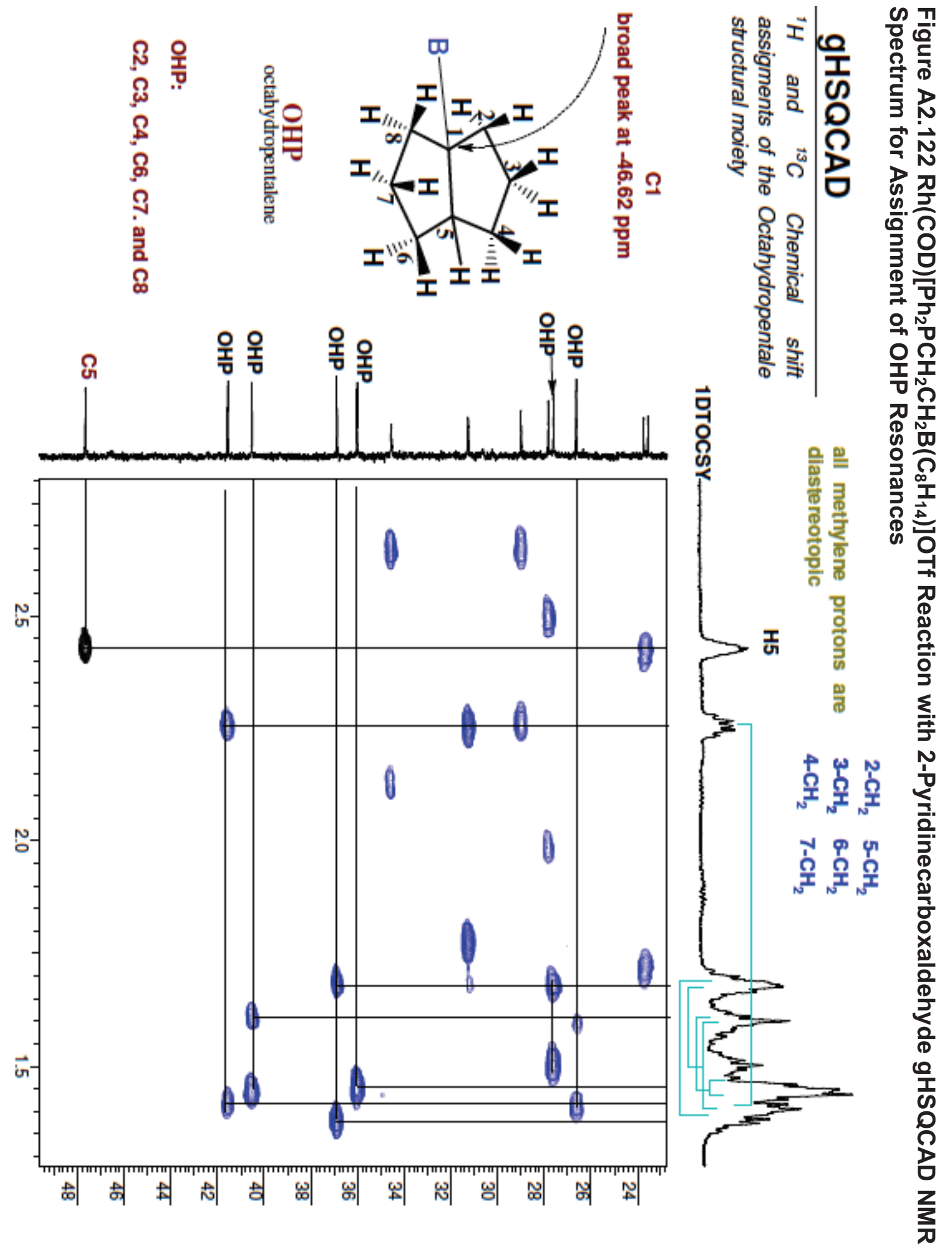

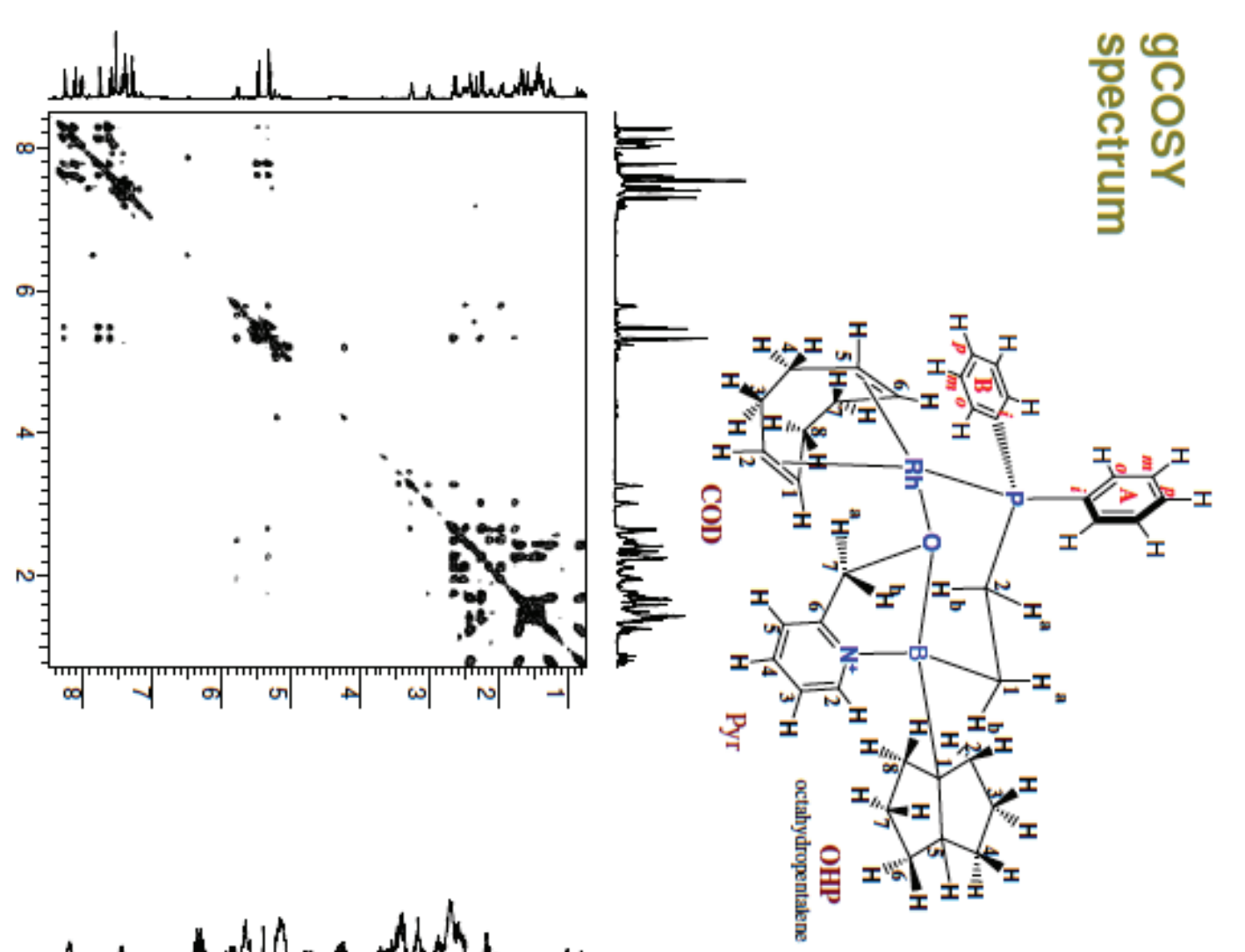

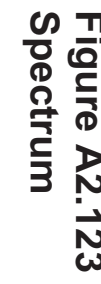

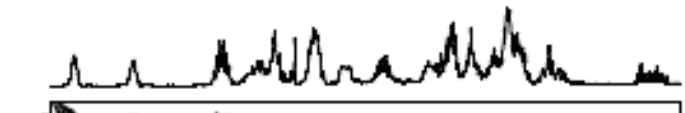
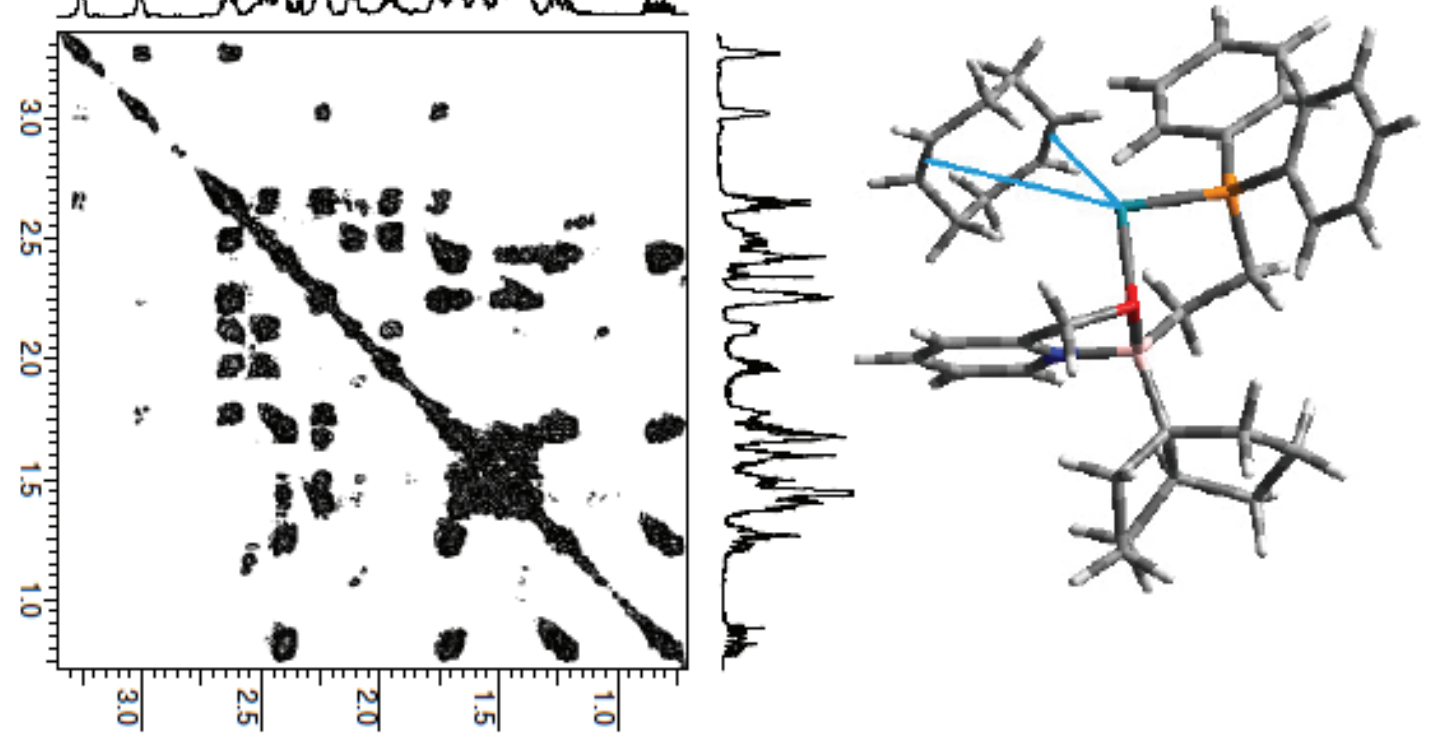

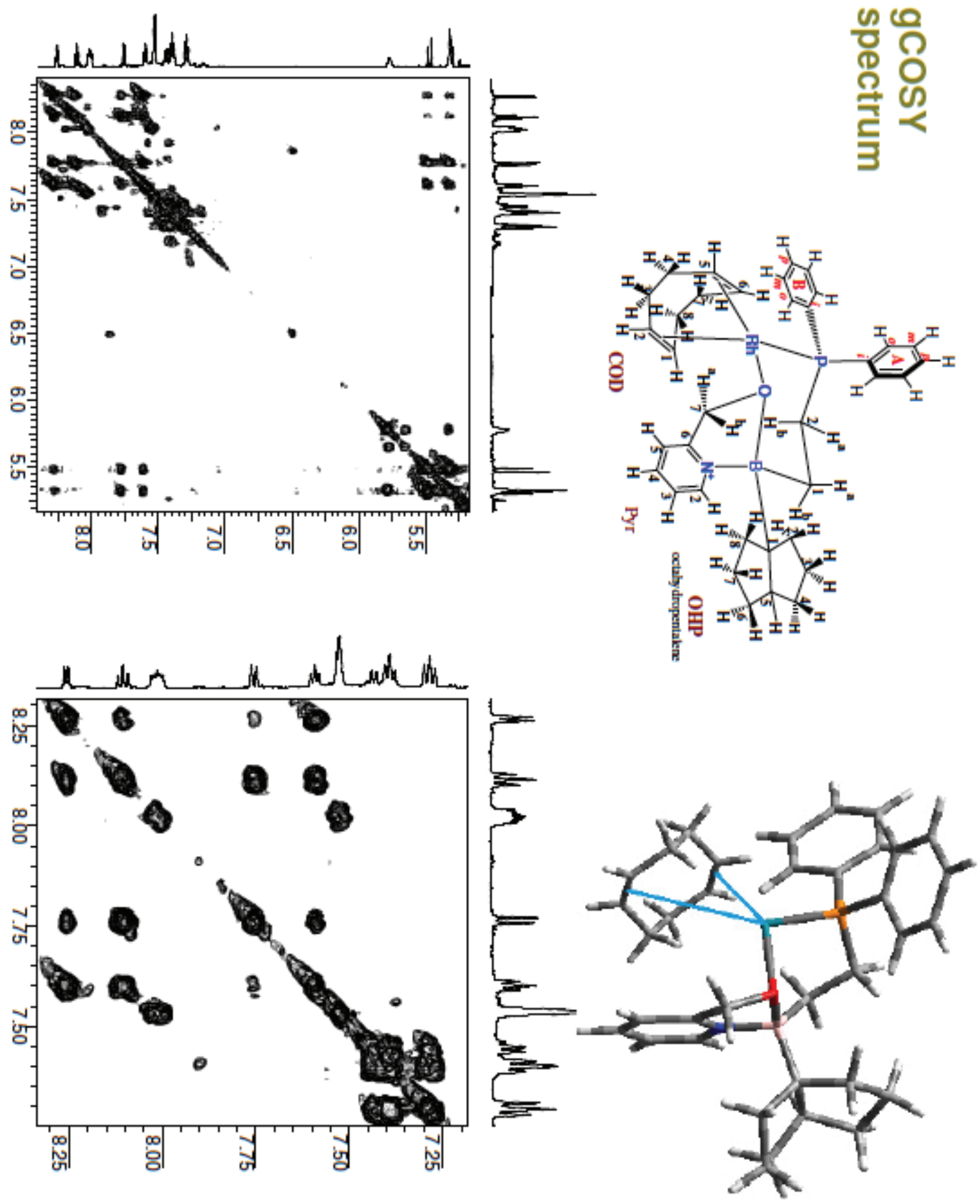


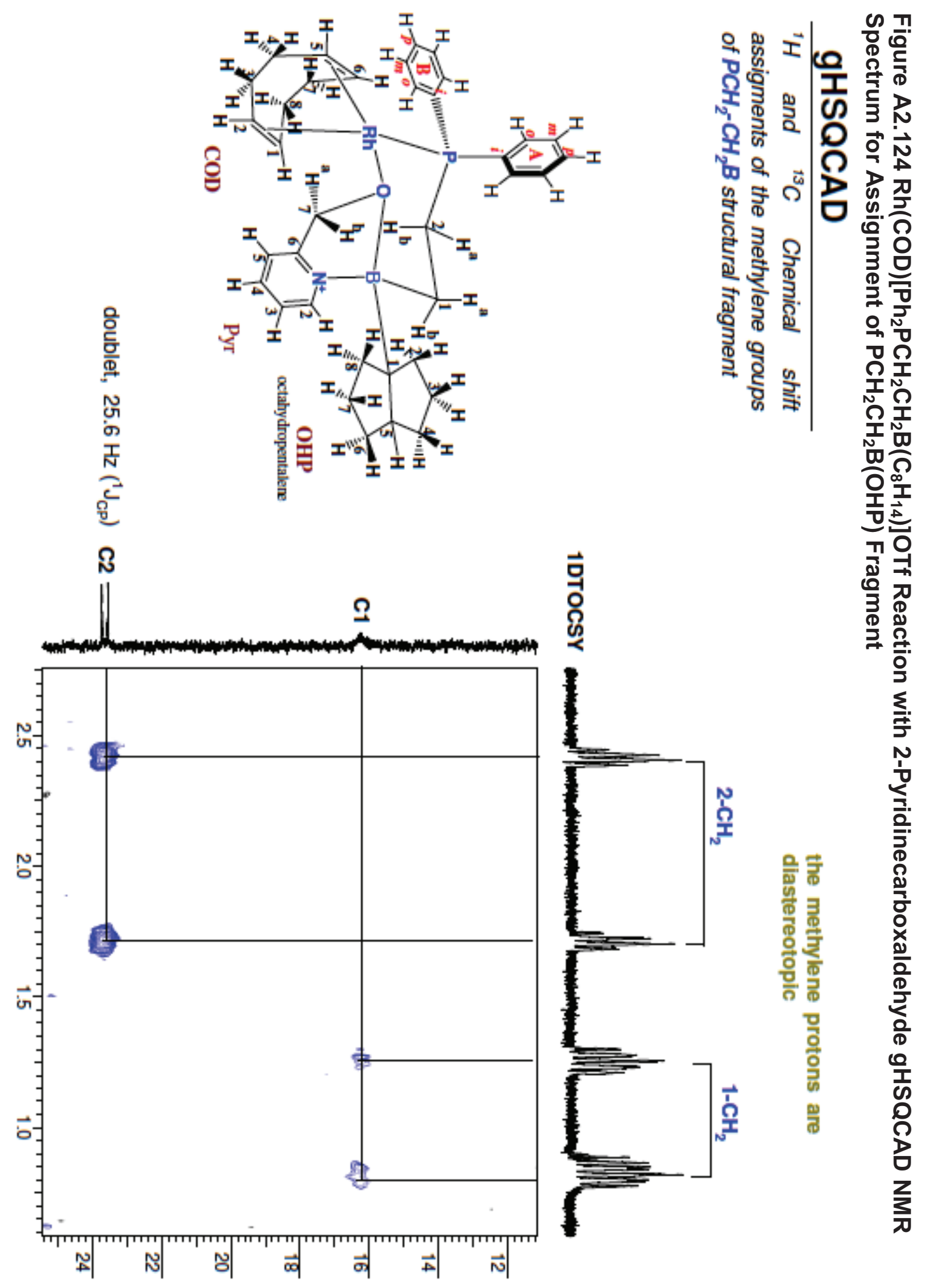




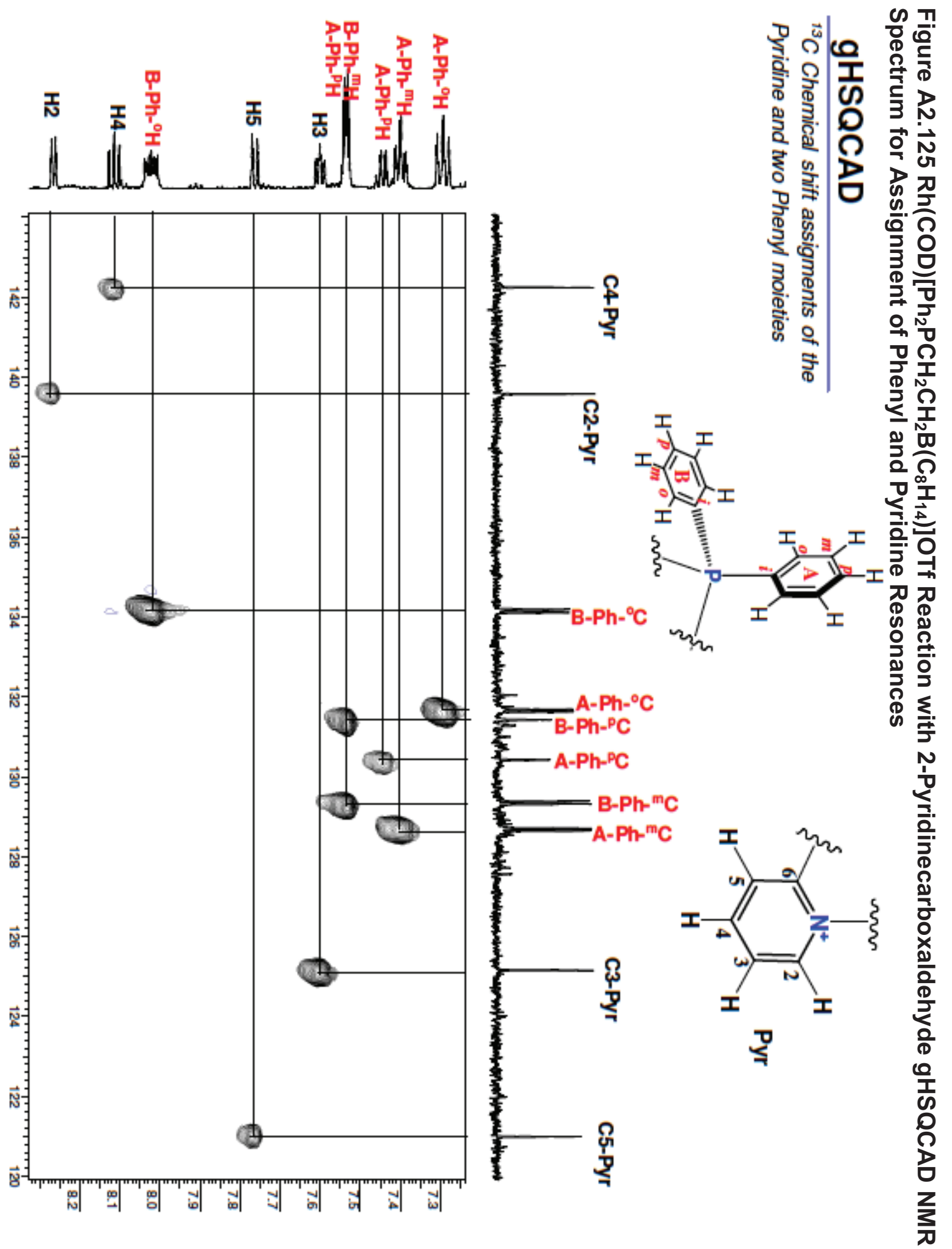



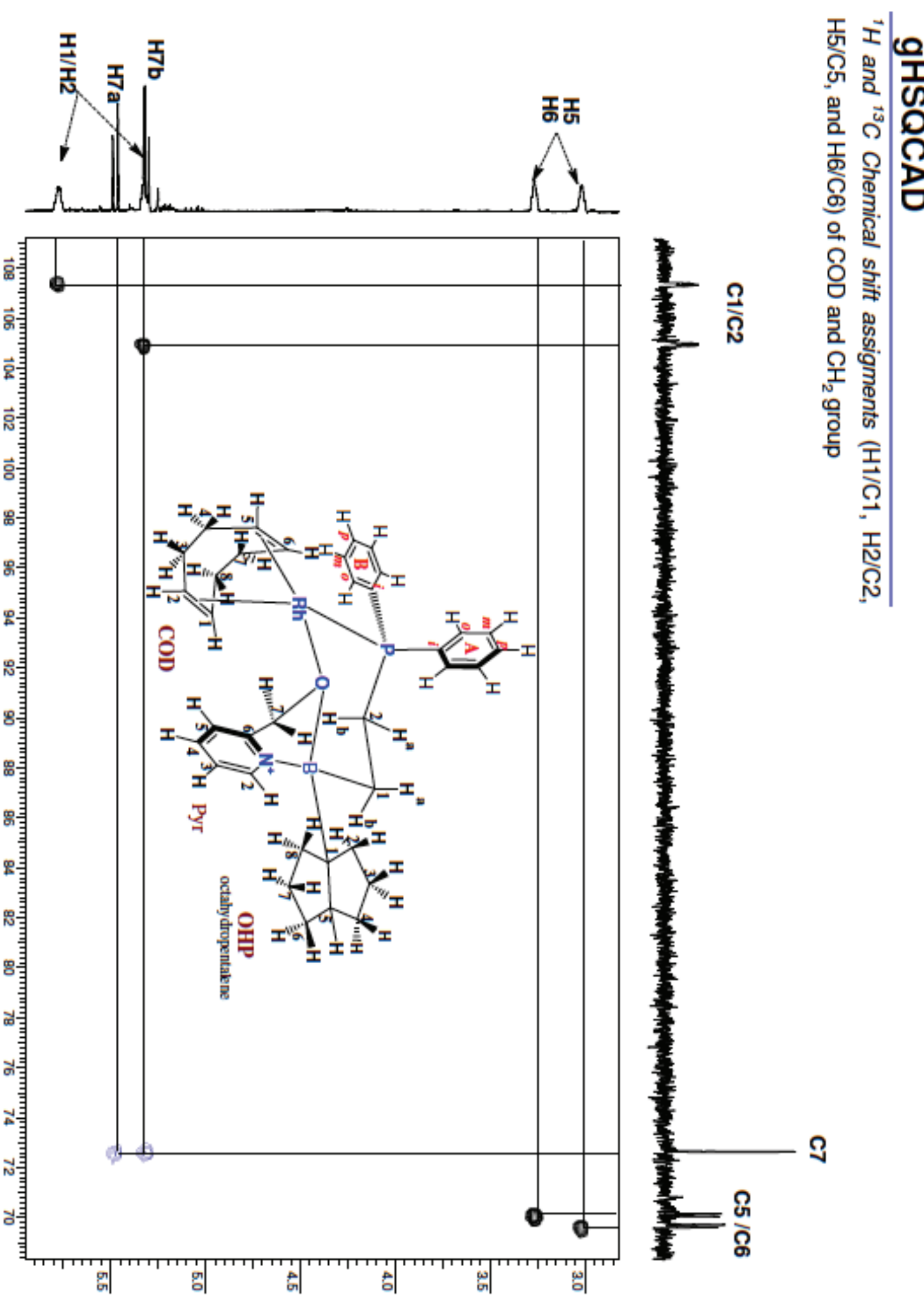

옹 꾼

जि



王 0

ก

(2) 곤

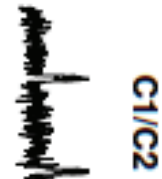

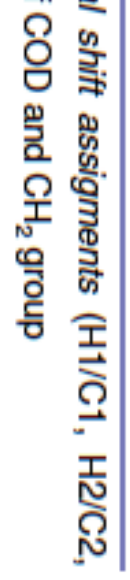
욜 ( $\frac{2}{3}$ 品 요 $\vec{N}$ $>$ \%

点 응

공으

을 뭄

욱 뭄

오

旁

高

(1)

D

刃 T

올 $\vec{E}$

옥 억

ก국

क 8

응.

오

$\leqslant$

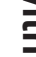

1

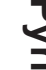

을 


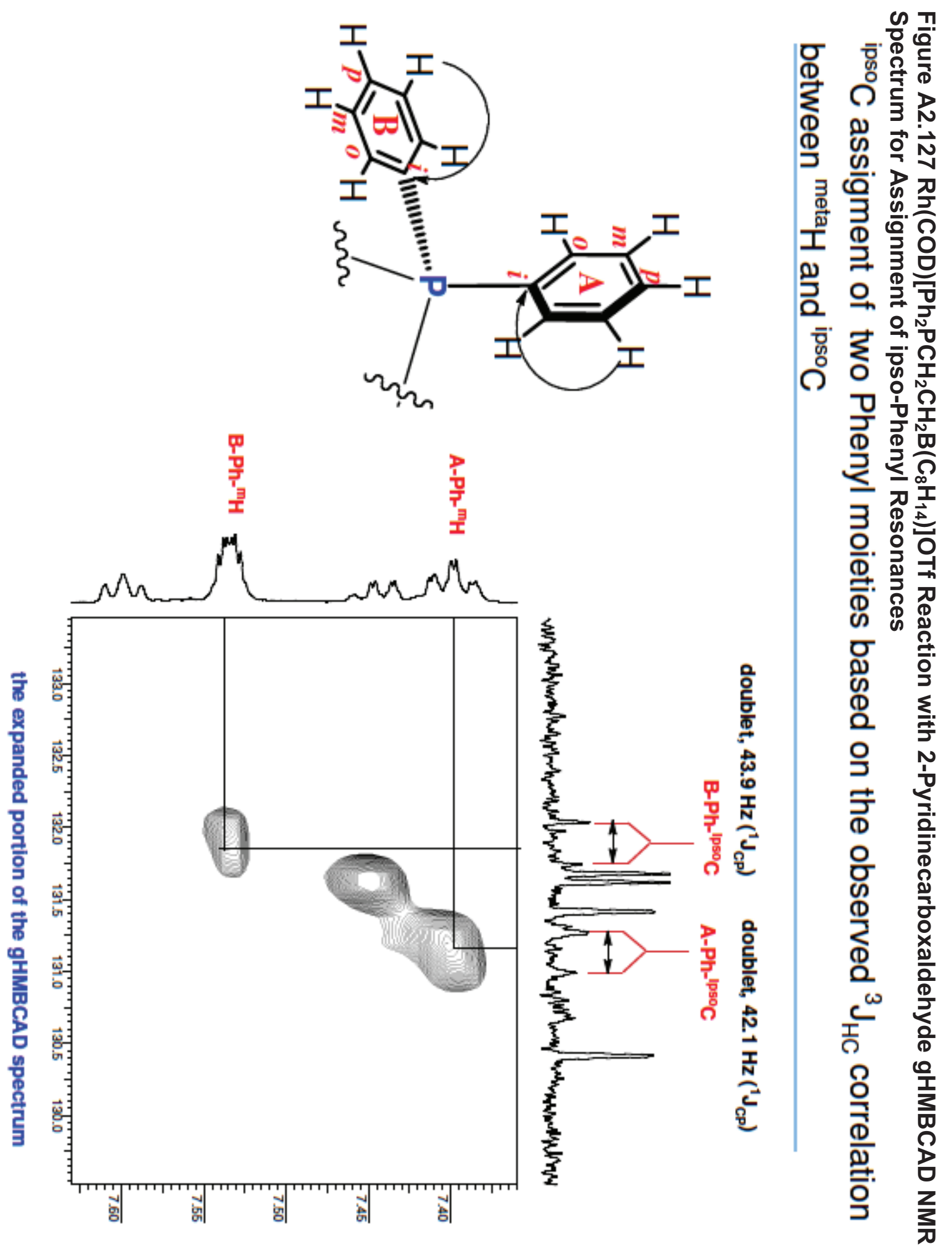



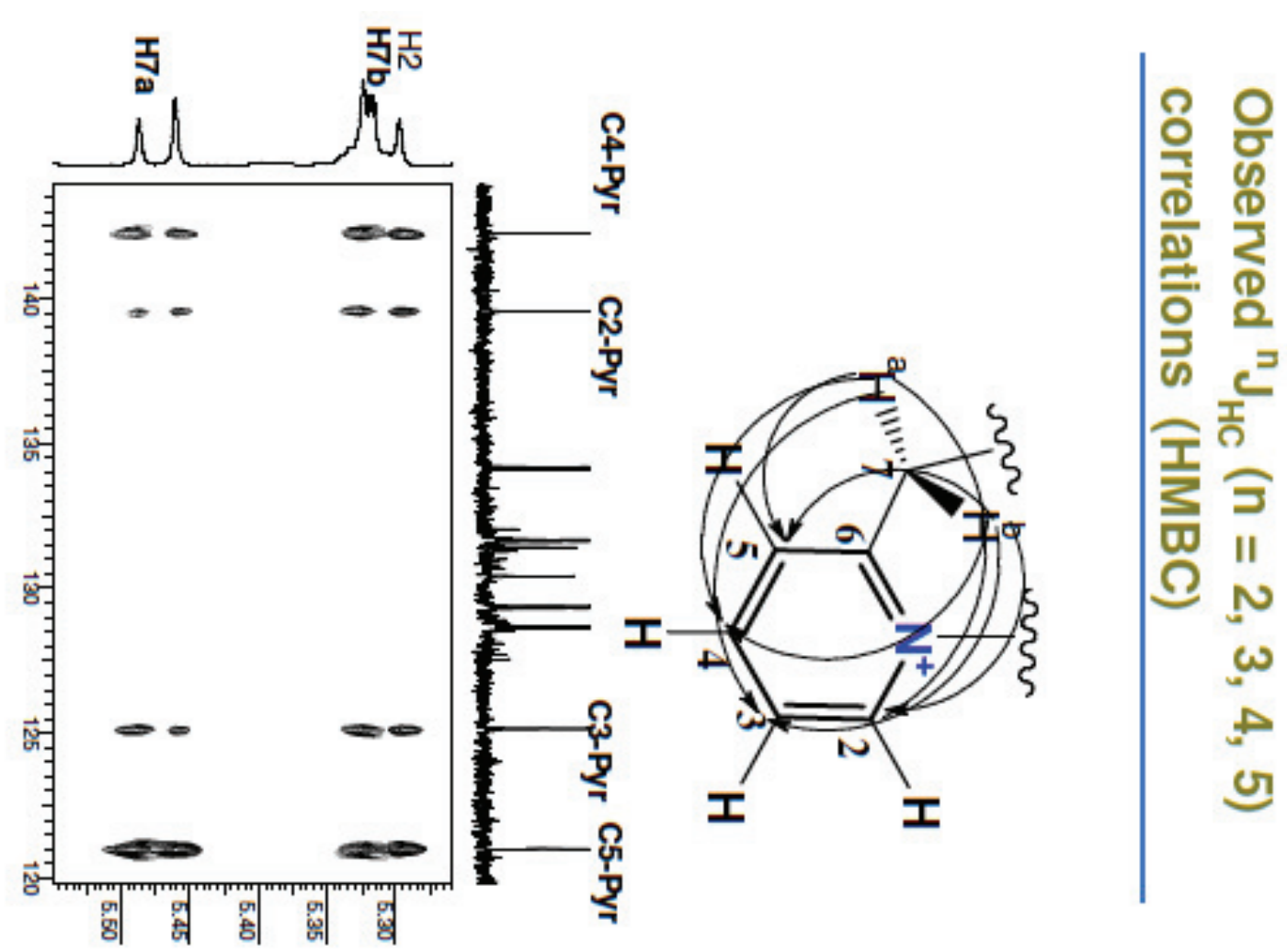

옹 꾸

올

空

3 N

욱

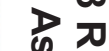

또동

흥

므

국

№

ํํำ

ง

음

w

$\rightarrow$ o

๗I

돈

怘

굴

๑

뭉

은

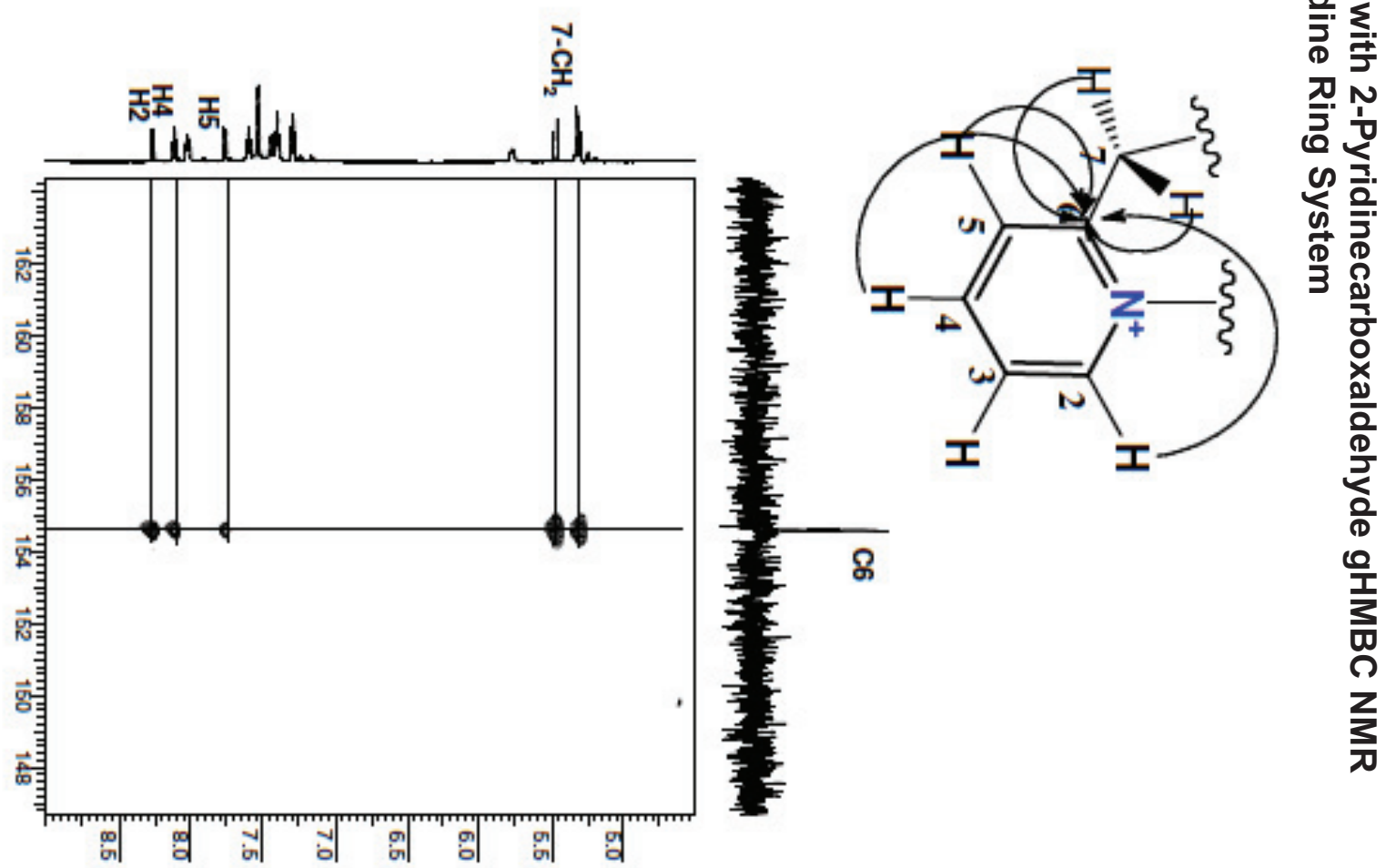



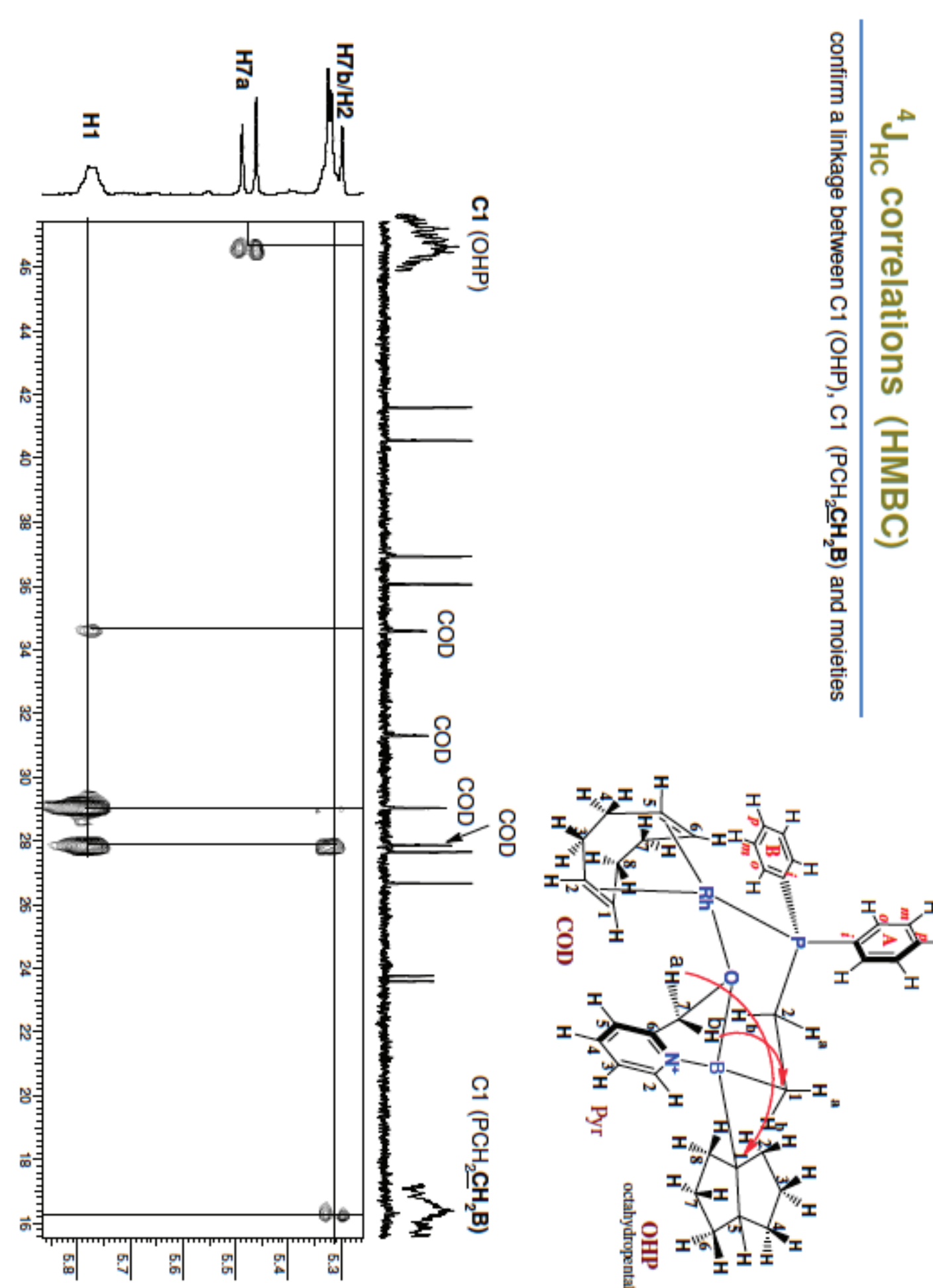

옹 꾼

ำ

站

孚

을 승

D品

․ㅗㄷㅗ

뜩

윽

雨

옥

(⿻)

T工

ลิ

至 $\frac{1}{\text { N }}$

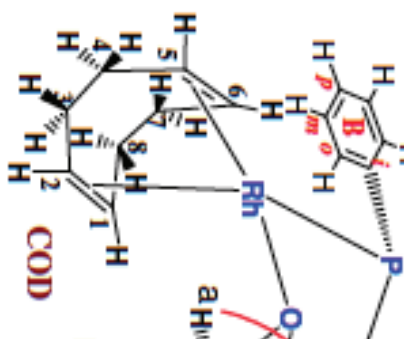

(D)

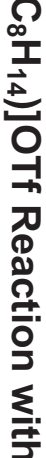

I
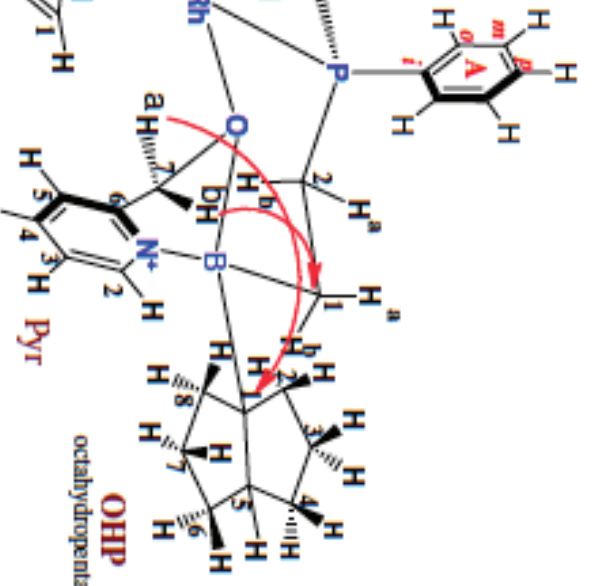


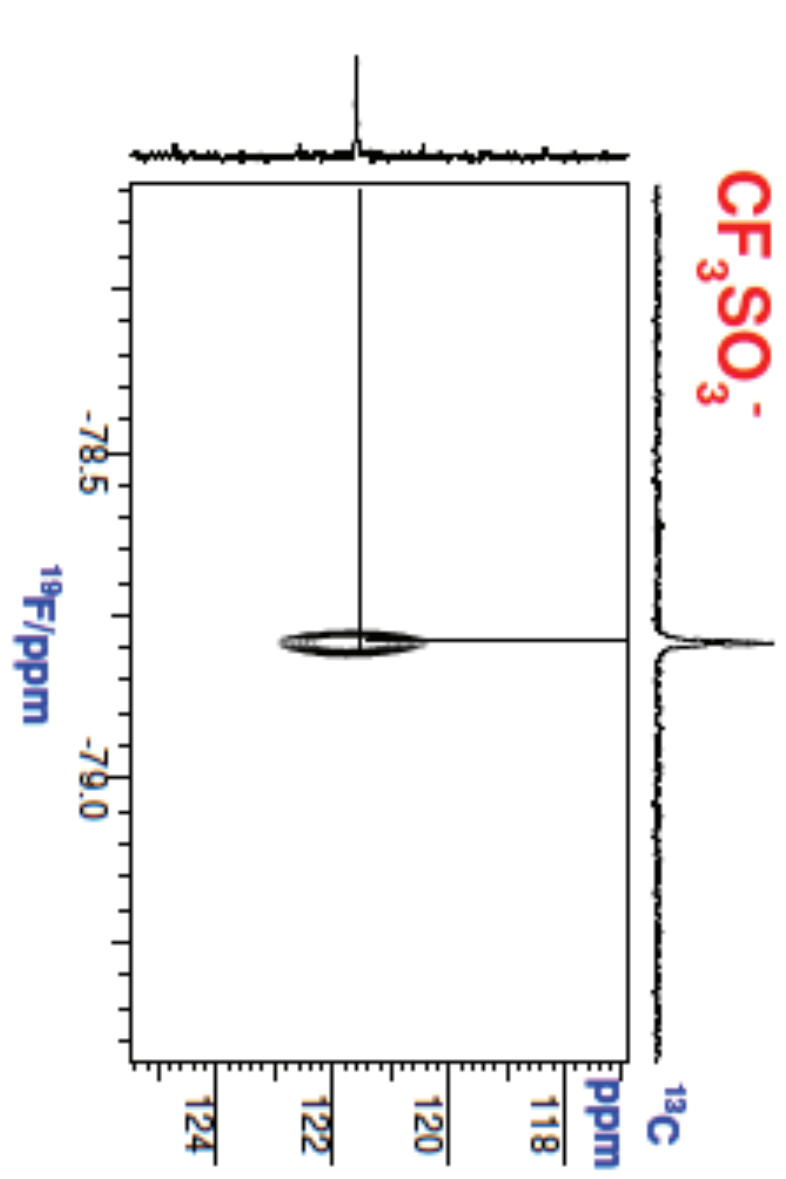

윰끄

ํㅗㅇ

$\stackrel{2}{7}$

兵

을 $\overrightarrow{0}$

D

음

을 응

Ф

군

옦 꾼

큭우

五

จ

市 1

ס

赵

음

(2)

를

กิ

7

Dृ

ก

웅

$\Sigma$

N

莫

흑

จ

ญ

궁

정

음

$\frac{2}{2}$

गे

$\Omega^{\vec{\omega}}$

음
亩
O
z
觉 